\title{
Test Excavations at the Culebra Creek Site, 41BX126, Bexar County, Texas
}

\author{
David L. Nickels \\ C. Britt Bousman \\ Department of Anthropology, Texas State University \\ Jeff D. Leach \\ Center for Archaeological Research \\ Diane A. Cargill \\ Center for Archaeological Research
}

Follow this and additional works at: https://scholarworks.sfasu.edu/ita

Part of the American Material Culture Commons, Archaeological Anthropology Commons, Environmental Studies Commons, Other American Studies Commons, Other Arts and Humanities Commons, Other History of Art, Architecture, and Archaeology Commons, and the United States History Commons

Tell us how this article helped you.

This Article is brought to you for free and open access by the Center for Regional Heritage Research at SFA ScholarWorks. It has been accepted for inclusion in Index of Texas Archaeology: Open Access Gray Literature from the Lone Star State by an authorized editor of SFA ScholarWorks. For more information, please contact cdsscholarworks@sfasu.edu. 


\section{Test Excavations at the Culebra Creek Site, 41BX126, Bexar County, Texas}

\section{Licensing Statement}

This is a work produced for the Texas Department of Transportation (TxDOT) by the report producer. TxDOT and the report producer jointly own all rights, title, and interest in and to all intellectual property developed under TXDOT's contract with the report producer. The report may be cited and brief passages from this publication may be reproduced without permission provided that credit is given to both TxDOT and the report producer. Permission to reprint an entire chapter, section, figures or tables must be obtained in advance from either the Supervisor of the Archeological Studies Branch, Environmental Affairs Division, Texas Department of Transportation, 125 East 11th Street, Austin, Texas, 78701 or from the report producer.

\section{Creative Commons License}

(c) (i) (9)

This work is licensed under a Creative Commons Attribution-NonCommercial 4.0 International License 


\section{Test Excavations at the \\ Culebra Creek Site, 41BX126, \\ Bexar County, Texas}

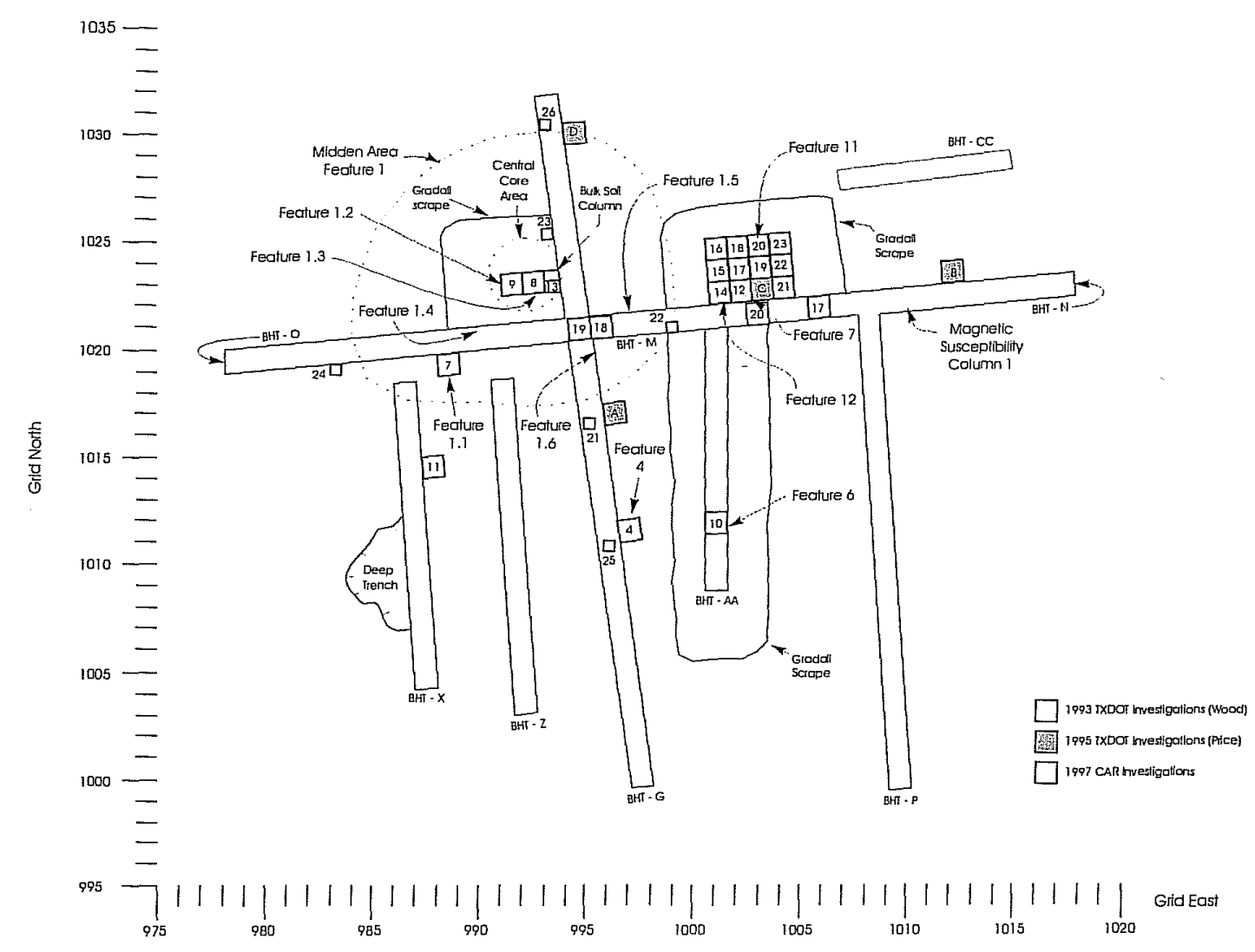

David L. Nickels, C. Britt Bousman, Jeff D. Leach, and Diane A. Cargill

with contributions by Stephen L. Black, J. Philip Dering, Charles D. Frederick, Wulf Gose, Richard Jones, Wilson W. McKinney, Kaylee A. McRae, Barbara A. Meissner, Bruce K. Moses, and Lee C. Nordt

Archaeological Survey Report, No. 265 Center for Archaeological Research The University of Texas at San Antonio
Archeological Studies Program, Report 3 Environmental Affairs Division Texas Department of Transportation 



\title{
Test Excavations at the Culebra Creek Site, 41BX126, Bexar County, Texas
}

\author{
David L. Nickels, C. Britt Bousman, Jeff D. Leach, \\ and Diane A. Cargill
}

Robert J. Hard and C. Britt Bousman

Principal Investigators

Texas Antiquities Committee Permit No. 1782

Archaeological Survey Report, No. 265

Center for Archaeological Research

The University of Texas at San Antonio
Archeological Studies Program, Report 3

Environmental Affairs Division

Texas Department of Transportation

Ccopyright 2001 [1998] 


\section{Copyright $(02001[1998]$}

Texas Department of Transportation (TxDOT) and Center for Archaeological Research, The University of Texas at San Antonio (CAR-UTSA)

\section{All rights reserved}

TXDOT and CAR-UTSA jointly own all rights, title, and interest in and to all data and other information developed for this project. Brief passages from this publication may be reproduced without permission provided that credit is given to TXDOT and CAR-UTSA. Permission to reprint an entire chapter, section, figures or tables must be obtained in advance from the Supervisor of the Archeological Studies Program, Environmental Affairs Division, Texas Department of Transportation, 125 East $11^{\text {th }}$ Street, Austin, Texas, 78701. Copies of this publication have been deposited with the Texas State Library in compliance with the State Depository requirements.

Printed by Thomas Reprographics Inc.

San Antonio, Texas

April 2001

jointly published by

Texas Department of Transportation

Environmental Affairs Division

Archeological Studies Program

Nancy A. Kenmotsu, Ph.D., Supervisor

Archeological Studies Program, Report No. 3

A. McGraw, Series Editor

and

Center for Archaeological Research

The University of Texas at San Antonio

Archaeological Survey Report, No. 265

Printed on acid-free, $60 \mathrm{lb}$. paper

ISBN: 1-930788-07-X 


\section{Abstract}

Archaeological test excavations were undertaken at 41BX126 on Culebra Creek to offset the impact from a proposed Texas Department of Transportation (TxDOT) highway improvement project on Loop 1604 in northwest Bexar County. Archaeological investigations were conducted in three field seasons: the first two seasons were conducted by TxDOT archaeologists and the third was directed by personnel from the Center for Archaeological Research (CAR) of The University of Texas at San Antonio. During the three projects, 55 hand-dug units, 29 backhoe trenches, 36 shovel tests, and eight Gradall trenches were excavated. Seventeen features were recorded; 25 radiocarbon assays were conducted; over 59,000 lithic artifacts were recovered and analyzed; 1,655 liters of sediment float samples were processed; $3,337 \mathrm{~kg}$ of burned rock were analyzed; and nearly $300 \mathrm{~g}$ of faunal material and 25 archaeomagnetic samples were analyzed. The testing revealed utilization of the site in the Early, Middle, and Late Archaic periods. The analysis of materials and results of all three field efforts are presented in this single volume.

Geoarchaeological investigations show that four terraces (T0, T1, T2, and T3) in the immediate site area accumulated from the Late Pleistocene through the Holocene. Five Stratigraphic Units (I-V) make up these terraces and overlap one another. The T2 terrace is composed of Stratigraphic Units II, III, and IV, while the T1 terrace consists mostly of Stratigraphic Units IV and V. Archaeological materials were discovered in situ within the T1 and T3 terraces and primarily within Stratigraphic Units III and IV. Radiocarbon assays indicate that Stratigraphic Unit IV formed between at least 4000-2000 B.P., Stratigraphic Unit III accumulated between approximately 11,500-4000 B.P., and Stratigraphic Unit II was accreting at least 17,500 years ago. Too little evidence exists to determine the full time ranges of sediment accumulation, and whether significant temporal gaps exist between the sedimentation of these geological units.

Archaeological excavations focused on three separate areas: A, B, and C. Area A is a new right-of-way east of the existing right-of-way. Excavations in this area defined a Late Archaic Montell component dating to approximately 2700 B.P. These materials include two burned rock features in situ within Unit IV on the scarp of the T2 terrace. This area probably was occupied by a small residential group during the Late Archaic period. Area B is east of Loop 1604 in the existing right-of-way and on the T2 terrace. Area B contains a Middle Archaic Nolan component in the upper portion of Stratigraphic Unit III, below a Late Archaic burned rock midden with a central subsurface oven in Unit IV. Area C is in the existing right-of-way west of Loop 1604. Excavations in this area investigated the possibility of an intact Early Archaic occupation; however, no evidence of one was found.

In Area B, the Nolan component consisted of lithic artifacts scattered among small burned rock features that probably served as hearths. This component is radiocarbon dated to approximately 4600 B.P. The Late Archaic burned rock midden was apparently used between 4000 B.P. and 2000 B.P. Subfeatures within the central oven indicate multiple cooking events. Ethnographic evidence suggests earth ovens contained food wrapped with insulating material over a layer of hot rocks heated by a coal bed. This was capped with dirt to seal the oven. When cooking was complete, the earth cap is removed to reach the food. CAR conducted earth-oven hot-rock experiments which indicated that local limestone could be used once or at the most twice. Local hot-rock cooking should generate a great deal of burned limestone debris. The framework of the feature at 41BX126 represents the cap and rock heating-element dumpings from separate cooking events as well as a few small intact burned rock features that served as ovens or hearths. At the base of the midden were a few depressions that may represent borrow pits used to obtain sediment for the central oven cap. Mixing of temporally distinct artifacts from the Nolan and later occupations occurs in and beyond the midden due to sediment excavation and transportation across the site, and redeposition of materials through erosion of materials off the framework. 


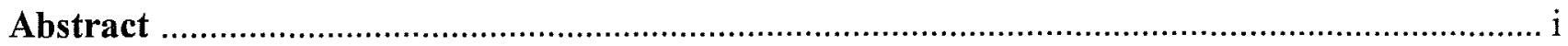

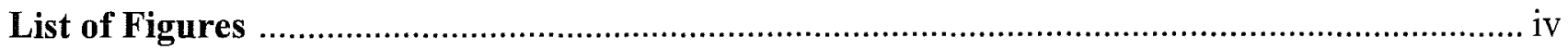

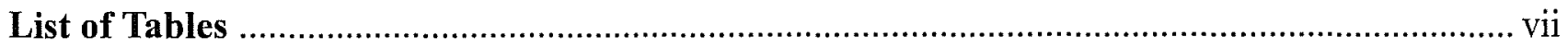

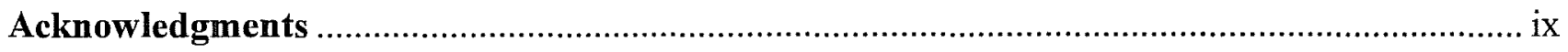

Chapter 1: Introduction

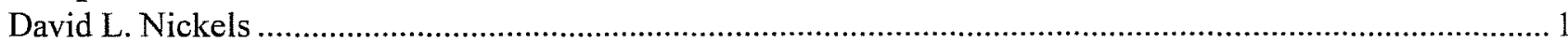

\section{Chapter 2: Setting}

David L. Nickels .

Chapter 3: History of Investigations at 41BX126

Diane A. Cargill .

Chapter 4: Methods

David L. Nickels, Diane A. Cargill, and Kaylee A. McRae 26

\section{Chapter 5: Geoarchaeology of 41BX126}

Lee C. Nordt

\section{Chapter 6: Testing Results}

David L. Nickels, Jeff D. Leach, Diane A. Cargill, Kaylee A. McRae, and C. Britt Bousman ....

Chapter 7: Cultural and Secondary Formation Processes:

On the Dynamic Accumulation of Burned Rock Middens

Jeff D. Leach and C. Britt Bousman

Chapter 8: Artifact Analysis

Wilson W. McKinney, C. Britt Bousman, David L. Nickels, and Kaylee A. McRae

Chapter 9: Plant Remains

J. Philip Dering

Chapter 10: Vertebrate Faunal Remains and Fish Otoliths

Barbara A. Meissner, Diane A. Cargill, and David L. Nickels

Chapter 11: Archaeomagnetic and Magnetic Susceptibility Analyses

Wulf A. Gose and David L. Nickels 
Chapter 12: Summary, Conclusions, and Recommendations

C. Britt Bousman and David L. Nickels .

References Cited

Appendix A: Geoarchaeological Investigations

Charles D. Frederick

Appendix B: Status Report 41BX126 Midden Recording

Charles D. Frederick and Stephen L. Black

Appendix C: Geomorphological Data

Lee C. Nordt

Appendix D: Estimating Rates of Burned Rock Discard:

Results from an Experimental Earth Oven

Jeff D. Leach, David L. Nickels, Bruce K. Moses, and Richard Jones

Appendix E: Artifact Data 284

Appendix F: Faumal Data

Barbara A. Meissner 298 


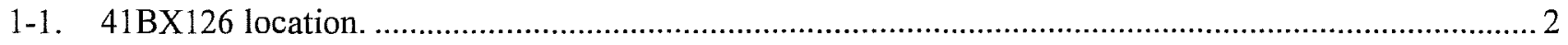

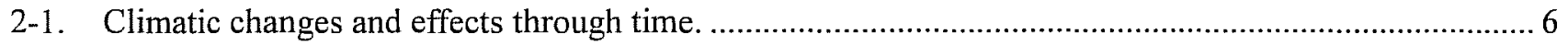

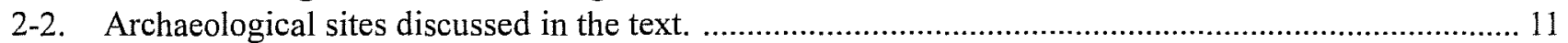

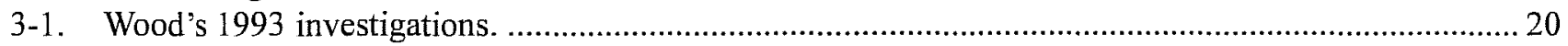

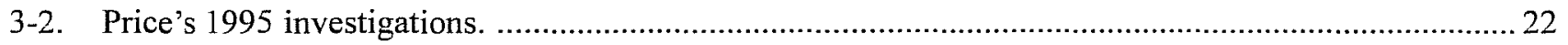

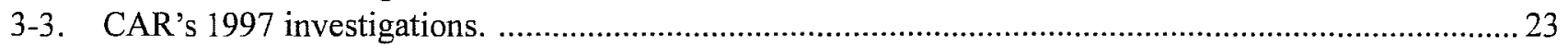

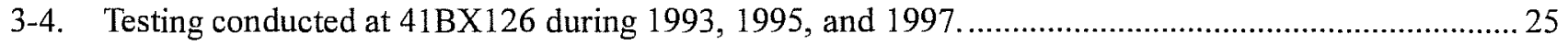

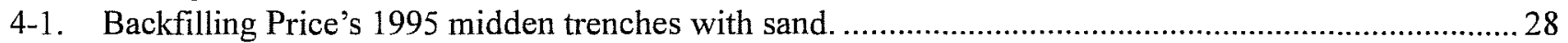

4-2. Monitoring backhoe trenching in the new right-of-way (1997). ................................................... 29

4-3. Gradall scraping top of center and northwest quadrant of the midden (1997).............................. 30

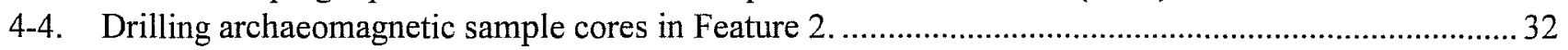

4-5. Cleaning and scraping trench wall for soil susceptibility sampling. ............................................. 32

4-6. Counting and size-sorting lithics during the preliminary debitage analysis. ......................................3. 34

4-7. Lab analyst size-sorting, counting, and weighing burned rock. .................................................... 34

5-1. Geomorphic map of late Quaternary alluvial landforms, erosional escarpments, and backhoe and Gradall trenches along Culebra Creek in the project area. ............................................................ 37

5-2. Schematic geologic cross section of Culebra Creek constructed for the east side of Loop 1604 from backhoe and Gradall trenches, deep sediment cores, and ${ }^{14} \mathrm{C}$ ages. ......................................... 39

6-1. Contour map of 41BX126 showing Areas A, B, and C. ..........................................................46

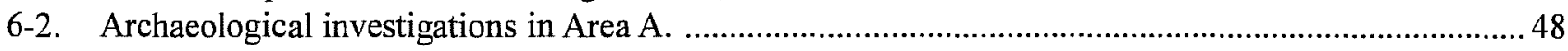

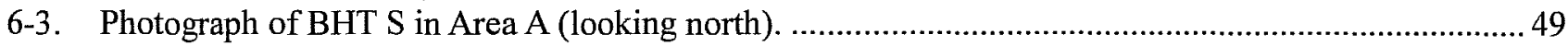

6-4. Photograph of Feature 2 in the west wall of BHT S in Area A.....................................................51

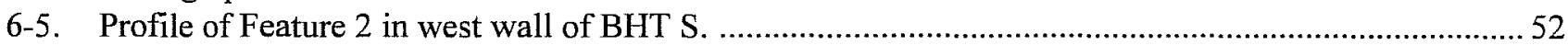

6-6. Photograph of TUs 1 and 2 showing Feature 2 as it was exposed in plan view at the bottom of Level 2 (facing southwest).................................................................................................. 53

6-7. Plan view of Feature 2, bottom of Level 2 in TU 1, Area A. ........................................................5 53

6-8. Feature 2: TU 2, bottom of Level 2, $20 \mathrm{~cm}$ bs (left); and TU 1, bottom of Level 4, $40 \mathrm{~cm}$ bs (right). .. 54

6-9. Feature 3 in the west wall profile of the southern end of BHT S, Area A....................................... 54

6-10. Plan view of Feature 3 (combined Levels 2 and 3), Area A. ........................................................ 55

6-11. Plan view of Feature 3 (combined Levels 1, 2, and 3), Area A. ....................................................5 56

6-12. Photograph of bottom of Level 2, Feature 5, TU 6 in Area A (facing east) ......................................5 57

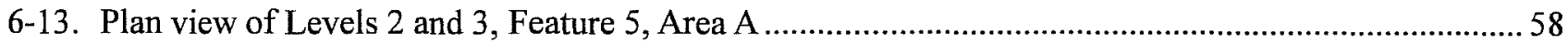

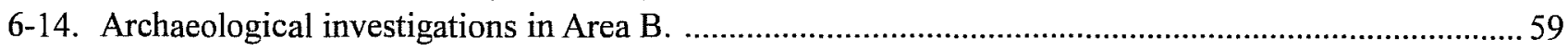

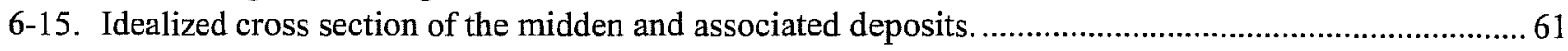

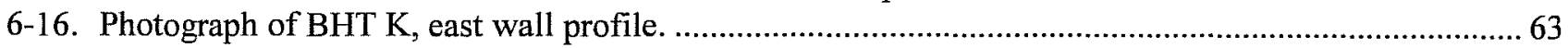

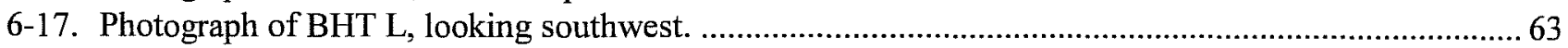

6-18. Composite profile of trenches in burned rock midden. .............................................................6. 67

6-19. Gradall scraping and BHT G revealed the midden's core as a gray-brown humus filled pit

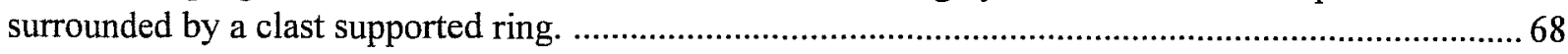

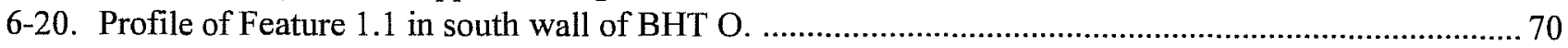

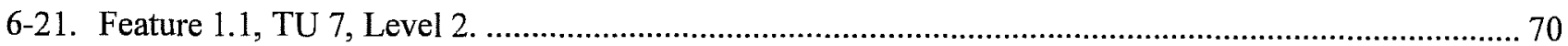

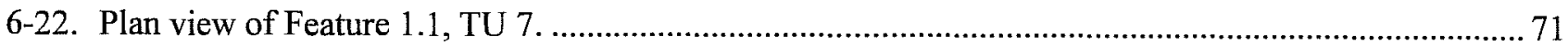

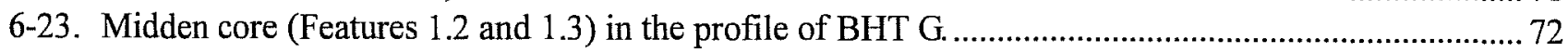

6-24. Photograph of Features 1.2 and 1.3 in the west wall profile of BHT G. .......................................... 73

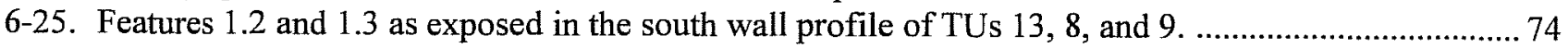


6-26. Photograph of Feature 1.2 (left) and Feature 1.3 (right) from above; from left to right, TUs 23,8 , and 9 .

6-27. Plan view of TUs 8,9 , and 13, Level 4. Feature 1.2 is in TUs 8 and 13...................................... 76

6-28. Feature 1.4. Ashy pit area overlain with burned rock feature in BHT O north wall profile.................8 80

6-29. Feature 1.5. Burned rock-filled pit beneath the midden framework in BHT O north wall profile ......... 81

6-30. Feature 1.6. Ring-shaped layer of burned rock beneath the midden framework in BHT G profile .......83

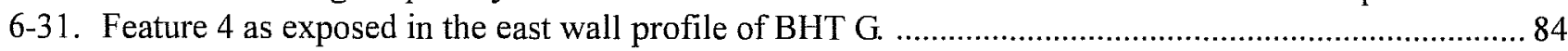

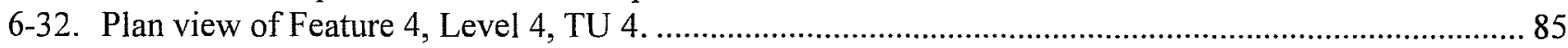

6-33. Photograph of Feature 6, TU 10, Level 1......................................................................... 86

6-34. Photograph of the burned rock uncovered in the bottom of Level 4 (40 cm below surface), TU A...... 87

6-35. Thin layer of burned rock in east wall of BHT X. .................................................................. 88

6-36. Photograph of BHT X and TU 11, Level 1, showing layer of burned rock in trench profile................89

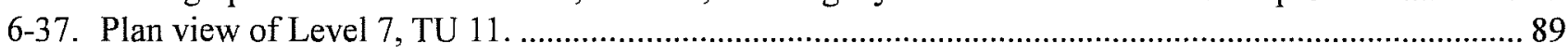

6-38. Mean flake length for TUs 12, and 14-18 in the block excavation. ............................................ 92

6-39. Mean flake length for TUs $19-23$ and Unit $\mathrm{C}$ in the block excavation. ..........................................93

6-40. Block excavation, schematic showing diagnostic artifacts, features, and radiocarbon dates...............94

6-41. Plan view of Feature 7 in TU C, $50-80 \mathrm{~cm}$ below the modern surface. ..........................................96

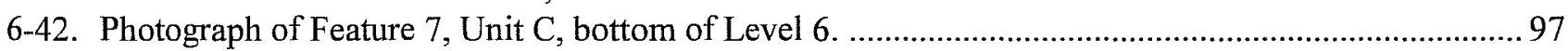

6-43. Photograph of Feature 7, Unit 12, bottom of Level 3 ......................................................... 97

6-44. Features 11 and 12 exposed in the block excavation between site elevations 100.1 and $99.9 \mathrm{~m}$, ca. $60-80 \mathrm{~cm}$ below the modern surface.

6-45. Feature 12 exposed in the block excavation between site elevations 100.0 and $99.8 \mathrm{~m}$,

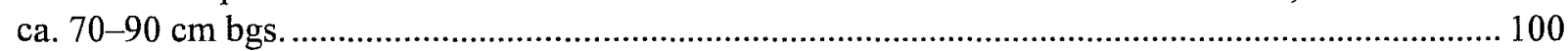

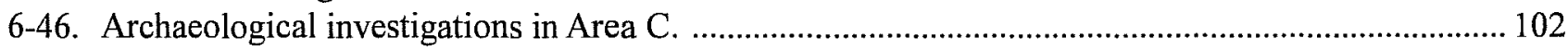

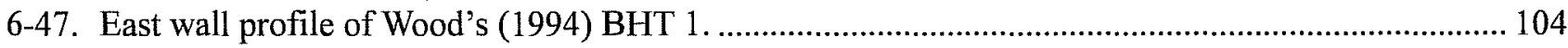

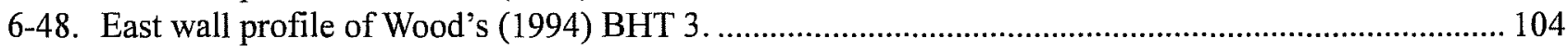

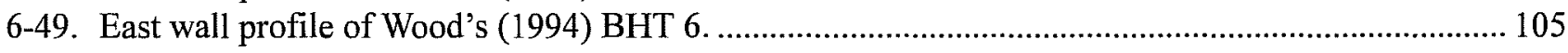

6-50. Wood's (1994) wall profiles of selected test units. ................................................................... 106

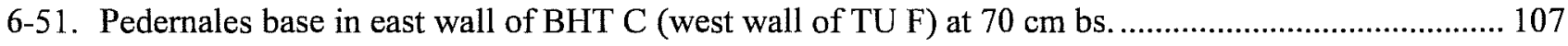

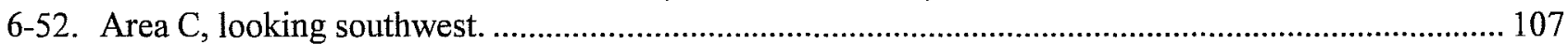

6-53. Photograph of CAR Gradall trenches in Area C, looking north. .................................................. 108

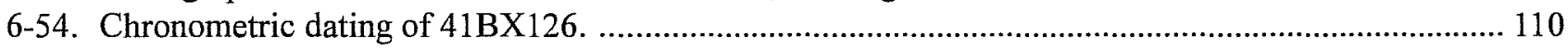

6-55. Photograph of the Nolan component in Level 3 of the Block Excavation. .................................... 115

6-56. Photograph of Nolan component in block excavations at varying depths within Level 4. ................ 116

7-1. Idealized profile of a 40-ft terrace along the Colorado River illustrating the intersecting hearth scenario for midden accumulation ........................................................................ 122

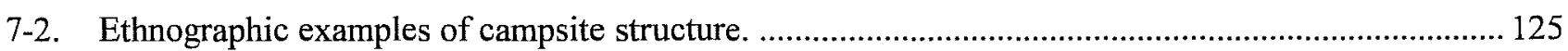

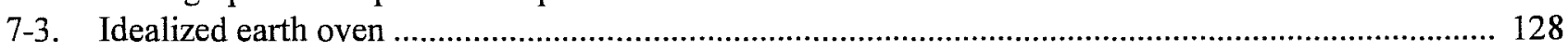

7-4. White Mountain Apache (Arizona) sealing an earth oven used to roast agave hearts. ...................... 129

7-5. White Mountain Apache opening the same oven depicted in Figure 7-4 . .................................. 130

7-6. Photograph of an experimental midden created by CAR investigators ......................................... 133

7-7. Photograph of the experimental deposit after it had been eroded via water. ................................... 134

7-8. Photograph of the Gradall removing sediment from the top of the midden deposit. ......................... 136

7-9. Features 1.2 and 1.3 in the central core area, following excavation........................................... 136

7-10. The distribution of lithic debitage in terms of density per cubic meter by size and investigator for Area B

7-11. The distribution of lithic debitage in terms of density per cubic meter by size and investigator for Area $\mathrm{C}$

7-12. Plan view of trenches and excavation units in Area B. 
7-13. Profile of the east wall of Unit II in BHT X showing the layer of stones extending away from the midden

7-14. Average maximum debitage size in TUs 8 and 9 by level in the $1 / 4$-inch fraction. ........................... 143

7-15. Average maximum debitage size in TUs 8 and 9 by level in the $1 / 1$-inch fraction........................... 143

8-1. Diagnostic artifacts. a: Bell; b: probable Bell; c: Bulverde; d, e: possible Bulverde; f, g: Carrizo. .... 148

8-2. Diagnostic artifacts. a-d, f, g: Castroville, e: probable resharpened Castroville; h, i: Darl. ............... 151

8-3. Diagnostic artifacts. a: Darl; b: Ellis; c-f: La Jita; g-i: Langtry................................................ 154

8-4. Diagnostic artifacts. a: Marcos; b-c: Marshall; d-e: Martindale; f-k: Montell. ............................... 158

8-5. Diagnostic artifacts. a: Montell; b, c, f-i: Nolan; d: Nolan-like; e: possible Nolan. .......................... 161

8-6. Diagnostic artifacts. a-i: Pedernales. ................................................................................. 165

8-7. Diagnostic artifacts. a, c, e: Pedernales; b, d: Pedernales preform; f: Tortugas; g: Uvalde; h: Williams.

8-8. Untyped dart point and bifaces. a: untyped dart point; b, c: gouges; d: graver; e: drill; f: Guadalupe tool,

8-9. Bifaces and unifaces. a: Butted knife; b: San Gabriel biface; c: burin; d: graver............................... 177

8-10. Miscellaneous artifacts. a: gouge; b: Clear Fork tool. ........................................................... 180

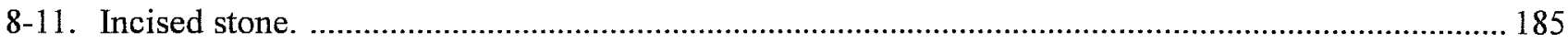

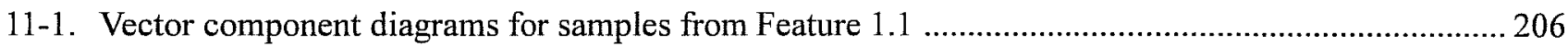

11-2. Equal-area stereographic projections of the directions of magnetization for samples from

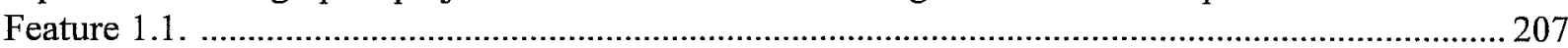

11-3. Plan view of Feature 1.2 in Level 5 of TU 8 showing locations of archaeomagnetic samples. ...........208

11-4. Vector component diagrams for samples from Feature 1.2 .......................................................209

11-5. Stereographic projections of the characteristic directions of magnetization for samples from

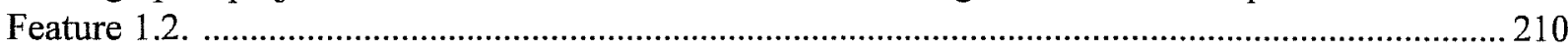

11-6. Vector component diagrams for samples from Feature 1.2 ..................................................... 211

11-7. Directions of the low- and high-temperature components for samples from Feature 2. .................... 212

11-8. Magnetic susceptibility profiles of soil samples from Area A, BHT S. ...................................... 213

11-9. Magnetic susceptibility profile 1 of soil samples from Area B, BHT N, located in the periphery

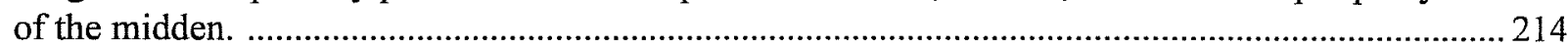

A-1. Location of trenches and stratigraphic units at 41BX126. .................................................... 255

A-2. Stratigraphic cross sections of Culebra Creek at 41BX126 as marked on A-1. .............................256

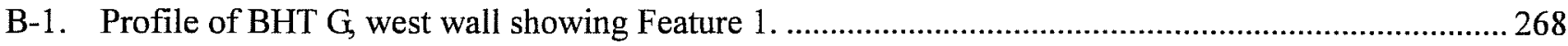

D-1. Schematic of the earth oven showing the various elements and the placement of the

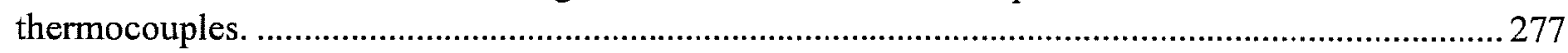

D-2. A line plot of the temperatures recorded within the various components of the oven. .....................279 
2-1. Cultural Chronology of South and Central Texas ................................................................... 13

6-1. Features and Associated Excavation Units (Features 8-10 not included) .......................................47

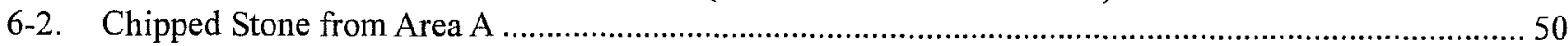

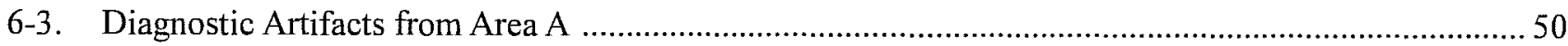

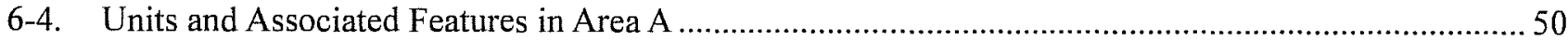

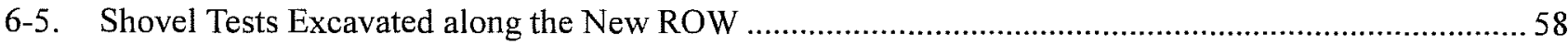

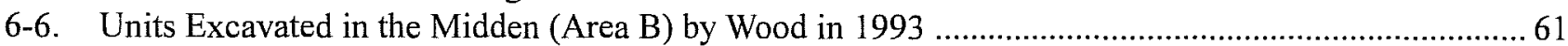

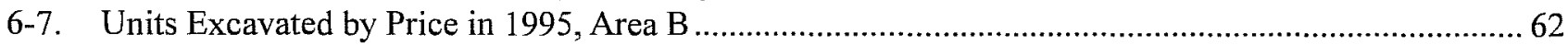

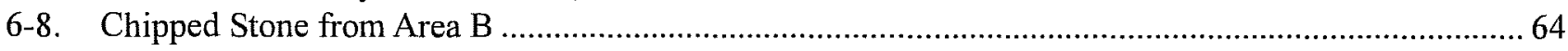

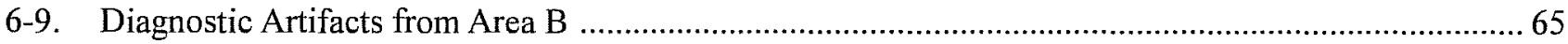

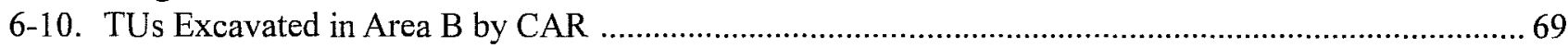

6-11. Mean Weights of Burned Rock, TU 8 ................................................................................. 73

6-12. Comparison of Artifact Counts and Stratigraphic Levels of Unit 12 and Unit C .............................90

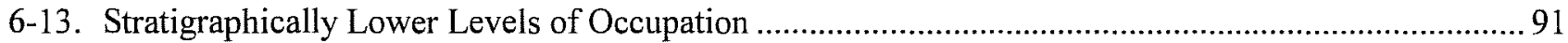

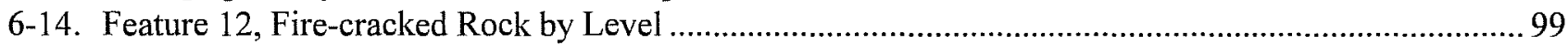

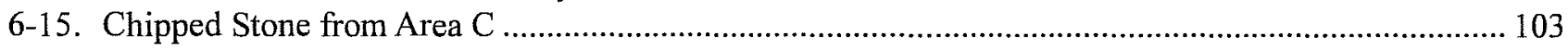

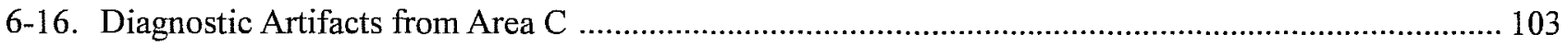

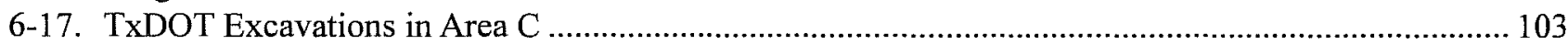

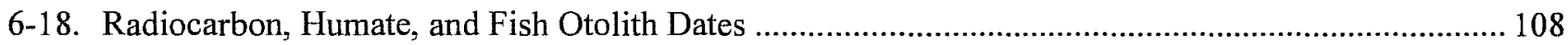

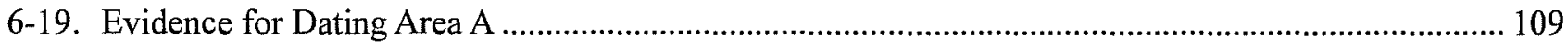

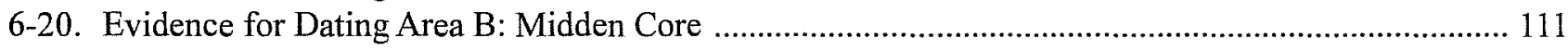

6-21. Evidence for Dating Area B: Midden Framework ............................................................... 112

6-22. Evidence for Dating Area B: Midden Periphery ..................................................................... 114

6-23. Evidence for Dating Area B: Nolan Component (Block Excavation) ........................................ 115

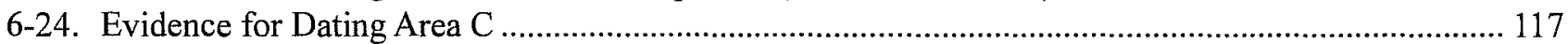

7-1. Total Volume $\left(\mathrm{m}^{3}\right)$ of Excavations in 1-x-1-m Units by Area and Investigator ............................... 138

7-2. Total Number of Lithic Debitage Recovered in 1-x-1-m Units by Area and Investigator ................... 138

7-3. Lithic Debitage Density per Cubic Meter Recovered in 1-x-1-m Units by Area and Investigator ....... 138

7-4. Average Size of Debitage in Subarea of Area B (1/4-inch fraction only) ......................................... 140

7-5. Lithic Debitage Recovered from TU 11, Area B-Periphery ............................................................ 142

7-6. Average Size of Burned Rock Recovered from TU 8, Central Core Area ...................................... 144

8-1. Biface Grain Size, Cortex, Burning, and Average Length by Reduction Stage .............................. 178

8-2. Frequency and Average Length of Bifaces by Cortex and Grain Size ............................................ 178

8-3. Frequency of Uniface Tool Blank Types by Grain Size, Cortex, and Burning; Average Length by Cortex and Tool Blank Types

8-4. Cortex Frequencies by Grain Size and Burning on Cores;

Average Length of Cores by Cortex and Grain Size ................................................................... 183

8-5. Number of Tools and Major Artifact Classes by Area .............................................................. 186

8-6. Number of Tools and Major Artifact Classes by Subarea in Area B ........................................... 187

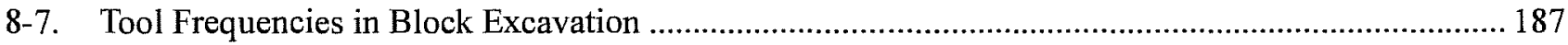

8-8. Frequency of Flake Types in Block Excavation ................................................................ 188

8-9. Ratio of Normal Flakes to Cores, and Biface Thinning Flakes to Bifaces and Projectile Points ......... 188

9-1. Flotation Sample Proveniences and Volumes ......................................................................... 192

9-2. Carbonized Plant Remains .................................................................................................. 193

9-3. Size Particle Distribution of Carbonized Wood in the Culebra Midden Samples ............................. 194 


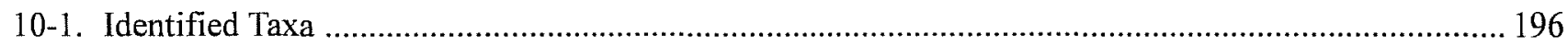

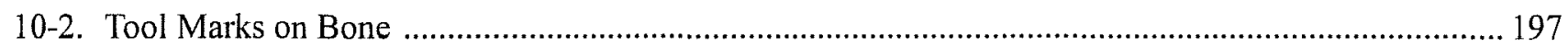

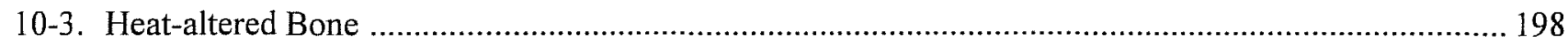

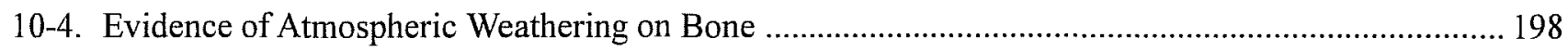

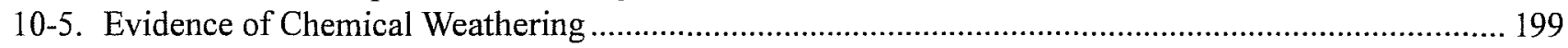

10-6. Comparison of Burned and Chemically Weathered Bone ……..................................................... 200

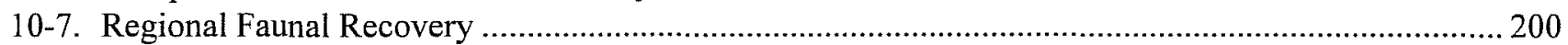

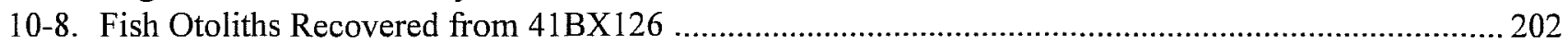

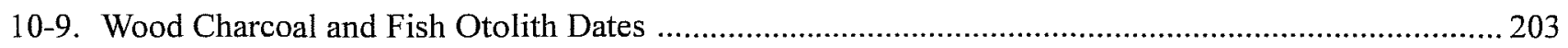

11-1. Archaeomagnetic Samples Collected from 41BX126 ................................................................... 204

12-1. List of Nolan Components in Texas ......................................................................................... 217

12-2. List of Montell, Marcos, and Castroville Components in Texas ……………………………............219

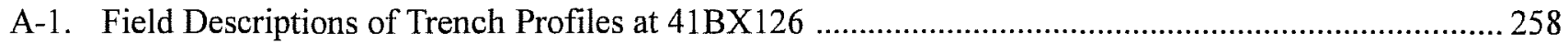

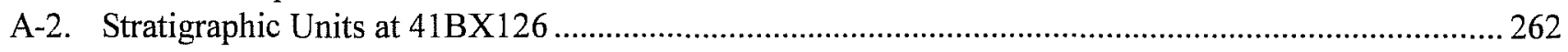

A-3. Location of Trenches at 41BX126 with Respect to the Terraces and the Deposits Beneath

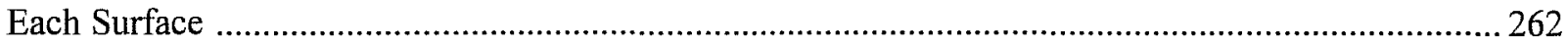

D-1. Cooking Temperatures for the Various Components in the Oven ...................................................22

D-2. Analysis of the Burned Rocks after Two Cooking Events ...............................................................228

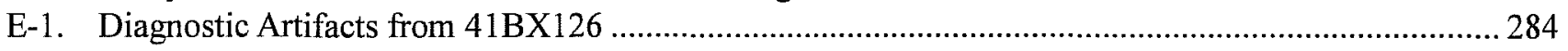

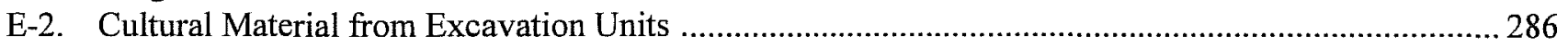

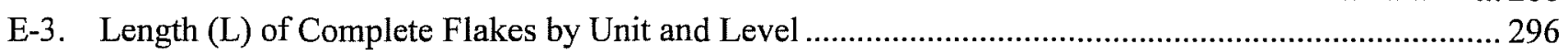

F-1. Faunal Material Recovered During Excavations at 41BX126 ........................................................300

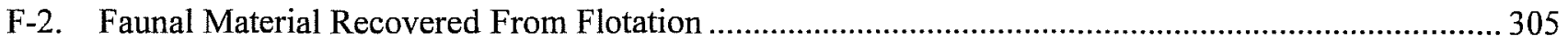




\section{Acknowledgments}

This project could not have been successful without the expertise and full cooperation of many people from numerous organizations. An integral part of investigative archaeology is the sharing of knowledge, thoughts, and ideas by professionals. We would like to thank several individuals who visited the Culebra Creek site and/or provided insights and provocative ideas and questions: James Abbott, Federico Almarez, Lewis Binford, Steve Black, Chris Caran, Susan Decker, Phil Dering, Lain Ellis, Glen Goode, Tom Hester, Kay Hindes, Brett Houk, Margaret Howard, Donald Johnson, James Karbula, Nancy Kenmotsu, Karl Kleinbach, David Kuehn, Chris Lintz, Rolfe Mandel, Raymond Mauldin, Al McGraw, Michael Petraglia, Dan Potter, Dennis Price, Richard Stark, Steve Tomka, Alston Thoms, Brad Vierra, and Pamela Wheat. Steve Black was kind enough to provide unpublished chapters from TARL's Wurzbach Road Project. We would like to single out the ideas and support of Alston Thoms who visited the site a number of times and was gracious enough to spend an entire Sunday at the site discussing midden formation and cooking with hot rocks.

Nancy Kenmotsu, Lain Ellis, and Al McGraw of the Texas Department of Transportation (TxDOT) office in Austin and Mary Richards from the San Antonio office were extremely helpful and instrumental in the implementation and scheduling of the project. The TxDOT field crew professionally assisted us with a backhoe, Gradall, and fencing.

Robert J. Hard served as principal investigator and C. Britt Bousman acted as co-principal investigator. Jeff D. Leach and Diane Cargill served as project archaeologists. CAR crew members who worked on the project included Ginny Chagnon, Donna Edmondson, Owen Ford, Chris Horrell, Richard Jones, Kimberly Kvernes, Tony Lyle, Kaylee McRae, Kristi Miller, Bruce Moses, Gloria Murguia, David Nickels, Bobby Rector, Ricky Robinson, and Andrew Scease.

Laboratory analysis was performed by Diane Cargill, Ginny Chagnon, Donna Edmondson, Chris Horrell, Richard Jones, Tony Lyle, Wilson McKinney, Kaylee McRae, Kristi Miller, Gloria Murguia, David Nickels, Bobby Rector, Ricky Robinson, Chris Horrell, Tony Lyle, and Owen Ford, who were frequently assisted by C. Britt Bousman. Barbara Meissner examined the faunal assemblage, and Anne Fox was consulted about the Historic artifacts recovered during testing. The mass of attribute data was entered into a computer database by Kaylee McRae. Mapping and illustrations were provided by Bruce Moses, Edgar Johnson, Fernando Londoño, and Kaylee McRae. Marcie Renner, CAR editor, prepared the report for publication in 1998, and in 2001Johanna Hunziker and Maryanne King compiled the reissue. 



\title{
Chapter 1: Introduction
}

\author{
David L. Nickels
}

\section{Project Description}

The Center for Archaeological Research (CAR) of The University of Texas at San Antonio (UTSA) conducted archaeological testing at the Culebra Creek site (41BX126), northwest Bexar County, Texas (Figure 1-1), in 1997. The testing is an element of a proposed highway improvement project which will impact the site. Two earlier testing projects by the Texas Department of Transportation (TxDOT) archaeologists identified cultural resources which required further archaeological testing to determine the eligibility of 41BX126 for nomination to the National Register of Historic Places (NRHP). Gregory Wood of TxDOT conducted testing at the site in 1993, as did Dennis Price of TxDOT in 1995. The archaeological investigations were accompanied by the continuation of geomorphological studies originally initiated by Charles D. Frederick during the 1995 testing project. Lee C. Nordt of Baylor University served as the consulting project geomorphologist during the 1997 project. This document reports the results of all three testing projects.

TXDOT funded the investigations through state appropriation and acted as the agency for oversight management of archaeological compliance-related activities during the duration of the testing. Because the planned construction project expanding Loop 1604 will include federal funds, making this a federal undertaking, it falls under the purview of the National Historic Preservation Act (NHPA) of 1966 (and subsequent amendments). The National Register of Historic Places (NRHP) and the Advisory Council for Historic Preservation (ACHP) were created by the NHPA. Section 106 of the NHPA states that the ACHP must be afforded a chance to comment when any cultural resources eligible for listing on the NRHP are located in an area to be affected by the actions of a federal agency or actions funded or permitted by federal agencies.
Under Sections 106 and 110 of the NHPA, the protection of cultural resources is related to their eligibility for listing on the NRHP which is in turn dependent on their "significance" as defined by the National Park Service (NPS) in 36 CFR 60. The National Historic Preservation Amendments of 1992 clarified Section 110 and directed federal agencies to establish preservation programs corresponding to their activities and effects on historic properties. Under Section 110, federal agencies may evaluate the significance of cultural resources not currently threatened to assist with the development of preservation planning. At the state level, the State Historic Preservation Officer (SHPO) at the Texas Historical Commission Department of Antiquities Protection (THCDAP) consults with and advises the lead agency (TXDOT in this case) about the implementation of the Section 106 and Section 110 processes. The federal regulatory process is described in detail in 36 CFR 800.

The purpose of the 1997 testing project was to investigate an additional piece of right-of-way (designated Area A by CAR) acquired by TxDOT since the two previous projects, and to evaluate the NRHP eligibility of $41 \mathrm{BX} 126$, as it was threatened by planned highway construction activities. Texas Antiquities Committee permit number 1782 was issued for the project. Fieldwork was conducted intermittently between January and May 1997. Robert J. Hard served as principal investigator and C. Britt Bousman acted as co-principal investigator. Daily field operations were directed by the project archaeologists, Jeff D. Leach and Diane A. Cargill. Crews varied from two to 12 CAR staff members and included Ginny Chagnon, Donna Edmondson, Owen Ford, Chris Horrell, Richard Jones, Kimberly Kvernes, Tony Lyle, Wilson McKinney, Kaylee McRae, Kristi Miller, Bruce Moses, Gloria Murguia, David Nickels, Bobby Rector, Ricky Robinson, and Andrew Scease. Field activities at the site included mapping, shovel testing, machine trenching, and excavating $1-\mathrm{x}-1-\mathrm{m}$ test units. 


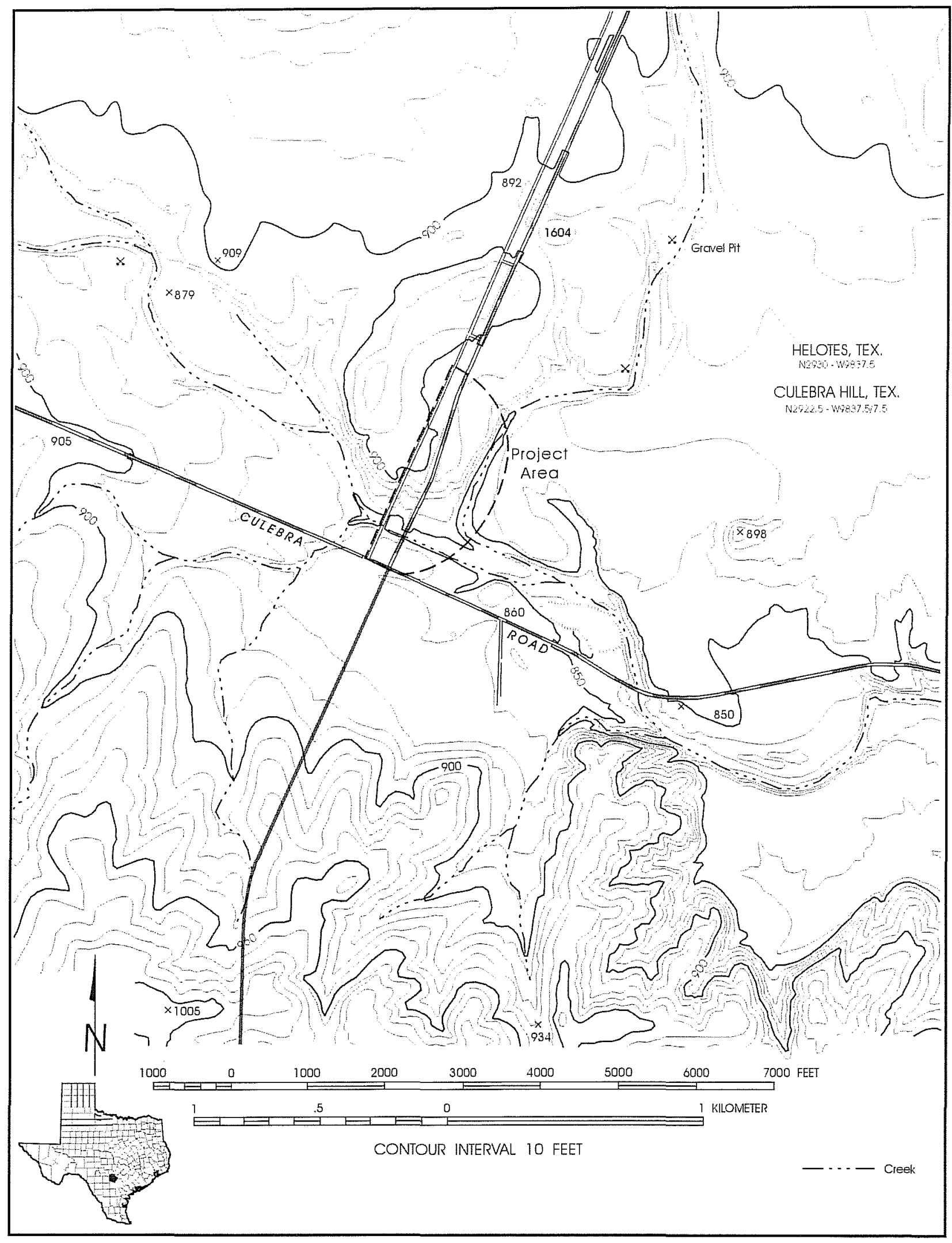

Figure 1. 41BX126 location. 
Laboratory analysis of the collected prehistoric artifacts and raw material was performed by Diane Cargill, Ginny Chagnon, Donna Edmondson, Chris Horrell, Richard Jones, Tony Lyle, Wilson McKinney, Kaylee McRae, Kristi Miller, Gloria Murguia, David Nickels, Bobby Rector, Ricky Robinson, Chris Horrell, Tony Lyle, and Owen Ford, who were frequently assisted by C. Britt Bousman. Barbara Meissner examined the faunal assemblage, and Anne Fox was consulted about the Historic artifacts recovered during testing. The mass of attribute data was entered into a computer database by Kaylee McRae. The artifacts, records, and other materials recovered or generated during the fieldwork and subsequent laboratory analysis are curated at CAR.

\section{Report Organization}

This report is divided into 12 chapters and six appendixes. The environmental background and archaeological context for the project area are discussed in Chapter 2. Chapter 3 synthesizes the documentation of the site during initial survey and two previous testing projects. Chapter 4 discusses the field and laboratory methodology employed during the three testing projects. Chapter 5 is an overview of the geomorphological investigations which were conducted during the 1997 testing project. The results of the archaeological testing are discussed in Chapter 6. Chapter 6 also provides evidence for chronometric dating of the site. The data presented in Chapter 6 and the accompanying appendices are used in Chapter 7 to discuss pertinent research issues related to the formation of burned rock middens identified during the testing. Chapter 8 presents the artifact analysis. Chapters 9 and 10 discuss macrobotanical and faunal remains. Chapter 11 presents the results and analysis of archaeomagnetic and soil susceptibility sampling. Specific recommendations about the eligibility of 41BX126 for NRHP nomination are presented in Chapter 12.

Supporting data are included in six appendixes to the report. Appendix A is Frederick's report of his 1995 geomorphological work at the site. Appendix B presents Frederick and Black's photomosaic recording of the burned rock midden. Appendix C contains descriptions and conclusions from the 1997 geomorphological study. Appendix D provides the results and interpretations of an experimental burned rock midden used to model the formation processes at 41BX126. Appendix E presents the raw attribute data for each artifact category. Finally, Appendix F presents the complete faunal data. 


\title{
Chapter 2: Setting
}

\author{
David L. Nickels
}

\section{Introduction}

The Culebra Creek site (41BX126) lies in the modern political boundary of western Bexar County near the confluence of Culebra and Helotes creeks at the base of the Balcones Escarpment. This advantageous location allowed the groups which occupied the site to exploit an ecotone encompassing riverine, upland, and semiarid adapted plants and animals. This chapter provides a synopsis of environmental and archaeological background information within an area encompassing the northern fringe of the south Texas plains, a western portion of the Gulf Coastal Plain, the southeastern edge of the Edwards Plateau, and the southern tips of the Post Oak Belt and Blackland Prairie.

\section{Regional Environmental Summary}

\section{Modern Environment}

Three major landform regions conjoin near 41BX126: the Balcones Escarpment of the Edwards Plateau, the Blackland Prairie, and the South Texas Plain (also known as the Rio Grande Plain). The Edwards Plateau, with elevations reaching $2,250 \mathrm{ft}$ above mean sea level (amsl) (Allison et al. 1975:76), is a hilly region, gradually sloping to the southeast, and ending in the escarpment running across the middle of the subregion. According to Van Auken (1988:45), the most characteristic flora include juniper (Juniperus ashei), plateau live oak (Quercus fusiformis), Texas persimmon (Diospyros texana), and agarita (Berberis trifoliata). In the western part of the region, mesquite (Prosopis glandulosa) and live oak (Quercus virginiana) are the dominant woody species (Blair 1950:112). Due to overgrazing by livestock and restricted range fires, much of the plateau has been overtaken by juniper in modern times (Buechner 1944:703-704; Van Auken 1993:199-210).
The Balcones Escarpment is a fault zone, curving through the center of the study area, consisting of blocky limestone, chalk, shale, and marl. The escarpment slopes to the southeast from about $700-1,000 \mathrm{ft}$ amsl (Taylor et al. 1991:119). The floral species are the same as those of the Edwards Plateau, with the addition of numerous riparian species in the river and creek bottoms (Van Auken 1988:55). The most economically important of these are nut trees, including oak, walnut, and pecan (Carya illinoensis) (Abbott and Woodruff 1986:24-30; Dalbey 1993:22). An intertwined diversity in biotic resources existing along the escarpment provides an ecotone which would allow humans to harvest a seasonal banquet of plants and animals (Collins 1995:366). Hall (1995:633-647) suggests a strong spatial relationship among prehistoric cemeteries and the distribution of nut-bearing species-particularly acorn (Quercus virginiana) and pecan trees-and prickly pear (Opuntia lindheimeri) tunas, and infers such a relationship is a result of being seasonally tethered to rich food resources. The rugged southern end of the plateau in the study area is incised by numerous southeasterly flowing rivers such as the Colorado, Guadalupe, San Antonio, Medina, Frio and Nueces, and their tributaries including Culebra and Helotes creeks.

The southern end of the escarpment includes areas of the Blackland Prairie, a rolling and well-dissected plain representing the southern extension of the true prairie running through the center of the country. The prairie was once dominated by tallgrass species such as little bluestem (Schizachyrium scoparium), big bluestem (Andropogon gerardii), Indiangrass (Sorghum linnaeanum), tall dropseed (Sporobolus asper), and silveus dropseed (Sporobolus silveanus). Much of this vegetation has been replaced by common invader species including mesquite, and huisache (Acacia smallii). Oaks, elms (Ulmus), cottonwoods (Populus), and native pecan are common along drainages (Gould 1975:11). 
The South Texas Plain is the western extension of the Gulf Coastal Plain. It is a nearly level to rolling plain which is moderately dissected by major river drainages through its northern half and by numerous intermittent creeks and the Bordas Escarpment in the south. The pre-Colonial vegetation was an open grassland mixed with brushy chaparral. Oaks, pecan, and ash were common along streams. Due in part to overgrazing and the exclusion of fire, the invasion of woody species has changed the vegetation into the "Texas brush country" dominated by mesquite, huisache, spiny hackberry (Celtis laevigata), whitebrush (Aloysia ligustrina), and others (Diamond et al. 1987:203-221; Gould 1975:12). Black (1989c:40) describes the Nueces-Guadalupe Plain subarea of the South Texas Plain as "areas of grass and thorny brush savannah" dissected by "narrow bands of riparian (streamside) vegetation" which Hester (1981) suggests are areas of "high density" resources. Studies along the San Antonio, Guadalupe, Frio, Sabinal and Nueces rivers suggest that flooding and modern climate have imposed a significant redistribution of riparian native vegetation (Ford and Van Auken 1982; Taylor 1982; Van Auken and Bush 1988; Wood and Wood 1988, 1989). The arid climate of the western portion of the Nueces-Guadalupe Plain changes to subhumid closer to the Gulf Coastal Plain (Hester 1981).

\section{Paleoenvironmental Data}

In order to understand past human behavior, we must know something of the environment in which prehistoric groups contended for resources. The changing scope and depth of paleoenvironmental studies provides broadly applicable schemes on climatic and vegetation shifts that have occurred over the past 18,000 years. More recent research continues to refine - and complicate-the big picture of Late Quaternary climatic change. Figure 2-1 depicts the climatic changes that have occurred over the past 12,000 years and the effects that those changes have had on vegetation and bison.

\section{Late Pleistocene}

The paleoclimate of Texas contains significant gaps "primarily due to the scarcity of deep, finely stratified, and well-dated deposits" (Stahle and Cleaveland 1995:51). However, inferences derived from an atmospheric general circulation model of simulated climatic influences over the past 18,000 years strongly correlate to evidence found in paleoenvironmental studies (Stahle and Cleaveland 1995:38-69). After the last full glacial episode around 18,000 B.P., Texas and northern Mexico were much wetter and colder than they are at present (Bryant and Holloway 1985:50). The South Texas Plain was a mosaic of woodlands, parklands, and scrub grasslands (Bryant and Holloway 1985:56). Between 20,000 B.P. and 14,000 B.P., pollen samples show that forests - pinyon-juniper woodlands in the Trans-Pecos area of west Texas and spruce-fir woodlands in central Texas-began to be replaced by spreading habitats of grass and scrub species, presumably because of increasingly warmer and drier conditions (Bryant and Holloway 1985:51-52). In the South Texas Plains, scrub grasslands began to dominate at the same time (Bryant and Holloway 1985:56).

In central Texas, pollen spectra from Boriack Bog suggest a shift from grasslands before 16,500 B.P. to woodlands before 12,500 B.P. in a moist and cool climate (Bousman 1994:79). The same spectra reveal a decline in spruce (probably cold-adapted) pollen by 15,000 B.P., indicating a trend toward a warmer climate. Bousman's (1992) oxygen isotope evidence from south Texas complements the bog pollen data, and suggests early warming by 15,000 B.P.

In south Texas, low resolutions of noble gases within the Carrizo aquifer in Atascosa and McMullen counties indicate that between 12,000 and 17,000 years ago temperatures were $5.2^{\circ} \mathrm{C}$ cooler than today (Stute et al. 1992:1000-1003), corroborating evidence of white spruce pollen found in Boriack Bog suggesting a mean temperature of about $5.5^{\circ} \mathrm{C}$ lower (Holloway and Bryant 1984; Stahle and Cleveland 1995). Nordt et al.'s (1994:80) analysis of $C_{3}-C_{4}$ plant ratios based $\delta^{13} \mathrm{C}$ values of organic carbon from the Applewhite project shows two shifts occurring in vegetation and 


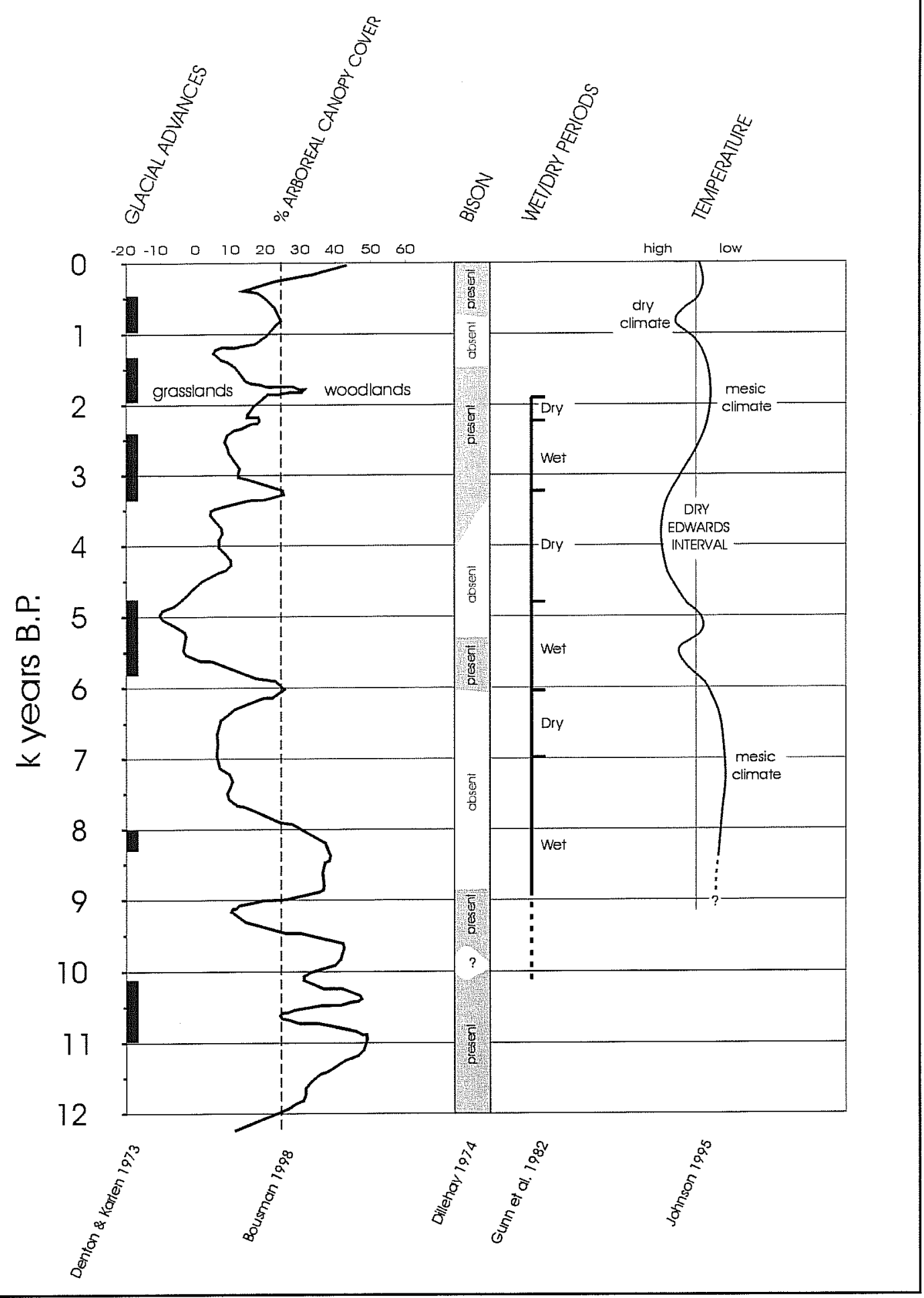

Figure 2-1. Climatic changes and effects through time.

climate during the Late Pleistocene. An increase in $\mathrm{C}_{4}$ plants (and temperature) is indicated for the thousandyear intervals of 14,000 to 13,000 B.P. and 11,000 to 10,000 B.P.
These indicators disagree with beetle fossils from pond sediments in north Texas (Elias 1994) which indicate a much cooler (less $10^{\circ} \mathrm{C}$ ) than modern average climate between 14,200 and 13,500 B.P. From Hall's Cave 
in the Edwards Plateau, and much closer to 41BX126, Toomey et al. (1993) argue that summer temperatures in the Late Pleistocene were $6^{\circ} \mathrm{C}$ cooler than present averages, and that by 13,000 B.P. (or 12,500 B.P. [Toomey and Stafford 1994]), the wetter interval became warm and more arid. Between 12,500 and 11,800 B.P., the Boriack Bog data indicate that a drier episode stimulated a brief shift to grasslands, again corroborated by oxygen-isotope ratios showing a cooler setting in south Texas (Bousman 1992, 1994:80). The Hall's Cave record indicates a wetter interval around 11,000 в.P. (Toomey and Stafford 1994).

\section{Early Holocene}

Pollen samples from the Llano Estacado and the dry caves of the Trans-Pecos region prompted Bryant and Shafer (1977:15-19) to suggest a trend of gradual warming and drying throughout the Holocene (after about 10,000 в.P.). Others (including Aten 1979; Gunn and Mahula 1977; MacNeish 1958:199) use data from Oklahoma, Eastern Texas, and the Sierra de Tamaulipas in Mexico to propose a more variable change from the colder Pleistocene to the modern climate.

More than 17 years ago, innovative research in opal phytolith analysis from archaeological sites on the Coastal Plain of south Texas (Robinson 1979) also showed that, at least since the Early Holocene, climatic change has been highly variable. Fluctuations in the Holocene trend are also suggested by Bousman (1994), based on the Boriack Bog and Weakly Bog data from central Texas. Toward the Pleistocene-Holocene boundary at about 10,000 B.P., arboreal species in the Boriack Bog spectra show a return of woodlands up to 9500 B.P., followed by their decline and a reestablished predominance of open vegetation communities. Woodlands that had been reestablished by 8750 B.P. were again replaced by grasslands by 7500 B.P. (Bousman 1994:80). Although poorly dated, Robinson (1979:109) associated his oldest phytolith sample with "Late Paleo-Indian or Pre-Archaic" and suggested an age of about 8000 B.P. The predominance of tall grass species, white oak phytoliths, a generally high frequency of other tree species (unidentifiable), and the overall small size of the grass phytoliths combined to indicate a wet environment.

\section{Middle Holocene}

The continuous decline of the woodlands in the Early Holocene was briefly checked around 6000 B.P., but resumed its slide until 5000 B.P. when arboreal pollen slowly increased with the appearance of a wetter climate (Bousman 1994:80). This brief mid-Holocene arid period indicated at Boriack Bog agrees with data presented by Nordt et al. (1994) from the Applewhite project in San Antonio, where a dry period for roughly the same time frame (6000 to 4800 B.P.) is indicated. Humphrey and Ferring (1994) discovered the same arid episode in north central Texas, but with greater duration (6500-4000 B.P.), agreeing with the revised interpretation from Hall's Cave that gives an episode between 7000 and 2500 B.P. (Toomey and Stafford 1994). A later occurrence between 5000 and 2500 B.P. (calibrated) is reported by Johnson and Goode (1994). The opal phytolith records from the Wilson-Leonard site in central Texas (Fredlund 1994) and two sites on Coleto Creek in south Texas (Robinson 1979:111) agree with increasing aridity in the Middle Holocene, indicated by spreading grasslands around 4400 B.P. and ca. 4500 B.P., respectively. However, a sample from slightly higher in the Coleto Creek strata with roughly the same age argues for a quickly appearing, yet brief wet episode (Robinson 1979:111), followed by a sample indicating a return to an arid climate up to ca. 2750 B.P.

Phytolith analysis of sediments from the Choke Canyon project (Robinson 1982:597-610) add to the claim of considerable climatic variability. Between 5300 and 4300 B.P., Robinson (1982:598) infers a cool, mesic climatic regime that shifts to a more arid period and then returns to conditions both cooler and wetter than today's by 3250 в.P.

\section{Late Holocene}

Varied indicators for a fluctuating climate in the Late Holocene continue, but do not necessarily agree. Nordt et al. (1994) suggest a warm and dry episode between 3000 and 1500 B.P. based on deposits from San Antonio. Toomey and Stafford (1994) see a wet period appearing about 2500 B.P. at Hall's Cave. Their observations agree with those of Robinson (1979:112), suggesting a very wet episode. Ricklis's (1994) study 
of oyster-growth patterns on the Texas Gulf coast tentatively implies a shift to a cooler climate at ca. 3000 B.P., emerging out of a much warmer Middle Holocene. The Gulf Coast data tend to agree with the Choke Canyon analysis, pointing to mesic conditions (similar to today's) by 2450 B.P. (Robinson 1982:598-599). Afterwards, a shift to more xeric conditions occurred by 1000 B.P., but Robinson suggests that they may have been more mesic than modern conditions. The predominance of short grass species nicely agrees with large quantities of bison remains documented in archaeological context at Choke Canyon (Robinson 1982:599). Grass pollen frequencies in the Boriack Bog and Weakly Bog pollen spectra indicate drying episodes at 1600-1500 B.P. and 500-400 B.P. (Bousman 1994:80).

\section{BX126: Specific Environmental Information}

41BX126 is located in western San Antonio in Bexar County, Texas (see Figure 1-1). The project area is within the Nueces-Guadalupe Plain, a northern biogeographical subarea of the South Texas Plains. Adjoining the Nueces-Guadalupe Plain to the east is the Gulf Coastal Plain, and beyond is the Gulf of Mexico, approximately $224 \mathrm{~km}$ to the east. A few kilometers to the north, plains give way to an abrupt rise: the Balcones Escarpment and prominent Edwards Plateau. The Balcones Escarpment serves as a geographical division between the Central Texas archaeological region to the north and the South Texas region to the south (Black 1989a).

\section{Climate}

The project area has a modified subtropical climate, with cool winters and hot summers (Taylor et al. 1991:118), primarily influenced by the low altitude, low elevations, and the Gulf of Mexico to the east. Daytime humidity ranges from $50-80$ percent throughout the year, while clear skies prevail over 70 percent of the summer and 50 percent of the winter. The coldest average month is January (average temperature: $62.3^{\circ} \mathrm{F}$ ), and the hottest average month is August (average temperature: $94 .{ }^{\circ} \mathrm{F}$ ) (Taylor et al. 1991:Table 11). Rainfall averages 27.89 inches (Taylor et al. 1991:Table 11), but a great deal of variation in rainfall exists from year to year, with 52.28 inches recorded in 1973 and 10.11 in recorded in 1917 (McGraw and Hindes 1987:37). The growing season averages 275 days south of the Balcones Escarpment (Taylor et al. 1991:119), between March 1 and December 1. Light snowfalls occur every three or four years (Taylor et al. 1991:118-119).

\section{Biotic Resources Surrounding 41BX126}

The area around 41BX126 is an ecotone incorporating diverse ecological communities, including Juniper-Oak-Mesquite Savanna, Blackland Prairie, Oak-Hickory Forest, and Mesquite-Chaparral Savanna (Johnson 1967:73). Stahle and Cleaveland (1995:55) suggest that the diversity in forest mottes was created from microenvironments existing in the late glacial period (ca. 15,000 B.P.). Blair (1950:112) notes that the joining of three biotic provinces occurs in Bexar County: the Texan (eastern half of the county), the Balconian (the Edwards Plateau and Balcones Escarpment), and the Tamaulipan (southwestern county, South Texas Plain).

The geographic location of the project area, essentially on the periphery of these three biotic provinces, provides a dynamic setting for a great diversity in riverine, uplands, and xeric vegetation and fauna. Two ecological settings dominate the project area landscape within the ecotone: uplands and creek zones. Descriptions of the project area prior to 1900 reveal that the uplands were once dominated by tall grasses, with occasional stands of brush and mesquite (Inglis 1964).

Early descriptions (1675-1722) of plant life by Spanish observers, who left a written record of the area in western Bexar County, suggest that mesquite and other thorny scrub were present in scattered mottes, while the land to the south was open grasslands with little or no brush (Inglis 1964:Plate 1). Later observers documented the change on the South Texas Plain from grassland/scrub grassland mosaic to the domination of thorny brush (Inglis 1964:Plates 1-3). By 1900 areas of southern and western Bexar County 
were described as "dense brush or chaparral" (Inglis 1964:Plate 3). Likely causes for this change in plant communities (when there were no discernible progressive changes in climate) are a combination of overgrazing and human interference with natural range fires (Black 1989b:15)

Historic alterations to the primary landscape include plowing, overgrazing, stream rechannelization, controlled burning, and the introduction of deep wells. These have undoubtedly caused lower water tables and have concurrently altered the plant and animal community. Many springs feeding the streams emanating from the Balcones Fault are now either dry or do not discharge sufficient flows to reach the South Texas and Gulf Coastal plains before evaporating or seeping into the sandy soils upstream (Brune 1981:75). Both Culebra and Helotes creeks are now intermittent drainages.

\section{Geology}

During the Upper Cretaceous period, approximately 78 million years ago (Judson and Kauffiman 1990:150), Austin Chalk and marls began forming and now comprise the bedrock underlying the project area and exposed at the edge of the site by Culebra Creek downcutting. Plio-Pleistocene Uvalde Gravels undercut by fine silt and gravels of the Leona formation are present in a small upland area above the site (Barnes 1983). Fluviatile terrace deposits draining sand, gravel, silt, and clay from the Edwards Plateau formed in the Late Pleistocene approximately 15,000 years ago along Culebra and Helotes creeks.

\section{Soils}

Alluvial soils of the Lewisville (LvB) and Patrick $(\mathrm{PaB})$ series make up the terraces on which 41BX126 rests. Lewisville soils are frequently thicker than Patrick soils because the latter generally lie atop a gravel layer about three feet below the surface. These series are generally dark grayish brown to brown in color, and calcareous with a weak blocky silty clay structure that tends to crack and shift with episodes of wetting and drying (Taylor et al. 1991:25-27, Sheet 34). Archaeological investigations are hampered by these dynamics because of the possibility that artifacts are displaced to deeper sediments if cracking occurs (Hester 1980).

\section{Lithic Resources}

Beyond the project area, rich sources of chert crop out in the Edwards Plateau region. Nodules and cobbles of high-quality Edwards chert gravels are commonly found eroding out of the limestone on the plateau itself, and in creekbed gravels originating in the plateau (Black and McGraw 1985; Potter et al. 1992). The headwaters of Culebra and Helotes creeks originate from the Edwards Limestone formations on the Edwards Plateau. No doubt the creekbeds in the project area contain fluvial deposits of the fine- to coarsegrained, medium to grayish brown, abundant cherts eroding out of the Edwards (Barnes 1983). Tarrant association $(\mathrm{TaB})$ soils found on the upland on the northern edge of the site has fist-size or larger chert cobbles in varying quantities (Taylor 1991:31, Sheet 34). $41 \mathrm{BX} 126$ lies $2.5 \mathrm{~km}$ east of the modern mapped edge of a Uvalde gravel distribution. Prolific raw material sources persist in the project area.

\section{Archaeological Background}

\section{Previous Research}

Large-scale surveys covering thousands of acres along the Balcones Escarpment and the eastern Edwards Plateau have been highly effective in discovering archaeological sites. Seventy-two sites were recorded on 5,600 acres at Camp Bullis in northern Bexar County (Gerstle et al. 1978). The survey covered the watersheds of upper Cibolo Creek, Ranger Creek, and upper Salado Creek. Thirty-four of those sites were associated with diagnostic lithic tools from the Paleoindian through Late Prehistoric periods. Thirtyfour sites were recorded during a 2,500-acre survey of the East and West Elm Creek branches of the upper Salado creek in the Encino Park area of northern Bexar County. Those sites contained Paleoindian through Late Archaic components (McGraw et al. 1977:1029). Thirty-one prehistoric sites dating from the Paleoindian through Late Prehistoric periods were 
found during a 604-acre survey of the upper Cibolo in southern Kendall County (Bass and Hester 1975:924; Kelly and Hester 1976:29). Nickels's (1998) survey of 103 acres peripheral to Cibolo Creek near Boerne in southern Kendall County recorded seven prehistoric sites. Paul McGuff recorded 28 prehistoric sites along Leon Creek in northern Bexar County in 1970 and 1971 (site reports on file at CAR). A survey of lower Medio Creek by McGraw (1977) documented 15 prehistoric sites. In 1987 CAR surveyed 3,539 acres and documented 52 sites along the Medina River for a cultural assessment of the area to be affected by the proposed Applewhite Reservoir (McGraw and Hindes 1987). Nickels et al. (1997a) surveyed 3,860 acres at Lackland Air Force Base in southwest Bexar County and recorded 68 prehistoric sites.

A few of the more significant sites in the region have been tested or excavated (Figure 2-2). The Richard Beene site (41BX831) is located on the Medina River, in the Applewhite Reservoir project area, $12 \mathrm{~km}$ south of Medina Annex. It was excavated in 1991 and further tested in 1995. The site is deeply buried in the first terrace (Applewhite Terrace) above the Medina. Its well-defined stratigraphy yielded artifacts and fauna representing a continuous occupation from the Paleoindian through Late Prehistoric periods (Thoms 1992:17-26, 1996). The Panther Springs Creek site (41BX228) on the Salado Creek drainage, $20 \mathrm{~km}$ north of the project area, was tested in 1979 and then again in 1992. Early Archaic through Late Prehistoric components were defined by diagnostic stone tools (Potter and Black 1995:23-54). Tested heavily in 1995, 41BX47 is a deeply buried, intact Paleoindian through Middle Archaic campsite on the terraces of Leon Creek, $25 \mathrm{~km}$ north of Lackland (Tennis 1996; Tennis and Hard 1995). Although not well published, Pavo Real (41BX52), in the Leon Creek floodplain at Loop 1604, is a Clovis and Folsom lithic workshop (Henderson 1980).

Ongoing research by the Texas Archeological Research Laboratory (TARL) at The University of Texas at Austin is resulting in a comprehensive assessment of the area to be impacted by the proposed Wurzbach Parkway. This includes the Walker Ranch Historic District on Panther Springs Creek, as well as other sites in the upper-middle Salado Creek watershed. The approach taken by TARL has been innovative and thorough. This is exemplified by the work at the Higgins site (41BX184), and the manner in which the Wurzbach research is being reported. The first two of a series of modules present the conceptual framework (Potter et al. 1995) and testing results from several prehistoric sites (Potter and Black 1995). The first module is particular useful for its explication of the concept of historic contexts and the offer of an intermediate framework in the absence of a regional planning document (Black and Potter 1995:45-51).

The Wurzbach research also presents the modern theoretical approach best suited for local prehistoric research: hunter-gatherer mobility and subsistence in an ecological context. Since Bexar County represents a transitional zone between three biotic provinces, with geomorphically and geographically changing landforms, different resources are available in each area. The potential for diverse site function across the county is high. The study of archaeological sites in the watershed areas of Salado Creek (Katz 1987; Quigg 1988), Leon Creek (Espey, Huston and Associates 1989; Henderson 1980), and Olmos Creek (Stothert 1989) helps in the total assessment of site distribution along watercourses. The recent and ongoing projects discussed above have direct implications for prehistoric cultural resources within the area surrounding 41BX126.

\section{Cultural Chronology}

\section{Prehistoric Chronology}

Several scholars have offered sound but differing arguments for cultural chronologies for central Texas. Using the earlier works of Suhm (1960), Johnson et al. (1962), and Sorrow et al. (1967) as a springboard, Weir (1976) and Prewitt (1981a, 1985) reviewed the archaeological data from central Texas and established a chronology defined by phases. Although some of their data have been criticized as unreliable and their phases critiqued (e.g., Collins 1995; Johnson 1987), they stimulated their colleagues to investigate empirical methods for inferring cultural behavior. Black (1989a, 1989b) reviewed the available data and offered a synthesis of prehistoric intervals. Collins 


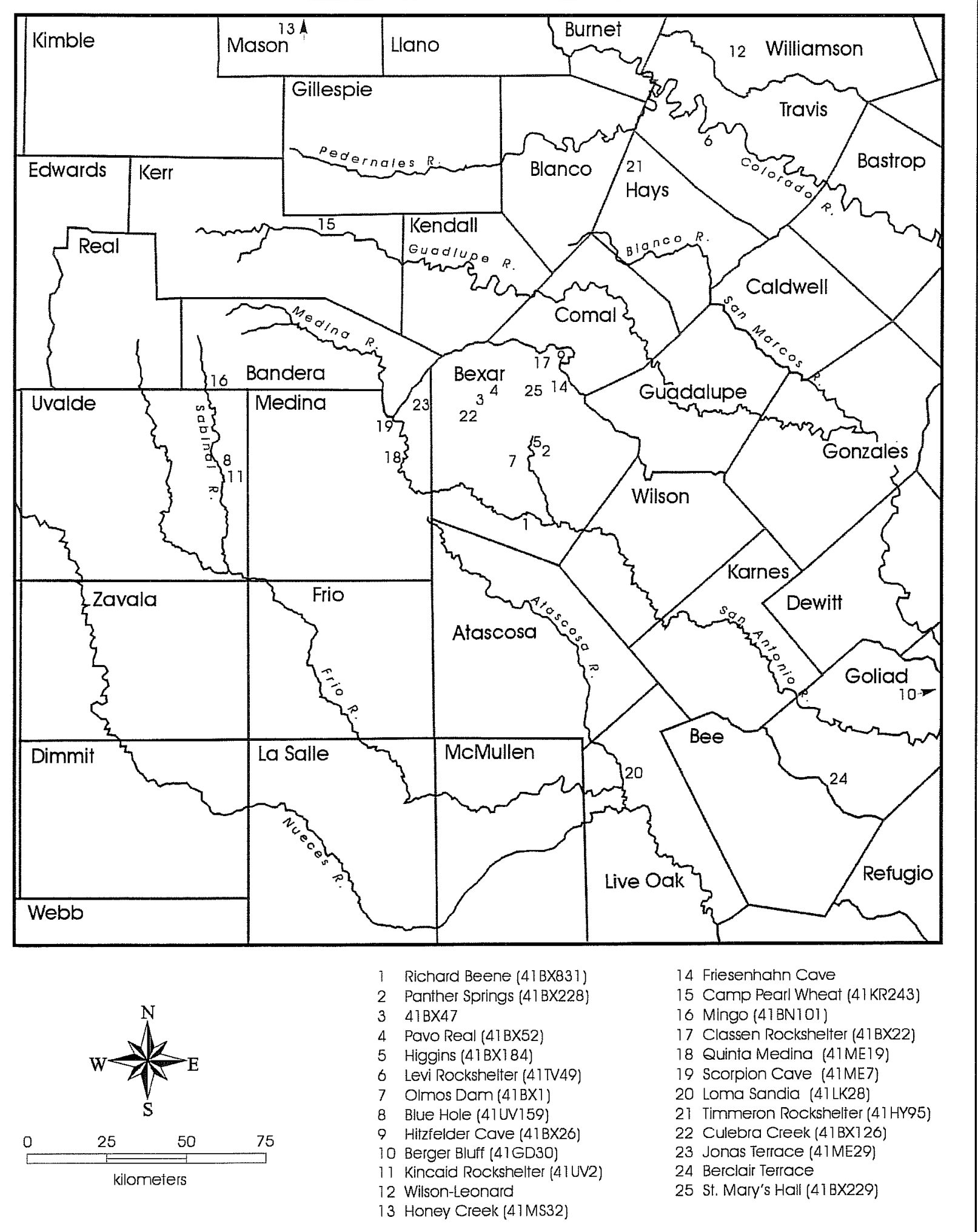

Figure 2-2. Archaeological sites discussed in the text. 
(1995) reviewed the archaeological and palynological evidence for central Texas and offered revised dates for human occupation from the Paleoindian through Historic periods.

Refining a cultural chronology for south Texas is much more problematic, due to the compressed nature of the archaeological record and limited excavations conducted in the region (Hester 1995:433). Hall et al. (1982:463, 1986:393-406) analyzed radiocarbon dates and artifact assemblages from Choke Canyon sites in western Live Oak and eastern McMullen counties to establish a local chronology. Black (1989c:39-62) synthesized available data from south Texas and offered a chronology similar to that of Hall et al. (1982). Both chronologies were considered by Turner and Hester (1993), who offer slightly different chronological periods based on evidence found more recently in south Texas. Supported by data retrieved from Loma Sandia in Live Oak County, Black (1995a:31-45) updated his south Texas chronology, again confirming that of Hall et al. (1982). Also considering Hall's scheme, Hester (1995:433) acknowledges the paucity of information that exists for south Texas and as such offers only a "general framework" for prehistoric periods particular to the region. The dates in Table 2-1 and the following discussion are derived primarily from Black (1995a), Collins (1995), and Hester (1995). A brief discussion of the Transitional Archaic as defined by Turner and Hester (1993) and Hester (1995) is also presented. All dates are approximate and given as ${ }^{14} \mathrm{C}$ years before present (в.P.), i.e., before 1950.

\section{Pre-Clovis}

Although humans may have inhabited the landscape before 11,500 B.P., solid evidence does not support their existence. The argument that artifacts recovered from Levi Rockshelter in Travis County are older than Paleoindian (Alexander 1983:133-145) is not supported by clustered radiocarbon dates or distinct artifact and extinct fauna assemblages within well-defined stratigraphy (Collins 1995:380-381). Although human behavior is inferred on stone artifacts from Friesenhahn Cave (Krieger 1964) and mammoth bones at the Waco Site (Fox et al. 1992:51-73), all are problematic for the same reasons given for Levi Rockshelter. From Hitzfelder
Cave, 30 miles north of San Antonio, Givens (1968:49) recovered several skulls described as "showing a combination of morphologically 'archaic' traits. In varying degrees, these have a pronounced supra-orbital torus, marked postorbital constriction, a sloping forehead, and are dolichocranic (longheaded)." Unfortunately, no radiocarbon dates are available to substantiate the surmised antiquity of the remains. The Middle Archaic points found with the burials suggest the skeletons are more likely 5,000 to 6,000 years old (Givens 1968). As Collins (1995:380-381) offers, eroded landforms are not likely to yield solid stratigraphic proof of human occupation earlier than late Pleistocene, and if we do find earlier occupations on stable landforms, what comprises the signature of a Pre-Clovis culture?

\section{Paleoindian}

This phase spans the period estimated at between ca. 11,500-8800 в.P. in central Texas (Collins 1995:381-383) and between 11,200-7,950 в.P. in south Texas (Hester 1995:433-436), although a few claims to older sites exist (Alexander 1963, 1983; Fox et al. 1992; Krieger 1964). The Paleoindian period began toward the close of the Pleistocene. Diagnostic artifacts include Clovis and Folsom projectile points. Certainly the wide distribution of Clovis-type points across most of North America and even into Central America suggests a wide dispersal of the people who made them (Kelly 1993; Wenke 1990:201). Within Texas's political boundaries, Meltzer and Bever (1995:47-81) documented the presence of 406 Clovis points in 128 of 254 counties. Other artifacts associated with the Clovis culture include bifaces and prismatic blades, engraved stones, bone and ivory points, stone bolas, ochre, and shaft straighteners.

In general the Paleoindian adaptation has been considered to be one of small bands of nomadic, biggame hunters following herds of Late Pleistocene fauna-including mammoth, mastodons, bison, camel, and horse-across North America (Black 1989a). More recently, emphasis has been placed on the wide diversity of plants and animals used for subsistence by these early Americans (Black 1989a; 
Table 2-1. Cultural Chronology of South and Central Texas

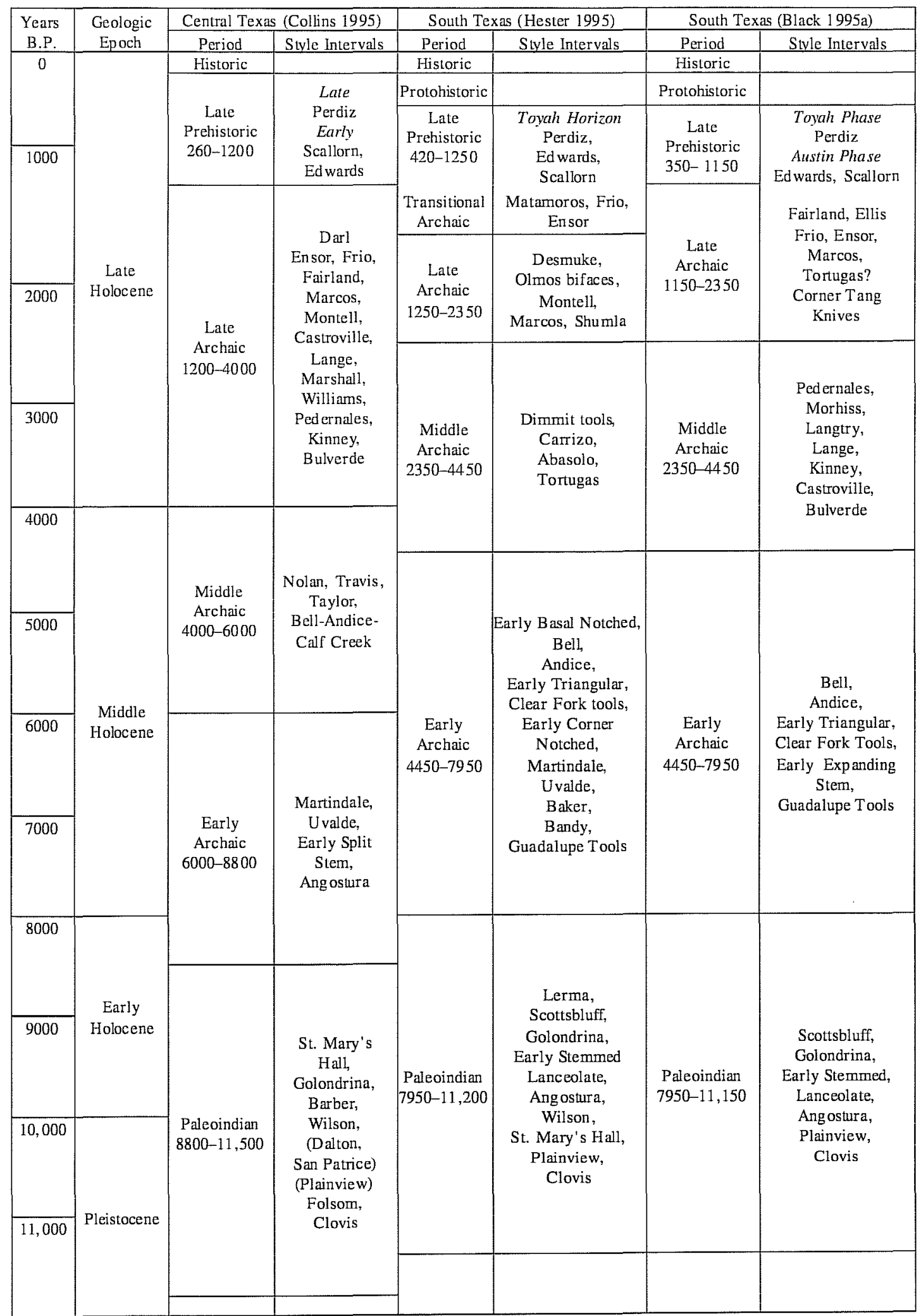


Hester 1983), such as turtles, tortoises, alligators, mice, badgers, and raccoons (Collins 1995:381), although they undoubtedly hunted the large animals as well (Dibble and Lorraine 1968). Known Clovis site types include killsites, quarries, caches, open campsites, ritual sites, and burials (Collins 1995:381-383; Hester 1995:433-436). A Folsom interval follows the Clovis. Folsom artifacts are fairly common in central and south Texas; however, no camp sites or killsites have been found south of Pavo Real in Bexar County (Hester 1995:434-435).

Most Paleoindian finds in central and south Texas have consisted of surface lithic scatters on upland terraces and ridges (Black 1989a:25, 1989c:48). A few Paleoindian components deeply buried in alluvium have been discovered, such as the Berclair Terrace site (Sellards 1940), the Berger Bluff site (Brown 1987), Kincaid Rockshelter (Collins et al. 1989), the Wilson-Leonard site (Collins et al. 1993), and at recent excavations of the Richard Beene site (Thoms et al. 1996). Many Paleoindian points have been recovered from surface contexts in Bexar and nearby counties (Chandler and Hindes 1993; Hester 1968a, 1968b; Howard 1974; Meltzer and Bever 1995; Nickels et al. 1997b). A late Paleoindian component with apparent high integrity has also been reported at the St. Mary's Hall site in Bexar County (Hester 1990:14-17, 1995:435).

As the warming that marked the transition from Pleistocene to Holocene climates began to take effect in Texas, prehistoric inhabitants adapted with changes in life style. This climatic shift is also marked by the decline and extinction of mammoth, mastodon, horse, camel, and giant bison (Bison antiquus). With the possible exception of the Berclair Terrace site (Sellards 1940), archaeological evidence suggests that after 8000 B.P., large gregarious game animals were either extinct or eliminated from Texas. Human hunters were forced to concentrate on deer, antelope, and other medium-size or smaller game. Changes in the subsistence base required technological shifts that mark the beginning of a new cultural period known as the Archaic.

\section{Early Archaic}

Collins (1995:383) dates the Early Archaic from 8800 to 6000 B.P. in central Texas, with three divisions based on projectile point types, while Hester (1995:436-438) identifies the Early Archaic with Early Corner Notched and Early Basal Notched dart points roughly dating between 7950 to 4450 B.P. The extinction of large herds of megafauna and the changing climate at the beginning of the Holocene stimulated a behavioral change by the Prehistoric inhabitants of south Texas (McKinney 1981). While the basic hunter-gatherer adaptation probably remained intact, an economic shift away from big game hunting was necessary. In general, more intensive exploitation of local resources in central Texas-such as deer, fish, and plant bulbs-is indicated by greater densities of ground-stone artifacts, fire-cracked rock cooking features, and more specialized tools such as Clear Fork gouges and Guadalupe bifaces (Turner and Hester 1993:246, 256). Weir (1976) speculates that Early Archaic groups were small and highly mobile, an inference from the fact that Early Archaic sites are thinly distributed and that diagnostic types are seen across a wide area, including most of Texas and northern Mexico. Story (1985) believes that population densities were low during this period, and that groups consisted of related individuals in small bands with "few constraints on their mobility" (Story 1985:39). Their economy was based on diffuse utilization of a wide range of resources, especially such year-round resources as prickly pear and lechugilla, as well as rodents, rabbits, and deer (Story 1985:38).

Sites near the study area with components from this period include 41BX47 (Tennis 1996), Richard Beene (Thoms et al. 1996), and several located on Camp Bullis in northern Bexar County (Gerstle et al. 1978) and at Choke Canyon (Hall et al. 1986).

\section{Middle Archaic}

Collins (1995:383) defines this intermediate interval of the Archaic as lasting from about $6000-4000$ B.P. in central Texas, but Hester (1995:438-441) suggests that the period between 4450 and 2350 B.P. more correctly 
reflects the Middle Archaic in south Texas. The Middle Archaic appears to have been a time of increased population, based on the large number of sites from this period in south and central Texas (Story 1985:40; Weir 1976:125, 128). The reasons for this increase are not known, but the amelioration of a very dry period (Altithermal) during the Early Archaic is often seen as the prime mover (Sollberger and Hester 1972:338; Story 1985:40). A wide variation in projectile point styles at the Jonas Terrace site suggest "a time of ethnic and cultural variety, as well as group movement and immigration" (Johnson 1995:285). On the South Texas Plains, exploitation of widely scattered, year-round resources such as prickly pear continued (Campbell and Campbell 1981:13-15), as did hunting deer and rabbit. However, a shift to concentrated, seasonal nut harvests in the riverine environments of the Balcones Escarpment seems to have occurred (Black 1989a). Weir (1976) believes that an expansion of oak on the Edwards Plateau and Balcones Escarpment led to intensive plant gathering and acom processing. He also believes that the widely scattered bands prevalent in the Early Archaic now began to coalesce, at least during the acorn-gathering season, into larger groups who shared the intensive work of gathering and processing the acorn harvest (Weir 1976:126). Many researchers believe burned rock middens result from this endeavor (Creel 1986; Prewitt 1991; Weir 1976). Other investigators doubt this conclusion (Black et al. 1993; Goode 1991), but the exact processes which formed the burned rock middens are still a matter of controversy (Black 1989a:28; Black et al. 1997; Hester 1991).

The common presence of deer remains in burned rock middens encourages the view that deer processing took place at these sites (Black and McGraw 1985:278; Weir 1976:125). Bison bone is encountered in archaeological sites in central and south Texas, at least occasionally, during all but the earliest part of the Middle Archaic (Dillehay 1974). There has been a tendency to equate presence of burned rock middens with $a b-$ sence of bison (Prewitt 1981a); however, examinations of several recent faunal reports show that after about 4500 B.P., bison and burned rock middens are contemporaneous, although not at the same sites, at least in the southern Edwards Plateau and northern South Texas Plain (Meissner 1993).

\section{Late Archaic}

Collins (1995:384) dates the final interval of the Archaic in central Texas to approximately $4000-800$ в.P. Hester believes the Late Archaic in south Texas may better be defined as between $2350-1250$ B.P. Some researchers believe populations increased throughout the Late Archaic (Prewitt 1985), while others feel populations remained the same or fell during this period (Black 1989a:30). Prewitt (1981a:80-81) asserts that the accumulation of burned rock middens nearly ceased during the course of this period; however, excavations at the Blue Hole site in Uvalde County (Mueggenborg 1994:1-74), the Honey Creek midden at 41 MS32 (Black et al. 1997), the Jonas Terrace site in Medina County (Johnson 1995), and the Mingo site in Bandera County (Houk and Lohse 1993:193-248) provide evidence that large cooking features up to 15 $\mathrm{m}$ in diameter were still very much in use (see also Black et al. 1997). The subsistence base is assumed to have broadened, favoring a wider variety of plants and animals (Black 1989a:30). By about 1450 B.P., bison had again disappeared (Dillehay 1974).

A proliferation of distinguishable human cemeteries has been attributed to this period (Hester 1995:439440). At Loma Sandia, these date between ca. 2550 and 2750 B.P. (Taylor and Highley 1995). Story (1985:44-45) believes the presence of cemeteries at sites such as Ernest Witte (Hall 1981), Hitzfelder Cave (Givens 1968), and Olmos Dam (Lukowski 1988) indicates that Late Archaic populations in central and south Texas were increasing and becoming more territorial.

Late Archaic points tend to be much smaller than Middle Archaic points. The most common are Ensor and Frio types (Turner and Hester 1993:114,122), both of which are short, triangular points with side notches. The Frio point also has a notched base (Turner and Hester 1993:122). Although inhabitants of the South Texas Plain near Brownsville and Rockport had begun to make pottery by about 1750 B.P., the northern part of the plain was still "pre-ceramic" until 1,000 years later (Story 1985:45-47). 


\section{Transitional Archaic}

A late subperiod or interval of the Late Archaic is frequently referred to as the Terminal Archaic or Transitional Archaic. Weir (1976) defines the Terminal Archaic as 1650-1150 B.P., while Turner and Hester (1993) cite data placing the Transitional Archaic as 2250-1250 B.P. Although Hester may lump current data into a Late Archaic period, he cautions that more evidence will likely result in what may be referred to as a "Terminal Archaic" period during the latter part of the Late Archaic in south Texas. This Terminal Archaic period is represented by diagnostics such as Ensor, Frio, and Matamoros points, which appear to overlap the Late Archaic and Late Prehistoric periods (Hester 1995:442). Weir (1976) believes this marked a transition period to localized area sites, a disappearance of burned rock middens and bison, and a reappearance of highly mobile hunters and gatherers. Others (Black and McGraw 1985; Peter 1982; Skelton 1977) argue that in some locations burned rock middens did not disappear and sites were more intensely occupied during the Transitional Archaic period.

\section{Late Prehistoric}

Collins (1995:385) recognizes that the commonly used date of 1200 в.P. for the end of the Archaic and beginning of the Late Prehistoric in central Texas is arbitrary, and Hester (1995:442) acknowledges the problematic issue of selected tools appearing at both Late Archaic and Late Prehistoric sites. A series of distinctive traits marks the end of the Archaic and the beginning of the Late Prehistoric period, including the technological shift to the bow and arrow and the introduction of pottery to central Texas and the northern South Texas Plain (Black 1989a:32; Story 1985:45-47). Most researchers agree the early Late Prehistoric period was a time of population decrease (Black 1989a:32). Though small burned rock middens associated with Scallorn and Edwards points have been found (Goode 1991:71; Houk and Lohse 1993:193248 ), they are rare. Settlement shifts into rockshelters such as Scorpion Cave in Medina County (Highley et al. 1978) and Classen Rockshelter in northern Bexar County (Fox and Fox 1967) have been noted (Shafer 1977; Skinner 1981). Cemeteries from this period often reveal evidence of conflict (Black 1989a:32). For example, an excavation of a burial just north of San Antonio (41BX952) revealed an Edwards point between two lumbar vertebra (Meissner 1991). Sites from the Austin phase include Quinta Medina (Guderjan et al. 1992; 1993) and Panther Springs Creek, 41BX228 (Black and McGraw 1985).

Beginning rather abruptly at about 650 B.P., a shift in technology occurred. This phase is characterized by the introduction of blade technology, the first ceramics (bone-tempered plainwares) in central Texas, the appearance of Perdiz arrow points, and alternately beveled bifaces (Black 1989a:32; Huebner 1991:346). Prewitt (1985) and Black (1989a) suggest this technology encroached from north-central Texas. Patterson (1988), however, notes the Perdiz point was first seen in southeast Texas by about 1350 B.P., and was introduced to the west some $600-700$ years later. Hester (1995:444) recognizes this phase as the "best documented Late Prehistoric pattern" throughout south Texas, with dates ranging between ca. $650 / 700$ to $300 /$ 350 B.P. (corresponding to Hester's A.D. $1250 / 1300$ to $1600 / 1650)$.

Steele and Assad Hunter (1986) argue for the occurrence of a distinct change in diet between the Late Archaic and the Late Prehistoric components in two sites at Choke Canyon Reservoir in south Texas. Analysis of the number of identified specimens (NISP) shows a marked increase in artiodactyl elements present during the late Late Prehistoric, an increase largely due to the addition of bison to the "menu" (Steele and Assad Hunter 1986:468). Huebner (1991) suggests that the sudden return of bison to south and central Texas resulted from a more xeric climate in the plains north of Texas, and increased grasses in the Cross-Timbers and Post Oak Savannah in north central Texas, forming a "bison corridor" into the South Texas Plain along the eastern edge of the Edwards Plateau (Huebner 1991:354-355). Sites from this period frequently have associated bison (Black 1986; Black and McGraw 1985; Henderson 1978; Hulbert 1985; Prewitt 1974).

The only archaeological evidence that domesticated plants were ever introduced in south or central Texas is a single corncob found in Late Prehistoric context in Timmeron Rock Shelter (Harris 1985). This single 
cob is not enough to postulate there was ever a significant presence of maize in the area. Only the arrival of the Spanish brought significant cultivars to south and central Texas.

\section{Historic Period}

The end of the Late Prehistoric and beginning of the Historic period in both central and south Texas should be characterized by written accounts of European contact with indigenous groups. Collins (1995:386-387) offers that the Historic period thus begins ca. 260 в.P. in central Texas; however, in south Texas Hester (1995:450-451) agrees with Adkins and Adkins (1982:242) when he suggests that the indigenous groups may have been affected by European influence, but we are only able to observe the materials in the archaeological record because the written accounts simply are not available. Hester would rather label this largely unknown period "Protohistoric."

The cultural context for the historic groups in the study area is largely conditioned by the presence of outside ethnic groups and regional power struggles. The numerous small groups of hunters and gatherers encountered by the early explorers and later Spanish intrusions are addressed in many sources (Campbell 1983; Campbell and Campbell 1985; Hester 1989; John 1975; Newcomb 1961; Swanton 1952). The various later intrusive groups, such as Tonkawa, Lipan Apache, and Comanche, are also described by numerous researchers (Ewers 1969; Hester 1989; Jones 1969; Kelley 1971; Newcomb 1961, 1993; Sjoberg 1953a, 1953b).

At the beginning of the seventeenth century, many south Texas Indian groups were being pushed northward by continual Spanish expansion. By the mid-seventeenth century, a new pressure on the Indians indigenous to the area began to come from the north: a nomadic group, the Apache adopted a more Plains-lifeway style of bison hunting once they acquired horses from the Spaniards (Campbell and Campbell 1985:27). Later, the Apaches were to be displaced by another group of nomadic, bison-hunting Indians - the Comanches - from the highlands of central Texas (Campbell 1991:111).
A combination of migration, demoralization, intergroup conflict, disease, and death due to warfare fragmented the native Indian groups, and forced continual mixing and remixing among them (Bolton 1915; Campbell 1975, 1991:345; León et al. 1961). Most of the native languages have been lost, although recent attempts at reconstruction are enlightening (e.g., Johnson 1994; Johnson and Campbell 1992). The establishment and relocation of Spanish Catholic missions along the San Antonio River in the early 1700s offered plentiful food and protection from outsiders, inducing many groups to enter the missions (Campbell and Campbell 1985; Chipman 1992; de la Teja 1988; Habig 1968a, 1968b; Hard et al. 1995; Inglis 1964). Although fear of the invading Apache and Comanche pressured many of the Indians to seek the protection of missions, they were now exposed to the exploitation of the Spanish (Campbell 1975:2, 1991:346-347).

In the autumn of 1785 , a treaty with the Comanche signaled the opening of a period of peaceful coexistence in which Comanches brought hides, meat, and tallow to the area to trade for goods and servicessuch as blacksmithing and gun repair-not available elsewhere (Poyo and Hinojosa 1991:125-126). The few Comanche who entered the missions were apparently women and children who were captured during punitive raids by Spanish soldiers (Campbell and Campbell 1985:26).

Apaches continued to range over the area between San Antonio and Laredo until the early $1800 \mathrm{~s}$, pushed southward by the invading Comanche who had moved into the Hill Country of central Texas (Campbell and Campbell 1985:27). Weary of warfare with the Comanche, a few Apache began seeking asylum in the missions (McGraw and Hindes 1987:367; West 1904:50). Few landowners, however, dared to live on their outlying lands until about 1840 , when a treaty with the Apaches brought peace for a while (de la Teja 1988:167).

The political environment of the early government is addressed by Espey, Huston and Associates (1989). Archaeological testing on the Medina River provided the first look at an early 1800 s ranch headquarters (McGraw and Hindes 1987). The newly formed government of Texas gave land grants that were large, 
consisting of around 5,000 acres for each property, and Spanish cattle ranching became prevalent south and southeast of San Antonio (Jackson 1986). However the political turmoil that permeated early Texas caused a near-complete European desertion of San Antonio following the Mexican War for Independence (Fehrenbach 1983).

Around 1840 settlers from Germany and Alsace-Lorraine and from other regions of the United States began to flood into San Antonio. Many of the Germans moved into the Hill Country to the north, settling into communities such as Boerne and New Braunfels, and raised sheep or cattle (Freeman 1994:5-9). As sheep and cattle markets emerged in the $1880 \mathrm{~s}$, ranchers and farmers settled south and west of San Antonio (Flanagan 1974; Lehmann 1969; Nickels et al. 1997a). The introduction of twentieth-century technologies such as mills and improved methods of production have shaped the area as it exists today (Fox et al. 1989; Tyler 1996). 


\title{
Chapter 3: History of Investigations at 41BX126
}

\author{
Diane A. Cargill
}

\section{Introduction}

Three archaeological testing projects have been conducted at site 41BX126. The first two investigations were carried out by TxDOT in 1993 and 1995. In 1997 41BX126 was tested by the Center for Archaeological Research (CAR) of The University of Texas at San Antonio.

41BX126 was originally recorded in 1971 by Paul McGuff and Ellen McGuff (1971) during an archaeological survey for the proposed construction of Loop 1604. The site was described as an open campsite, approximately $90 \times 30 \mathrm{~m}$ in size, consisting of a surface scatter of chert nodules, flakes, worked flakes, bifaces, and a possible Pedernales point.

Twenty years later, due to the proposed expansion of Loop 1604, Daymond Crawford of TxDOT resurveyed 41BX126 in March 1991. The site however, was not recommended for testing due to the noted surface disturbances resulting from past highway construction and heavy off-road traffic. Two months later, on May 20, Bob Mallouf and Dan Prikryl of the Texas Historical Commission (THC) visited 41BX126 and expanded the site boundary to include an area west of Loop 1604, and an area both north and south of the original site boundary east of the highway.

In August 1993, the site was once again resurveyed by TxDOT archaeologists. At that time, 41BX126 was recommended for testing to establish site boundaries and to assess significance of the cultural deposits. Testing was conducted in the existing right-of-way during a two-week period beginning September 20, 1993 (Wood 1994). This investigation was followed by additional testing in 1995 by TxDOT to determine the site's eligibility for inclusion in the NRHP. However, 41BX126 was not evaluated for listing in the NRHP until additional testing by CAR (current project) was conducted.

\section{Investigation}

Testing of 41BX126 was implemented "to determine the nature of the deposits and cultural contexts, to determine the site's eligibility as a candidate for the $\mathrm{Na}$ tional Register of Historic Places, and to assess the site's eligibility for designation as a State Landmark" (Wood 1994:1). Twenty-six hand-excavated units, eight machine-excavated trenches, and 31 shovel tests were excavated on both the east and west side of Loop 1604 (Figure 3-1). Wood (1994) reports that less than two percent of the site within the right-of-way was sampled by the testing project.

Shovel tests were excavated to gain preliminary insight about the vertical and horizontal extent of the subsurface deposit at 41BX126. The testing indicated that the site was approximately $250 \mathrm{~m}$ east/west along Culebra Creek, by $500 \mathrm{~m}$ north/south. Once the site boundaries had been defined by shovel tests east and west of the highway, test units were placed on the west side to sample as much of the site as possible as this area appeared to be the least disturbed (Wood 1994). Test units were also placed on the east side of Loop 1604 to investigate and define the extent of the burned rock midden. Hand-excavated units were placed near remaining tree stands under the assumption that this area of the site was less impacted by previous road construction and cultivation activities. In addition, mechanically excavated trenches were placed on both sides of the highway to identify deeply buried cultural deposits.

The testing project documented the existence of a "partially" undisturbed burned rock midden located on the northern terrace above Culebra Creek east of Loop 1604. Chipped lithic artifacts recovered from TU 19 (in the central area of the burned rock midden) suggested that a stratigraphically lower component underlying the midden at $80-100 \mathrm{~cm}$ below surface (bs) might be separable from a stratigraphically higher 


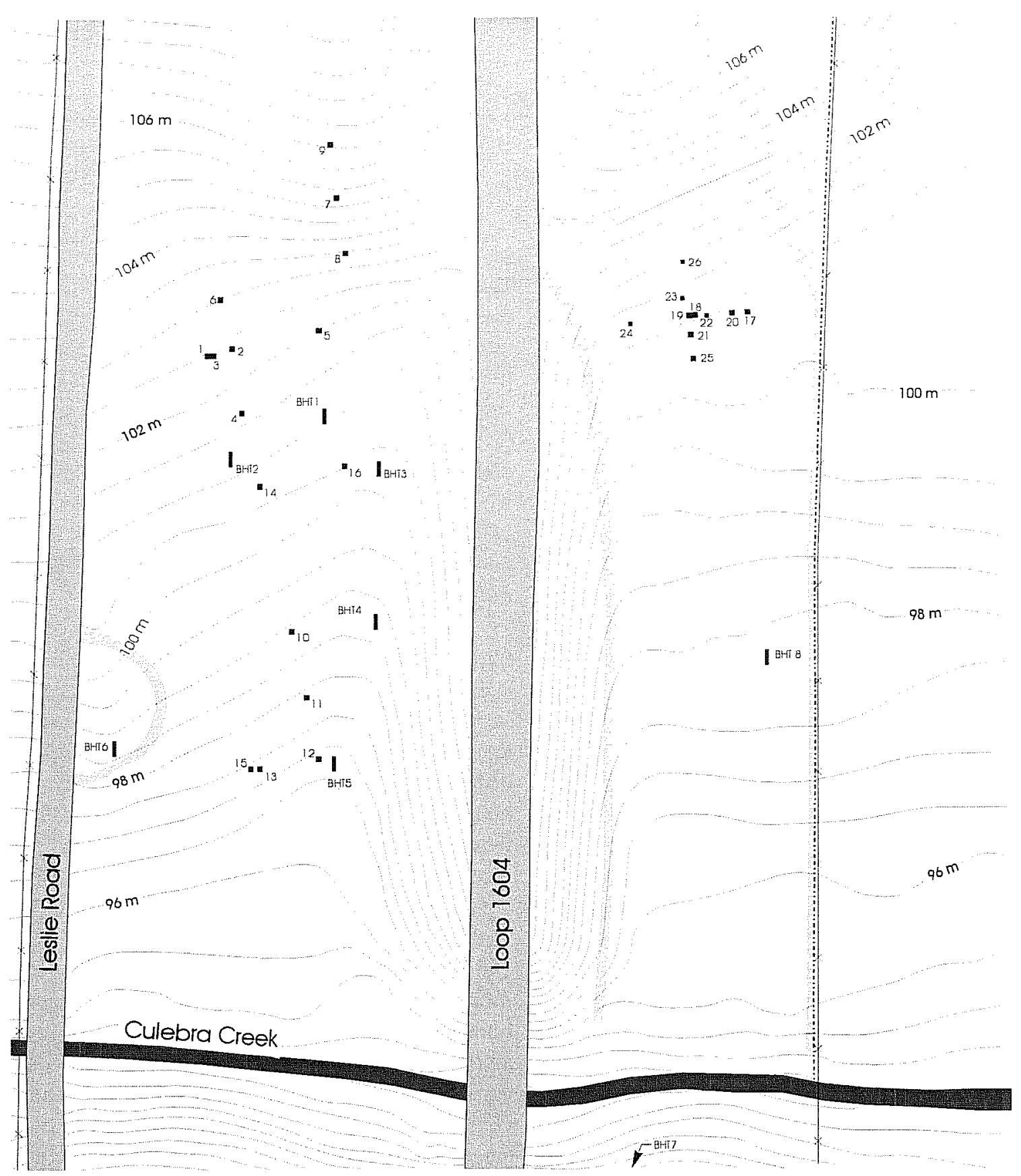

Wood's Investigations
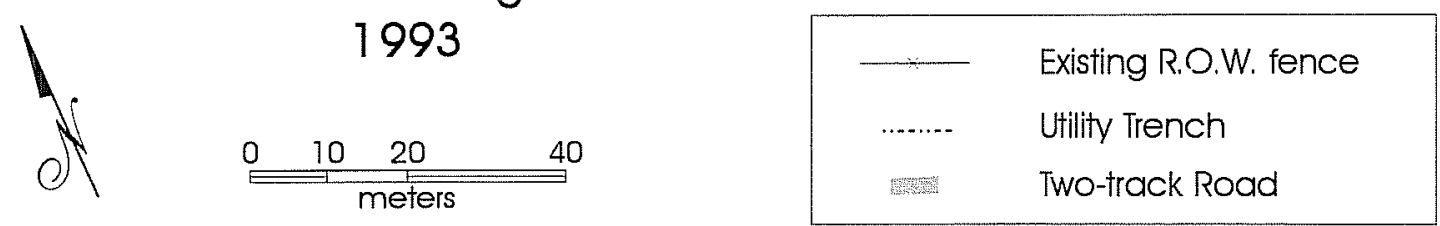

Figure 3-1. Wood's 1993 investigations. Small squares indicate 50-x-50-cm test units, large squares represent $1-\mathrm{x}-1-\mathrm{m}$ test units, and long rectangles indicate backhoe trenches. 
component at $40-70 \mathrm{~cm}$ bs (a decrease of lithic artifacts occurred between 70 and $80 \mathrm{~cm} \mathrm{bs}$ ). Cultural features were not identified west of the highway; however, two early Archaic points (later determined by CAR to be Middle and Late Archaic, see Chapter 7) were recovered at the same depth, $20-30 \mathrm{~cm} \mathrm{bs}$, in two separate units $30 \mathrm{~m}$ apart.

The 1993 testing project demonstrated that 41BX126 potentially exhibited cultural and physical integrity (Wood 1994). However, the excavation was limited and the data inconclusive for evaluating the site in terms of the general criteria of "significance" as put forth by the NRHP, and the more restrictive definitions developed for small archaeological sites (Price 1995).

\section{Investigation}

TxDOT returned to 41BX126 in 1995. Fieldwork was conducted from March 8-April 28, 1995, under the direction of Dennis Price. Based on the results from the 1993 testing project, the goal of the 1995 investigation was to determine the cultural and physical integrity of the possible Early Archaic component west of the highway. If such a component was identified, specific objectives were to 1 ) recover ethnobotanical and zooarchaeological remains, 2) determine the existence and integrity of an earlier component underlying the midden, and 3) search for discrete deposits with physical and cultural integrity closer to Culebra Creek.

The field investigation included six test units (TUs) and 15 backhoe trenches (BHTs) (Figure 3-2). Four of the six units were located east of Loop 1604 in the burned rock midden area, and the remaining two were placed west of the highway, adjacent to Trench $\mathrm{C}$ to search for a possible Early Archaic component. In addition, mechanical trenches were excavated on both sides of Loop 1604. Six were located on the west side of Loop 1604 and the remaining nine were placed on the east side of the highway.

Concurrent with the 1995 investigations by Price, supplemental work was conducted by Steve Black and Charles Frederick from the Texas Archeological Research Laboratory to document and sample the burned rock midden and to perform limited geomorphological investigation of the site as a whole. Photomosaics of three walls exposed in Trench G, M, and O were constructed, and bulk matrix samples for the recovery of ethnobotanical remains, as well as special purpose samples for micromorphology and magnetic susceptibility analysis were collected from different areas of the midden.

The midden was described as annular, exhibiting a soft matrix supported center, and a clast supported ring or framework (Black 1995b; Frederick, Appendix B). In addition, Black (1995b) and Frederick (Appendix B) identified features inside and outside the midden, which apparently contributed to the overall formation of the midden structure. These included "stringers" of scattered rock located outside the periphery, and pits located within the midden's framework, center or core, and margins.

Results of the 1995 investigation demonstrated that an intact burned rock midden was present east of Loop 1604. Based on midden projectile points, and an associated humate date (collected from a nearby trench), the midden appeared to have formed after ca. 4500 B.P. In addition, the recovery of a possible Guadalupe tool from a depth of $62 \mathrm{~cm}$ bs indicated the potential existence of an earlier component underlying the burned rock midden. Testing conducted on the west side of Loop 1604 was unable to support or negate the existence of a possible Early Archaic component. As planned by TxDOT, the analysis of the recovered material by Price in 1995 and the subsequent task of writing the report became CAR's responsibility.

\section{Investigation}

CAR archaeologists conducted the third field investigation at 41BX126 in January and February 1997, and returned in May 1997. Initially CAR's goals included evaluating the burned rock midden's potential for faunal and botanical preservation; identifying a possible earlier component underlying the midden; testing the area off-midden and the new right-of-way to the east for cultural resources; and assessing the potential existence of an Early Archaic component west of the highway (Figure 3-3). For management purposes and reading clarity, following the fieldwork CAR divided 


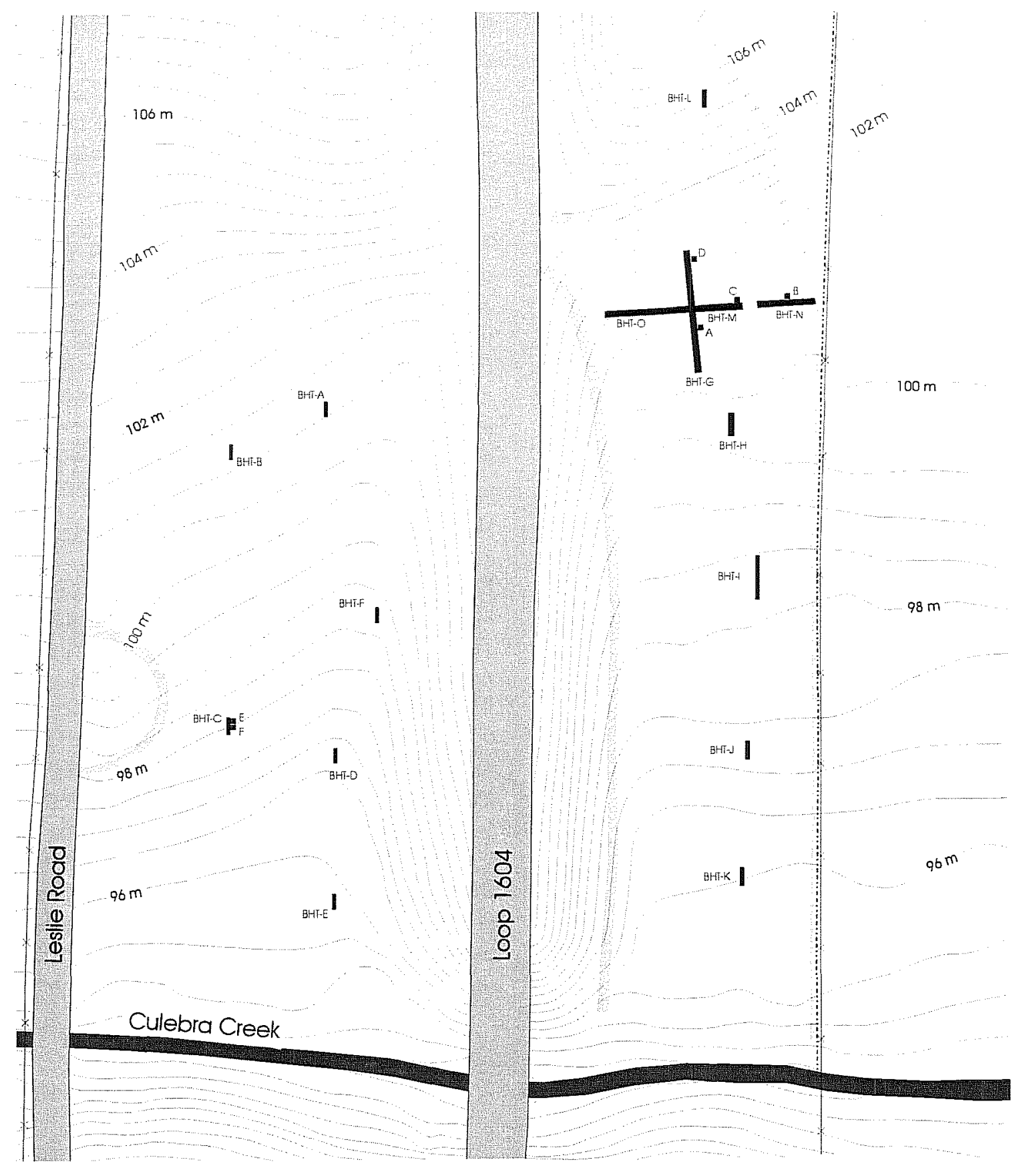

Price's Investigations
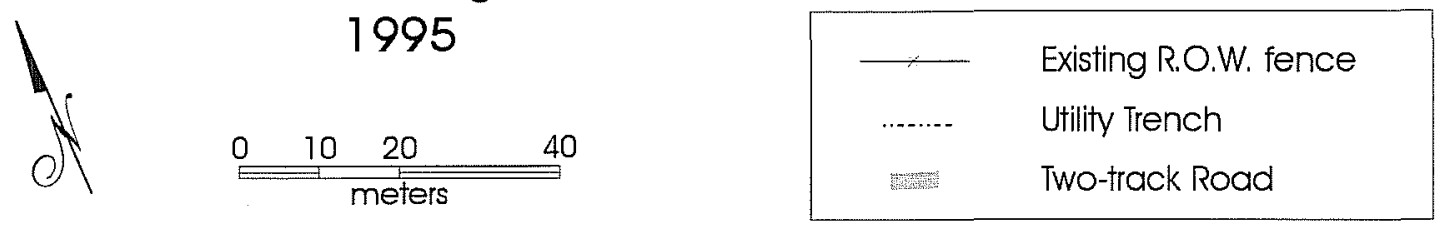

Figure 3-2. Price's 1995 investigations. Squares indicate 1-x-1-m test units, long rectangles represent backhoe trenches. 


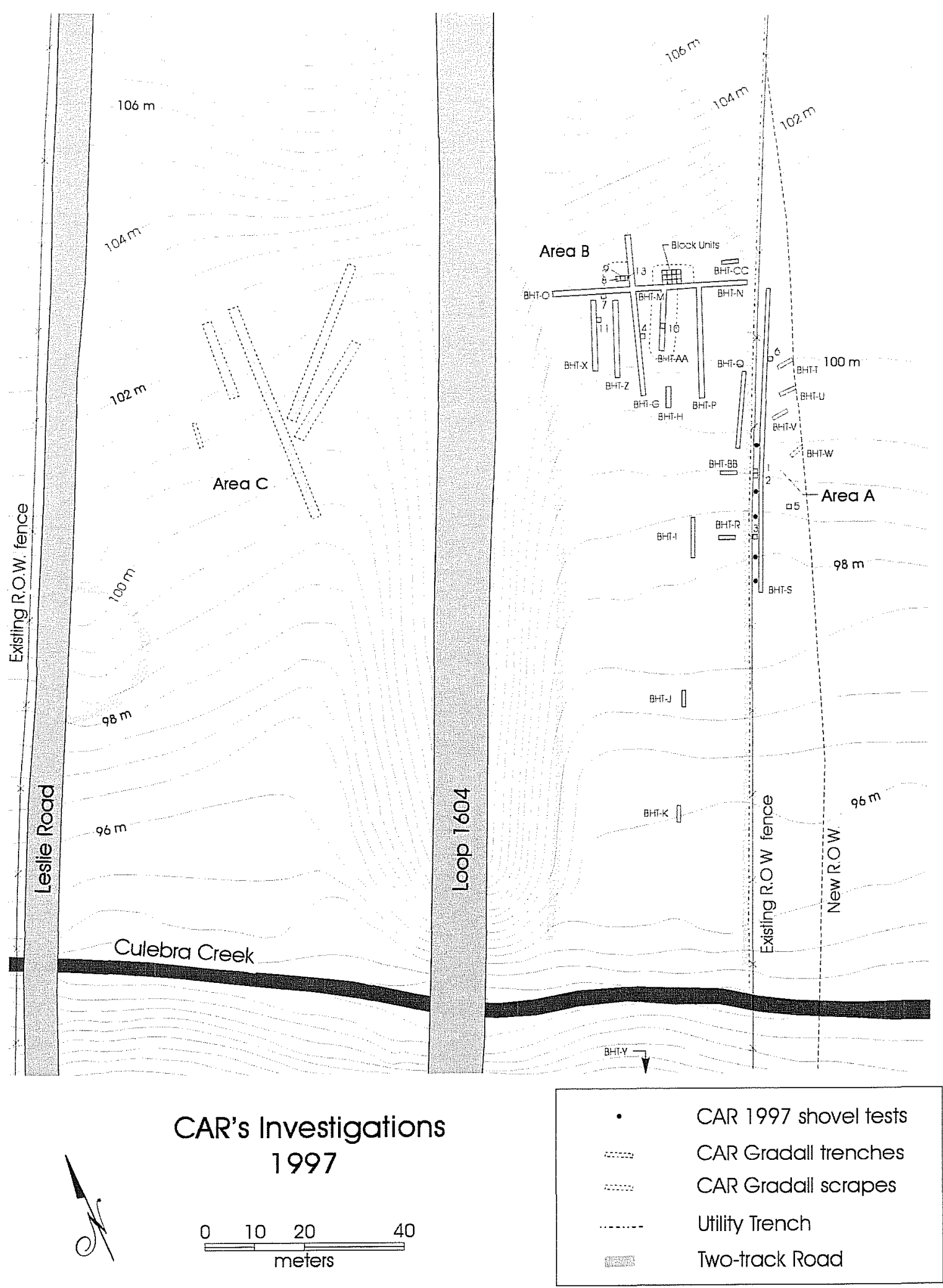

Figure 3-3. CAR's 1997 investigations. Squares indicate 1-x-1-m test units, long rectangles represent backhoe trenches. 
the site into three areas: Area A being the newly acquired right-of-way; Area $B$ being the area east of Loop 1604 comprising the main midden and peripheral features; and Area $\mathrm{C}$ being the portion of the site west of Loop 1604.

After reviewing the preliminary results with TxDOT and THC archaeologists, CAR returned to the site in May 1997 to gain additional information on an identified Nolan component that occurred stratigraphically below the midden. This effort resulted in a small block excavation immediately east of the midden. Figure 34 illustrates the location of excavations at 41BX126 during all three testing projects. The methods and results of these investigations are discussed in Chapters 4 and 6, respectively, and a recommendation of eligibility for listing in the National Register of Historic Places is provided in Chapter 12. 

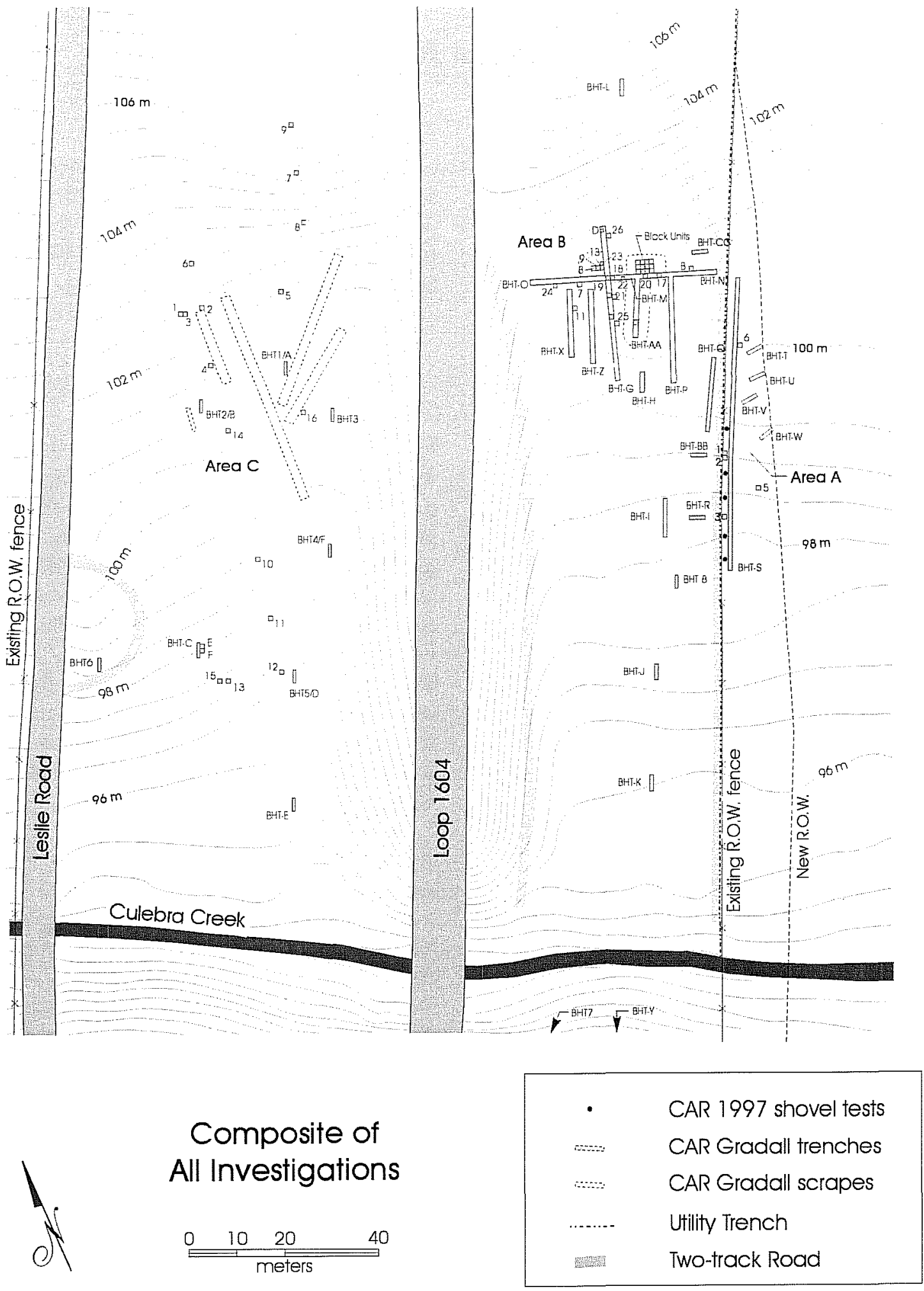

Figure 3-4. Testing conducted at 41BX126 during 1993, 1995, and 1997. Small squares indicate test units, long rectangles represent backhoe trenches. 


\section{Chapter 4: Methods}

\section{David L. Nickels, Diane A. Cargill, and Kaylee A. McRae}

\section{Introduction}

During the three projects conducted at 41BX126, 55 $1-\mathrm{x}-1-\mathrm{m}$ and $50-\mathrm{x}-50-\mathrm{cm}$ hand-dug units, 37 backhoe trenches, and 36 shovel tests were excavated to investigate and evaluate the site. This chapter provides a discussion of the field methods used at 41BX126 by Wood in 1993, Price in 1995, and CAR in 1997. Also provided are the laboratory methods performed by CAR for all the investigations.

Wood's field methods were designed to document the vertical and horizontal distribution of subsurface deposits at 41BX126, and more importantly, to assess the significance of those deposits. Much of the 1993 investigation focused on the area of the site west of Loop 1604, as this area was believed to be less affected by prior road construction activities. However, the area of the site east of the highway (containing the burned rock midden) was tested as well. Results from the 1993 investigation documented the existence of a "partially" undisturbed burned rock midden east of the highway (Wood 1994), and a possible Early Archaic component west of Loop 1604. Based on these results, Price (1995) directed his efforts primarily on the burned rock midden east of the highway, and to a lesser extent, tested the area of the site west of the Loop 1604. Concurrent with Price, Steve Black and Charles Frederick from TARL conducted additional work on and off the midden. The 1995 investigation documented an intact burned rock midden and a possible earlier component underlying the midden. Testing results west of Loop 1604 were inconclusive in documenting the presence of an Early Archaic component. With that information, the 1997 investigation by CAR was designed to identify the possible Early Archaic component west of the highway, test the burned rock midden for organic material preservation, test areas off-midden for evidence of occupation, test the newly acquired rightof-way for a younger burned rock midden and/or component, and prepare a comprehensive map of archeological investigations at 41BX126. Based on the results from the 1995 and 1997 investigations, CAR returned to the site in May 1997 to sample a horizontally discrete, possible Nolan component.

\section{Wood's Field Methodology (1993)}

During a two-week period beginning September 20, 1993, Wood conducted an archaeological investigation at 41BX126 (Figure 3-1). Thirty-one shovel tests placed east and west of Loop 1604 were excavated to gain preliminary insight into the vertical and horizontal extent of the subsurface deposit at 41 BX 126 . Shovel tests, approximately $30 \times 30 \mathrm{~cm}$ in plan view, were excavated in 10-cm arbitrary levels. Depth ranged from 15-50 $\mathrm{cm}$ below the surface (bs) depending on soil depth and rockiness. Excavated material was screened through $1 / 4$-inch wire mesh and all artifacts were collected. Shovel tests were not plotted and could not be relocated.

Based on cultural material recovered from the shovel tests, Wood enlarged the site boundary to $250 \mathrm{~m}$ east/ west by $500 \mathrm{~m}$ north/south. Once the site boundary had been defined, test units were placed on the west side to sample as much of the site as possible, as this area appeared to be the least disturbed (Wood 1994). Testing was conducted on the east side to investigate and define the extent of the burned rock midden. Handexcavated units were placed near remaining tree stands with the assumption that this area of the site was less impacted by previous road construction and cultivation activities.

Twenty-six units were hand excavated. Units were excavated in arbitrary $10-\mathrm{cm}$ levels until either sterile soil, unconsolidated caliche-marl, or limestone bedrock was encountered. Test units (TUs) were numbered consecutively from 1 through 26 , and each 
10-cm level was assigned an alphabetical designation from A through I (e.g., 10-C would indicate the third level of TU 10). Seventeen of the 26 units (TUs $1-8$, $10-14$, and 17-20) were $1 \times 1 \mathrm{~m}$ in size, the remaining nine (TUs 9,15,16, and 21-26) were $50 \times 50 \mathrm{~cm}$. Ten TUs (17-26) were excavated to investigate the burned rock midden, with TUs 18 and 19 placed on the central part of the midden. The remaining 16 TUs (1-16) were placed west of the highway (Figure 3-1). Equipment used during hand excavation included trowels, and flat and spade shovels. Screening of all hand-excavated matrix was accomplished using 1/4inch wire mesh and all observed artifacts were collected. Unit and level information was recorded on standard TXDOT record forms.

Eight backhoe trenches (numerically designated 1-8) were excavated to identify deeply buried cultural deposits. The average width of each trench was $1.5 \mathrm{~m}$, length ranged between 5 and $10 \mathrm{~m}$, and the average depth was $1.73 \mathrm{~m}$ (Wood 1994). Two BHTs (7 and 8) were excavated on the east side of Loop 1604 and the remaining six (1-6) were placed on the west side of the highway (Figure 3-1). Trowels were used to clean the trench walls to aid in the identification of possible features, and profiles on one wall of each trench were documented. During the 1993 excavation, Wood (1994) took 77 color print photographs.

Wood mapped the site using an engineer's transit. All test units were placed on a grid system using the existing Loop 1604 right-of-way as a baseline. Absolute elevations were derived for the site's units, burned rock midden, and topography from a 866.99-ft Texas Highway Department Survey benchmark "located on the southeast corner of the Loop 1604 bridge across Culebra Creek" (Wood 1994:7).

\section{Price's Field Methodology (1995)}

In March and April 1995, TxDOT archaeologist Dennis Price directed the second investigation at 41BX126. Six 1-x-1-m units were excavated in arbitrary $10-\mathrm{cm}$ levels using trowels, shovels, picks, and in some instances, a hammer drill. Units were assigned an alphabetical designation (A-F) and each $10-\mathrm{cm}$ level was given a number (e.g., A-4 indicates the fourth level of Unit A). Units were placed adjacent to backhoe trenches and dug to a minimum depth of one meter and a maximum depth of $1.6 \mathrm{~m}$. Four of the six units were located east of Loop 1604 in the burned rock midden area, and the remaining two were placed west of the highway, adjacent to BHT C (Figure 3-2). Soil was screened through $1 / 4$-inch wire mesh. Profiles were drawn of three walls of each test unit. Bulk soil samples, $50 \times 50 \mathrm{~cm}$, were collected in $10-\mathrm{cm}$ levels from Units $C$ and $D$; and soil samples, $25 \times 50 \mathrm{~cm}$, were collected in $10-\mathrm{cm}$ levels from Units $\mathrm{E}$ and $\mathrm{F}$. Unit excavation information was recorded on TxDOT record forms for all six units.

Fifteen BHTs were excavated and assigned alphabetical designations A-O. Six (A-F) of the 15 trenches were located on the west side of Loop 1604 and the remaining nine $(\mathrm{G}-\mathrm{O})$ were placed on the east side of the highway (Figure 3-2). Test units placed on the burned rock midden in 1993 (Figure 3-1) were relocated in 1995, and BHTs M, O, and G were excavated in the form of a cross through those units (Figure 32 ). The width of each trench was approximately 1.5 $\mathrm{m}$, length varied between 2 and $18 \mathrm{~m}$, and depth ranged from roughly one meter to greater than three meters below ground surface. Profiles of the north walls of BHTs $M$ and $O$ and the east wall of BHT $G$ were drawn.

Price took 491 photographs during the 1995 excavation: 277 color slides (of which 29 were a photomosaic of BHT G, east wall profile) and 214 color prints. A standard form was not used for the photographic log, Price simply typed up a photographic log for each roll and descriptions of each photo. A running number was assigned for each photograph taken.

In March 1995, concurrent with the TxDOT field investigation, Steve Black and Charles Frederick from the Texas Archeological Research Laboratory (TARL) conducted supplemental work at 41BX126 to document and sample the burned rock midden and to perform limited geomorphological investigation of the site as a whole. They mapped the site using a Sokkia Electronic Distance Measurer (EDM) Total Station. Price and Black took 423 black-and-white prints, color prints, and color slides of this operation. Photomosaics of three walls exposed in BHTs G, M, and O were 
constructed. The photographs taken of these walls included both color slide and black-and-white print film. One hundred forty-six of the photographs taken were color slides. One hundred forty-one black-and-white the possession of CAR. A standard TARL photographic log was used to record each photograph. In making the photomosaic, Black and Frederick photographed the midden profile at $0.5-\mathrm{m}$ intervals using a macro lens. In addition, bulk matrix samples for the recovery of ethnobotanical remains and special samples for micromorphology and magnetic susceptibility analysis were collected from the midden area.

Fifteen bulk matrix samples were collected from different areas of the midden for the recovery of ethnobotanical remains. Ten to 12 liters were collected from each of the following defined areas: the "ring" or framework supported area, the center or matrix-supported area, and an ash-dump feature. In addition, bulk matrix samples were taken from two probable basinshaped rock filled features occurring beneath the framework supported area in BHTs M and O, close to the base of the midden. Seven magnetic susceptibility samples were collected: two from the framework-supported area, two from the matrix-supported area, one from the ash feature in BHTs $\mathrm{M}$ and $\mathrm{O}$, and two from photos were reported in the photo log but are not in

the edge of the midden (one north and one south). In addition, approximately eight samples were collected from the fine-grained matrix in the center and framework area and beneath the midden for soil micromorphology analysis. To protect the main midden and other features, Price filled in all BHTs and TUs with sand (Figure 4-1).

\section{CAR's Methodology (1997)}

\section{Field Methods}

During a three-week period beginning January 15 , 1997, CAR conducted the third testing project at 41BX126. In addition, CAR returned to the site on May 13, 1997, for one week to investigate the possible existence of a discrete Nolan component.

Prefield operations included a thorough review of the data from the initial survey (McGuff and McGuff 1971) and the previous testing projects (Black 1995b; Frederick, Appendix A; Price 1995; Wood 1994). Field investigations conducted by CAR included Gradall and backhoe trenches; shovel tests; 1-x-1-m hand-excavated units; site mapping; geomorphological studies (Nordt, Chapter 5); and the collection of bulk matrix, archaeomagnetic, and

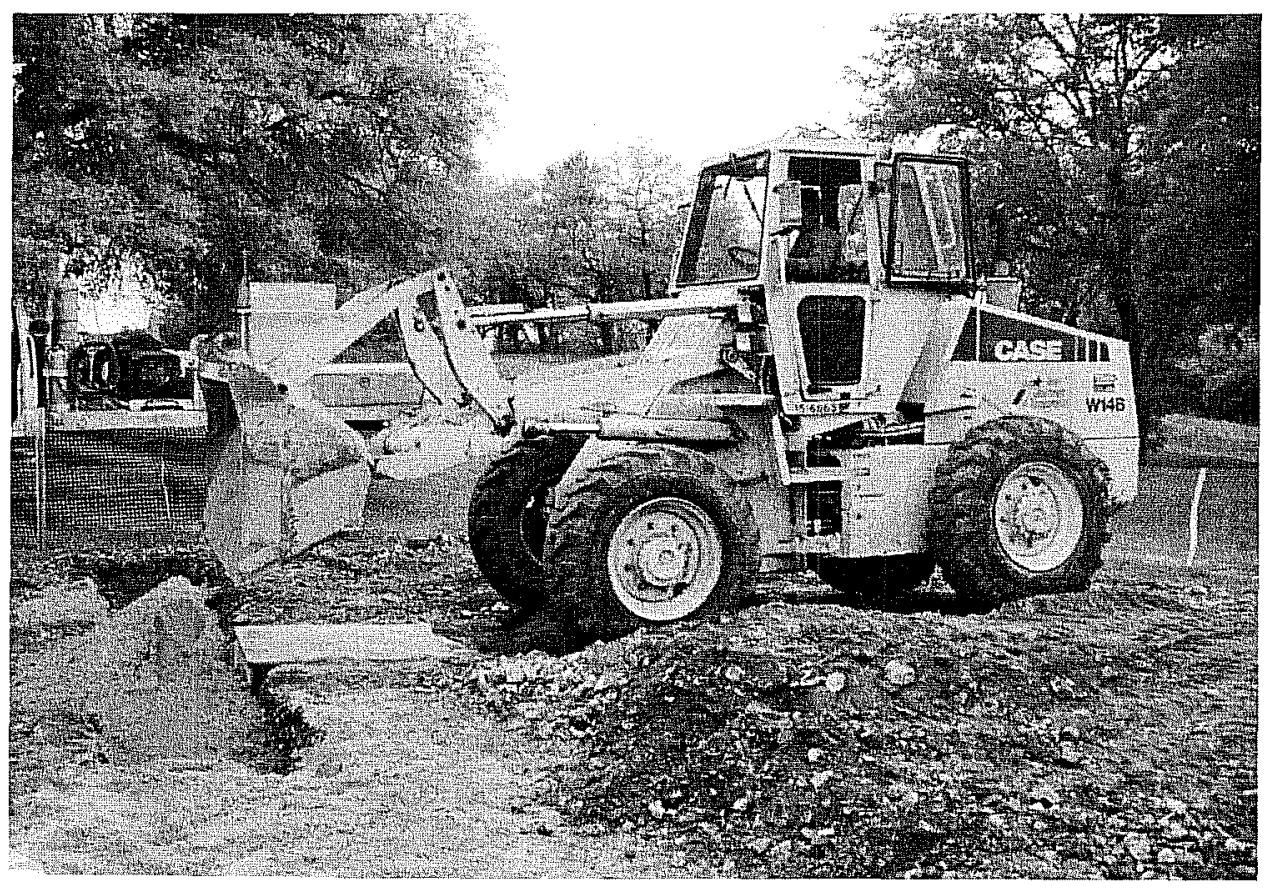
magnetic susceptibility samples.

\section{Mapping}

During the current investigation, CAR acquired TxDOT survey maps of the area and field maps drawn by Wood (1994) and Price (1995). In 1997 TxDOT surveyors staked the newly acquired rightof-way and showed CAR staff the location of three benchmarks. The site datum established by Wood had not survived, so a new

Figure 4-1. Backfilling Price's 1995 midden trenches with sand. 
datum was established for the 1997 testing phase and was tied into the TxDOT benchmark using an EDM and data collector.

All backhoe trenches, test units, and eight of 31 shovel tests from the 1993 and 1995 projects were relocated and mapped using the EDM. The same instrument was used throughout the 1997 project to record locations of new trenches, units, shovel tests, point-plotted artifacts, features, areas of high artifact density, unit datum elevations, and area topography. Each evening, mapping data was downloaded from the data collector to a database spreadsheet loaded onto a computer hard drive in the CAR lab. The data was checked for accuracy and maps were produced using Surfer software.

\section{Backhoe Trenching}

Twenty-one BHTs (Figure 3-4) were excavated by CAR east of Loop 1604 to expose features and to address geoarchaeological issues. Six of the BHTs (GL) excavated had originally been dug by Price and backfilled with sand; to avoid confusion, CAR retained the letter designations assigned by Price. New trenches excavated by CAR were assigned letter designations

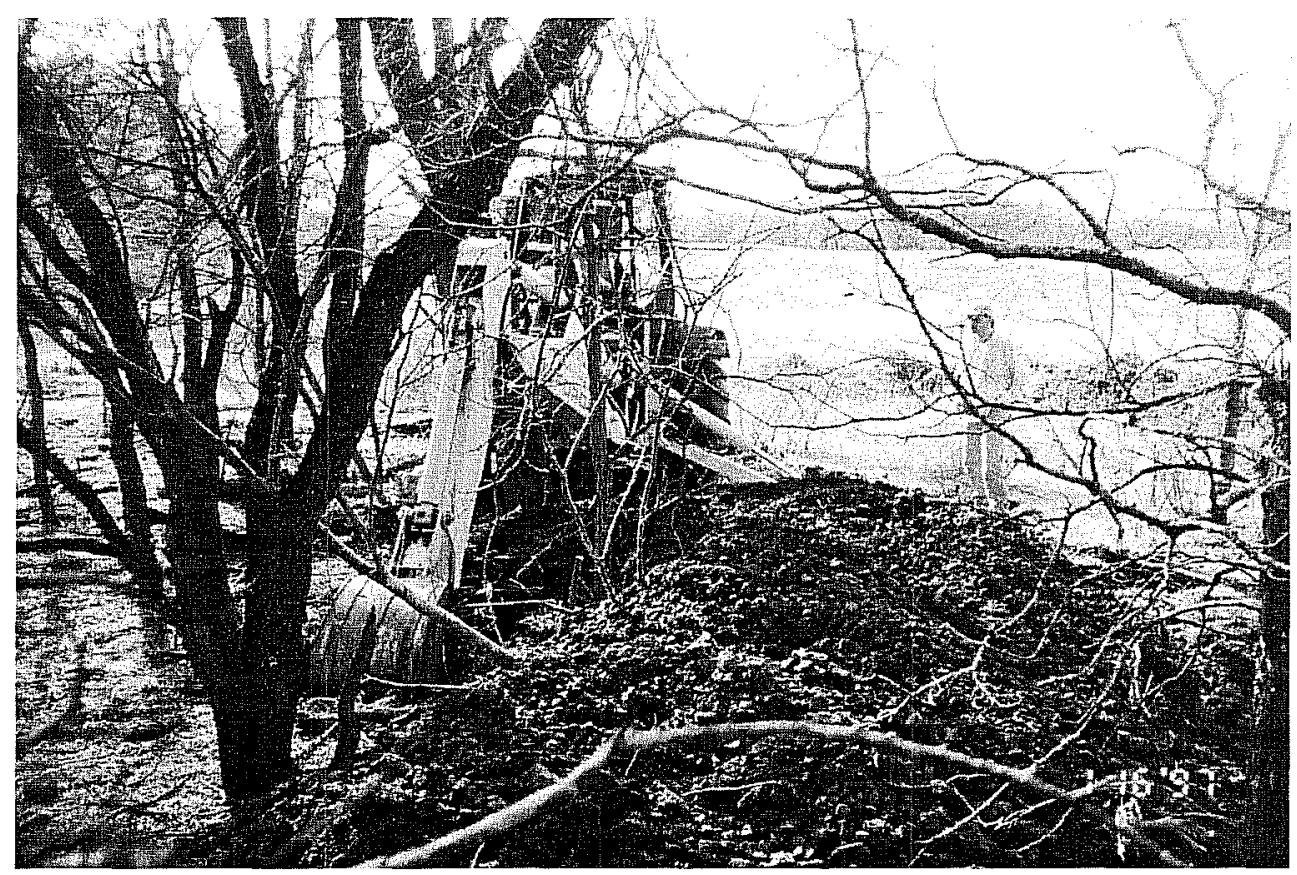

Figure 4-2. Monitoring backhoe trenching in the new right-of-way (1997). where Price left off (i.e., Price's last trench was assigned the letter $O, C A R$ 's first new trench was designated $P$ ). When $C A R$ reached $Z$, the remaining three trenches were assigned double-letter designations (AA, BB, and CC). CAR also modified some of Price's trenches by extending BHT $\mathrm{G}$ to the west and excavating the area between BHTs $M$ and $N$, which resulted in the connection of BHTs $\mathrm{M}$ and $\mathrm{N}$, and ultimately the formation of one long trench comprised of BHTs M, N, and O. For CAR's purposes, BHT $\mathrm{MNO}$ is considered one trench and only counted once in CAR's total count.

Seven BHTs (G, MNO, P, AA, CC, X, and Z) were excavated in and immediately adjacent to the burned rock midden to investigate overall midden form and structure, internal midden features, and the possibility of identifying an earlier component underlying the midden deposit. Eight BHTs (Q-W and BB) were excavated by CAR to identify cultural features located off-midden and within the new right-of-way (Figure 4-2), and to aid in the geomorphological assessment of the site. Finally, 1995 BHTs I, J, and K were reopened for additional geomorphological studies.

In 1997 trenches were excavated using a backhoe and an operator provided by TxDOT. Trenches were excavated to a depth of between 1.5 and $5 \mathrm{~m}$ using a 28-inch backhoe bucket. Although no backfill matrix was screened, all trenching operations were monitored by CAR archaeologists. Select backhoe trench profiles were drawn and described by the project geomorphologist Lee Nordt (Chapter 5 and Appendix C). Additionally, CAR staff examined the trench walls for evidence of buried cultural material and features. Firecracked rock features and artifacts observed in 
the walls were flagged and point-provenienced with the EDM. Diagnostic artifacts were assigned a Special Collections number, then collected. The presence of features and artifact densities observed in the trench walls provided a basis for the placement of test units.

\section{Gradall Trenching and Scraping}

The recovery of two Early Archaic corner-notched points from two of Wood's test units (approximately $30 \mathrm{~m}$ apart) west of Loop 1604 at ca. $30 \mathrm{~cm}$ bs suggested the possible existence of a horizontally discrete Early Archaic component. During the current project, CAR excavated five Gradall trenches (GTs) on the west side to identify this component. Trench dimensions were approximately $80 \mathrm{~cm}$ depth, $2 \mathrm{~m}$ width, and 5-20 m length. The Gradall operator skillfully removed a few centimeters of soil at a time.

Three areas on the east side of Loop 1604 were scraped with a Gradall to investigate burned rock midden form and off-midden features. Approximately $30 \mathrm{~cm}$ of alluvial and colluvial sediments were removed from a 12$\mathrm{x}-12-\mathrm{m}$ area in the northwest quadrant of the midden (Figure 4-3), a 10-x-15-m area adjacent to and southeast of the midden was scraped of approximately $35 \mathrm{~cm}$ of soil, and approximately $40 \mathrm{~cm}$ of overburden was removed in a third area above the block excavation east of the midden. Scraping was done in all three areas by removing thin $(<5 \mathrm{~cm})$ layers of sediments until the desired depth was achieved. The Gradall proved to be an effective tool for locating features and removing overburden with a minimal amount of damage to features or targeted sediments.

\section{Unit Excavations}

Twenty-three test units (TUs) were excavated during the current testing project. Units were dug in 5- and $10-\mathrm{cm}$ arbitrary levels using trowels, picks, and shovels. Units were assigned numerical designations (123). Twenty-two of the TUs were $1 \times 1 \mathrm{~m}$, and TU 13 was $.4 \times .8 \mathrm{~m}$ in size. During trenching activities by $\mathrm{CAR}$, notes were made on areas of the site containing artifact and fire-cracked rock concentrations and pointplotted diagnostics. Those notes were compared to the results obtained from previous testing to assist in the placement of TUs in areas offering the greatest potential for encountering buried deposits. Four units were placed within the burned rock midden, three $(8,9$, and 13 ) in the matrix-supported center (or core area), and one (7) in the rock-supported framework. Eleven units (12 and 14-23) were configured as a block east of the burned rock midden, three units $(4,10$, and 11$)$ were placed immediately off-midden in the periphery, and the remaining five units $(1-3,5$, and 6$)$ were excavated in the new right-of-way. With the exception of samples collected for flotation, all excavated material was screened through 1/4-inch mesh. In addition, CAR reopened TUs A, B, C, and D previously excavated by Price to review and compare stratigraphy.

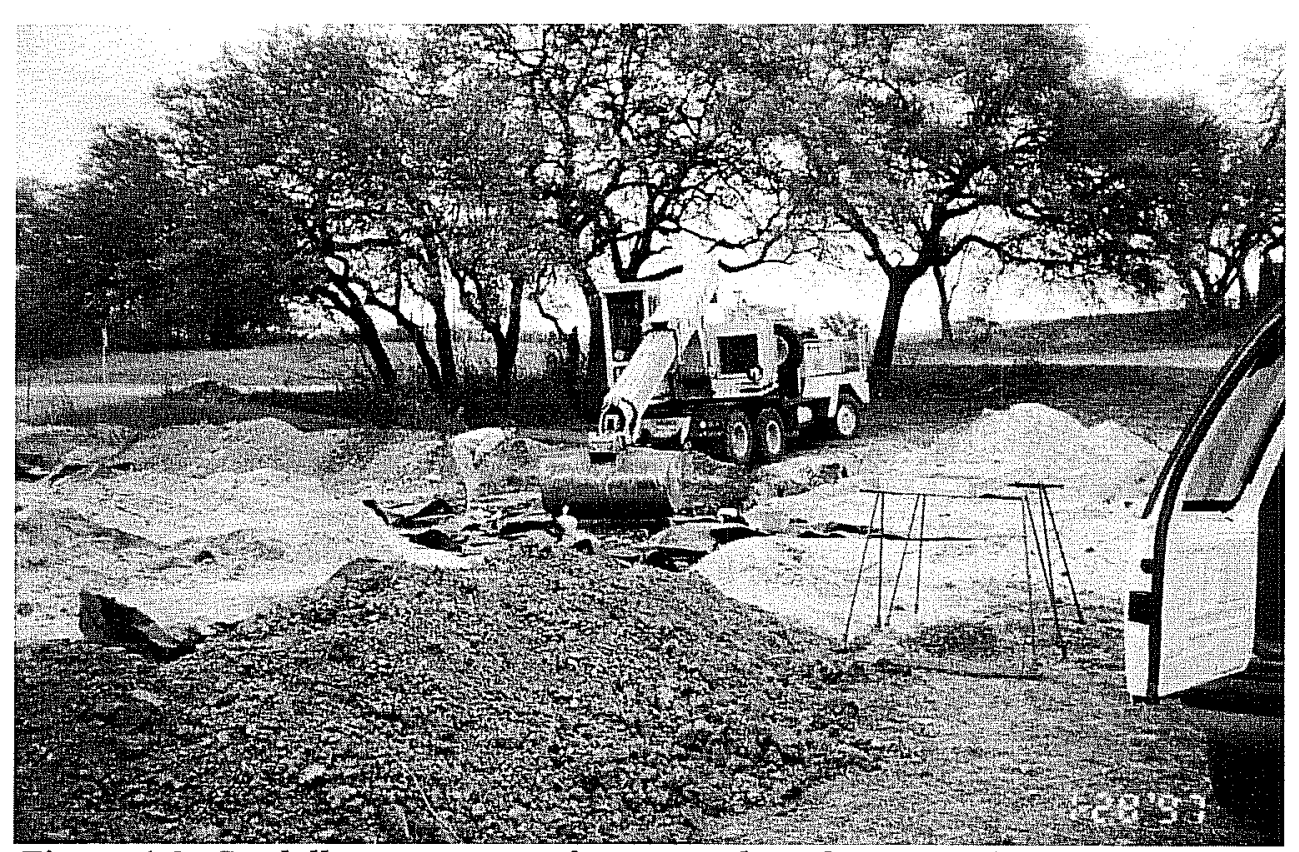

Figure 4-3. Gradall scraping top of center and northwest quadrant of the midden (1997). 
Each unit was located on the established site grid and identified in field notes by the coordinates of its southwest corner. Unit datums were established $10 \mathrm{~cm}$ above the ground surface, adjacent to the highest corner of the unit. Units were excavated beginning at the existing ground surface, with the exception of TU 10 (where approximately the top $40 \mathrm{~cm}$ of soil was removed with a Gradall), TU 11 (top $25 \mathrm{~cm}$ of construction fill removed and screened), TU 12 (top $50 \mathrm{~cm}$ removed and screened), and TUs 14-23 (top $40 \mathrm{~cm}$ of sediments were removed prior to excavation of the block). TUs $14-23$ in the Block Excavation area were excavated in 10-cm levels, with the exception of Levels 3 and 4 which were dug in 5-cm sublevels. Artifacts, burned rock, and soil samples collected from these sublevels were distinguished from the 10 - $\mathrm{cm}$ levels by a designation of "upper $5 \mathrm{~cm}$ " or "lower $5 \mathrm{~cm}$ " for the level (e.g., Level 3-Upper $5 \mathrm{~cm}$ ). Pedestaled burned rock which extended into both the upper and lower $5 \mathrm{~cm}$ of a level was collected and designated "general" (e.g., $3 \mathrm{G}$ indicates all $10 \mathrm{~cm}$ of Level 3). This holds true as well for lithic material recovered from soil associated with the pedestaled burned rock. Level 4 of TU 4 was also dug in two 5-cm levels.

A sediment sample of at least two liters was collected from the center of every $10-\mathrm{cm}$ level for flotation analysis. This allowed for the recovery of a sample of materials which would have passed through the larger 1/4-inch screen size (see Laboratory Methodology). Additional samples were collected in and around features or from soils that appeared to be organically enriched by human occupation.

In general, a single Field Sack (FS) number was assigned to all material recovered from within a 5- or 10-cm level. Therefore, lithic debitage, burned rock, fauna, and flotation samples from within a single level would be given the same FS number. Field Sack numbers were recorded on a Master Data Recovery Form, along with provenience information and types and quantities of material collected. The only exception to this method occurred when a point-plotted artifact was recovered within a level. A specifically provenienced artifact, such as a diagnostic projectile point or charcoal, was given a unique FS number or a Special Collection number, which was also recorded on the Master Data Recovery Form. In the CAR lab at the end of each day, this form was checked against the recovered material to account for all artifacts collected in the field. Artifacts and charcoal recovered from trench profiles and given special collection numbers were shot in with the EDM prior to their collection.

Feature and sub-feature numbers were assigned when identified. Feature 1 was assigned to the entire burned rock midden. Sub-feature numbers were assigned to features located in the core or framework of the midden. Feature numbers 8,9 , and 10 initially assigned by CAR were redesignated Features 1.4, 1.5, and 1.6 after determination that these features were in the framework of the midden. Therefore, feature numbers 8,9 , and 10 are no longer included in the current project's inventory. Profiles of Features 2, 3, and 4, identified in a wall of a BHT, were drawn. Plan views of all features present in TUs were drawn and photographed.

\section{Shovel Tests}

Five shovel tests were placed in the new right-of-way (Area A) to evaluate artifact density stratigraphically related to burned rock features evident in the wall of BHT S. All tests were approximately $30 \mathrm{~cm}$ in diameter, and excavated in 10-cm arbitrary levels to a minimum depth of $40 \mathrm{~cm}$ bs and a maximum depth of 65 $\mathrm{cm}$ bs. All sediments were screened through $1 / 4$-inch wire mesh. Shovel test data -including sediment texture, consistency, structure, and color, as well as gravel size and frequency, and artifact content-were recorded on CAR forms. Artifacts removed from subsurface contexts were collected.

\section{Archaeomagnetic Samples}

CAR drilled and collected 120 core samples from five levels in 13 separate units for archaeomagnetic analysis. Fire-cracked rocks from various features were drilled in place using an Echo E-ZCore rock drill, model D-2801, with a one-inch diamond-tipped bit. The angle and dip were recorded using a Brunton compass mounted on a goniometer (Figure 4-4). The elevation of each sample relative to the unit datum was also recorded. A plan view was drawn of the drilled rocks with the archaeomagnetic sample number assigned by CAR. 


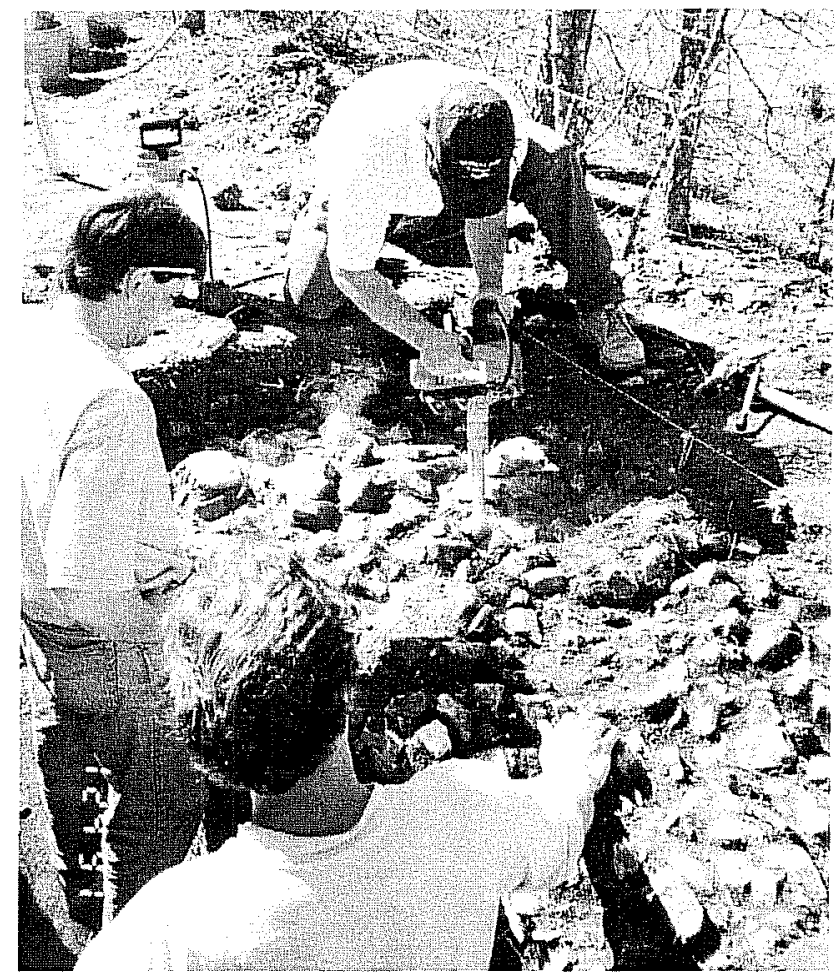

Figure 4-4. Drilling archaeomagnetic sample cores in Feature 2.

After each sample was scored and marked with a permanent marker to ensure proper alignment during the laboratory processing phase, samples were removed and placed in separate labeled bags.

Although 120 samples were drilled and collected from the site, after reviewing their proveniences in relation to soil stratigraphy, available charcoal samples, diagnostic artifacts, and debitage patterning, only 25 were selected for analysis. These were taken to WulfGose at the Paleomagnetic Laboratory, Department of Geological Sciences, The University of Texas at Austin. There the samples were cut down to 0.9 inches in length and labeled with Pelican ink. Next they were placed in a helium-cooled cryogenic magnetometer to record their natural remanent magnetization signature. They were then subjected to thermal demagnetization to as high as $600^{\circ} \mathrm{C}$ in increments of $50^{\circ} \mathrm{C}$. After each heating event they were allowed to cool and their magnetic signature was measured in the magnetometer and recorded on a computer database before being reheated to the next higher increment (see Chapter 11).

\section{Soil Susceptibility Samples}

One hundred thirty-six soil susceptibility samples were collected from 41BX126 by CAR in 1997. Samples were removed in a miniature column fashion from the walls of BHTs M and X. First, the area of the wall to be sampled was scraped to insure a recent exposure to the atmosphere. A 4-x-4-cm soil sample was taken vertically from top to bottom in three-centimeter increments (Figure 4-5). The samples were collected in labeled bags and their proveniences recorded on a field form before being transported to the CAR lab. All samples were taken to Wulf Gose at the Paleomagnetic Laboratory, Department of Geological Sciences, The University of Texas at Austin. Once there, the soils were removed from bags and placed in plastic

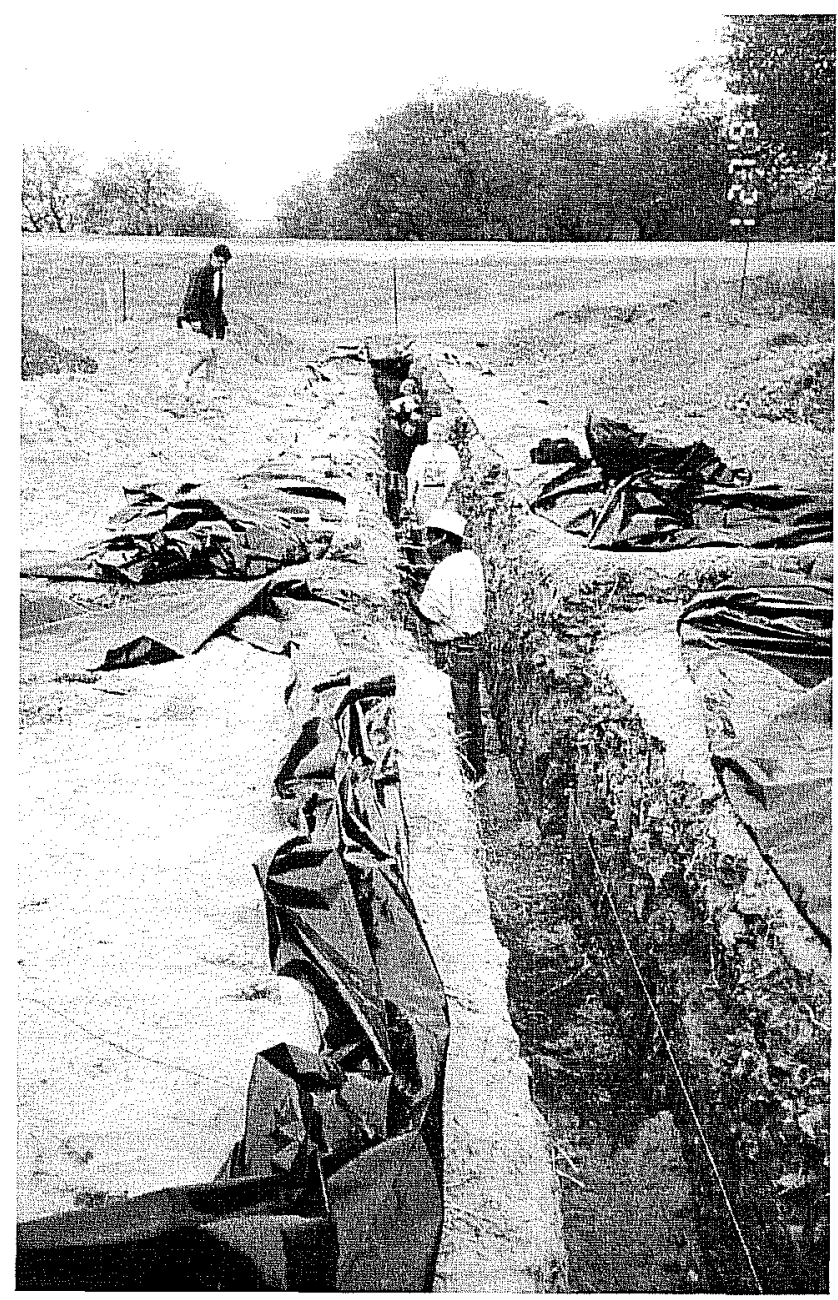

Figure 4-5. Cleaning and scraping trench wall for soil susceptibility sampling. 
two-centimeter cubes. The cubes were labeled alphabetically to provide a cross reference with their provenience at the site. Each sample was then placed in a normal magnetometer at room temperature to measure its magnetic susceptibility. The data were recorded on a computer database (see Chapter 11).

\section{Photographic Documentation}

In 1997 CAR staff took 211 photographs using color and black-and-white print, and color slide film. Photographs were recorded on standard CAR photo forms in the field. CAR used Cannon, Mimaya, and Fuji cameras for all field photographs. In addition to photographing general excavation activities, particular attention was given to features, profiles, and plan views. The negatives are stored on CDs.

\section{Laboratory Methods}

Cultural material recovered from 41BX126 during the 1993, 1995, and 1997 investigations was inventoried at the CAR laboratory. Lithic artifacts recovered from the three investigations were analyzed by CAR archaeologists. Additionally, burned rock collected during the 1995 and 1997 testing projects was analyzed by CAR staff, and all flotation material recovered from the two investigations was processed at the CAR lab. Most of the laboratory processing and analyses ran concurrent with the fieldwork, with the exception of several of the 1995 float samples which were processed prior to the start of the 1997 field investigation.

As discussed above, the 1993 and 1995 investigations used different lot numbering systems on their artifact bags. During analyses at the CAR lab, problems arose with Price's point-plotted artifacts and Wood's lot system as this caused duplicate designations between Wood and Price. The overlapping occurs on Price's lots $4 a-c, 5 a-f$, and $7 a-d$. All discrepancies between the two lot systems were resolved by the uniformity of writing on the bags and drawings of the point-plotted artifacts within the specimen catalog. Also, the difference between Price's lot numbers and the current project's field sack (FS) numbers is a prefix of
"FS" before CAR's assigned number. Thus, an artifact bag labeled 81 came from Price's excavation and one labeled FS 81 came from the 1997 excavation.

In 1997, the CAR laboratory processed 59,318 lithic artifacts, 1,655 liters (1,748 quarts) of float samples, and $3,337 \mathrm{~kg}$ (over 3.67 tons) of burned rock. Artifacts and samples were separated by artifact type and recovery context to facilitate analysis. For example, lithics recovered in the field had a recovery context of $1 / 4$-inch screen size, while those recovered during the flotation process had a recovery context of $1 / 16^{-}$ inch screen size. The majority of burned rock was collected during excavation, however, some burned rock was collected from the $1 / 4$-inch screen size.

\section{Lithic Artifacts}

Processing of lithics recovered from the $1 / 4$-inch screen began with washing and sorting into debitage and tool categories. All debitage from $1 / 4$-inch and $1 / 16$-inch screen contexts from the 1993, 1995, and 1997 investigations was included in the preliminary debitage analysis. In this analysis, individual lithics were sorted by a concentric size chart and counted (Figure 4-6). Data from this analysis was recorded and subsequently entered into an Excel spreadsheet. A second type of analysis was made on all whole flakes recovered from the Block Excavation (see Chapter 6). This consisted of the identification of flake type (i.e., normal, biface thinning, uniface, sequence, and notching). This analysis was done on all whole flakes recovered from both $1 / 4$-inch and $1 / 16$-inch screen contexts from the Block excavation area. Data were entered on an Excel spreadsheet.

Tools from the 1993, 1995, and 1997 investigations were identified and separated from the debitage. Tools were categorized as projectile points, bifaces, unifaces, cores, and choppers. Individual tool categories were further analyzed by specific attributes designed for each tool type (see Chapter 8). Artifacts collected from the 50-x-50-cm units during the 1993 TxDOT project were reported to have been recovered in 10-cm levels (Wood); however, artifact forms and bags indicate that the artifacts were combined and not separated by level. 


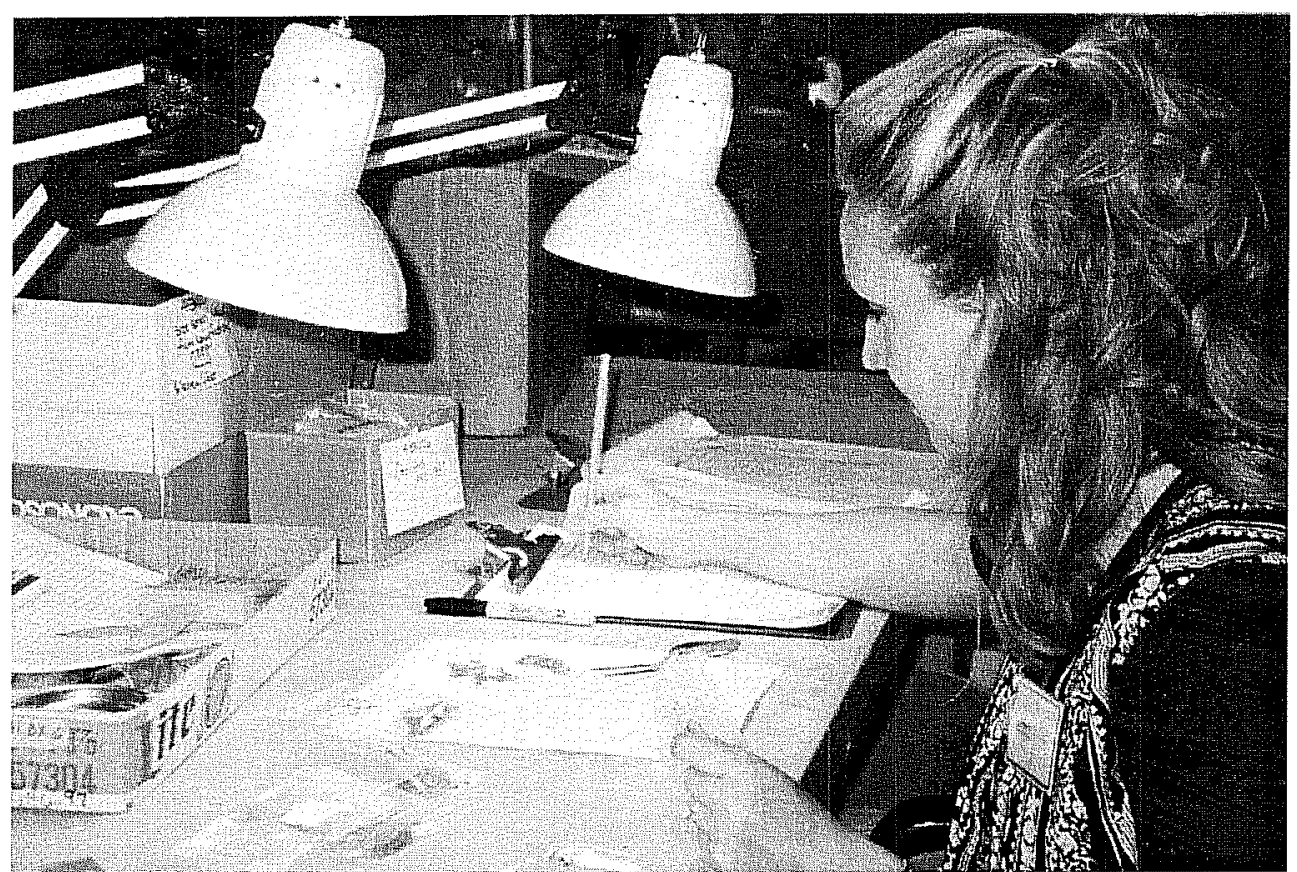

Figure 4-6. Counting and size-sorting lithics during the preliminary debitage analysis.

\section{Flotation}

The 1995 and 1997 flotation samples were processed outside and behind the CAR laboratory (flotation samples were not collected during the 1993 investigation). Each sample was measured in quarts before processing. Samples were processed in 10 gallon buckets by adding water, stirring, and pouring off the suspended botanical remains into a $1 / 32$-inch carburetor filter. The process was repeated three times for each five quarts processed. The heavy fraction of the float sample was then wet-screened through a $1 / 15^{- \text {inch }}$ screen and set out to dry with the light fractions (botanical remains). Light fractions were later sent to Phil Dering at Texas A\&M University for analysis (see
Chapter 9). Heavy fractions were picked for lithic artifacts and fish otoliths.

\section{Burned Rock}

As with the flotation samples, the CAR laboratory processed burned rock collected from both the 1995 and the 1997 excavations. Burned rock was analyzed from the following units: CAR's TUs 1, 7, 8, 9, and 14-23; and Price's TUs A-F. The burned rock analysis included differentiating rock types (limestone, sandstone, quartz, etc.), size sorting, counting, and weighing (Figure 4-7). Fresh breaks on the burned rocks were noted and counted separately from facets created through heating. During excavation, burned rock was separated from natural gravels and the burned rock was collected (see Appendix E for results).

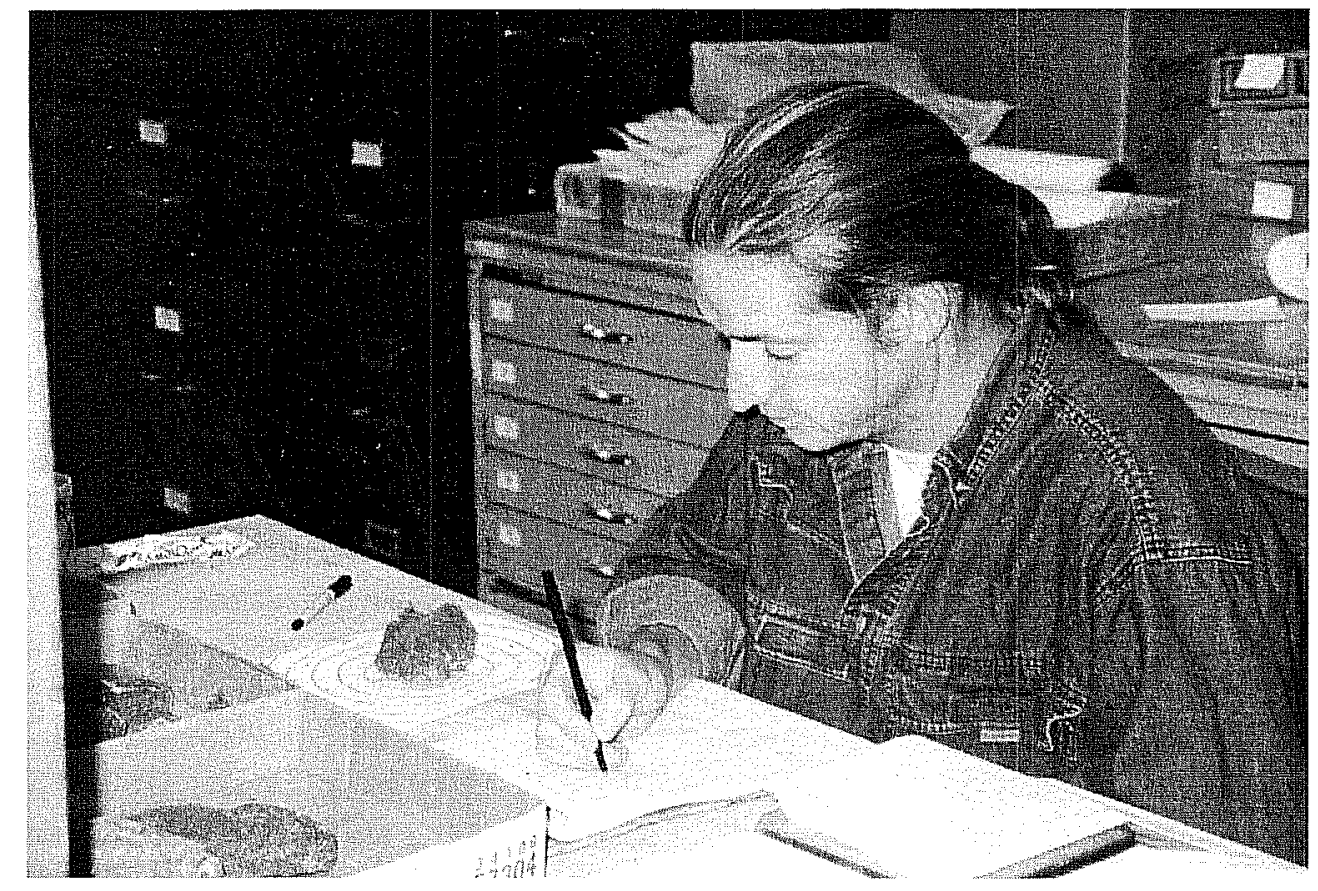

Figure 4-7. Lab analyst size-sorting, counting, and weighing burned rock. 


\section{Carbon Dating}

Wood charcoal samples were processed independently of the CAR laboratory. Fifteen samples, four collected in 1995, and 11 collected in 1997, were submitted by CAR to INSTAAR (INSTAAR Radiocarbon Laboratory) for radiocarbon analysis. In addition, Frederick (Appendix A) and Nordt (Chapter 5) each submitted three bulk sediment samples to Beta Analytical for dating. For a discussion of radiocarbon dates see Chapter 7.

\section{Curation}

Lithics processed in the CAR laboratory were washed, air-dried, and stored in archival-quality bags. Acidfree labels were placed in all artifact bags. Each bag was labeled with a provenience or corresponding lot number. Tools recovered from all excavations were labeled with permanent ink and covered by a clear coat of acrylic. Artifacts from each investigation were separated by type and stored in acid-free boxes. Boxes were labeled with standard labels. Burned rock collected during the 1995 and 1997 excavations was discarded after analysis. Heavy fraction, light fraction, and other samples (i.e., ${ }^{14} \mathrm{C}$, archaeomagnetic samples) were also placed in acid-free boxes.

Field notes, forms, photographs, and drawings were placed in labeled notebooks. Photographs, slides, and negatives were placed in archival-quality sleeves. All notebooks are stored in acid-free boxes. Documents and forms from the 1997 excavation were printed on acid-free paper. A copy of the site report and all computer disks pertaining to the 1997 investigation of the Culebra Creek site are stored in an archival box and curated with the field notes and documents. Artifacts, notes, documents, and photographs from the 1993, 1995, and 1997 excavations at 41BX126 are permanently housed at the CAR laboratory on the UTSA campus. 


\section{Chapter 5: Geoarchaeology of 41BX126}

\section{Lee C. Nordt}

\section{Introduction}

The purpose of the geoarchaeological investigation of 41BX126 along Culebra Creek was to map the late Quaternary alluvial landforms, describe the alluvial stratigraphy, interpret environments of deposition, and discuss site formation and preservation potentials for the prehistoric archaeological record. Initial investigation of the alluvial deposits were conducted by Charles Frederick in 1995 (Appendix A), and this study builds upon and elaborates the results of this first study.

Culebra Creek is a low-order tributary which joins with Helotes Creek in the southeastern part of the project area (Figure 5-1). This combined drainage network enters Leon Creek approximately $10 \mathrm{~km}$ to the east. The Culebra Creek drainage basin covers mainly the Austin Chalk, Edwards Limestone, Pecan Gap Chalk, Glen Rose Limestone, and Buda Formation of Cretaceous age, and Uvalde Gravels of Quaternary age (Barnes 1983). These deposits contribute alluvium to the Culebra Creek drainage basin consisting of limestone and siliceous clasts, and sands, silts, and clays that are rich in carbonate.

The Soil Survey of Bexar County, Texas (Taylor et al. 1991) shows Trinity and Frio frequently flooded soils within the modern channel of Culebra Creek, and Patrick and Lewisville soils on adjacent low terraces. These soils are all weakly developed and indicate a Holocene age for alluvial deposition. This interpretation coincides with the geologic mapping of Quaternary terraces in the area (Barnes 1983).

Geoarchaeological investigations were performed in an earlier archaeological testing phase in the project area (Frederick, Appendix A) and are referred to periodically. However, the results of the current geomorphic investigation vary from the previous investigation because of the availability of additional core samples, a closer view of soil-stratigraphic relations, and additional carbon-14 $\left({ }^{14} \mathrm{C}\right)$ assays.

\section{Methods}

Reconstruction of the late Quaternary alluvial history of Culebra Creek in the vicinity of 41BX126 was based on: 1) numerous charcoal ${ }^{14} \mathrm{C}$ ages from the burned rock midden and associated hearths; 2 ) three bulk sediment humate ${ }^{14} \mathrm{C}$ ages; 3) time-diagnostic artifacts; 4) soil-stratigraphic exposures provided by 16 backhoe and Gradall trenches (BHTs and GTs) and 14 drill cores taken by the Bureau of Economic Geology; and 5) three ${ }^{14} \mathrm{C}$ bulk sediment humate ages obtained by Frederick during the previous archaeological testing phase (Appendix A).

Carbon-14 dating on charcoal and humate samples was performed by the Institute of Arctic and Alpine Research and Beta Analytic. Three ${ }^{14} \mathrm{C}$ ages from the previous phase of geological investigations were performed on bulk sediment humates and not corrected for ${ }^{13} \mathrm{C}$ fractionation (Appendix A). Three sediment bulk humate ages were determined by atomic mass spectrometry for the current phase of geological investigations and corrected for ${ }^{13} \mathrm{C}$ fractionation. All ages are reported in years before present (в.P.).

The soil-stratigraphic descriptions were written from Gradall trenches and archaeological test units following standards and procedures of the Soil Survey Division Staff (1993) and Folk (1980). Soil-stratigraphic descriptions from the current investigation are given in Appendix C. For descriptions from the previous investigation by Charles Frederick, see Appendix A.

Terrace designations follow the format $\mathrm{T} 3, \mathrm{~T} 2, \mathrm{~T} 1$, and T0 (floodplain), from oldest to youngest. Highway construction personnel note that all Holocene landforms flood periodically, thus the term "flood terrace" was invoked. Stratigraphic units were identified as unconformably bound packages of sediment. Units were labeled $\mathrm{I}-\mathrm{V}$, from oldest to youngest. 


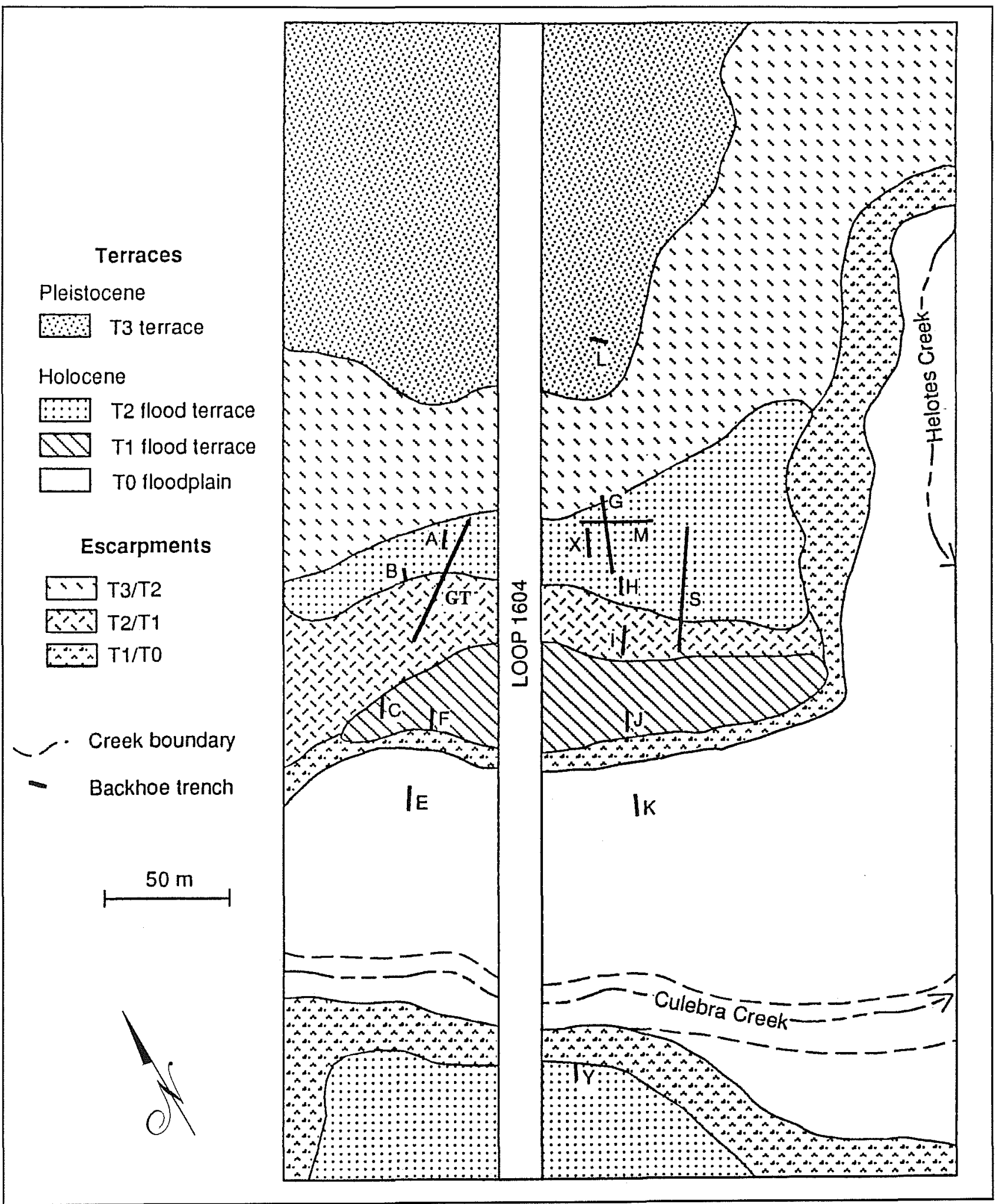

Figure 5-1. Geomorphic map of late Quaternary alluvial landforms, erosional escarpments, and backhoe and Gradall trenches along Culebra Creek in the project area. 


\section{Stratigraphy}

A complex alluvial stratigraphic sequence was constructed by Culebra Creek during the late Quaternary. In the project area, these alluvial deposits form five depositional landforms: the Pleistocene T3 terrace on the north side of the project area; the Holocene T2 flood terrace on both sides of the valley (also associated with 41BX126 on the north side of the valley); the Holocene T1 flood terrace on the north side of the valley; and the modern T0 floodplain adjacent to Culebra and Helotes creeks (Figure 5-1). Erosional escarpments separate terrace from terrace, and the terraces from the floodplain (Figure 5-1).

Five fluvial units were also recognized in the project area (Figure 5-2): Unit I (Pleistocene); Unit II (latest Pleistocene); Unit III (early to middle Holocene); Unit IV (late Holocene); and Unit V (modern). Units II, III, and IV were subdivided into fluvial (IIa, $\mathrm{IIa}, \mathrm{IVa}$ ) and colluvial (IIc, IIIc, IVc) facies. A deeply buried paleosol was also identified in the upper part of Unit II.

\section{T3 Terrace}

The T3 terrace along Culebra Creek is situated more than $12 \mathrm{~m}$ above the modern low-water channel on the north side of the valley (Figure 5-1). It is gently rolling and possibly consists of a complex of several terrace levels. Based on exposures provided by local out crops and BHT L (Appendix C), the associated soil typically has an A-Bss-Ckm horizon sequence. The upper layers consist of dark colored clays, whereas the $\mathrm{Ckm}$ has formed in waterworn siliceous pebbles and cobbles, or on limestone bedrock. Waterworn clasts verify that a veneer of stream alluvium exists in the area, which is designated as Unit I for the project area. According to carbonate accumulations in soils of the southwestern United States (Machette 1985), the T3 terrace and underlying alluvial deposit along Culebra Creek are Pleistocene in age. The radiocarbon chronology developed for 41BX126 supports this hypothesis.

\section{T2 Flood Terrace}

The T2 flood terrace forms the oldest landform within the Holocene valley of Culebra Creek (Figure 5-1). It is situated 5-7 m above the modern low-water channel on both sides of the valley. The T3 terrace and T2 flood terrace are separated by an erosional escarpment with a relief of 4-6 $\mathrm{m}$ (Figure 5-1). Excluding the surface veneer, two alluvial units, two colluvial units, and a deeply buried paleosol occur beneath the T2 flood terrace on the north side of the valley (Figures 5-1 and 5-2; BHTs $I, X, M$, and G). Unit Ila is the oldest of the units and is deeply buried. The Unit IIa facies consists of basal grain supported pebbles that grade conformably up into strong brown to reddish yellow loams (Appendix C). The upper $40-60 \mathrm{~cm}$ consists of a truncated $\mathrm{Bk}$ horizon, reflecting a period of quasi-landscape stability and soil formation.

A colluvial wedge, designated Unit IIc, emanates from the north valley wall and interfingers with Unit IIa (Figures 5-1 and 5-2; BHT G). Consequently, the alluvial and colluvial facies of Unit II appear to have formed simultaneously. The colluvial unit contains many matrix supported and angular pebbles and cobbles that are partly cemented with carbonate (Appendix $\mathrm{C}$ ). The carbonate cement may have originated from water moving down the T3/T2 escarpment along the colluvial and bedrock contact.

One bulk sediment humate age from the paleosol in top of Unit Ila dates to $17,670 \pm 100$ B.P. (Figure 5-2). This demonstrates that valley alluvium and adjacent sideslope colluvium were being deposited along Culebra Creek in the latest Pleistocene. A period of quasilandscape stability and soil formation occurred shortly after this time, perhaps near the Pleistocene/Holocene boundary.

The next alluvial unit in the Holocene valley of Culebra Creek is designated Unit III, which stratigraphically overlies Unit II beneath the T2 flood terrace. Unit III is buried by a complex of alluvium and colluvium on the northeast side of the valley (BHTs X, S, H, M, and G), but forms the constructional T2 flood terrace on the northwest (BHTs A and B, and the GT) and south 
South

$\mathrm{T} 2$

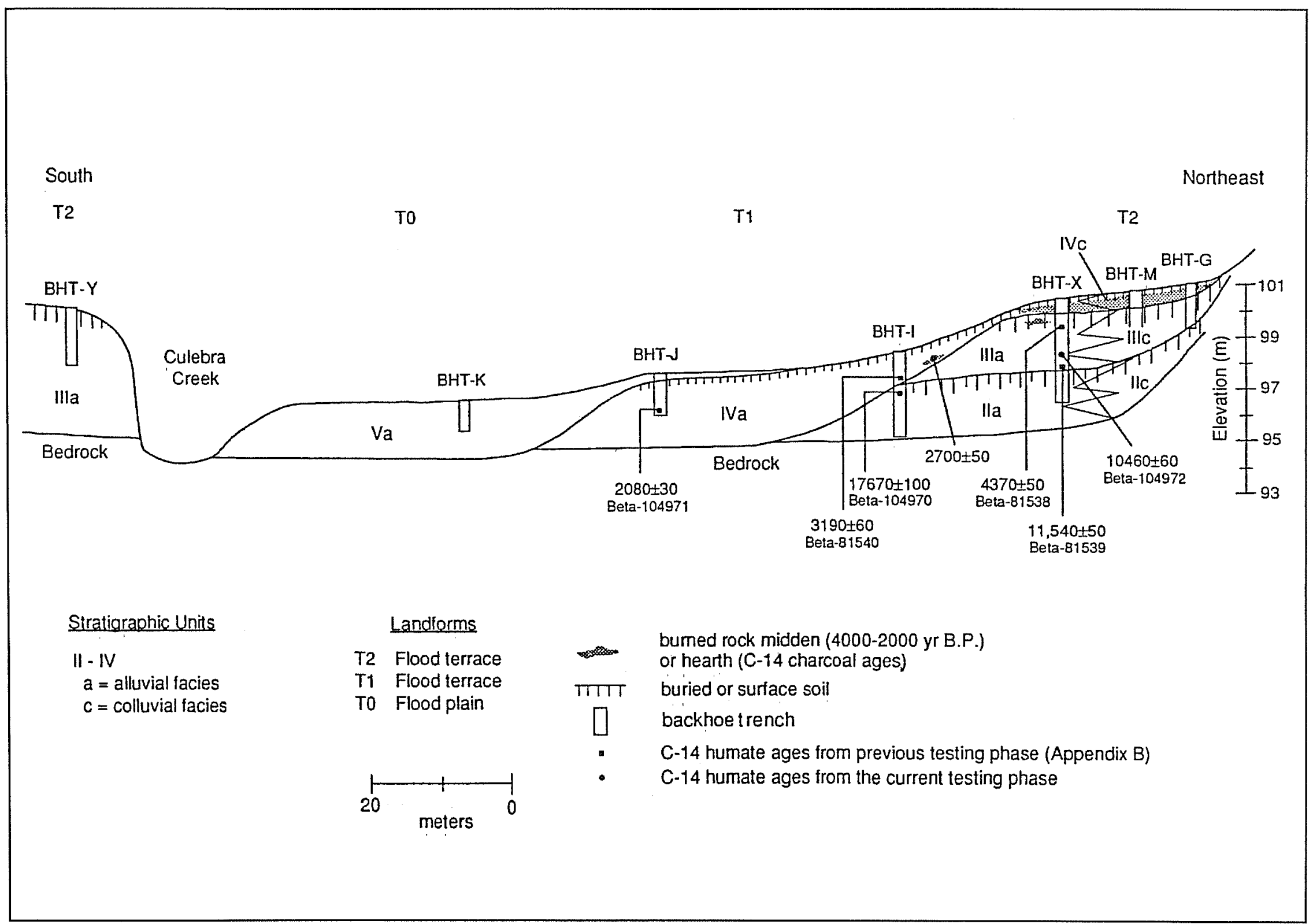

Figure 5-2. Schematic geologic cross section of Culebra Creek constructed for the east side of Loop 1604 from backhoe and Gradall trenches, deep sediment cores, and ${ }^{14} \mathrm{C}$ ages. 
(BHT Y) sides of the valley (Figures 5-1 and 5-2). An unconformity was identified below a depth of $180 \mathrm{~cm}$ in BHT C on the northwest side of the valley (Appendix C) that may correlate with a truncated remnant of Unit III (BHT C in the current testing phase was excavated to only a depth of $160 \mathrm{~cm}$ ). Unit III in the GT on the northwest side has experienced virtually no carbonate loss and therefore could not have served as a source for the underlying carbonate-enriched zone in IIa. Unit III may represent a cut and fill sequence from Unit II, or Unit III may be conformable with Unit II. The soil in Unit II represents a non-deposition period in the Clovis Drought, approximately 13,000 to 12,000 years ago. Consequently, the $\mathrm{Bkm}$ horizons identified in the previous investigation in BHTs A and B (Appendix A) are probably indurated remnants of Unit IIa and IIc (Figure 5-1).

Unit III along Culebra Creek consists mainly of dark brown to reddish brown silty clay loams and silty clays (Appendix C). Subsoils are weathered to Bss and Bkss horizons. On the south side of the creek, grain-supported channel gravels were exposed at the base of the cutbank below BHT Y (Figures 5-1 and 5-2). Finegrained deposits and the absence of channel gravels suggest that Unit IIIa on the north side of the valley consists entirely of floodbasin sediments and that the Unit III channel never migrated across the site to the north wall of the Holocene valley (Figure 5-2).

Whether buried on the northeast side of the valley or surficially exposed on the northwest or south side, the Unit IIIa subsoil has filaments of calcium carbonate and slickensides. This occurs because the Unit III soil to the northeast was not buried deeply enough to terminate pedogenesis. Consequently, the surface horizon of the weathering zone in the top of Unit III has been transformed into a Bk horizon since burial. Interestingly, accumulations of carbonate filaments is actually greater in the buried Bk horizon of Unit III beneath the midden, perhaps because of calcium inputs from overlying anthropogenic ash deposits. On the south side of the valley where burial of Unit IIIa never occurred, the soil has been forming continuously since Unit IIIa deposition terminated.

A colluvial wedge, designated as Unit IIIc, interfingers with Unit IIIa on the northeast side of the valley (Figures 5-1 and 5-2; BHTs G and M). This unit contains an abundance of matrix-supported and angular pebbles with the fine-grained sediments having dark brown to brown colors. On the northwest side of the valley, BHTs A and B and the GT may be comprised partly of fine-grained colluvium.

Bulk sediment humate ${ }^{14} \mathrm{C}$ ages of $11,540 \pm 50$ (Appendix $C$ and Table 6-19) and 10,460 \pm 60 were obtained from near the base of Unit IIIa (Figures 5-1 and $5-2$; BHT X). These ages represent a maximum for the time of deposition because of probable contamination from "old" carbon typical for great alluvial depths in Central Texas (Nordt 1992). A ${ }^{14} \mathrm{C}$ age of $4370 \pm 50$ from BHT H was obtained from bulk sediment humates (Appendix $\mathrm{C}$ and Table 6-19) in what is now identified as Unit IIIa (Figures 5-1 and 5-2). A date of $4630 \pm 40$ from the Nolan component in Area $B$ suggests this is only slightly younger than the wood charcoal ${ }^{14} \mathrm{C}$ age. Because the bulk sediment ${ }^{14} \mathrm{C}$ age came from a depth of only $140 \mathrm{~cm}$ and is probably enriched in modern organic carbon, it represents a minimum for the time of deposition. Regardless, deposition of Unit III had terminated by 4000 B.P. according to the earliest occupation of the overlying midden.

\section{T1 Flood Terrace}

The T1 flood terrace is situated three to four meters above the modern low-water channel of Culebra Creek. It is separated from the T2 flood terrace on the north side of the Holocene valley by an erosional escarpment with a relief of $1-2 \mathrm{~m}$ (Figure 5-1). Scattered burned rock on the surface of Unit III is clearly truncated by this erosional episode. The associated alluvium is designated Unit IVa, which consists of stratified layers of pebbles and brown, dark brown, very dark gray, and very dark grayish brown loams (Figures 5-1 and 5-2). This unit forms the constructional T1 flood terrace is some areas (BHTs J, F, and C) and partly overlaps Unit IIIa as a floodbasin facies in other areas (BHTs I and S) (Figures 5-1 and 5-2). The surface soil is weakly developed with minimal accumulations of subsurface pedogenic carbonate $(\mathrm{Bw}$ horizon).

A colluvial unit, designated Unit IVc, forms a veneer that buries Unit IIIa and IIIc on the north side of the valley and eventually interfingers with the floodbasin 
facies of Unit IVa near BHT X (Figures 5-1 and 5-2). The alluvial and colluvial facies differ in that the latter contains an abundance of matrix-supported and angular pebbles. The alluvial and colluvial facies of Unit IV appear to have formed coevally.

In the project area of Culebra Creek, charcoal ${ }^{14} \mathrm{C}$ ages from the burned rock midden reveal that site occupation, and thus deposition of Unit IVa and IVc, occurred between approximately 4000 and 2000 B.P. The earlier ages were from prehistoric pits and the central core of the midden excavated into underlying Unit III deposits, and may slightly predate the initiation of deposition of Unit IV. However, ${ }^{14} \mathrm{C}$ ages of $3190 \pm 60$ (BHT I) and 2700 \pm 50 (BHT S) from the base of Unit IVa indicates that deposition was underway by this time (Figures 5-1 and 5-2; Table 6-19). $\mathrm{A}^{14} \mathrm{C}$ age from BHT I demonstrates that deposition of Unit IVa was definitely ongoing by 2000 B.P. (Figures 5-1 and 5-2).

\section{T0 Floodplain}

The youngest Holocene unit of Culebra Creek, Unit $\mathrm{Va}$, is inset to Unit IVa adjacent to the modern channel on the north side of the valley (Figures 5-1 and 52; BHTs $\mathrm{K}$ and $\mathrm{E}$ ). This unit is associated with the T0 floodplain situated between 1.5 and $2 \mathrm{~m}$ above the modern low-water channel. The erosional escarpment separating the $\mathrm{T} 1$ flood terrace from the floodplain also impinges on the $\mathrm{T} 2$ flood terrace and $\mathrm{T} 3$ terrace adjacent to Helotes Creek (Figure 5-1). Unit Va consists of stratified pebbles and cobbles and very dark gray loams (Figures 5-1 and 5-2). In BHTs J and C, a veneer of lighter-colored Unit Va sediments bury Unit IVa (Figures 5-1 and 5-2; Appendix C).

\section{Stratigraphic Summary}

The $\mathrm{T} 3$ terrace is the oldest alluvial landform preserved in the project area of Culebra Creek. The associated alluvial unit, Unit I, has been weathered to a soil with a carbonate enriched subsurface layer described as a $\mathrm{Ckm}$. Degree of soil development indicates a Pleistocene age.
Based on a ${ }^{14} \mathrm{C}$ age from Unit Ila near the base of the T2 flood terrace, a period of channel downcutting had occurred before 17,000 B.P. that transformed T3 from a floodplain to a terrace. Deposition of Unit II then proceeded on the north side of the valley and continued to near 11,000 B.P. Flood frequency decreased during the latter stages of Unit II deposition, resulting in a period of soil formation. Sideslope colluvium, designated Unit IIc, emanated from the north valley wall coevally with deposition of Unit IIa.

Based on stratigraphic position, lithology, and soil development, Unit IIa and IIc appear to correlate the Georgetown alluvium and Georgetown colluvium, respectively, of the Fort Hood Military Reservation (Nordt 1992, 1995, 1997). At Fort Hood, these deposits dated to no earlier than 12,000 B.P., which precedes the ages of Unit II along Culebra Creek by some 5,000 years. It is unclear whether Unit II along Culebra Creek was deposited earlier than elsewhere, or whether the ${ }^{14} \mathrm{C}$ sample was contaminated with "old" organic carbon. In fact, Nordt (1992) has discovered that bulk sediment humates consistently dated up to 2,000 years older than associated charcoal.

Deposition of Unit IIIa was underway shortly after 11,000 B.P. and continued until near 4000 B.P. The Holocene valley widened considerably at this time as the Culebra Creek meander belt migrated to the south. It is unknown how much of Unit II was eroded at this time, but it is clear that the Unit IIIa channel never migrated across the T2 flood terrace on the north side of the valley. Unit IIIc colluvium was deposited simultaneously with Unit IIIa alluvium.

Units IIIla and IIIb appear to correlate with the Fort Hood alluvium and Fort Hood colluvium of the Fort Hood Military Reservation based on stratigraphic position, lithology, and soil development (Nordt 1992, 1995, 1997). At Fort Hood, these deposits dated to between approximately 8000 and 4500 B.P. based on charcoal. Associated ${ }^{14} \mathrm{C}$ ages of bulk sediment humates dated to as early as 10,000 B.P. in Fort Hood, consistent with Unit III humate ages along Culebra Creek.

A third period of channel downcutting occurred in the Culebra Creek valley sometime between 4000 and 2700 B.P. It was this episode that transformed T2 from 
a floodplain to a flood terrace, formed the erosional escarpment separating the $\mathrm{T} 2$ and $\mathrm{T} 1$ flood terraces, and truncated Units II and III. After downcutting, deposition of Unit IVa then proceeded and did not terminate until sometime after 2000 B.P. The Unit IVa channel was migrating to the south during this time, as floodbasin deposits veneered the $\mathrm{T} 2$ flood terrace during periodic flooding. Sideslope colluvial processes were also activated, resulting in deposition of Unit IVc across the T2 flood terrace on the north side of the valley. Although colluviation likely occurred for more than 2,000 years, minimal thickness suggests that the sediment supply on the north valley wall was becoming depleted. There is no clear evidence for late Holocene colluviation of the northwest side of the project area.

Nordt $(1992,1995,1997)$ dated deposition of the West Range alluvium and West Range colluvium to between approximately 4000 and 600 B.P. in the Fort Hood Military Reservation. The early part of deposition of Unit IVa and IVc temporally coincides with the late Holocene alluvial units from Fort Hood. Based on correlation to Fort Hood, deposition of Unit IV may have been ongoing up to between 1000 and 600 B.P.

The fourth and final episode of channel downcutting along Culebra Creek occurred after 2000 B.P., and perhaps sometime between 1000 and 600 в.P. This event transformed $\mathrm{T} 1$ from a floodplain to a flood terrace. Channel migration continued south to the current position of Culebra Creek. During channel migration, Unit Va was deposited and the T0 floodplain constructed. With continued flooding, a veneer of Unit $\mathrm{V}$ alluvium was also deposited across part of the T1 flood terrace. Nordt $(1992,1995,1997)$ dated deposition of the Ford alluvium to the last 600 years in the Fort Hood Military Reservation, which probably coincides with deposition of Unit Va along Culebra Creek.

\section{Geoarchaeology}

\section{Site Preservation Potentials}

Based on ${ }^{14} \mathrm{C}$ ages, stratigraphic relations, and soil development, Unit I deposits and the T3 terrace along Culebra Creek are Late Pleistocene in age (Figures 5-1 and 5-2). Thus, cultural materials in a primary context will most likely be confined to the terrace surface and potentially span the entire record of human prehistory.

Units Ila and IIc appear to be latest Pleistocene in age and therefore may contain deeply stratified Paleoindian features (Figures 5-1 and 5-2). Units IIIla and IIIc are mainly early to mid Holocene in age and therefore may have deeply stratified Paleoindian or Early to Middle Archaic components (Figures 5-1 and 5-2). Unit III forms the constructional T2 flood terrace on the south and northwest sides of Culebra Creek, which may have surface sites spanning the latter part of the Early Archaic and up to the present. The surface of Unit IIIa and IIIc on the north side of the valley will have features dating to a relatively narrow time around 4000 B.P. because of burial by Units IVa and IVc at this time.

The burned rock midden at $41 \mathrm{BX} 126$ formed on top of Units IIIa and IIIc of the T2 flood terrace on the northeast side of the valley (Figures 5-1 and 5-2). Based on time-diagnostic artifacts and ${ }^{14} \mathrm{C}$ ages, it appears that use of the midden began around 4000 в.P. Remains of this initial occupation were evident as features that had been excavated into the upper part of Unit III. The remainder of the burned rock midden apparently formed concomitant with deposition of Units IVa and IVc between approximately 4000 and 2000 в.P. Because long-term occupation occurred simultaneously with slow deposition of Units IVa and IVc, mixed assemblages of features will be compressed within a narrow depth-zone. This assemblage should contain Middle and Late Archaic features within the deposit and perhaps Late Prehistoric features near the ground surface. Because of more rapid deposition, vertical superpositioning of features will more likely occur within Unit IVa beneath the T1 flood terrace to the south of the site. The Late Prehistoric may also be buried within Unit Va.

The contextual integrity of components of 41BX126 was undoubtedly disturbed to some extent during burial by fluvial and colluvial processes. Floodbasin facies of fluvial environments, and perhaps finegrained colluvial deposits, typically contain buried features approximating a primary context. In contrast, features buried in channel or coarse-grained colluvial facies may have a greater degree of disturbance during burial. It follows that features buried in thick 
floodbasin or fine-grained colluvial deposits of Unit IIIa, and perhaps Unit IIIc, will have the greatest contextual integrity based on environment of deposition. The block excavation east of the main midden was in this context. The midden is buried within fine-grained floodbasin deposits of Unit IVa and somewhat coarsergrained colluvial deposits of Unit IVc. Although perhaps not as favorable for preservation in a primary context as in Units IIIa and IIIc, the main part of the midden was probably not subjected to intense erosion during its formation. However, the southern edge was apparently truncated during channel downcutting sometime between 4000 and 2700 B.P.

Soil-stratigraphic descriptions within and adjacent to the site revealed numerous biocasts. The origin of these features is probably from rooting, earthworm activity, and activities of other macro-organisms such as rodents. These processes will undoubtedly rearrange cultural components from their primary context. However, quantifying the amount of disturbance from biological activity at $41 \mathrm{BX} 126$ is not tenable without further data. Slickensides form in subsoils during wetting and drying cycles from lateral soil movement in response to confining overburden pressures. Fortunately, the bulk of the site is associated with colluvial deposits (Unit IIII) not having slickensides nor the disruptive forces produced by these features. However, on the margins of the site to the south and west where fine-grained floodbasin facies occur, slickensides are prevalent. Consequently, in these areas artifacts can be shifted from their primary context by sediment shrink/swell activity.

\section{Site Formation}

The timing of erosional and depositional episodes along Culebra Creek in the project area is critical for understanding the formation of 41BX126 and for inferring associated settlement patterns. The presence of Units IIa and IIc beneath the T2 flood terrace demonstrates that the north side of the valley was cut by a Unit II channel during the latest Pleistocene (Figures 5-1 and 5-2). During the early Holocene, the Unit IIIa meanderbelt remained to the south of the project area as it constructed the broad T2 flood terrace. Fine-grained floodbasin sediments from this channel eventually buried Unit II in the vicinity of 41BX126 (Figure 5-2).

The Unit IIIa meanderbelt was apparently migrating toward the project area in the middle Holocene. Sometime between 4000 and 2700 B.P. on the north side of the valley near the project area, the T2 floodplain was transformed to a flood terrace in response to channel downcutting. This erosional episode crosscut Units Ila and IIIa and formed the escarpment that now separates the T2 and T1 flood terraces (Figure 5-2). After downcutting, the Culebra Creek channel began migrating towards its current position to the south as it constructed the T1 flood terrace and deposited Unit IVa (Figure 5-2). Landscape transformation after channel downcutting would have reduced flooding on the T2 flood terrace, and perhaps made the area more favorable for long-term human occupation.

Temporal and spatial constraints indicate that the erosional unconformity separating Units III and IV, and the $\mathrm{T} 2$ and $\mathrm{T} 1$ flood terraces, was cut during prehistoric occupation at 41BX126. Initial occupation apparently occurred near 5000 B.P. when the T2 flood terrace was still an actively aggrading floodplain. The soil at this time probably consisted of an A-C profile that was wetter than the modern soil. It appears that the burned rock midden use occurred after channel downcutting around 4000 B.P. As a consequence, early occupation of the site occurred in a floodplain setting, whereas midden occupation occurred adjacent to an entrenched channel of Culebra Creek on a quasistable flood terrace. This landscape interpretation could explain why initial occupation at 41BX126 consisted of ephemeral prehistoric encampments (a few discrete hearths and light scatter of artifacts) and why long-term midden occupation did not occur until later.

Deposition of Units IVa and IVc continued and eventually buried the midden with a veneer of alluvium and colluvium, perhaps after occupation ceased. During this time Culebra Creek continued to migrate away from the midden and to the south when the last episode of downcutting occurred. This episode formed the escarpment now separating the $\mathrm{T} 1$ flood terrace and T0 floodplain. Continued channel migration to the south formed the T0 floodplain during deposition of Unit Va. 
As Culebra Creek began its migration from the immediate vicinity of the site and toward the south sometime between 4000 and 2700 B.P., the T2 flood terrace at $41 \mathrm{BX} 126$ would have flooded less and less frequently. Whereas this may have made the area more suitable for long-term occupation, the channel would also have been considerably further away from the site. It is difficult to assess the influence these two opposing forces had on prehistoric subsistence strategies and settlement patterns. Regardless, occupation of the site terminated shortly after 2000 B.P., which coincides with the last episode of downcutting of Culebra Creek, construction of the T0 floodplain, and deposition of Unit Va.

Based on characteristics of the physical environment, the T2 flood terrace on the north side of the valley may have been viewed as a favorable location for occupation and for the formation of 41BX126 because of: 1) being located between the confluence of Culebra and Helotes creeks; 2) less frequent flooding during formation of the midden than before midden occupation; 3) a nearby lithic source consisting of chert pebbles and cobbles on the adjacent erosional escarpment leading up to $\mathrm{T} 3$; 4) a fertile and moist soil adjacent to a water source; and 5) protection from the wind. 


\section{Chapter 6: Testing Results}

\section{David L. Nickels, Jeff D. Leach, Diane A. Cargill, Kaylee A. McRae, and C. Britt Bousman}

\section{Introduction}

As outlined in Chapter 3, the Culebra Creek site has a complex excavation history. After the site was originally recorded in 1971, TxDOT archaeologist Greg Wood conducted test excavations in 1993. This was followed by additional test excavations in 1995 by Dennis Price, also of TxDOT. Based on the results of Wood's and Price's investigations and a newly acquired right-of-way (ROW) not previously tested, CAR returned to the site in 1997 for a third round of testing.

The 1993 test excavations resulted in a brief report (Wood 1994), and the work performed by Price in 1995 was reviewed for the 1997 investigations. This chapter presents the findings of all three testing projects. The general field methodology and history of the testing projects are outlined in Chapters 3 and 4, and briefly touched upon here. The three projects are discussed separately in most sections, as the sequence of excavations is necessary to clarify, and in some cases justify, the rationale for a given set of recovery methods. In other sections, however, the results of the three projects are meshed together as one.

For analysis, the site is divided into three areas: Areas $\mathrm{A}, \mathrm{B}$, and $\mathrm{C}$ (Figure 6-1). The area designations are strictly for management purposes and do not conform to any prehistoric divisions. However, the areas and subareas do provide a useful segregation of the deposits for subsequent analytical comparisons. Area designations are used primarily for discussing portions of the site that received some form of archaeological investigation, mainly hand-excavated units. Therefore, many of the backhoe trenches (BHTs) and Gradall trenches (GTs) throughout the site do not conform to an ascribed area or lie between two areas (e.g., BHTs in and around Areas A and B). For the purposes of this chapter, BHTs and GTs are not necessarily treated as area specific unless they fall wholly within an area or have excavation units placed along the edges (e.g., BHT G in Area B). Numerous burned rock features were found in Areas $A$ and $B$; the excavation units and associated features are presented in Table 6-1.

Area A, investigated only by CAR, is located east of a barbed-wire fence, east and southeast of the burned rock midden, in the new ROW. Area B contains the burned rock midden and is defined as the area between Loop 1604 and the barbed-wire fence separating Area $A$ on the east. This area was investigated during all three projects. Area $\mathrm{C}$ is located along the western side of Loop 1604, and was also tested during the three projects.

In his report, Wood (1994:7) notes that 31 shovel tests were excavated; however, CAR was unable to locate a map showing their locations or to detect these shovel tests in the field. Additionally, no artifacts from Wood's shovel tests could be located. Beyond mentioning that shovel tests had been excavated, Wood did not provide any analysis of the shovel test material in his report. Therefore, no analysis of shovel test data from Wood's investigations is included in this chapter. Note that the 31 shovel tests reported by Wood should not be confused with his eight $50-\mathrm{x}-50-\mathrm{cm}$ units which are referred to as "controlled shovel tests."

\section{Area A: The New ROW}

Area $\mathrm{A}$ includes the excavations conducted within the newly acquired ROW east of the existing fence line (Figure 6-2). This area was not tested in 1993 or 1995 as TxDOT did not have the need for the additional ROW at that time. The northern portion of Area A consists of the T2 terrace; and midway through the area, this terrace is eroded and slopes down to the $\mathrm{T} 1$ terrace. 


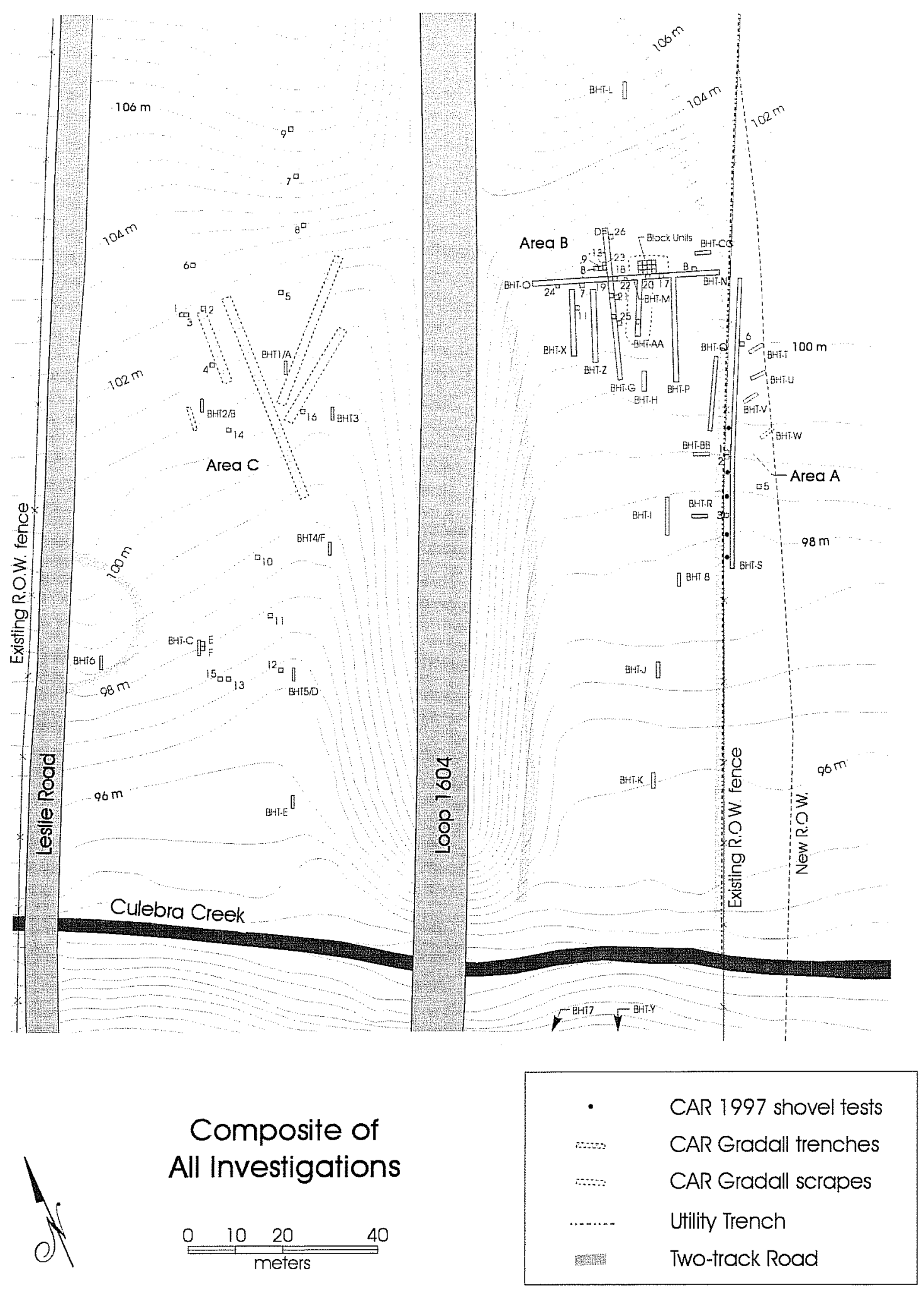

Figure 6-1. Contour map of $41 B X 126$ showing Areas $A, B$, and $C$. Small squares indicate test units, long rectangles represent backhoe trenches. 
Table 6-1. Features and Associated Excavation Units (Features 8-10 not included)

\begin{tabular}{|c|c|c|c|c|c|}
\hline Feature\# & Area & Subarea & TU(s) & Depth (cm bs) & Remarks \\
\hline 1.1 & B & Midden Framework & 7 & $20-50$ & Burned rock-lined pit \\
\hline 1.2 & B & Midden Central Core & $8,9,13$ & $10-45$ & Burned tabular stones \\
\hline 1.3 & B & Midden Central Core & $8,9,13$ & $40-70$ & Large burned cobbles \\
\hline 1.4 & B & Midden Framework & BHT O & $20-90$ & Basal pit \\
\hline 1.5 & B & Midden Framework & BHT O & $55-75$ & Burned rock-filled pit \\
\hline 1.6 & B & Midden Framework & BHT G & $15-30$ & Burned rock-ringed oven \\
\hline 2 & A & A & 1,2 & $15-50$ & Burned rock oven \\
\hline 3 & A & A & 3 & $5-30$ & Burned rock cluster \\
\hline 4 & B & Midden Periphery & 4 & $15-40$ & Burned slab-lined oven \\
\hline 5 & A & A & 6 & $15-34$ & Burned rock cluster \\
\hline 6 & B & Midden Periphery & 10 & $35-55$ & Burned rock cluster \\
\hline 7 & B & Block Excavation: Nolan & C, 12,14 & $55-75$ & Large burned cobbles \\
\hline 11 & B & Block Excavation: Nolan & 18,20 & $55-75$ & Large burned cobbles \\
\hline 12 & B & Block Excavation: Nolan & 14,15 & $65-85$ & Large burned cobbles \\
\hline
\end{tabular}

Investigations in Area A included BHTs, handexcavated test units (TUs), STs, and mapping. Five BHTs, including one long trench (BHT S) and four shorter ones (BHTs T, U, V, and W) were excavated in this area. BHTs were excavated to a maximum depth of $1.5 \mathrm{~m}$. This depth exposed profiles from the surface, through Stratigraphic Unit IV and into the thick, underlying Stratigraphic Unit III on Terraces 1 and 2 (see Chapter 5). Following trenching activities, five units (TUs 1-3, 5, and 6) were hand excavated along the length of the ROW, and five STs were excavated along the southern end of BHT S (Figure 6-3). The BHTs and hand-excavated units were spaced to include investigations on both the $\mathrm{T} 1$ and $\mathrm{T} 2$ terraces (see Chapter 5). Appendixes to this report provide quantitative data on cultural material recovered from all three testing projects, including 5,730 chipped stone (Table 6-2), five diagnostic projectile points (Table 63), $4.02 \mathrm{~g}$ of bone, and over $164 \mathrm{~kg}$ of fire-cracked limestone from Area A. Twelve archaeomagnetic core samples and 99 soil susceptibility samples were collected in the field, and numerous charcoal samples were recovered both in the field and laboratory flotation processes from Area $A$. Two charcoal samples and five archaeomagnetic cores from Feature 2 were selected for analysis. All 99 soil samples were analyzed for their magnetic susceptibility (see Chapter 11).

The initial trench (BHT S) was cut to investigate a scatter of burned and unburned rocks observed on the surface of the T2 terrace. This rock scatter extends east onto privately owned land. Based on the depth of the burned rock layer exposed in a looter's hole (ca. $30 \mathrm{~cm} \mathrm{bs}$ ) and subsequent excavations in this area (see below), the limestone cobbles on the surface appeared to be stratigraphically above those features observed in the BHT and unit profiles, suggesting that the surface material post-dated the other cultural deposits observed in this area of the site. However, the sporadic scatter of altered surface limestone showed no apparent patterning generally associated with features. Although the material could have been brought to the surface from plowing, that explanation was dismissed due to the presence of mature mesquite trees and the absence of plow marks on any of the rocks. A second explanation is that the burned rock is from a looting pit and further scattering across the surface was caused by cattle grazing in the area. It is also possible that the surface material is a result of a form of tree-throw (see Johnson and Watson-Stegner 1990) associated 
Area B

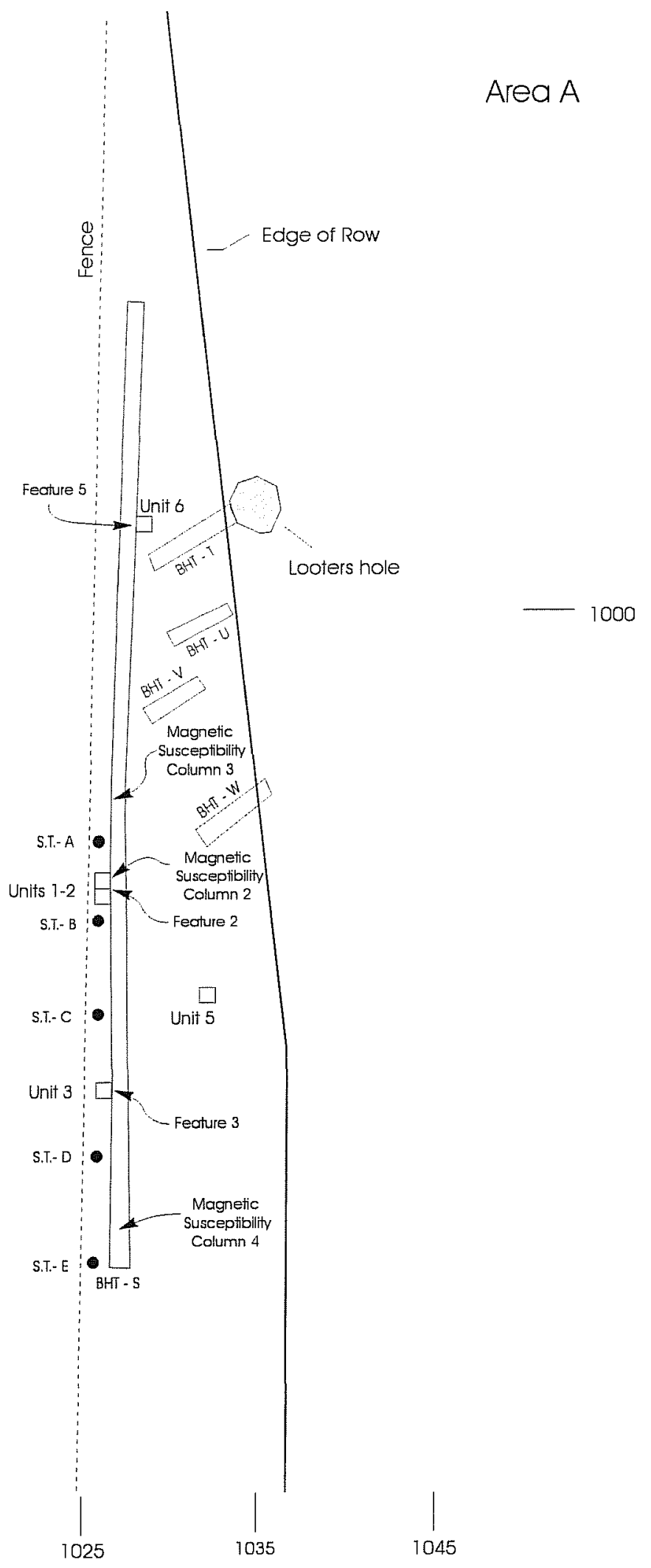

Figure 6-2. Archaeological investigations in Area A. 


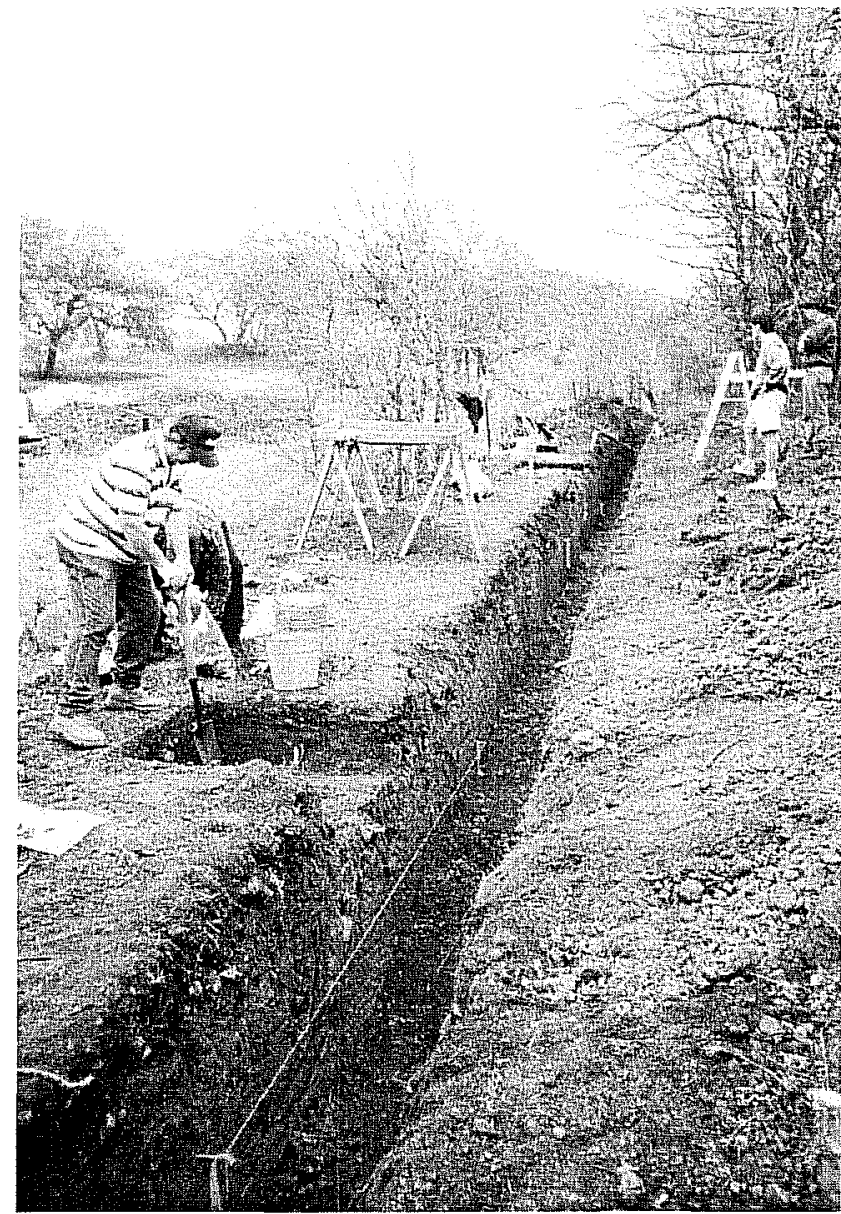

Figure 6-3. Photograph of BHT $S$ in Area $A$ (looking north).

with clearing and pushing of trees and other vegetation to make way for grazing. Simply, when a tree and other vegetation was ripped or pushed over, cultural material attached and intermingled in the root systems would be displaced to the surface. These materials would then spread across the surface. The latter is the more likely scenario. Nevertheless, three buried burned rock features (Features 2, 3, and 5) were discovered in the trench walls of BHT S.

Four lateral trenches ( $T, U, V$, and $W$ ) excavated east of BHT S revealed very little subsurface material. BHT $T$ was dug to examine the extent of a burned rock feature exposed in a looter's pit adjacent to the newly acquired ROW (Figure 6-2). Unexpectedly, an examination of the walls in BHT T revealed only sparsely distributed artifacts and burned rock below the surface. Thus it appears that the majority of the burned rock associated with the looter's hole does not extend into the new ROW and is a separate feature. Cleaning and examination of the walls in BHTs $\mathrm{U}, \mathrm{V}$, and $\mathrm{W}$ likewise revealed limited amounts of scattered debitage and burned rock, much of which was confined to the upper portion of Stratigraphic Unit IV.

Five units were excavated in the newly acquired ROW (Table 6-4). Four of the units (TUs 1-3 and 6) were placed in areas where cultural deposits of burned rocks and artifacts were exposed along the profile of BHT S and a single unit (TU 5) was excavated in an area just east of BHT S to acquire data on artifact distribution and density away from features (Figure 6-2). Although numerous sparse clusters of burned rock were observed along the profile of BHT S, they did not appear as integral clusters, and therefore were not assigned feature numbers. Individual features are described below. Feature 1 is the burned rock midden and is discussed in the Area B section.

\section{Feature Excavations}

\section{Feature 2}

The first feature identified during trenching operations in Area A was a large concentration of burned rock exposed in the east and west walls of BHT S, subsequently labeled Feature 2 (Figure 6-4). AMontell point (SC 9) was found in the profile. Along the west wall profile of the trench, Feature 2 appeared as a continuous horizontal layer of burned rock approximately five meters long and $35 \mathrm{~cm}$ thick (Figure 6-5). On the opposite side of the trench (east wall profile), the feature was thinner and only approximately two meters in length. The reduction of the feature in the eastern profile suggested that the BHT had clipped its eastern edge and its center extended toward the west.

Two units (1 and 2) were placed over what appeared to be the center and thickest portion of Feature 2. Both units were simultaneously excavated to evaluate a larger exposed area in plan view. A Pedernales point was found above the top of the feature in TU 2, Level 1. Fire-cracked rock was not collected or analyzed from TU 2; however, field observations suggest that 
Table 6-2. Chipped Stone from Area A

\begin{tabular}{|c|c|c|c|c|c|c|c|c|c|c|c|}
\hline \multicolumn{2}{|c|}{ Cores } & \multicolumn{2}{|c|}{ Debitage } & \multicolumn{2}{c|}{ Unifaces } & \multicolumn{2}{c|}{ Bifaces } & \multicolumn{2}{c|}{ Points } & \multicolumn{2}{c|}{ Total } \\
\hline$\#$ & $\%$ & $\#$ & $\%$ & $\#$ & $\%$ & $\#$ & $\%$ & $\#$ & $\%$ & $\#$ & $\%$ \\
\hline 5 & $<1$ & 5693 & 99.4 & 13 & $<1$ & 16 & $<1$ & 5 & $<1$ & 5730 & 100 \\
\hline
\end{tabular}

Table 6-3. Diagnostic Artifacts from Area A

\begin{tabular}{|c|c|c|c|c|}
\hline Type & Interval & TU/ST/BHT & Level & Investigator \\
\hline Montell & Late Archaic & 1 & 2 & CAR \\
\hline Montell & Late Archaic & 1 & 4 & CAR \\
\hline Pedernales & Middle Archaic & 2 & 1 & CAR \\
\hline Montell & Late Archaic & B & 2 & CAR \\
\hline Marshall & Late Archaic & S, Fea 2 & 2 & CAR \\
\hline
\end{tabular}

Table 6-4. Units and Associated Features in Area A

\begin{tabular}{|c|c|c|c|}
\hline \multirow{2}{*}{ TU } & \multicolumn{2}{|c|}{ Coordinates $^{\natural}$} & $\begin{array}{c}\text { Associated } \\
\text { Feature(s) }\end{array}$ \\
\cline { 2 - 4 } & East & North & 2 \\
\hline 1 & 1025.69 & 983.68 & 2 \\
\hline 2 & 1025.74 & 984.69 & 3 \\
\hline 3 & 1025.84 & 972.28 & none \\
\hline 5 & 1031.97 & 979.11 & 5 \\
\hline 6 & 1029.20 & 1008.70 & \\
\hline
\end{tabular}

${ }^{\text {a }}$ Coordinates are for the southwest corner of the unit and are relative to the site datum (E1000/N1000).

the feature rocks in TU 2 were collected from the same population as those in TU 1 . Small fire-cracked rocks $(<5 \mathrm{~cm})$, in no observed pattern, were scattered throughout Level 1 of TU 2. The top of the feature was fully exposed as a dense layer of fragmented burned rock at the bottom of Level $2(20 \mathrm{~cm}$ below the surface [bs]) (Figure 6-6). Excavation in TU 2 was terminated after a plan view was drawn and the feature photographed.

Excavation in TU 1 was continued to examine the center of the feature in profile. A Montell point was found in Level 2 of TU 1. Fifty fire-cracked rocks (mean weight: $98.17 \mathrm{~g}$ ) were recovered from Level 1, TU 1.
Two hundred fifty-five fire-cracked rocks (mean weight: $80.42 \mathrm{~g}$ ) were found throughout Levels 2 and 3 in TU 1.

Seven hundred fifty-eight distinctively larger rocks with a mean weight of $158.75 \mathrm{~g}$ were uncovered in TU 1, Level 4 (30-40 cm bs), where another Montell point was found. Based on field observations, several of the large rocks appeared to be intact (Figure 6-7). The larger stones encountered at this level were in stark contrast to the numerous small and fragmented ones in the upper levels of each unit (Figure 6-8). A third Montell point was recovered from the upper 3 $\mathrm{cm}$ of Level 4. The mean weight of fire-cracked rocks 


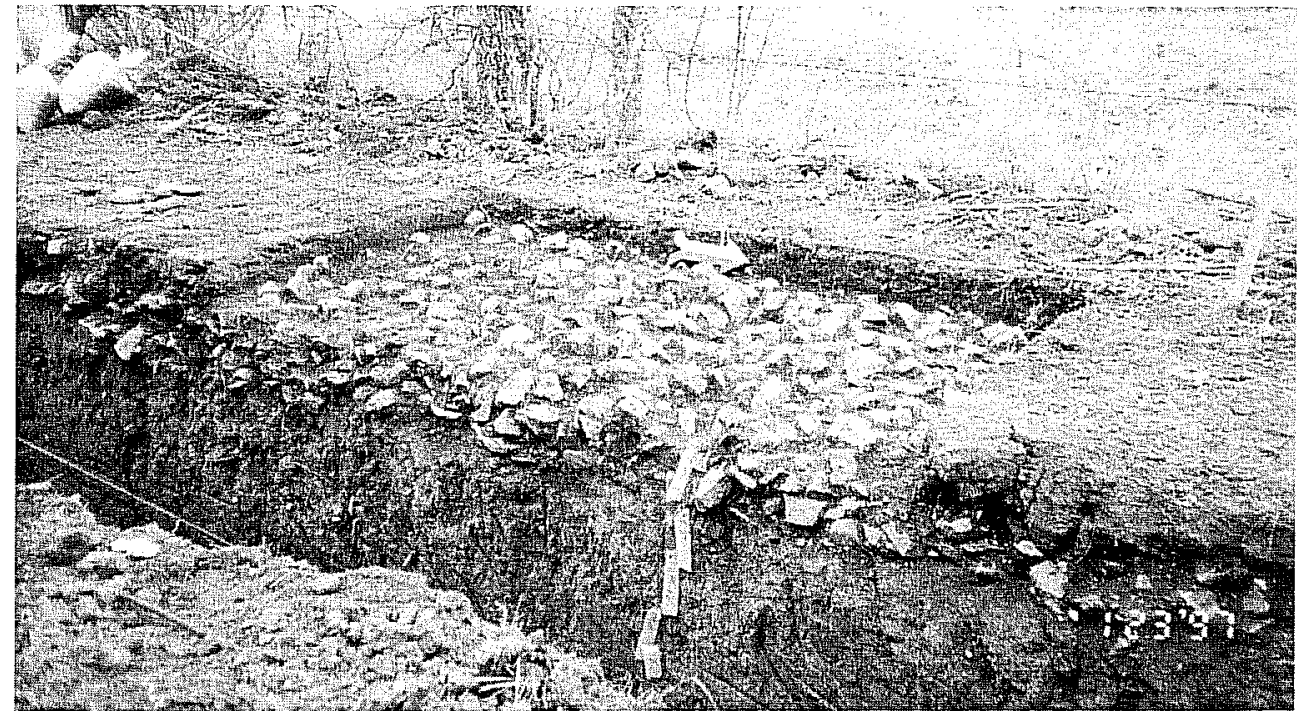

Figure 6-4. Photograph of Feature 2 in the west wall of BHT S in Area A.

so, this feature may have been encountered during the construction of a utility trench which runs in a north-south direction and is located just west of the existing fence line (Figure 6-2).

\section{Feature 3}

A second burned rock cluster (Feature 3) approximately three meters long was exposed near the top of the west wall in BHT S, just

dropped to $134.88 \mathrm{~g}$ in Level 5, the bottom of the feature. Excavation continued in TU 1 to Level 7, with no fire-cracked rock larger than a golf ball observed below Level 5; none of the fire-cracked rock was collected for analysis. Our interpretation is that this layer of larger stone, with a thickness of ca. $20 \mathrm{~cm}$ (Levels 3 and 4), represents a heating element with some intact rocks. This is supported by archaeomagnetic analysis which indicates that five of the seven sampled rocks had been only slightly disturbed since they cooled. Four of the seven exhibited a distinct high temperature magnetization, suggesting they may have been reused. Our interpretation that Feature 2 is sitting on an ancient living surface (Stratigraphic Unit III) is supported by the results of soil susceptibility analysis which indicates a distinctive peak in magnetic susceptibility at the stratigraphic unconformity between Unit III and Unit IV. A further discussion of archaeomagnetic and soil susceptibility sampling is given in Chapter 11.

Two radiocarbon dates were obtained for Feature 2 in TU 1. Wood charcoal floated from soil samples yielded a date of $2700 \pm 50$ в.P. in Level 3 , and a date of $2780 \pm 50$ B.P. in Level 4 . The only faunal material recovered was $0.13 \mathrm{~g}$ from Level 3 near the top of the feature in TU 1 (Chapter 10). The only identifiable archaeobotanical remains identified from Feature 2 soil samples was live oak charcoal (Chapter 9). The overall morphology of the feature, as defined in profile and plan view, suggests that the feature extends to the west. If above Stratigraphic Unit III and within the thinning and sloping Stratigraphic Unit IV (Figure 6-9). Feature 3 is located seven meters south and slightly downslope from Feature 2. The sloping terrace surface coincided with the cultural material lenses visible in the profile (see Figure 6-9), implying Features 2 and 3 were constructed during the same period of landform stability. Field observations suggested that Feature 3 offered a high degree of integrity and was thus selected for testing. Based on BHT S profiles TU 3 was placed in what was the expected center of the feature.

Rocks from this unit were not collected and analyzed, however observations on size can be made from the plan view drawings done in the field. Forty-five burned rocks ranging in size from 3-19 $\mathrm{cm}$ were pedestaled in Level 1. They presented no coherent intact feature pattern, and after drawing and photographing they were removed. A pattern of larger rocks became evident in Level 2 as a 45 -cm-wide by one-meter-long concentration, but with no apparent rock-size sorting. The burned rocks were more densely concentrated in Levels 2 and 3, with the base at ca. $30 \mathrm{~cm}$ bs (Figure 6-10). Seventy-eight rocks ranging in size from 3-13 $\mathrm{cm}$ were documented in Level 2 . Forty-one rocks ranging in size from 3-19 $\mathrm{cm}$ were documented in Level 3. Distinguishing a horizontal pattern was difficult due to the limited plan view offered by a $1-x-$ $1-\mathrm{m}$ unit. However there was a noted absence of burned rock along the north edge of the unit in Level 1 , 


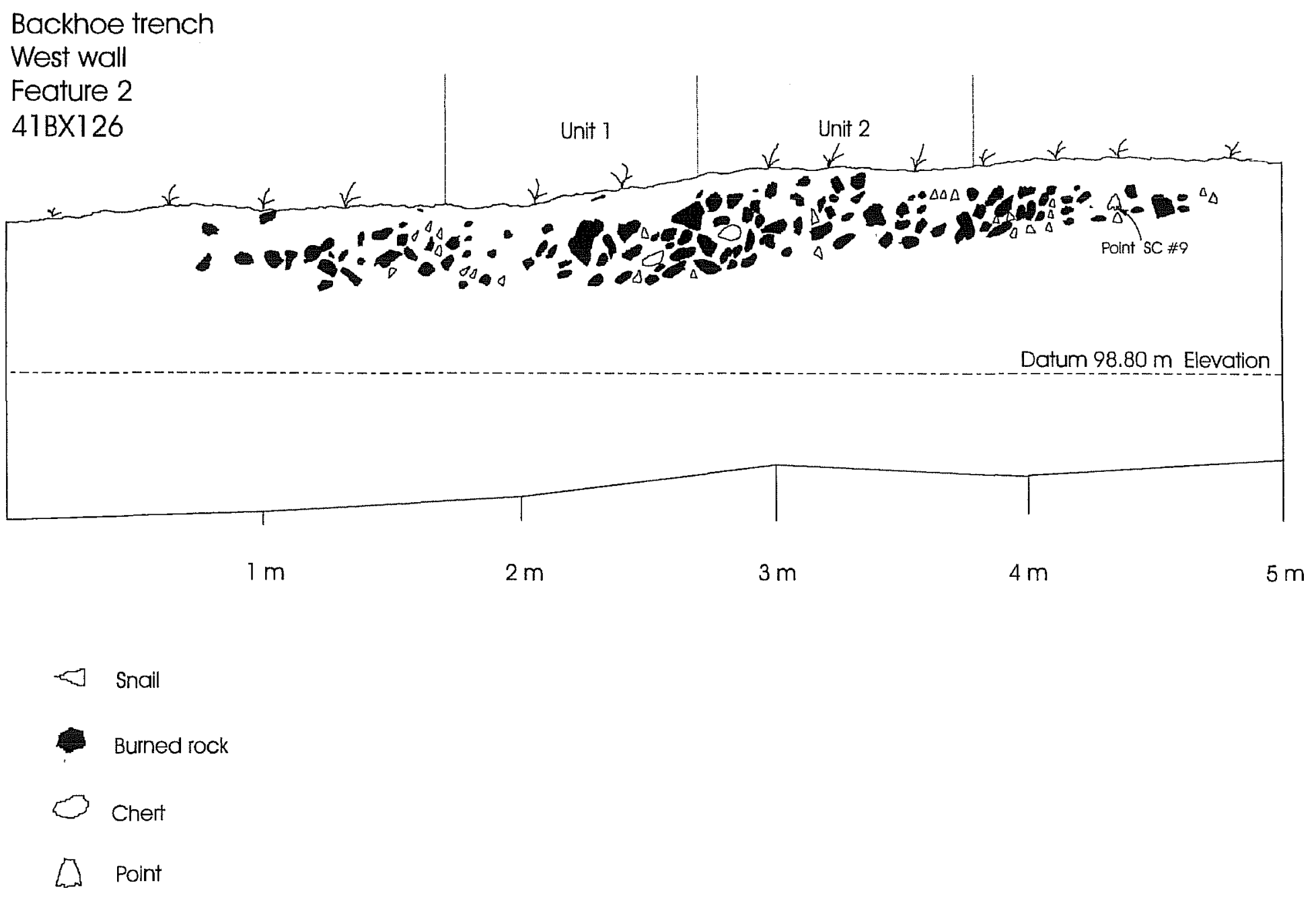

Figure 6-5. Profile of Feature 2 in west wall of BHT S. 


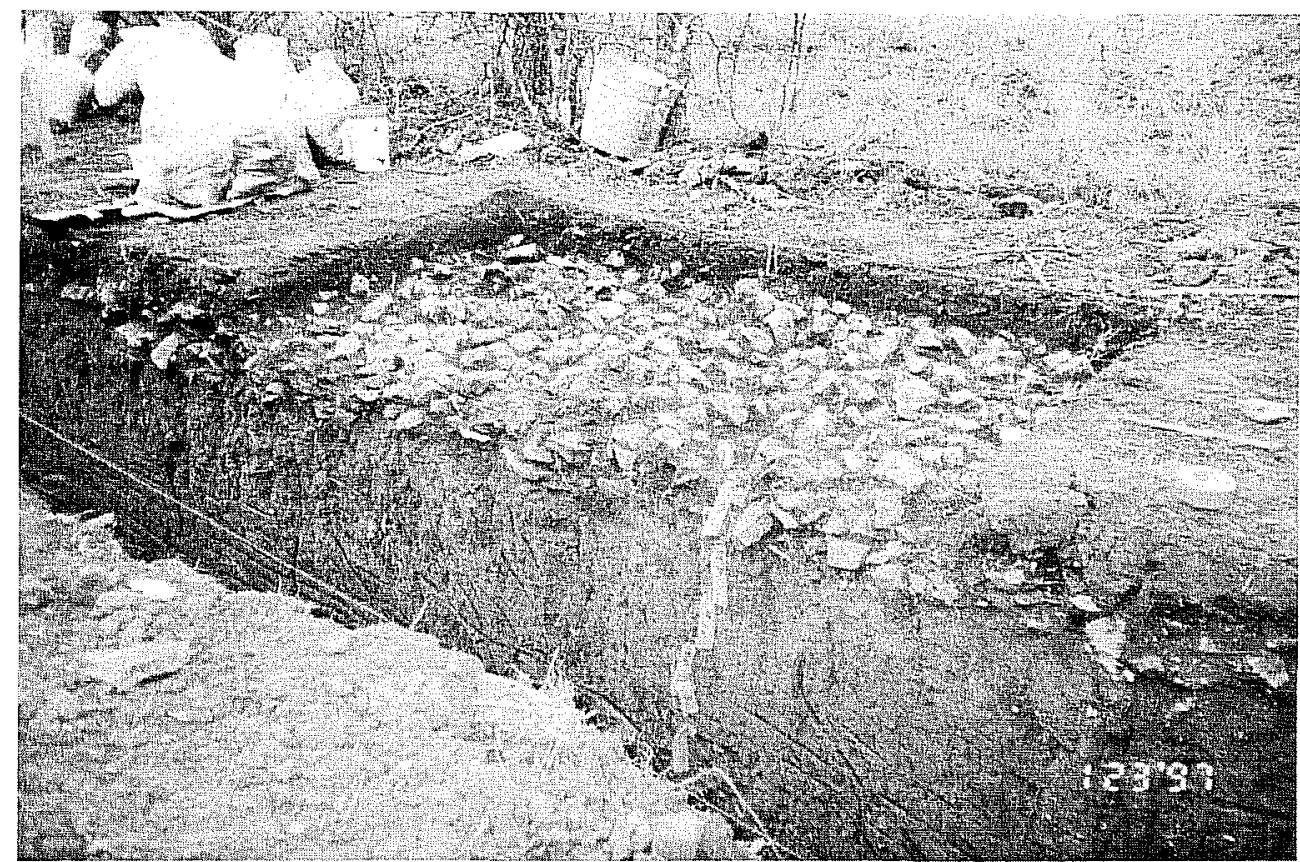

Figure 6-6. Photograph of TUs 1 and 2 showing Feature 2 as it was exposed in plan view at the bottom of Level 2 (facing southwest).

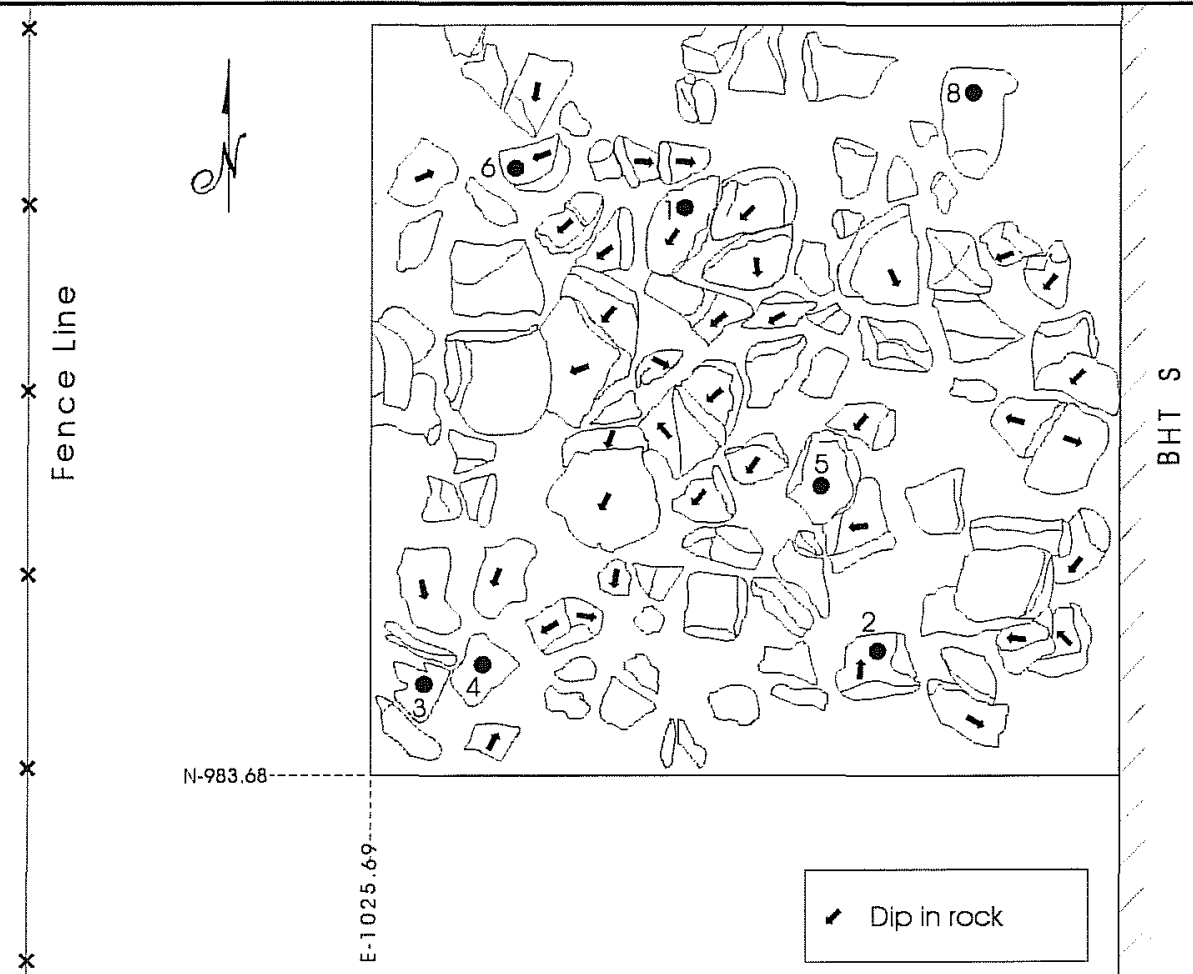

Figure 6-7. Plan view of Feature 2, bottom of Level 2 in $T U$ 1, Area A. Numbered rocks were drilled, and cores were submitted for archaeomagnetic analysis. 


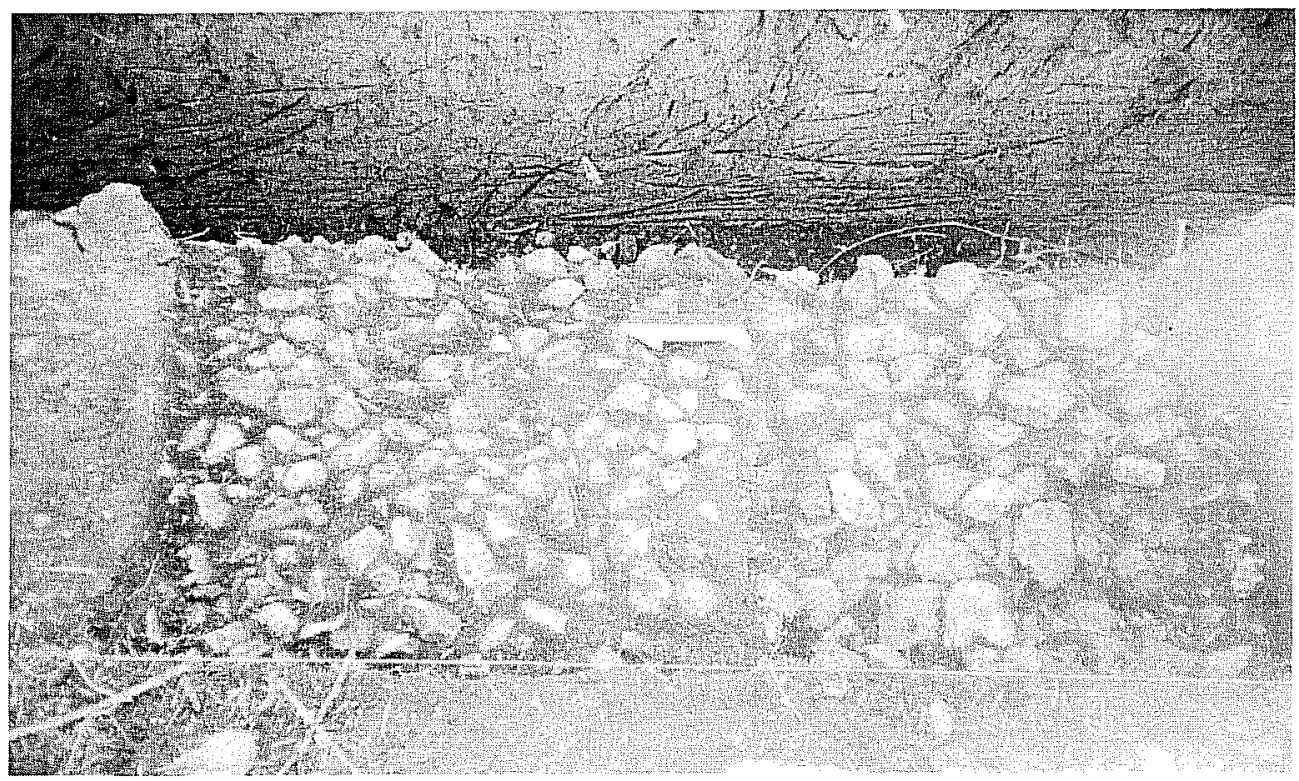

Figure 6-8. Feature 2: TU 2, bottom of Level 2, $20 \mathrm{~cm}$ bs (left); and TU 1, bottom of Level 4, $40 \mathrm{~cm}$ bs (right). Note size difference in rocks.

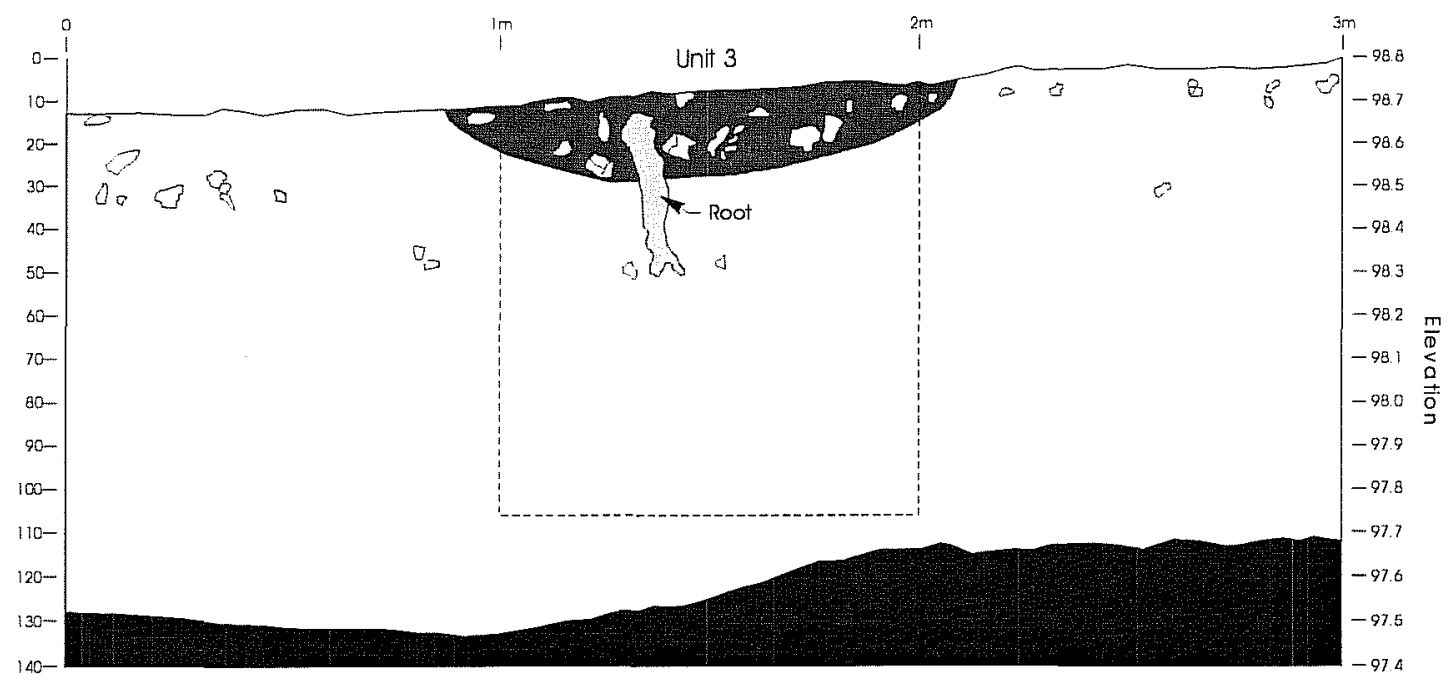

$$
\frac{0 \quad 10 \quad 20 \quad 30 \quad 40 \quad 50}{\text { centim ete } 15}
$$

Figure 6-9. Feature 3 in the west wall profile of the southern end of BHT S, Area A. Dashed line shows the boundary of TU3. 


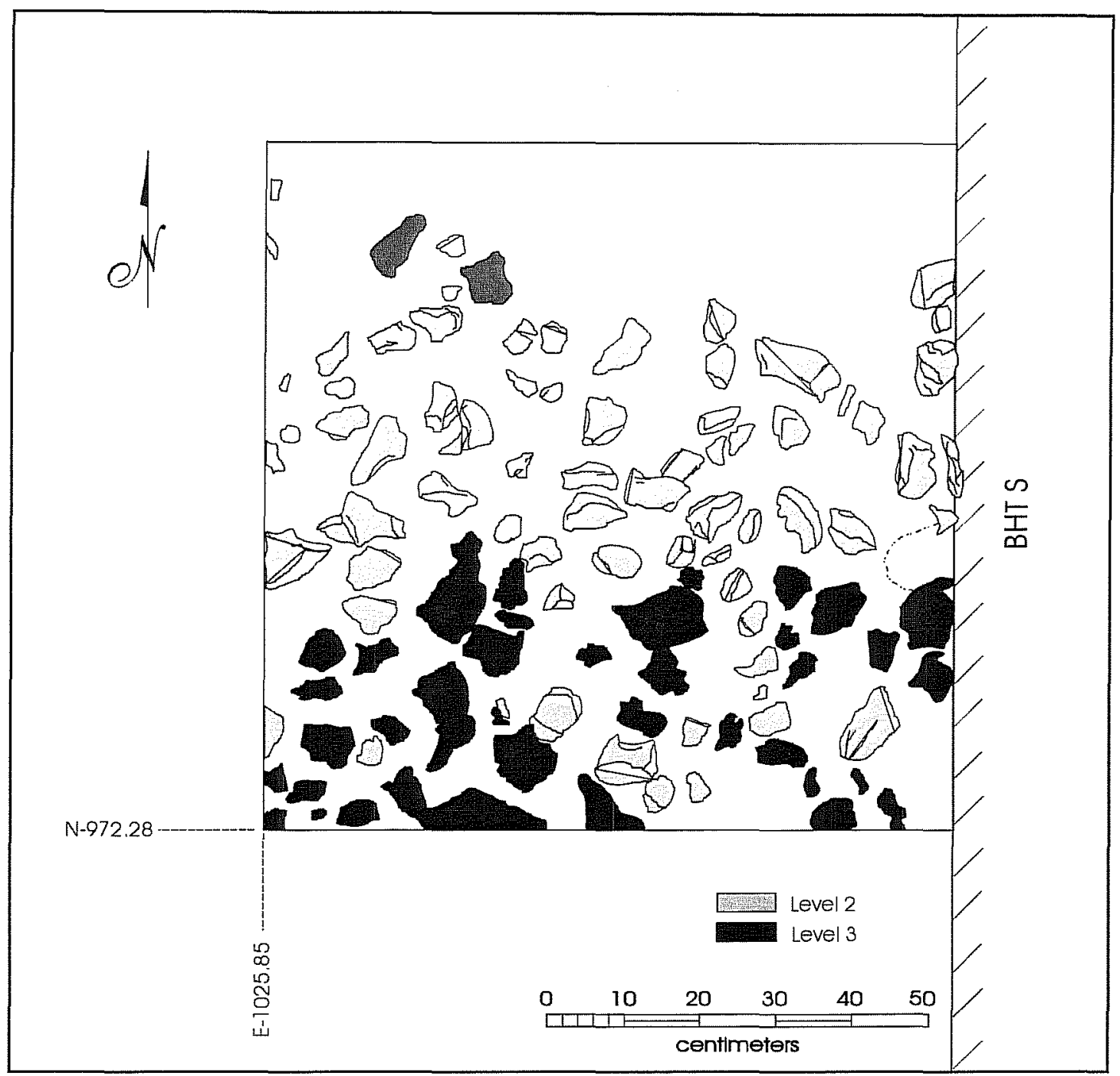

Figure 6-10. Plan view of Feature 3 (combined Levels 2 and 3), Area A.

followed by a predominance of burned rock in the middle of the unit in Level 2, and then in the south quarter of the unit in Level 3 (Figure 6-11). That information, along with the fact that many rocks were resting in an observed sloping pattern toward the south, suggests TU 3 was excavated through part of the outer edge and central cooking area of a burned rock feature. Although five archaeomagnetic samples were taken, none were submitted for analysis. Soil susceptibility samples collected from the west wall profile of BHT $S$ just south of Feature 3 indicate a peak in magnetic susceptibility at approximately the same level as the bottom of Feature 3 (Chapter 11). Accordingly, quantities of cultural material decreased significantly below Level 3. TU 3 excavations were terminated at
$77 \mathrm{~cm}$ below the surface. One charcoal sample was recovered from the bottom of Level 3, but no radiocarbon dates were obtained. No diagnostic artifacts were found in Feature 3, only $0.09 \mathrm{~g}$ of faunal material was recovered, and no archaeobotanical remains were recovered from Feature 3.

\section{Feature 5}

Another single layer of five burned rocks extending approximately one meter in length was exposed in Stratigraphic Unit IV of the east wall of BHT S, approximately $10-20 \mathrm{~cm}$ below the surface, $24 \mathrm{~m}$ north of Feature 2 (Figure 6-2). This layer of burned rock 


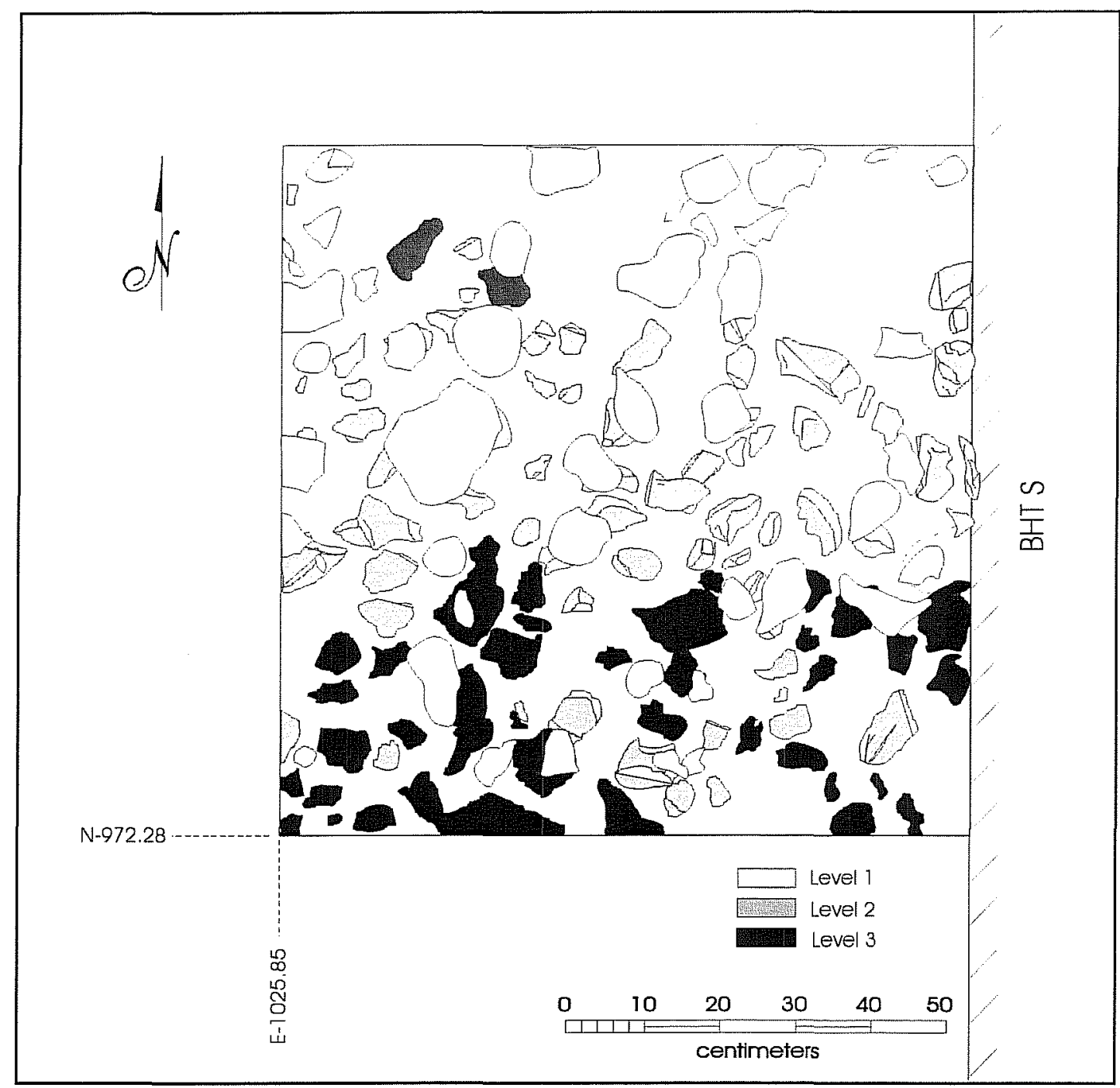

Figure 6-11. Plan view of Feature 3 (combined Levels 1, 2, and 3), Area A.

was designated Feature 5. Though no pit was discernible, the stones appeared to form a basin shape. A single unit (TU 6) was placed adjacent to the trench wall over the center of the burned rock feature.

Exposure of the feature at $10 \mathrm{~cm}$ bs (Level 1) provided no clear evidence of spatial patterning in the burned rock, and did not manifest itself until well into Level 2 (10-20 cm below surface). Rocks from this unit were not collected or analyzed; however, observations on size can be made from the plan view drawings (Figures 612 and 6-13). In plan view, the feature appeared as a scatter of 70 mostly small, fragmented rocks ranging in maximum length between 3 and $17 \mathrm{~cm}$, with no discernible pattern. Interestingly, the burned rock appeared to thin toward the northern end of the unit, suggesting a possible "edge" or limit of the scattered rock observed in the looter's pit six meters to the east. Three bifaces and a uniface were recovered from the top of the feature (Level 2). All rocks were pedestaled, the feature was photographed and sketched at $20 \mathrm{~cm}$ bs (Figure 612), and excavation continued. While a few additional burned rocks were uncovered, again no clear patterning was discernible (Figure 6-13), except that most of the feature was in the eastern half of the unit. The basin-shape of the feature noted in profile was not evident in the test unit. AButted Knife biface was recovered from Level 3. At the bottom of Level $3(20-30 \mathrm{~cm}$ below surface), corresponding stratigraphically with the top of Stratigraphic Unit III, the quantity of burned rock and artifacts dropped considerably. Due to the small size of the burned rock, no archaeomagnetic samples 


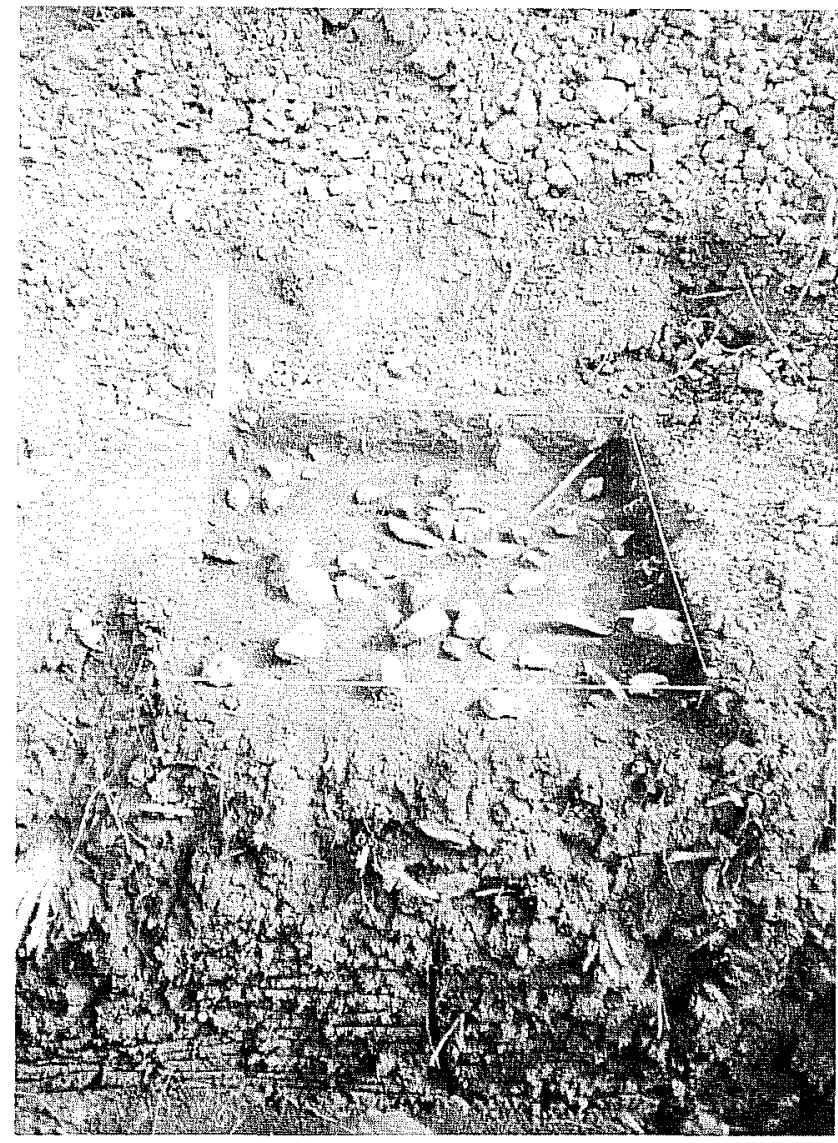

Figure 6-12. Photograph of bottom of Level 2, Feature 5, TU 6 in Area A (facing east).

were recovered. However magnetic susceptibility samples taken in BHT S, a few meters south of Feature 5 indicates a peak in magnetic susceptibility at approximately $30 \mathrm{~cm}$ below the surface, the same level as the bottom of Feature 5. Only $1.27 \mathrm{~g}$ of fauna were recovered from Feature 5 (Chapter 10). No charcoal or diagnostic artifacts were recovered, and the only archaeobotanical remains identified was an indeterminable species of wood near the base of the feature in Level 4 (Chapter 9). The bottom of Feature 5 extended four centimeters into Level 4 , or $34 \mathrm{~cm}$ below the surface. TU 6 excavation was terminated in the underlying Stratigraphic Unit III at $80 \mathrm{~cm}$ bs (Level 8).

\section{Non-Feature Unit}

In addition to the units excavated over features exposed in BHT S, a single unit (TU 5) was placed in a nonfeature area east of BHT S, between Features 2 and 3 (see Figure 6-2). This area was selected to evaluate the eastern extent of those cultural deposits identified within the trench wall, and in TUs 1,2, and 3. Excavation of TU 5 yielded a limited amount of cultural material (Appendix E) and no identifiable features. Excavation continued from the surface through the thin Stratigraphic Unit IV and into Stratigraphic Unit III to $50 \mathrm{~cm}$ below the surface. Testing results indicate that the quantity of cultural materials decreases with increased distance east of BHT S. However, only one unit was excavated east of BHT S and this area could be better sampled using larger block excavations. Nevertheless, the materials do appear to be "thinning" to the east. No diagnostic artifacts or charcoal were recovered from TU 5. Less than one gram of faunal material and no archaeobotanical remains were recovered from TU 5 (Chapter 10).

\section{Shovel Tests}

In a corroborating effort to evaluate artifact densities relative to distance from features, five shovel tests (A, $B, C, D$, and $E$ ) were placed along the western edge of BHT S (see Figure 6-2). One ST (A) was placed north of Feature 2 (TUs 1 and 2), two (B and C) were excavated between Features 2 and 3 (TU 3), and two were excavated south of Feature 3 (D and E). Generally, artifact densities in shovel test levels near excavation units were consistent with those found in corresponding unit levels that contained features. Shovel tests farther away from feature units demonstrated a sparsity of artifacts. A third Montell dart point was recovered from Level 2 in Shovel Test B (Table 6-3). No charcoal or faunal remains were recovered. Table 6-5 provides the coordinates of those five shovels tests.

\section{Area B: The Midden}

Area B, located east of Loop 1604 and west of the existing fenceline (Figure 6-1), includes the midden and the area immediately surrounding it (Figure 614). This area was first tested by Wood in 1993 . Wood excavated 10 units (Figure 3-1) in an attempt to define the morphology of the burned rock midden, the most prominent feature of $41 \mathrm{BX} 126$. Area B was tested again by Price in 1995. The latter's investigations (Figure 3-2) included nine backhoe trenches and 


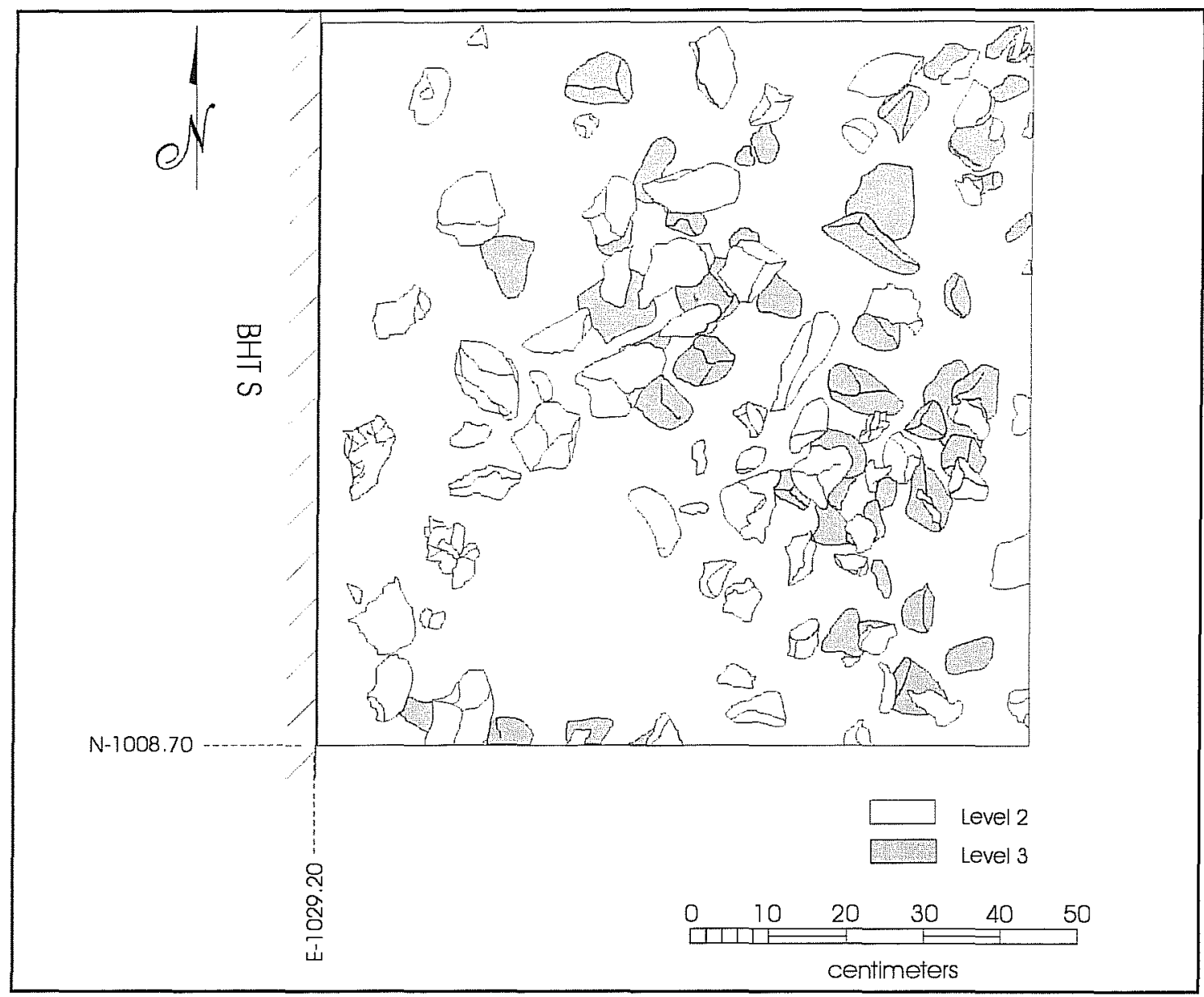

Figure 6-13. Plan view of Levels 2 and 3, Feature 5, Area A.

Table 6-5. Shovel Tests Excavated along the New ROW

\begin{tabular}{|c|c|c|c|}
\hline \multirow{2}{*}{$\begin{array}{c}\text { Shovel } \\
\text { Test }\end{array}$} & \multicolumn{2}{|c|}{ Coordinates } & \multirow{2}{*}{$\begin{array}{c}\text { Depth } \\
\text { (cm bs) }\end{array}$} \\
\cline { 2 - 4 } & East & North & 60 \\
\hline A & 1025.83 & 989.63 & 50 \\
\hline B & 1025.84 & 981.01 & 50 \\
\hline C & 1025.47 & 977.11 & 50 \\
\hline D & 1025.90 & 967.69 & 50 \\
\hline E & 1025.89 & 961.87 & \\
\hline
\end{tabular}




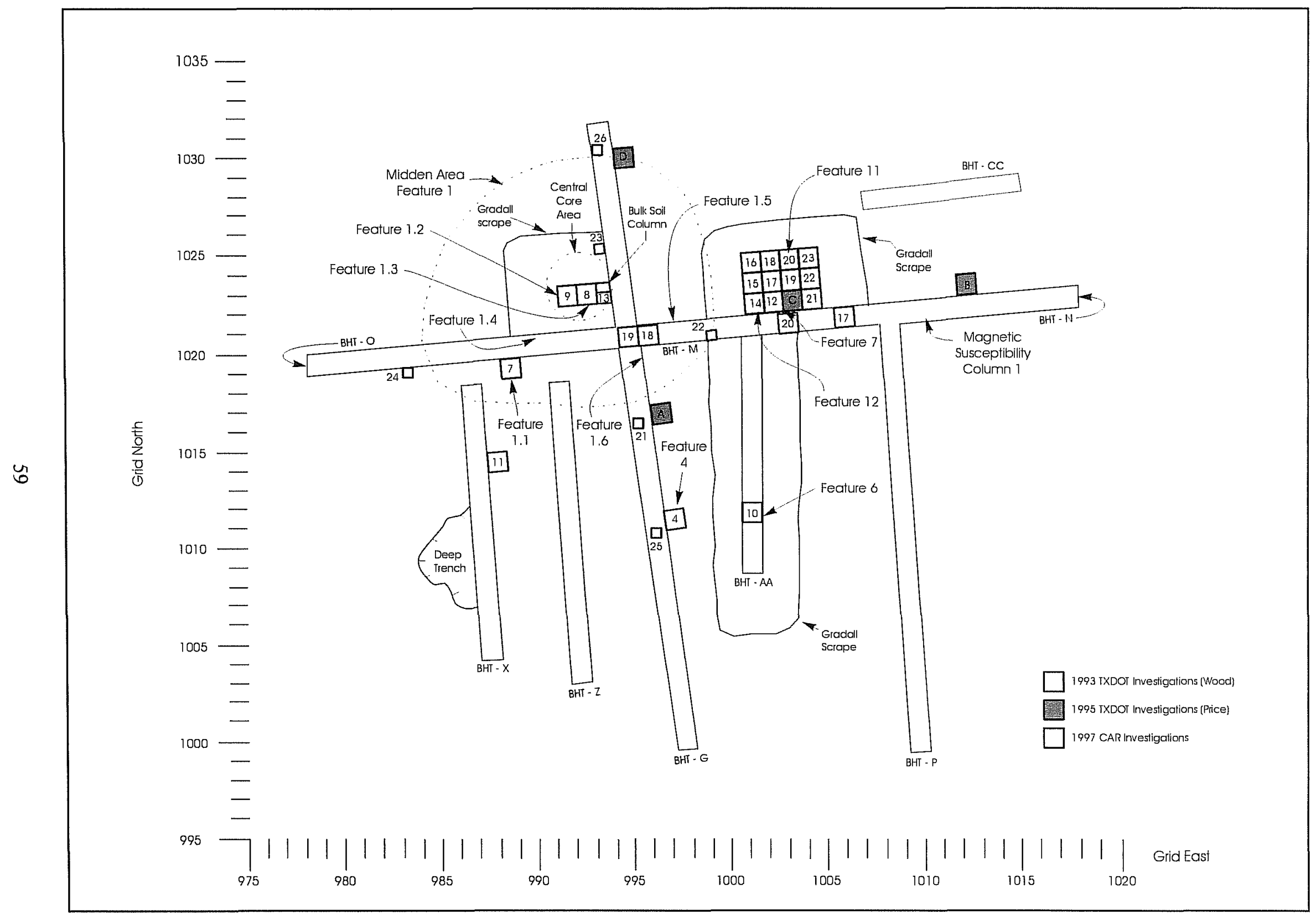

Figure 6-14. Archaeological investigations in Area B. 
four test units, as well as detailed recording of the profiles and a preliminary geomorphic study. CAR's current investigations (Figure 3-3) included BHTs, hand-excavated units, a geomorphic study, and extensive sampling and mapping.

Due to the size and complexity of the midden and associated deposits, Area B (Figure 6-14) is divided into four subareas for the following discussion: central core, framework, periphery, and block excavations. Backhoe trenching and Gradall scraping over the midden uncovered the central core area. This area is defined by a shallow depression $3-4 \mathrm{~m}$ in diameter, forming the center of the midden and containing sediment and cultural material supported by large and small rocks suspended in fine-grained matrix (Appen$\operatorname{dix} \mathrm{A}$ ). This central area is surrounded by a dense, rock-supported, convex, ring-shaped framework area. The latter is about $50 \mathrm{~cm}$ thick at its highest point, and drops abruptly toward the outer edges. The framework is distinguished from the central core area by its clast-supported (rock-on-rock) structure. The framework is often referred to as the torus (Appendix B) or ring of the midden (Weir 1976). Around the framework area is the periphery. The periphery includes the areas beyond the edge of the framework. The distinction between the two areas is admittedly somewhat arbitrary, but is demarcated where the dense mass of burned and fragmented rocks that make up the framework "pinch-off" into a thinner layer of rock. The periphery, especially those materials located immediately adjacent to the midden, may be associated with the midden. Cultural materials around the midden proper are often referred to as "smear" or "scatter" that has eroded off the higher midden deposit. As outlined in Chapter 7, many of the smaller clasts (e.g., debitage) and sediments deposited in the periphery may be the result of sheet wash associated with erosion of the midden deposit. The periphery also includes a number of intact feature and artifact deposits that may or may not be associated with the midden.

The periphery is further considered as either upslope or downslope of the midden. The midden deposit at $41 \mathrm{BX} 126$ is situated on a gently sloping terrace that dips to the south and southwest. The upslope area is defined as the area immediately north of the midden's central core and framework area. This area of the midden's periphery is dominated by colluvial gravels, mixed with lesser amounts of burned rock and sediment and other cultural material either washed off the bedrock slope or midden or deposited by flood waters of Culebra Creek (see Chapters 5 and 7, and Appendix C). The downslope area receives much less colluvial deposition, but a relatively greater amount of deposition occurs from sediment and cultural material washing off the midden's framework area and from alluvial deposition. Both the upslope and downslope areas at 41BX126 have received overbank alluvial deposits from Culebra Creek during recent flooding events, more so for the lower downslope side of the midden. Though curtailed by flood-control projects, flood waters in recent years have covered Area B. The final subarea in Area B is designated as the block excavation, and was undertaken to investigate a possible Nolan component. The block excavation, located east of the midden and its framework, includes the cultural material and features within Stratigraphic Unit III and IV, below the base of the midden (Figure 6-15). Although the block excavation conducted during the current project will dominate the discussion, data from previous test units excavated into the submidden deposits will be included.

Below we outline the investigations conducted in Area $\mathrm{B}$ during the two TxDOT projects. This brief outline provides the reader with a general overview of the previous investigations and sets the stage for the discussion of the more recent and intensive CAR investigations. The results of the three investigations are then integrated and discussed in greater detail.

\section{Previous Investigations by TxDOT}

Wood's (1994) excavations in Area B included four 1-x-1-m units (17-20) and six 50-x-50-cm units (2126) (Table 6-6) in the midden area (Figure 6-14). Results of those tests revealed the presence of a partially undisturbed burned rock midden with associated artifacts, approximately six meters in diameter and extending to $67 \mathrm{~cm}$ bs. Artifacts recovered from this area included five dart points (Pedernales, La Jita, Darl, Bulverde, and untyped), modified flakes, biface fragments, gravers, a burin, a biface blank, and debitage (Wood 1994:18-23). In addition to the prehistoric material, a few historic artifacts (e.g., glass and plastic) 


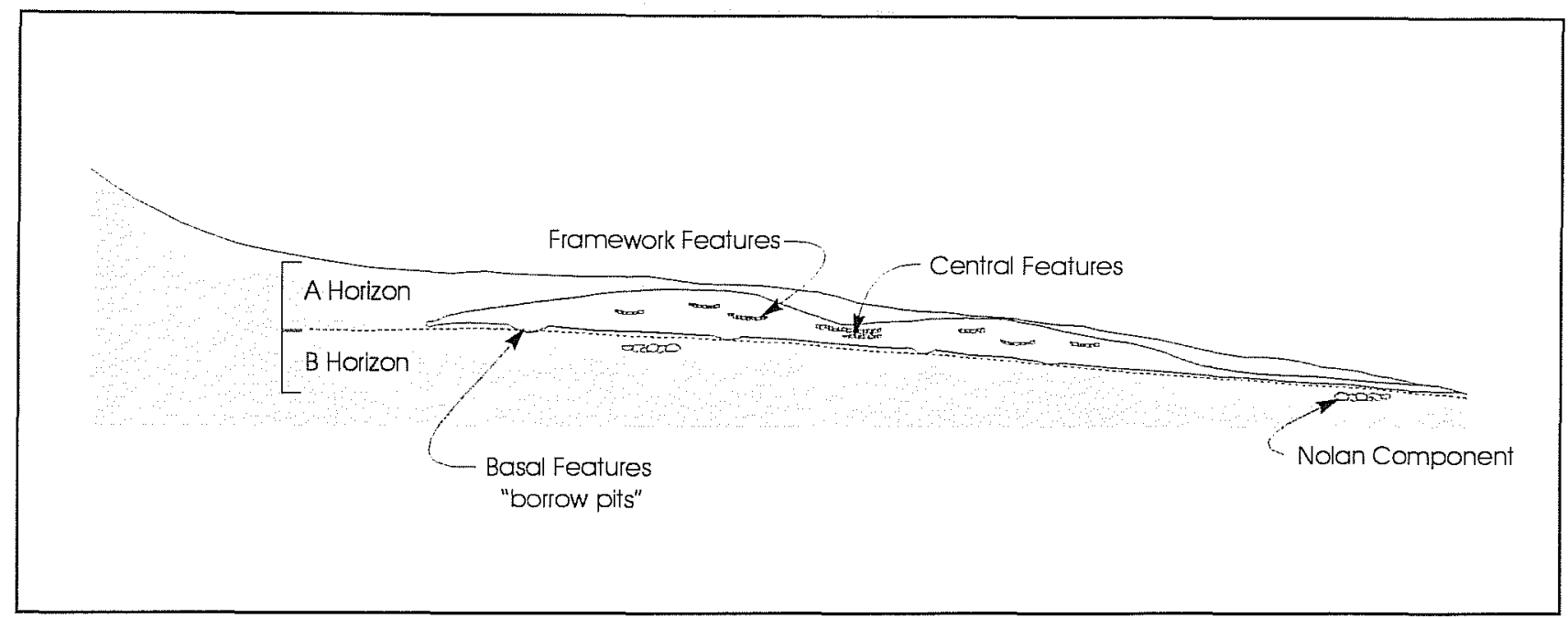

Figure 6-15. Idealized cross section of the midden and associated deposits.

Table 6-6. Units Excavated in the Midden (Area B) by Wood in 1993

\begin{tabular}{|c|c|c|c|c|}
\hline $\mathbf{T} \mathbf{U}^{\mathrm{a}}$ & TU Size & $\begin{array}{l}\text { Levels } \\
(10 \mathrm{~cm})\end{array}$ & Subarea & Associated Feature(s) ${ }^{c}$ \\
\hline 17 & $1 \times 1 \mathrm{~m}$ & 7 & periphery & none \\
\hline 18 & $1 \times 1 \mathrm{~m}$ & 2 & framework & 1 \\
\hline 19 & $1 \times 1 \mathrm{~m}$ & 10 & framework & 1 \\
\hline 20 & $1 \times 1 \mathrm{~m}$ & 8 & periphery & none \\
\hline 21 & $50 \times 50 \mathrm{~cm}$ & 3 & framework & 1 \\
\hline 22 & $50 \times 50 \mathrm{~cm}$ & 5 & framework & none \\
\hline 23 & $50 \times 50 \mathrm{~cm}$ & 5 & central core & 1 \\
\hline 24 & $50 \times 50 \mathrm{~cm}$ & 5 & periphery & none \\
\hline 25 & $50 \times 50 \mathrm{~cm}$ & 5 & periphery & none \\
\hline 26 & $50 \times 50 \mathrm{~cm}$ & 5 & periphery & none \\
\hline
\end{tabular}

Units, unit size and levels reported by Wood (1994:Table 1); subarea and associated features reported by CAR.

a Coordinates are not available for these units.

b See Figure 6-14.

c Feature association was assigned by CAR during the 1997 investigations. These associations are derived from notes and maps available as to the location of Wood's units in relation to the midden. Note that the midden has been designated Feature 1. 
were recovered from the uppermost levels and are thought to be in a disturbed context. The presence of road gravel and yellowish sediment in the upper 5-8 $\mathrm{cm}$ of the units excavated in this area revealed the depth of disturbance caused by construction activities associated with Loop 1604.

From the field notes and the report prepared by Wood, it is impossible to pinpoint exactly where his units were located. The available data and maps, however, show the relationship of the units to one another, but do not relate to permanent datum points. Our placement of the units comes from Dennis Price (personnel communication 1997) who states that he cut a north/south BHT through TUs 19, 21, 23, 25, and 26 and an east/west BHT through TUs 17, 18, 20, 22, and 24. However, after reopening the BHTs excavated by Price (discussed below), CAR investigators were only able to locate evidence in the walls of the BHTs for TUs 23 and 24. The BHTs that were reported to have been dug through the 1993 units were less than one meter in width and therefore the edges of at least some of the units should have been visible in the walls of the BHTs. Nevertheless, we have to assume that the backhoe trenches excavated first in 1995, and again in 1997, effectively removed any evidence of most of the excavations by Wood in this area. Figure 6-14 shows our best estimation of the locations of those units.

The midden discovered by Wood in his 1993 investigations was designated Feature 1 by CAR (see below). All units, new or old, falling within the ascribed boundaries of the midden proper (central core and framework areas) were considered Feature 1 units. Based on Wood's plotted locations, available notes and photographs, as well as the plotted locations, field notes, photographs, and subsequent excavations by Price and CAR (see below), Wood's TUs 18, 19, 22, and 23 were designated Feature 1, midden units. Although TUs 17, $20,21,24,25$, and 26 , are still in the midden area, these units are interpreted as "off-midden," or peripheral to the midden's core and framework.

Price's investigations were targeted at gathering additional data from a possible earlier component underlying the midden and identifying discrete short-term occupation events that could yield floral and faunal data. The lower component was identified from a bimodal distribution of lithic material in Wood's TU 19.

To gather the additional data, Price excavated four BHTs (G, M, N, and $O$ ) and four 1-X-1-m units (A, B, $\mathrm{C}$, and $\mathrm{D}$ ) in and around the midden (Table 6-7, Figure 6-14). Although three BHTs excavated through the midden ( $G, M$, and $O$ ) exposed the full extent of the midden's vertical dimensions, its horizontal extent to the west could not be determined. A trench $($ BHT $\mathrm{N}$ ) excavated immediately east of the midden demonstrated the "thinning" of midden deposits in that direction. In addition to BHTs excavated through the midden, four BHTs $(\mathrm{H}-\mathrm{K})$ were dug south of the midden and one (BHT L) was dug on top of the hill to the north. Trench photographs of BHTs $\mathrm{K}$ and $\mathrm{L}$ are provided in Figures 6-16 and 6-17.

Table 6-7. Units Excavated by Price in 1995, Area B

\begin{tabular}{|c|c|c|c|c|c|}
\hline $\mathbf{T} \mathbf{U}$ & $\begin{array}{l}\text { TU } \\
\text { Size }\end{array}$ & $\begin{array}{l}\text { Levels } \\
(10 \mathrm{~cm})\end{array}$ & Coordinates & $\begin{array}{l}\text { Structural } \\
\text { Location }\end{array}$ & $\begin{array}{l}\text { Associated } \\
\text { Feature(s) }\end{array}$ \\
\hline $\mathrm{A}$ & $1 \times 1 \mathrm{~m}$ & 15 & N1016.2/E996.1 & periphery & none \\
\hline B & $1 \times 1 \mathrm{~m}$ & 16 & N1026.1/E1011.9 & periphery & none \\
\hline $\mathrm{C}$ & $1 \times 1 \mathrm{~m}$ & 15 & $\mathrm{~N} 1022.2 / \mathrm{E} 1003.0$ & periphery & 7 \\
\hline $\mathrm{D}$ & $1 \times 1 \mathrm{~m}$ & 12 & N1029.5/E994.0 & framework & 1 \\
\hline
\end{tabular}

a Coordinates are for the southwest corner of the unit and are relative to the site datum (E1000/N1000) established by CAR in 1997.

b See Figure 6-13.

c Note that the feature numbers were assigned during CAR's 1997 investigations. 
During the course of the 1995 investigations, Steve Black and Charles Frederick conducted limited investigations of the midden and documented the site's stratigraphy (Frederick, Appendix A; Frederick and Black, Appendix B). Frederick provided a valuable first step in determining the terrace sequence at the site, and subsequent geomorphic investigations at the site further refined the temporal framework of the site formation processes (Nordt, Chapter 5).

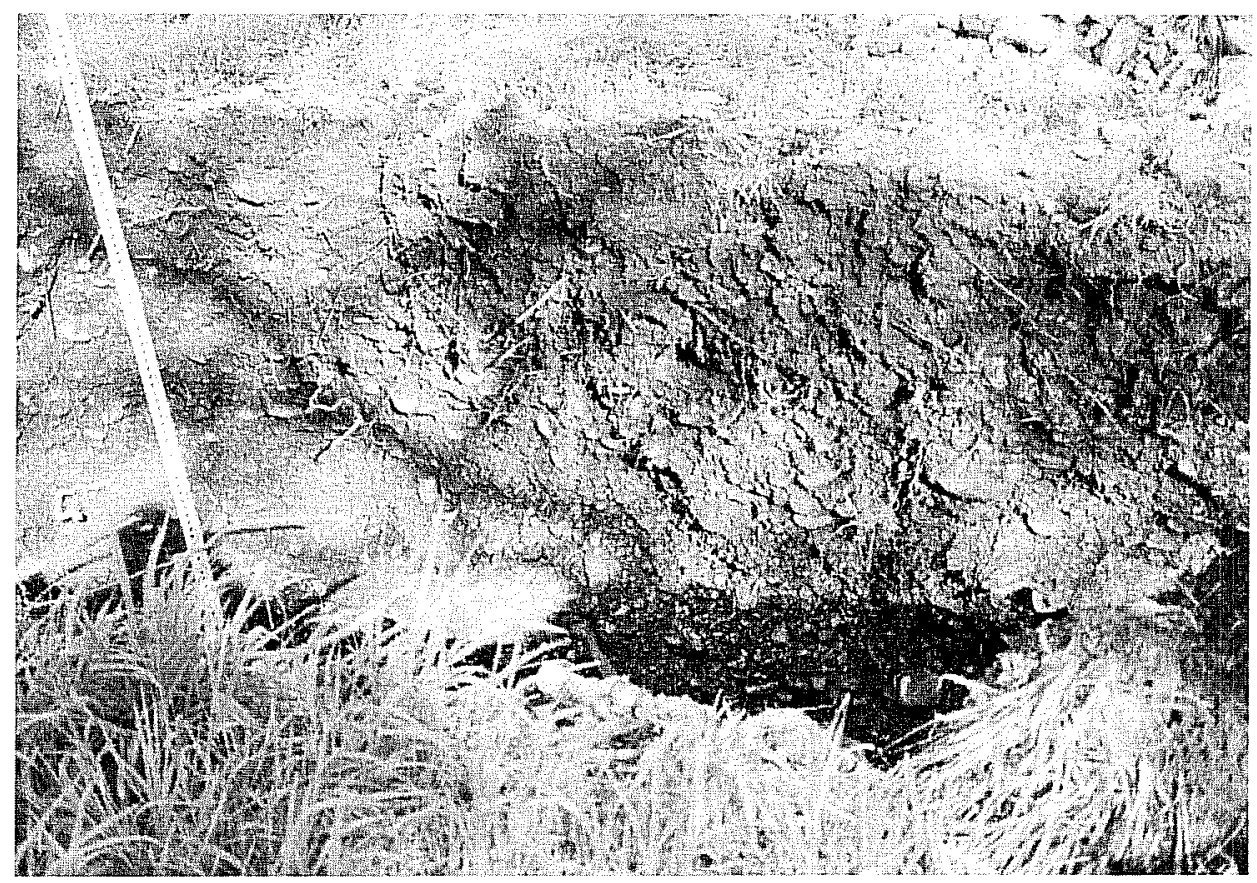

Figure 6-16. Photograph of BHT K, east wall profile.

Four test units (TUs A, B,

$C$, and D) were excavated contiguous with trench walls in this area in 1995 (Figure 6-14). Only one of the units (D) was actually excavated in the midden as it was later defined by CAR (see below). TU A was placed in the midden's periphery just outside and south of the torus. TU C was excavated east of the midden's torus over a feature exposed in the trench wall stratigraphically below the midden, and TU B was excavated well away (east) from the midden's torus to investigate the extent of cultural deposits off-midden. These investigations produced a large quantity of chipped stone debris and tools, with diagnostic artifacts representing the Early Archaic through Late Archaic II time periods (Table 3-1).

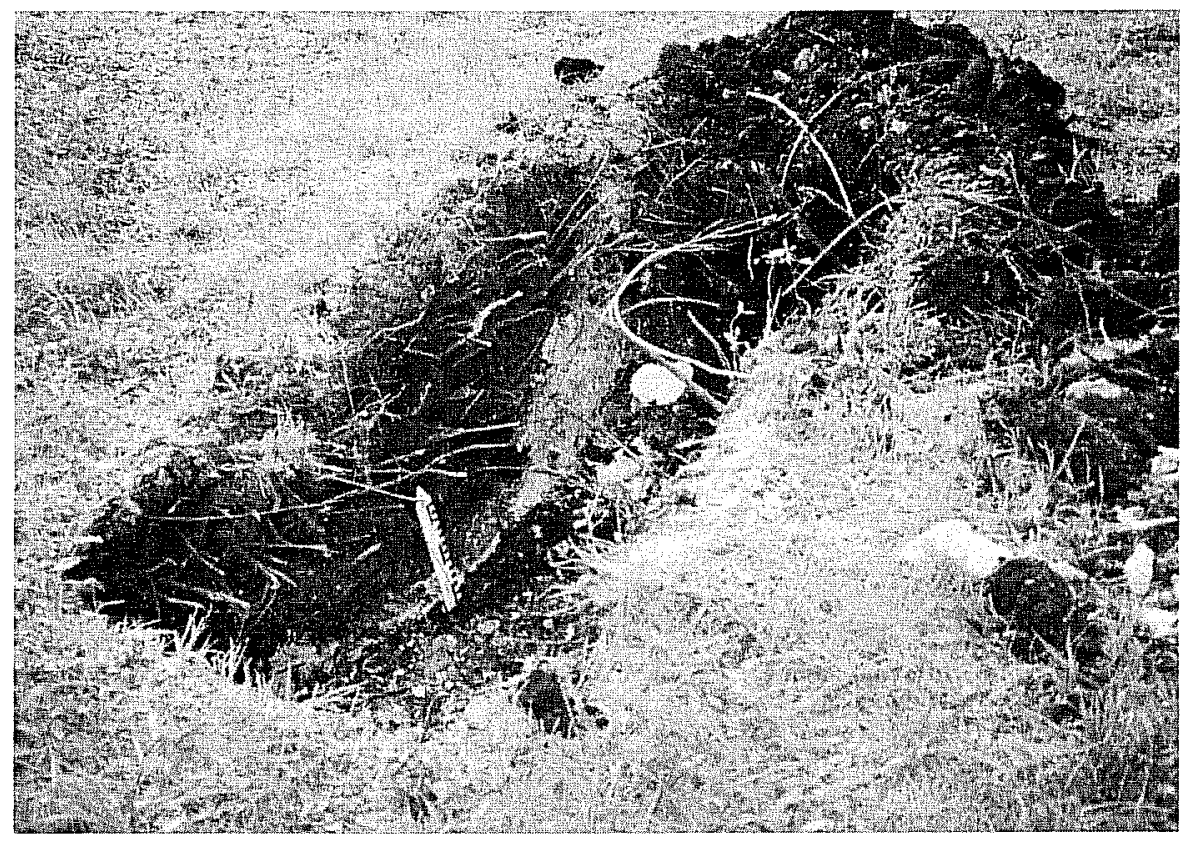

Figure 6-17. Photograph of BHT L, looking southwest.
The sum of the 1995 investigations demonstrated, in combination with the earlier work in 1993, that the midden was largely undisturbed from activities associated with the construction of Loop 1604. Mapping and documentation of the midden by Black and Frederick revealed that it had a central area (between, and west of, TUs A and D) and possibly other intact structural elements, both within and below the midden. TxDOT investigations also documented an intact feature (later designated Feature 7) underlying the midden in TU C. The results of the TxDOT investigations are provided in greater detail below. 


\section{CAR Investigations}

Area B is the most extensively investigated area on the site, with the vast majority of CAR's effort being expended in this area. CAR's investigations began by cleaning out the existing trenches and units excavated in 1995, extending several trenches and excavating new ones, excavating $231-x-1-m$ units, digging five shovel tests, and conducting detailed mapping and sampling (Figure 6-14). All of the previous units (A, B, C, and D) excavated in this area by Price in 1995 were relocated. As noted above, only two of the test units (TUs 23 and 24) from Wood's 1993 excavations could be located. If the reader will recall, Wood's units were reported to have been removed by the 1995 trenching activities. However, Wood's TU 20 appears in Black's photomosaic profile of the south wall of BHT M; we could, therefore, correctly locate it on Figure 6-14.

As outlined above, the complexity of the midden area warrants a division of the area into four subareas for analytical and management purposes (see Figure 614). These include the central core area, midden framework, midden periphery, and block excavation areas. The midden core and framework are combined and discussed first, as this discussion encapsulates the entire midden deposit and sets up the discussion for the other subareas. The midden periphery is discussed next, followed by the block excavation. Also note that distinctions are made between upslope and downslope locations of units in the periphery during the following discussion. This distinction is to highlight the complexity of the deposition and erosion environment that characterizes Area B (discussed in greater detail in Chapter 7). Also note that while a unit or set of units may be located in the central core, framework, and periphery areas, most of the lower levels in these units extend into the underlying Stratigraphic Unit III, and therefore stratigraphically below the midden. As noted above, the focus of the block excavation discussion centers on the adjacent units east of the midden proper (see Figure 6-14). These investigations were directed at the possible Nolan-age component deposits in Stratigraphic Unit III.

Thirteen wood charcoal samples collected from Area B were submitted for analysis; three from the midden's core, four from the framework, three from the periphery, and three from levels underlying the midden in the block excavation. In addition, 52,156 pieces of chipped stone (Table 6-8) including 55 diagnostic artifacts (Table 6-9), $294.45 \mathrm{~g}$ of fauna, and over 3,337 $\mathrm{kg}$ (3.67 tons) of fire-cracked limestone were recovered. TU 11 in the midden's periphery yielded the greatest weight of faunal material by volume of sediments screened and floated (Chapter 10). Five archaeomagnetic samples from Feature 1.1 and 10 from Feature 1.2 were submitted for analysis. One soil susceptibility column consisting of 36 samples was also analyzed (Chapter 11).

\section{Core and Framework Areas (Feature 1)}

The large accumulated mass of charred and fragmented rock has been designated Feature 1 -the midden, with a ring or torus measuring approximately $12-14 \mathrm{~m}$ in diameter and a 3-4-m central core extending ca. 60 $70 \mathrm{~cm}$ below the modern surface. Features recognized within the midden have been assigned subfeature numbers (e.g., Feature 1.1, 1.2, 1.3, and so on). BHTs excavated through the midden have, for the most part, exposed the midden horizontally and vertically, while the horizontal distribution of the core and torus were further enhanced by scraping off the overburden on its northern and western edges with a Gradall.

Results of the initial test excavations (1993) in the midden did little more than define the feature as a

Table 6-8. Chipped Stone from Area B

\begin{tabular}{|c|c|c|c|c|c|c|c|c|c|c|c|}
\hline \multicolumn{2}{|c|}{ Cores } & \multicolumn{2}{c|}{ Debitage } & \multicolumn{2}{c|}{ Unifaces } & \multicolumn{2}{c|}{ Bifaces } & \multicolumn{2}{c|}{ Points } & \multicolumn{3}{c|}{ Total } \\
\hline$\#$ & $\%$ & $\#$ & $\%$ & $\#$ & $\%$ & $\#$ & $\%$ & $\#$ & $\%$ & $\#$ & $\%$ \\
\hline 40 & $<1$ & 51,545 & 98.8 & 350 & $<1$ & 163 & $<1$ & 58 & $<1$ & 52,156 & 100 \\
\hline
\end{tabular}


Table 6-9. Diagnostic Artifacts from Area B

\begin{tabular}{|c|c|c|c|c|c|}
\hline Type & Interval & Subarea & TU/BHT & Level/Elev. & Invest. \\
\hline Martind ale & Early Archaic & Central Core & TU 9 & 6 & CAR \\
\hline Uvalde & Early Archaic & Central Core & TU 8 & 5 & CAR \\
\hline Nolan & Mid. Archaic & Central Core & TU 9 & 2 & CAR \\
\hline Castroville & Late Archaic & Central Core & TU 8 & 3 & CAR \\
\hline Castroville & Late Archaic & Central Core & TU 9 & 3 & CAR \\
\hline Ellis & Late Archaic & Central Core & TU 8 & 2 & CAR \\
\hline Marshall & Late Archaic & Central Core & TU 9 & 2 & CAR \\
\hline Pedernales & Late Archaic & Central Core & TU 9 & 2 & CAR \\
\hline Pedernales preform & Late Archaic & Central Core & TU 9 & 2 & $\mathrm{CAR}$ \\
\hline Pedernales preform & Late Archaic & Central Core & TU 9 & 2 & CAR \\
\hline Clear Fork gouge & Early Archaic & Framework & TU 18 & 3 & Wood \\
\hline Guadalupe tool & Early Archaic & Framework & TU D & 9 & Price \\
\hline La Jita & Mid. Archaic & Framework & TU 7 & 5 & CAR \\
\hline La Jita & Mid. Archaic & Framework & TU D & 2 & Price \\
\hline Nolan & Mid. Archaic & Framework & TU D & 5 & Price \\
\hline Bulverde & Late Archaic & Framework & Trench G & 9 & Price \\
\hline Pedernales & Late Archaic & Framework & GT & Backdirt & CAR \\
\hline Bell & Mid. Archaic & Periphery & TU 11 & 7 & CAR \\
\hline Carrizo & Mid. Archaic & Periphery & TU 11 & 4 & CAR \\
\hline Carrizo & Mid. Archaic & Periphery & TU 11 & 4 & CAR \\
\hline La Jita & Mid. Archaic & Periphery & BHT O & Backdirt & CAR \\
\hline La Jita & Mid. Archaic & Periphery & TU 17 & 2 & Wood \\
\hline Bulverde & Late Archaic & Periphery & TU 20 & 3 & Wood \\
\hline Castroville & Late Archaic & Periphery & BHT X & Backdirt & CAR \\
\hline Castroville & Late Archaic & Periphery & TU A & 1 & Price \\
\hline Darl & Late Archaic & Periphery & TU 4 & 5 & CAR \\
\hline Darl & Late Archaic & Periphery & TU 4 & 6 & CAR \\
\hline Darl & Late Archaic & Periphery & TU 20 & 5 & Wood \\
\hline Langtry & Late Archaic & Periphery & Surface* & Surface & Price \\
\hline Marcos & Late Archaic & Periphery & BHT P & Backdirt & CAR \\
\hline Montell & Late Archaic & Periphery & BHT P & Backdirt & CAR \\
\hline Montell & Late Archaic & Periphery & TU 4 & 3 & CAR \\
\hline Montell & Late Archaic & Periphery & TU 11 & 1 & CAR \\
\hline Pedernales & Late Archaic & Periphery & BHT O & 100.373 & CAR \\
\hline Pedernales & Late Archaic & Periphery & BHT O & Backdirt & CAR \\
\hline Pedernales & Late Archaic & Periphery & TU 17 & 3 & Wood \\
\hline Pedernales & Late Archaic & Periphery & Trench G & Backdirt & Price \\
\hline
\end{tabular}


Table 6-9. continued

\begin{tabular}{|l|l|l|c|c|c|}
\hline \multicolumn{1}{|c|}{ Type } & \multicolumn{1}{|c|}{ Interval } & \multicolumn{1}{c|}{ Subarea } & TU/BHT & Level/Elev. & Invest. \\
\hline Pedernales preform & Late Archaic & Periphery & TU 11 & 4 & CAR \\
\hline Williams & Late Archaic & Periphery & TU 11 & 2 & CAR \\
\hline San Gabriel biface & Trans. Archaic & Periphery & Trench G & Backdirt & Price \\
\hline Langtry & Mid. Archaic & Block Excavation & TU 19 & 3 & CAR \\
\hline Langtry & Mid. Archaic & Block Excavation & TU 17 & 4 & CAR \\
\hline Nolan & Mid. Archaic & Block Excavation & TU 12 & 3 & CAR \\
\hline Nolan & Mid. Archaic & Block Excavation & TU 16 & 3 & CAR \\
\hline Nolan & Mid. Archaic & Block Excavation & TU 16 & 3 & CAR \\
\hline Nolan & Mid. Archaic & Block Excavation & TU 17 & 4 & CAR \\
\hline Nolan & Mid. Archaic & Block Excavation & TU 23 & 3 & CAR \\
\hline Nolan-like & Mid. Archaic & Block Excavation & TU 12 & 3 & CAR \\
\hline Tortugas & Mid. Archaic & Block Excavation & TU 14 & 4 & CAR \\
\hline Castroville & Late Archaic & Block Excavation & TU 16 & 1 & CAR \\
\hline Bulverde & Late Archaic & Block Excavation & TU 16 & 5 & CAR \\
\hline Montell & Late Archaic & Block Excavation & TU 12 & 1 & CAR \\
\hline Pedernales & Late Archaic & Block Excavation & TU 18 & 3 & CAR \\
\hline Pedernales & Late Archaic & Block Excavation & TU C & 5 & Price \\
\hline Castroville & Late Archaic & Unknown & BHT ? & Backdirt & Price \\
\hline Castroville & Late Archaic & Unknown & BHT ? & Backdirt & Price \\
\hline
\end{tabular}

* Midway between Trenches $\mathrm{H}$ and $\mathrm{J}$ on the floodplain.

burned rock midden. The subsequent trenching and excavations by Price in 1995 and midden documentation by Frederick and Black (Appendix B) documented the horizontal and vertical dimensions of the midden. Frederick and Black were quick to note that the midden had visible structure. That is, the profiles afforded by the trenching clearly demonstrated that the midden was annular in form and possessed a "soft-center or sediment supported center." This midden structure was well documented in a photomosaic and line drawing of the west wall of the north-south trench (BHT $\mathrm{G})$. Their line drawing was scanned and adapted by CAR (Figure 6-18). A photomosaic of the east-west trench (BHTs $\mathrm{M}, \mathrm{N}$, and $\mathrm{O}$ ) produced by Frederick and Black was scanned and reproduced as a line drawing by CAR (Figure 6-18). The field inspection and photo documentation reveal an area in the center of the mosaic with lesser amounts of burned rock (matrix-supported) surrounded by a ring of rock-supported matrix (clast-supported; rock-on-rock). Importantly, the photomosaic revealed a number of rock layers, defined by a contiguous pavement of larger rocks within and possibly above the framework of the midden. Finally, Frederick and Black identified basal pit features (Appendix B) stratigraphically below the base of the midden from which radiocarbon-datable wood charcoal was obtained.

The 1997 investigations by CAR in Area B began with cleaning out the previous BHTs and units excavated by Price in 1995 . As all were backfilled with sand and some of the trenches marked, they were easy to relocate and clean. Sand in the trenches was removed with a backhoe, while sand from the test units was removed manually.

As the goals of the 1997 testing project included investigating possible off-midden deposits within the 


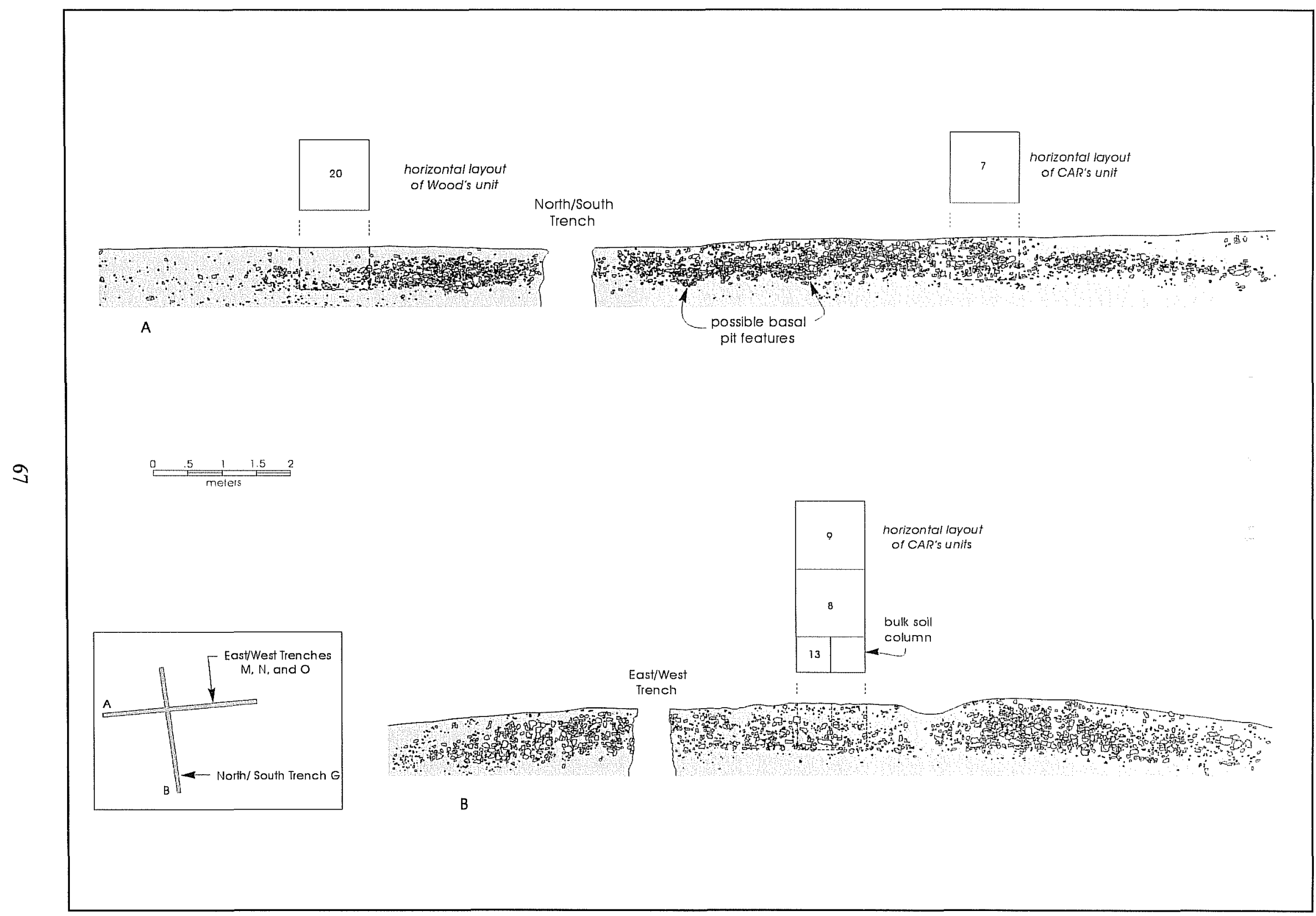

Figure 6-18. Composite profile of trenches in burned rock midden. A: BHTs M, N, and O based on photomosaic; B: BHT G based on line drawings. 
periphery and assessing the potential of intact deposits stratigraphically below the midden, we decided to lengthen and connect several of the existing trenches and to excavate new ones. Toward this end, BHT G was extended several meters to the south, BHTs $M$ and $\mathrm{N}$ were connected to the east of the midden, BHT O was extended to the west, and new BHTs $H, P, X, Z$, $\mathrm{AA}$, and $\mathrm{CC}$ were excavated (Figures 6-1 and 6-14).

In the core and framework of Feature 1, eight units were excavated: Controlled shovel tests $18,19(30 \mathrm{x}$ $30 \mathrm{~cm})$, and $23(50 \times 50 \mathrm{~cm})$ by Wood in 1993, TU D in 1995 by Price, and TUs 7, 8, 9, and 13 by CAR (Table 6-10) in 1997 (Figure 6-14). As mentioned, the exact location of the units excavated in Feature 1 by Wood in 1993 are unknown and assignment to subareas in the midden is our best postulation.

After the trench profiles were cleaned, the structure of the midden as noted by Frederick and Black was clearly evident. The core area identified in the photomosaic of the west wall profile of BHT G was the most obvious of the structural features. However, the core area was not visible in the east wall of the same trench. Therefore, BHT $\mathrm{G}$ appears to have clipped the eastern edge of the central core area. Note that the central area was not visible in the north wall of BHT O near the intersection with BHT G (see Figure 6-14).

To expose the central area, the upper $10 \mathrm{~cm}$ of sediment (sloping surface) overlying the ring or torus of the burned rock feature was removed with a Gradall (see Figure 4-3). This overburden was gently scraped in 5-cm levels until the top of the burned rock torus had been exposed. Interestingly, the Gradall scrape visually enhanced the torus or ring portion of the feature, which rose up from the central core area, peaked, and dropped off toward the outer edges. The central core area became clearly visible in plan view as darker and matrix-supported sediments contrasted sharply with the outer clast supported torus. This resulted in an extraordinary plan view of the northern portion of the midden (Figure 6-19). The partial plan view exposure, in combination with the trench profiles, revealed a classic annular or ring midden. Based on the profiles and Gradall stripping, the midden (Feature 1) has an estimated diameter of 12-14 $\mathrm{m}$. It should be noted that the 12-14-m diameter is based on the extent of the central core and framework area. Extending in all directions from the midden is an almost continuous but markedly thinner layer of burned rock. In places, mainly to the west of the midden in BHT O (Figure 6-18), this periphery rock layer is two and three stones (ca. $15 \mathrm{~cm}$ ) thick.

In addition to the central core area exposed by the backhoe and Gradall work, several contiguous rock

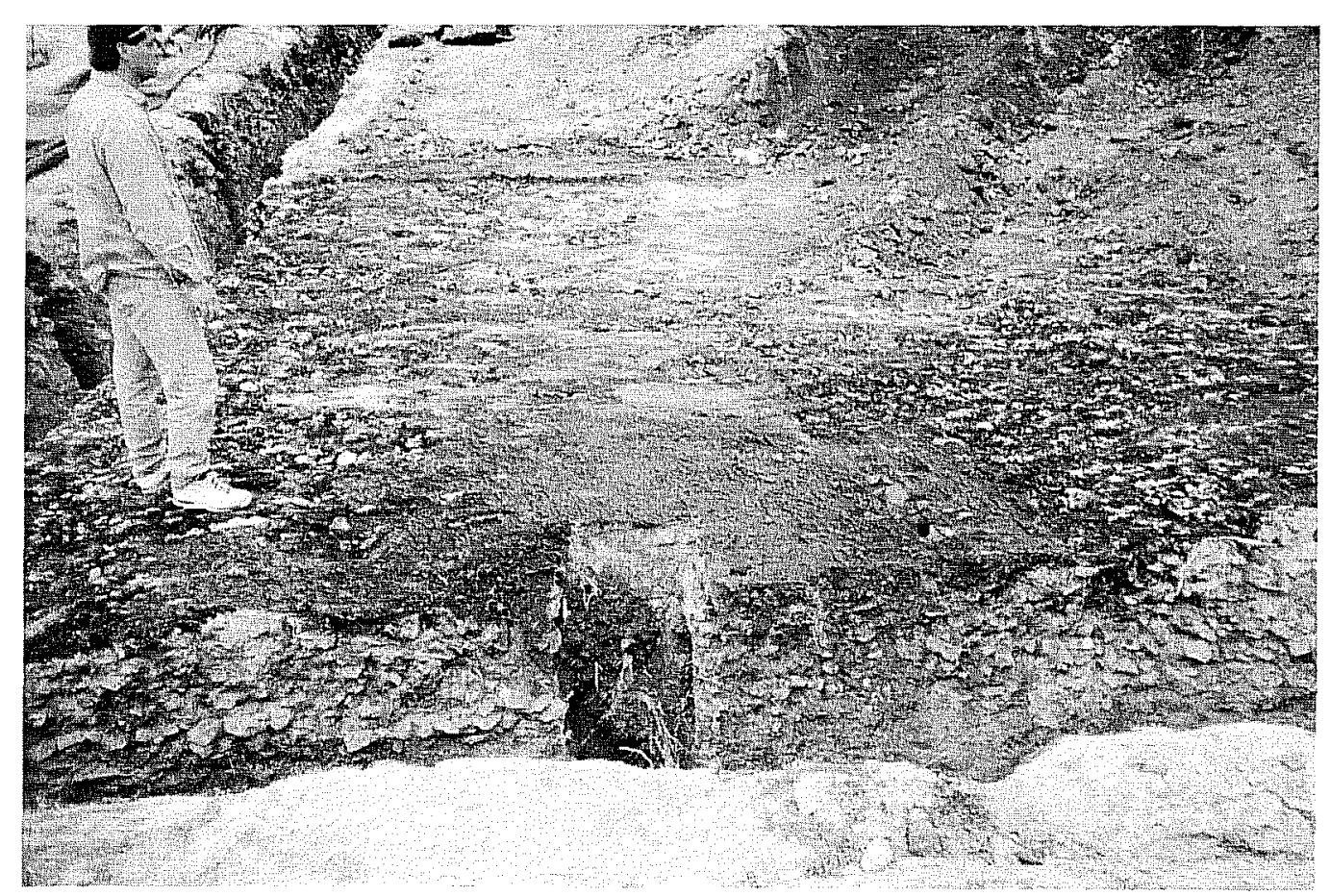

Figure 6-19. Gradall scraping and BHT G revealed the midden's core as a gray-brown humus filled pit surrounded by a clast supported ring. Frederick's bulk soil column is seen in the center. 
Table 6-10. TUs Excavated in Area B by CAR (some unit numbers overlap with Wood's)

\begin{tabular}{|c|c|c|c|c|c|c|}
\hline \multirow{2}{*}{ TU } & \multirow{2}{*}{ TU Size } & \multirow{2}{*}{$\begin{array}{l}\text { Levels } \\
(10 \mathrm{~cm})\end{array}$} & \multicolumn{2}{|c|}{ Coordinates" } & \multirow{2}{*}{$\begin{array}{l}\text { Structural } \\
\text { Location }\end{array}$} & \multirow{2}{*}{$\begin{array}{l}\text { Associated } \\
\text { Feature(s) }\end{array}$} \\
\hline & & & East & North & & \\
\hline 4 & $1 \times 1 \mathrm{~m}$ & 9 & 996.48 & 1011.54 & periphery & 4 \\
\hline 7 & $1 \times 1 \mathrm{~m}$ & 8 & 988.04 & 1019.08 & framew ork & 1 and 1.1 \\
\hline 8 & $1 \times 1 \mathrm{~m}$ & 6 & 992.33 & 1022.87 & central core & $1,1.2$, and 1.3 \\
\hline 9 & $1 \times 1 \mathrm{~m}$ & 6 & 991.32 & 1022.86 & central core & $1,1.2$, and 1.3 \\
\hline 10 & $1 \times 1 \mathrm{~m}$ & 4 & 100.50 & 1011.49 & periphery & none \\
\hline 11 & $1 \times 1 \mathrm{~m}$ & 7 & 987.32 & 1014.25 & periphery & none \\
\hline 12 & $1 \times 1 \mathrm{~m}$ & 5 & 1001.91 & 1022.03 & periphery & 7 \\
\hline 13 & $50 \times 50 \mathrm{~cm}$ & 6 & 991.33 & 1022.87 & central core & $1,1.2$, and 1.3 \\
\hline 14 & $1 \times 1 \mathrm{~m}$ & 5 & 1000.91 & 1022.03 & block excavation & 12 \\
\hline 15 & $1 \times 1 \mathrm{~m}$ & 5 & 1000.91 & 1023.03 & block excavation & 12 \\
\hline 16 & $1 \times 1 \mathrm{~m}$ & 5 & 1000.91 & 1024.03 & block excavation & none \\
\hline 17 & $1 \times 1 \mathrm{~m}$ & 5 & 1001.91 & 1023.03 & block excavation & none \\
\hline 18 & $1 \times 1 \mathrm{~m}$ & 5 & 100.91 & 1024.03 & block excavation & 11 \\
\hline 19 & $1 \times 1 \mathrm{~m}$ & 5 & 1002.91 & 1023.03 & block excavation & none \\
\hline 20 & $1 \times 1 \mathrm{~m}$ & 5 & 1002.91 & 1024.03 & block excavation & 11 \\
\hline 21 & $1 \times 1 \mathrm{~m}$ & 5 & 1003.91 & 1022.03 & block excavation & none \\
\hline 22 & $1 \times 1 \mathrm{~m}$ & 5 & 1003.91 & 1023.03 & block excavation & none \\
\hline 23 & $1 \times 1 \mathrm{~m}$ & 5 & 1006.91 & 1024.03 & block excavation & none \\
\hline
\end{tabular}

${ }^{a}$ Coordinates are for the southwest corner of the unit and are relative to the site datum (E1000/N1000).

layers were located throughout the framework of the midden. Black and Frederick noted several of these in their line drawing (Figure 6-18). These possible features were defined by relatively flat layers of large $(>20 \mathrm{~cm}$ diameter) limestone rocks that stood in contrast to the surrounding smaller $(3-19 \mathrm{~cm})$ rocks. Identifying these rock layers as possible features is difficult. They look very much like burned rock features that the Sotoleros of northern Chihuahua make. Large piles or stacks of cobbles to be used in future ovens are frequently enveloped by the discarded burned rocks from previously used features (Brown and Leach 1997). These piles of rocks then would be scattered around and often buried by the growing mass of discard associated with the rock ovens. Along with units that were excavated in the central area (see below), a single unit was excavated over one of the better-defined framework rock layers which was designated Feature 1.1.

\section{Feature Excavations}

\section{Feature 1.1}

To assess the possibility that the apparently separate but distinct rock layers within the framework of the midden were indeed separate features (intact heating elements), the largest, and most pronounced of the rock layers was selected for excavation. A rock layer in the south wall of BHT O, located southwest of the central core (see below), was excavated. The rock layer was assigned Feature 1.1, the first subfeature investigated within Feature 1 (the burned rock midden).

In profile, Feature 1.1 appeared as a nearly flat layer of large $(>20 \mathrm{~cm})$, limestone cobbles extending approximately $1.5 \mathrm{~m}$ along the south wall of BHT O, approximately $20-50 \mathrm{~cm}$ bs (Figures 6-18, 6-20, and 


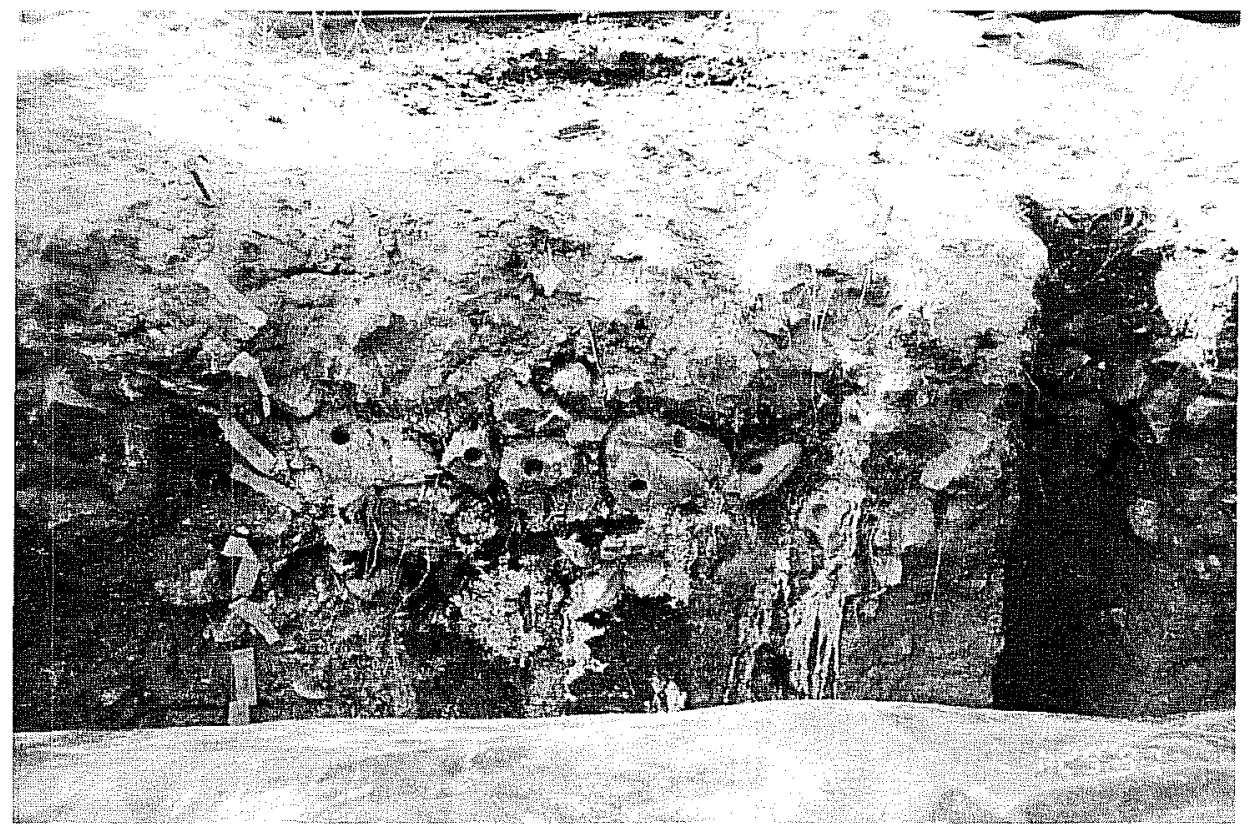

Figure 6-20. Profile of Feature 1.1 in south wall of BHT $O$. Note that large cobbles have been drilled for archaeomagnetic cores.

The top of the feature was encountered in Level 2, 20 $\mathrm{cm}$ bs. The mean weight of burned rocks in Level 2 dropped to $77.62 \mathrm{~g}$. Larger burned rock cobbles were again observed in the field at approximately $25 \mathrm{~cm}$ bs (Level 3), and subsequent analysis provided a mean weight of $103.11 \mathrm{~g}$. At this level, excavators appeared to be exposing the top of the feature. The larger rocks were left pedestaled and excavation continued into the underlying level (Level 4). At 30- $40 \mathrm{~cm}$ bs (Level 4), the feature appeared as a layer of large limestone cobbles $(>20$ $\mathrm{cm}$ ), several of which

6-21). The larger limestone rocks and the overall flatness of the feature helped define it in profile. None of the feature was apparent in the north wall profile of BHT O, suggesting the backhoe removed its northern edge. Although difficult to discern from the profile, the feature did not appear to be setting in a pit of any appreciable depth. A rchae omagnetic samples were taken from rocks in the trench wall, before hand excavation began (Figure 6-20).

To test the feature, a single unit (TU 7) was placed over its apparent center as exposed in profile. Larger burned rock cobbles were encountered $5 \mathrm{~cm}$ bs, but no apparent pattern was observed in the field, and later analysis of Level 1 burned rocks indicated a mean weight of $181.48 \mathrm{~g}$.

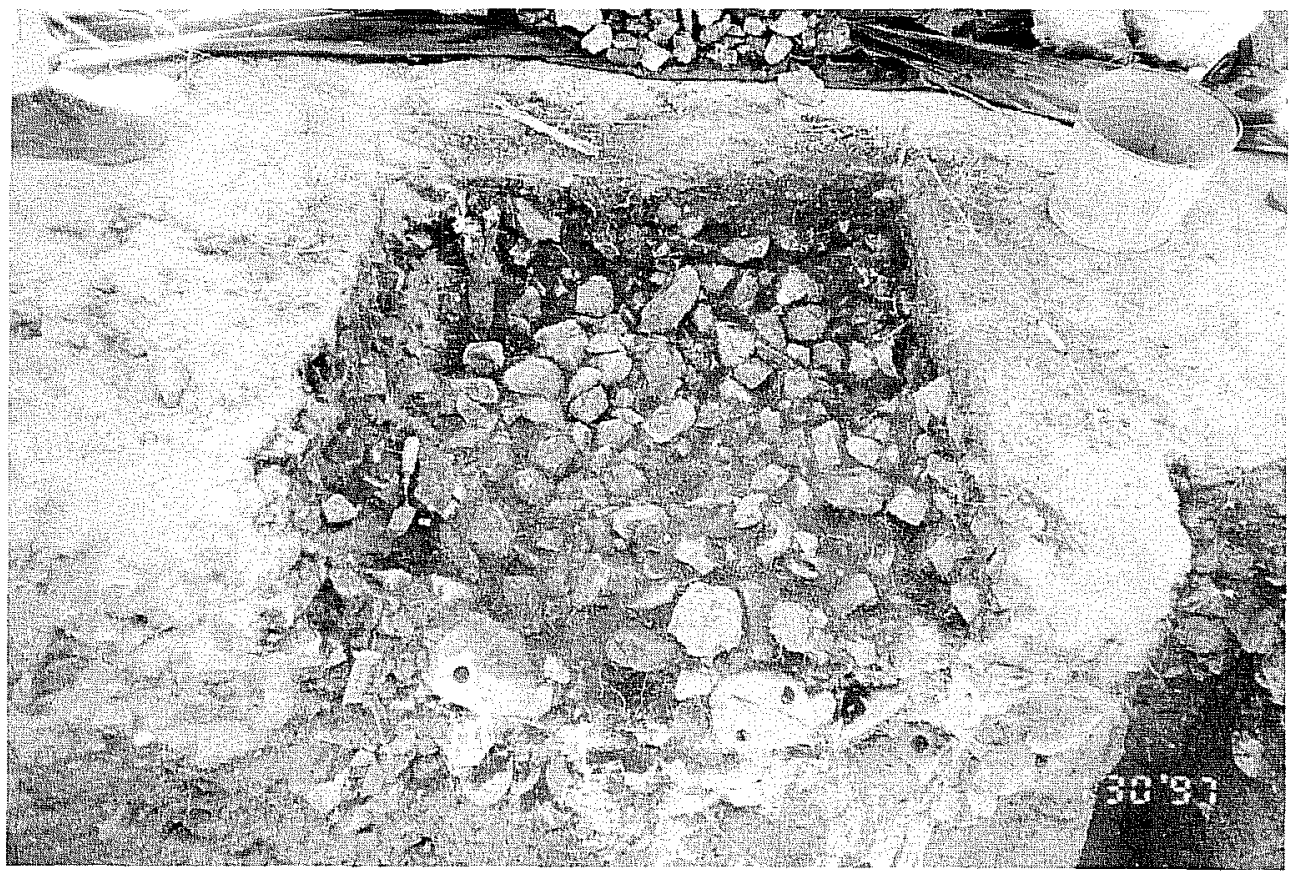

Figure 6-21. Feature 1.1, TU 7, Level 2. Note that the larger cobbles near the bottom have been drilled for archaeomagnetic cores. 


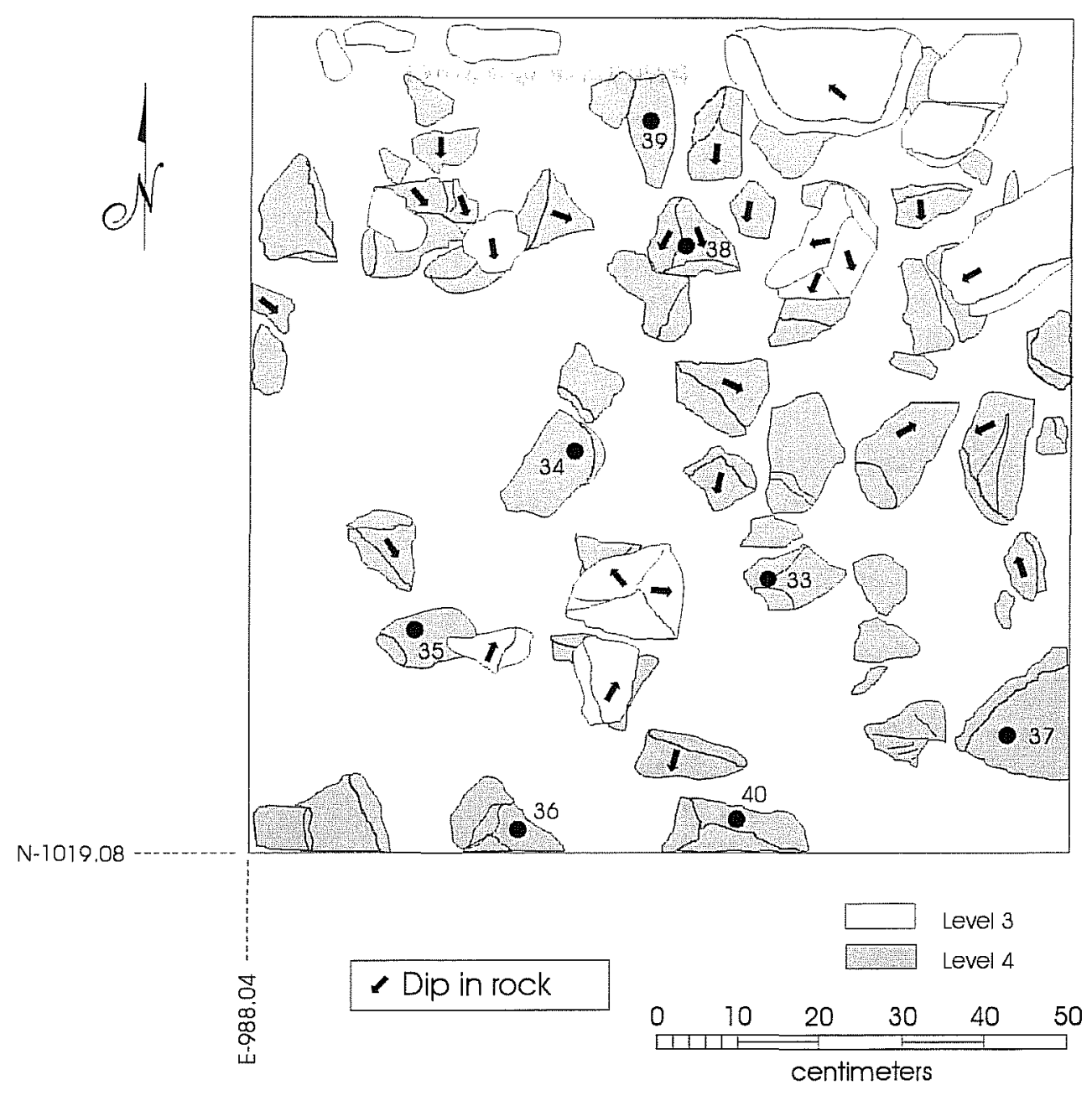

Figure 6-22. Plan view of Feature 1.1, TU7. The plan view is a composite of the bottom of Level 3 and the top of Level 4 . Note that several of the rocks were sampled for archaeomagnetic analysis.

archaeomagnetic analysis of eight core samples taken from between 23 and $40 \mathrm{~cm}$ bs (upper Level 3 to lower Level 4) indicates that seven of the eight had cooled in place (Chapter 11). The base of Feature 1.1 was encountered in Level 5 , ca. $50 \mathrm{~cm}$ bs. No archaeomagnetic samples were taken from Level 5. The base was defined in the field by the occurrence of larger rocks in Level 5 bs. Levels 3 and 4 above. In Level 6 the size of burned rocks again decreased. Laboratory analysis of the burned rock confirmed the field observations: burned rock size defined the upper part of the feature in Levels 2, 3, and 4, and the base of the feature in Level 5. Mean weights of burned rock for Levels 2-8 respectively are: $77.62 \mathrm{~g}, 103.11 \mathrm{~g}$, $105.37 \mathrm{~g}, 302.31 \mathrm{~g}, 79.90 \mathrm{~g}, 17.86 \mathrm{~g}$, and $12.10 \mathrm{~g}$.
Other than an increase in the size of stone, no other evidence for the feature, such as a change in soil color or texture, was observed in the field. However subsequent laboratory analysis revealed that besides burned rock size, artifacts and faunal remains associated with Feature 1.1 excavation levels helped delineate its depth. A Middle Archaic La Jita dart point (Johnson and Goode 1994; Turner and Hester 1993:140; Table 3-1) were found associated with the base of Feature 1.1 in Level 5. The only faunal remains recovered from eight levels in TU 7 were from Levels 4, 5, and 6 (1.42 g; Chapter 10). Archaeobotanical analysis of samples revealed an indeterminable wood species in Levels 3 and 4, and live oak in Level 5 (Chapter 9). A flotation sample taken from Level 3 
yielded enough wood charcoal to obtain a radiocarbon date of $2980 \pm 50$ B.P. Archaeomagnetic analysis of eight selected core samples indicated that seven of the eight cored rocks had not been disturbed since their last heating event (Chapter11).

As expected, the excavation of BHT O cut the northern edge of the feature and the feature continues into the south and west walls of the unit. An absence of large cobbles on the eastern edge of the unit suggests it does not extend further in that direction.

In sum, the available information suggests that Feature 1.1 does in fact represent a portion of an intact heating element within the framework of the larger midden. It was recognizable in profile as a layer of larger cobbles overlain with a clast-supported matrix of smaller rocks possessing a greater number of fractures than in the larger cobbles of Feature 1.1. The center of this feature was not detectable by a change in sediment structure, texture or color, and it did not appear to have been dug into the underlying Stratigraphic Unit III sediments. For these reasons it appears to be a separate feature constructed during the use of the larger midden, and the discard of the larger midden enveloped and covered it.

\section{Features 1.2 and 1.3}

One of the bulk soil columns taken by Frederick in 1995 (Figure 6-18) was from the central core area of the midden. The majority of the western portion of this column was still visible in the west wall of BHT G (Figures 6-23 and 6-24).

After scraping off the upper $10 \mathrm{~cm}$ of overburden from the surface of the midden with a Gradall, a 3-4-m diameter central pit was exposed. The central core was filled with a gray-brown organically rich sediment following its last use(s) (Figure 6-19). CAR staff decided that a single $1-\mathrm{x}-1-\mathrm{m}$ unit would not be sufficient to document any feature(s) encountered in this area. Therefore our excavations in the central core consisted of two 1-x-1-m units (8 and 9) and one partial unit (13). Archaeologists who have worked in burned rock middens or similar features are aware of the difficulties in trying to identify discrete rock features within a rock matrix. The identification of features in such contexts is best approached in large, areal excavations. Though a much larger block would have been ideal, the two contiguous 1-x-1-m units (and one partial unit $80 \times 40 \mathrm{~cm}$ ) provided an adequate view of the encountered features.

TUs 8, 9, and 13 were laid out on an east/west orientation to cross cut the center of the central core area. The units were also placed to catch the edge of the central pit area as it rose to the framework surrounding the central core area (Figures 6-23 and 6-24).

The excavations began $10 \mathrm{~cm}$ below the original ground surface (Gradall scraping over the convex midden ring created an uneven hummocky surface); therefore, descriptions of Features 1.2 and 1.3 (as well

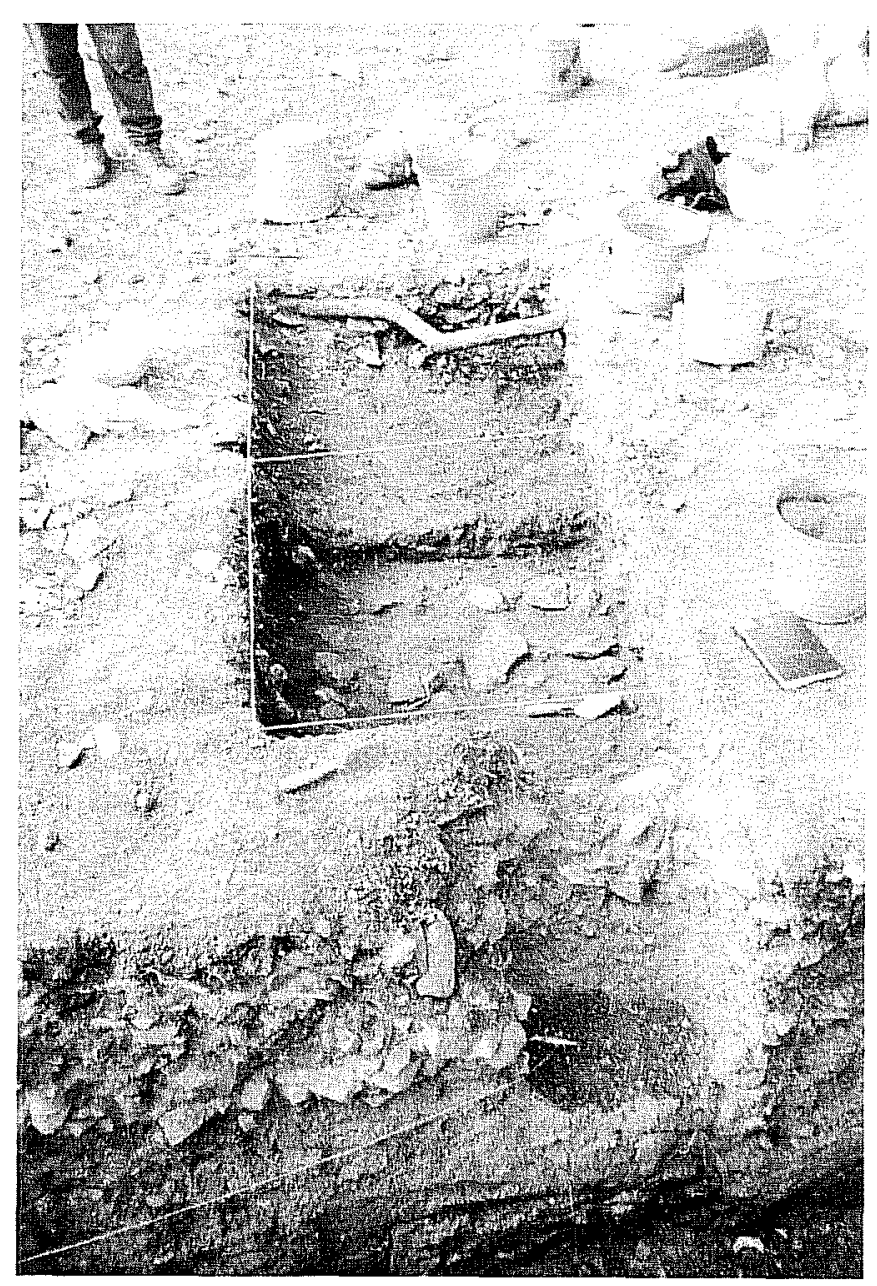

Figure 6-23. Midden core (Features 1.2 and 1.3) in the profile of BHT G. Note Wood's TU 23 in the trench wall, with CAR's adjacent TUs 9 and 8 (looking west). 


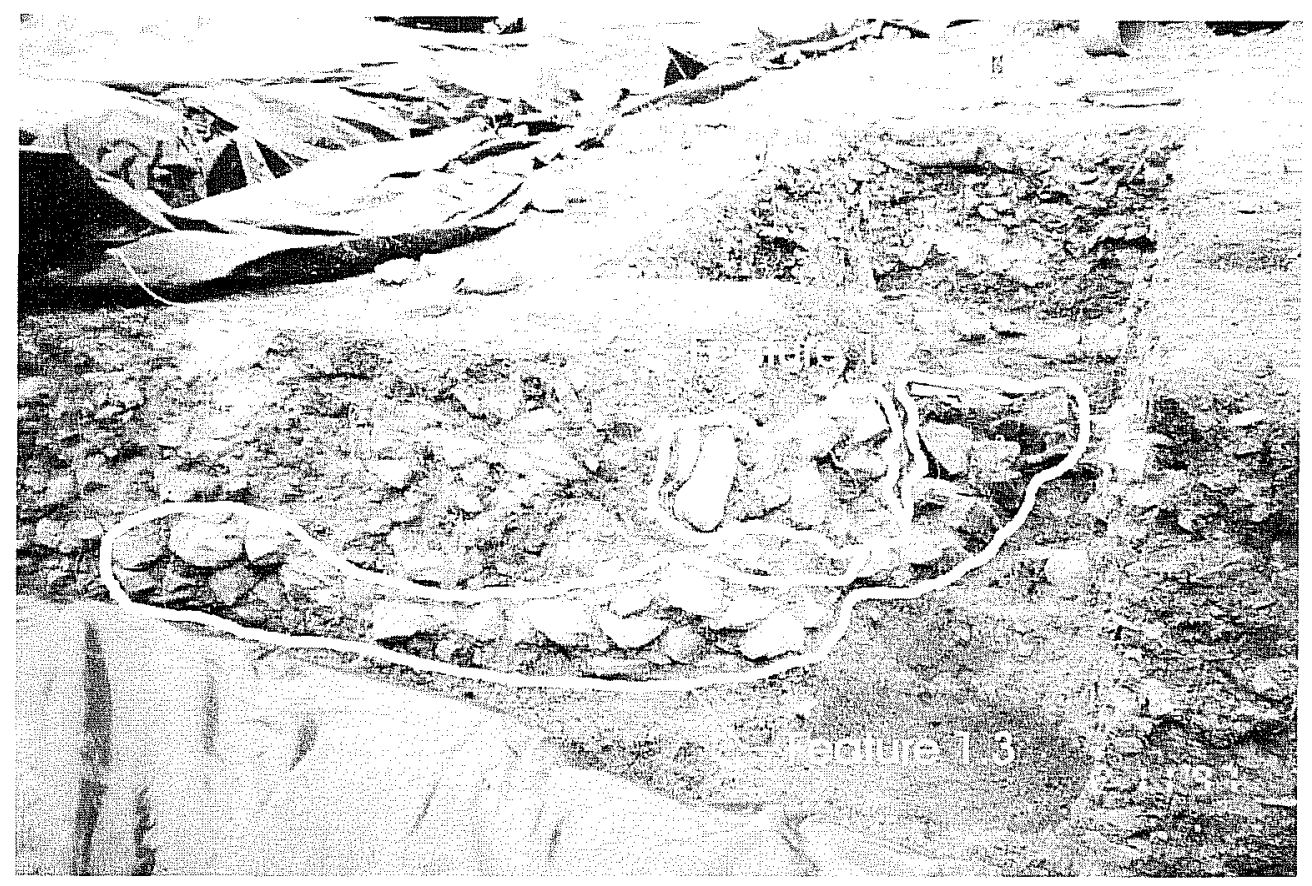

Figure 6-24. Photograph of Features 1.2 and 1.3 in the west wall profile of $B H T G$. Note that the features are stacked immediately on top of one another with little or no separation between the two.

as Features 7, 11, and 12) are discussed in terms of depth below the original ground surface (bgs), i.e., before scraping with the Gradall. TUs 8 and 9 were excavated simultaneously. As evidenced on the surface, the upper three levels were dominated by a sediment-supported matrix, with lesser amounts of burned rock relative to the generally clast supported underlying three levels. This pattern was evident in the BHT profile (Figure 6-18) and confirmed our expectations about the sedimentation in the central area.
Feature 1.2

Fire-cracked rocks from 15 to $40 \mathrm{~cm}$ bgs in TUs 8 and 13 were labeled Feature 1.2 (Figures 614 and 6-25). Although large quantities of firecracked rock were in the feature (Table 6-11), it appeared as a sloping arrangement of flat, tabular limestone rocks resting on distinctly larger, and more rounded cobbles. The fire-cracked rocks above these tabular and larger cobble stones had been smaller, and square or rectangular with no apparent pattern or alignment. The flat ones may represent the bottom of a slab-lined oven. In the field, excavators observed the sloping of the tabular pieces, particularly so in the northeast corner of TU 8, as they appeared to slope inward to the southwest and downward in a bowl shape.

Later laboratory analysis of the burned rock demonstrated subtle patterns in rock type frequencies and weight by level. Level $1(10-20 \mathrm{~cm}$ bgs) consisted of loosely packed sediment matrix with 158 cobbles with

Table 6-11. Mean Weights of Burned Rock, TU 8

\begin{tabular}{|c|c|c|c|c|}
\hline \multirow{2}{*}{ Level } & \multicolumn{2}{|c|}{ Cobbles } & \multicolumn{2}{c|}{ Tabular } \\
\cline { 2 - 5 } & $\overline{\mathbf{x}} \mathbf{w t} \mathbf{( g )}$ & $\#$ & $\overline{\mathbf{x}} \mathbf{w t} \mathbf{( g )}$ & $\#$ \\
\hline 1 & 244.75 & 158 & 148.1 & 21 \\
\hline 2 & 93.38 & 423 & 132.85 & 41 \\
\hline 3 & 64.80 & 1206 & 135.02 & 82 \\
\hline 4 & 49.78 & 623 & 29.05 & 217 \\
\hline 5 & 109.36 & 825 & 183.45 & 31 \\
\hline 6 & 125.43 & 28 & - & 0 \\
\hline
\end{tabular}




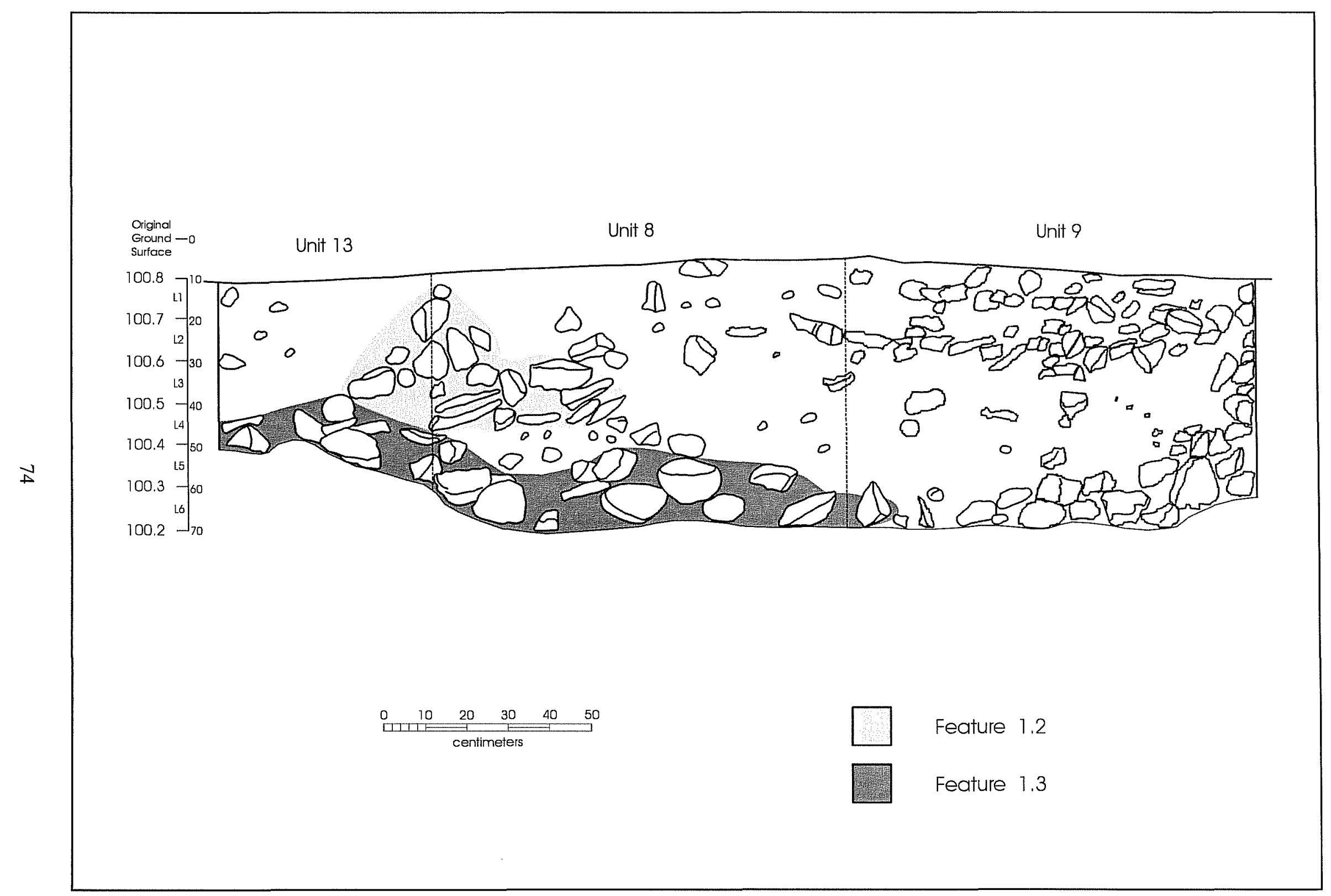

Figure 6-25. Features 1.2 and 1.3 as exposed in the south wall profile of TUs 13,8 , and 9. 
a mean weight of $244.75 \mathrm{~g}$, and 21 tabular pieces of limestone with a mean weight of $148.1 \mathrm{~g}$ (Table 611). Burned rock analysis from Level $2(20-30 \mathrm{~cm}$ bgs) indicates that the number of tabular pieces increased $(n=41)$ over Level 1 , as did the number of cobbles $(n=423)$. However, the mean weights of cobbles decreased significantly ( $244.75 \mathrm{~g}$ to $93.38 \mathrm{~g}$ ) while the mean weights of tabular pieces remained nearly the same (148.1 g to $132.85 \mathrm{~g}$ ). As excavation continued into Level $3(30-40 \mathrm{~cm}$ bgs) the cobbles increased in frequency but became smaller in size, while the tabular pieces increased in both quantity and mean weight (Table 6-11). In Level 4 (40-50 cm bgs), laboratory analysis shows that the tabular pieces become more fragmented; the number $(n=217)$ increases but the mean fragment weight is $29.05 \mathrm{~g}$. Within the same provenience, the cobbles get smaller; both the quantity and mean weight of cobbles decrease.

Archaeologists in the field observed that the burned rock at the bottom of Feature 1.2 in TU 8 (50-60 cm bgs [Level 5]) generally sloped downward from southeast to northwest in a bowl-shaped pattern (Figure 6-26). Feature 1.2, as exposed in plan view in TU 8, appeared to have extended back into the south and east walls of the excavation area. After closer inspection of the west wall of BHT G, it was clear that portions of the feature were exposed in the trench profile. To expose a larger portion of the visible feature, the small "soil balk" (Figure 6-26) adjacent to TU 8, Frederick's bulk soil column, and the edge of BHT $\mathrm{G}$ was designated TU 13 (see Figure 6-14). As the focus of the investigations were on the feature, and an adequate sample of material was obtained from the excavation of the levels above the feature in TU 8 , the upper $40-50 \mathrm{~cm}$ of overburden in TU 13 was removed as a single unit and passed through the screen (note that no sediment samples were taken).

After excavating TU 13, it became clear that the feature extended across both units. However, the main concentration of rocks appeared to be in TU 8 and extending into TU 13 (Figures 6-25 and 6-27). The eastern edge of the feature had been removed by the excavation of BHT G. The feature did not continue across the trench into the east wall of BHT G. Many of the large limestone rocks that made up the feature appeared to have broken in place during use and had not moved since their firing and subsequent cooling.

We estimate the feature was between 1.8 and $2.5 \mathrm{~m}$ in diameter. Though difficult to discern, the sloping rocks suggest the heating element was setting in an earthen pit. Fewer flat tabular rocks were present at the bottom of Level 5 compared to those in Level 4 . These tabular ones that were encountered in Level 5 were sloping down toward the center of the unit. Archaeomagnetic samples were taken and the larger rocks removed. Upon removing the tabular rocks, charcoal smears were observed on their undersides, suggesting they may have been placed on a bed of coals. Reddish

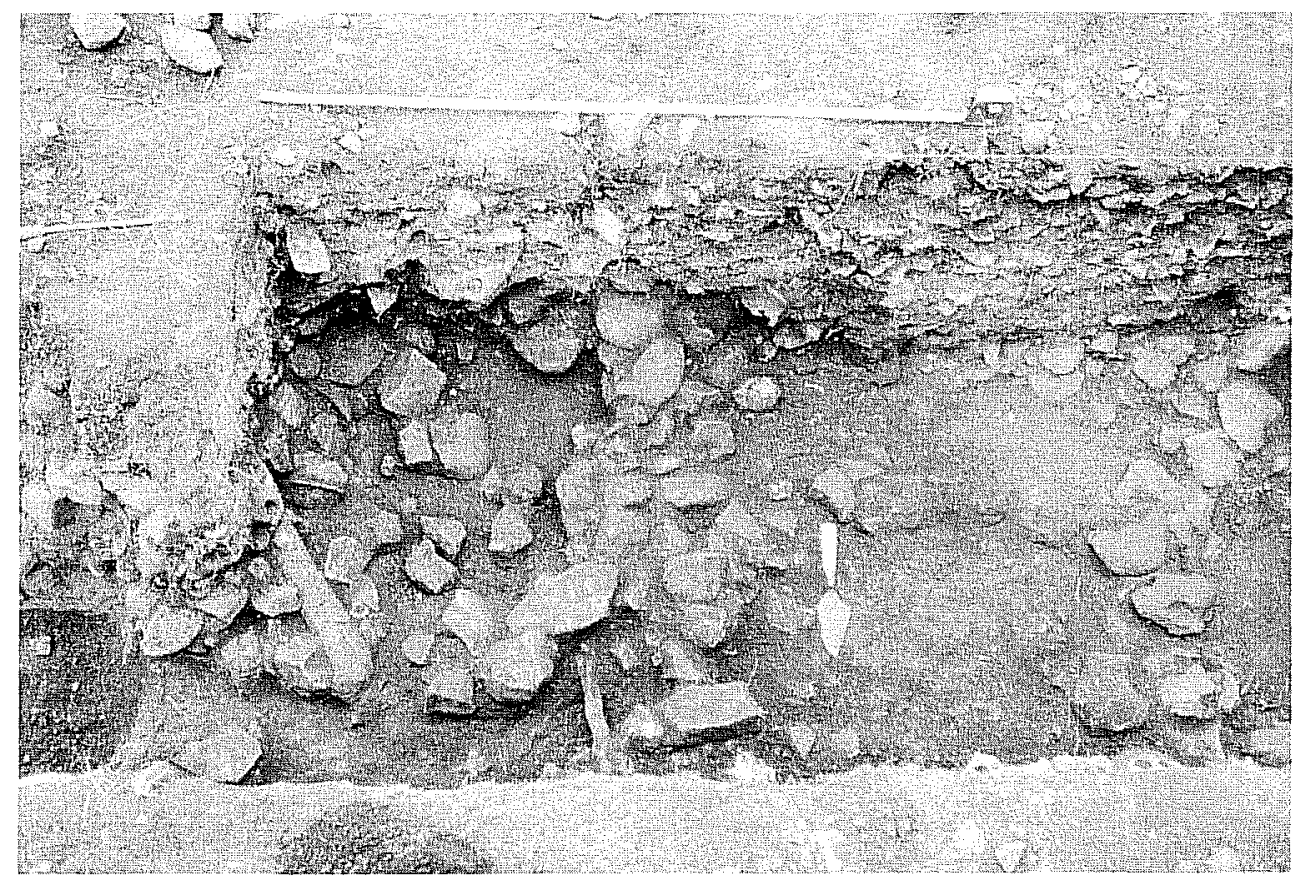

Figure 6-26. Photograph of Feature 1.2 (left) and Feature 1.3 (right) from above; from left to right, $T U$ s 23,8 , and 9. 


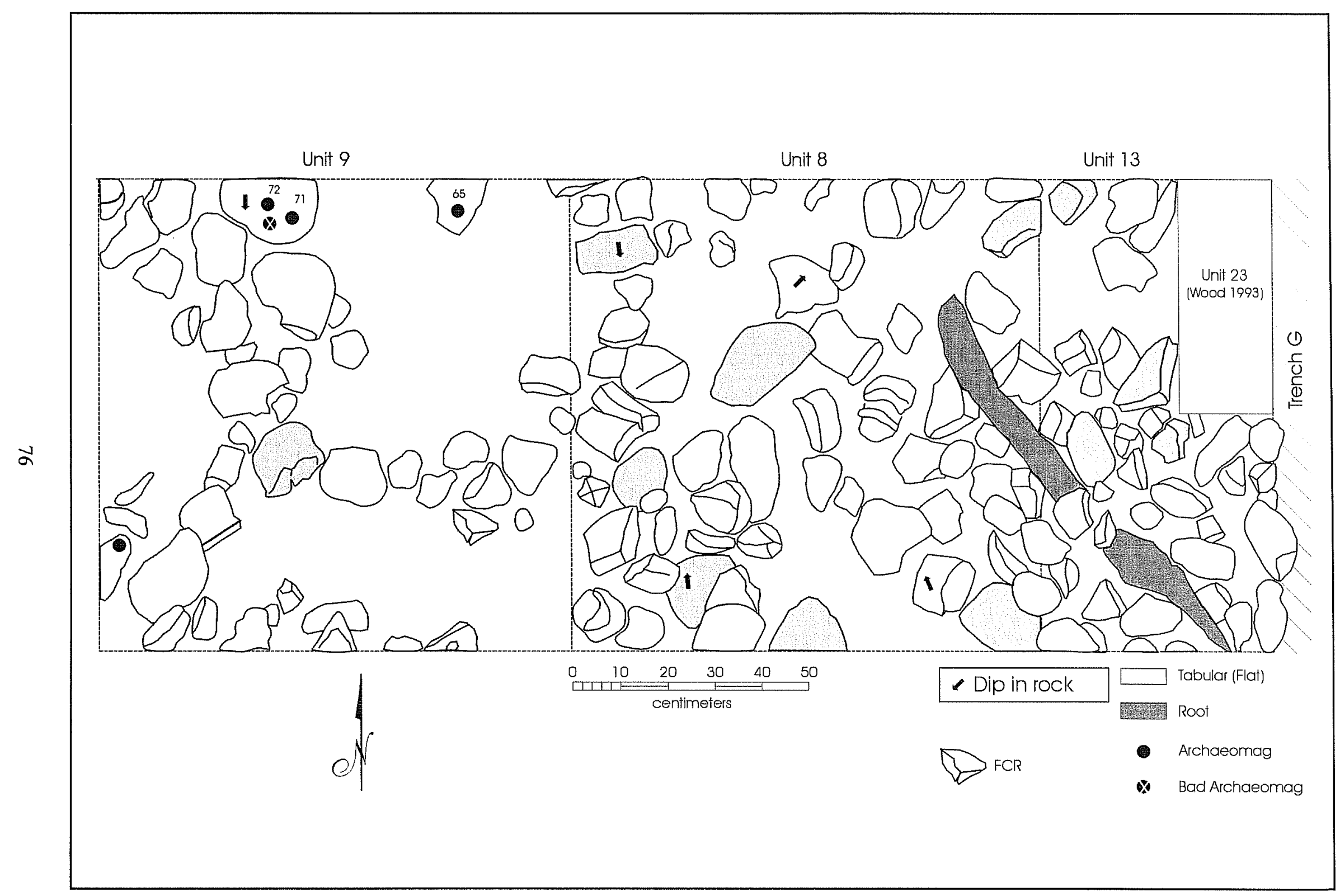

Figure 6-27. Plan view of TUs 8, 9, and 13, Level 4. Feature 1.2 is in TUs 8 and 13. 
soil identified as a Stratigraphic Unit III and IV unconformity appeared at the bottom of Level 6 .

Ten of 14 archaeomagnetic samples taken from Feature 1.2 were submitted for analysis. The results indicate that nine of the 10 rocks were likely "recycled" or reheated, and that all 10 may have been only slightly disturbed since they were last used and then allowed to cool (Chapter 11). Although three diagnostic artifacts were recovered from TU 8, none can be directly associated with Feature 1.2. A Late Archaic Ellis point was in the northeast quadrant of Level 2 in the core's sediment matrix. A Late Archaic Castroville from Level 3 was found in the screen, and an Early Archaic Uvalde point which was found at the extreme bottom of Level 5 is included in the discussion of Feature 1.3. No diagnostic artifacts were found in TU 13. Lithic debitage assemblages by level demonstrate a bimodal pattern in TU 8, but the pattern cannot be directly associated with any feature. Specks of charcoal and ash were observed throughout TUs 8 and 13. Three charcoal samples from these two units were sent to Beta Analytic for dating. Two of the samples were collected in situ (i.e., $50 \pm 70$ B.P. and $3040 \pm 70$ B.P.) and one was recovered from a flotation sample (i.e., $4050 \pm 50$ в.P.). These three samples may be problematic because of charcoal translocation. Two dates from Level 5 are $2950( \pm 70)$ B.P. and $4050( \pm 50)$ B.P. A third date from Level 6 will be included in the discussion of Feature 1.3. Level 5 is primarily a transitional layer of sediments and small rock fragments separating Feature 1.2 and 1.3 and thus the dates from Level 5 could be indirectly associated with either feature. Following the same argument three species of wood identified from Level 5 archaeobotanical samples are arboreal legume, live oak and hackberry (Chapter 9). The available evidence indicates that Feature 1.2 was an intact heating element, or hot-rock bed, in an earth oven.

\section{Feature 1.3}

Archaeologists observed a second distinct layer of tabular pieces overlying larger cobbles, and separated from Feature 1.2 only by highly fragmented pieces underlying Feature 1.2. This second "layering of rocks" in Level 5 noted in the field and designated as Feature 1.3 (see Figure 6-25) appeared to slope inward and downward in a bowl shape. Feature 1.3 was found in Levels 4 and 5 (40-60 cm bgs) of TU 13, Levels 5 and $6(50-70 \mathrm{~cm}$ bgs) of TU 8, and Level 6 (60-80 cm bgs) of TU 9 (Figures 6-14 and 6-25). Burned rock was not collected and analyzed from TU 9. Therefore Feature 1.3 discussions are based upon field observations, notes, photographs, and cultural material distributions. After Feature 1.2 rocks in TU 8 were sampled for archaeomagnetic analysis, they were removed and excavation continued into Levels 5 and 6 (50-70 $\mathrm{cm}$ bgs). A few of the rocks from the overlying Feature 1.2 protruded into Level 5, however the upper portion of Feature 1.3 was discernible in Level 5 as a tightly clustered layer of large ( $>20$ $\mathrm{cm}$ ) and small limestone cobbles overlain with tabular pieces. This layer of rocks appeared to slope inward and downward in a bowl shape toward the southwest, indicating a "pit center" in that direction. Sediment in the interstices was a gray-brown organic rich loam, very similar to the sediment overlying and within Feature 1.2. Simultaneous excavation of Level 5 in TU 9 revealed loose, sediment-supported matrix except in the southwest quadrant where larger (ca. 15 $\mathrm{cm}$ ) rocks were exposed. These larger burned rocks were tightly "locked" together with little fill in the interstices. Excavation of Level $6(60-70 \mathrm{~cm} \mathrm{bgs})$ in TU 9 revealed the same phenomena; however, an interesting spatial pattern noted in Level 6 for Feature 1.3 was gaps between burned rocks (Figure 6-26). At first glance, it looked like areas where excavators had inadvertently removed burned rocks from the feature, but this was not the case. It is unknown if these gaps are cultural, that is, were rocks once in this location and subsequently moved during oven use/construction, or is the pattern a result of some natural disturbance process. Although large roots were noted growing throughout these two units, none was large enough or near enough to account for the absence of rocks in certain areas of the unit. As discussed above, TU 13 also revealed the continuance of Feature 1.3 in Levels 4 and 5. After removing the overburden from TU 13, the same distinct feature (1.3) consisting of large limestone cobbles and tabular pieces underlaid Feature 1.2 (Figure 6-25). Much like Feature 1.2, rocks in the underlying layer appeared to be stacked on top of one another.

Two diagnostic dart points recovered from TUs 8 and 9 can be associated with Feature 1.3. No diagnostic artifacts were found in TU 13. A Late Archaic Bulverde 
point was found in the upper portion of Feature 1.3, at the bottom of Level 5 ( $80 \mathrm{~cm}$ bgs) on the eastern edge of TU 8. An Early Archaic Martindale point base was found in Level 6(80-90 cm bgs) of TU 9. Wood charcoal from Level 6, TU 8 yielded a radiocarbon date of $3040( \pm 70)$ B.P. Archaeobotanical analysis of float samples revealed hackberry in Level 5 , TU 13, and diffuse porous hardwood and an indeterminable wood in Level 6, TU 8. Agarita, an indeterminable wood, and a chittimwood seed were recovered from Level 6, TU 9 (Chapter 9). Although faunal material was recovered from Level 5 in TUs 8, 9 and 13, its association with either Feature 1.2 or 1.3 is problematic. The faunal assemblage (Chapter 10) that can be most directly associated with Feature 1.3 came from float samples out of Level 6 in TUs 8 (4.78 g) and 9 (7.08 g). No fauna was retrieved from Level 6 in TU 13. As with faunal material, associating chipped stone recovered from Level 5 with either Feature 1.2 or 1.3 may be problematic. However it is interesting that 61.8 percent of the chipped stone recovered from TUs 8 and 9 came from the bottom two levels (Appendix E). An analysis of Feature 1.3 reveals an abrupt increase in the quantity and size of both tabular and cobbled burned rock in Level 6. Eleven archaeomagnetic samples were taken from Feature 1.3 burned rocks in Level 6, TU 9, but were not submitted for analysis.

Features 1.2 and 1.3:

\section{A Subtle Difference in TU 8}

Admittedly, some rocks may have protruded from one level to the next and thus mixed when pulled and collected, however laboratory analysis of burned rock in Level 5 reveal the subtle differences between Features 1.2 and 1.3. As shown in Table 6-11, the mean weight of tabular rocks in Level 5 increases significantly from that of Level 4 (29.05 to $183.45 \mathrm{~g}$ ), as does the mean weight of cobbles (49.78 to $109.36 \mathrm{~g}$ ). In Level 6 the 28 cobbles present have a mean weight increase to $125.43 \mathrm{~g}$, but tabular rocks are totally absent. The large cobbles in the bottom of Level 6 are believed to represent the bottom of Feature 1.3 in TU 8. No tabular rocks were present in this level. Stratigraphically, the bottom of Feature 1.3 rests on reddish sediments which Nordt (Chapter 5) defines as Stratigraphic Unit III. Features 1.2 and 1.3 appear to be intact heating elements representing multiple uses of the central core area for an undetermined number of rock/earth ovens built in the center of the midden.

\section{Features 1.4, 1.5, and 1.6}

Several rock-filled pits and larger rock layers were noted in backhoe trench profiles stratigraphically aligned with or just below the bottom of the midden deposit. Frederick (Appendix A) noted several of these and collected bulk-soil samples from four of these "features." From the available profiles, these features appeared as shallow, basin-shaped pits extending from the bottom of the larger midden deposit into the top of the underlying Stratigraphic Unit III, or as distinctively larger rock alignments stratigraphically within the main midden's framework or periphery. Five such pit and rock alignment features were noted in the walls of the trenches in the midden area. The distinctly larger rock alignments may represent smaller cooking ovens constructed within the framework of periphery of the main midden that have been enveloped by the continuum of midden construction. The pit features were defined by the rock fill, and not by pits per se. Because of their shallow depth, had it not been for the rock fill it is unlikely they would have been detected.

Morphologically, the one attribute that sets the rockfilled pits apart from the other features identified in the midden (e.g., Features 1.1 and 1.2), is a lack of patterning in the rock, and the generally small size of the pit. The rocks and sediment in these features are jumbled, with no patterning in size or arrangement in burned rocks.

These features represent either the remains of feature types we do not fully understand, the remains of natural low spots, or culturally dug borrow pits that were subsequently buried. Because none of these features was observed in the opposite wall profiles, they are believed to be cultural rather that natural. The pit features could be the result of turbation, although this is unlikely given the basin shape and consistent depth below the midden deposit. They may also represent the remains of features that date to the early development of the midden that were subsequently covered by the by-products of countless (re)constructions of 
earth-ovens in the midden's central core area. As argued in Appendix D, a substantial quantity of sediment is needed in the construction of an earth oven. This sediment would be gathered from, among other places, areas in and around the cooking facility. The gathering or borrowing of sediment would result in borrow pits that would ultimately fill-in through time. The amount of time, distance from the growing mass of discarded rock, and intensity of on-site activities in the area of the cooking facility would determine when these borrow pits would fill in, and the kinds of materials they would contain. Unfortunately, none of these rock-filled pits has been formally excavated at the Culebra Creek site.

CAR mapped the located features in profile and recovered charcoal samples from two of them in the field. Two sampled rock-and-sediment-filled pits and one rock alignment were designated Features 1.4, 1.5 and 1.6. Two of the rock-filled pits (Features 1.4 and 1.5) sampled by Frederick were noted as having wood charcoal present (note that the bulk-soil samples collected by Frederick were not processed by flotation). These two, plus a sample collected by CAR in the field from an internal rock alignment (Feature 1.6), were submitted for radiocarbon analysis (see Chronometric section below).

\section{Feature 1.4}

Feature 1.4 is an ashy area identified by Frederick in the north wall of BHT O, five meters west of BHT G (see Figure 6-18). It is beneath the ring or torus and near the base of the main midden (Feature 1). CAR relocated this ashy area and defined a rock feature overlying a matrix filled basal pit 20 to $90 \mathrm{~cm}$ below the surface in BHT O, $5 \mathrm{~m}$ west of its junction with BHT G (Figure 6-14), and designated it Feature 1.4 (Figure 6-28). Frederick (Appendix A) described the ashy area as "relatively rock-free just below rocky midden area... Charcoal chunks observed." CAR documented the feature as ca. $40 \mathrm{~cm}$ thick at its thickest, and ca. $90 \mathrm{~cm}$ long. The rocks within the feature were distinctly larger (to $15 \mathrm{~cm}$ ) than those within the surrounding rock supported matrix in the upper $20 \mathrm{~cm}$. The top of the rocks in the feature were $20 \mathrm{~cm}$ bs and extended to a depth of $90 \mathrm{~cm}$ bs. The convex bottom of Feature 1.4 extended ca. $20 \mathrm{~cm}$ into a layer of ashy, calcium carbonate rich, rock-free sediments. The feature was not distinguishable in the opposite trench wall. A charcoal sample taken by Frederick, and later submitted by CAR to Beta Analytic for processing, yielded a radiocarbon date of $2280 \pm 60$ B.P. Whether this basal feature filled with sediment supported matrix is a natural or cultural phenomena is unclear. It was only observable within the trench wall and was not excavated.

\section{Feature 1.5}

Feature 1.5 was identified in the north wall of BHT O by Frederick (Appendix A) as a rock-filled pit beneath the ring or torus and near the base of the main midden (Feature 1). CAR relocated the rock-filled pit extending from $55-75 \mathrm{~cm}$ below the surface (bs) in BHT O, $4.5 \mathrm{~m}$ east of its juncture with BHT G (Figure 6-14) and designated it as Feature 1.5 (Figure 6-29). Frederick (Appendix A) described the feature as:

a fairly distinctive basin-shaped pit protruding downward from the approximate base of the midden. Pit is well defined only by rocks... As we removed (a bulk matrix sample) it looked like a rock-filled pit. Rocks stopped at inferred edge. Some charcoal (small chunks) observed, including possible seed fragments... Pit fill more dirt than rocks.

CAR documented the feature as ca. $20 \mathrm{~cm}$ thick at its thickest, and ca. $70 \mathrm{~cm}$ long. The larger rocks making up the feature were only ca. $10 \mathrm{~cm}$ in diameter but they were distinct within the surrounding sediment supported matrix (see Figure 6-29). The feature was not distinguishable in the opposite trench wall. A charcoal sample taken by TARL and later submitted by CAR to Beta Analytic for processing yielded a radiocarbon date of $3920 \pm 60$ B.P. Whether this rock-filled pit feature filled with clast supported matrix is a natural or cultural phenomena is unclear. It was only observable within the trench wall and was not excavated. 


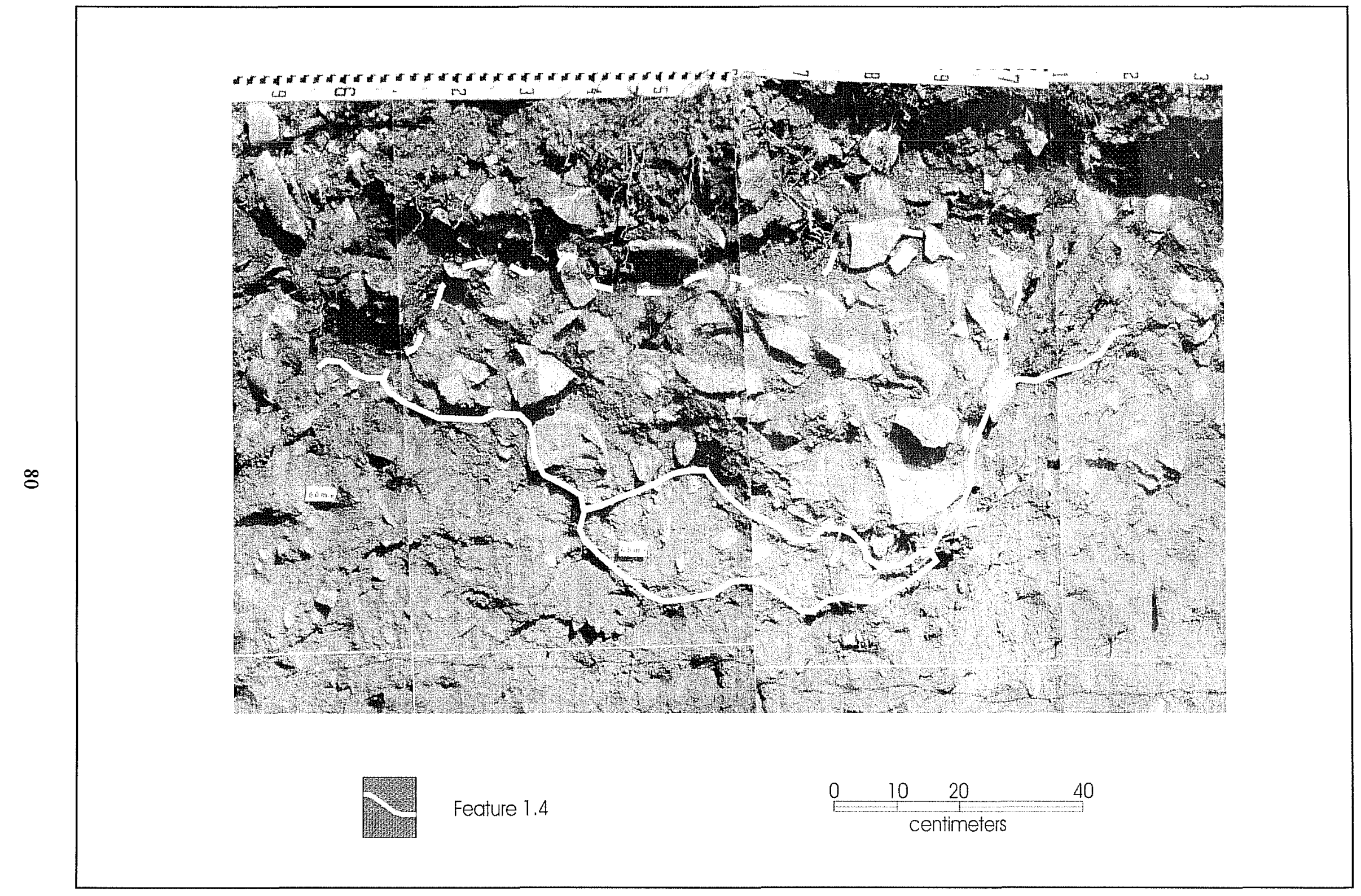

Figure 6-28. Feature 1.4. Ashy pit area overlain with burned rock feature in BHT O north wall profile (adapted from Frederick and Black's [Appendix B] photomosaic). 


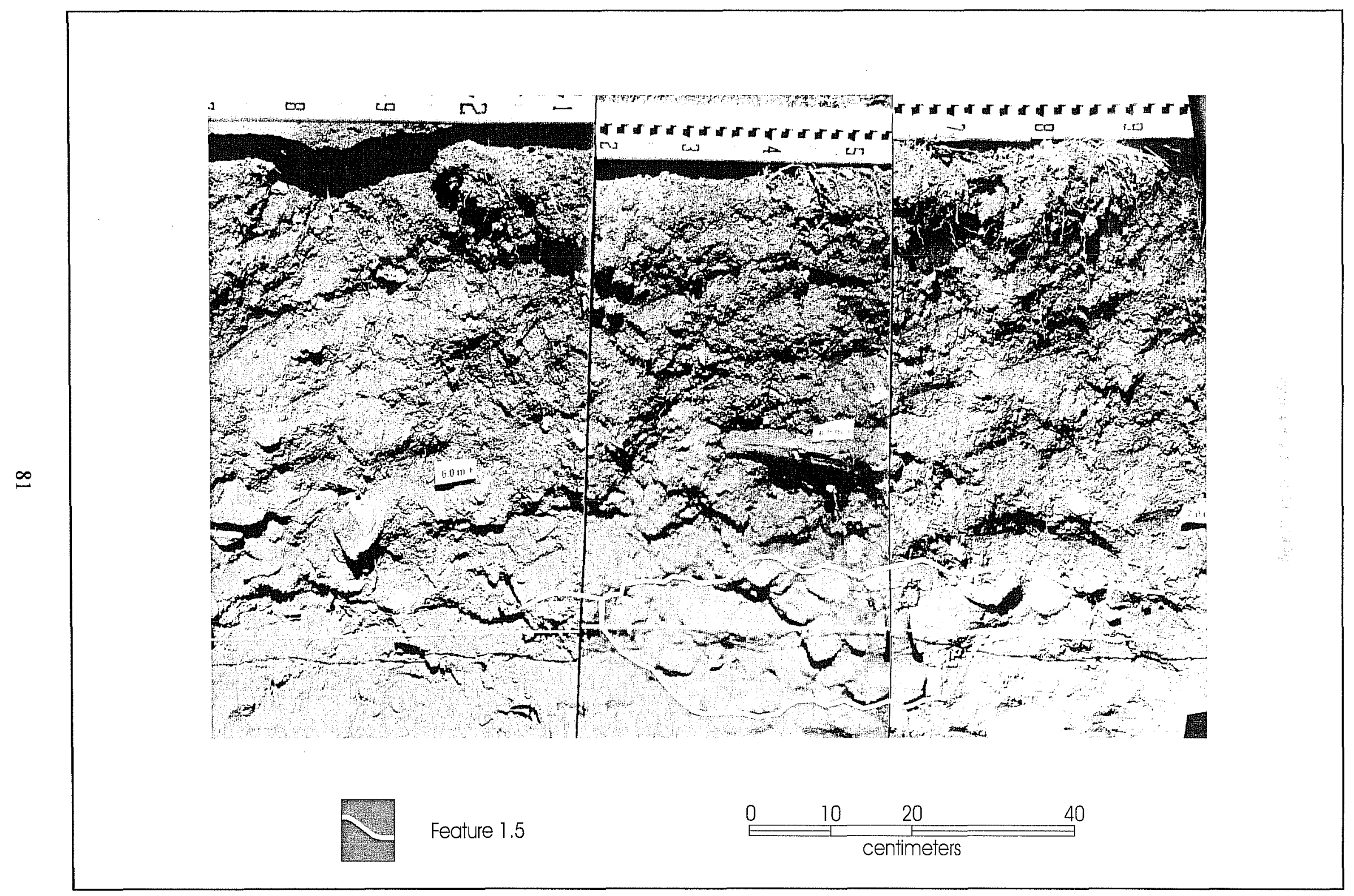

Figure 6-29. Feature 1.5. Burned rock-filled pit beneath the midden framework in BHT O north wall profile (adapted from Frederick and Black's [Appendix B] photo-mosaic). 


\section{Feature 1.6}

Feature 1.6 was identified in the east wall profile of BHT G by Frederick (Appendix A) as a distinct layer of larger rocks in a ring shape within the midden's framework (Feature 1). Frederick and Black (Appendix B) described the ringed rock feature as "a dense rock ring deposit. Much rock, but no visible charcoal. Lower 2/3 of midden. Brown matrix at the bottom (beneath midden). Rocks very dense." CAR relocated the ringed rock alignment from $15-30 \mathrm{~cm}$ below the surface in BHT G, one meter south of its junction with BHT O (Figure 6-14), and designated it Feature 1.6 (Figure 6-30). The feature was defined by its sloping, large tabular rocks up to $20 \mathrm{~cm}$ in diameter which were overlying smaller rock-supported matrix. Black and Frederick's annotated photomosaic describes the feature as having "several slabs inclined toward center in wall." CAR documented the feature as ca. $15 \mathrm{~cm}$ thick at its thickest, and ca. $110 \mathrm{~cm}$ long. While documenting the feature, CAR collected a charcoal sample from the trench wall within the feature. The sample yielded a radiocarbon date of $3920 \pm 60$ B.P.; the same date as for Feature 1.4. Whether this rock alignment feature is a natural or cultural phenomena is unclear. It was only observable within the trench wall and was not excavated.

\section{The Periphery}

The periphery encompasses the subarea of Area B that lies outside the core and framework areas. One of CAR's goals in testing 41BX126 was to assess the potential for off-midden deposits. The periphery was extensively tested with BHTs, TUs, and a Gradall (Figure 6-14). It was clear from the exposures provided by the numerous BHTs that cultural material extended in all directions from the midden proper. Only partial testing of rock layers and features in the periphery was conducted. Much of this material represents features and the residue of countless reconstructed burned rock cooking features in and around the larger, burned rock midden.

Price's initial trenching provided extensive profile views in BHTs $G, M, N$, and $O$. During CAR's investigations, BHTs $\mathrm{M}$ and $\mathrm{N}$ were connected, and $\mathrm{BHT}$
$G$ was extended south several meters. In addition, new BHTs P, X, Y, and AA were excavated, and three areas were scraped with a Gradall (note that the Gradall trenches on the site were not assigned numbers or letters). The sum of the previous and additional BHTs and Gradall work revealed the horizontal extent of the cultural deposits to the east and south of the midden core. The northern end of BHT G demonstrated that the deposit extended to the toe of the colluvial slope. However, the western extent of the cultural deposits were not determined. BHT $O$ was excavated as far west as possible without encountering Loop 1604. Artifacts and burned rock continued in the western end of the trench. Inspection of BHTs and GTs west of Area B (across highway in Area C) showed very little cultural material. This demonstrates that the cultural deposits from the western edge of the midden probably terminated somewhere beneath Loop 1604 .

It appears, based on available information, that Wood's TUs $17,20,21,24,25$, and 26 are located in the periphery area. Based on Wood's work and the exposures afforded by the BHTs, Price excavated TUs A, $B$, and $C$ in the periphery area. CAR's investigations included TUs 4, 10, and 11. A block of units (TUs 1423) was also excavated east of the midden to investigate the possible Nolan component in Depositional Unit IV in the B horizon (submidden). The Nolan component investigations, while in the periphery area, are discussed below in the Block Excavation section.

The units excavated by Wood in the midden's periphery were targeted at defining the extent of the burned rock midden and measured either $1 \times 1 \mathrm{~m}$ or $50 \times 50$ $\mathrm{cm}$ (Table 6-6). None of the units excavated by Wood defined any features, but all produced chipped stone and burned rock. Based on the extensive trench exposures, Price placed TU A three meters south of the dense concentration of burned rock making up the midden's framework, and TU B 14 m east of the midden framework to test the extent of cultural material to the east. In addition, TU C was placed seven meters east of the framework area adjacent to the north wall of Trench M. TU C produced a possible Guadalupe tool and a potential rock feature stratigraphically below the midden deposit. Price's TU C was the only unit to produce a feature, though it was not assigned a number at the time (later designated Feature 7 by CAR). 


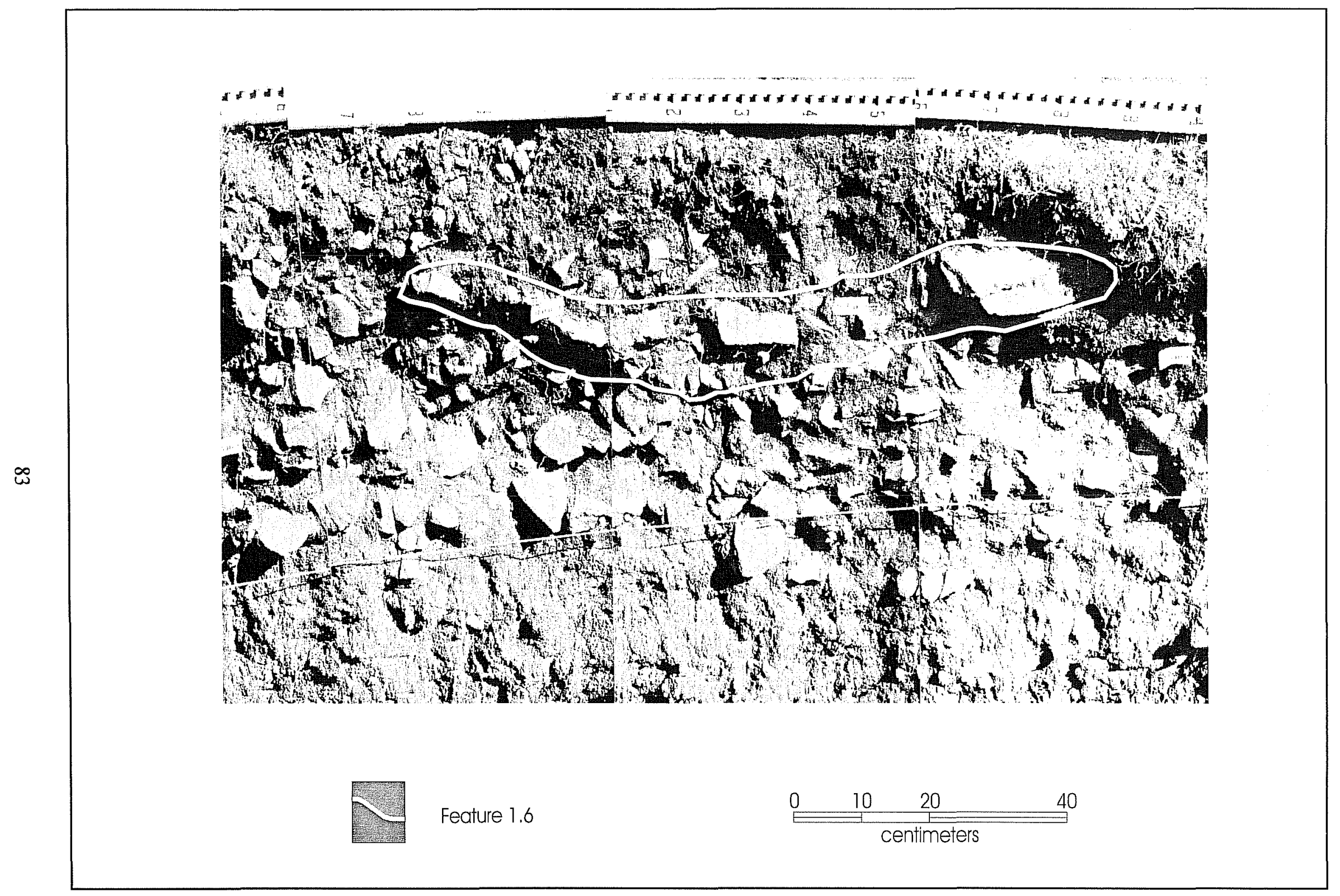

Figure 6-30. Feature 1.6. Ring-shaped layer of burned rock beneath the midden framework in BHT G profile (adapted from Frederick and Black's [Appendix B] photomosaic). 
Investigations in TU C produced the first recognition of a possible underlying component and provided the basis for a block excavation. In addition, TU 12 was excavated adjacent to Price's TU C to gather additional information on the burned rock exposed in this area (Feature 7). The results of testing in TU C and the adjoining block of CAR's units are discussed in this chapter under the Block Excavation section.

CAR's investigations in the periphery targeted possible features and dense artifact bearing deposits. This included Feature 6 (TU 10) identified in the GT southeast of the midden deposit, Feature 4 exposed in the east wall of BHT G (TU 4), and a dense concentration of lithics located downslope of the midden in BHT X (TU 11). The following discusses the features and dense artifact area documented in the periphery by CAR.

\section{Feature 4}

Feature 4 was first identified in the east wall and south end of Trench $\mathrm{G}$. In profile the feature appeared as a layer of burned rock in a shallow basin approximately
$190 \mathrm{~cm}$ in length, $25 \mathrm{~cm}$ thick, and $15 \mathrm{~cm}$ below surface (Figure 6-31). The basin shape of the feature and the larger rocks $(10-20 \mathrm{~cm})$ that made up the feature stood in contrast to the smaller $(3-8 \mathrm{~cm})$ rocks that were in the east wall profile. Feature 4 was also observed in the west wall profile of the same trench. The portion of the feature in the west wall structurally resembled the east wall profile.

Level 1 of Feature 4 exposed road construction fill at approximately $10 \mathrm{~cm}$ bs. In profile, the fill continued another $2.2 \mathrm{~m}$ south of TU 4 . Level $2(10-20 \mathrm{~cm} \mathrm{bs})$ contained about 20 large burned rocks averaging 8$10 \mathrm{~cm}$ in length. Most of the burned rock was concentrated in the north and south ends of the unit. Fine specks of charcoal were noted throughout this level.

In Level $3(20-30 \mathrm{~cm}$ bs) larger concentrations of burned rock were uncovered, though still above the feature as it was defined in profile. Approximately 17 of 53 ( 32 percent) exposed burned rocks were over 10 $\mathrm{cm}$ in length. Four of the largest burned rocks (ca. 15 $\mathrm{cm}$ ) were tilted in a manner that suggested a feature boundary to the east and west. Artifacts from this level
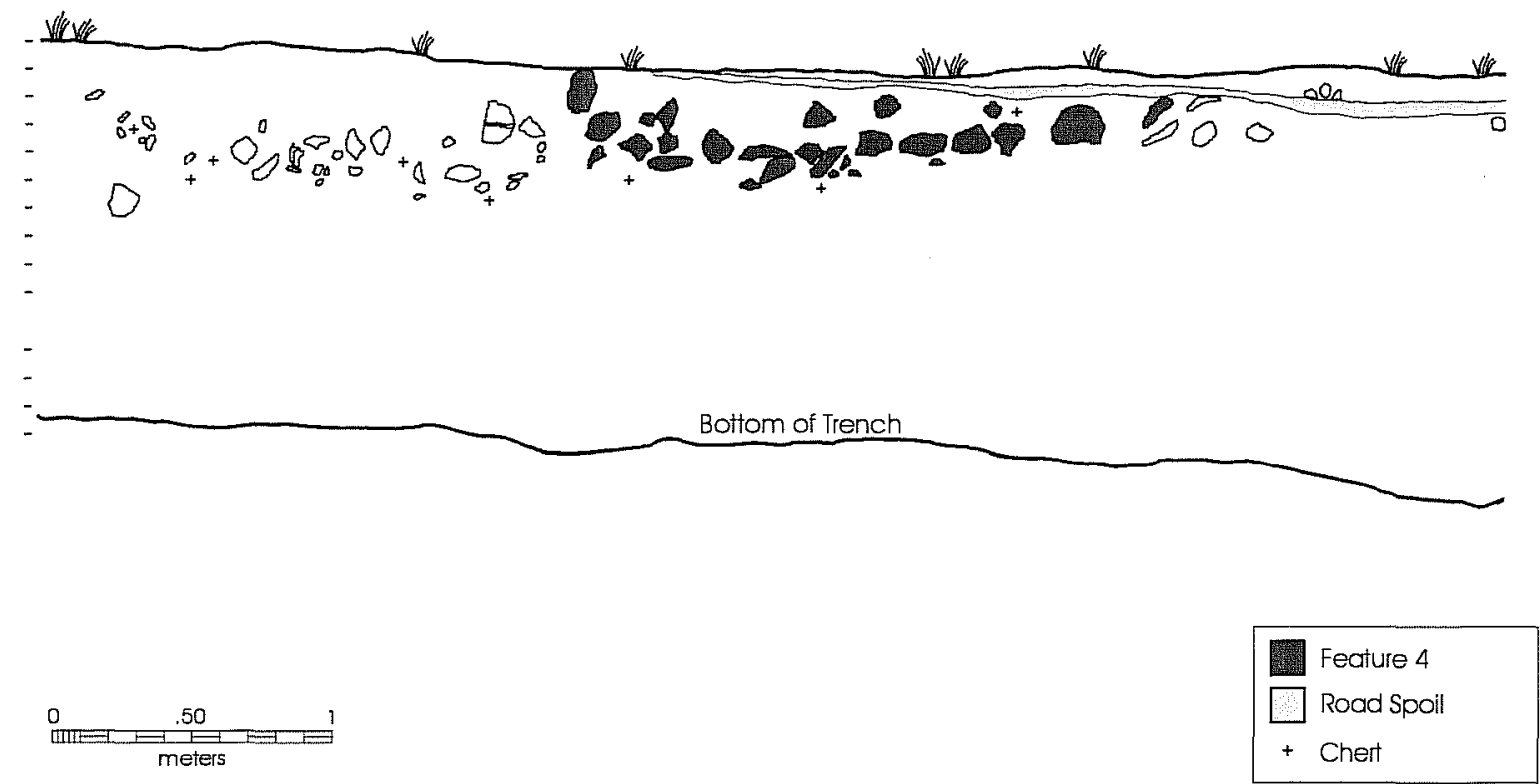

Figure 6-31. Feature 4 as exposed in the east wall profile of BHT G. 
included one core from the north end of the unit and an unusual incised stone excavated from the west side of the unit.

Suggested as the feature surface, Level $4(30-40 \mathrm{~cm}$ bs) contained the highest concentration of burned rock (Figure 6-32). The feature became better defined as a dense layer of large and small pieces of burned limestone. Level 4 was excavated in $5-\mathrm{cm}$ increments to control for any variations in feature morphology. Much like the previous level, the top five centimeters of Level 4 contained a high density of large, flat pieces of burned rock. Twenty-one of 70 (30 percent) burned rocks in this upper level were over $10 \mathrm{~cm}$ in length. Seven archaeomagnetic samples were drilled from the burned rocks in the upper five centimeters of Level 4.
The density of rock in the feature appeared to drop in the northeast, with the greatest amount of large rock located in the west-central portion of the unit. As evidenced in the profile, the concentration suggests that BHT G had clipped the western edge of the feature. The bottom five centimeters of Level 4 also had a high concentration of burned rock in the west half of the unit. The burned rock from this area of the level averaged about eight centimeters in length. A total of 57 burned rocks were visible at the bottom of Level 4 ( $40 \mathrm{~cm} \mathrm{bs).} \mathrm{Two} \mathrm{charcoal} \mathrm{samples} \mathrm{were} \mathrm{collected} \mathrm{from}$ separate concentrations of burned rock in the north and south end of the western half of the unit. Large flakes were found above the charcoal sample taken from the south end of the unit. Although the charcoal and archaeomagnetic samples from this unit were not submitted for analysis, Phil Dering (Chapter 9) examined the macrobotanical remains and found no identifiable structure in the six, very small $(<1 \mathrm{~mm})$ charcoal fragments recovered.

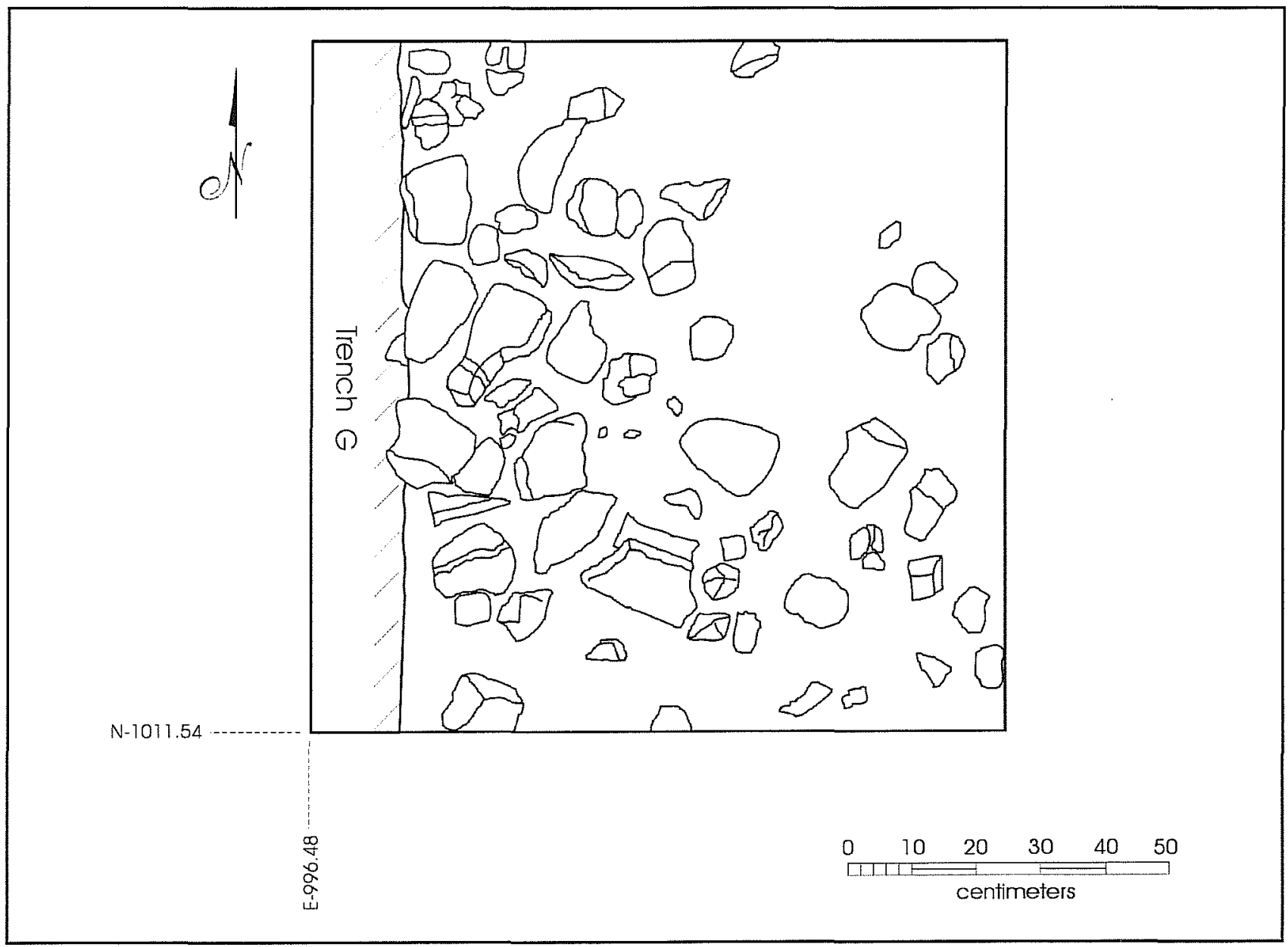

Figure 6-32. Plan view of Feature 4, Level 4, TU 4. 
Feature 4 terminated in the lower half of Level 4 . Levels 5-9 were excavated after burned rock was pulled from the bottom of Level 4 at $40 \mathrm{~cm}$ bs. Level 5 was excavated to $50 \mathrm{~cm}$ bs. Small gravels replaced the burned rock found in the previous levels. Two small animal bone fragments were recovered from Level 5 (Chapter 10). Level 6 was excavated to $60 \mathrm{~cm}$ bs. A Late Archaic Darl point was located in the northwest side of this unit at $53 \mathrm{~cm}$ bs. Small amounts of flakes and burned rock were recovered from Levels 6-9. Excavation stopped at $90 \mathrm{~cm}$ bs. Feature 4 is interpreted as a slab-lined cooking oven that was spatially separate from the main midden (Feature 1).

\section{Feature 6}

Feature 6 is located south of BHT M and was first exposed in a Gradall scrape (see Figure 6-14). The Gradall scrape was excavated to a depth of $35 \mathrm{~cm}$ bs. The scrape exposed a continuous, but sparse, scatter of burned rock and artifacts extending from the southeastern edge of the midden. The densest concentration of burned rock in this area was designated Feature 6 and tested with TU 10.

Excavation of Level 1 began in the bottom of the Gradall scrape at approximately $35 \mathrm{~cm}$ below original ground surface (bgs). In this level, burned rock that had originally defined the feature was completely exposed. Approximately 18 of 39 (46 percent) burned rocks were $10-12 \mathrm{~cm}$ in length. Although a tree root was observed, much of the feature appeared to be in situ. Twelve burned rocks $(8-10 \mathrm{~cm}$ in length) formed a semicircular alignment extending approximately 80 $\mathrm{cm}$ in diameter from the northeast to the west side of the unit (Figure 6-33). One medial section of a biface was located in the southwest corner of the unit at 44.5 $\mathrm{cm}$ bs. Burned rock that had been pedestaled was removed before Level 2 was excavated. No archaeomagnetic samples were collected from this unit.

In Level 2 (45-55 cm bgs) a small circle of stones (approximately $30 \mathrm{~cm}$ in diameter), was observed in the southwest end of the unit. The six burned rocks in this circle ranged from $8-10 \mathrm{~cm}$ in size. Three large flakes were found on the periphery of this burned rock alignment.

No burned rock was recovered from Level 3 (55-65 $\mathrm{cm}$ bgs). Artifacts recovered from this level include an untyped projectile point and a piece of hematite. Both were excavated from the center of the unit. The soil in this level abruptly changed from soft to hardpacked soil. Excavations halted in the next level (4) at a depth of $75 \mathrm{~cm}$ bgs. No burned rock or artifacts were recovered from this level. TU 10 was later removed by the excavation of BHT AA.

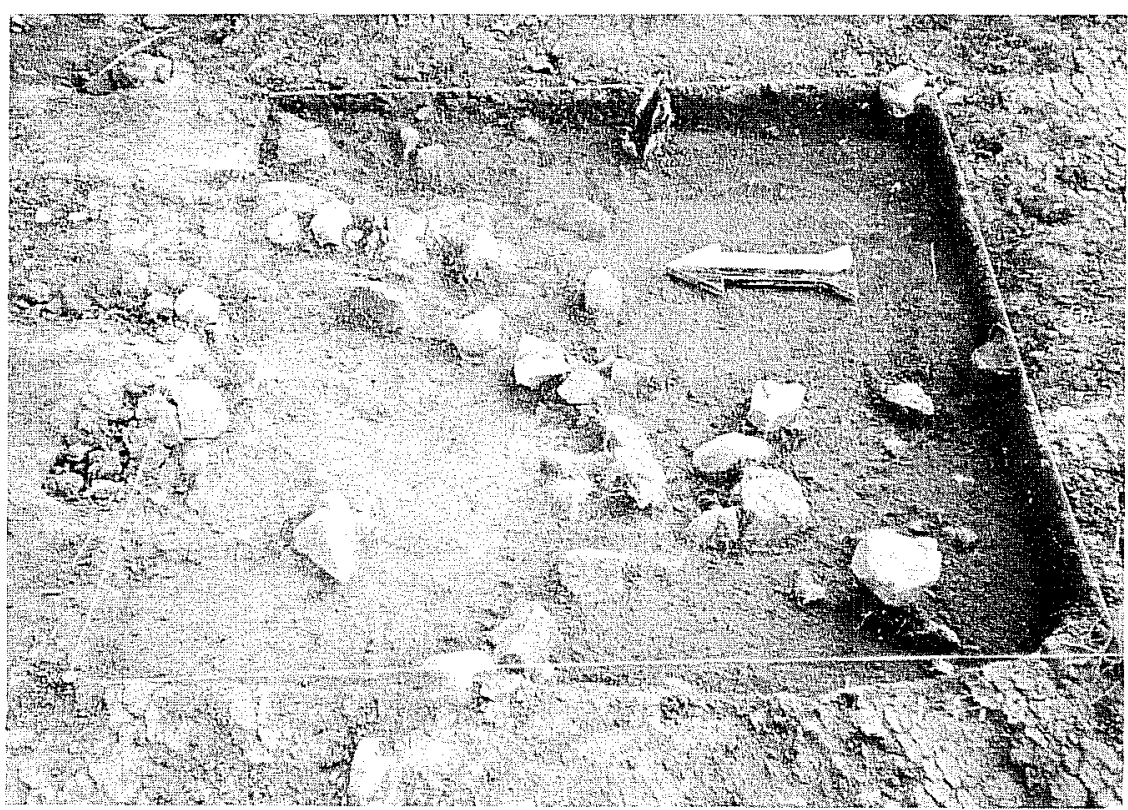

Figure 6-33. Photograph of Feature 6, TU 10, Level 1.
Feature 6 may have had additional burned rock removed during Gradall trenching. Due to this prior removal of $35 \mathrm{~cm}$, the interpretation of this feature is limited. This feature appears to be different from Feature 4 discussed above. Feature 6 may represent a scatter of burned rock simply pitched out of a nearby cooking feature, a small hearth.

\section{Non-feature TUs}

Non-feature units were excavated throughout the periphery by both 
TxDOT investigators and CAR. As mentioned, Wood placed a number of units around the midden in an attempt to define its limits and Price excavated units to test the deposits associated with the midden. CAR excavated TU 11 southwest of the midden to gather information on material that might be washing off the midden and being deposited downslope.

The units excavated by Wood (TUs 17, 20, 21, 22, 24, 25 , and 26) all produced chipped stone and burned rock (Appendix E), but no features were designated. Price's TU A was placed immediately south of the midden where the framework pinched-off into a thinner layer of stone, and it produced a large number of chipped stone artifacts and a possible feature (Figure 6-34). Unlike CAR's excavation of TU 10 which began in the bottom of a Gradall scrape $35 \mathrm{~cm}$ below the modern surface (encountering Feature 6 in the first level, $35 \mathrm{~cm}$ below modern surface), Price began excavating from the surface, and encountered a layer of burned rock in the bottom of Level $4(30-40 \mathrm{~cm} \mathrm{bs})$ in his TU A. It is difficult to discern from the notes and photographs if the burned rock in TU A actually represents a feature (e.g., some sort of heating element or hearth pit), or a scatter of burned rock associated with the midden or off midden activities. Further excavation of the unit by Price revealed a $20-25-\mathrm{cm}-$ thick layer of matrix-supported burned rock. Due to its close proximity to the midden framework, it is suggested that the material located downslope of the framework area is a mixture of materials that washed off the midden, as well as off midden materials that have been disturbed by activities such as feature building (see Chapter 7).

Price's TU B, located approximately $12 \mathrm{~m}$ east of the midden framework along the northern edge of BHT N, was excavated to investigate the eastern extent of cultural deposits in this area of the site. Of special interest was the possibility of cultural material located between the midden and the burned rocks exposed in a looter's hole (see Area A discussion above) located east/southeast of TU B. Results from this unit revealed no definitive features and demonstrated that the density of cultural material drops as you move away from the midden.

The only non-feature unit excavated in the periphery by CAR (except for the block excavation discussed below) was TU 11. This unit is located south/southwest of the midden and was observed in the east wall of BHT $\mathrm{X}$. Here, the midden scatter or smear pinches into a thin layer of burned rock and artifacts, which extends south along the profile in BHT X, approximately 35 $\mathrm{cm}$ bs (Figure 6-35 and 6-36). As argued in Chapter 7, this downslope area should contain materials generated from activities taking place within and around the midden, as well as materials that washed off the midden deposit during its use. Also of interest was the apparent dip in the burned rock at this location in BHT X. That is, the bottom of the burned rock scatter took a slight dip into the underlying Depositional Unit III, indicating the surface on which the burned rock was deposited was undulating. As argued above, these undulating surfaces are probably anthropogenic and may represent areas where sediment was borrowed for use in the construction of earth ovens in the midden (see Chapters 7 and 8). Also of interest, the thin layer of burned rock

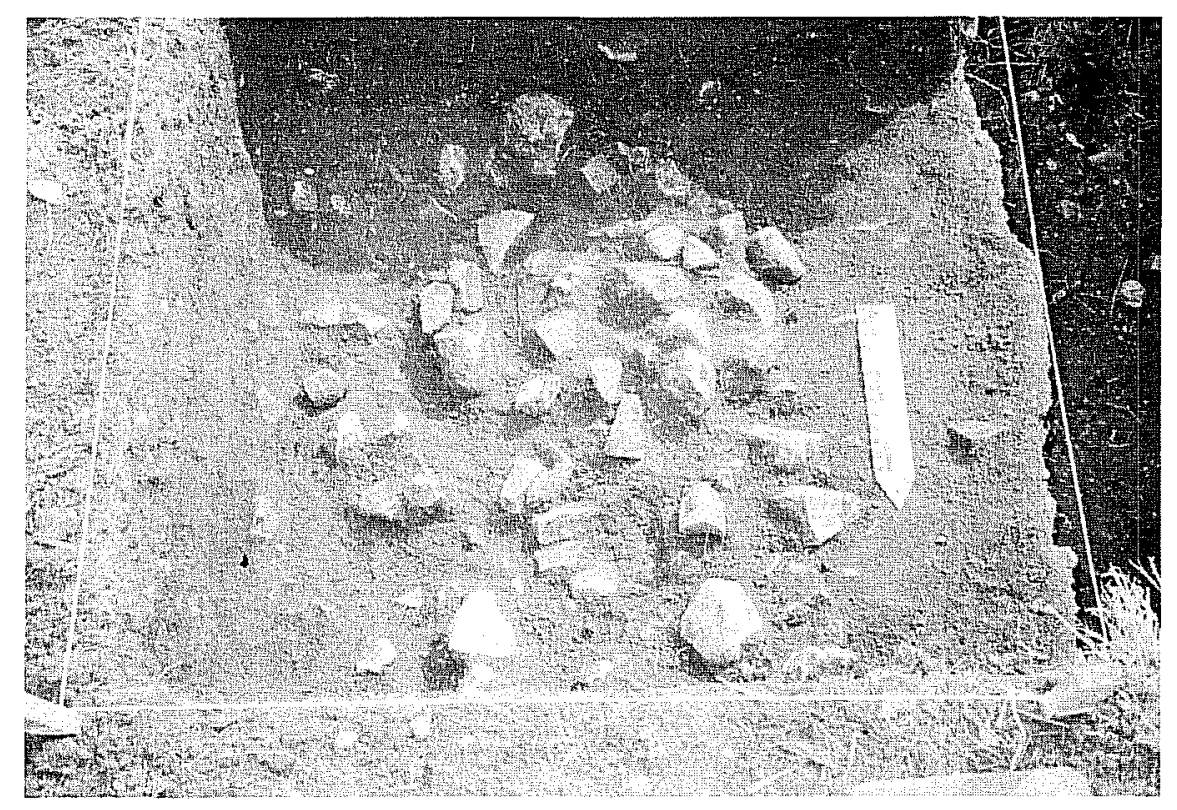

Figure 6-34. Photograph of the burned rock uncovered in the bottom of Level 4 (40 cm below surface), TUA (photograph taken by Dennis Price, 1995). 


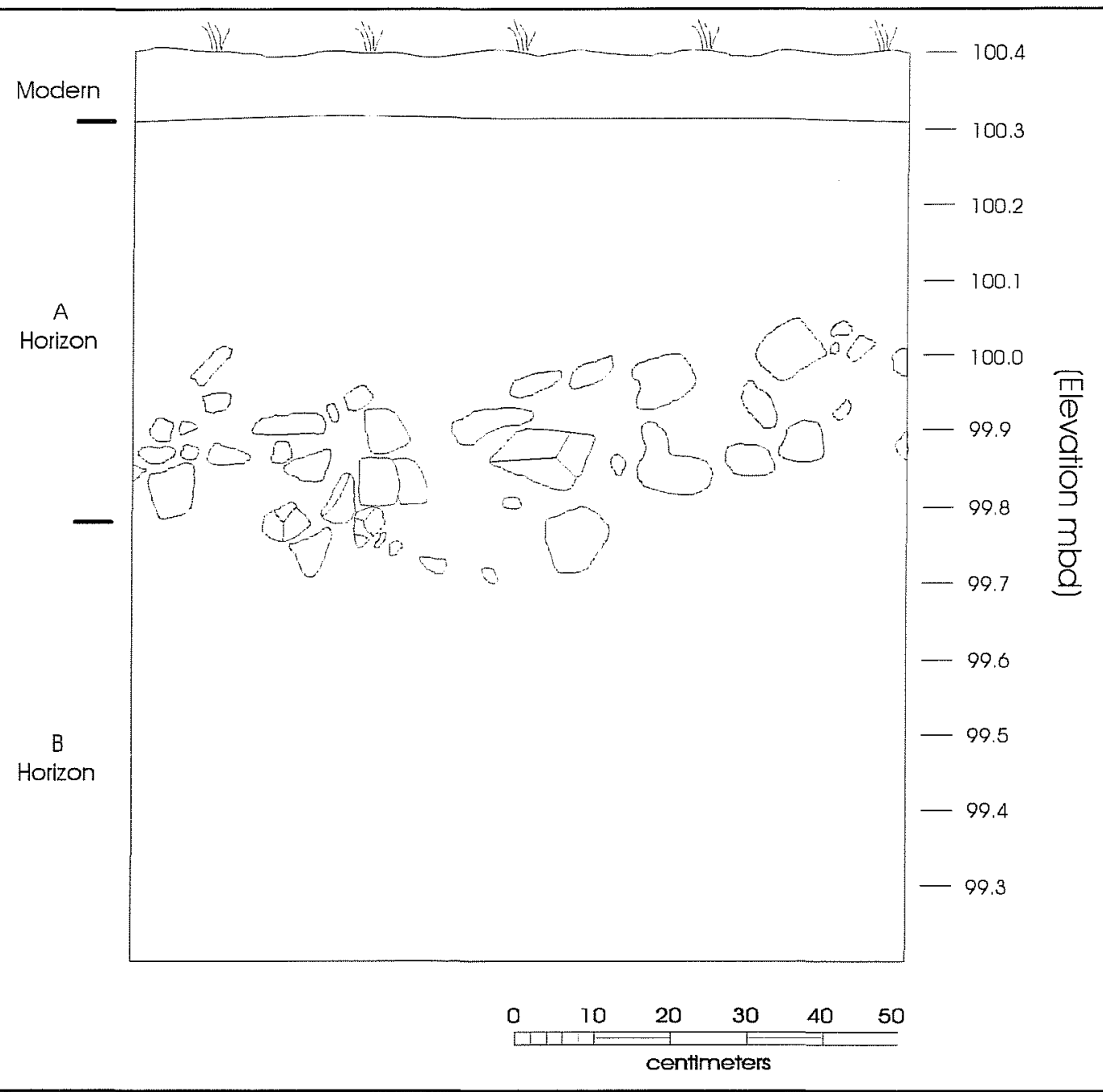

Figure 6-35. Thin layer of burned rock in east wall of BHT X. TU 11 was placed here (see Figure 6-14).

in BHT X is sitting on a buried surface that is truncated by erosion. This erosion forms the slope between $\mathrm{T} 2$ and $\mathrm{T} 1$ (see Chapter 5).

TU 11 was excavated from the modern surface through the burned rock and into the underlying Depositional Unit III (note that the upper $25 \mathrm{~cm}$ of the unit were not screened). The scatter of burned rock visible in trench profiles was encountered at approximately 30 $40 \mathrm{~cm}$ below the surface in Level 4 . The amount of faunal material recovered increased only slightly from $2.37 \mathrm{~g}$ in Level 1 to $4.38 \mathrm{~g}$ in Level 2, $6.56 \mathrm{~g}$ in Level 3 , and then dramatically to $31.4 \mathrm{~g}$ in Level 4 . The amount of faunal material then decreased to $21.97 \mathrm{~g}$ in Level 5. Burned rock was recovered from all levels to a depth of approximately $50-60 \mathrm{~cm}$ bs. At this point (into Depositional Unit III), the amount of burned rock and chipped stone decreased dramatically from the upper levels, and the amount of faunal material decreased to $4.71 \mathrm{~g}$.

In the last level of this unit (60-70 cm bs: Level 7), a possible pit comprised of a brown, gray clay and burned rock, was noted along the southern edge of the unit (Figure 6-37). The remainder of Level 7 was comprised of a reddish orange soil that Nordt (Chapter 5) has identified as Depositional Unit III. The excavators noted that burned rock from the overlying Level 6 extended down into the pit, suggesting that the burned rock in the pit was associated with the burned rock in Level 6. Notably, the amount of faunal material in Level 7 increased to $28.94 \mathrm{~g}$. The distinction between the darker Stratigraphic Unit IV fill and the reddish Stratigraphic Unit IV soil defined 


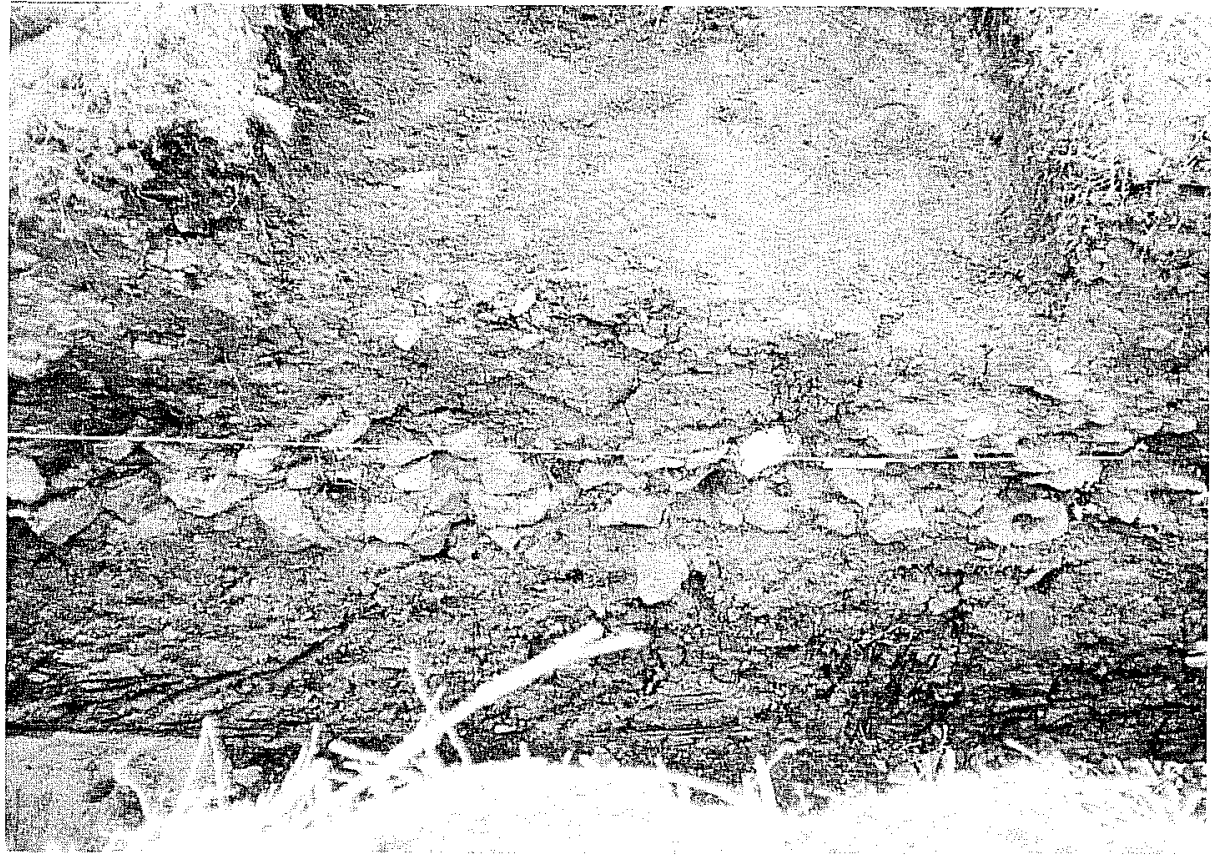

Figure 6-36. Photograph of BHT X and TU 11, Level 1, showing layer of burned rock in trench profile.

the outline of the pit. Although a layer of burned rocks was visible in the west wall of BHT X (Figure 6-35), the pit was not discernible (note the pit was not assigned a number). The portion of the exposed pit suggests that the feature is not a natural phenomenon, and may be another example of sediment borrowing.

\section{Backhoe Trench CC}

Backhoe Trench CC (Figure 6-14) was placed in the midden's periphery on the last day of the field work to investigate the possibility of a second large midden or smaller burned rock features northeast of the main midden (Feature 1). Although the consulting geomorphologist was not available to describe the trench profile, the project archaeologist examined the 5-ft-deep trench walls and observed only ephemeral traces of burned rock and a few flakes, with no horizontal or vertical patterning.

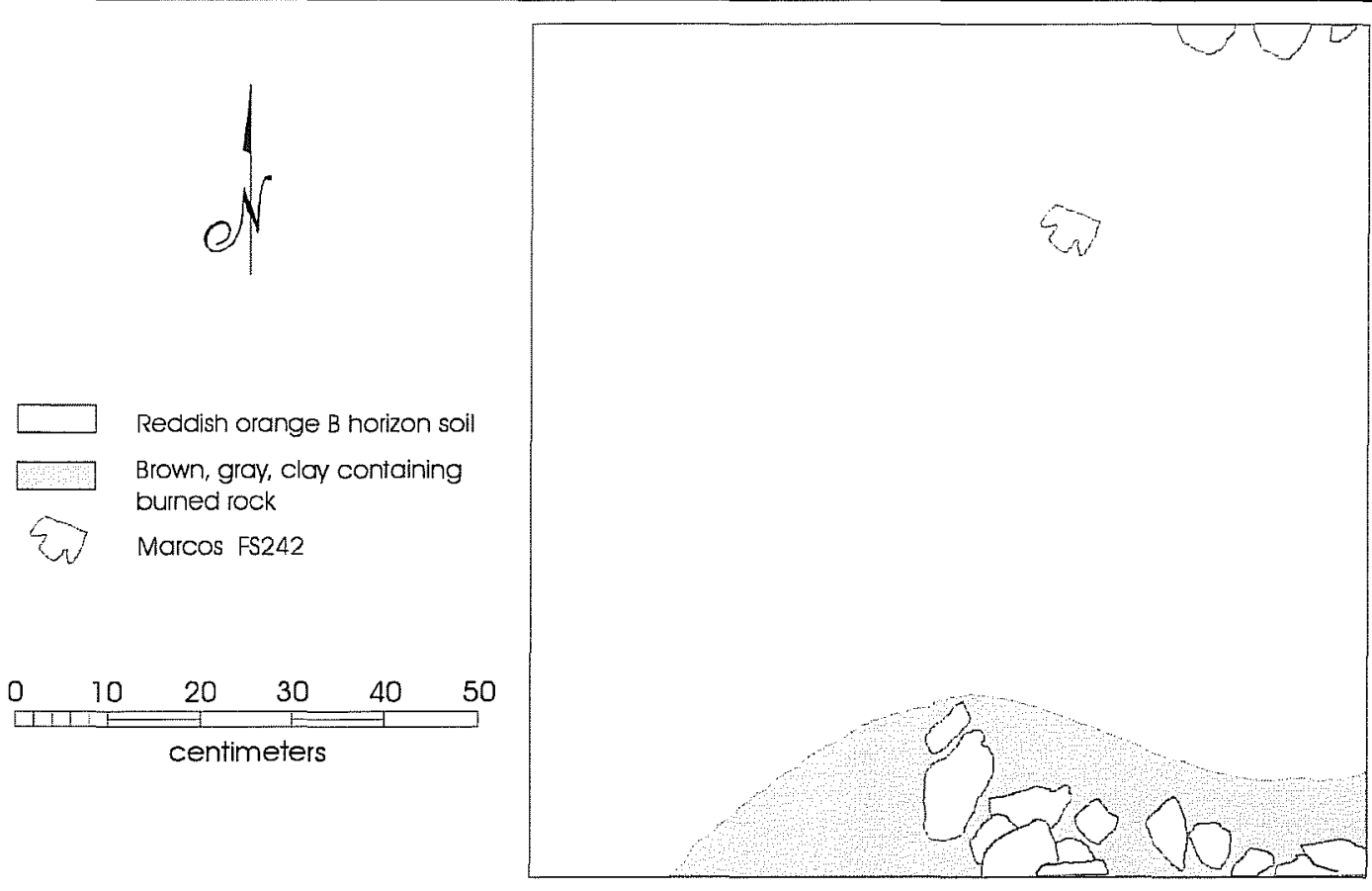

Figure 6-37. Plan view of Level 7, TU 11. Note possible pit on southern edge of unit. 


\section{Block Excavation}

This section summarizes excavation of a block of 12 units placed in the midden periphery, ca. two meters east of the framework (Figure 6-14) and extending below the level of the base of the midden. Price's decision to place the initial test unit at this location stemmed from the exposure of a horizontal concentration of rounded cobbles $60-80 \mathrm{~cm}$ bs in the north wall profile of BHT M. There was no sign of this cobble layer in the opposite (south) wall of the trench. The cobbles, as large as $10 \mathrm{~cm}$ in diameter, were located about four meters east of the midden framework and they collectively exhibited the shape of a broad, shallow basin more than a meter across. Excavation of TU $\mathrm{C}$ at this point confirmed the presence of an apparently intact burned rock feature (subsequently labeled Feature 7 by CAR) in association with artifacts such as debitage and a unifacial Clear Fork tool (Price 1995). Early during investigations by CAR, a single unit (TU 12) was placed west of and adjacent to TU $\mathrm{C}$ to locate the continuation of this burned cobble feature. This resulted in the exposure of the western edge of the feature and the recovery of two projectile points identified as Nolan and Nolan-like.
During the CAR excavations, several of the burned rocks uncovered in Unit 12 were sampled for archaeomagnetic analysis, charcoal samples were collected, and large float samples were taken from the feature and surrounding area. In combination with the tools recovered by TxDOT, this lower component had a fairly large tool to debitage ratio when compared to the overlying midden deposits. At the western end of Trench $M$ the CAR excavations recovered a La Jita projectile point from the backdirt spoil, but adhering sediment indicated that the point came from Stratigraphic Unit III sediment. Based on the evidence from Trench M, Unit C, and Unit 12 (Table 6-12), there appeared to be a stratigraphically well-defined Nolan component with the potential for radiocarbon dating.

At Culebra Creek (41BX126) the underlying Middle Archaic component is stratigraphically distinguishable from the midden deposit and contains burned rock features, debitage, tools, diagnostic projectile points, and botanical remains. To get a larger sample of the Middle Archaic material, CAR expanded the excavation area around Feature 7 identified in Units $\mathrm{C}$ and 12. This included excavation of ten $1-\mathrm{x}-1-\mathrm{m}$ units. As the focus of these investigations was the

Table 6-12. Comparison of Artifact Counts and Stratigraphic Levels of Unit 12 and Unit C

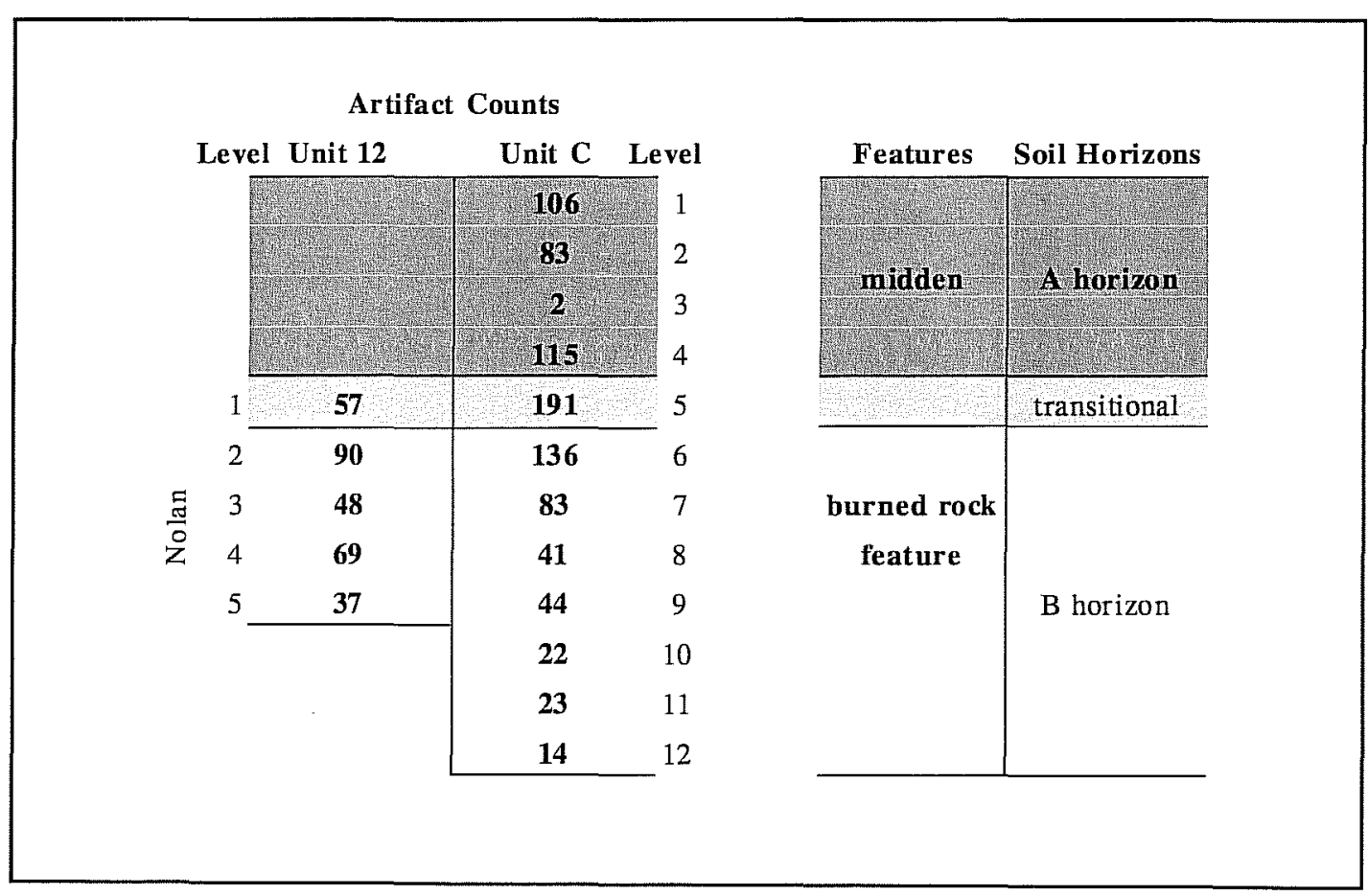


underlying material, the overburden was mechanically removed to about $10 \mathrm{~cm}$ above the deposit. The area sampled was not immediately below or downslope from the burned rock midden, thus lessening the chance of contamination with more recent components.

Following the fieldwork, an analysis of complete flakes recovered from the block excavations was conducted. Mean flake length was used to indicate the stratigraphic differences in artifact size sorting. Vierra (1997) examined the vertical movement of artifacts through soil horizons and successfully correlated the data with occupation levels. The data from the block excavation at Culebra appears to provide evidence of lithic reduction occurring in the upper levels, downward movement of smaller debitage through Stratigraphic Unit IV, and then a second episode (occupation) of lithic reduction occurring in the lower levels. Such activities (occupations) should appear as a bimodal distribution when graphed by level. Figures 6-38 and 6-39 illustrate the mean flake length distribution for the block excavations. Based on the bimodal distributions, the levels in Table 6-13 apparently constitute a second occupation.

Next, a stratigraphic profile of the north wall of the block excavations was overlain with a three-dimensional schematic showing diagnostic projectile point and radiocarbon date proveniences (Figure 6-40). The schematic was used as supporting evidence that the Nolan component was a distinct component stratigraphically below the main midden.

\section{Nolan Component Features}

The stratigraphic position of Feature 7 slightly below the level of the midden framework (which in Trench $M$ stops $5.4 \mathrm{~m}$ east of Trench $\mathrm{G}$ about $50 \mathrm{~cm} \mathrm{bs)}$ together with the presence of Nolan points and an associated Clear Fork tool, suggested the possibility of a discrete Middle Archaic occupation (ca. 4500-4000 в.P.), more deeply buried and predating the formation of the burned rock midden. This established the need for further testing to ascertain the nature and extent of that occupation. TUs 14-23, adjoining TUs $C$ and 12 , were subsequently opened to meet this objective, re- sulting in the identification of two more burned rock features (Features 11 and 12, see below) in the same stratum as Feature 7. This lower component appears to lie principally within a Bk Horizon $10-15 \mathrm{~cm}$ below the boundary of Stratigraphic Unit IV, the A Horizon, that slopes slightly to the southeast. In Trench G, west of the block excavation, Bkb1 lies $57-92 \mathrm{~cm}$ bs (Nordt, Chapter 5).

As sufficient data was recovered from the upper levels of the midden periphery, the top $45 \mathrm{~cm}$ of overburden was removed manually over TU 12 and with a Gradall over TUs 14-23 in order to expose the Nolan component. To permit the recognition and study of medium scale features comparable to Feature 7 in TUs $\mathrm{C}$ and 12 , ten surrounding units were excavated as one block and all levels were taken down simultaneously. Excavation of units 14-23 began on the Gradall scraped surface $(45 \mathrm{~cm} \mathrm{bgs})$ and commenced in arbitrary $10-\mathrm{cm}$ levels, but changed to

Table 6-13. Stratigraphically Lower Levels of Occupation

Based on Bimodal Distribution of Mean Flake Length in the Block Excavation

\begin{tabular}{|c|c|c|}
\hline Unit & Level & Depth bs (cm) \\
\hline$C$ & 7,8 & $70-80$ \\
\hline 12 & 3,4 & $65-85$ \\
\hline 14 & $3 \mathrm{~L}, 4 \mathrm{U}, 4 \mathrm{~L}$ & $70-85$ \\
\hline 15 & $3 \mathrm{~L}, 4 \mathrm{U}, 4 \mathrm{~L}$ & $70-85$ \\
\hline 16 & $3,4 \mathrm{U}, 4 \mathrm{~L}$ & $65-85$ \\
\hline 17 & $3 \mathrm{~L}, 4 \mathrm{U}, 4 \mathrm{~L}$ & $70-85$ \\
\hline 18 & $4 \mathrm{U}, 4 \mathrm{~L}$ & $75-85$ \\
\hline 19 & $3 \mathrm{~L}, 4 \mathrm{U}, 4 \mathrm{~L}$ & $70-85$ \\
\hline 20 & $3 \mathrm{~L}, 4 \mathrm{U}, 4 \mathrm{~L}$ & $70-85$ \\
\hline 21 & $3 \mathrm{U}, 3 \mathrm{~L}, 4 \mathrm{U}$ & $65-80$ \\
\hline 22 & $3 \mathrm{~L}, 4 \mathrm{U}$ & $70-80$ \\
\hline 23 & $3 \mathrm{~L}, 4 \mathrm{U}$ & $70-80$ \\
\hline
\end{tabular}

Note: $3 U=$ upper $5 \mathrm{~cm}$ of Level 3; $3 \mathrm{~L}=$ lower $5 \mathrm{~cm}$ of Level 3 


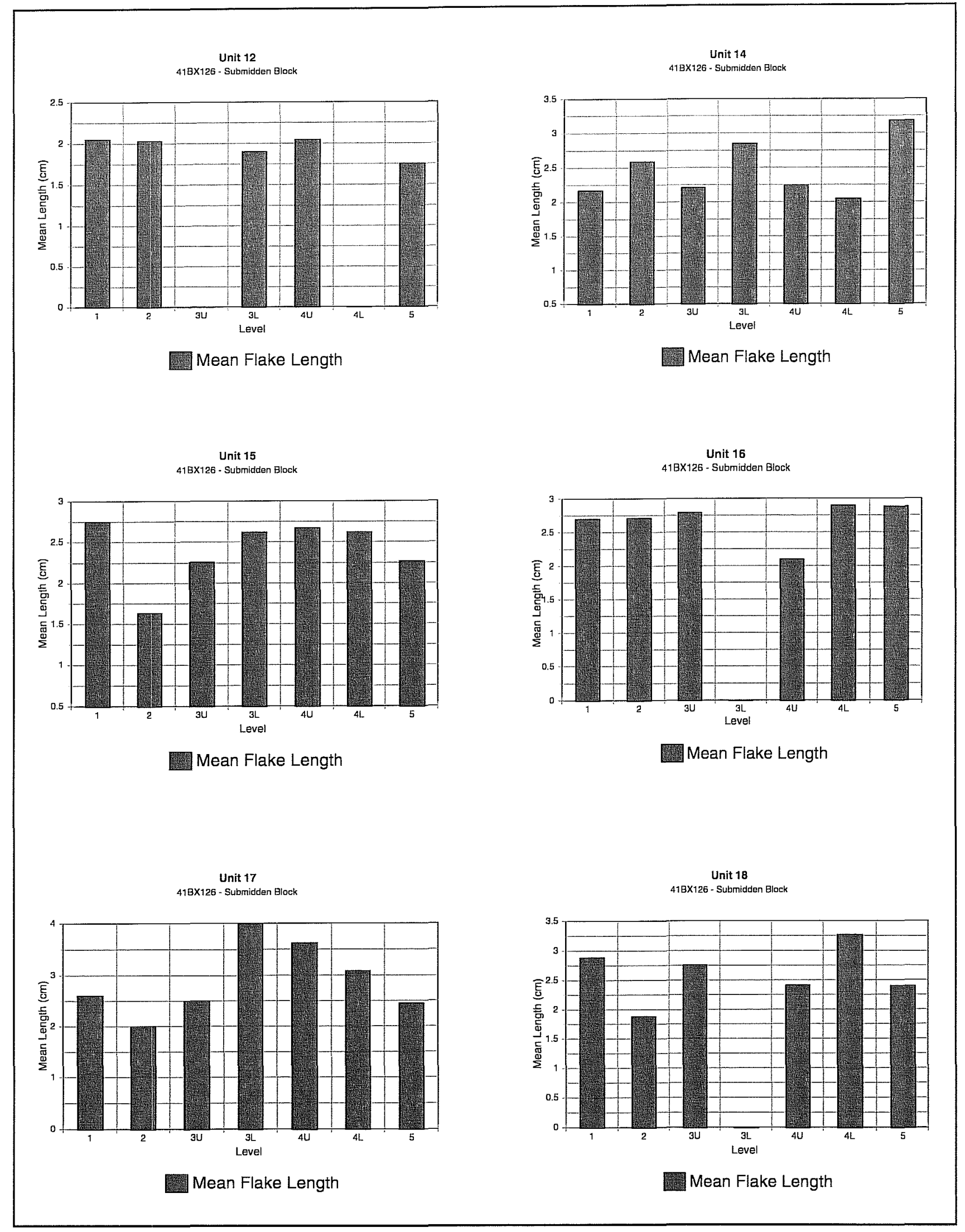

Figure 6-38. Mean flake length for $T U$ s 12, and 14-18 in the block excavation. 


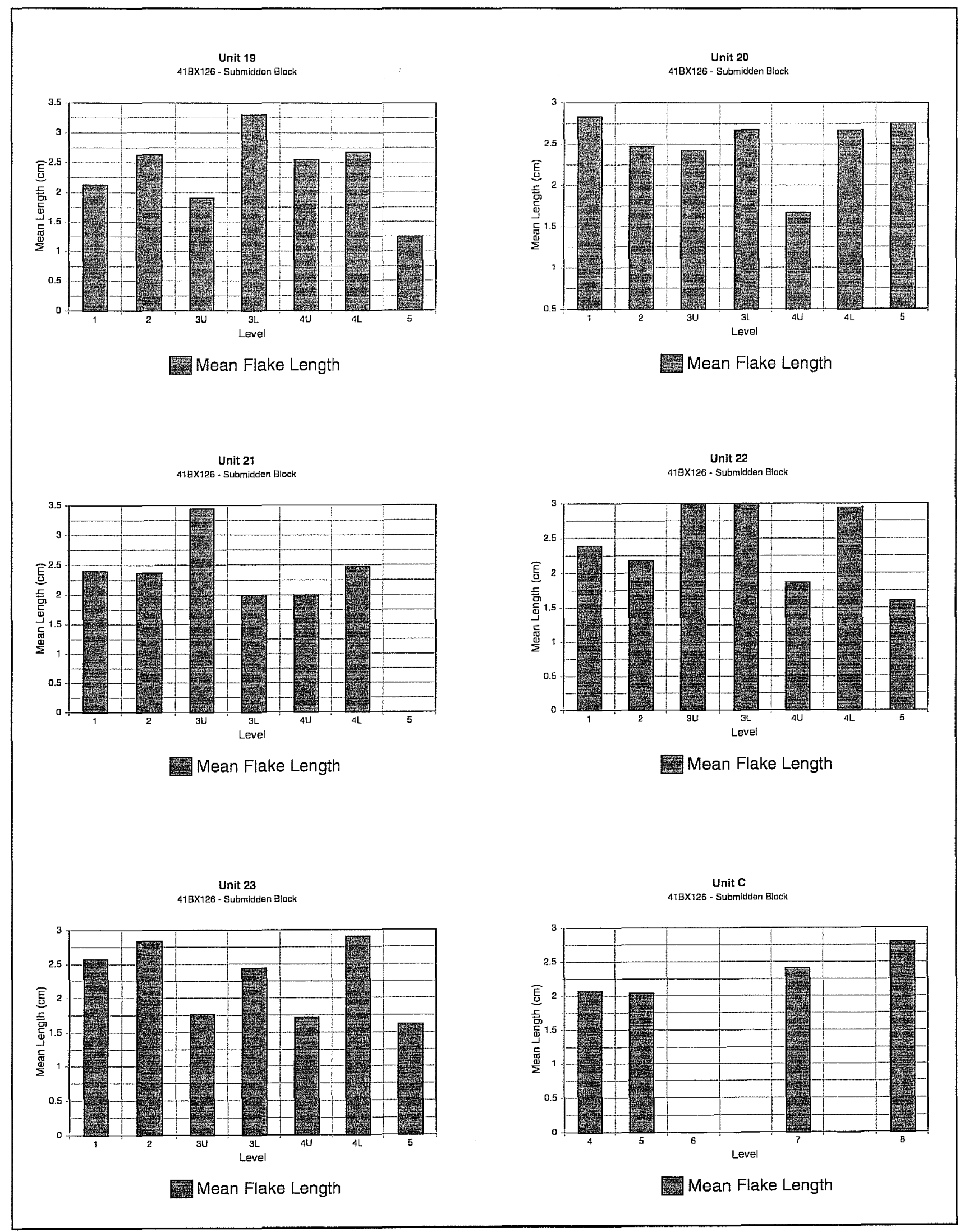

Figure 6-39. Mean flake length for TUs 19-23 and TUC in the block excavation. 

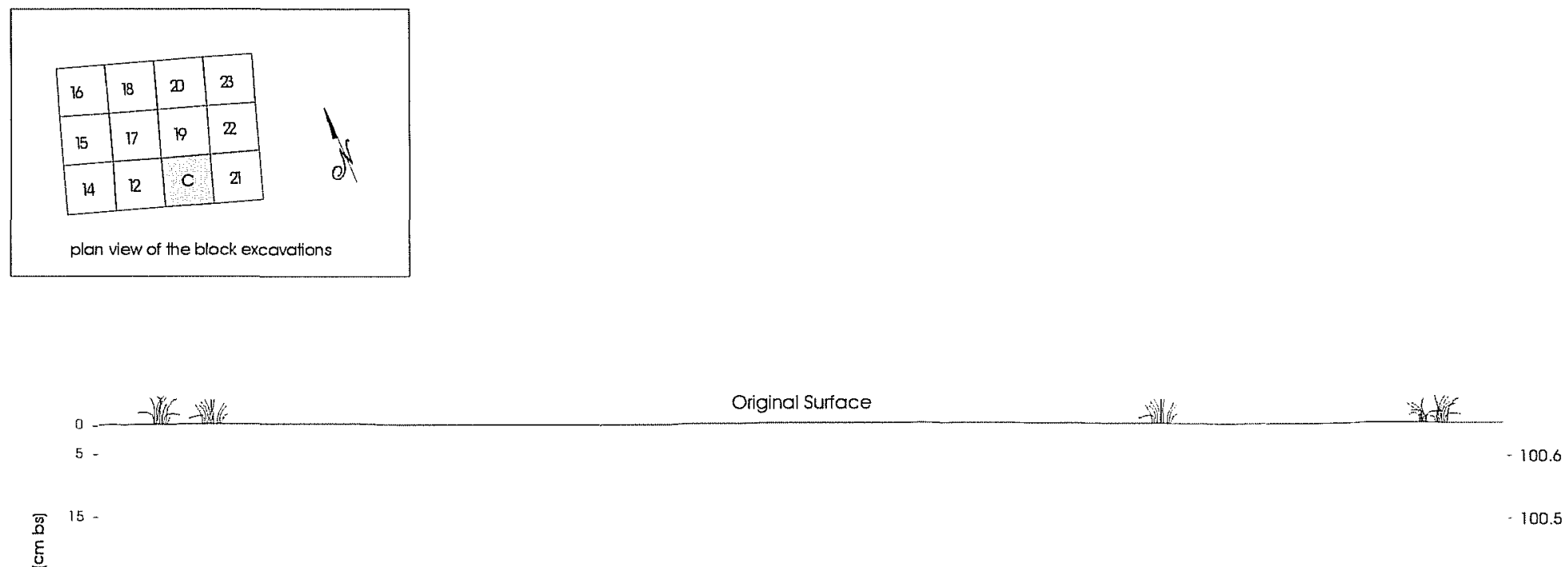

Surface After Scraping

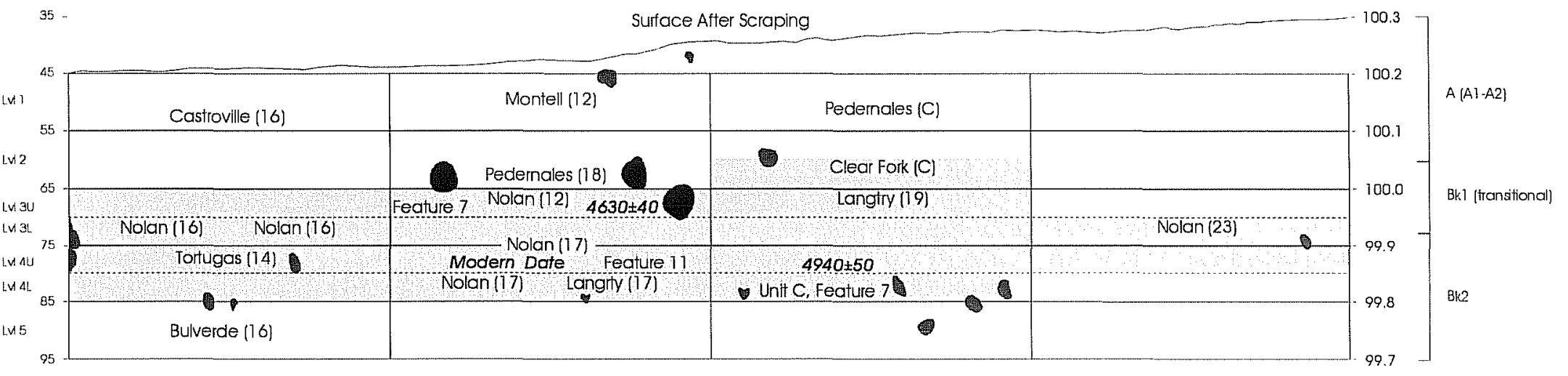

(23) unit number

- rodent burrow

- limestone rock

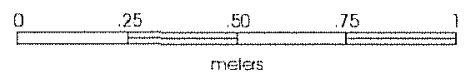

Note: vertical scale has been exaggerated

Figure 6-40. Block excavation, schematic showing diagnostic artifacts, features, and radiocarbon dates. Shading represents the Nolan component. 
5-cm levels at $70 \mathrm{~cm}$ bgs in most units (about $5 \mathrm{~cm}$ above Stratigraphic Unit III), to facilitate the identification of a possible Nolan component at the same level as Feature 7. Using these tactics, Features 11 and 12 were exposed intact. Thirty-nine of the burned rocks from those features were sampled for archaeomagnetic analysis, as were four burned rocks from Feature 7 (TU 12); however, none of those analyses has been conducted. Float samples were collected from Features 11, 12, and the surrounding areas. Samples from the block excavation units were not submitted for archaeobotanical testing. Three radiocarbon assays were obtained from wood charcoal.

\section{Feature 7}

As noted above, a layer of rounded cobbles was documented in the northern profile of Trench $M$, differing in appearance and composition from the darker, more compact midden deposit that tapered out just west and $10-15 \mathrm{~cm}$ above the major part of the cobble layer. The largest of these cobbles were concentrated in the one-meter section of the profile subsequently excavated as TU C (Figure 6-41). The same layer of cobbles appeared to extend to the west in the profile in a twometer section later excavated as TUs 12 and 14 .

Although none of the burned cobbles excavated in TU C from $50-80 \mathrm{~cm}$ bgs was subjected to archaeomagnetic analysis, detailed notes were taken on each in terms of disposition, color change, and development of a "rind" due to thermal alteration. The level from $50-60 \mathrm{~cm}$ bgs contained 39 cobbles and fire-cracked rock ranging from about $5-22 \mathrm{~cm}$ in diameter, of which 15 were examined in detail. Six of these were noted to have been thermally cracked in situ, and most showed pronounced thermal alteration at least on the top side, all indicating that the rock accumulation was relatively undisturbed. The next level, from $60-70 \mathrm{~cm}$ bgs, contained a Clear Fork uniface and 42 cobbles exhibiting varying degrees of thermal alteration, 10 of which were noted to have been cracked in situ. Distribution of the cobbles, especially in the $60-70 \mathrm{~cm}$ level, indicated that the suspected feature might extend to the west past the limits of TU C. This evidence formed the basis for placement of TU 12 .
After the top $45 \mathrm{~cm}$ of overburden were removed, excavation of TU 12 began, and located the apparent western edge of the cobble concentration, now designated Feature 7 , between 60 and $75 \mathrm{~cm}$ bgs (bottom half of Level 2 to the base of Level 3). The precise correlation of excavation levels documented in TUs $\mathrm{C}$ and 12 is less clear. Since $45 \mathrm{~cm}$ of overburden had been manually removed from TU 12 before excavation was resumed by CAR, it is difficult to relate the excavation records; nevertheless, judging from profiles, plan views and excavators' field notes, site elevations 100.05 and 99.9 in TU 12 appear approximately equivalent to $60-75 \mathrm{~cm}$ bgs as established in TU C, that is, Level 6 and the upper half of Level 7.

In TU C, the top of the cobble layer was exposed about $50 \mathrm{~cm}$ bgs and extended as deep as $80 \mathrm{~cm}$ bgs (Figure 6-42). In TU 12, the tops of larger cobbles and firecracked rocks were exposed in the lower half of Level 2 (60-65 cm bgs) and extended to the bottom of Level 3 (75 cm bgs) (Figure 6-43). The concentration of cobbles and fire-cracked rock in the eastern part of TU 12, though not as dense as in TU C, indicates as expected from examination of the north wall in Trench $M$ that the feature in TU 12 is the western edge of a circular hearth feature in a shallow basin that was deeper and centered in the western part of TU C and more than a meter in diameter. Bottom elevations for the larger cobbles and fragments $(>16 \mathrm{~cm})$ exposed in the $50-70 \mathrm{~cm}$ levels of TU $C$ ranged from $61-76 \mathrm{~cm}$ bgs in TU 12. Below that, only small burned rock fragments were encountered.

A Montell point proximal fragment was recovered at $51 \mathrm{~cm}$ bgs, above the feature in TU 12 and a Pedernales point was recovered above the feature in TU C. Both types are considered diagnostic of the Late Archaic. A unifacial Clear Fork tool, representative of the Early to Middle Archaic, was recovered in TU C at $62 \mathrm{~cm}$ bgs, under one of the hearth rocks. A thermally damaged Nolan dart point and a Nolan-like point diagnostic of the Middle Archaic were recovered in TU 12 at $65-75 \mathrm{~cm}$ bgs, just outside the edge of the feature. Two ${ }^{14} \mathrm{C}$ dates of significance to the interpretation of Feature 7 were obtained. Wood charcoal recovered in situ from TU 12 yielded a date 


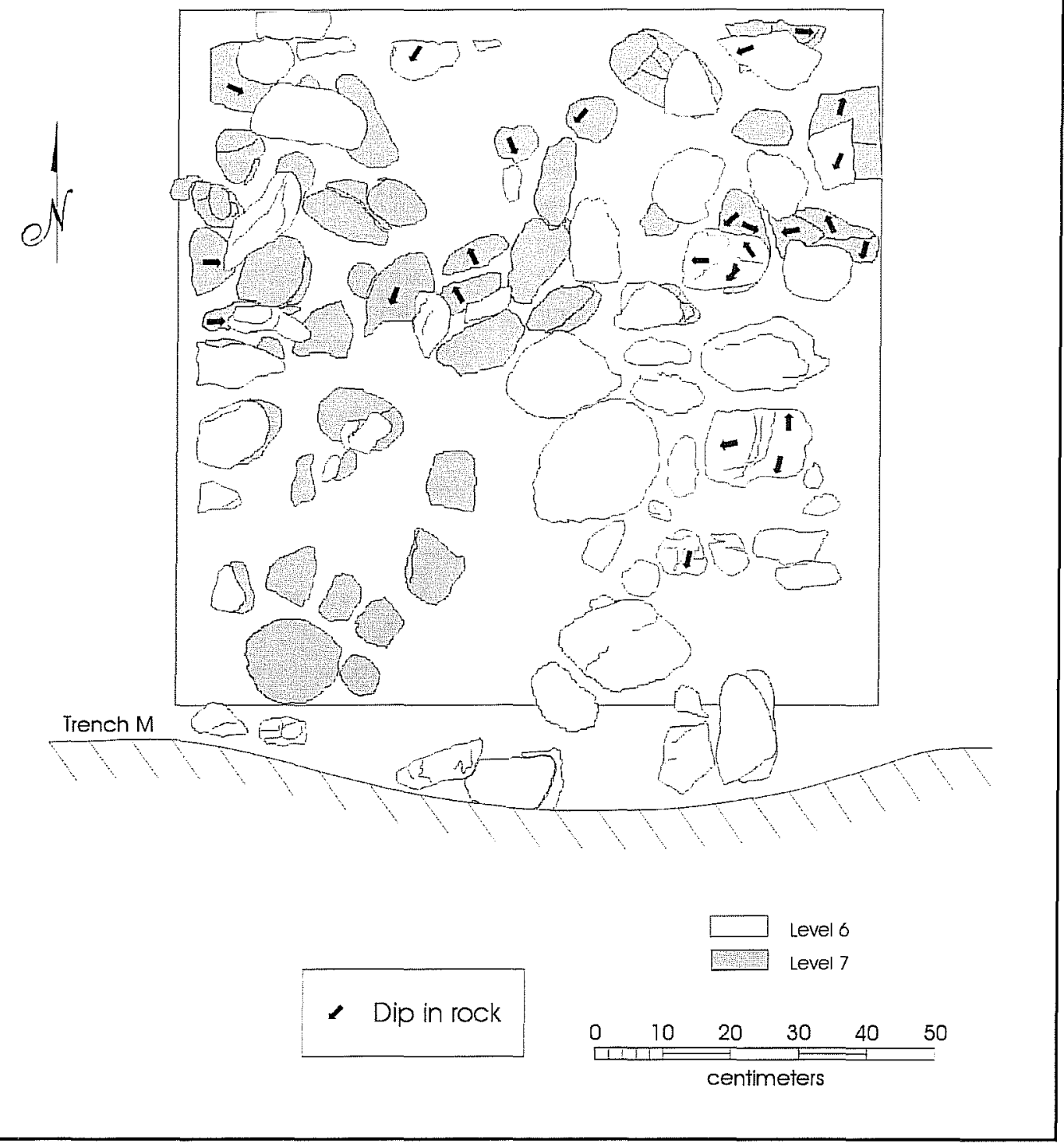

Figure 6-41. Plan view of Feature 7 in TUC, 50-80 cm below the modern surface, estimated to be between site elevations 99.8 and $100.1 \mathrm{~m}$.

of $4630( \pm 40)$ в.P. in Level 3, while a similar sample recovered from Stratigraphic Unit III in TU C yielded a date of $4940( \pm 50)$ B.P. in Level 8 (equivalent to Level 4 in TU 12), below the feature. Faunal material recovered from the feature in TU $\mathrm{C}$ weighed $0.4 \mathrm{~g}$ and included six vertebrate long bone fragments $(0.05 \mathrm{~g})$ that had been burned. Recovered from the edge of the feature in TU 12 were 11 vertebrate bone fragments, some of which were burned, weighing a total of 0.26 g. Archaeobotanical remains were not recovered from Feature 7. Both excavators noted an increased presence of calcium carbonate in the upper level of the feature, as well as the beginning of a transition between the brown Stratigraphic Unit IV and reddish orange Stratigraphic Unit III. Stratigraphic Unit III sediment inclusions were present between the burned rocks in the feature. The base of the feature appears well situated on or just within Stratigraphic Unit III.

Little was found in the level surrounding the feature. TU 21, immediately adjacent to TU C to the east, contained a few rocks in Level 3, probably associated with the eastern edge of the feature. A core and large late-stage biface were recovered in Level 2. A concentration of debitage was found in the southeast corner of Level 3 in Stratigraphic Unit III. Very few 


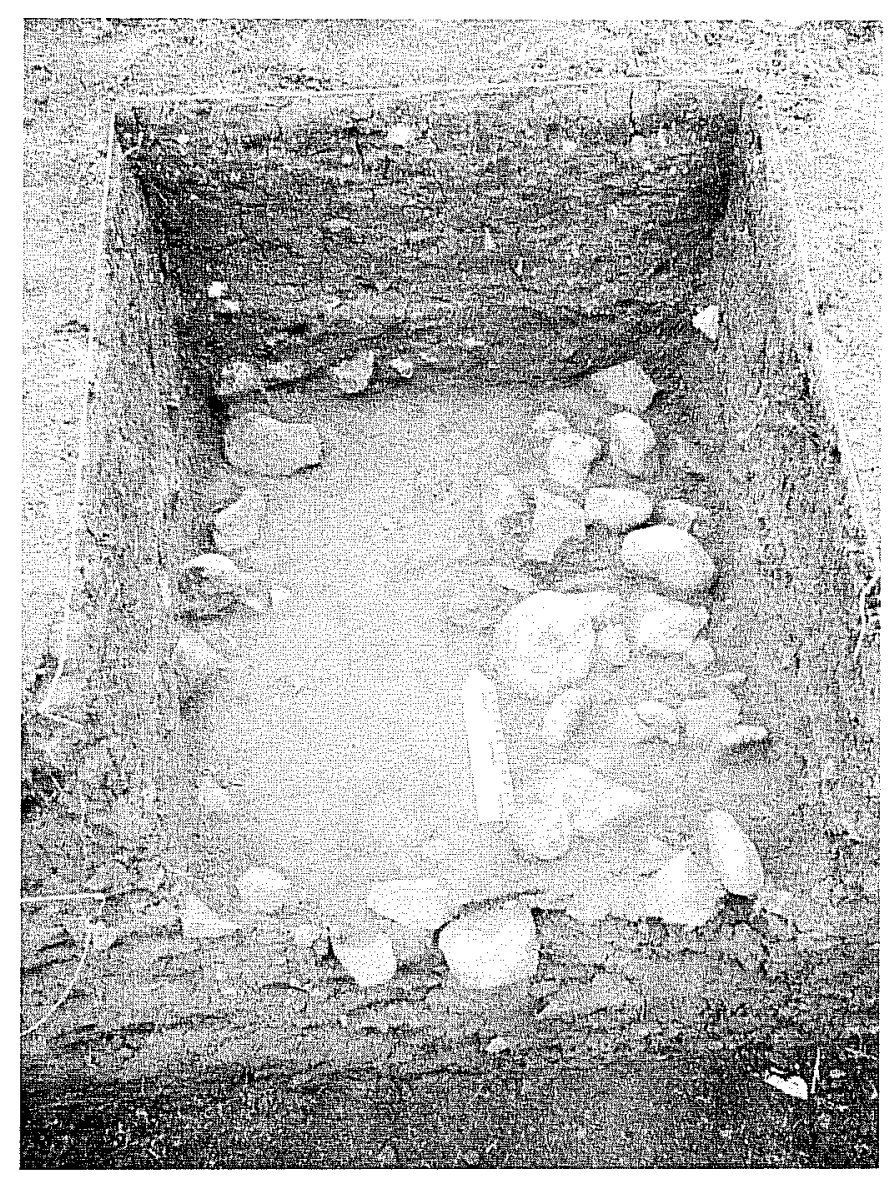

Figure 6-42. Photograph of Feature 7, Unit C, bottom of Level 6.

\section{Feature 11}

Feature 11 is described as an apparently intact horizontal cluster of burned rock limestone cobbles distributed in a somewhat circular fashion, although no internal patterning is clearly evident. The feature was exposed between 55 and $75 \mathrm{~cm}$ bgs in TUs 18 and 20 (Figure 6-44). The cobbles were distinctly larger and more closely spaced than those in the surrounding excavation units, and two flat tabular rocks were noted among the cobbles. Most of the larger rocks $(\mathrm{n}=59$; mean weight $850.91 \mathrm{~g}$ ) were seated in Level 3 at about $85 \mathrm{~cm}$ bgs. Smaller burned rocks were found on the western edge of the feature in TU 18, Level $3(\mathrm{n}=41$; mean weight $241.0 \mathrm{~g})$ and in the upper part of the feature in TU 20, Level $2(n=51$; mean weight $242.14 \mathrm{~g}$ ). Although archaeomagnetic samples were collected from burned rocks in Feature 11, project constraints did not allow for their analysis.

One radiocarbon sample from TU 18, Level 4, yielded a modern date, which is consistent with the highly disturbed nature of the deposits in this unit and in the adjoining northeast corner of TU 16 . The matrix of TU 18, Level 1 ( $45-55 \mathrm{~cm}$ bgs) was described as loose soil with bits of plastic, and Levels 2 and 3 in

rocks were found in the southern halves of TUs 17 and 19 , immediately north and possibly upslope from the feature.

Feature 7 is interpreted as a separate cooking oven approximately $1.3 \mathrm{~m}$ in diameter, which appears to have been constructed on or in Stratigraphic Unit III. Despite the apparent basin shape of the cobble layer in the Trench $M$ profile and in the unit records, no pit was discernible during excavation of either unit.

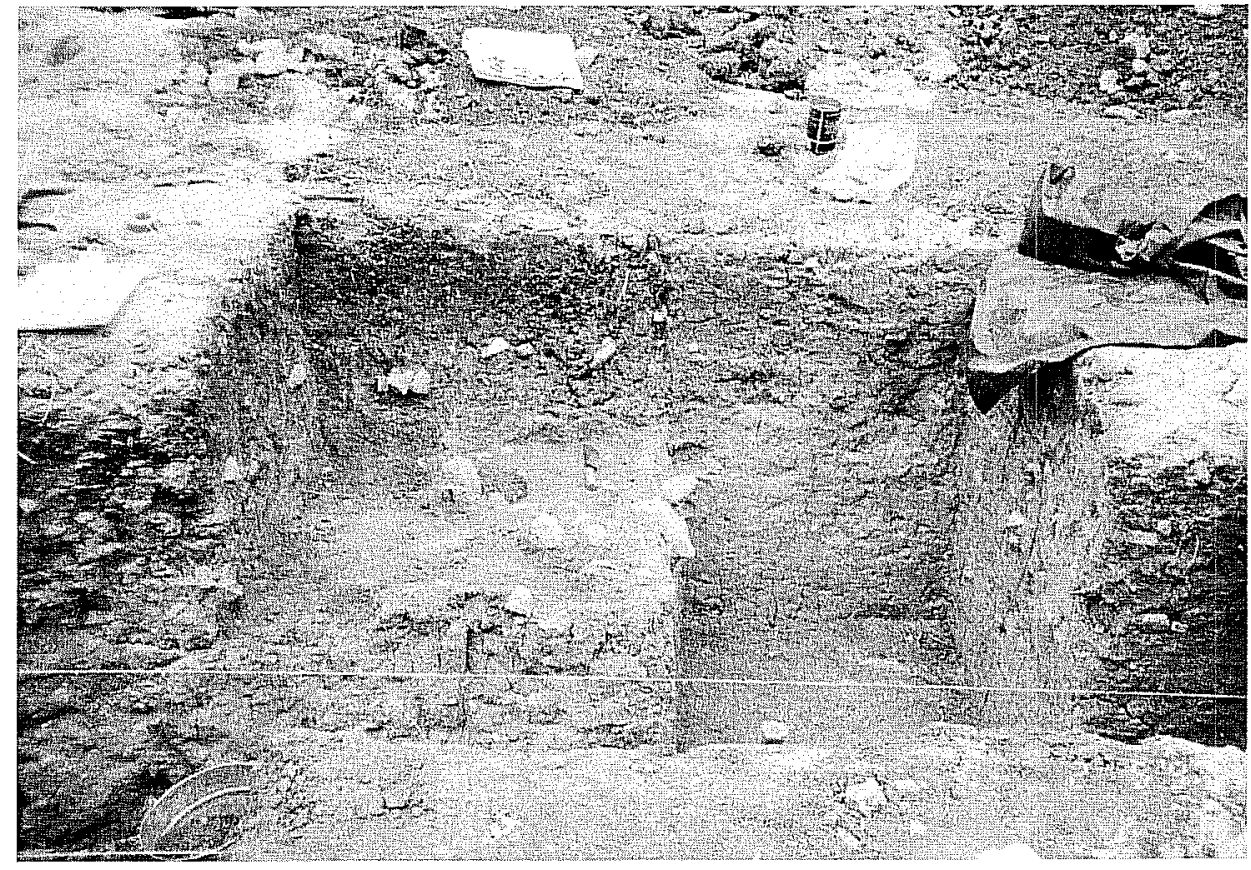

Figure 6-43. Photograph of Feature 7, Unit 12, bottom of Level 3. Note the thin scatter of rocks marking the midden surface in the profile above Feature 7. 


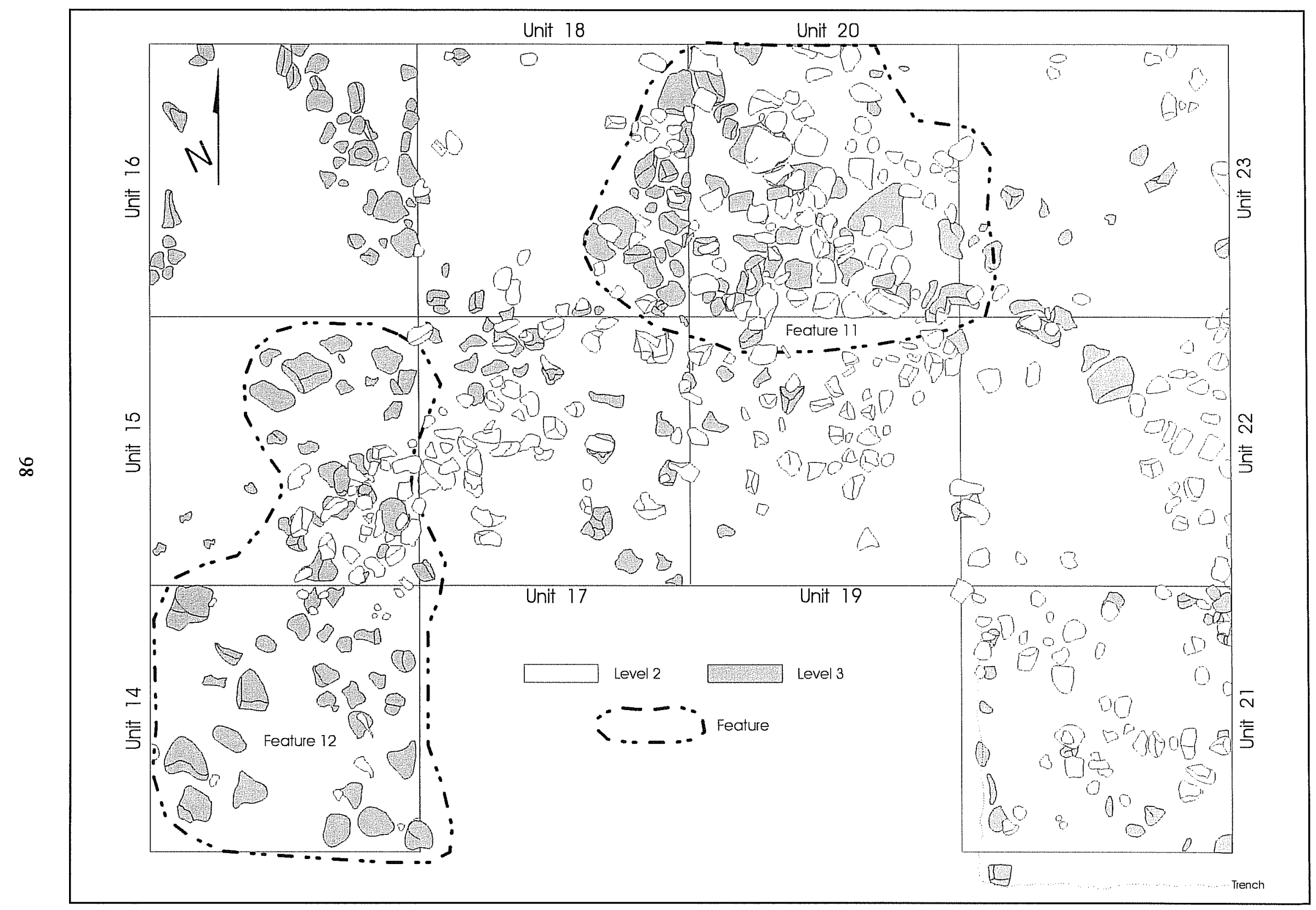

Figure 6-44. Features 11 and 12 exposed in the block excavation between site elevations 100.1 and $99.9 \mathrm{~m}, \mathrm{ca} .60-80 \mathrm{~cm}$ below the modern surface. 
the western half of TU 18 away from the feature contained number of rodent burrows and "soft spots" in the matrix. Two Late Archaic projectile points-a Castroville and a thin, broad-bladed Pedernales - were recovered from the disturbed area at $54 \mathrm{~cm}$ bgs and 65 $\mathrm{cm}$ bgs respectively, and an initial Late Archaic Bulverde point was recovered from Level $5(85-95 \mathrm{~cm}$ bgs) in the eastern part of TU 16 , although the excavator noted an apparent absence of animal burrow disturbances nearby.

Around the periphery of Feature 11, a scatter of small fire-cracked rocks was discernible in the northern parts of TUs 17 and 19, possibly representing downslope movement of lighter components of the feature. Aside from three or four larger rocks immediately southeast of the feature, there is not an appreciable amount of fire-cracked rock around the margins to the east. Recovered from TU 18, Level 5 (85-95 cm bgs) was a rabbit (Sylvilagus sp.) radius fragment weighing 0.28 $\mathrm{g}$, burned and exhibiting butchering marks (see Chapter 10). Archaeobotanical remains were not recovered from Feature 11.

Feature 11 is interpreted as a separate cooking oven approximately $1.3 \mathrm{~m}$ in diameter. This feature appears to have been constructed on or in Stratigraphic Unit III; reddish Stratigraphic Unit III sediment inclusions were present between the rocks in the feature. No evidence of a pit or basin was discerned as the cobbles were removed from the feature.

\section{Feature 12}

Feature 12 is described as a loosely integrated horizontal cluster of burned rock limestone cobbles distributed in an elongated pattern across TUs 14 and 15 between 65-85 cm bgs (Levels 3 and 4; Figure 6-45). In the field it appeared that the feature was situated in Levels 2 and 3 (Figure 6-44), and when Level 4 was fully exposed in both units, little significant patterning was noted: there was little to suggest this was part of the feature discerned in the level above. However, laboratory analysis of the fire-cracked rock from these units suggests that there is a continuum from Level 3 to Level 4 since the preponderance of the burned rock extracted from Levels $2-4$ in both units came from
Level 4 (Table 6-14), and that the rock mapped in TU 15, Level 2 may in fact not be part of Feature 12.

In Level 3, the cobbles appear to be in two intersecting clusters. The southern cluster fills all of TU 14, while the TU 15 cluster occupies the eastern half of the square, and measures ca. $95 \times 60 \mathrm{~cm}$. Larger rocks positioned in the middle of the level had a mean weight of $295.77 \mathrm{~g}(\mathrm{n}=21)$ in TU 14 and a mean weight of $240.17 \mathrm{~g}(\mathrm{n}=40)$ in TU 15. In the field, it appeared that the feature went no deeper. No significant firecracked rocks appeared in the bottom of Level 3 in TU 14, while in TU 15 the mean weight dropped to $95.31 \mathrm{~g}(\mathrm{n}=40)$. The picture appeared little changed in the upper part of Level 4, where rocks situated entirely in the top $5 \mathrm{~cm}$ had a mean weight of $121.46 \mathrm{~g}$ $(n=15)$ in TU 14 and $45.21 \mathrm{~g}(\mathrm{n}=24)$ in TU 15. However, in the middle and bottom of Level 4 , the mean weights peaked sharply: $357.66 \mathrm{~g}(\mathrm{n}=33)$ and 366.95 $\mathrm{g}(\mathrm{n}=23)$ in TU 14 , with $339.46 \mathrm{~g}(\mathrm{n}=13)$ and $115.57 \mathrm{~g}$ $(n=44)$ in TU 15. Within the feature, it would appear that there are more and heavier rocks in the southern end, which may be the working part of the heating element.

Conversely, a cluster of rocks in Level 2 in TU 15 appeared initially to be part of Feature 12, although it is clearly part of a scatter of similar-sized rocks in the western part of adjacent TU 17, Level 2 and seems now to be unrelated to the feature. Mean weight of

Table 6-14. Feature 12, Fire-cracked Rock by Level

\begin{tabular}{|c|c|c|c|c|}
\hline \multirow{2}{*}{ Level } & \multicolumn{2}{|c|}{ TU 14 } & \multicolumn{2}{c|}{ TU 15 } \\
\cline { 2 - 5 } & Count & Mean wt. (g) & Count & Mean wt. (g) \\
\hline 1 & - & - & - & - \\
\hline 2 & - & - & 46 & 200.68 \\
\hline $3 \mathrm{U}$ & 14 & 87.78 & 27 & 49.5 \\
\hline 3G & 21 & 295.77 & 40 & 240.17 \\
\hline 3L & - & - & 40 & 95.31 \\
\hline 4U & 15 & 121.46 & 24 & 45.21 \\
\hline 4G & 33 & 357.66 & 13 & 339.46 \\
\hline 4L & 23 & 366.95 & 44 & 115.57 \\
\hline 5 & 34 & 135.85 & 25 & 232.08 \\
\hline
\end{tabular}

Note: $3 U=$ Upper $5 \mathrm{~cm}$ of Level 3; $3 \mathrm{~L}=$ Lower $5 \mathrm{~cm}$ of Level $3 ; 3 \mathrm{G}=$ all $10 \mathrm{~cm}$ of Level 3 . 

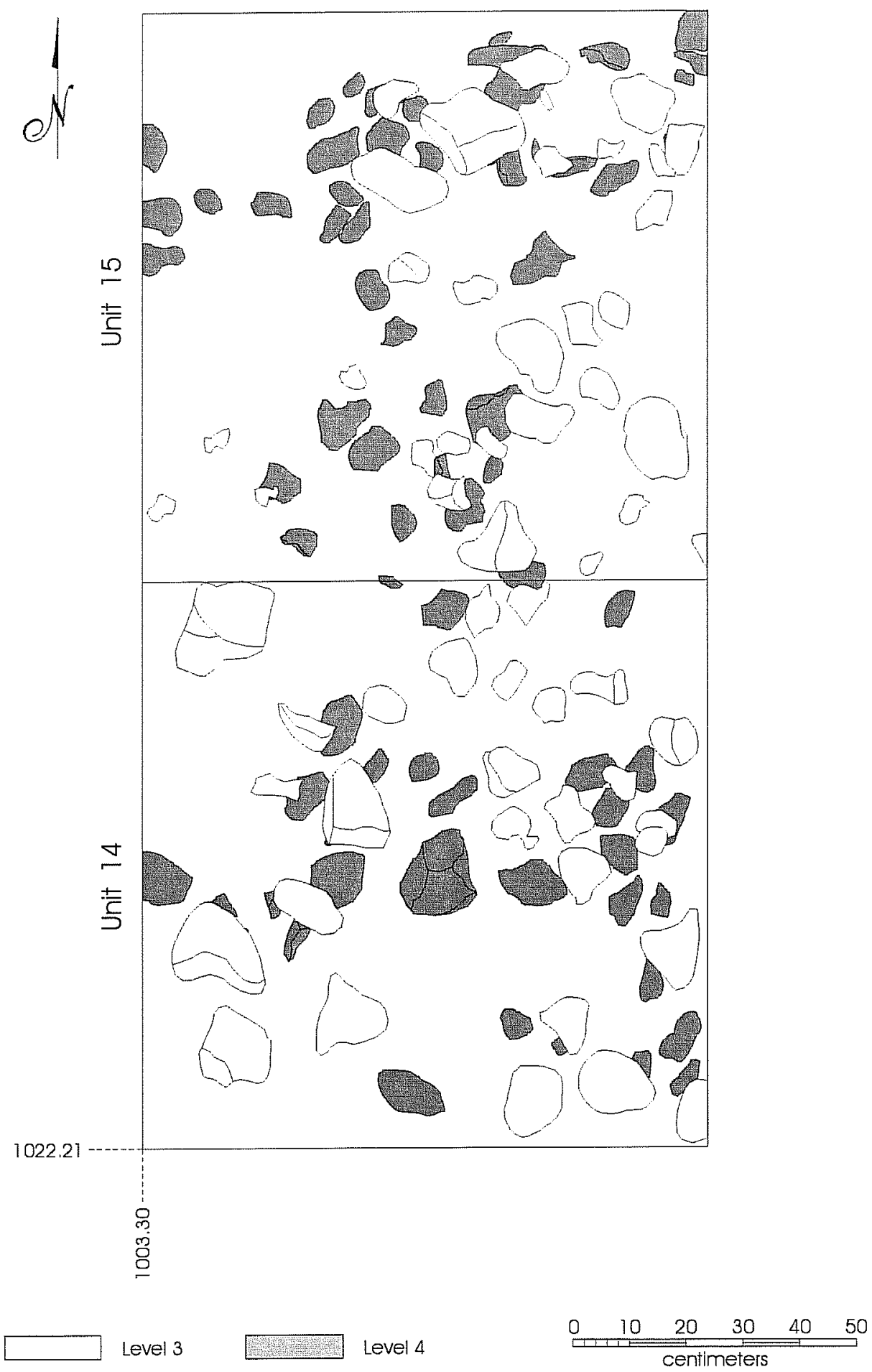

Figure 6-45. Feature 12 exposed in the block excavation between site elevations 100.0 and $99.8 \mathrm{~m}$, ca. $70-90 \mathrm{~cm}$ bgs. 
fire-cracked rocks in this level of TU 15 is $200.68 \mathrm{~g}$, while in TU 17 it is $282.11 \mathrm{~g}$, including a few larger specimens that were part of Feature 11. The rocks found in TU 14, Level 2 were too few and too small to be recorded, a further indication that Level 2 contains no part of Feature 12.

A Tortugas point and a deer-sized mammalian long bone were found in the upper $5 \mathrm{~cm}$ of TU 14, Level 4 . At this same level in TU 15, in the stratigraphic unconformity between Unit III and Unit IV (A/B transition), were found a distal biface fragment and a proximal biface fragment. Although archaeomagnetic samples were collected from burned rocks in Feature 12 , none was submitted for analysis; nevertheless, many of the cobbles in the feature appeared to be undisturbed. No evidence of a pit or basin was discerned.

Surrounding the feature in Level 3, the western half of TU 15 and the southern third of TU 16 are almost devoid of rocks. Two Nolan points were recovered near the center of TU 16, Level 3 (ca. $78 \mathrm{~cm}$ bgs). A Langtry point was found in TU 17 at $90 \mathrm{~cm}$ bgs near a small animal burrow.

As with Feature 11, this feature appears to have been constructed on or in Stratigraphic Unit III, which begins in these units between 77 and $80 \mathrm{~cm}$ bgs (Level 4). Reddish Stratigraphic Unit III sediment inclusions were present within the feature. Although Feature 12 is interpreted as a small separate cooking oven, it appears to be stratigraphically concomitant with Feature 11 and it may be that what are seen here as two separate features, were one feature before being disturbed.

\section{Area C: West of Loop 1604}

Area $\mathrm{C}$ encompasses the portion of $41 \mathrm{BX} 126$ west of Loop 1604 (Figure 6-1). The combined investigations in this area include $12 \mathrm{BHTs}, 161-\mathrm{x}-1-\mathrm{m}$ and two $0.5-$ $\mathrm{x}-0.5 \mathrm{~m}$ hand-excavated units, 31 shovel tests (Wood 1994), five Gradall trenches, and mapping of the site (Figure 6-46). Appendix E at the end of this report provides quantitative data on cultural material recovered from all three testing projects in Area C, including 2,116 chipped stone (Table 6-15), five diagnostic artifacts (Table 6-16), and $15.3 \mathrm{~kg}$ of firecracked rock. No fauna was recovered from the excavations. No archaeomagnetic cores or soil susceptibility samples were collected in the field. One charcoal sample was recovered but not submitted for analysis.

Wood (1994) tested Area C in 1993 (Table 6-17), and found no evidence of features. He further suggested that the upper deposits in the higher elevations of Area $\mathrm{C}$ were disturbed. However, two dart points identified as Early Barbed or Early Corner Notched were recovered from the third level $(20-30 \mathrm{~cm}$ bs) in TUs 5 and 16 (approximately $30 \mathrm{~m}$ apart), which prompted a recommendation for further testing in Area C. CAR later identified these two points as a Martindale and a Bell. Wood provided detailed profiles of Trenches 1, 3 , and 6 and selected test units (Figures 6-47-6-50).

In 1995 Price excavated six BHTs (A-F) in Area C. Price recovered a proximal Pedernales fragment from TU E between $30-40 \mathrm{~cm}$ bs and another proximal Pedernales fragment from Trench $\mathrm{C}, 70 \mathrm{~cm}$ bs (Figure 651). Frederick (Appendix A) conducted the geoarchaeological work and identified four distinct terrace deposits ( $\mathrm{T} 0-\mathrm{T} 3$ ) with four depositional units (2-5) ranging in age from modern to Late Pleistocene. Although no features were observed during this investigation, Price's evaluation of cultural material suggested a strong correlation among increased quantities of chipped stone and identifiable snail species in Levels 1 and 5 of TUs E and F. Noted disturbances included a two-centimeter diameter root in TU E, Level 5 , an ant nest in TU F, Level 3, roots in Level 4, and vertical cracks in the clay in Levels 8, 9 and 12.

CAR returned to Area C in 1997 and relocated previous trenches and units excavated by Wood and Price (Figure 6-52). Five Gradall trenches (Figure 6-53) were placed across the area to investigate the possibility of an Early Archaic component suggested by Wood's recovery of two Early Archaic Barbed (Notched) points found ca. $30 \mathrm{~cm}$ bs. No evidence of features or an intact cultural component was found. Therefore, with the concurrence of TxDOT and THC personnel, no further testing was conducted in Area C. 

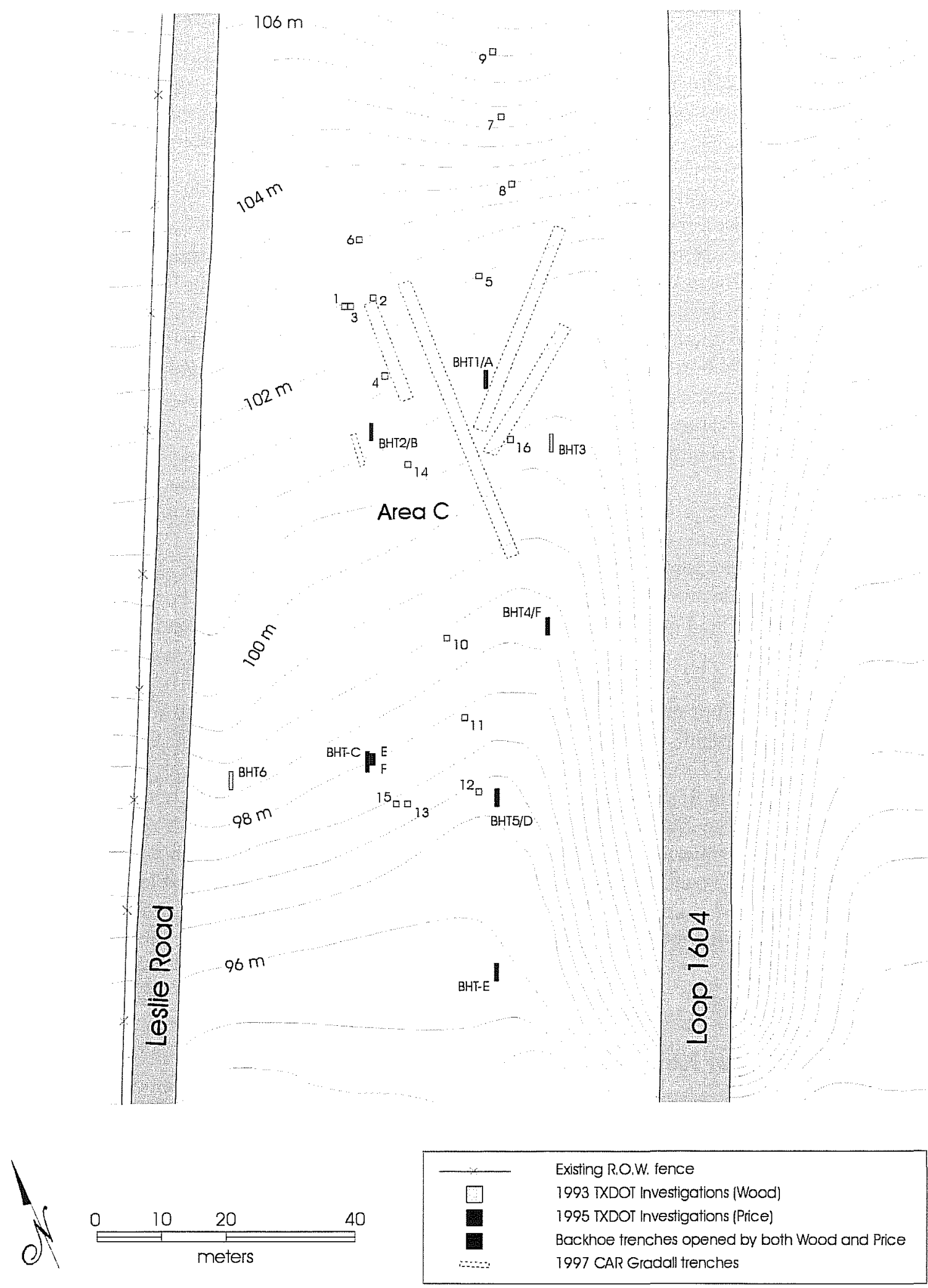

Figure 6-46. Archaeological investigations in Area $C$. 
Table 6-15. Chipped Stone from Area C

\begin{tabular}{|c|c|c|c|c|c|c|c|c|c|c|c|}
\hline \multicolumn{2}{|c|}{ Cores } & \multicolumn{2}{|c|}{ Debitage } & \multicolumn{2}{c|}{ Unifaces } & \multicolumn{2}{c|}{ Bifaces } & \multicolumn{2}{c|}{ Points } & \multicolumn{2}{c|}{ Total } \\
\hline$\#$ & $\%$ & $\#$ & $\%$ & $\#$ & $\%$ & $\#$ & $\%$ & $\#$ & $\%$ & $\#$ & $\%$ \\
\hline 5 & $<1$ & 2045 & 96.6 & 54 & 2.6 & 8 & $<1$ & 5 & $<1$ & 2116 & 100 \\
\hline
\end{tabular}

Table 6-16. Diagnostic Artifacts from Area C

\begin{tabular}{|c|c|c|c|c|}
\hline Type & Interval & TU/BHT & Level & Investigator \\
\hline Pedernales & Middle Archaic & Surface Find & Surface & CAR \\
\hline Bell & Middle Archaic & TU 5 & 3 & Wood \\
\hline Martindale & Early Archaic & TU 16 & 3 & Wood \\
\hline Pedernales & Middle Archaic & TU E & 4 & Price \\
\hline Pedernales & Middle Archaic & Trench C & Backdirt & Price \\
\hline
\end{tabular}

\section{Chronometric Investigations}

Nordt (Chapter 5) and Frederick (Appendix A) discuss the sediment deposition and soil-formation processes that have occurred along Culebra Creek in the area of $41 B X 126$ over the past 17,000 years. Specifically, they identified a Stratigraphic Unit III which formed between 17,000 and 4,000 years ago, and Stratigraphic Unit IV which formed on top of Unit III between 4,000 and 2,000 years ago. The preceding sections of this chapter have presented detailed results and some discussion of the archaeological excavations at the site. The purpose of this section is to build on Nordt's and Frederick's findings and the archaeological excavation results in order to synthesize the chronometric information in a coherent manner.

Three lines of evidence are available for dating deposits at Culebra Creek. The first is from timediagnostic artifacts, mainly projectile points and a few other tools. Sixty diagnostic projectile points, two projectile-point preforms, and four other tools were recovered (Appendix E, Table E-1). The diagnostic tools are fully described in Chapter 8 . The second line of evidence involves absolute dating techniques and includes radiocarbon dating of wood charcoal, fish otoliths, and soil humates (organic carbon). Fifteen wood charcoal and six humate dates were obtained (Table 6-18). The third technique involves stratigraphy.
Table 6-17. TxDOT Excavations in Area C

\begin{tabular}{|c|c|c|c|}
\hline TU & TU Size & Depth & Investigator \\
\hline 1 & $1 \times 1 \mathrm{~m}$ & $.5 \mathrm{~m}$ & Wood \\
\hline 2 & $1 \times 1 \mathrm{~m}$ & $.5 \mathrm{~m}$ & Wood \\
\hline 3 & $1 \times 1 \mathrm{~m}$ & $.5 \mathrm{~m}$ & Wood \\
\hline 4 & $1 \times 1 \mathrm{~m}$ & $.5 \mathrm{~m}$ & Wood \\
\hline 5 & $1 \times 1 \mathrm{~m}$ & $.6 \mathrm{~m}$ & Wood \\
\hline 6 & $1 \times 1 \mathrm{~m}$ & $.5 \mathrm{~m}$ & Wood \\
\hline 7 & $1 \times 1 \mathrm{~m}$ & $.4 \mathrm{~m}$ & Wood \\
\hline 8 & $1 \times 1 \mathrm{~m}$ & $.4 \mathrm{~m}$ & Wood \\
\hline 9 & $50 \times 50 \mathrm{~cm}$ & $.3 \mathrm{~m}$ & Wood \\
\hline 10 & $1 \times 1 \mathrm{~m}$ & $.6 \mathrm{~m}$ & Wood \\
\hline 11 & $1 \times 1 \mathrm{~m}$ & $.5 \mathrm{~m}$ & Wood \\
\hline 12 & $1 \times 1 \mathrm{~m}$ & $.6 \mathrm{~m}$ & Wood \\
\hline 13 & $1 \times 1 \mathrm{~m}$ & $.5 \mathrm{~m}$ & Wood \\
\hline 14 & $1 \times 1 \mathrm{~m}$ & $.4 \mathrm{~m}$ & Wood \\
\hline 15 & $1 \times 1 \mathrm{~m}$ & $.5 \mathrm{~m}$ & Wood \\
\hline 16 & $50 \times 50 \mathrm{~cm}$ & $.4 \mathrm{~m}$ & Wood \\
\hline $\mathrm{E}$ & $1 \times 1 \mathrm{~m}$ & $1 \mathrm{~m}$ & Price \\
\hline $\mathrm{F}$ & $1 \times 1 \mathrm{~m}$ & $1.5 \mathrm{~m}$ & Price \\
\hline
\end{tabular}




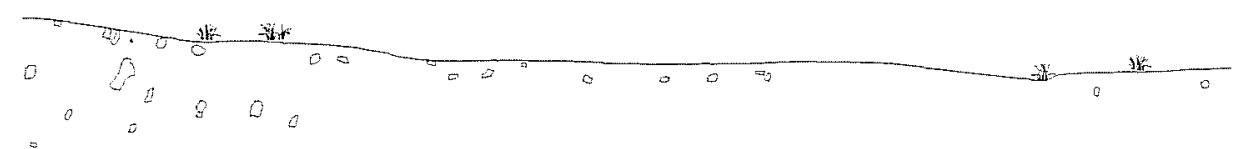

datum line 2.59

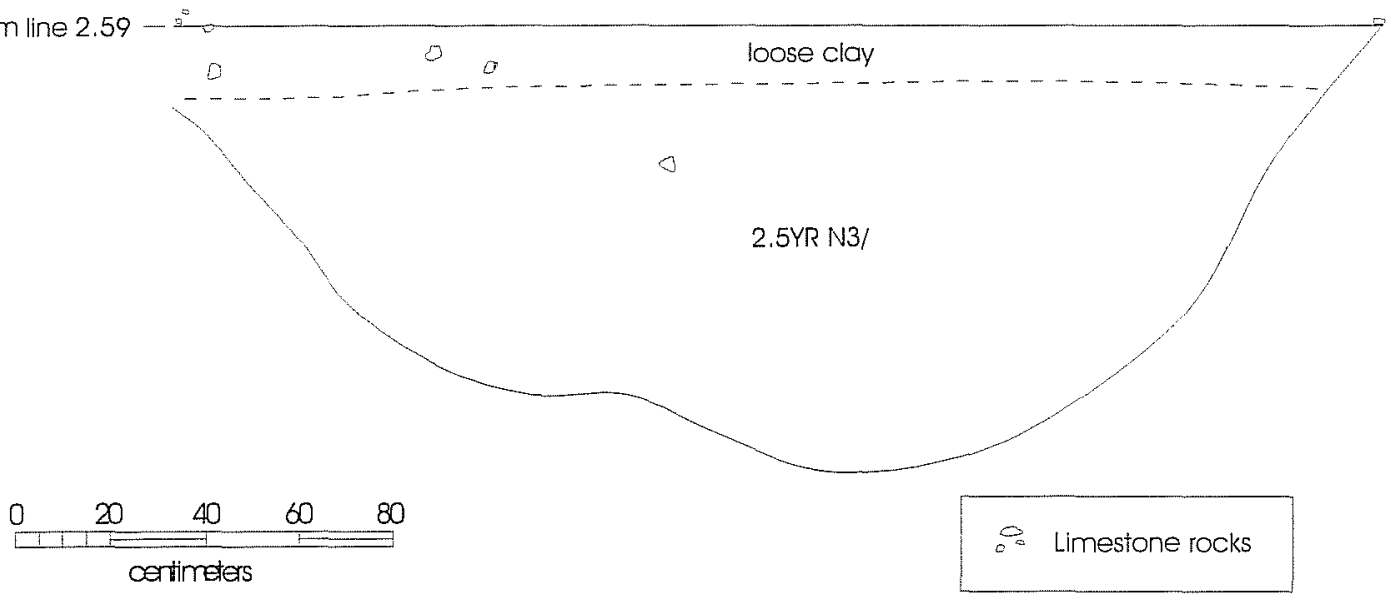

Figure 6-47. East wall profile of Wood's (1994) BHT 1.

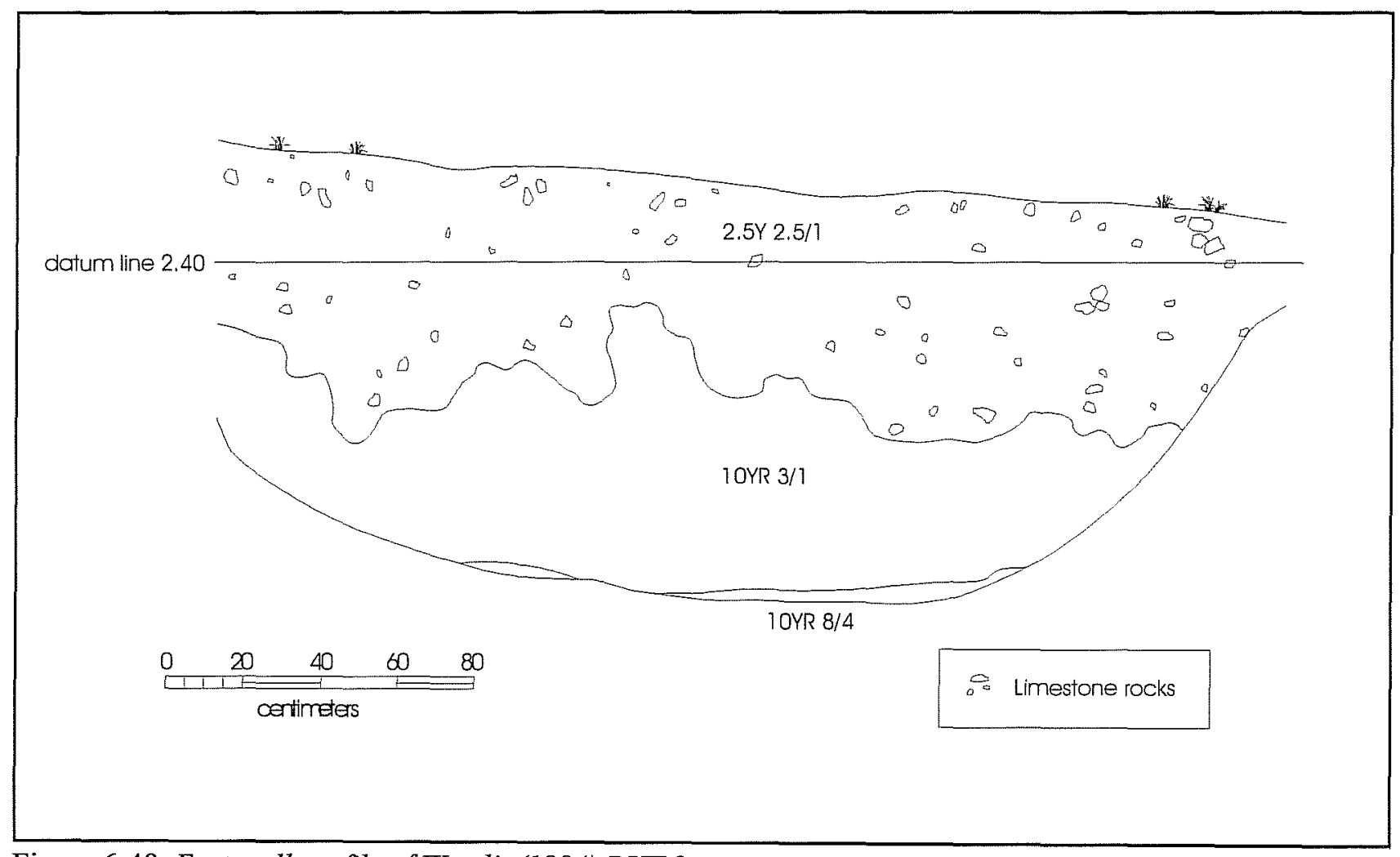

Figure 6-48. East wall profile of Wood's (1994) BHT 3. 

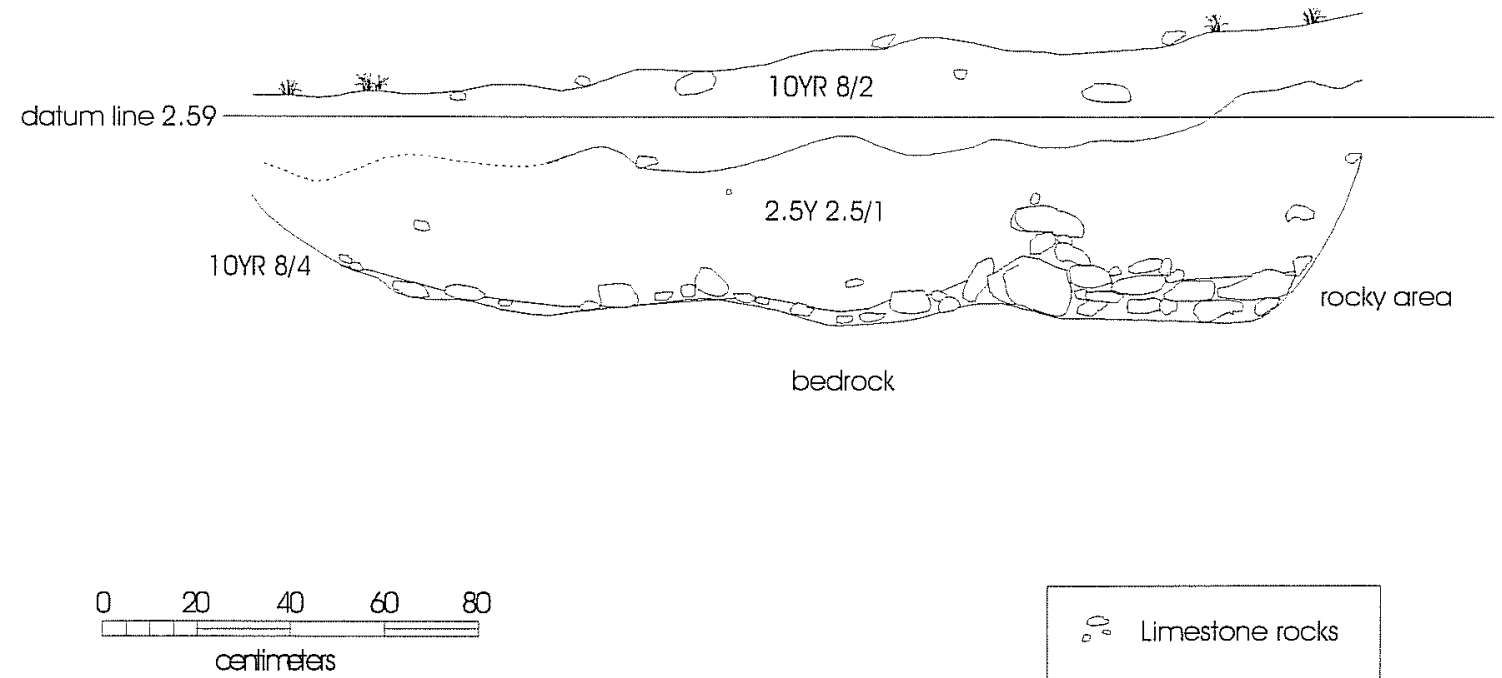

: Limestone rocks

Figure 6-49. East wall profile of Wood's (1994) BHT 6.

This includes, at its broadest level, the terrace sequences outlined by Nordt (Chapter 5) and Frederick (Appendix A). This may also include the stratigraphic ordering or superposition of depositional units, and the artifacts within these units. Finally, selected samples of fish otoliths from the block excavations in Area B were submitted for dating. However, the otolith dates are around 1,750 to 3,060 years earlier than the wood charcoal dates (Table 6-18); therefore we believe they are problematic and do not correctly represent the occupation of the site. A further discussion of fish otolith recovery is discussed in Chapter 10 .

\section{Dating Area A}

The available evidence suggests that burned rock Features 2, 3, and 5 in Area A were utilized contemporaneously with the burned rock midden in Area B during the Central Texas Late Archaic, between at least 2600 and 2880 в.P. (Tables 3-1 and 6-19, Figure 6-54). There is not sufficient evidence from which to determine the length of occupation.
Two absolute dates were obtained for Area A: a wood charcoal date of $2700 \pm 50$ B.P. is from a float sample recovered between 99.4 and $99.3 \mathrm{~m}$ site elevation in Feature 2, TU 1, Level 3, and a wood charcoal date of $2780 \pm 50$ B.P. is from a float sample recovered from between 40 and $50 \mathrm{~cm}$ bs (Level 4) in Feature 2, TU 1 (Tables 6-18 and 6-19). This date falls within the range for the proposed chronological popularity of the Montell, Marshall, and Pedernales projectile points recovered from Area A, considered diagnostic to the Central Texas Late Archaic interval. Their proposed period of use ranges between approximately 1700 and 3300 B.P. (Collins 1995:Table 2). A Butted Knife biface recovered from Area $\mathrm{A}$ is also considered contemporaneous with the Late Archaic occupation, between 2600 B.P. and 2250 B.P. (Turner and Hester 1993:243). Although no humate dates were obtained from Area A, Feature 2 lies stratigraphically on the eroded surface of a T2 terrace within Unit IV alluvial deposits which Nordt (Chapter 5) believes formed after 4000 B.P. 


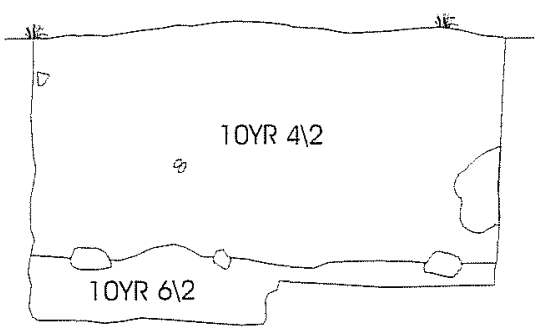

Area C: Test Unit 5 West Wall

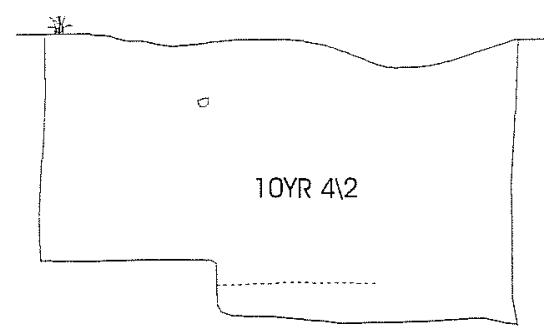

Area C: Test Unit 12 East Wall

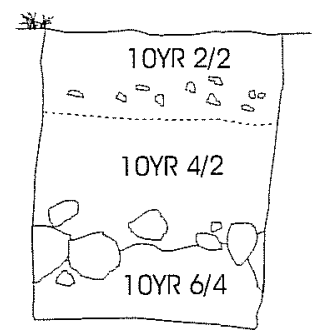

Area B: Test Unit 22 East Wall

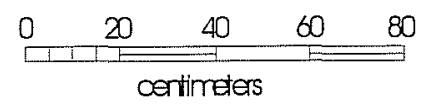

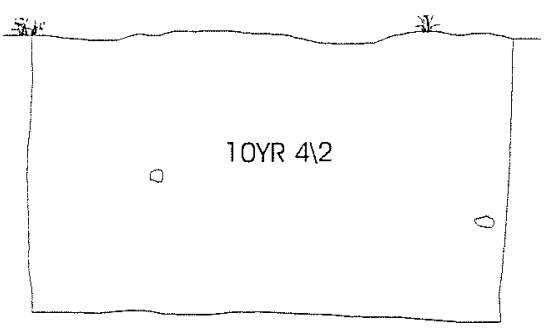

Area C: Test Unit 10 East Wall

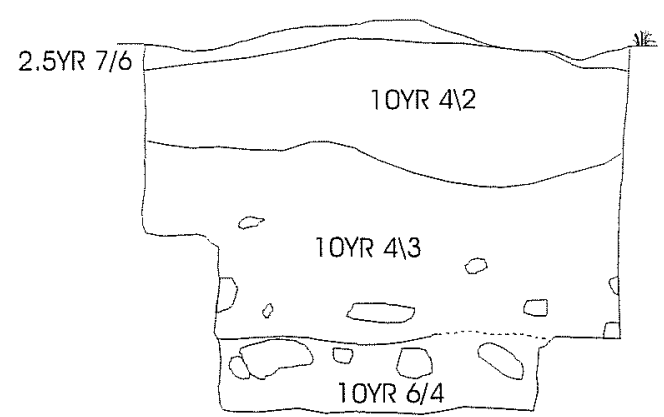

Area B: Test Unit 17 North Wall

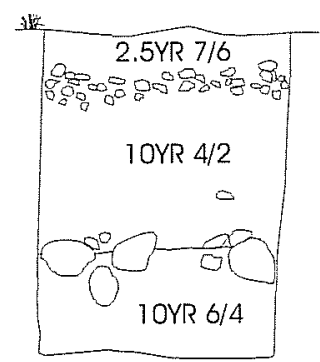

Area B: Test Unit 24 North Wall

$$
\text { : Limestone rocks }
$$

Figure 6-50. Wood's (1994) wall profiles of selected test units. 


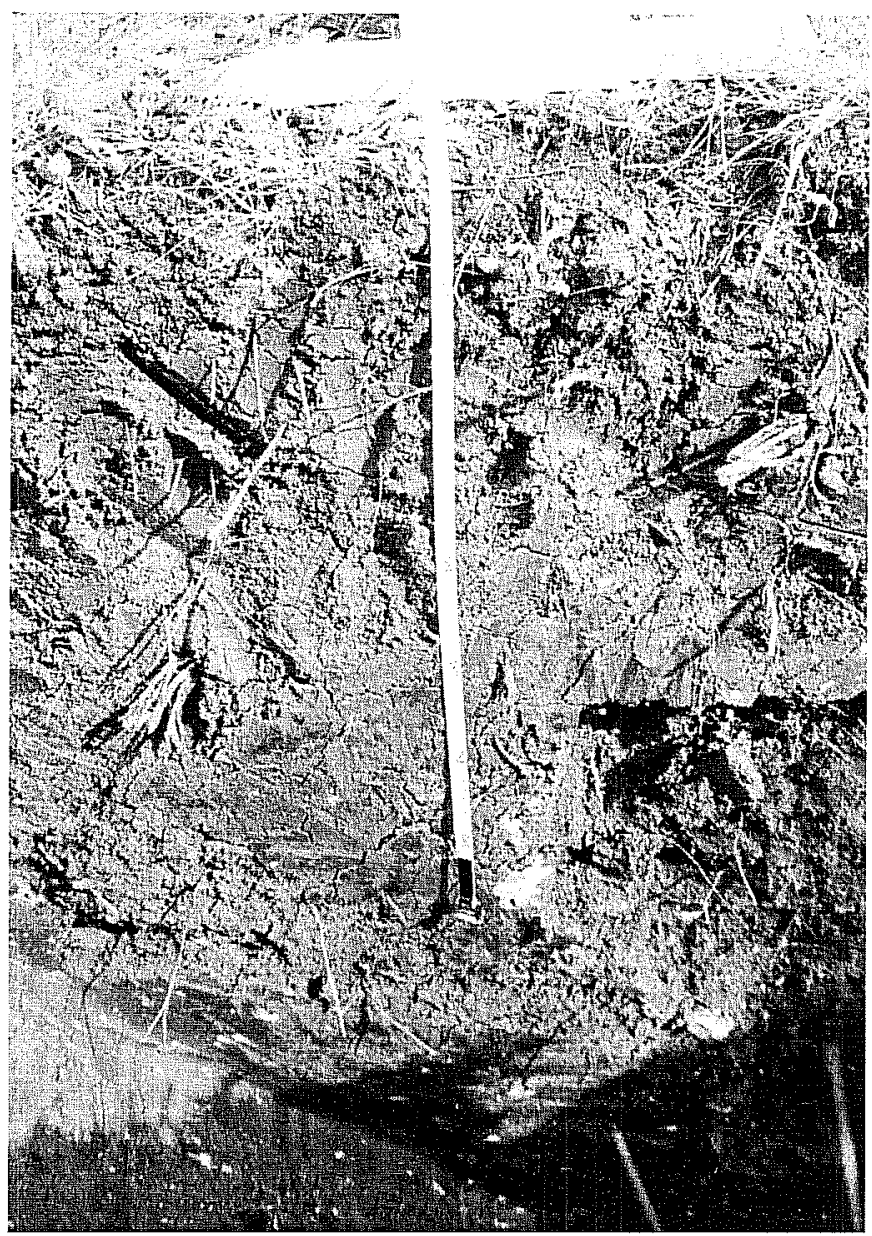

Figure 6-51. Pedernales base (to right of end of tape) in east wall of BHTC (west wall of TUF) at $70 \mathrm{~cm} \mathrm{bs}$.

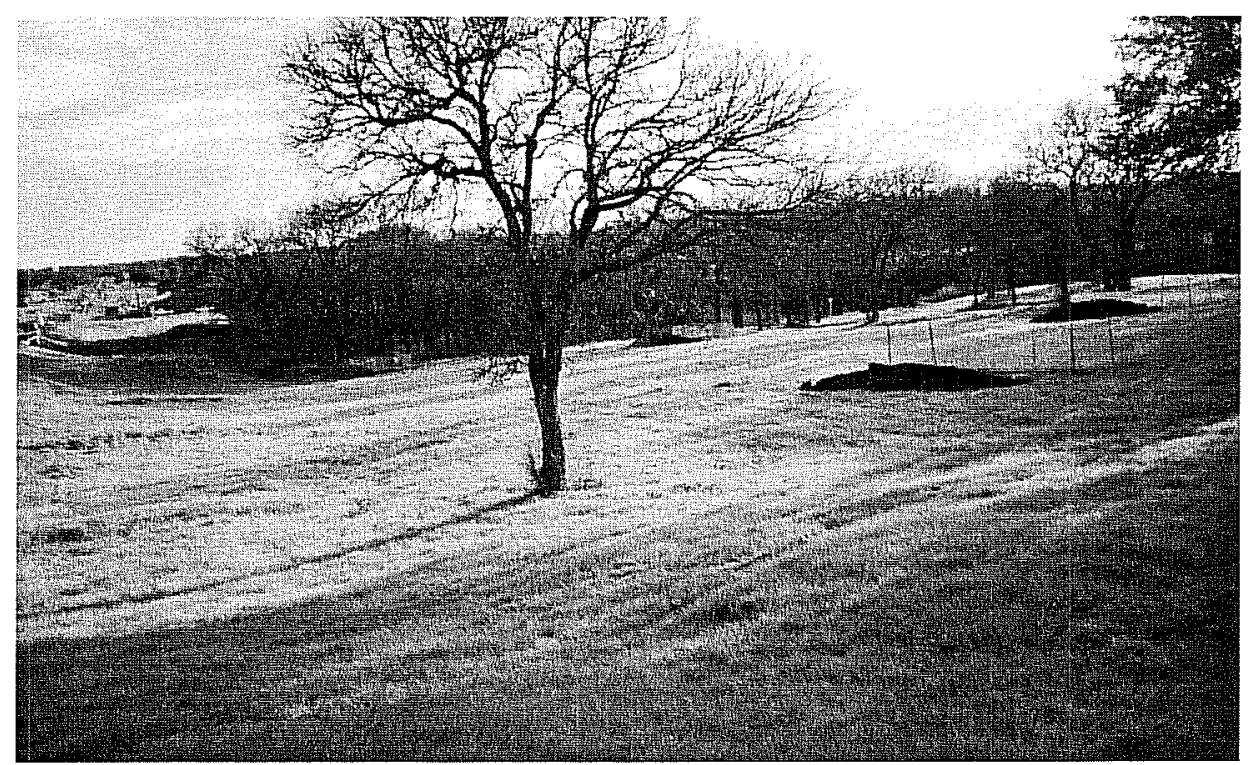

Figure 6-52. Area C, looking southwest. From left to right: Price's 1995 BHTs E, C, A, and B (indicated by backhoe dirt).

\section{Dating Area B}

Thirteen wood charcoal dates were obtained from Area B: three from within the midden's core, four from its framework, three from its periphery, and three from the Block Excavation. In addition, Frederick (Appendix A) obtained one humate date from the midden's peripheral area, stratigraphically about $40 \mathrm{~cm}$ below the base of the main midden.

\section{The Midden Core}

Two features were documented within the midden's core: 1.2 and 1.3 (Table 6-1). Three wood charcoal samples (Table 6-20) taken from Features 1.2 and 1.3 date to $2950 \pm 70$ B.P., $3040 \pm 70$ B.P., and $4050 \pm 50$ B.P. Level 2 in TUs 8 and 9 contained one Middle Archaic (Nolan) and five Late Archaic points (Ellis, Marshall, and Pedernales). Referring to Collins's (1995:Table 2) and Hester's (1995) estimated relative point chronologies for Central and South Texas, the time span of these four points ranges from ca. 2100-4400 в.P. Excavation of Level 3 in TUs 8 and 9 yielded two Late Archaic Castroville points. The Castroville is argued as a diagnostic between ca. 1700 and 2100 B.P. An Early Archaic point (Uvalde) was found $20 \mathrm{~cm}$ below the Castroville in Level 5 . The appearance of Uvalde points is arguably around 7000-6000 B.P. (Collins 1995:Table 2). Level 6 in TU 9 contained an Early Archaic Martindale point. Martindale points also appear in the archaeological record contiguous with Uvalde projectile points, between ca. 7000 and 6000 B.P. Stratigraphically, Nordt (Chapter 5) posits that the midden rests on the surface of a T2 terrace composed of Stratigraphic Unit III (formed between 11,000 and 4,000 B.P.) and within Stratigraphic Unit IV which formed between 4000 and 2000 B.P. 


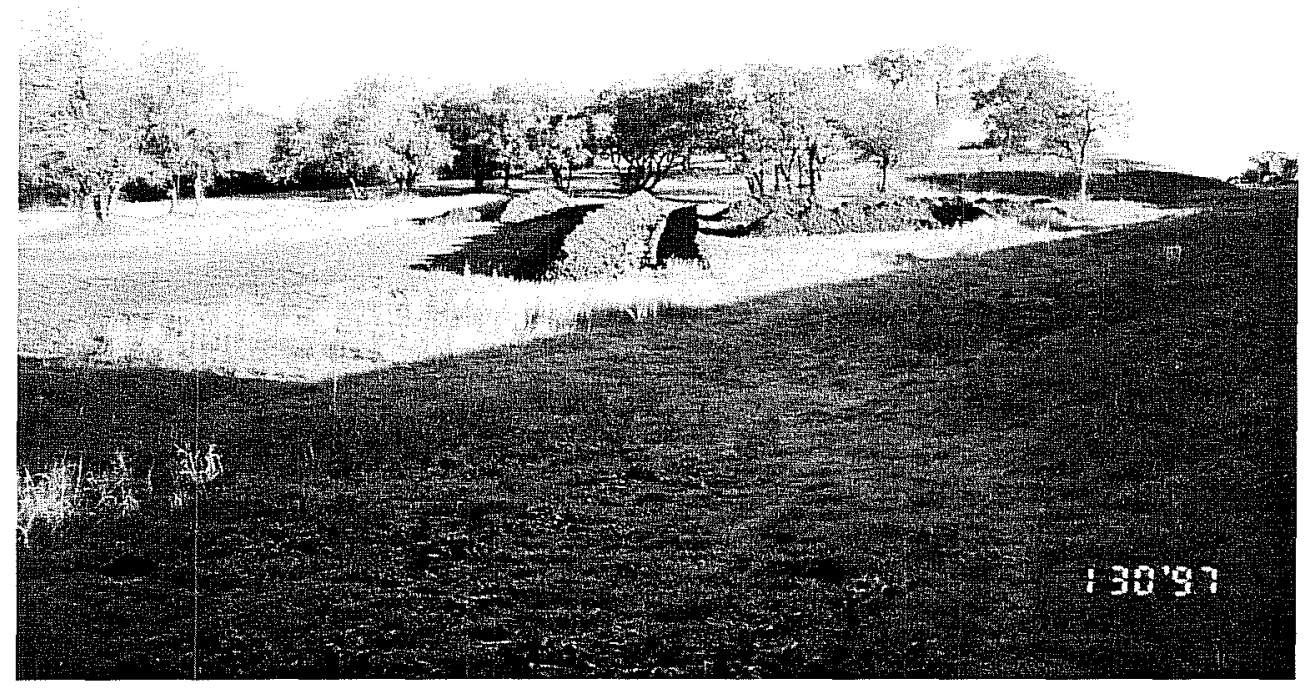

Figure 6-53. Photograph of CAR Gradall trenches in Area C, looking north.

Table 6-18. Radiocarbon, Humate, and Fish Otolith Dates

\begin{tabular}{|c|c|c|c|c|c|c|c|}
\hline Lab No. & Material & Context & Feature & $\begin{array}{c}\text { Years } \\
\text { B.P. }\end{array}$ & SD ( \pm ) & $\begin{array}{c}{ }^{13} \mathbf{C}^{12} \mathbf{C} \\
\text { Ratio (\%o) }\end{array}$ & Source \\
\hline NSRL-3524 & wood charcoal & TU 7, Lvl 3 & 1.1 & 2980 & 50 & -2.5 & this report \\
\hline NSRL-3521 & wood charcoal & TU 8, Lvl 6 & 1.3 & 3040 & 70 & -24.8 & this report \\
\hline NSRL-3522 & wood charcoal & TU 13, Lvl 5 & $1.2 / 1.3$ & 2950 & 70 & -25.2 & this report \\
\hline NSRL-3523 & wood charcoal & TU 8, Lvl 5 & $1.2 / 1.3$ & 4050 & 50 & -2.50 & this report \\
\hline NSRL-3525 & wood charcoal & TU 11, Lvl 3 & - & 2180 & 50 & -2.6 & this report \\
\hline NSRL-3526 & wood charcoal & TU 11, Lvl 4 & - & 2170 & 50 & -24.8 & this report \\
\hline NSRL-3527 & wood charcoal & TU 11, Lvl 6 & - & 2750 & 50 & -26.6 & this report \\
\hline NSRL-3563 & wood charcoal & BHT O & 1.4 & 2280 & 60 & -25.4 & this report \\
\hline NSRL-3564 & wood charcoal & BHT O & 1.5 & 3920 & 60 & -25.7 & this report \\
\hline NSRL-3565 & wood charcoal & BHT G & 1.6 & 3920 & 60 & -26.5 & this report \\
\hline NSRL-3520 & wood charcoal & TU 1, Lvl 3 & 2 & 2700 & 50 & -26.7 & this report \\
\hline NSRL-3519 & wood charcoal & TU 1, Lvl 4 & 2 & 2780 & 50 & -2.6 & this report \\
\hline NSRL-3698 & wood charcoal & TU 12, Lvl 3 & 7 & 4630 & 40 & -25.7 & this report \\
\hline NSRL-3699 & wood charcoal & TU 18, Lvl 4 & 7 & modern & - & 23.3 & this report \\
\hline NSRL-3697 & wood charcoal & TU C, Lvl 8 & 7 & 4940 & 50 & -25.0 & this report \\
\hline Beta-81538 & sediment & Trench H; & & 4370 & 50 & -25.0 & $\begin{array}{c}\text { Frederick } \\
\text { (Appen. A) }\end{array}$ \\
\hline Beta-81539 & sediment & $\begin{array}{c}\text { Trench H; } \\
245 \text { cm bs }\end{array}$ & & 11540 & 50 & $-25.0 \%$ & $\begin{array}{c}\text { Frederick } \\
\text { (Appen. A) }\end{array}$ \\
\hline
\end{tabular}


Table 6-18. Continued...

\begin{tabular}{|c|c|c|c|c|c|c|c|}
\hline Lab No. & Material & Context & Feature & $\begin{array}{l}\text { Years } \\
\text { B.P. }\end{array}$ & SD $( \pm)$ & $\begin{array}{c}{ }^{13} \mathrm{C} /{ }^{12} \mathrm{C} \\
\text { Ratio (\%o) }\end{array}$ & Source \\
\hline Beta- 81540 & sediment & $\begin{array}{l}\text { Trench I; } \\
116 \mathrm{~cm} \mathrm{bs}\end{array}$ & & 3190 & 60 & $-25.0 \%$ & $\begin{array}{c}\text { Frederick } \\
\text { (Appen. A) }\end{array}$ \\
\hline Beta-1 04970 & sediment & $\begin{array}{c}\text { Trench I; } \\
176-186 \mathrm{~cm} \mathrm{bs}\end{array}$ & & 17670 & 100 & $-23.6 \%$ & this report \\
\hline Beta-1 04971 & sediment & $\begin{array}{c}\text { Trench J; } \\
154-164 \mathrm{cmbs}\end{array}$ & & 2080 & 30 & $-20.6 \% o$ & this report \\
\hline Beta-104972 & sediment & $\begin{array}{c}\text { Trench X; } \\
210-220 \mathrm{~cm} \text { bs }\end{array}$ & & 10460 & 60 & $-20.5 \%$ & this report \\
\hline Beta-108796 & otoliths & TU $12, \mathrm{Lvl} 3$ & 7 & 6380 & 60 & $-6.7 \%$ & this report \\
\hline Beta-108797 & otoliths & TU C, Lvl 8 & 7 & 6570 & 50 & $-5.8 \%$ & this report \\
\hline Beta-108798 & otoliths & TU 9, Lvl 6 & 1.3 & 6100 & 60 & $-6.3 \%$ & this report \\
\hline Beta-108799 & otoliths & TU 8, Lvl 5 & $1.2 / 1.3$ & 5420 & 80 & $-7.2 \%$ & this report \\
\hline
\end{tabular}

Table 6-19. Evidence for Dating Area A

\begin{tabular}{|l|l|l|}
\hline \multicolumn{1}{|c|}{ Evidence } & \multicolumn{1}{|c|}{ Provenience } & \multicolumn{1}{c|}{ Interval/Date } \\
\hline \multirow{2}{*}{ Charcoal Date } & Feature 2 & $2700( \pm 50)$ B.P. \\
\cline { 2 - 4 } & Feature 2 & $2780( \pm 50)$ B.P. \\
\hline Stratigraphy & Unit IV, T2 & ca. 4000-2000 B.P. \\
\hline Diagnostic Artifacts & & \\
\hline Marshall & BHT S, Feature 2, Lvl 2 & Late Archaic \\
\hline Butted Knife Biface & TU 6, Lvl 3 & Late Archaic \\
\hline Pedernales & TU 2, Lvl 1 & Late Archaic \\
\hline Montell & TU 1, Lvl 2 & Late Archaic \\
\hline Montell & TU 1, Lvl 4 & Late Archaic \\
\hline Montell & ST B, Lvl 1 & Late Archaic \\
\hline
\end{tabular}

Alluvial and colluvial deposits of Stratigraphic Unit IV enveloped the midden either after it was constructed, or during its period of construction. Regardless, deposition of Stratigraphic Unit IV ended ca. 2000 в.P.

Based on the available evidence presented above, the midden's core apparently formed between 4400 and 2000 B.P. (Figure 6-54, Table 6-20). The more important chronological question is whether it formed over the entire 2,400-year time frame, or over a 1,100-year span as the wood charcoal dates indicate. Absolute wood charcoal dates ranging between ca. 2950 and
4050 B.P. would normally be the accepted range of midden usage, and the stratigraphic ages of deposition are acceptable as contemporaneous with midden usage. However even on a gross scale the Early Archaic Uvalde and Martindale points are not acceptable as concomitant with the age of the midden. Hence the issues are 1) the potential mixing of artifacts, and 2) the potential translocation of charcoal in an organic rich environment. Nordt suggests slow sediment deposition and concomitant midden construction contributes to mixed artifact assemblages. Moreover, the midden's anthromantle at $41 \mathrm{BX} 126$ was most likely 


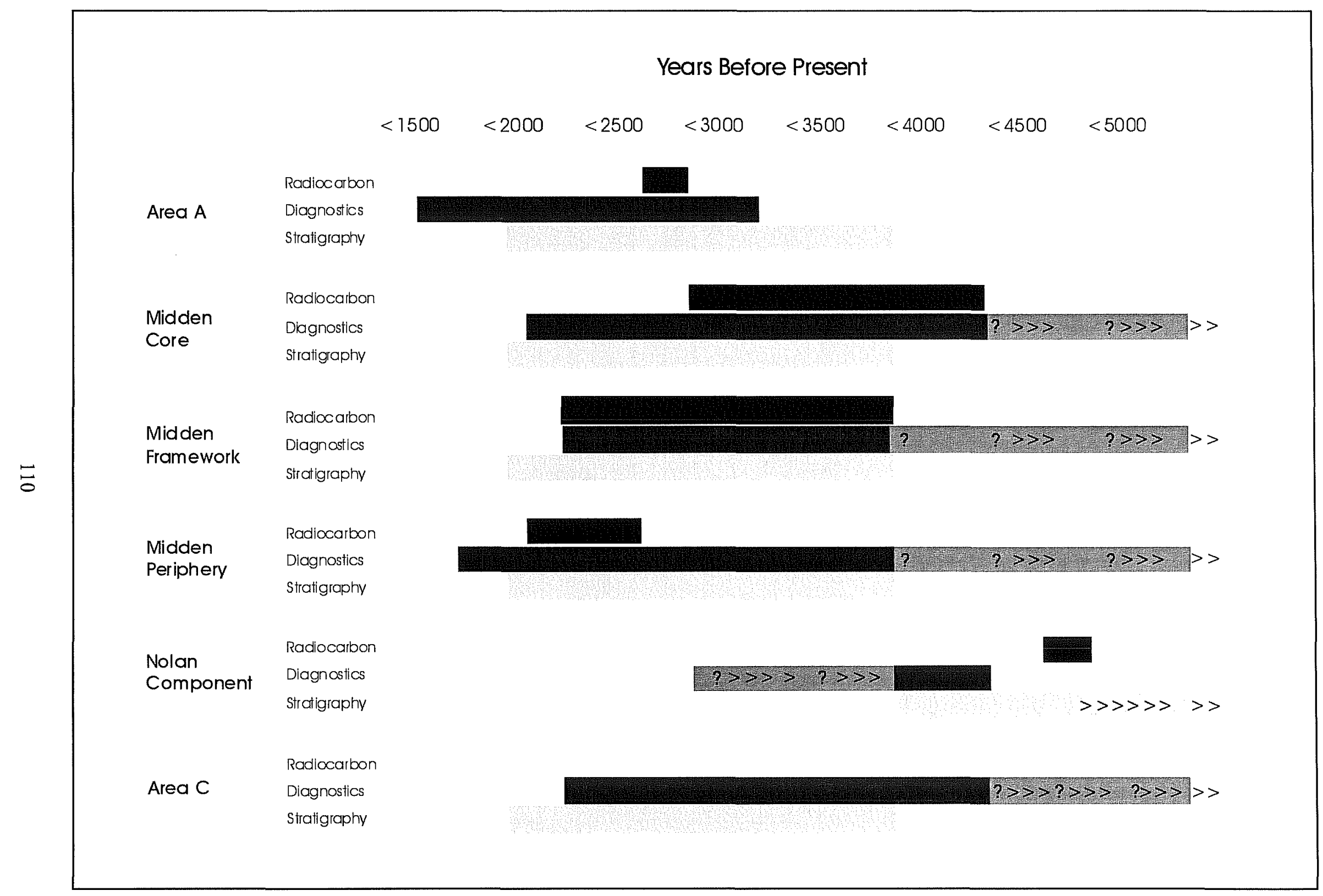

Figure 6-54. Chronometric dating of 41BX126. 
Table 6-20. Evidence for Dating Area B: Midden Core

\begin{tabular}{|l|l|l|}
\hline \multicolumn{1}{|c|}{ Evidence } & \multicolumn{1}{|c|}{ Provenience } & \multicolumn{1}{c|}{ Interval/Date } \\
\hline \multirow{2}{*}{ Charcoal Dates } & Feature 1.2 & 3040 B.P. $( \pm 70)$ \\
\cline { 2 - 3 } & Feature 1.2 & 2950 B.P. $( \pm 70)$ \\
\cline { 2 - 3 } & Feature 1.2 & 4050 B.P. $( \pm 50)$ \\
\hline Stratigraphy & Units III-IV, T2 & ca. 4000-2000 B.P. \\
\hline Projectile points & & \\
\hline Ellis & TU 8, Lv1 2 & Late Archaic \\
\hline Castroville & TU 8, Lv1 3 & Late Archaic \\
\hline Marshall & TU 9, Lv1 2 & Late Archaic \\
\hline Pedernales & TU 9, Lv1 2 & Late Archaic \\
\hline Pedernales preform & TU 9, Lv1 2 & Late Archaic \\
\hline Castroville & TU 9, Lvl 3 & Late Archaic \\
\hline Travis & TU 8, Lvl 5 & Middle Archaic \\
\hline Nolan & TU 9, Lv1 2 & Middle Archaic \\
\hline Uvalde & TU 8, Lvl 5 & Early Archaic \\
\hline Martindale & TU 9, Lv1 6 & Early Archaic \\
\hline
\end{tabular}

Note: Proveniences pertain to CAR (1997) unless otherwise noted.

built from sediment borrowed from around the midden; thereby causing artifacts of earlier occupations lying on or below the surface to become part of the midden assemblage. Recent experiments with burned rock midden formation processes suggest that a midden as large as that at $41 \mathrm{BX} 126$ can form very quickly, over a matter of a few hundred years or perhaps even decades (Appendix D), suggesting the possibility of a restricted period of use.

\section{The Midden Framework}

Wood charcoal radiocarbon assays were obtained from four features $(1.1,1.4,1.5$, and 1.6) in the midden's framework (Table 6-1). A date of $2980 \pm 50$ B.P. came from Feature 1.1, $2280 \pm 50$ B.P. from Feature 1.4, $3920 \pm 60$ B.P. from Feature 1.6, and $3920 \pm 60$ B.P. from Feature 1.6 (Table 6-21). Two Early Archaic tools, three Middle Archaic dart points, and two Late Archaic dart points were recovered in the midden's framework (Table 6-21).
Collectively, it is argued that the seven diagnostic artifacts can be associated with a period between 4000 and 7950 B.P. (Collins 1995; Hester 1995). A Late Archaic Bulverde point was found in BHT G, $90 \mathrm{~cm}$ bs (Level 9). The Bulverde arguably dates to around 4000-3300 B.P. A Late Archaic Pedernales was found in Gradall trench backdirt. A Nolan point (Middle Archaic) was recovered from Level 5 in TU D. Nolan points are prevalent in archaeological records dating to ca. $4000-4500$ в.P. Two Middle Archaic La Jita points were found, one in TU D, Level 2; and one in TU 7, Level 5. The La Jita date to $4500-4000$ в.P. (Collins 1995:Table 2). The sixth diagnostic artifact is a Guadalupe tool recovered from TU D, Level 9. Finally, a Clear Fork tool was found in TU 8, Level 3. The Clear Fork and Guadalupe tools could date to as early as 10,000 B.P. (Black 1995b; Bousman 1997; Hester 1995; Turner and Hester 1993). Stratigraphically, the midden framework lies on top of Unit IIIa and IIIc of the T2 flood terrace which stopped forming ca. 4000 B.P. Stratigraphic Unit IV enveloped the framework until about 2000 B.P. (Nordt, Chapter 5), during and perhaps after midden use. 
Table 6-21. Evidence for Dating Area B: Midden Framework

\begin{tabular}{|l|l|l|}
\hline \multicolumn{1}{|c|}{ Evidence } & \multicolumn{1}{|c|}{ Provenience } & \multicolumn{1}{c|}{ Interval/Date } \\
\hline Charcoal Date & Feature 1.1 & 2980 B.P. $( \pm 50)$ \\
\hline Stratigraphy & Units IIIa and c; IV, T2 & ca. 4000-2000 B.P. \\
\hline Diagnostic Artifacts & & \\
\hline Bulverde & Trench G, Lvl 9 (Price) & Late Archaic \\
\hline Pedernales & GT, Lvl 2 & Late Archaic \\
\hline Nolan & TU D, Lvl 5 (Price) & Middle Archaic \\
\hline La Jita & TU D, Lvl 2 (Price) & Middle Archaic \\
\hline La Jita & TU 7, Lvl 5 & Middle Archaic \\
\hline Clear Fork & TU 18, Lvl 3 (Wood) & Early Archaic \\
\hline Guadalupe Tool & TU D, Lvl 9 (Price) & Early Archaic \\
\hline
\end{tabular}

Note: Proveniences pertain to CAR (1997) unless otherwise noted.

Based solely on the diagnostic artifacts recovered, the framework appears to have formed sometime between 7950 and 2300 B.P. (Table 6-21). However, the four radiocarbon dates ranging from 3920-2280 B.P., and the 4,000-year-old terrace surface upon which the base of the framework rests provide a more restricted beginning date. As stated above, one La Jita point came from TU 7, Level 5 (the same level as the ca. 4000year-old Nolan point) which is stratigraphically consistent with the underlying Unit III (Bk) depositional surface, and the unit upon which the base of the midden sets. A second La Jita point came from the upper $20 \mathrm{~cm}$ of the framework (Level 2 in TU D), well above the contact between Stratigraphic Unit III and the base of the framework, and stratigraphically within deposition Unit IV which formed between 4,000 and 2,000 years ago. Also problematic with dating the midden based solely on diagnostics artifacts is the presence of the Guadalupe tool, which some researchers (e.g., Black 1995b; Hester 1995) posit is an Early Archaic tool. However, the specimen recovered from deep (Level 9; $80-90 \mathrm{~cm} \mathrm{bs)} \mathrm{within} \mathrm{TU} \mathrm{D} \mathrm{is} \mathrm{ca.} 20 \mathrm{~cm}$ below the top of Stratigraphic Unit III and the midden base. Thus a number of Early Archaic and Middle Archaic tools are below the midden in the upper portion of Unit III. Nevertheless, artifacts in the framework indicate mixed assemblages.

The issue of a mixed artifact assemblage is as problematic within the framework as it is for the core. Nordt suggests slow sediment deposition and concomitant midden construction contributes to mixed artifact assemblages. As we argue elsewhere in this document, 1) the midden's anthromantle at 41BX126 was in part built from borrowed sediment around the midden, thereby causing artifacts of earlier occupations lying on or below the surface to become part of the midden assemblage; and 2) recent experiments with burned rock midden formation processes suggest that even one as large as the midden at 41BX126 can form very quickly, over a matter of a few hundred years or even decades (Appendix D). The older Clear Fork and Guadalupe tools may represent an earlier occupation at the site before the midden formed, possibly as early as 6650 B.P. (Hester 1995). In fact, Nordt (Chapter 5) states that Stratigraphic Units IIIa and IIIc upon which the base of the midden rests "are mainly early to mid Holocene in age and therefore may have deeply stratified Paleoindian or Early to Middle Archaic components." Nordt (Chapter 5) further offers that based on time-diagnostic artifacts and ${ }^{14} \mathrm{C}$ ages, it appears that use of the midden began around 4000 B.P. Remains of this occupation were evident as features [Features 1.4 and 1.5] that had been excavated into the upper part of Stratigraphic Unit III. The remainder of the burned rock midden apparently formed concomitant with deposition of Unit IVa and IVc between approximately 4000 and 2000 B.P.

This suggests that basal and pit features 1.4 and 1.5 were dug into the ca.-4,000-year-old T2 terrace surface, displacing and mixing artifacts from earlier occupations. Subsequent borrowing from the surrounding sediments to construct the main midden 
above Features 1.4, and 1.5 caused further mixing. In the final analysis, we believe that all the diagnostic artifacts found in the framework do not represent a period when the midden was being used. Admittedly, radiocarbon dates are subject to the same secondary processes that complicate the context of the diagnostic artifacts. However, the four radiocarbon dates and the stratigraphy most probably reflect the midden's chronometric use range of between 4000 and 2000 B.P. (Figure 6-54).

\section{The Midden Periphery}

Although no radiocarbon dates are available for the slablined oven (Feature 4), and the burned rock cluster (Feature 6) excavated within the midden's periphery, three charcoal dates were obtained from TU 11 (Table 6-22). Floated charcoal from Level 3 dated to $2180 \pm 50$ B.P.; Level 4 dated to $2170 \pm 50$ B.P.; and Level 6 dated to $2750 \pm 50$ B.P. Twenty-three diagnostic artifacts were recovered from five excavation units and three backhoe trenches. Seventeen of the 23 are diagnostic of the Late Archaic interval, five of the Middle Archaic, and one of the Transitional Archaic (Table 6-22). Referring to Collins's (1995:Table 2) and Hester's (1995) proposed point chronologies, the Late Archaic points range in age from ca. 4000 B.P. through ca. 1000 B.P. The five Middle Archaic point ages range between ca. 6000 and ca. 2350 B.P. The Transitional Archaic San Gabriel biface can be placed between 1750 B.P. and 1450 B.P. (Turner and Hester 1993:273). Stratigraphically, Features 4 and 6 rest upon what Nordt (Chapter 5) has identified as depositional Unit III which began forming around 11,000 years ago and stopped forming by about 4,000 years ago. The envelopment of these two features by Stratigraphic Unit IV occurred between 4000 B.P. and 2000 в.P. (Figure 6-54).

As with the midden framework, the entire diagnostic assemblage is not a valid indicator of the time period during which Features 4 and 6, and the midden's periphery were being utilized. As discussed in "The Midden Core" and "The Midden Framework" sections, the artifact mixing evident within the midden periphery, although to a lesser degree, is caused by the cultural borrowing of sediments to construct earth ovens. Instead, radiocarbon dates from TU 11, along with Nordt's assessment of sediment deposition are more reliable indicators of the chronometric placement of Features 4 and 6 between 4000 and 2000 B.P.

The argument for sediment borrowing not only helps explain how artifacts dating as much as 1,500 years (5500 B.P.) earlier than the midden's and concomitant features' usage are present within those features, but also strongly suggests the existence of at least an Early Archaic component underlying the midden and buried within Nordt's Stratigraphic Unit III. Problematic, however, with the argument for sediment borrowing is the presence of diagnostic artifacts which are argued to date as much as 1,000 years after the midden's abandonment. To address this issue we must examine the San Gabriel biface and the three Darl points which, according to Collins (1995), fall outside the apparent latest, 2000 B.P., date for the periphery. One Darl was recovered from Level 5 in TU 4, a second also from TU 4 in Level 6, and a third from Level 5 in Wood's TU 20. Collins (1995: Table 2) posits that the Darl was used most commonly between 1200 and 1000 B.P. However Turner and Hester $(1993: 101,273)$ associate the Darl point with the Transitional Archaic, ca. 1750 B.P., and as previously stated, the San Gabriel with the Transitional Archaic between 1450 B.P. and 1750 B.P. These dates are within 250 years of our dates for the midden's periphery, a relatively dated period which can associate the Darl and the San Gabriel with the latest use of the midden.

\section{The Nolan Component}

A distinct Nolan component is evident in Levels 3 and 4 of CAR's units (Figures 6-55 and 6-56), and Levels 6 and 7 of Price's TU C within the block excavation area. Depending on the stratigraphy within each of the units, the Nolan component is generally located between 65 and $85 \mathrm{~cm}$ bs (site elevations $100.0-99.80 \mathrm{~m})$.

Three distinct, large burned-cobble clusters (Features 7,11 , and 12) were identified within the Nolan component. Three radiocarbon dates were obtained from two of the three features (Table 6-19). A date of $4940 \pm 50$ B.P. came from a flotation sample at the base of Feature 7 in TU C, Level 8, and a date of $4630 \pm 40$ B.P. came from an in situ chunk of charcoal in the upper portion of Feature 7. Charcoal from a flotation 
Table 6-22. Evidence for Dating Area B: Midden Periphery

\begin{tabular}{|c|c|c|}
\hline Evidence & Provenience & Interval/Date \\
\hline \multirow[t]{3}{*}{ Charcoal Dates } & TU 11, Lvl 3 & 2180 B.P. $( \pm 50)$ \\
\hline & TU 11, Lvl 4 & 2170 B.P. $( \pm 50)$ \\
\hline & TU 11, Lvl 6 & 2750 B.P. $( \pm 50)$ \\
\hline Stratigraphy & Unit IIIa & ca. 2700 B.P. \\
\hline \multicolumn{3}{|l|}{ Diagnostic Artifacts } \\
\hline San Gabriel Biface & Trench G, Backdirt (Price) & Transitional Archaic \\
\hline Bulverde & TU 20, Lvl 3 (Wood) & Late Archaic \\
\hline Castroville & BHT X, Lvl 1 & Late Archaic \\
\hline Castroville & TU A, Lvl 1 (Price) & Late Archaic \\
\hline Darl & TU 4, Lv1 5 & Late Archaic \\
\hline Darl & TU 20, Lvl 5 (Wood) & Late Archaic \\
\hline Darl & TU 4, Lvl 6 & Late Archaic \\
\hline Langtry & Surface (Price)* & Late Archaic \\
\hline Marcos & BHT P, Backdirt & Late Archaic \\
\hline Montell & TU 4, Lvl 3 & Late Archaic \\
\hline Montell & TU 11, Lvl 1 & Late Archaic \\
\hline Montell & BHT P, Backdirt & Late Archaic \\
\hline Pedernales & TU 17, Lvl 3 (Wood) & Late Archaic \\
\hline Pedernales & Trench G, Backdirt (Price) & Late Archaic \\
\hline Pedernales & BHT O, 100.373 elev. & Late Archaic \\
\hline Pedernales & BHT O, Backdirt & Late Archaic \\
\hline Pedernales Preform & TU $11, \mathrm{Lv} 14$ & Late Archaic \\
\hline Williams & TU 11, Lv1 2 & Late Archaic \\
\hline Bell & TU 11, Lv1 7 & Middle Archaic \\
\hline Carrizo & TU 11, Lvl 4 & Middle Archaic \\
\hline Carrizo & TU $11, \mathrm{Lvl} 4$ & Middle Archaic \\
\hline La Jita & BHT O, Backdirt & Middle Archaic \\
\hline La Jita & TU 17, Lvl 2 (Wood) & Middle Archaic \\
\hline
\end{tabular}

* Midway between Trenches $H$ and $J$ on the floodplain.

Note: Proveniences pertain to CAR (1997) unless otherwise noted.

sample taken in and around Feature 11 proved to be modern. All diagnostics within the Nolan component can be associated with the Middle Archaic in Central or South Texas (Table 2-1): one Tortugas, one Langtry, one Nolan-like, and five Nolan dart points were recovered from the Nolan component (Tables 6-9 and 6-23). Other diagnostics recovered from the Block Excavation that cannot be associated with the distinct Nolan component are two Late Archaic Pedernales points, one Bulverde, one Castroville, one Montell, and one Middle Archaic Langtry (Appendix E, Table E-1). The temporal range of the Nolan type has been placed as early as 6000 B.P. (Turner and Hester 1993:164). However, Johnson and Goode (1994:2428 ) consider the Nolan interval to date from no earlier than 4950 B.P., and Collins (1995) dates the Nolan interval from $4500-4000$ B.P. The Langtry is diagnostic of the Middle Archaic San Felipe period, ca. 4100 3200 в.P. in the Lower Pecos region (Turpin 1991). The Tortugas which is often confused with Early 


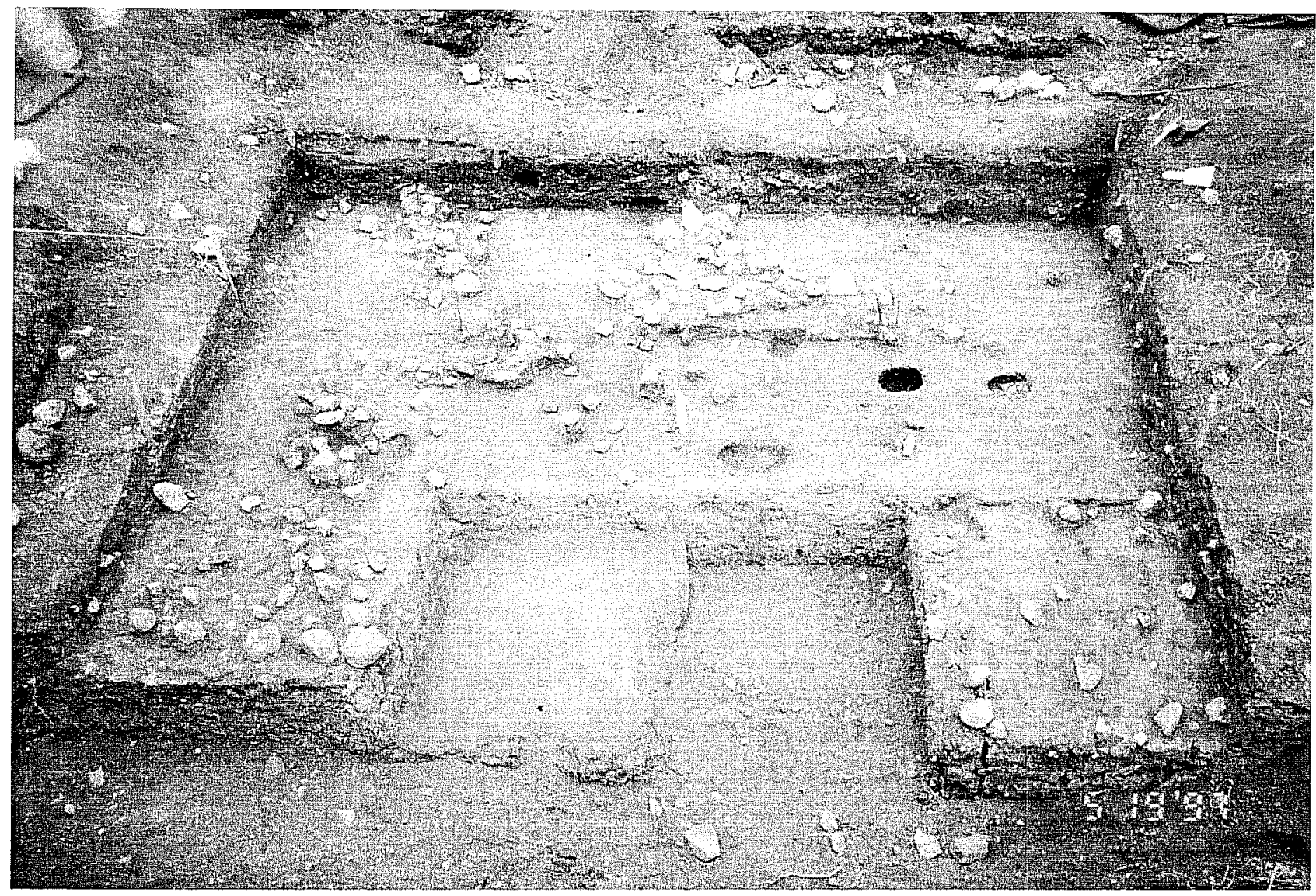

Figure 6-55. Photograph of the Nolan component in Level 3 of the block excavation. Note Features 11 and 12 , and burrows. Also TU C and TU 12 excavated below the block.

Table 6-23. Evidence for Dating Area B: Nolan Component (Block Excavation)

\begin{tabular}{|l|l|l|}
\hline \multicolumn{1}{|c|}{ Evidence } & \multicolumn{1}{|c|}{ Provenience } & \multicolumn{1}{c|}{ Interval/Date } \\
\hline \multirow{2}{*}{ Charcoal Dates } & TU 12, Lvl 3 & $4630( \pm 40)$ B.P. \\
\cline { 2 - 3 } & TU 18, Lvl 4 & Modern \\
\cline { 2 - 3 } & TU C, Lvl 8 & $4940( \pm 50)$ B.P. \\
\hline Stratigraphy & Units IIIa\&c, T2 & ca. 11,000-4000 B.P. \\
\hline Diagnostic Artifacts & \multicolumn{2}{|c|}{} \\
\hline Nolan & TU 12, Lvl 3, Upper $5 \mathrm{~cm}$ & Middle Archaic \\
\hline Nolan-like & TU 12, Lvl 3, Upper $5 \mathrm{~cm}$ & Middle Archaic \\
\hline Nolan & TU 16, Lvl 3, Lower $5 \mathrm{~cm}$ & Middle Archaic \\
\hline Nolan & TU 16, Lvl 3, Lower $5 \mathrm{~cm}$ & Middle Archaic \\
\hline Nolan & TU 17, Lvl 4, Lower $5 \mathrm{~cm}$ & Middle Archaic \\
\hline Nolan & TU 23, Lvl 3, Lower $5 \mathrm{~cm}$ & Middle Archaic \\
\hline Tortugas & TU 14, Lvl 4, Upper $5 \mathrm{~cm}$ & Middle Archaic \\
\hline Langtry & TU 17, Lvl 4, Lower $5 \mathrm{~cm}$ & Middle Archaic \\
\hline
\end{tabular}

Note: Proveniences pertain to CAR (1997) unless otherwise noted. 


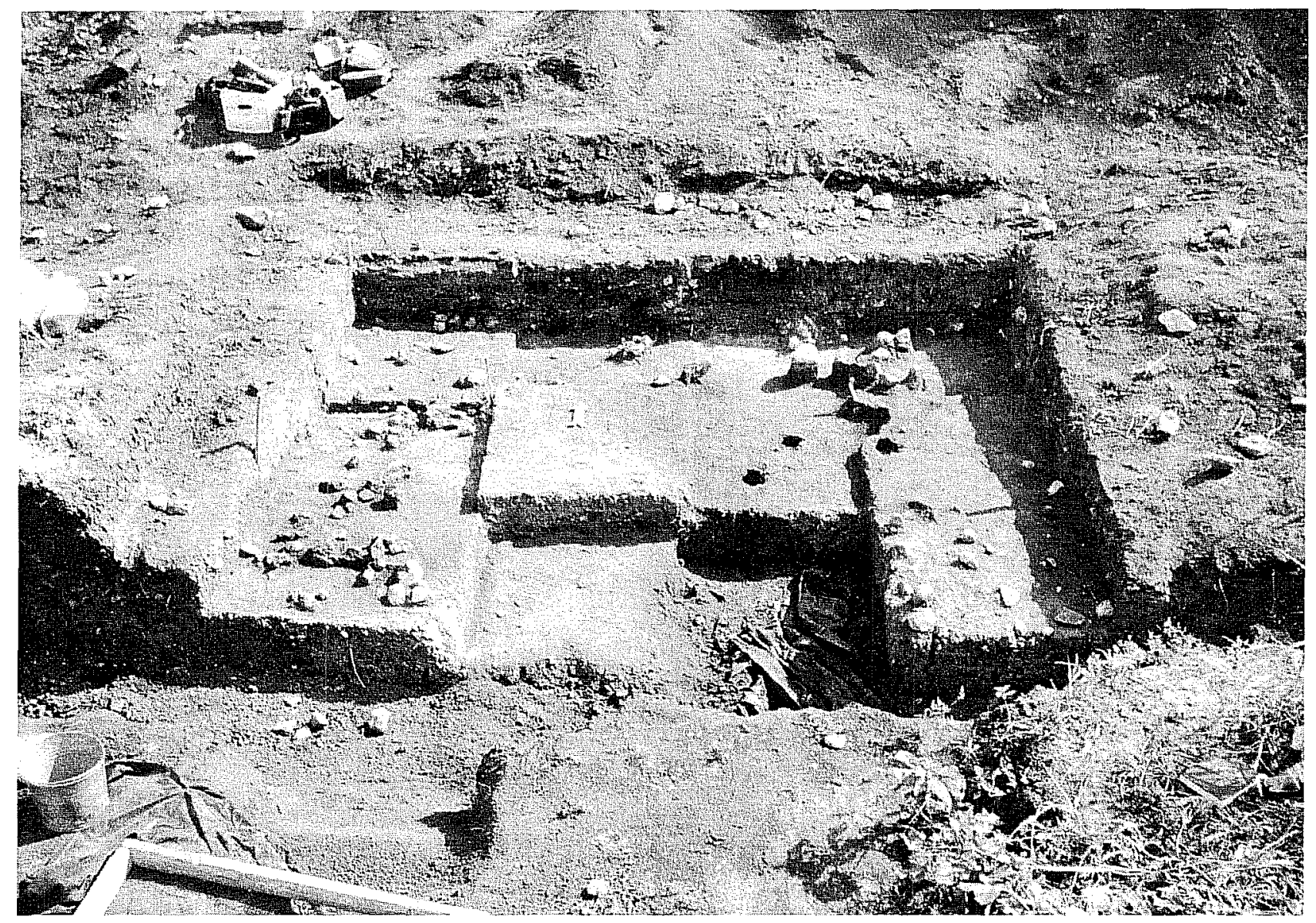

Figure 6-56. Photograph of Nolan component in block excavations at varying depths within Level 4.

Triangular (Early Archaic), dates to between 2800 2550 B.P. Stratigraphically, the Nolan component lies below the midden, and within the top $10-15 \mathrm{~cm}$ of Nordt's defined Stratigraphic Unit III which formed between 11,000 and 4,000 years ago. A bulk soil humate date of $4370 \pm 50$, obtained from adjacent BHT $\mathrm{X}$ at a site elevation of $99.80 \mathrm{~m}$, is stratigraphically consistent with the bottom of the Nolan component. However, Nordt suggests this assay is slightly too young.

Based on the best available evidence, the Nolan component at $41 B \times 126$ certainly dates between 4940 and 4000 в.P. (Table 6-23, Figure 6-54). Based solely on the eight diagnostic points recovered, it would appear that the Nolan component should be dated later, between 4500 and 2800 B.P. However, absolute dates obtained for the cultural component and the sediments enveloping its base are more reliable predictors of occupation period. The single humate date of $4370 \pm 50$ B.P. certainly represents an acceptable range with the charcoal date of $4630 \pm 40$ в.P. The ${ }^{14} \mathrm{C}$ assay of $4940 \pm 50$ в.P. is stratigraphically at the base of the Nolan component. The absolute dates are also closely aligned with the predominance of Nolan points (6 of 8) which are argued as diagnostic between 4000 and 4500 B.P. Even the single Langtry point is argued to be diagnostic between 4100 and 3200 B.P. Problematic with dating the component based solely on diagnostics is the presence of the later Tortugas (2800-2550 в.P.). As stated previously, the Tortugas is often confused with the Early Triangular and so its place in the chronology of point types is still questionable. A detailed discussion of this particular Tortugas is given in Chapter 8 .

\section{Dating Area C}

No features were encountered and no absolute radiocarbon dates were obtained from Area C. However the area can be discussed in terms of relative and stratigraphic chronologies. Three Late Archaic Pedernales, 
a Middle Archaic Bell, and an Early Archaic Martindale were recovered from the area (Table 6-24). Stratigraphically, the excavation units which yielded two Pedernales, a Bell, and a Martindale are situated on the western edge of the same T2 terrace which contains the midden and Nolan component in Area B (Nordt, Chapter 5) and as such it consists of Stratigraphic Unit III, estimated as forming between 11,000 and 4,000 years ago. Then from 4,000-2,000 years ago, Stratigraphic Unit IV inundated the archaeological remains on or within Stratigraphic Unit III. The relative point chronology is similar to that of Area $B$. The Pedernales points are associated with the period from ca. 2300-3200 в.P., the Bell between ca. 5000 and 5800 B.P., and the Martindale between 5800 B.P. and 7000 B.P. (Collins 1995). Most obvious is that the small sample of diagnostics range from Late to Early Archaic. With no radiocarbon dates and only limited testing, we do not have sufficient evidence with which to confidently date the area. Based on the available evidence (Table 6-24), it appears that Area $C$ was occupied during the same intervals as Area B; however, no distinct features or Archaic buried components were recognized.

\section{Summary}

Three archaeological testing and geoarchaeological investigation projects have been conducted by Wood in 1993, Price in 1995, and CAR in 1997. For management purposes CAR divided the site into three areas: Area A being the new right-of-way east of Loop 1604, Area $B$ being the main midden and its periphery between Area A and Loop 1604; and, Area C being west of Loop 1604 (Figure 2-1). In all, 29 backhoe trenches were opened and in some cases reopened, 55 test units were excavated, 36 shovel tests were dug, and five Gradall trenches, and three Gradall scrapes were excavated. The investigations documented 17 burned rock features - six which could be directly associated with the construction of a main midden and 11 which were interpreted as separate heating or cooking features-and a discrete Nolan component stratigraphically below the base of the midden. Over 59,000 lithic artifacts, 1,655 liters (1,753 quarts) of flotation samples, $3,337 \mathrm{~kg}$ (3.67 tons) of burned rock, and nearly $300 \mathrm{~kg}$ of faunal material were collected, processed, and analyzed to some extent at the CAR lab (Chapter 10 and Appendix F). Nineteen flotation samples were analyzed for macrobotanical remains at Texas A\&M University (Chapter 9). One hundred twenty archaeomagnetic samples from eight features were collected; twenty-five of those samples from three features were processed at the Texas Paleomagnetism Laboratory at The University of Texas at Austin. One hundred thirty-six soil susceptibility samples were also processed at the Paleomagnetism Laboratory (Chapter 11). Geoarchaeological investigations further defined the four terraces and four depositional units contributing to the site's formation processes. For chronometric dating, 15 wood charcoal and six sediment assays were obtained, and 66 diagnostic artifacts were recovered.

Table 6-24. Evidence for Dating Area C

\begin{tabular}{|l|l|l|}
\hline \multicolumn{1}{|c|}{ Evidence } & \multicolumn{1}{|c|}{ Provenience } & \multicolumn{1}{c|}{ Interval/Date } \\
\hline Stratigraphy & Units III-IV, T2 & ca. 4000-2000 B.P. \\
\hline Diagnostic Artifacts & & \\
\hline Pedernales & TU E, Lv1 4 (Price) & Late Arch aic \\
\hline Pedernales & Surface, N1080 E929 & Late Archaic \\
\hline Pedernales & Trench C, Backdirt (Price) & Late Archaic \\
\hline Bell & TU 5, Lvl 3 (Wood) & Middle Archaic \\
\hline Martindale & ST 16, Lvl 3 (Wood) & Early Archaic \\
\hline
\end{tabular}

Note: Proveniences pertain to CAR (1997) unless otherwise noted. 
In sum, the best available evidence suggests 41BX126 was either continuously or intermittently occupied for periods of unknown duration between around 5,0002,000 years ago (Figure 6-54). Although the recovery of an Early Archaic Clear Fork Gouge, A Guadalupe tool, two Martindale points, and a Uvalde point hint of an earlier human presence, further investigations will be required to document an Early Archaic occupation. The three testing projects have provided the evidence that hunter-gatherers occupied a nearly stable T2 terrace along Culebra Creek and left behind cultural material identified as a discrete Nolan component between 5,000 and 4,000 years ago. As the T2 stabilized around 4,000 years ago, its surface was occupied by others who constructed burned rock features, including the main midden between 4,000 and 2,000 years ago. Gentle flooding episodes enveloped the midden and peripheral burned rock feature from around 2,000 years ago to the present. 


\title{
Chapter 7: Cultural and Secondary Formation Processes: On the Dynamic Accumulation of Burned Rock Middens
}

\author{
Jeff D. Leach and C. Britt Bousman
}

\section{Introduction}

Among Texas archaeologists is a growing consensus on the behaviors responsible for the formation of burned rock middens. Nevertheless, even a cursory review of the literature illustrates that over the years numerous theories have been put forward to explain these enigmatic features that have fascinated and perplexed Texas archaeologists for almost a century (e.g., Abbott et al. 1996; Black and McGraw 1985; Black et al. 1997; Collins 1991, 1994, 1995; Creel 1986, 1991; Goode 1991; Hester 1970, 1971; Katz 1987; Kelly 1961; Kelley and Campbell 1942; Kleinbach et al. 1995; Pearce 1919; Peter 1982; Prewitt 1991; Quigg and Ellis 1994; Treece et al. 1993a; Weir 1976). In recent years, a renewed interest in burned rock middens has sparked the organization of workshops, symposia, and even an edited volume (e.g., Hester 1991).'

Considerable progress in burned rock research has been made since the early excavations and interpretations of Pearce (1919). Archaeologists have become more rigorous in their field and analytical methods (e.g., Abbott and Frederick 1990; Goldberg 1995; Potter et al. 1995), and more sophisticated and critical of their quantitative techniques. In their review of nearly 80 years of burned rock research in Texas, Black et al. (1997) set the stage for current and future research, and analyze and synthesize a huge, seemingly amorphous, mass of archaeological data on burned rock middens. In the end, Black and Creel (1997) conclude that most middens in central Texas do, indeed, exhibit internal structure and are annular (ring) features that functioned as central-focused ovens. Black and Creel (1997) provide strong arguments that show middens are not the result of systematic communal dumping. Along with Thoms (1996) they suggest that a wide range of resources, both plant and animal, were probably processed in these pit ovens using "cook stones."

Most researchers agree that the masses of charred and fragmented stone that make up these impressive features are the by-products of cooking with hot-rocks. While the actual processes that resulted in the deposition and fragmentation of charred rocks and the food(s) they cooked is still undetermined, the use of stones as heat-sinks for transferring heat to foodstuffs that require prolonged cooking is widely accepted. However, archaeologists begin to diverge and split into camps when midden content is interjected into the issue of midden formation. By content, we mean the various biotic and abiotic materials recovered from middens (Collins 1991:9). These can include, but are not limited to, chipped-stone debitage and tools, ground stone, faunal and floral remains, snails, mussel shells, ornaments, burials, ceramics, and so on. This may also include intrusive (non-cultural) items as well.

It is suggested here that the content within these middens, not the charred and fragmented rocks, have played the pivotal role in structuring and forming the various theories on midden formation. For example, based on their work at Fort Hood, Kleinbach et al. (1995; see also Abbott et al. 1996) argue for separating burned rock middens into two categories: middens and mounds. ${ }^{2}$ Briefly, "a burned rock mound is defined as an accumulation of burned rock (typically limestone) exhibiting discernible relief above the ground surface and having a fairly regular, circular or oval shape in plan view" (Kleinbach et al. 1995:773). Whereas, a burned rock midden "is a relatively thick, amorphous deposit of buried burned rock that does

${ }^{1}$ Buckley (1990) and Hodder and Barfield (1991) provide similar reviews of burnt mound or Fulachta fiadh (cooking place) research in the Old World. 
not exhibit significant relief and varies greatly in shape and size" (Kleinbach et al. 1995:775). ${ }^{3}$ However, the authors suggest that "the strongest argument for the asserted distinction between burned rock mounds and middens concerns differences in artifact content" (Kleinbach et al. 1995:782, emphasis added). Middens contain a greater number of artifacts than mounds, which "implies that the two types of features represent distinct and separate cultural phenomena" (Kleinbach et al. 1995:783). ${ }^{4}$ The authors interpret the middens, with their greater artifact numbers and variety (which also includes fauna), as evidence of multifunctional facilities. On the other hand, the mounds, with their low artifact numbers and variety (and dearth of fauna), as evidence of a limited range of activities/ functions for features. The burned rock are treated in a gross manner with little detailed analysis.

In another example at the Mustang Branch site, Collins (1994:171) interpreted the wide range of cultural material recovered from the midden as evidence that "such activities as hunting, carcass processing, stone-boiling bone for the production of bone grease, flint knapping, manufacturing and maintenance of various perishable artifacts, and plant food collecting and processing transpired on and near the midden." These two examples indicate that the content, not the burned rocks, receive the greatest analysis and interpretative effort.

These examples (and countless others) demonstrate the difficulty of interpreting the content of many middens. Understandably, inferences about the behavior(s) responsible for midden formation are largely based on content, with much less emphasis on the fragmented rocks and the features themselves.
Aside from assessing midden function(s) and formation through content, chronological issues have relied heavily on cross dating of diagnostic artifacts recovered from middens. The presence of diagnostic artifacts, among the fragmented rocks, is perhaps one of the most perplexing components of these features. Projectile points (dart and arrow points) and other lithic material associated with the cooking of foods in earth-ovens has been explained as trash dumps or middens. Since Black and Creel (1997) have discounted this idea no satisfactory explanation for this association exists. Many researchers often account for earlier projectile points as evidence of recycling and scavenging. However, these secondary behavioral processes (Schiffer 1987) are called upon very selectively by investigators, and often fall short of explaining the quantities of diagnostic artifacts and other materials mixed in amongst the charred and fragmented rocks. This impasse is due, in no small part, to the dearth of middle-range (Binford 1980, 1983) and site formation (e.g., Schiffer 1972, 1975, 1976, 1983, 1987; Stein 1987) theory governing burned rock research. Richard Stark, Susan Decker, and Stephen Black of the Texas Archaeological Research Laboratory have recently organized a series of experimental workshops (Headwaters Group) to conduct actualistic studies that will result in an enhanced understanding of burned rock features. These workshops and experiments should further our understanding of hot-rock technology when the results are synthesized and disseminated.

The next section of this chapter provides a site formation model for studying large, burned rock features. Then the implications of the test excavations at Culebra Creek are discussed (detailed findings are given in Chapter 6).

${ }^{2}$ Researchers working at Fort Hood (Abbott et al. 1996; Kleinbach et al. 1995) recently proposed a distinction between burned rock mounds and middens based on overall morphology and artifact content. For the purposes of this report, the term midden is maintained for the most part. However, this point is revisited later in the chapter and new terminology proposed. The Fort Hood researchers also recognize other forms of burned rock features they call rock concentrations and hearths.

${ }^{3}$ Black and Creel (1997:288-289) review the Fort Hood data and assess the midden versus mound controversy. They question the need to divide burned rock mounds into midden and mound categories.

${ }^{4}$ This is admittedly an oversimplification of the arguments made by the Fort Hood researchers. The reader is referred to the numerous reports outlining their findings (Abbott and Trierweiler 1995; Trierweiler 1994, 1996). 
Specifically, it is suggested that 1) the bulk of the midden at $41 \mathrm{BX} 126$ formed from the discard of earth, fragmented rock, and other detritus associated with the pit baking of foods in earth-ovens constructed, dismantled, and rebuilt numerous times in a centrally focused area; 2) other intact rock-lined features are present within the framework of the midden and have contributed to its formation; 3) an undetermined but significant percentage of the midden's artifactual content is in a secondary context having been introduced to the midden through borrowing of sediment; 4) borrowing of sediment used in the construction of earthen caps for earth-ovens is evidenced as basal rock-filled pits (borrow pits) that extend below the midden; 5) we cannot confidently rely on the content of the midden, especially the torus, to address research issues such as temporal use and function of the midden, itself, because of sediment borrowing and the potential of mixing occupations; and 6) the formation and subsequent mass wasting of spoil associated with the numerous cooking events directly and indirectly altered the midden's immediate environ, resulting in a complex depositional history of the midden deposit. It is also suggested that this burned rock midden and other middens are best viewed from a site formation perspective, with emphasis on cultural and secondary processes. The term anthromantle (discussed below) is introduced to characterize the dynamic processes involved in the accumulation and subsequent denudation of these deposits.

\section{A Brief Review of Burned Rock Research in Central and South-central Texas}

In this section, previous burned rock midden research is briefly discussed. Black et al. (1997; see especially Chapter 4: Scenarios of Midden Accumulation) provide a comprehensive synthetic overview of midden research, the reader is referred to that source for a thorough treatment of the topic (also see Hester 1991). Collins (1991:5, 1994), following Prewitt (cited in Collins 1991), summarizes the prevailing hypothesis that have been put forward to untangle the formation of burned rock middens, as follows: 1) burned rock middens are the result of construction of intersecting hearths on a stable surface at a single locality over a long period of time; 2) burned rock middens are the result of the centralized dumping of domestic refuse, including broken hearth rocks; 3 ) burned rock middens are the remains of earth ovens; and 4) burned rock middens are accumulations of rock cooking slabs broken from heat. These four interpretive scenarios, and various forms of them, dominate the burned rock midden literature. Middens as intersecting hearths and as centralized dumps deserve some comment and will be briefly addressed in the following section. The remaining two hypothesis (middens as earth-ovens or accumulations of cooking slabs) are integrated with the arguments of Black et al. (1997) (i.e., middens were centrally focused cooking facilities) later in this chapter.

\section{Kelley and Campbell's Intersecting Hearths}

In 1942 Kelley and Campbell published an article entitled "What Are the Burnt Rock Mounds of Texas?" In this paper they outline the formational history of "burnt mounds" from work conducted by the WPAUniversity of Texas archaeological project along the Colorado River near Austin. Briefly, "burnt rock mounds were developed by the use and re-use of favored areas for the building of stone-lined hearths ... burnt rock mounds were not purposefully constructed and do not in themselves constitute a cultural trait" (Kelley and Campbell 1942:322, emphasis added). Kelley and Campbell were interested in explaining why burnt mounds formed and citing the earlier work of Pearce (1919), they express dissatisfaction with the lack of explanation of "why hearths should continue to be built in the same places, so that burnt rock mounds should be formed" (Kelley and Campbell 1942:320, emphasis in the original).

At a general level, Kelley and Campbell see the fragmented and charred rocks that make up the burnt rock mounds as originating from hearths used for baking and roasting. "Prolonged and repeated heating caused the hearthstones to break up into many angular fragments. The hearths were then cleared of old stones and relined, or else abandoned. Later other hearths were built in the same area, the result being a complex assemblage of superimposed and intersecting hearths" (Kelley and Campbell 1942:320; see also Huskey 
1935; Suhm 1959, 1960). Kelley and Campbell (1942:Figure 38) outline their intersecting hearth theory in an idealized profile of a $40-\mathrm{ft}$ terrace along the Colorado River (Figure 7-1). They argue that hearth stones and artifacts located at the bottom of the profile (the oldest material) were incidental inclusions, scattered about by stream flow as a result of the "camp" being located on a low, swampy area near the stream. As the terrace built up, the area became "more attractive as a camping place for man" (Kelley and Campbell 1942:321). Early in the depositional sequence (above the lowest cultural material),

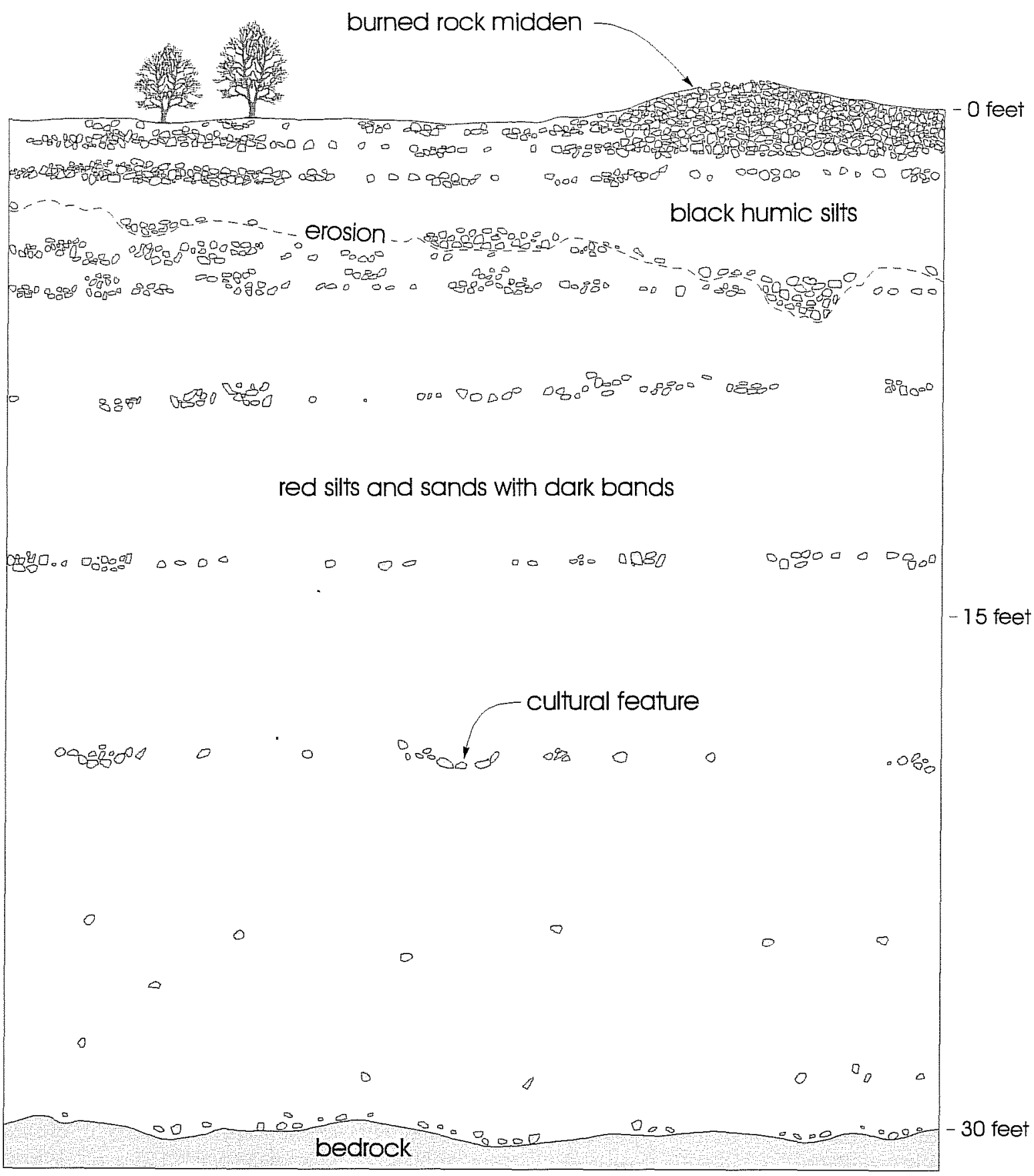

Figure 7-1. Idealized profile of a 40-ft terrace along the Colorado River illustrating the intersecting hearth scenario for midden accumulation (adapted from Kelley and Campbell 1942:Figure 38). 
rock-lined hearths and artifacts were scattered about the surface, with very little evidence of prolonged use. As the terrace became higher, over-bank deposition decreased, resulting in stable land surfaces. These stable, non-aggrading surfaces were subject to greater prehistoric use resulting in a series of overlapping hearths and other settlement debris. And finally, in the latter stages of terrace development, these accruing masses of settlement debris "assume topographic prominence and become, in effect, proto-middens or small mounds" (Kelley and Campbell 1942:321). Kelley and Campbell see these thick rock surfaces as well-drained (never waterlogged) and thus desirable for the location of future habitations.

Kelley and Campbell's model of intersecting hearths is possibly the most widely cited explanation of middens. As pointed out by Black (1997:84), the intersecting hearth scenario should not result in the oval or circular outline characteristic of many Texas burned rock middens. Simply, if middens formed as overlapping occupation, an irregular shape, not a circular one would result. The oval and circular morphology of middens investigated along the Colorado River did not go unnoticed by Kelley and Campbell (1942:231), and they state that "hearths seem to have been built in compact circular or oval groupings. This may indicate family groupings, separate occupations by small groups, or the influence of some natural feature." The observation by Black and many others that the oval or circular plan view of most (but not all) of the burned rock middens of Texas as well as the American Southwest and northern Mexico indicates a centrally focused activity, is the single most compelling argument against this formation process.

\section{Communal Dumps}

Sorrow (1969) and Hester (1970, 1971) interpret the dearth of artifacts and the jumbled structure of middens at the John Ischy and La Jita sites, respectively, as evidence of communal dumping. Hester (1971:123) argues that if burned rock middens were favored hearth areas, as laid out by Kelley and Campbell "then there should be more debris mixed in among the hearth stones." At the La Jita site, Hester notes a lack of chipped stone and fauna in the midden area, compared to an abundance of cultural material found in the adjacent terrace deposits. In addition, Hester (1971:124125) notes that a higher percentage of burned fauna, thermally altered chipped stone, ash, and charcoal flecks were present in the adjacent terrace deposits than in the midden proper. These findings, and the absence of any features in the midden, led Hester to conclude that when hearth stones broke into small, angular fragments from prolonged exposure to heat, the stones were then "gathered up and dumped elsewhere" (Hester 1971:124). Under this scenario, middens formed as heaps of discarded material and as a result would not contain any internal structure (i.e., intact and articulated features).

Middens as communal dumps cannot be widely accepted as a dominate midden formation behavior because many burned rock middens investigated in Texas and elsewhere contain intact heating elements (Black et al. 1997; Howard 1991), such as the midden at Culebra Creek (see Chapter 6). In addition, if middens formed through dumping of materials accumulated during camp maintenance activities (Dunnell and Stein 1989; O'Connell 1987; Tani 1995; Vance 1987), we would not expect microrefuse (e.g., small lithics, fauna) in any appreciable amount. That is, maintenance activities often sort material by size. Larger items, such as cores, fire-cracked rock, larger pieces of fauna and lithics, and so on, can be efficiently picked and swept up as a function of their size, whereas smaller items, like small debitage and fauna, are left behind as they escape the fingers and sweeping tools and work themselves into the substrate (Fladmark 1982; Hull 1987; Metcalfe and Heath 1990; Murray 1980; Wandsnider 1996). In the case of chipped stone debris, microrefuse would be present in middens if the inhabitants are knapping over baskets or blankets of some sort (Gallagher 1977), effectively capturing their falling debris which then can be dumped in mass in the midden area.

Equally important, but often not considered by the proponents of the dump hypothesis, is site structure and how dumps become a part of the archaeological record of hunter-gatherer sites in Texas. The analysis of intra-site spatial organization, or site structure, is based on the patterned distribution of features, artifacts, and other cultural and natural materials in space we affix 
as sites. In hunter-gatherer groups, these patterns can be structured to no small degree by group size and composition, settlement size, number of dwellings, length of occupation (both anticipated and actual), number and variety of activities, environment, social relationships and status, warfare, and/or threats from large predators (e.g., Binford 1978, 1980, 1983, 1987; Gould 1980; Hitchcock 1982, 1987; Kent and Vierich 1989; O'Connell 1987; Silberbauer 1981).

In the hunter-gatherer sites of central and south-central Texas, do we really expect people to dump refuse in a single, central (possibly peripheral) location? A cursory review of the ethnographic and ethnoarchaeological literature suggests that while groups often dispose of refuse in patterned ways, these dumps/heaps/middens often surround the camp and can consist of numerous dumps (e.g., Gamble and Boismer 1991; Hard and Snyder 1997; Hietala 1984; Hitchcock 1987; Kent 1987; Kroll and Price 1991; O'Connell 1987). These dumps are often located on the periphery of the camp and form either an arc or completely surround the camp (Figure 7-2). The number and size of the dumps appear to correlate with number of occupants and the length of stay. Consequently, a single or limited number of dump locations will often represent a relatively short occupation and as such constitute a limited amount of refuse. As can be seen, the typical burned rock midden in Texas does not represent a limited amount of refuse by anyone's standards.

\section{Cultural and Secondary Formation Processes}

As suggested earlier in this chapter, few archaeological phenomena have perplexed Texas archaeologists as much as burned rock middens. While great strides in midden research have been made in recent years (e.g., Black et al. 1997; Collins 1994; Kleinbach et al. 1995; Treece et al. 1993b), researchers continue to grapple with issues that are common-place for other types of archaeological deposits in this and surrounding regions. First and foremost, are issues of chronology and function. Until a recent synthesis of radiocarbon assays by Black and Creel (1997), the prevailing hypothesis was that most burned rock middens dated to the Archaic period (Prewitt 1981a, 1991). This interpretation was based on a limited number of radiocarbon assays and relied considerably on diagnostic artifacts recovered from midden deposits. Black and Creel (1997) conclude, however, that use of burned rock middens extended well into the Late Prehistoric period.

As outlined by Collins (1991; see also Collins 1994), to understand burned rock middens and the role they may have played on the larger hunter-gatherer landscape of central and south-central Texas, we must frame our research at various, but complimentary, scales. At one end, the macro-scale, burned rock middens must be considered against a backdrop of different environs and across thousands of square kilometers. Creel's $(1986,1991,1997)$ analyses provide a good model for macro-scale analyses. At this scale we may see patterns that are not otherwise possible at the site, river valley, or even the county level. At the other end, Collins points to the importance of microscale studies. Depending on the level of effort and the research strategies governing the investigations, this may include individual charcoal flecks, microdebitage, individual features or suites of features.

Our focus is at the level of site formation (meso-scale) coupled with some micro-scale analysis. The most abundant and distinctive material in burned rock middens are the angular fragments of discarded stone. Many middens also contain significant quantities of chipped stone, such as the midden at Culebra Creek, while others do not (e.g., Hester 1971; Kleinbach et al. 1995; Sorrow 1969). Equally significant, but not nearly as abundant, are faunal, floral, mollusks, and a wide range of ecofacts. The sum of these materials in and among the burned rock has traditionally been relied upon by the investigator to reconstruct the range of activities that transpired within the midden. While "variability in the archaeological record is the ultimate source of information for all archaeological inquiry" (Tani 1995:231), this variability, as evidenced in the content of burned rock middens, has, in our opinion, confounded our understanding of the role these facilities may have played in the larger settlement systems of the region. It is the content, not the piles of fire-broken rocks themselves, that have caused this confusion. 


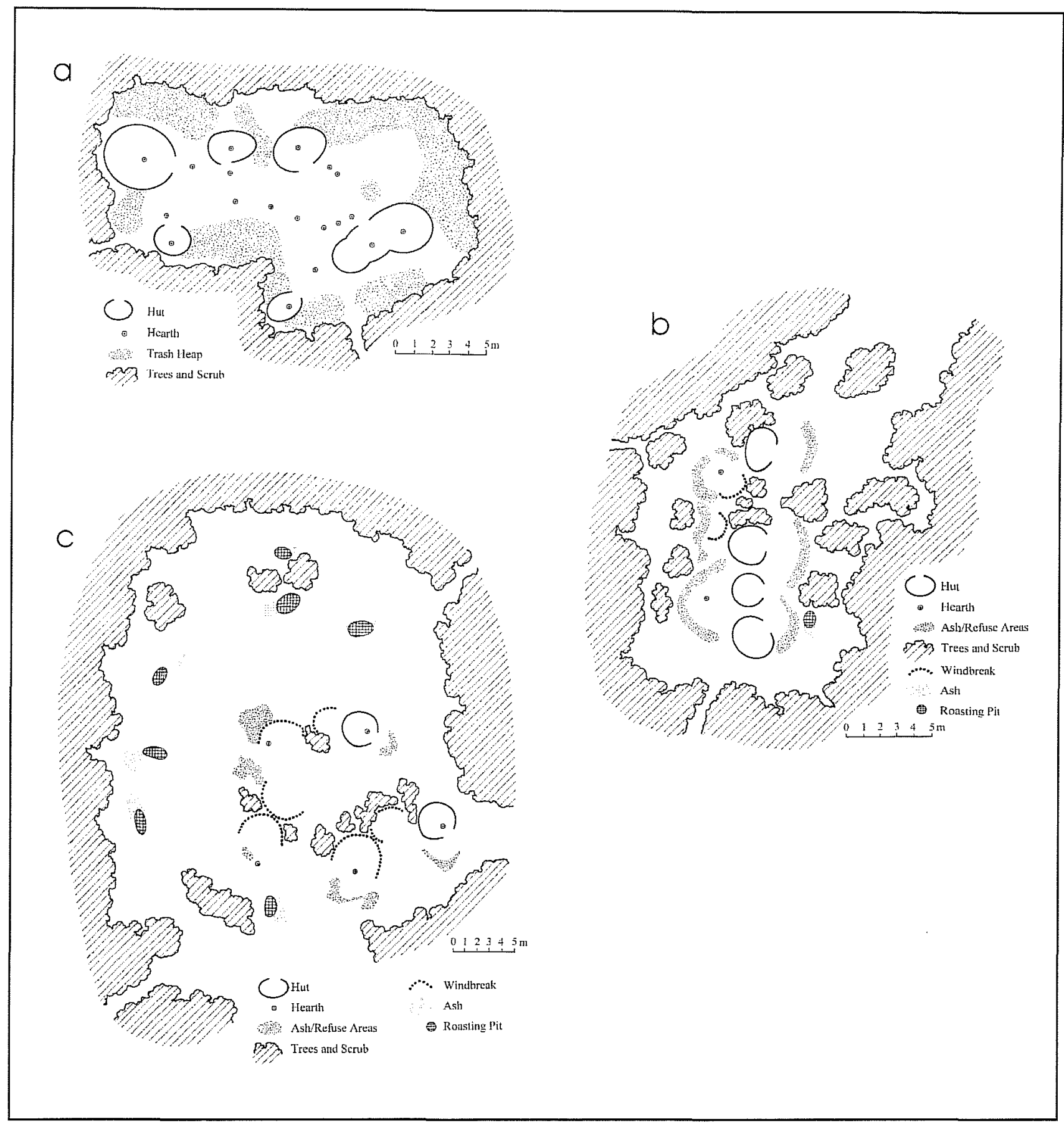

Figure 7-2. Ethnographic examples of campsite structure. (a) A typical Efe Pygmy (Ituri Forest, Zaire) campsite showing the location of trash heaps, huts, fire hearths, camp perimeter, and central open area (modified from Fisher and Strickland 1991:Figure 2; see also Fisher 1987 and Fisher and Strickland 1989). (b) A Basawari (also known as San or Bushman) short-term hunting and gathering camp in the Kalahari (Botswana) occupied by eight individuals for less than three months (modified from Kent and Vierich 1989: Figure 9.4). Illustration shows the location of grass huts, hearths, windbreaks, ash/refuse areas, and ash associated with a roasting pit. (c) A Basawari short-term hunting and gathering camp (note that the camp was originally intended to be a long-term camp) in the Kalahari (Botswana) occupied by fourteen individuals for less than three months (modified from Kent and Vierich 1989:Figure 9.8). Illustration shows the location of grass huts, hearths, windbreaks, ash/refuse areas, and ash associated with a number of roasting pits. 
The following section reviews ideas concerning the formation of earth ovens. Importantly, the building, use, dismantling, and reconstruction of earth ovens is discussed as a disturbance activity. Select findings from the test excavations at Culebra Creek are introduced in the discussion. While the data at Culebra Creek are limited (i.e., only test excavations), they do provide hints regarding cultural and secondary site formation processes.

\section{Building and Using Earth-Ovens: A Surface-Disturbing Activity}

Archaeologists who have worked on burned rock features in this and other areas have relied to some degree on the ethnographic literature to interpret their findings. The ethnographic literature abounds with examples of cooking with stone world-wide. It is also a truism that one can find ethnographic analogies for many technological or functional scenarios relating to cooking with rocks. Clearly, the adaptive advantages of cook-stone technology (Thoms 1996) in food preparation is evidenced by its frequency in the ethnographic record. Its use spans the Holocene and extends across the archaeological landscape of central and south-central Texas. Burned rock may have played a role in terminal Pleistocene occupations as well (Collins 1997; Collins et al. 1993).

In this section we do not offer a review of how and what foods are cooked in earth ovens as documented in the ethnographic record. Ellis (1997:Table 3) provides an exhaustive review of cooking techniques and heat transfer mechanisms involving hot rocks. However, we do draw upon a few ethnographic examples of cooking food in earth ovens to highlight critical processes in the formation of large, burned rock features. The few examples are not meant to advocate one cooking technique over another, or to determine which resources were processed in Texas burned rock middens. These examples are selected to underscore some common steps involved in cooking with rocks in earth ovens.

\section{Cooking with Hot Rocks}

The archaeological investigations at Culebra Creek identified a number of burned rock features (see Chapter 6), most distinct of which is the burned rock midden. Near the geographical center of the midden, test units revealed rock layers interpreted as intact heating elements for earth ovens. Within this central area, multiple ovens were built, dismantled, and rebuilt. This confirms the arguments presented by Black and Creel (1997). The cumulative residuum of these events are what today we see as the burned rock midden.

Some of the most famous accounts of cooking in pits with hot-rocks come from the American Southwest and northern Mexico. For example, Castetter et al. (1938:28-29) note the following about pit baking agave among the Mescalero and Chiricahua Apache:

Pits in which the crowns were baked were about ten to twelve feet in diameter and three or four feet deep, lined with large flat rocks...Upon this, oak and juniper wood was placed, and before the sun came up was set on fire. By noon the fire had died down, and on these hot stones was laid moist grass, such as bunch grass... The largest mescal crown was selected...they threw it in and threw the other crowns after it...After the mescal had been covered with the long leaves of bear grass and the whole with earth to a depth sufficient to prevent steam from escaping.

Castetter et al. (1938:45) also note the following about pit baking among the southern Diegueño of California:

In this region, pits averaged six feet in diameter with nine feet as the maximum. They were dug in sandy soil and lined with boulders, the latter often extending high enough on the margin to form a raised rim... after the boulders were sufficiently heated a matting of agave leaves were laid. Upon this the agave flower stalks or crowns were placed, and in turn covered with another layer of leaves. The charge was then baked over with sand...The pits were used over and over again each season. Due to the clearing out of 
the pits and replacement of fire-cracked boulders with new ones, some pits have a marginal refuse dump of considerable size.

The preceding accounts (see also Barrett and Gifford 1933; Beals 1932; Bell and Castetter 1941; Boas 1930; Carlson and Jones 1940; Castetter and Opler 1936; Castetter and Underhill 1935; Chestnut 1902; Hardy 1977; Holt 1946; Hough 1907; Kroeber 1932; Opler 1941; Pennington 1963; Sapir and Spier 1943; Smith 1933; Sorenson 1976; Tunnel and Madrid 1990) illustrate some basic steps followed in the construction and use of an earth oven for cooking foods that require long-term exposure to heat. This includes digging a pit, laying in collected stone, adding fuelwood, and setting on fire. Once the fire has burned down and the stones are sufficiently hot, a layer of vegetation is laid down to protect the food from the hot coals and rocks (moist insulating material also provides much needed moisture during the cooking process). The food being cooked is loaded, more insulating material is added on top of the food, and finally an earthen cap is applied to the top of the mass. Once adequate time has passed for cooking, the oven is dismantled, the food removed, and the process repeated (Figure 7-3). And, as noted among the southern Diegueño of California, heaps of discarded rock begin to accumulate on the periphery of the oven facility with each season of use (Castetter et al. 1938:45).

Of the various components and steps (pit, stones, fuelwood, packing material, food, earthen cap) involved in constructing and using an earth oven, all but the earthen cap component/step have received attention and quantification by archaeologists. For example, researchers often measure pit lengths and depths to estimate potential volumes of food(s) being processed. Depending on the types of food and cooking environment, these data then can be used to estimate the caloric output of the feature per cooking event. The size, weight, and type of stone used are often considered to estimate the amount (kgs) of wood needed to fire the oven and heat the stones, which in turns informs us about long-term cooking/heating performance of the facility and the energy that went into an individual firing event.
The earthen cap, which is the last but critical step in the process and functions as a thermal barrier, seals the oven and allows the food to cook. Like the heating element, the earthen cap is an essential component of the oven; in fact, the earthen cap may be the most critical component of the earth oven. Constructing an earth oven, collecting the resources and materials, digging the pit, firing the oven, and so on, take a great deal of energy to successfully cook food with hot-rocks (see Thoms 1989). A haphazardly constructed cap, one that is too thin or does not adequately cover the feature, will result in rapid heat loss and undercooked food. Simply, a successful earth oven is only as good as its heating element and earthen cap. All the labor that goes into collecting the fuelwood, stone, food, and firing the oven, would be lost if an inadequate cap were applied.

The earthen cap, as illustrated in the two accounts of pit baking cited above, is the final stage in earth oven construction. The importance of the earthen cap in the pit baking of foods has been unappreciated by us, and probably most researchers. The amount of sediment required to properly seal an oven is not well documented in the ethnographic or experimental literature. Experimental research conducted during the course of these investigations suggests that even a moderate size oven, just a meter in diameter, required almost half a cubic meter of sediment $(490 \mathrm{kgs}[1,080$ lbs] of sandy loam) to adequately seal the oven (see Appendix D).

The crux of this chapter focuses on the earthen cap used to seal ovens and the sediment borrowed for its construction. For the following discussion we make the assumption that foods cooked in hot-rock ovens were covered and sealed with earth. This assumption is probably a fair one, as most ethnographic accounts of cooking in earth ovens describe an earthen cap. While other forms of sealing the oven, such as with animal skins, are possible, sediment appears to be the most effective cap. If earth was used to cap ovens and middens represent the discarded capping materials of cooking events, then the likelihood that ground disturbance resulted from gathering sediment for caps is a distinct possibility. 

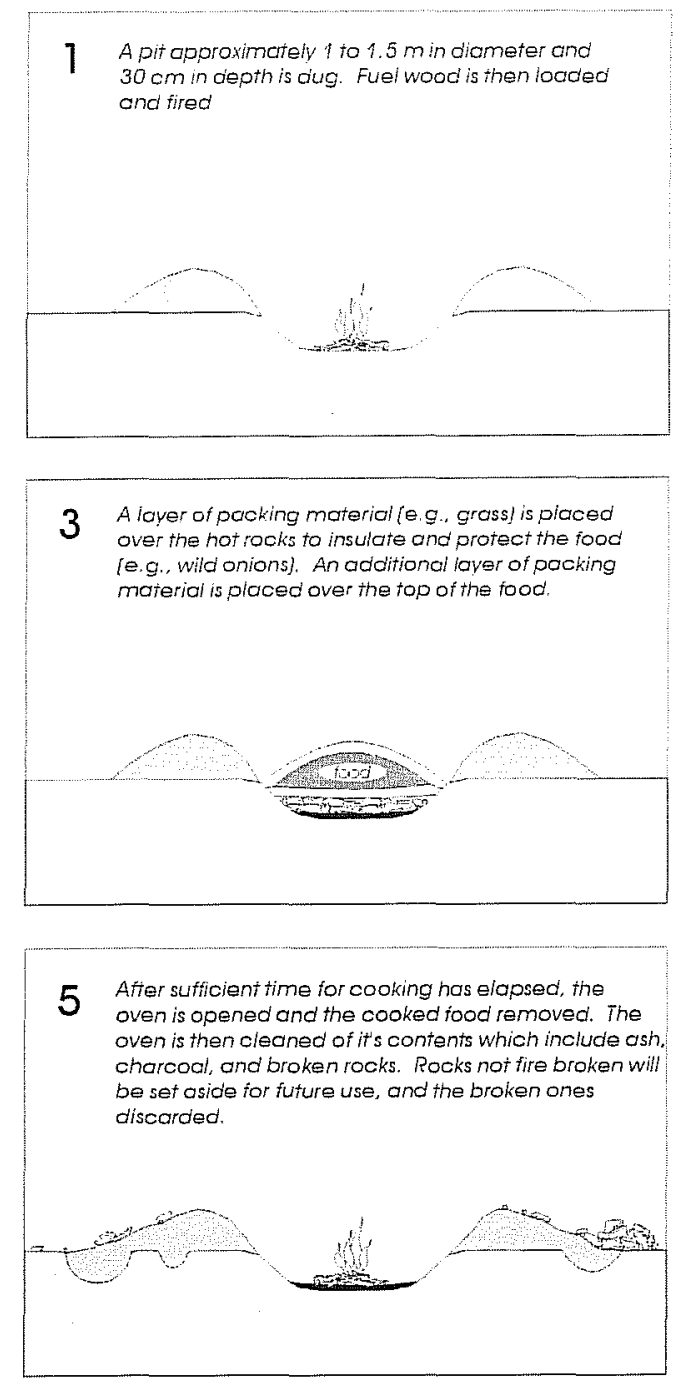

7 An earthen cap is agoin constructed over the central area. The cap now begins to incorporate some of the spent limestone from the first firing. New borrow pits continue to develop as earth is needed.

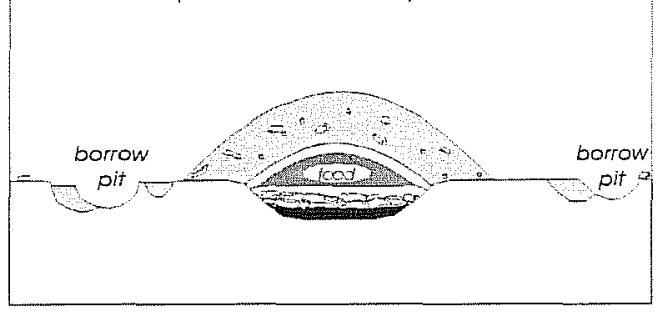

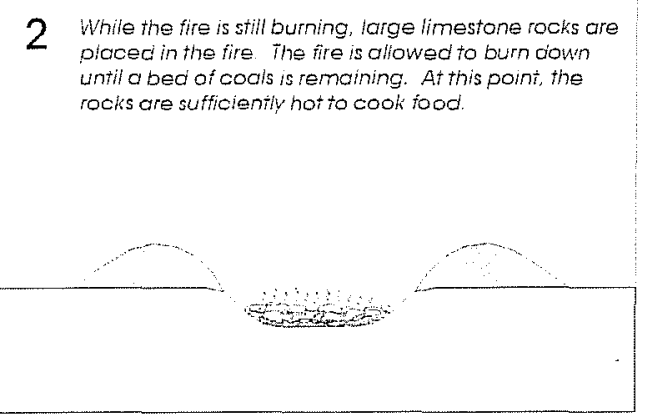

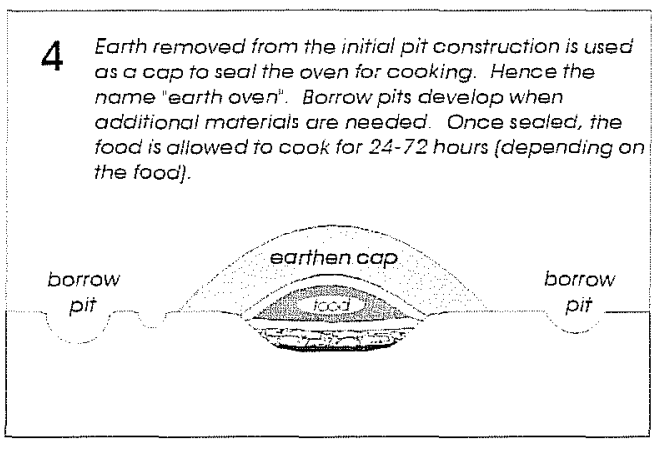

6 The cycle continues with another firing using both reused stones and new ones.

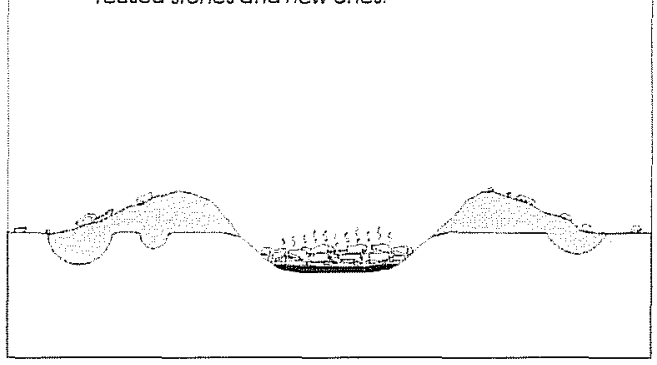

8 As the process continues, refuse from earlier firings becomes ever more integrated into the matrix of the earthen caps as well as filling in the borrow holes. Artifacts lying about the surface will also be incorporated into the amassing spoil heap via the borrowing of earth for capping material. This may, and often will, include antifacts that are behoviorally unrelated to cooking in the earth oven.

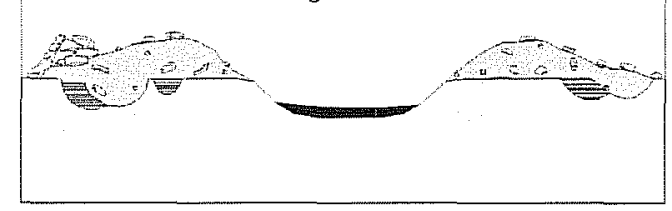

Figure 7-3. Idealized earth oven. Initially a pit is dug (1) and the sediment from the excavated pit piled on the edge. The pit is loaded with fuelwood and set afire and stones tossed on the fire. Once the fire has died down (2) and the stones are sufficiently heated, the stones and coals are spread evenly over the bottom of the pit. The packing material is added (3), then the food, more packing material, and finally the earthen cap (4). Note that the sediment excavated from the original pit is used as well as additional borrowed sediment. Once the food has been cooked, the oven is dismantled (5) and the cooked food removed. The borrow pits around the oven are filled with detritus associated with the dismantling of the oven. The entire process is repeated (6 and 7) and the waste of repeated cooking events accumulate (8). 
Figure 7-4 shows a 1906 photograph of a White Mountain Apache woman and children covering (sealing) an oven loaded with agave. Given the size of the women dumping the basket of earth on the oven, the earthen cap probably was over one meter in height and covered an area approaching three meters in diameter, though the cap may have been 30-60 cm (1224 ) inches thick. This suggests that the underlying pit was fairly large and could have held several hundred pounds of agave. Several things are important in the photograph. First, the size of the earthen cap suggests a considerable amount of sediment is needed to seal the oven. As discussed above, a small, experimental oven constructed during the course of this project required over 1,000 pounds of soil, which only formed a mound approximately $50 \mathrm{~cm}$ in height, to effectively seal a small oven (see Appendix D). Based on the size of the cap depicted in the photograph, several tons of sediment must have been gathered and borrowed to seal the oven. The second important detail illustrated in the photograph is the children collecting what appears to be sediment for the woman to place on the oven. While one child is collecting sediment from near the oven, the two children in the background are collecting sediment some distance from the oven proper. In other words, sediment is being borrowed from a

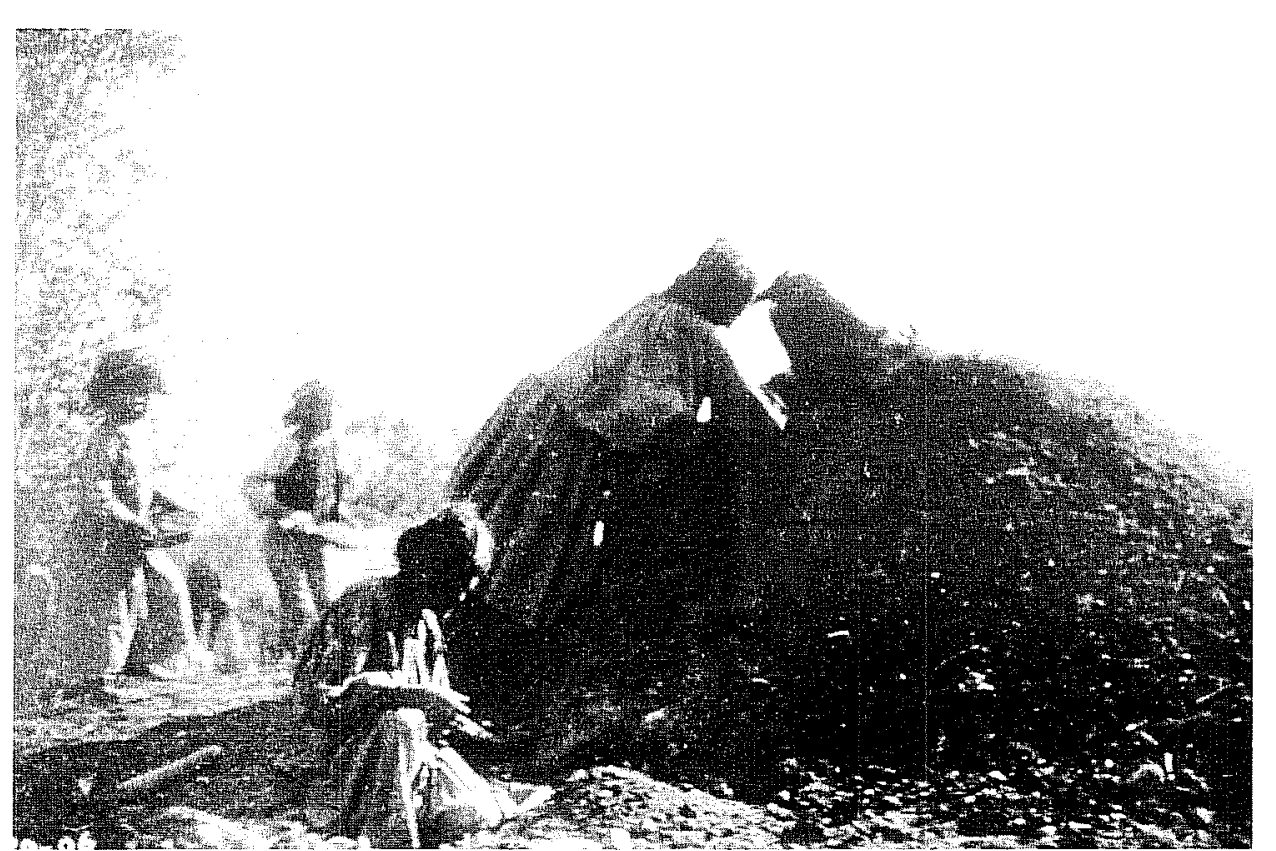

Figure 7-4. White Mountain Apache (Arizona) sealing an earth oven used to roast agave hearts. Photograph taken in 1906 (reproduced with permission of the Smithsonian Institution). variety of locations throughout the area. It is significant that Black (1997:175-176) notes that a midden at $41 \mathrm{MK} 8$ was dug into the underlying sediment and this must represent the borrowing of sediment, perhaps for capping material, at that site.

Also visible in the photograph, stones and other material have been incorporated into the cap in the borrowed sediment. This material includes stones of various sizes and miscellaneous sticks and other perishable remains. Some of this transported material is more visible in a closer photograph of the oven after it was opened (Figure 7-5). In this photograph, a White Mountain Apache woman and man are removing the agave hearts from the central portion of the oven with long sticks. In the foreground are the stones and other material along the edge of the dismantled oven cap that has been spread around the pit as it was removed. There is no doubt that this cap included much smaller material not easily visible in the photograph.

The borrowing of sediment to cap earth ovens is a cultural formation process (Schiffer 1987; Tani 1995) that has been under appreciated in midden formation studies in Texas. The process of borrowing sediment will not only result in the transport of sediment throughout the site area, but will act as a medium to move and mix artifactual material as well. Whether sediment is being borrowed to build an adobe or rammed earth wall in the American Southwest or Middle East, or to construct an earthen mound for a house or a temple in the American Southeast or central Mexico, the displacement of cultural and non-cultural materials in artifact-laden sediment is well-known. This process is recognized among researchers working with anthropogenically disturbed deposits. However, the implications of the 


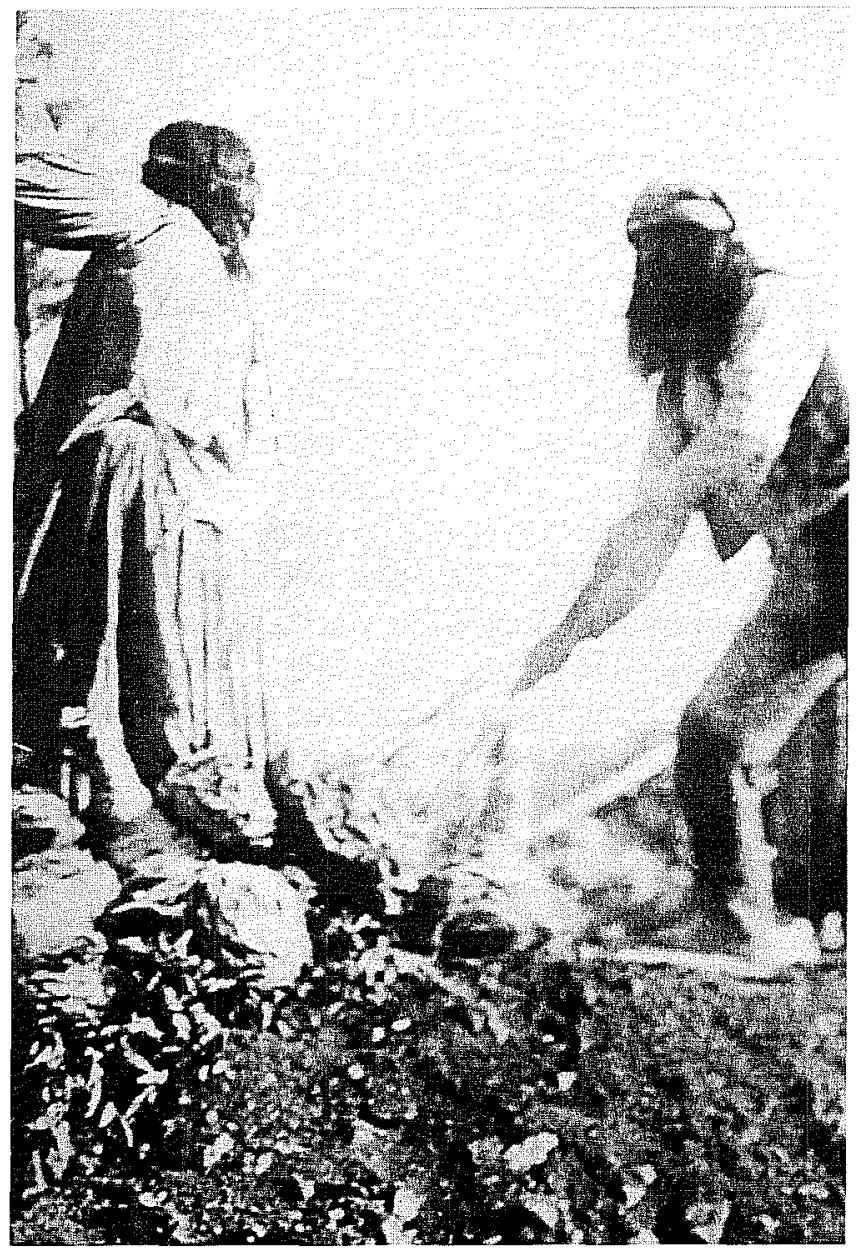

Figure 7-5. White Mountain Apache opening the same oven depicted in Figure 7-4. Note the long sticks being used to move the agave heads and the rocks and other materials mixed in with the sediment that once was the cap (reproduced with permission of the Smithsonian Institution).

secondary transport of artifacts in sediment borrowed and gathered on Texas burned rock midden sites has not been considered in detail. While investigators like Treece et al. (1993a:528), Black (1997:256), and Black and Creel (1997:280) have discussed this formation process, its impact on midden chronology and function has not been fully developed. It is our limited understanding of this most basic physical process that has impeded research of these cultural deposits.
If a mass of charred and fragmented stone in a midden represents the residue of a small number, or perhaps even hundreds of firing events, then it must have also included the same number of earthen caps. ${ }^{5} \mathrm{We}$ learned from our experimental oven (see Appendix D), that sediment excavated from the initial pit could be used in the construction of the cap. However, it was necessary to add (borrow) additional sediment to properly seal the oven. Following the initial firing, it is possible to recycle sediment used in the construction of the next cap, much the same way cook-stone and packing material can be recycled. However, recycling sediment for reuse is much like excavating a deep unit; frequently the backdirt is insufficient to fill the hole. We argue for a similar problem in recycling sediment for earthen caps. While we do not suggest that each firing event would require a fresh load of earth for the cap, we do think that sediment will need to be continually borrowed for cap construction. This is simply a function of sediment being spread about during the dismantling of the oven. As the number of firings increase in a given location, the amount of thermal fractured and discarded rocks grows as well (see Black 1997:265-266). As the earthen caps are dismantled and sediment settles in the interstices of the stone, more sediment is required with subsequent firings.

The amount of sediment borrowed following the initial firing is not known. These data do not exist in the ethnographic or experimental literature concerning earth ovens. Even if the majority of the sediment from each cap was re-used in the next firing, for example 70-80 percent, a large amount of borrowed sediment would be needed throughout the use-life of even a moderate size midden, assuming their use as ovens. In the case of Culebra Creek, this would represent many cubic meters of borrowed sediment weighing several tons.

Large amounts of borrowed sediment would be needed for even one season of oven use. As illustrated by the White Mountain Apache, sediment is borrowed from in and around the cooking facility. We refer to this area as the borrow zone. The borrow zone would be

${ }^{5}$ Black (1997:265-266) calculates the amount of burned rock in various middens and then estimates the number of ovens represented by these middens; however, these estimates are based on rock reuse rates that appear too high. 
the area within a site that is disturbed by collecting sediment. The size of this area could depend on a number of factors such as the size and location of the oven area, location of the cooking facility within the site and its relation to other features or activity areas, depth of unconsolidated sediments, number of working individuals, total number of individuals to be fed, personal preference, and so on. Artifacts and other materials can be incorporated into the midden through secondary processes within the borrow zone. The earlier, i.e., premidden, use of the surface on which the midden is formed along with the length of time the midden was used will determine the temporal and function range of the materials recovered from the midden deposit. That is, the artifacts and ecofacts recovered during the archaeological excavation of a midden along with those discarded by the users of the midden will represent the range of prehistoric activities that transpired on or near the midden. Black and Creel (1997:280) called this process incorporation and clearly distinguish it from scavenging. Thus, depending on previous occupations and the rates of sedimentation on the site, the excavation of borrow pits may incorporate materials dating thousands of years earlier into the midden deposit.

This is not to say that all artifacts and ecofacts recovered from middens are in a secondary context, clearly they are not. But determining which materials inform us about true midden use and function, and which ones have been introduced via borrowing, remains a difficult task. The movement and consolidation of these materials into the midden can result in the mixing of temporally and functionally unrelated materials. This model of disturbance and transportation of artifacts from different stratigraphic contexts into a single anthropogenic node is, we propose, exactly what so many middens in Texas represent. Some artifacts and other materials may remain in their original discard locus, however original contexts are difficult to determine. This range of materials leads many researchers to the conclusion that middens were multi-functional facilities, as evidenced by artifact and fauna variety, and that these activities transpired over thousands of years, as evidenced by the wide-range of diagnostic points found within them.
As argued here, the content of middens is largely a function of the size of the zone of borrowing and the activities, both before and during midden use, that fall within that zone. This may include everyday activities that are contemporaneous with the use of an earth oven facility, but may also include cultural materials from activities that are organized very differently and have nothing to do with the use of a location for cooking foods in earth ovens. It is also interesting to note that some middens have few artifacts, while others have a great many. While this may, in part, be a function of archaeological excavation strategies and methods - screen size, placement and number of units, or preservation in the case of flora and fauna, it does pose an interesting question. Under the proposed model of midden formation, content is directly related to past and current activities occurring within the zone of borrowing. On sites where the oven facility(ies) is (are) located on the periphery of the camp (Hard and Snyder 1997), and if few pre-midden activities transpired in this location, then the amount of material available for incorporation into the midden during the borrowing of sediment could be limited. If the oven facility is placed in a location where previous activities resulted in the deposition of material and/or the oven facility is located more centrally within the camp structure, then the likelihood that materials of many periods will be subject to secondary transport is greatly increased.

The role of the oven facility or site within the organization of the settlement may have a dramatic impact on the content of middens. This point is well illustrated at Fort Hood. As stated in the onset of this chapter, Fort Hood researchers (Abbott et al. 1996; Kleinbach et al. 1995) have drawn a distinction between middens and mounds based on surface morphology, structure, and content. Abbott et al. (1996:582) state that "mounds and middens on Fort Hood are indeed structurally and artifactually distinct classes of features representing different types of prehistoric behavior." The Fort Hood researchers note that all $(n=18)$ of the artifact-poor mounds are located in upland settings and that of the middens $(\mathrm{n}=55)$, the majority (83.9 percent) are located in lowland areas (Abbott et al. 1996:Table 8.9). An important distinction between upland and lowland settings is the availability of water and other resources that thrive in these 
environments. The lowland midden sites are situated on alluvial and colluvial deposits located along or near valley margins: valleys that have water. The upland mound sites however, are located away from these valleys on benches and eroded surfaces that are subject to sheet wash and slope wash sedimentation (Abbott et al. 1996:610). We argue that these two settings offer very different settlement opportunities for prehistoric groups.

While both upland and lowland settings were chosen for the construction of earth ovens that resulted in the accumulation of middens/mounds, they did not play similar roles in the larger settlement system. Under the model of midden formation argued here, the middens, with their greater artifact numbers and variety, are located in better-watered areas, areas that may have been preferred for a greater range of non-oven related activities and reoccupied often. These more heavily used locations result in a greater amount of material that could be incorporated into the midden via borrowing. Conversely, upland settings located away from the better-watered valleys may have been less attractive places on the landscape, resulting in fewer occupations and less artifactual material being generated. This decreases the likelihood of archaeological materials being incorporated into midden/ mound deposits. These upland settings may represent primarily special-activity or limited-use locations with the lowland settings hosted both limited or special activities as well as more complex residential uses. We do not see the function(s) of the large, burned rock features (mounds and middens) as being different at these two settings. As the Fort Hood researchers point out, their strongest argument concerning the differences in these features concerns artifact content (Abbott et al. 1996:594). The artifact content, we argue, is a function of the material lying within the zone of borrowing: the greater the activity (both past and present), the more material that is likely to be incorporated into the midden deposit.

Equally important in the formation of middens is what happens to these deposits once they fall into disuse. The borrowing of sediment for the construction of earthen caps directly impacts the site area, and indirectly affects the site by altering the immediate environ and promoting erosion, resulting in anthropogenic induced sedimentation on and around the area of disturbance and the midden. The following section discusses midden erosion.

\section{Middens as Lag Deposits}

As ovens are built, fired, dismantled, and rebuilt, a ring or arc of discarded rock from heating elements, sediment from earthen caps, and vegetal material (i.e., packing material), begins to accumulate and grow upward and outward with each firing. Figure 7-6 shows a simulated and experimental earth oven constructed by CAR investigators (see Appendix D). The ring of spent and discarded material represents a number of firings and forms a low mound around the center of the oven pit. As the experimental oven and the dismantled White Mountain Apache oven shows (see Figure 7-5), the amassing pile of waste is dominated by sediment, followed by discarded stones and other materials.

During the use-life of an oven, the discarded material constituting the ring or arc will be trampled, scattered, and disturbed as it serves as a platform or working surface for subsequent firing of new ovens. This was evident in our experimental work and illustrated in the White Mountain Apache oven (see Figure 7-5). As this anthropogenic deposit grows upward and outward on the site, its unconsolidated and poorly sorted structure is subject to subsidiary processes, such as wind and rain erosion. This erosion will result in the movement of finer materials (e.g., sediment, smaller artifacts, smaller stones) outward and downslope (Evans and Limbrey 1974; see also Milne 1936). To get an idea of how this deposit might erode, we simulated a rainstorm by shooting water into the air for several hours (over a two-day period) with a hand held water hose so that it would fall on the deposit in which archaeological materials were placed. However crude, this simulation did provide useful information and provide insight into some key processes.

Figures 7-6 and 7-7 are before and after photographs of the experimental deposit. The results of the simulated erosion were significant. As expected, the ring of sediment, stone, charcoal, and chipped stone that was placed in the ring washed and lagged downward 


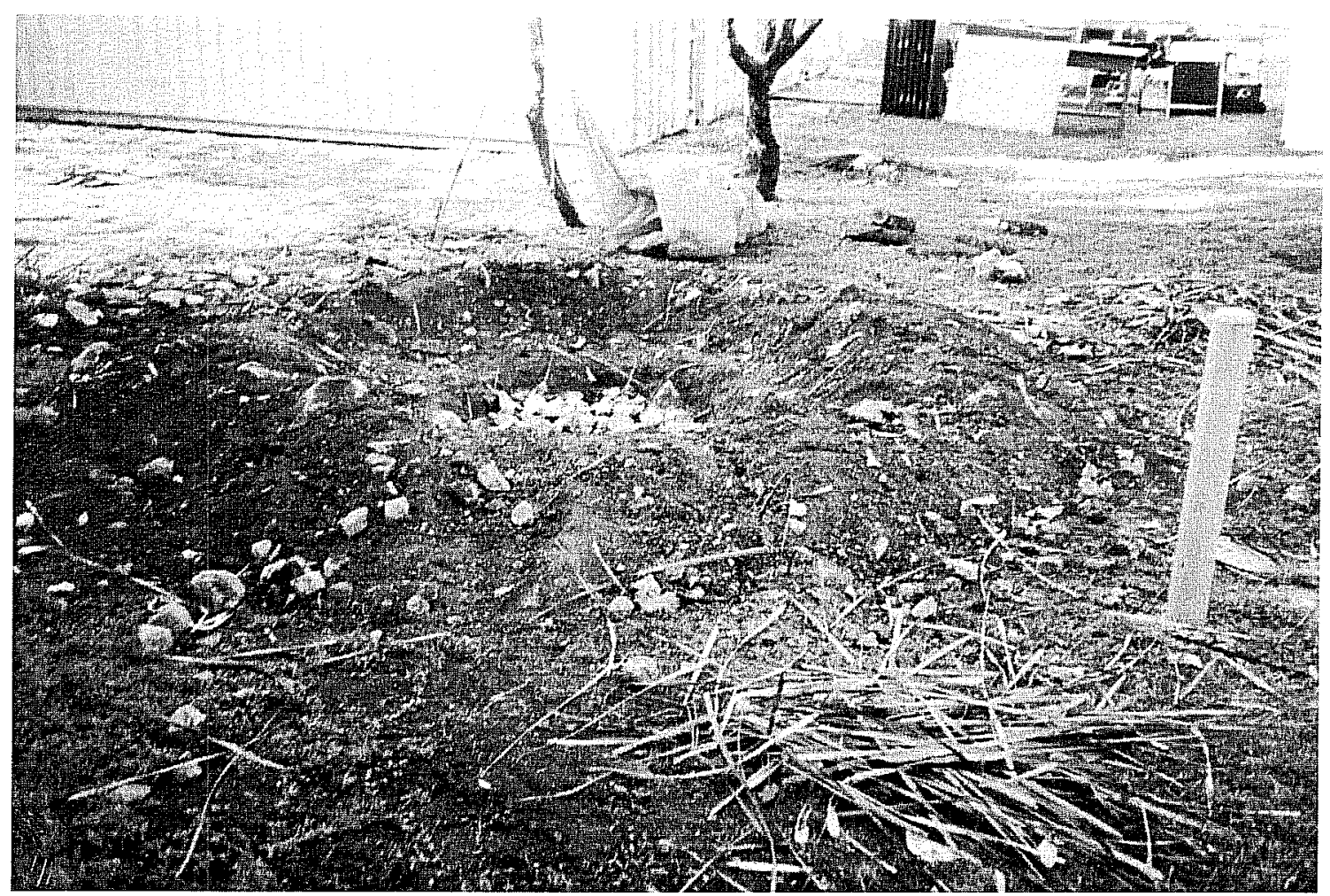

Figure 7-6. Photograph of an experimental midden created by CAR investigators (see Appendix $D)$. Note that the ring, or discard, surrounding the oven facility is dominated by sediment, followed by rock and other material. The last heating element can be seen in the center of the ring.

exposing the ring of fire-broken stone. The finer sediments washed off the deposit and formed an apron or miniature alluvial fan around the edge of the stone ring. The center of the deposit, which contained an open pit with the remains of the last heating element still intact, filled in with sediment. Importantly, charcoal, chipped stone, and various sizes of burned rock also moved outward and inward some $15-20 \mathrm{~cm}$ from the torus of the ring as it deflated downward.

Additional natural rains through the summer eroded the sediment matrix further away from the surface rocks, causing them to stand out even more distinctly on the torus, and resulting in an upper ring surface composed primarily of burned rocks. Also, vegetation sprouted on the core (mainly grasses and small weeds), on the torus (small-to-large weeds and fewer grasses) and outer periphery of the torus (mainly large weeds such as sunflower). Beyond the torus edge the vegetation cover is the original domestic grass cover and is little altered. Additionally, sediment in the central core has cracked due to drying. One crack was $65 \mathrm{~cm}$ long and up to $13 \mathrm{~cm}$ deep. These cracks were not straight, but composed of multiple segments joined at bends and with multiple tributary cracks adjoined in a polygonal network of cracks. The erosion, plant roots, and cracks all increase the probability of postdepositional artifact and organic material mixing. Also these processes would accelerate the decomposition of organic materials such as bone and charcoal by accentuating wetting and drying cycles.

The experimental oven points to some revealing processes in the formation of burned rock deposits. The most interesting, from our point of view, is the outward movement of sediment, artifacts, charcoal, burned rocks, and other materials lying within the deposit when subject to erosion. As these materials move due to sheet wash, they increase the horizontal extent of the deposit and create strata with an anthropic origin (Stein 1990). As the midden deposit grows, the apron will increase in depth as well, although portions of the apron may be covered by the leading edge of the growing midden deposit. The apron deposit, as a stratigraphic unit, will contain the history of the midden through successive erosional events. Under this model of midden formation, 


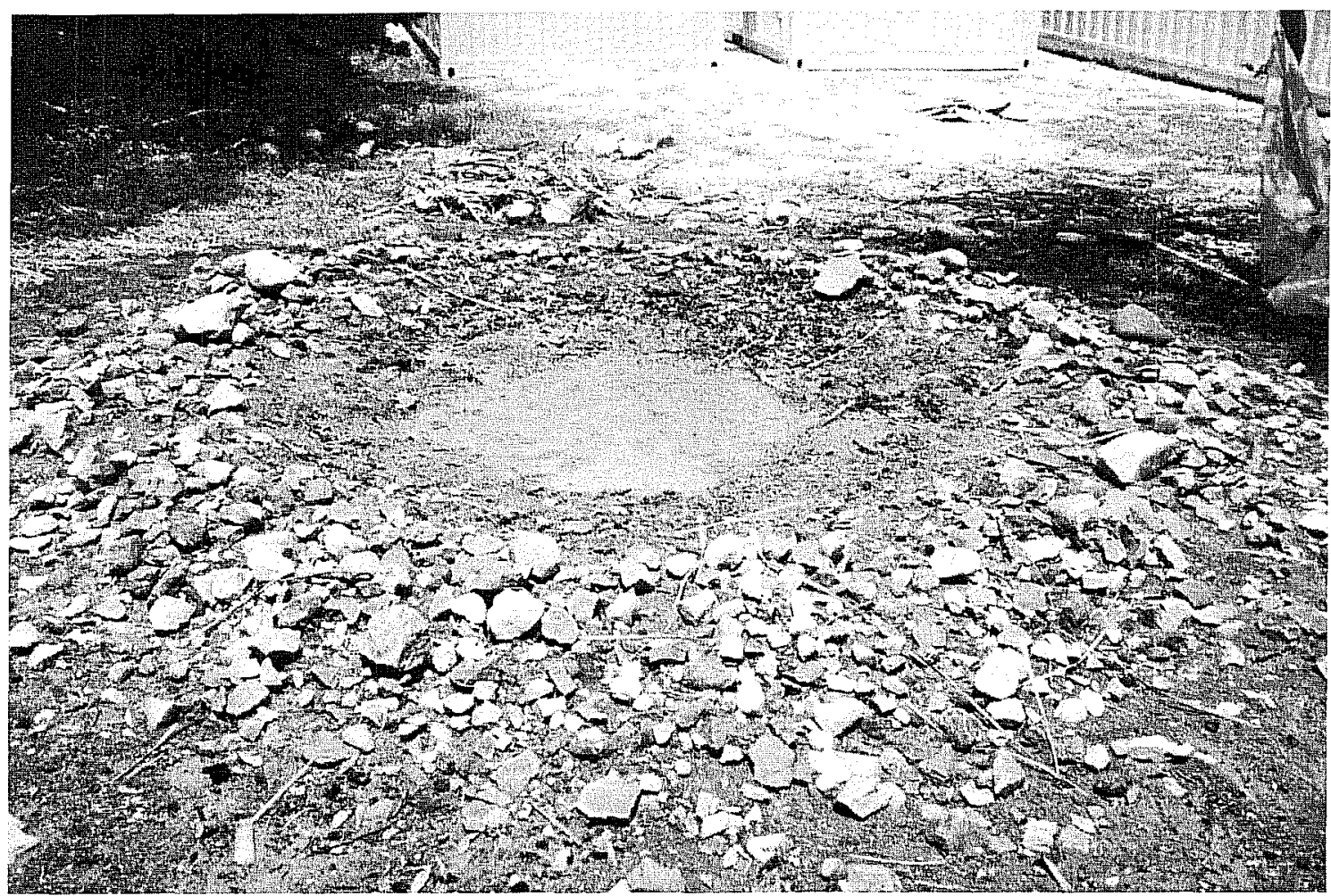

Figure 7-7. Photograph of the experimental deposit after it had been eroded via water. Note that the finer sediment has been transported outward to form an apron around the ring of now lagged stone and that the central pit area is now covered with sediment.

the mixing of activities and possibly time periods through borrowing sediment, could result in reversed stratigraphy or at the least a mixed cultural stratigraphy in the apron deposit.

When excavating burned rock middens, archaeologists often see the area immediately beyond the densely packed charred and fragmented rock (the apron), as structurally different from the framework of the midden (see Chapter 6). This is an obvious distinction, as one is dominated by stone and the other by sediment matrix. However, materials within the apron are often interpreted as post-midden deposits, especially as one moves up the profile. That is, if the apron has any depth at all, the lowest levels within a unit excavated in the apron, the levels that coincide with the surface on which midden sits, will be interpreted as middenrelated material. As the depth of the apron increases, the higher excavation levels and the materials within them are seen as being laid down after the midden formed. Attention to how the midden deposit erodes reveals that the depositional history of the apron is much more complicated.
Likewise, the central portion of the midden containing the oven(s), though cleaned out and maintained during the use-life of that location, will fill with sediment and materials washing inward from the edge of the ring. The core area will contain a deposit very similar to the apron; that is a deposit full of material (artifacts) that is, in part, temporally and functionally unrelated to midden use. However, the fill in the core area will or should differ in one important aspect, the size of materials. As the core area initially fills, the wall and edges are at their steepest angles, thus allowing larger materials to move by gravity to the low areas. As the area fills and the angle of the walls decrease, the overall size of materials should decrease as a function of gravity. At its highest point, the central core area should be dominated by matrix.

\section{Middens as Anthromantles}

The results of our limited but revealing experiment clearly demonstrate that once materials and sediment 
enter the midden deposit, they are subjected to geological transport processes during subsequent erosional events. If this midden formation model is applicable, then burned rock middens formed as growing masses of charred and broken stones used as heating elements in earth ovens. During this process, volumes of ash and charcoal were generated by the firing and subsequent cleaning of the pit areas, and quantities of vegetal material were probably used as insulation material and discarded on the midden. Also, by-products of processed food and massive quantities of refuse-laden sediment used to cap the ovens were also discarded on the site. An understanding of how these by-products, or spoil, are created is crucial to our understanding of these features. However, just as crucial is the post-depositional processes that these deposits undergo following abandonment. We argue that many burned rock middens can best be understood as multilayered biomantles (Johnson 1989, 1990; Johnson and Watson-Stegner 1990; Johnson et al. 1987), growing upward and outward through each successive use and dismantling of the oven facility (Black 1997).

Johnson (1990:84; see also Soil Survey Staff 1993) defines biomantles as "one or more differentiated layer of soil produced by bioturbation." The two most widely recognized forms of bioturbation, or pedoturbation, are those by burrowing animals (faunal turbation) and tree uprooting (floral turbation) (Butzer 1982; Hole 1961; Schiffer 1987; Wilkins 1989; Wood and Johnson 1978). In the case of faunal turbation, the burrowing animal displaces sediments and other materials within the burrow upward onto the surface into a spoil pile. Likewise, sediment and other materials that are attached or intermingled in the root system of trees that are blown over by wind or other process, will displace materials upward. This pedoturbation can result in the destruction of soil horizons and the homogenizing of soil profiles and, in the context of an archaeological deposit, destruction or obliteration of features, distinct artifact horizons, and the vertical and horizontal movement of artifacts within the deposit (Johnson 1989; Leach and Mauldin 1997).
Burned rock middens are somewhat analogous to a spoil pile left at the entrance to a coyote or badger burrow, or an unattended pile of dirt. Through the passage of time, this spoil or pile of sediment, which in the case of burrowing and turbative animals, can include a wide range of clasts brought to the surface via the burrowing, will erode through subsidiary processes such as rain splash, slope wash, and wind, ultimately lagging downward through the winnowing and washing out of finer sediment (Milne 1936). In the case of our burned rock spoil, with its volumes of dirt and other materials, the same process would result in the deflation and compression of the mound. The finegrained matrix, which constitute sediment and micro refuse, is subject to transport. This sheet wash material will then be deposited at the toe of the midden as alluvial/colluvial deposits, with the lowest areas receiving the greatest amounts of deposition.

The midden and its associated off-midden deposits are the result of the interaction between human land-use and disposal practices within the natural context, physiographic, and micro-topographic parameters of the site area. The subsequent erosion results in a denuded midden, bare of its fine sediment, and more tightly packed in its downward movement. Burned rock midden deposits are true biomantles, and we suggest the term anthromantle to characterize these dynamic deposits created by humans and subsequently eroded by natural processes. ${ }^{6}$

\section{The Midden at Culebra}

As outlined in Chapter 6, the excavations at Culebra Creek have a long and complicated history. CAR's investigations were the third in a series of testing projects. The midden, Feature 1, was initially tested by Wood in 1993, and it was more fully exposed by Price in 1995. With the help of TARL researchers, Steve Black and Charles Frederick, Price and his crew exposed large portions of the midden in profile by mechanically excavating backhoe trenches. The profiles afforded by the trenching defined the feature vertically and, with limitations, horizontally.

${ }^{6}$ Also note that the term "anthropic epipedon" has been used by soil scientists (Olson 1981:Table 22; see also Soil Survey Staff 1993) to describe anthropogenically created deposits; however, we prefer "anthromantle." 


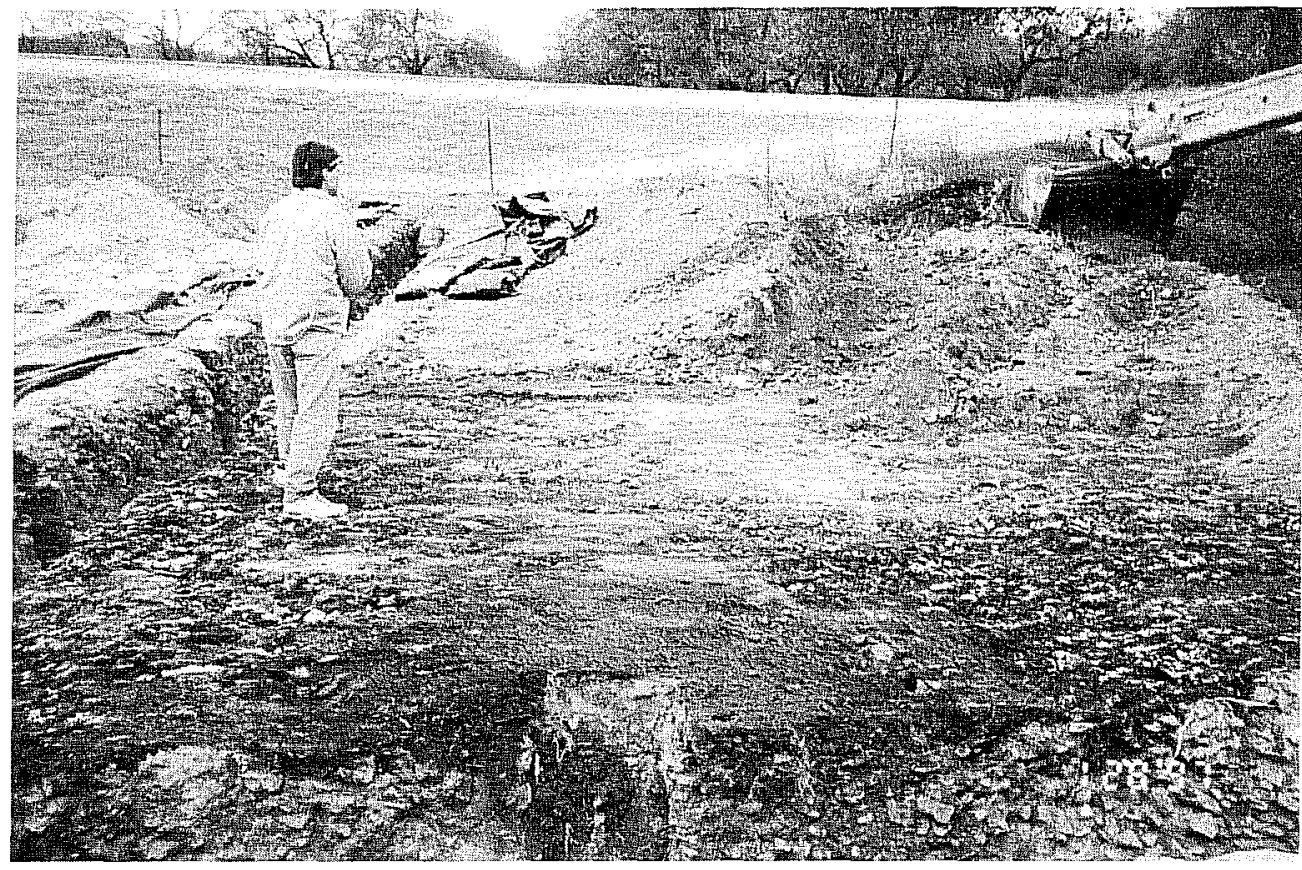

Figure 7-8. Photograph of the Gradall removing sediment from the top of the midden deposit. Note the darker area (matrix-supported) in the foreground which represents the central core area that filled following disuse. evident in the 1995 investigations (see Appendix B), was fully exposed in plan view (Figure 7-8). In plan view, this area was visible as a matrixsupported circular deposit, measuring approximately $3-3.5 \mathrm{~m}$ in diameter, with few pieces of burned rock.

Also clearly visible in profile was a layer of larger stones in the rock-supported lower portions of the profile (Figure 7-9). Later excavations in this central core area revealed a series of rock layers (Features 1.2 and CAR investigators reopened Price's trenches and excavated a number of other trenches in the midden area. In addition, a portion of the northern side of the midden was exposed with a Gradall (Figure 7-8). The Gradall work proved to be the most illuminating of all the mechanical efforts. While the backhoe trenches revealed key information about the vertical geometry of the midden deposit, the removal of the thin layer of sediment overlying the midden produced a threedimensional view not otherwise visible in the backhoe trenches. From this perspective, it was clear the midden was annular in morphology with a central sedimentfilled core. Importantly, the central core area that was

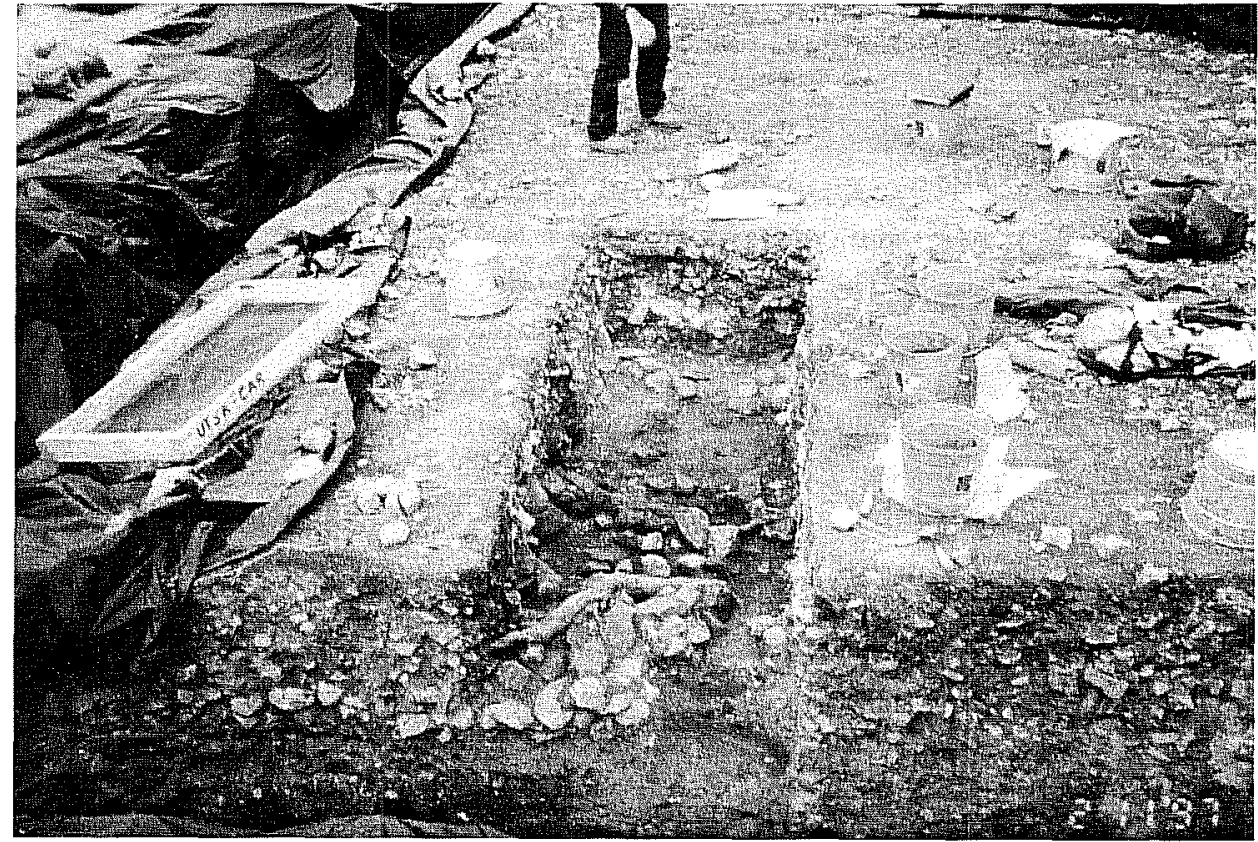

Figure 7-9. Features 1.2 and 1.3 in the central core area, following excavation. The features are visible as a layer of larger stones in the trench profile and at the bottom of the excavation units. 
last use, heating elements used in an earth oven(s). After this area within the midden fell into disuse, the central core area filled with sediment, burned rocks, and artifacts from the surrounding ring. Units excavated in this central area produced an extraordinary amount of chipped stone debitage. TUs 8 and 9 alone yielded 11,815 pieces, most of which were picked from the heavy fractions of a large number of float samples recovered in this area.

Unless the prehistoric inhabitants were systematically dumping refuse in this abandoned core area - a real possibility - this catchment basin filled naturally as the edges and tops of the ring or torus eroded downward, transporting sediment and materials. As the basin began to fill, the size of the materials that washed into this area also should have decreased with the infilling of the basin, finally resulting in only sediment filling the upper most portions of the basin. This was clearly evident from the profiles and plan views of the central core area (see Figures 6-19 through 6-23).

In addition to the central core features identified in the center of the midden, several other features were noted. These included layers of large stone within the framework of the midden and rock-filled pits at the base of the midden. Clearly features other than the central core features contributed stone to the midden (e.g., Feature 1.1), and archaeomagnetic analysis of the burned rock showed these features were intact. It appears that the framework or torus of the midden was being used as a platform for constructing other ovens.

These framework features appear to have been constructed in the discarded rubble originating from the central midden oven. At least a dozen or so of these features were visible in the trench profiles cut through the midden area. The number of features in the profile suggest that a great many of these may lie throughout the framework. However, we suggest that the majority of the discarded rock that constitutes the midden originated from earth ovens built in the central core area. This is supported by the annular or circular shape of the entire deposit rather than an irregular or amorphous shape that would be expected if these satellite features were equal contributors to the overall midden.
The rock-filled pits noted along the basal portion of the midden were first noted by Price, Black, and Frederick. These basal features, as seen in profile, are very different morphologically than the features noted in the central core area and framework. The actual pits themselves were not readably visible, but were rather defined by the rocks within the presumed pit. The fill of the pits is jumbled and looks very much like the structure of the midden framework. These rock-filled pits could be due to a number of phenomenon, but we think they represent the remains of borrow pits. Similar features are documented on a number of burned rock midden sites throughout Texas, but they are not interpreted as borrow pits. These borrow pits are located within the borrow zone and are simply filled with discarded material as the midden grows outward or filled with eroded material if not covered.

Unfortunately, this model was developed in the lab and experimentally after the final phase of excavation was completed on the Area B midden at Culebra Creek, and excavation strategies were not designed to assess the validity of this model. Nevertheless, evidence in support of artifact transportation off the midden into the apron (periphery) or the core is presented below, and this can stand as a preliminary test of the model. However, because three separate testing projects with potentially three individual collection strategies investigated Area B, an assessment of possible collection bias is necessary.

\section{Archaeological Collection Biases}

As three separate testing projects were conducted at 41BX126, it seems prudent to assess possible collection biases between the three field projects. In addition to the size sorting issues, any types or avenues of analysis would clearly be influenced by significant differences in the collection of archaeological materials and artifacts. The most straightforward assessment can be made by comparing debitage recovery rates by debitage size classes. In order to achieve this, one must first calculate the various volumes excavated by the different investigators, and these data are presented in Table 7-1. These calculations are limited to $1-\mathrm{x}-1-\mathrm{m}$ units in the various areas of the site. 
Table 7-1. Total Volume $\left(\mathrm{m}^{3}\right)$ of Excavations in 1-x-1-m Units by Area and Investigator

\begin{tabular}{|l|r|r|r|r|}
\hline Investigator & Area A & Area B & Area C & All Areas \\
\hline Wood & none & 2.2 & 4.4 & 6.6 \\
\hline Price & none & 5.5 & 2.7 & 8.2 \\
\hline CAR & 2.9 & 10.0 & none & 12.9 \\
\hline
\end{tabular}

Table 7-2. Total Number of Lithic Debitage Recovered in 1-x-1-m Units by Area and Investigator

\begin{tabular}{|l|r|r|r|r|}
\hline Investigator & Area A & Area B & Area C & All Areas \\
\hline Wood & NA & 1344 & 650 & 1994 \\
\hline Price & NA & 7404 & 697 & 8101 \\
\hline CAR & 1378 & 15583 & NA & 16961 \\
\hline
\end{tabular}

Table 7-3. Lithic Debitage Density per Cubic Meter Recovered in 1-x-1-m Units by Area and Investigator

\begin{tabular}{|l|r|r|r|r|}
\hline Investigator & Area A & Area B & Area C & All Areas \\
\hline Wood & NA & 610.9 & 147.7 & 302.6 \\
\hline Price & NA & 1346.2 & 258.1 & 987.9 \\
\hline CAR & 475.2 & 1558.3 & NA & 1314.8 \\
\hline
\end{tabular}

Lithic debitage totals in these same excavation areas are presented in Table 7-2. These numbers represent the individual pieces of lithic debitage collected from 1/4-inch screens. Both CAR and Price also screened selected sediments through $1 / 16$-inch screens, but Wood did not. By eliminating the $1 / 15$-inch screen data, a direct comparison can be made between all three projects. Lithic debitage density values can easily be calculated by dividing the total number of recovered items by the excavated volume (Table 7-3).

The density values in Table 7-3 strongly suggest that dramatic differences exist, especially between Wood and the other two efforts. Exactly why the recovery rates differ is not clear from this table. The differences between the Price and CAR recovery rates is probably not significant since CAR and Price sampled portions of the site slightly differently, i.e., midden and nonmidden contexts in Area B. A comparison by debitage size helps to clarify the situation further. Two distribution plots, one for Area $\mathrm{B}$ and one for Area $\mathrm{C}$
(Area A was investigated only by CAR), were created showing the recovery rates in terms of density and by maximum dimension and by investigator (Figures 710 and 7-11). The Area B plot shows that Wood's recovery is reasonably close to those of CAR and Price for the larger pieces of debitage, but dramatically lower for the smaller pieces, especially those debitage pieces smaller than four centimeters. The differences between CAR and Price are not so dramatically different to suggest a serious bias. The pattern is similar for Area C where Price's and Wood's recovery is dramatically different for items smaller than three centimeters (CAR did not conduct controlled excavations in Area C). These plots appear to suggest that Wood did not collect smaller items with the same intensity as the other investigators and it appears that his debitage samples are biased toward the larger items. This bias makes it difficult to investigate ratios between debitage and other artifacts, and these forms of analysis, while planned, were eliminated and certainly not recommended with the data published here. 


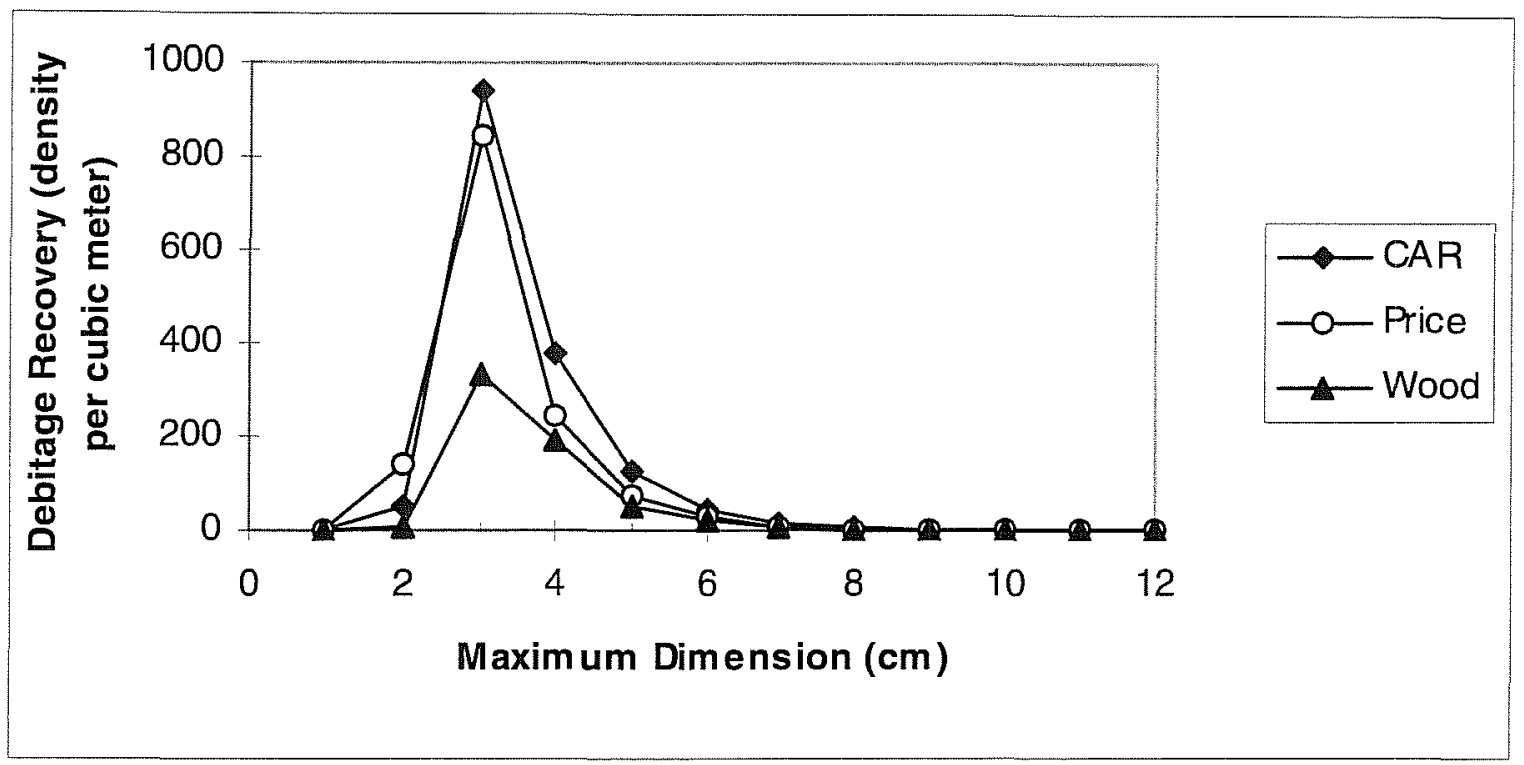

Figure 7-10. The distribution of lithic debitage in terms of density per cubic meter by size and investigator for Area $B$.

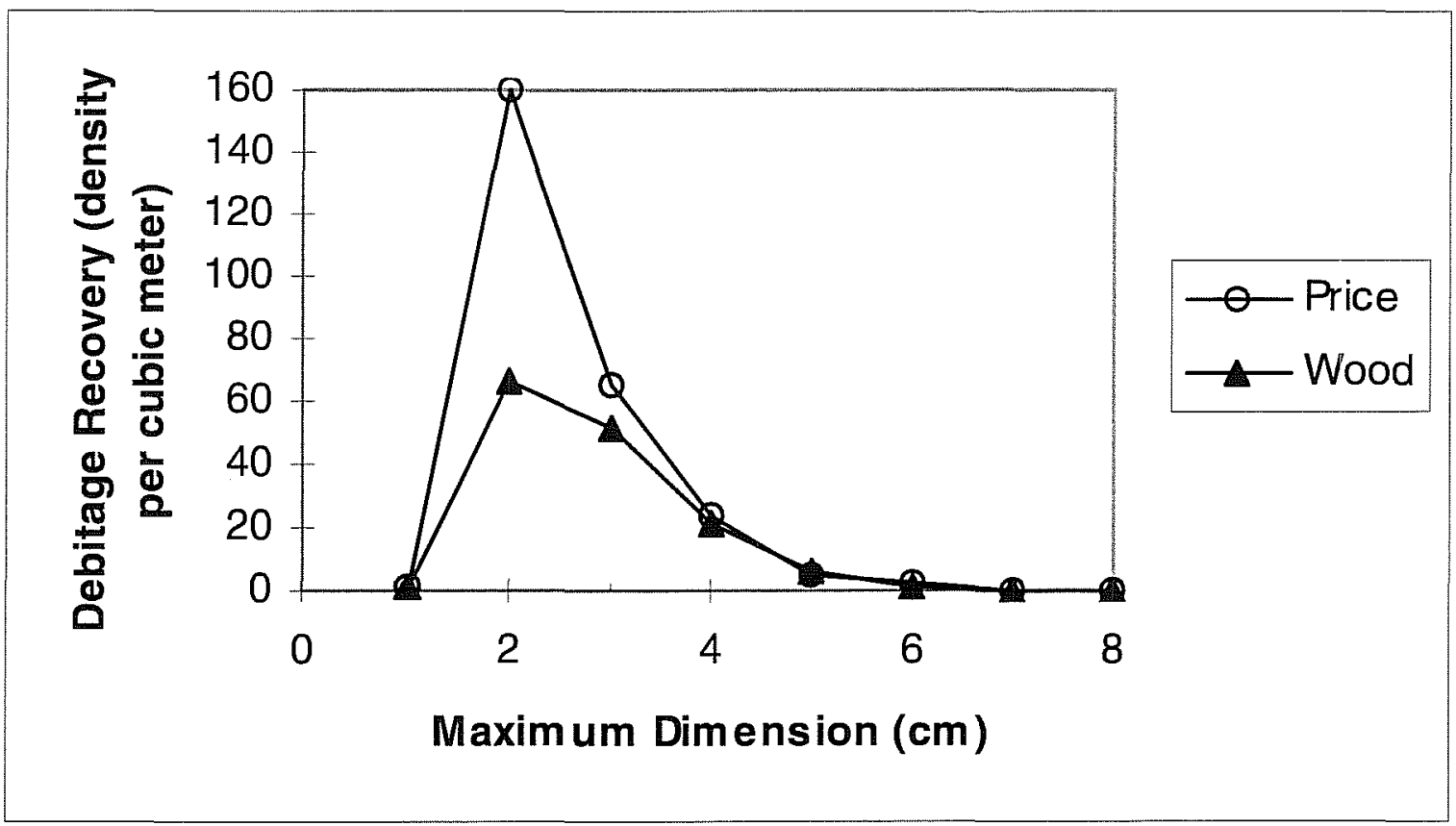

Figure 7-11. The distribution of lithic debitage in terms of density per cubic meter by size and investigator for Area $C$.

\section{Patterns in Size Sorting of Lithic Debitage in Area B}

The above analysis strongly suggests that Wood's data cannot be used to assess the size sorting of artifacts by post-depositional geological processes in Area B or any other area. However, the data collected by Price in 1995 and CAR in 1997 appear to be biased in a similar fashion and thus can be used together to assess this model. The differences in average size of lithic artifacts in the 1/4-inch screened material are presented by the four subareas of Area B in Table 7-4. These data show that the largest debitage is in the midden core and the smallest debitage is in the midden 
Table 7-4. Average Size of Debitage in Subarea of Area B (1/4-inch fraction only)

\begin{tabular}{|l|c|c|c|c|}
\hline & Core & Framework & Periphery & Block Excavation \\
\hline Ave. Debitage Size $(\mathrm{cm})$ & 2.60 & 2.50 & 2.29 & 2.53 \\
\hline $\mathrm{n}=$ & 2438 & 3989 & 8152 & 8409 \\
\hline
\end{tabular}

periphery. If erosion and slope wash were moving artifacts horizontally from the surface of the framework downslope to the periphery then smaller average sizes of debitage in the periphery would be expected and help to confirm this general model. As the values in Table 7-4 indicate, the periphery does have smaller average sizes of debitage. However, one would also expect that the core would have, on average, smaller debitage than the framework, but the reverse pattern is present. It is possible that human transportation of sediments and artifacts, i.e., dumping, in the core created a size selection of debitage (see Appendix E), but this cannot be determined.

Before tackling the core and debitage size-sorting, the argument of natural redistribution of materials can be assessed with the frequency and size of debitage in TU 11, which is located in the periphery. TU 11 is situated immediately downslope (southwest) of the midden core and three to four meters from the edge of the framework (Figure 7-12). In the northern end of the BHT X profile, the midden framework dropped off dramatically into a thin layer of burned limestone averaging 2-3 stones thick and thinning with distance (south) from the midden. TU 11 was excavated to sample the off-midden material, but data from this unit can be used to help test the likelihood that material was eroded off the midden and redeposited on the apron in the area classified as the periphery.

Excavations in this unit consisted of seven arbitrary levels beginning at the original ground surface $(100.30$ $\mathrm{m}$ ) and continuing to a depth of $70 \mathrm{~cm}(99.60 \mathrm{~m})$ (Figure 7-13). The upper $10 \mathrm{~cm}$ of sediment in the unit was not screened or considered a level as it was full of modern artifacts and gravel from the initial construction of Loop 1604. The counts of lithic debitage recovered from this unit along with the average size of lithic debitage in the $1 / 4$-inch fraction are presented in Table 7-5. A total of 4,701 pieces of lithic debitage was recovered from this unit, which included the screened (1/4-inch), and floated $\left(1 / 16^{-i n c h}\right)$ fractions. Both fractions are included.

The greatest number of lithic debitage was recovered from Level 4, with 1,358 pieces of debitage. Levels 4 and 5 also correspond with the densest layer of burned rock, and this density can be linked to the scatter of burned rock leading away from the midden, as evidenced in the Unit 11 profile (see Figure 7-13). The base of this rock layer represents the surface on which the midden was constructed, and this surface is the contact between the A and B horizons as well as Sedimentary Units III and IV (see Nordt, Chapter 5). Also note that while not depicted in Figure 7-13, limited amounts of burned rock were recovered from throughout the various levels in TU 11.

Average debitage size (see Table 7-5) is larger in those levels below the base of the midden in the Sediment Unit III/B horizon (Levels 6 and 7). This material predates midden construction. In levels that are contemporaneous with the midden or post-date the midden, in general Levels 4 and 5, have with the greatest frequency of burned rock as well as the largest debitage. The increase in debitage from Level 6 to Level 5 reflects the general increase in artifact density found in other units in Area B. At this point it is unclear if the burned rocks and debitage in Levels 4 and 5 were transported solely by slope wash. It seems highly likely that a portion of this material was discarded or trampled in place. However, above the obvious burned rock levels, in Levels $1-3$, there is a clear decline in size except for Level 1. This again suggests that size sorting occurs vertically in this portion of the site as predicted by the model outlined above. In a large measure, this is probably due to the geological process of slopewash and erosion as the periphery filled with sediment washed from the framework of the midden. 


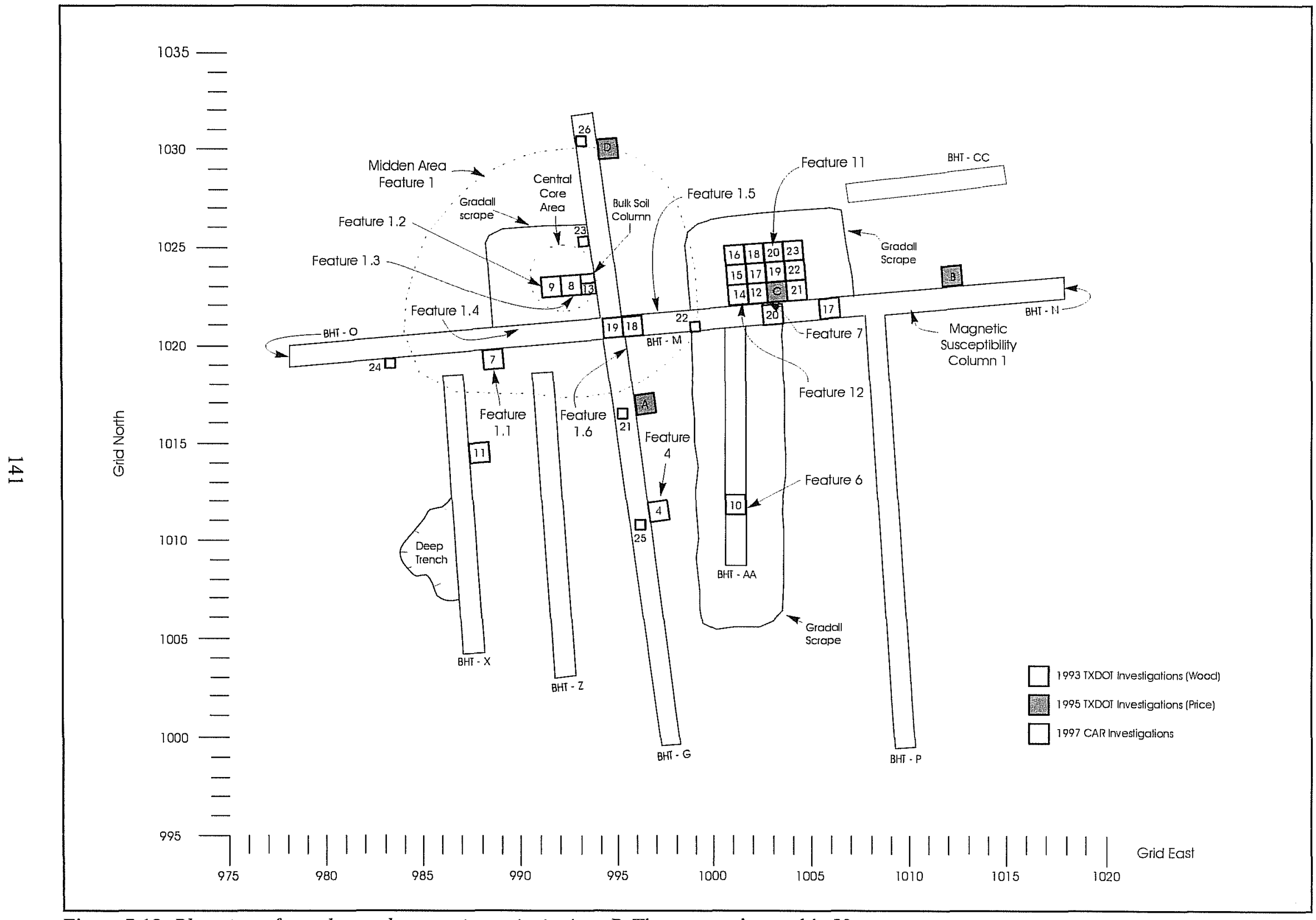

Figure 7-12. Plan view of trenches and excavation units in Area $B$. The contour interval is $50 \mathrm{~cm}$. 


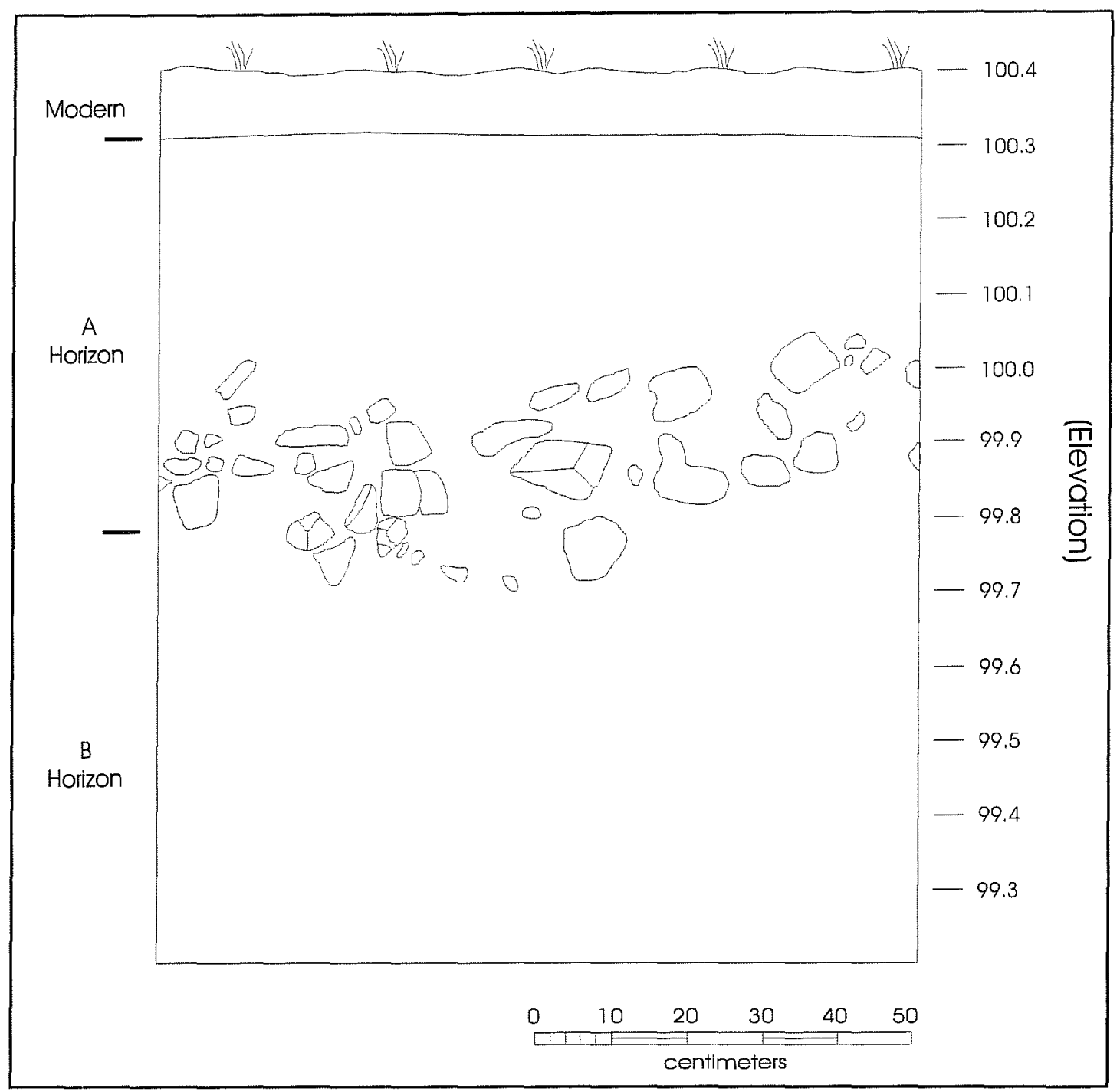

Figure 7-13. Profile of the east wall of Unit II in BHT X showing the layer of stones extending away from the midden.

Table 7-5. Lithic Debitage Recovered from TU 11, Area B-Periphery

\begin{tabular}{|c|c|c|c|c|}
\hline Level & Elevation (mbd) & Debitage Number & $\begin{array}{c}\text { Average } \\
\text { Size (cm) }\end{array}$ & $\begin{array}{c}\text { Midden } \\
\text { Context }\end{array}$ \\
\hline 1 & $100.3-100.2$ & 724 & 2.44 & above \\
\hline 2 & $100.2-100.1$ & 737 & 2.02 & above \\
\hline 3 & $100.1-100.0$ & 828 & 2.37 & above \\
\hline 4 & $100.0-99.9$ & 1,358 & 2.40 & within \\
\hline 5 & $99.9-99.8$ & 611 & 2.44 & within \\
\hline 6 & $99.8-99.7$ & 244 & 2.89 & below \\
\hline 7 & $99.7-99.6$ & 209 & 3.08 & below \\
\hline
\end{tabular}




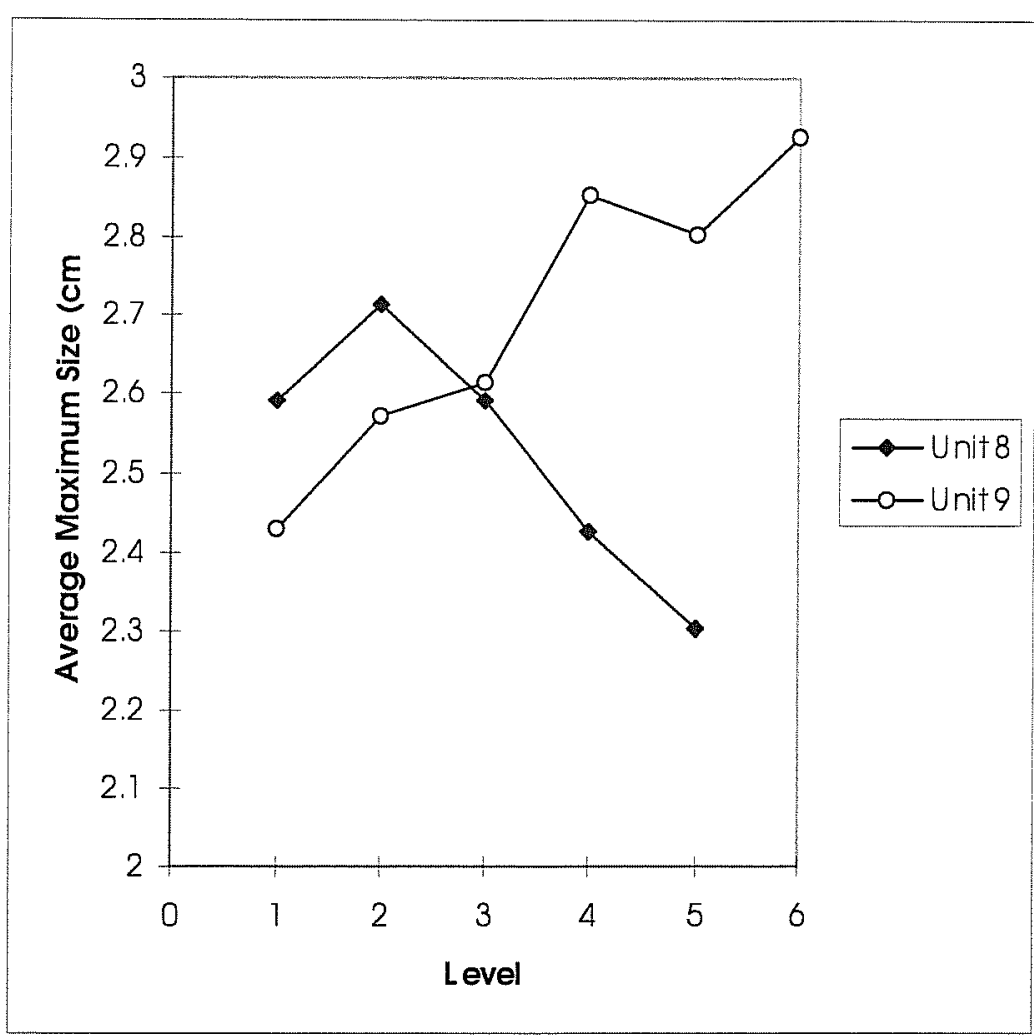

Figure 7-14. Average maximum debitage size in TUs 8 and 9 by level in the $1 / 4$-inch fraction.

Now to return to the apparent contradiction of debitage size in the midden core. This can be more fully investigated by inspecting the average size of debitage and burned rock by level in the two core excavation units (TUs 8 and 9). These $1 / 4$-inch results (Figure 7-14) show that in TU 8 average debitage size increases from Level 5 to Level 2 and then declines in Level 1. However, in TU 9 debitage size generally declines in average size from Level 6 to Level 1 . As most of the matrix in TU 8 was floated, the size patterns in this unit are probably biased by this selection process. The $1 /{ }_{16}$-inch results do not provide a simple pattern either (Figure 7-15), nevertheless the patterns in TUs 8 and 9 do show a similarity in direction of change. It could be argued that the $1 / 16^{-}$-inch material reflects three upward fining cycles from large to small (Levels 6 to 5,4 to 3 , and 2 to 1 ). An inspection of the profile for TUs 8 and 9 (see Figure 6-25) shows that multiple rock layers exist and these seem to represent multiple episodes of use and filling.

In addition, the size distribution of burned rock from the central core area suggest some sorting during in filling. Table 7-6 presents the average size of analyzed burned rock from TU 8 by level. Though less than ideal, the data clearly show a trend with the largest burned rock at the bottom to smaller burned rock in the middle. The increase in burned rock size at the top appears to reflect the layer of burned rock at the top of Feature 1.1 in Figure 6-21.

Again these results are somewhat ambiguous, but if these materials were eroded or fell into the core, then they were derived from a population of artifacts with a specific size distribution. The only measure of this population is the samples in TUs 8 and 9. It seems reasonable to suggest that the original debitage population may have biased the results. This is a situation commonly referred to in geological studies

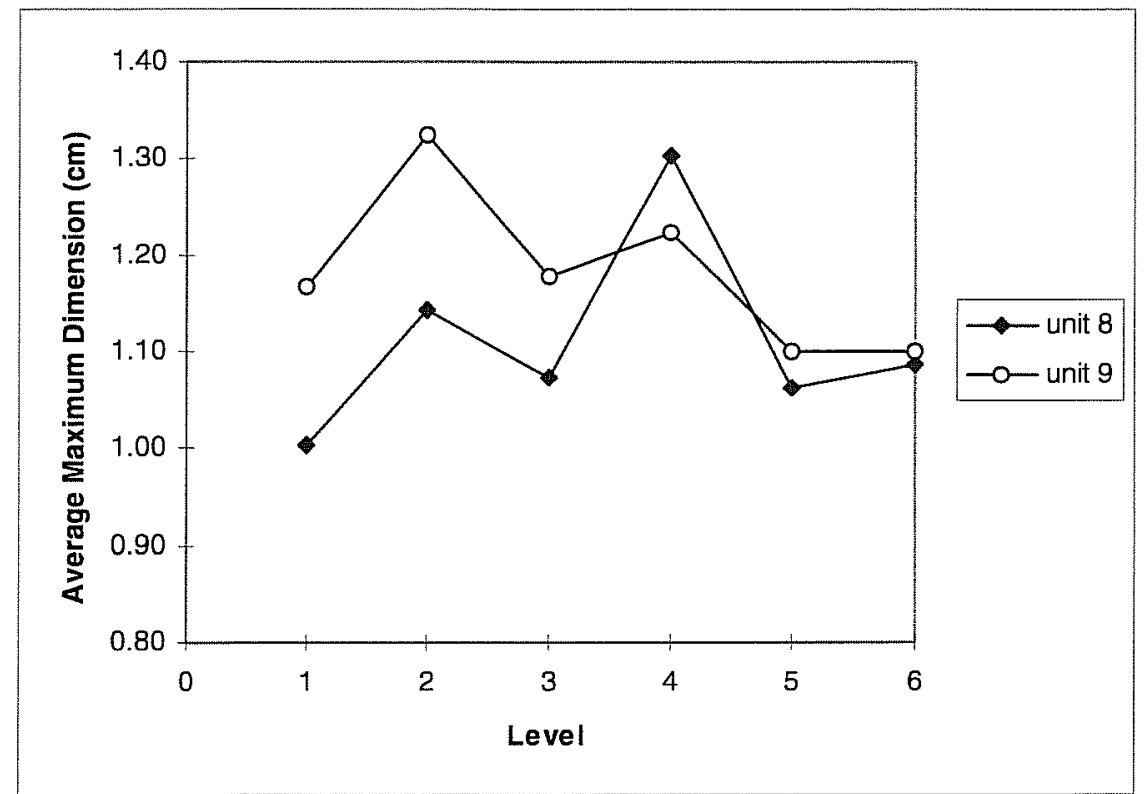

Figure 7-15. Average maximum debitage size in TUs 8 and 9 by level in the $1 / 16^{-i n c h ~ f r a c t i o n . ~}$ 
Table 7-6. Average Size of Burned Rock Recovered from TU 8, Central Core Area

\begin{tabular}{|c|c|c|}
\hline Level & A verage Size $(\mathbf{c m})$ & Number Analyzed \\
\hline 1 & 5.62 & 213 \\
\hline 2 & 5.72 & 527 \\
\hline 3 & 4.73 & 1345 \\
\hline 4 & 4.07 & 887 \\
\hline 5 & 6.93 & 383 \\
\hline 6 & 7.4 & 30 \\
\hline
\end{tabular}

as a sediment supply bias. In other words, if only large pieces of debitage are available for transportation, then only large debitage will be moved by erosion or gravity. Although not a strong argument, the general decline in $1 / 4$-inch debitage size in TU 9 and the final decline in TU 8 and the cycles in $1 / 16^{\text {-inch debitage do }}$ suggest that size sorting did occur during the in-filling of the midden core. It is also important to realize that the side wall of the central core cooking feature probably was steeply sloping, and that material could easily dislodge from any of the exposed layers, and thus reduce the size sorting effect of slopewash. While we do not consider these results to be conclusive, they do support the model presented in the beginning of this chapter. That is, as the central core area fills with sediment following abandonment, artifacts and other materials will erode and wash into the low area. The materials should decrease in overall size as the angle of the core area walls decreases through filling. Importantly, the excavation in the core area revealed substantial quantities of debitage overlying the last use features identified in this area, suggesting this material was deposited after the central core area fell into disuse. In the future more carefully collected data should be amassed to further investigate this issue.

It also appears that within the sediment mantle that formed the apron skirting the midden, burned rock and artifacts were deposited as the midden was used, grew, and eroded. This is indicated by the presence of burned rock and a large number of chipped stone artifacts situated stratigraphically above the surface (Unit III/IV contact) on which the midden was constructed and spread. It is highly likely that these materials were transported and deposited by both human and geological processes. Additionally, there is evidence that these materials were further mixed by both faunal and floral turbation (rodents, insects, and roots), however these processes appear to be minor when compared to the anthropogenic and geologic processes outlined above. It is also clear that no significant post-midden occupation, such as a Late Prehistoric habitation, occurred at the site, and it is not a source of more recent materials mixed with the pre-midden and midden occupations.

Mixing of materials (pre-midden and midden occupations) can be monitored by looking at the distribution of diagnostic artifacts (see Chapter 6). The presence of Middle Archaic projectile points above or with Late Archaic projectile points in a number of contexts strongly suggests a process of turbation. While faunal and floral turbation may share some of the blame, we must also consider the distinct likelihood that these materials were transported to the midden in borrowed sediment and subject to further movement as the midden eroded during and after use. The same processes that move artifacts, also transport and move wood charcoal and fauna. This was evident at Culebra Creek where a number of assays from the midden suggest several millennium of use and the assays in the core were reversed. The radiocarbon assays on fish otoliths may also reflect the mixing of older materials into younger deposits, although their consistently older assays suggest that issues concerned with old carbon update must be considered as well. These arguments indicated that we cannot simply take the earliest and latest radiocarbon dates and propose the midden was used during this time period. Dated materials from earlier and unassociated occupations could be incorporated into the midden and then selected for radiocarbon analysis by archaeologists.

\section{Conclusion}

The purpose of this chapter has been to discuss a set of cultural and natural formation processes that have resulted in the accumulation of large, burned rock features. Site formation studies, for the most part, have been either not discussed in burned rock midden research, or discussed very selectively, although see Black 1997 and Ellis 1997 for excellent recent 
exceptions. The lack of attention to formation studies has put researchers at a disadvantage, resulting in decades of often complex interpretative scenarios for explaining these enigmatic deposits. Understandably, artifactual content of middens has driven current hypothesis concerning midden formation and use. The content as argued here may have resulted from a complex set of cultural and natural processes. The cultural behavior of borrowing sediment for use in earthen caps has played a poorly realized role in the formation of midden deposits, and when complemented by natural erosional and pedogenic processes, this has resulted in the homogenizing of site stratigraphy and activities into a single anthropogenic node.

The term anthromantle has been introduced to characterize the complex and bioturbative nature of these deposits. Human activities associated with their formation have resulted in the direct and indirect deposition of sediment and materials within a very limited space. As a result, the way we excavate and interpret these deposits should take into account the potential effects of rain splash and sheet wash on forming strata within and around the midden. Anthromantles should not be treated as flat, stratified, or undisturbed. They are not. Areas within and around these deposits may reflect a convoluted use and depositional history that must be considered during excavation and subsequent analysis. This also requires archaeologists to question the association of materials (all materials) in space and to develop methods for addressing this most basic issue.

Clearly the presence of mass quantities of charred and fragmented rock (and features within) should be our vehicle to understanding the role(s) these features played in hunter-gatherer subsistence, cooking technology, and landscape use. If we can accept the fact that varying amounts of the midden deposits might be in a secondary context, then the utility in interpreting these features using artifact context is limited, or at the very least not straight forward. Armed with this knowledge and by using well designed investigation strategies and approaches, we can begin to more fully understand this most ubiquitous archaeological phenomenon of the Edwards Plateau. Continued persistence in using artifact content and distributions to understand midden function and chronology, except at a gross (macro) scale, probably will not shed light or new insights on the processes responsible for the formation and alteration of burned rock middens.

The forgoing model, developed as the analysis progressed, has suggested some basic cultural and geological processes for midden formation. This model, when applied to a site that has been excavated with these processes in mind, should be able to fully assess the potential and limitations of the proposed model. The data collected at Culebra Creek was not collected with this model in mind. The limited excavations by CAR, and the two previous TxDOT projects, focused on a very specific research and management questions. As such, the current project is not a robust test of the model. However, the collected data do suggest support of the model. Importantly, the foregoing analysis (see also Chapters 6 and 8) reveals that some of our expectations about the movement of materials will be complicated.

It is hoped that the proposed model of midden formation can be utilized in future midden studies. It is no great secret that many archaeologists in Texas see these deposits as mixed and thus lacking in research potential. The current attitude about middens is an understandable one, as agencies who pay for the excavation and analysis of these deposits often see little return for the resources and energy expended and researchers believe their time could be more profitably spend investigating other types of sites. If we can begin to see middens for what they are, anthromantles, then we may be able to unravel the analytical potential of these deposits. Until researchers more critically evaluate what they are inferring from the content of middens, no substantial progress will be forthcoming.

In closing, we realize the foregoing discussion on midden formation may not be popular. It is also likely that the theoretical framework laid out will be found lacking, and will require improvement and modification in future studies. But it is a start-and we believe a start in the right direction. 


\section{Chapter 8: Artifact Analysis}

\section{Wilson W. McKinney, C. Britt Bousman, David L. Nickels, and Kaylee A. McRae}

\section{Introduction}

This chapter describes the methods used to catalogue and analyze the artifacts collected at the Culebra Creek site, 41BX126. Over 60,000 artifacts were recovered during the excavations in 1993, 1995, and 1997. These artifacts are broken down into categories of Prehistoric and Historic. The Prehistoric artifacts were further divided into chipped stone and incised stone categories. Since only a few Historic artifacts were recovered, each specimen is discussed individually.

\section{Prehistoric Artifacts}

\section{Chipped Stone}

In total, 60,067 chipped-stone artifacts were recovered during the 1993, 1995, and 1997 excavations at 41BX126. During the analysis, the artifacts were subdivided into the following classes: projectile points $(n=69)$, bifaces $(n=199)$, unifaces $(n=427)$, cores $(n=52)$, choppers $(n=2)$, and unmodified debitage $(n=59,318)$. After artifacts were catalogued, classes were analyzed according to a variety of attributes. The chosen attributes provided a thorough technological and morphological characterization of the lithic assemblage at the Culebra Creek site. The attributes for each artifact class are defined below.

\section{Projectile Points}

One of the smaller classes of chipped stone artifacts is projectile points. This class, however, is one of the more important artifact categories because it can provide information on cultural affiliations and chronology. For projectile points, the following attributes were recorded: raw material type, raw material quality, burning, projectile point subgroup, projectile point type, serration, beveling, completeness, break type, maximum length, blade length, blade width, haft length, neck width, base width, and maximum thickness.

No Late Prehistoric arrow points were found at Culebra Creek, only Archaic dart points. Each point was classified into one of the following subgroups: dart point, dart point preform, or dart point blank. In this system, blanks are usually bifacial artifacts that appear to be the proper shape and size to be made into a dart point, but they lack any notching and therefore do not have barbs or shoulders. No blanks were identified in the collection from the Culebra Creek site. Preforms are recognizable as a stage of dart point manufacture in that they have barbs and/or shoulders but were not completed. Therefore, any incomplete projectile point with a manufacturing break was classified as a preform rather than as a finished point.

Dart points and preforms were then assigned to a projectile point type based on the commonly accepted point typology developed by others for central and south Texas (e.g., Turner and Hester 1993). Points which could not be assigned with confidence to a previously established type were coded as either "untyped" or "untypable." The former term indicates that the point does not conform to any known or defined type. The latter designation was generally reserved for fragmentary specimens lacking enough diagnostic attributes to determine their size or shape.

If a point was incomplete, the break was coded as either use/resharpening related, manufacture, postdepositional, or indeterminate. Length and width measurements were made only for those dimensions that were complete. 


\section{Dart Points}

Sixty diagnostic dart points, two diagnostic dart point preforms, and seven untypable dart point fragments were recovered from investigations during 1993, 1995, and 1997 at the Culebra Creek site. All but one, a Pedernales point ( $\mathrm{SC} 21)$, are made of fine-grained chert and several have been burned or were otherwise exposed to intensive heat. The preforms can be classified as Pedernales, and are described with that type. Three of the relatively complete points could not be assigned to a type, even approximately, while four fragmentary bifaces, although clearly parts of dart points, lacked necessary identifying features. These will be discussed at the end of this section. No arrow points were recovered from any part of the site.

\section{Bell}

Bell dart points were defined by Shafer (Sorrow et al. 1967:12, 14, Figure 10) as a provisional type on the basis of 14 specimens recovered from lower levels at the Landslide site (41BL85) at Stillhouse Hollow Reservoir. Noting the excellent workmanship of the type specimens, Shafer singled out their large barbs and overall thinness as distinctive attributes, and distinguished them from Shumla, Marshall, and Castroville points, all occurring later in the archaeological sequence. The reference to Shumla was necessary because Suhm et al. (1954:480, Plate 119) had illustrated at least one Bell point with the type description for Shumla. Shafer's definition of Bell gained rapid acceptance (Jelks 1978; Wesolowsky et al. 1976). Subsequently, Prewitt (1983) distinguished Bell and Andice points, principally on the basis of the greater size and stem length of Andice. While Weber (1986) argued that there was no typological separation between Bell and Andice when a large sample was subjected to quantitative analysis, the distinction, nevertheless, has since been accepted as valid (Turner and Hester 1993:80).

The position of Bell points in a larger tradition transcending central and southwest Texas was first noted by Parker and Mitchell (1979:26-27) and Story (1985:36), who pointed out the resemblance of the supposedly Early Archaic Bell and "Early Barbed" point types to the Middle Archaic Calf Creek type of Oklahoma, Arkansas and Southern Missouri, with an estimated age of 6950-4950 B.P. Johnson (Johnson and
Goode 1994:24-25), in his detailed reconsideration of the Texas archaic, recognizes that Bell points are intrusive from the eastern Woodlands, brought in by bison hunters during what he designates the Bell/Calf Creek interval of the Middle Archaic about 5600-4300 B.P. Collins (1995:383-384, Table 2) calls it the BellAndice-CalfCreek interval of the Middle Archaic from about 6000 B.P. to as late as 5000 B.P. Hester (1995:437438) sees a "Calf Creek Horizon," including Bell and Andice, as part of his Early Basal Notched Horizon spreading across southern Texas into northeastern Mexico. He dates this period to about $5450-4450$ B.P.

One Bell point and one "probable Bell,", both incomplete, have been recovered during the course of investigations at 41BX126. The Bell point (Figure 8-1a) is of mottled gray chert and is missing all or part of both barbs, a large part of one blade edge, and a small part of the tip. Edge damage on both sides of the scar left by the missing tip suggest the point has been used as an awl or drill, with or without prior modification. Though damaged, the blade of this point is well within the typical range. The stem is $11 \mathrm{~mm}$ long and 14.5 $\mathrm{mm}$ wide at the neck, expanding to $21 \mathrm{~mm}$ at the base. Thickness is $6.5 \mathrm{~mm}$. This artifact was identified originally as an "Early Corner Notched" or "Early Barbed" dart point (Wood 1994:20). It is from Area C, TU 5, Level C.

The point identified as a "probable Bell" (Figure 8-1b) is a proximal fragment of dark brown chert, broken diagonally just above the barbs. It is heavily fire damaged, with potlid fractures on the stem and neck of one face. The tip of one barb and the corners of the slightly expanding base are missing. Even in undamaged condition, the barbs are quite short for a Bell point, and the remaining edges of the blade are atypically straight and parallel. Width at the barbs is $36 \mathrm{~mm}$. The stem is $11.5 \mathrm{~mm}$ long and $16.5 \mathrm{~mm}$ wide at the neck. Maximum thickness is $7 \mathrm{~mm}$. This point is from the midden periphery, Area B, TU 11, Level 7.

\section{Bulverde}

The Bulverde type has been variously assigned to the Early, Middle and Late Archaic, depending on the investigator and the region. The type was originally named "Bulverde Barbed" and ascribed to the Edwards Plateau aspect (Late/Transitional Archaic) by Kelley 


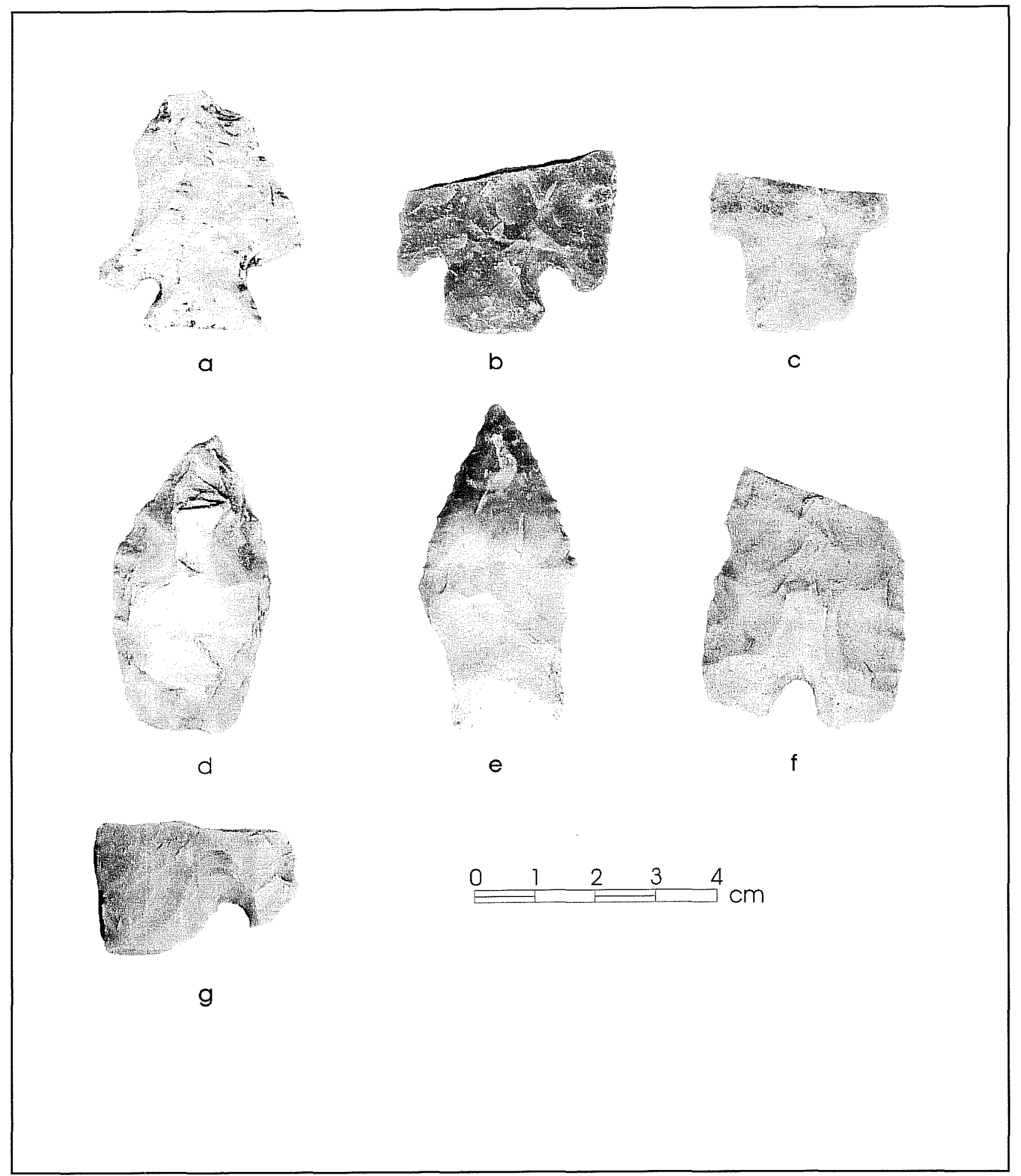

Figure 8-1. Diagnostic artifacts. a: Bell; b: probable Bell; c: Bulverde; d, e: possible Bulverde; f, g: Carrizo. 
(1947a:124, Plate 14; Newell and Krieger 1949:170, Figure 59) in a restricted segment of central Texas along the Colorado River northwest of Austin, Texas. Miller and Jelks (1952:176) defined the type, and Suhm et al. (1954:404) broadened both the spatial and temporal distributions to the whole of central Texas from about 4950-1450 B.P. Since that time, Bulverde has been assigned to the Clear Fork and Middle Archaic/Round Rock phases at Canyon Reservoir (Johnson et al. 1962), the Early Archaic/Clear Fork phase at Camp Bullis (Gerstle et al. 1978:65), and the Marshall Ford phase of the Middle Archaic (Prewitt 1981a:79), leading Black and McGraw (1985:116) to comment that the type may be long lived. Turner and Hester (1993:82) place the type late in the Early Archaic ca. $4950-4450$ B.P. Johnson, in his reassessment of the central Texas Archaic (Johnson and Goode 1994:29-30), moves up the start of the Late Archaic to about 4250 B.P. and opens the period with a "Bulverde interval." Johnson suggests that the Bulverde type is intrusive onto the Edwards Plateau from the north or northeast, and represents the beginning of a style (and cultural) continuum including Pedernales and Montell intervals. Collins (1995:384, Table 2) follows this, but suggests an even earlier start for the Late Archaic and dates the Bulverde interval ca. $4000-3000$ B.P.

The relatively broad blades of the Bulverde type are usually triangular with straight to convex edges, sometimes almost leaf-shaped, with prominent shoulders that are usually barbed, sometimes square. Rectangular or slightly contracting stems are characterized by basal thinning that produces a wedge shape and often forms a sharp edge at the base, which may be slightly convex or concave but is usually straight and often with slightly rounded corners.

One Bulverde stem fragment and two possible Bulverde points have been recovered at the Culebra Creek site. The Bulverde proximal fragment (Figure 8-1c) is made of pinkish tan chert, possibly heat treated, with strong shoulders. Basal thinning produced a wedge-shaped cross-section for the proximal half of the stem. The point is $30 \mathrm{~mm}$ at the barbs and has a stem that is $16 \mathrm{~mm}$ long, $20 \mathrm{~mm}$ wide at the neck and $18 \mathrm{~mm}$ wide at the base. It is $8 \mathrm{~mm}$ thick. This point is from the midden periphery, Area B, TU 20, Level 3.
A possible Bulverde point (Figure 8-1d) is classifiable as such only on the basis of the shape and cross-section of the presumed stem. The massive blade of this specimen has been considerably resharpened, leaving a 12-mm-thick knot at the midpoint of the artifact (which is $49.5 \mathrm{~mm}$ long) that may have inhibited further rejuvenation to remove step fractures visible around the tip. Extensive lateral reworking has resulted in the absence of clearly identifiable shoulders, making it difficult to specify where the blade ends and the stem begins. In this aspect, it resembles the "stubby" points associated with Bulverde points at $41 \mathrm{BX} 228$ (Black and McGraw 1985:116, Figure 20). The widest $(26 \mathrm{~mm})$ and thickest $(12 \mathrm{~mm})$ parts of this artifact roughly coincide, producing an even contraction from midpoint to the slightly rounded corners of the base and an equally regular diminution in the wedge-shaped cross-section from midpoint to base, which measures $12 \mathrm{~mm}$ across. This point was recovered from the midden framework in Area B in the wall of Trench G, ca. $90 \mathrm{~cm}$ below surface.

Figure 8-1e is a possible Bulverde made of dark gray chert grading to subcortical material and is missing the barbs off both shoulders. The lateral edges are lightly serrated. This point is $53.5 \mathrm{~mm}$ long and $8 \mathrm{~mm}$ thick at the shoulders. The stem is $18.5 \mathrm{~mm}$ long and $21 \mathrm{~mm}$ wide at the neck, with slightly concave edges contracting to $18 \mathrm{~mm}$ at the base, which is wedge shaped and slightly concave. The stem appears to be slightly, perhaps fortuitously, beveled on one left edge. Because of its deep stratigraphic position in the site, this point was closely examined for its resemblances to both Nolan and Travis types. This point was recovered from the block excavation in Area B, TU 16, Level 5.

\section{Carrizo}

This triangular unstemmed point with a deep, distinctive U-shaped notch centered in the base was defined by House and Hester (1967) and is found primarily in Dimmit, Zavala, LaSalle, and Frio counties of south Texas (Hester 1980:98), although specimens have turned up in other areas of south central Texas as well (Weir 1979:26, Figure 10t; Woerner and Highley 1983:6), including Bexar County (Black and McGraw 1985:127, Figure 23e; Fox 1975:Figure 4q). Initially assigned simply to the Archaic (Hester 1980), the timespan for this point style has since been narrowed 
to the south Texas Middle Archaic about 4450-2350 B.P. (Hester 1995:438).

Usually exhibiting excellent workmanship and fine flaking, Carrizo points have straight to slightly convex lateral edges and may have a convex to straight base with rounded corners. The latter, along with the basal notch, give it a heart-shaped outline (Turner and Hester 1993:184).

Two Carrizo points were recovered from 41BX126. Figure 8-1f is a proximal fragment with a medial fracture and lateral damage on one edge, and is made of tan chert. It has convex lateral edges and a convex base. Basal thinning flakes produce a wedge-shaped cross-section, co-extensive with the depth of the bifacially flaked basal notch $(6.5 \mathrm{~mm})$. The blade is 33.5 $\mathrm{mm}$ wide and $7 \mathrm{~mm}$ thick. This point was recovered from the midden periphery in Area B, TU 11, Level 4.

Figure 8-1g is a badly damaged medial fragment. Identification is based on the remaining U-shaped part of the basal notch and its relation to the undamaged remainder of one lateral edge. This point was recovered from the midden periphery in Area B, TU 11, Level 4.

\section{Castroville}

Kelley (1947a:124) named the "Castroville Convex Base" dart point type and considered it diagnostic of the Round Rock Focus, but the type was first described by Miller and Jelks (1952:176). Suhm et al. (1954:408) more fully defined the type as having a large, triangular blade with straight to slightly convex (rarely concave) lateral edges. Shoulders may be small but well defined, but may have long, massive barbs. Basal notching sometimes results in broad barbs with square ends on line with the base, and very broad square or expanding stems. Bases may be straight or convex.

Castroville points are distinctive markers of the Late Archaic (2700-2400 B.P., Turner and Hester 1993:86) and are frequently associated with Montell and Marcos points, with which they are sometimes confused. Johnson (Johnson and Goode 1994:36, Footnote 24) considers Castroville a marker of the transition from Late Archaic I to Late Archaic II about 2550 B.P. Collins (1995:Table 2) puts Castroville in the MarcosMontell-Castroville interval in the last half of the Archaic, perhaps 2300-1600 B.P.
Castroville and Montell dart points were associated with the most recent bison kill at Bonfire Shelter in the Lower Pecos, where Montell and a large number of Castroville points were found in Bone Bed 3, radiocarbon dated to about 2900-2300 B.P. (uncorrected). Castroville in particular, considered intrusive in the area, was thus convincingly linked to hunters who probably had followed the bison from the north (Dibble and Lorraine 1968:51-55, 76, Table 5).

Six Castroville points and one possible Castroville were recovered at $41 \mathrm{BX} 126$. The Castroville shown in Figure $8-2 \mathrm{a}$ is a heavily re-worked artifact that retains the distinctive stem and base, allowing it to be typed. Both lateral edges of this 60 -mm-long tool have been bifacially reshaped to form concave working edges, which have been scarred by step fractures concentrated roughly in the central area of each reworked edge. Both concavities begin about $10 \mathrm{~mm}$ from the unmodified distal tip. The larger extends $35.5 \mathrm{~mm}$ along one edge to a point on the original stem edge, the shoulder having been removed in the process. The shorter reworked edge extends $27 \mathrm{~mm}$ to a point just above what would have been the shoulder, which appears to have broken or been removed. The expanding stem and base appear to be unmodified, except for one broken corner. This artifact was recovered from the midden periphery, Area B, TU A, Level 1.

Shown in Figure 8-2b is a proximal fragment with a use fracture and one barb broken. It was made of brown chert. The blade is $6 \mathrm{~mm}$ thick at the break. The stem is $15 \mathrm{~mm}$ long and $24 \mathrm{~mm}$ wide at the neck, contracting to $27 \mathrm{~mm}$ at the base. This point was recovered from the midden periphery in Area B, Trench $\mathrm{X}$, east wall.

Figure 8-2c shows a proximal fragment with a transverse use fracture and damaged base. It has very short barbs and is made of tan chert. It is $9.5 \mathrm{~mm}$ thick with a stem neck width of $21.5 \mathrm{~mm}$. This piece was recovered from the backdirt of one of the backhoe trenches (not identified in the TxDOT records) in Area B.

Figure $8-2 d$ is a picture of a proximal fragment with transverse fracture of indeterminate nature that produced a shatter scar quite unlike a normal snap. The material is a dark brown translucent chert. One barb is missing and the remaining one is very short. The 


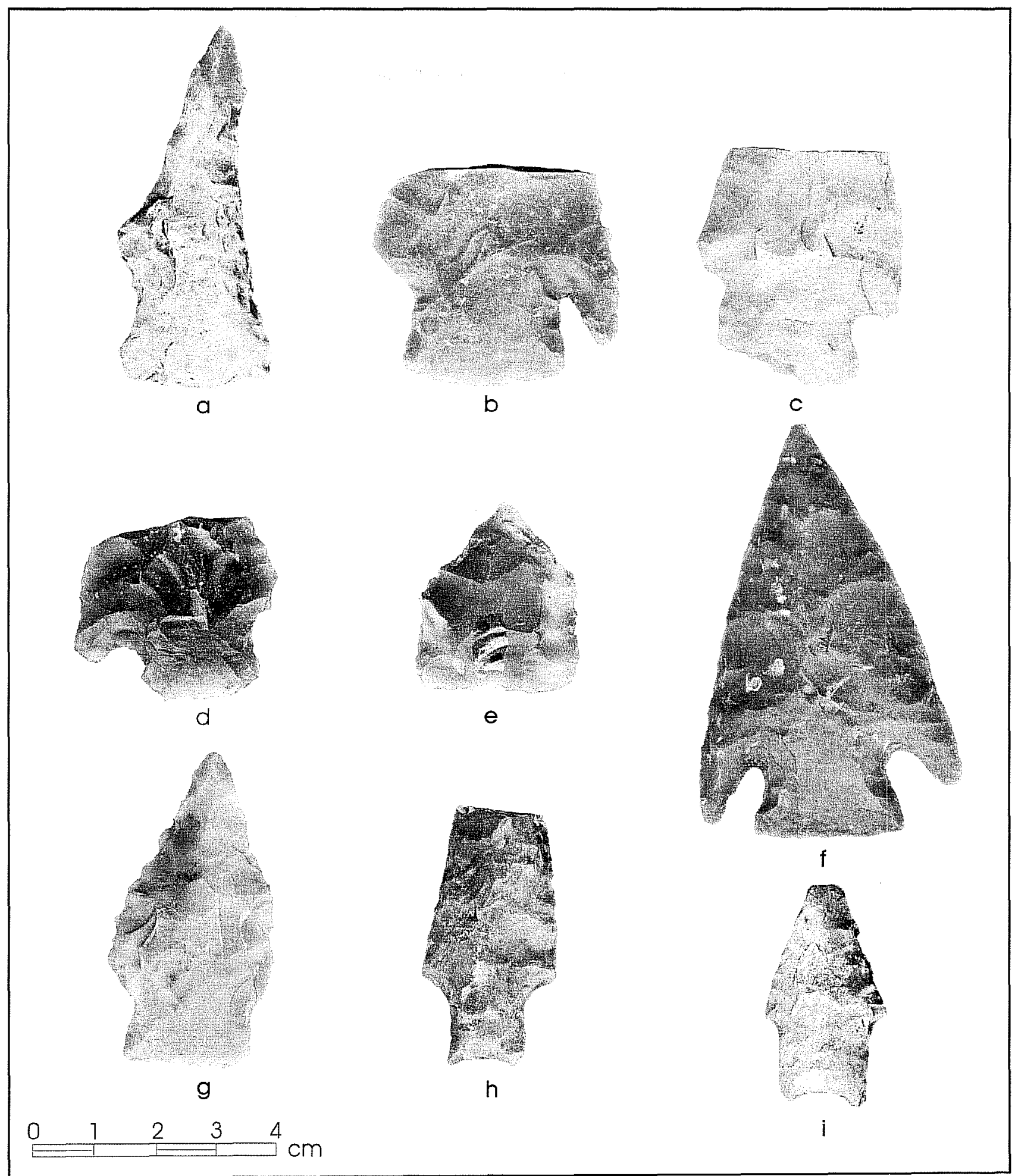

Figure 8-2. Diagnostic artifacts. a-d, f, g: Castroville; e: probable resharpened Castroville; h, i: Darl. 
wedge-shaped stem appears damaged at the base. The stem is $11.5 \mathrm{~mm}$ long with a $19 \mathrm{~mm}$ wide base. Thickness is $8.5 \mathrm{~mm}$. This fragment was recovered from the backdirt of one of the trenches (not identified in the TxDOT records) in Area $B$.

Figure 8-2e, probably a Castroville point, is an intensively resharpened "stubby" dart point (Black and McGraw 1985:116) made of dark brown semi-translucent chert with banded tan inclusions. Blade and stem together measure $31 \mathrm{~mm}$ long, with the blade measuring $17.5 \mathrm{~mm}$ long and $26.5 \mathrm{~mm}$ wide. The only classifiable part of this point is the broad, square stem, which has a wedge-shaped cross-section, straight base and rounded corners. The stem is $13.5 \mathrm{~mm}$ long, $25 \mathrm{~mm}$ at the neck and $26.5 \mathrm{~mm}$ wide at the base. These characteristics allow for assignment to the Castroville type. This point was recovered from the midden central core, Area B, TU 8, Level 3.

Shown in Figure 8-2f is a complete point, except for missing a very small part of the tip. One barb is longer than the other and is in line with the convex base. The shorter barb is nevertheless a product of a deeper basal notch. The length of this point is $69 \mathrm{~mm}$; width at the barbs is $44 \mathrm{~mm}$. Both blade and stem exhibit a pronounced dorsal ridge compared with the essentially flat worked surface of the opposite face, giving it a planoconvex cross section with a maximum thickness of 8 $\mathrm{mm}$. The stem is $14 \mathrm{~mm}$ long and $20 \mathrm{~mm}$ at the neck, expanding to $25 \mathrm{~mm}$ at the base. This point was recovered from the midden core, Area B, TU 9, Level 3.

Figure 8-2g is of a complete but extensively reworked point $52 \mathrm{~mm}$ long made of grayish tan chert. The blade is straight with rounded shoulders, the barbs apparently having been removed during rejuvenation. Blade width is $27.5 \mathrm{~mm}$ at the shoulders and it is $8.5 \mathrm{~mm}$ thick. The stem is $10 \mathrm{~mm}$ long and expands from a neck $19.5 \mathrm{~mm}$ wide to a straight base $21 \mathrm{~mm}$ wide. This point was recovered from the midden periphery, Area B, TU 16, Level 1.

\section{Darl}

"Darl Stemmed" was defined as a provisional type by Miller and Jelks (1952:175) on the basis of points recovered in the area of Belton Reservoir. They noted that it is similar in outline to the Yarbrough type of east Texas, but has a "semi-serrated" blade on most specimens, a result of thin pressure flaking. As defined by Suhm et al. (1954:414), Darl points have long, narrow triangular blades with straight to slightly convex lateral edges, frequently with a steep, narrow bevel on the right of each face. Some specimens have fine serrations on the blade, even when beveled. Shoulders vary from square to almost absent. Stems are rectangular to expanding, sometimes ground smooth or beveled on the sides. During further investigations at Belton Reservoir (Shafer et al. 1964) and at the Evoe Terrace site (41BL104) in Stillhouse Reservoir (Sorrow et al. 1967:61, 64), Darl points were sorted into two groups: Darl 1 with long, triangular, frequently beveled blades, weak to non-existent shoulders, generally parallel, sometimes beveled or smoothed stem edges and straight to concave bases; and Darl 2, with well-shouldered triangular blades, definitely expanding stems with concave bases, and no beveling or smoothing on stem or blade. Shafer and Sorrow assigned Darl to the Transitional Archaic, following the lead of Johnson et al. (1962) at Canyon Lake. A resemblance to Figueroa dart points in the Lower Pecos was noted (Sorrow et al. 1967:64).

Subsequently, Prewitt (1974, 1981a:82, 1981b:91, 96) suggested discarding the type name Darl on grounds that it represented several distinctive groups of artifacts of differing ages, and replacing it with three categories: Mahomet, representative of the Late Archaic Driftwood phase, 1400-1250 B.P.; Hoxie, representative of the Early Archaic San Geronimo phase, contemporary with Martindale points; and Zephyr, which he considered possibly Middle Archaic, more common in north-central and west-central Texas. Under this redefinition, Mahomet points possess gently beveled blades, tiny serrations, and sometimes alternately beveled but rarely smoothed stems. Hoxie points on the other hand are always more crudely made and more steeply beveled (to the right) but rarely serrated. Hoxie stems are usually alternately beveled and always smoothed or ground on the edges. Turner and Hester (1993:101, 130) accepted the Hoxie type, but continue to use Darl, dating it to the Transitional Archaic about 1750 B.P., while treating Mahomet and Zephyr as varieties or subtypes. 
Johnson (Johnson and Goode 1994:36, Figure 2) postulates a Darl-Figueroa interval of the upper Late Archaic, ending about 1350 в.P. Collins (1995:Table 2) follows suit, making Darl a style marker of the last interval of the Late Archaic, 2550-1350 B.P.

Three Darl specimens were recovered at Culebra Creek, none of which exhibits blade or stem beveling or smoothing. They would conform in this regard to the Mahomet style.

Shown in Figure 8-2h is a proximal fragment made of light brown chert and is missing up to a quarter of the blade due to a transverse use fracture. The body is 22 $\mathrm{mm}$ wide and has straight edges. The stem is $13 \mathrm{~mm}$ long and has concave sides and base. The stem is 12.5 $\mathrm{mm}$ wide at the neck and $13 \mathrm{~mm}$ wide at the base. The fragment is $8 \mathrm{~mm}$ thick. This fragment was recovered from the midden periphery, Area B, TU 20, Level 5.

Figure $8-2 \mathrm{i}$ is a Darl point made of gray chert, and is complete except for the tip. The blade is $6.2 \mathrm{~mm}$ thick and $20.5 \mathrm{~mm}$ wide at the shoulders, and has straight edges. The stem is $12 \mathrm{~mm}$ long and contracts from 15 $\mathrm{mm}$ at the neck to a concave base $14 \mathrm{~mm}$ wide. This point was recovered from the midden periphery, Area B, TU 4, Level 5.

Figure 8-3a is of a well-made complete Darl point of mottled gray and tan chert with a small chip missing from the side of the distal tip. The blade is thin and narrow: $7 \mathrm{~mm}$ thick and $29.5 \mathrm{~mm}$ wide at the shoulders. Overall length is $81 \mathrm{~mm}$. The stem is $13 \mathrm{~mm}$ long and relatively narrow, expanding from $16 \mathrm{~mm}$ at the neck to $17 \mathrm{~mm}$ at the base, which is slightly concave with rounded corners. The base resembles the Marshall type, which was the initial identification for this point; however, the absence of barbs, the straight edges, and the thinness and narrowness of the blade, do not conform to the Marshall definition and lead to the reclassification of this point as a Darl. This specimen was recovered from the midden periphery, Area B, TU 4, Level 6.

\section{Ellis}

Although widely distributed in small numbers across the state, except for the upper Panhandle and southwest
Texas, Ellis is primarily an east Texas type, which Krieger (Newell and Krieger 1949:166, Figure 57) originally named "Ellis Stemmed" and defined to distinguish it from the contracting-stem Gary point, emphasizing its smaller size but with wider shoulders, expanding stem and straight base. Temporally, it was placed in a pre-ceramic Archaic or Woodland context.

Miller and Jelks (1952:171-172, 189) reported a number of these points from Belton Reservoir and described "Ellis Stemmed" as a relatively small dart point characterized by an expanding stem (though less than "Ensor Stemmed") and strong shoulders. They noted that Ellis Stemmed points were found in both the Edwards Plateau and Central Texas aspects (Middle to Late Archaic), but aligned the type with the Austin Focus (initial Late Prehistoric) in central Texas and the Alto Focus in east Texas.

Bell (1960:32, Plate 16) notes that points of this type are common in Oklahoma and have been reported from most parts of the Mississippi basin. Suhm et al. (1954:420) renamed the type Ellis and estimated the age as 2950-1450 (or 950) B.P. Hester (1980:101) placed Ellis in the Late Archaic through Late Prehistoric, but later (Turner and Hester 1993:113) assigned it to the Middle to Late Archaic, about 3950-1250 B.P., a bit of an early start, perhaps, but largely equivalent to the Late Archaic of Johnson and Goode (1994) and Collins (1995).

Ellis points are crudely flaked with short, thick triangular blades and straight to convex lateral edges. Corner notching produces prominent- to well-barbed shoulders and wide, slightly expanding stems with generally straight edges. Bases are straight to convex (Suhm et al. 1954:420; Turner and Hester 1993:113).

One Ellis point (Figure 8-3b), was recovered from the Culebra Creek site. It is a complete, exceptionally well made and symmetrical point of light brown semi-translucent chert. The specimen is $45.5 \mathrm{~mm}$ long and $29 \mathrm{~mm}$ wide, at the large end of the range for the type, but is only $5.5 \mathrm{~mm}$ thick and has very delicate barbs. The slightly expanding stem is $9.5 \mathrm{~mm}$ long with a $15 \mathrm{~mm}$ neck and a $17.2 \mathrm{~mm}$ base. The Ellis point was recovered from the midden core, Area B, TU 8, Level 2. 


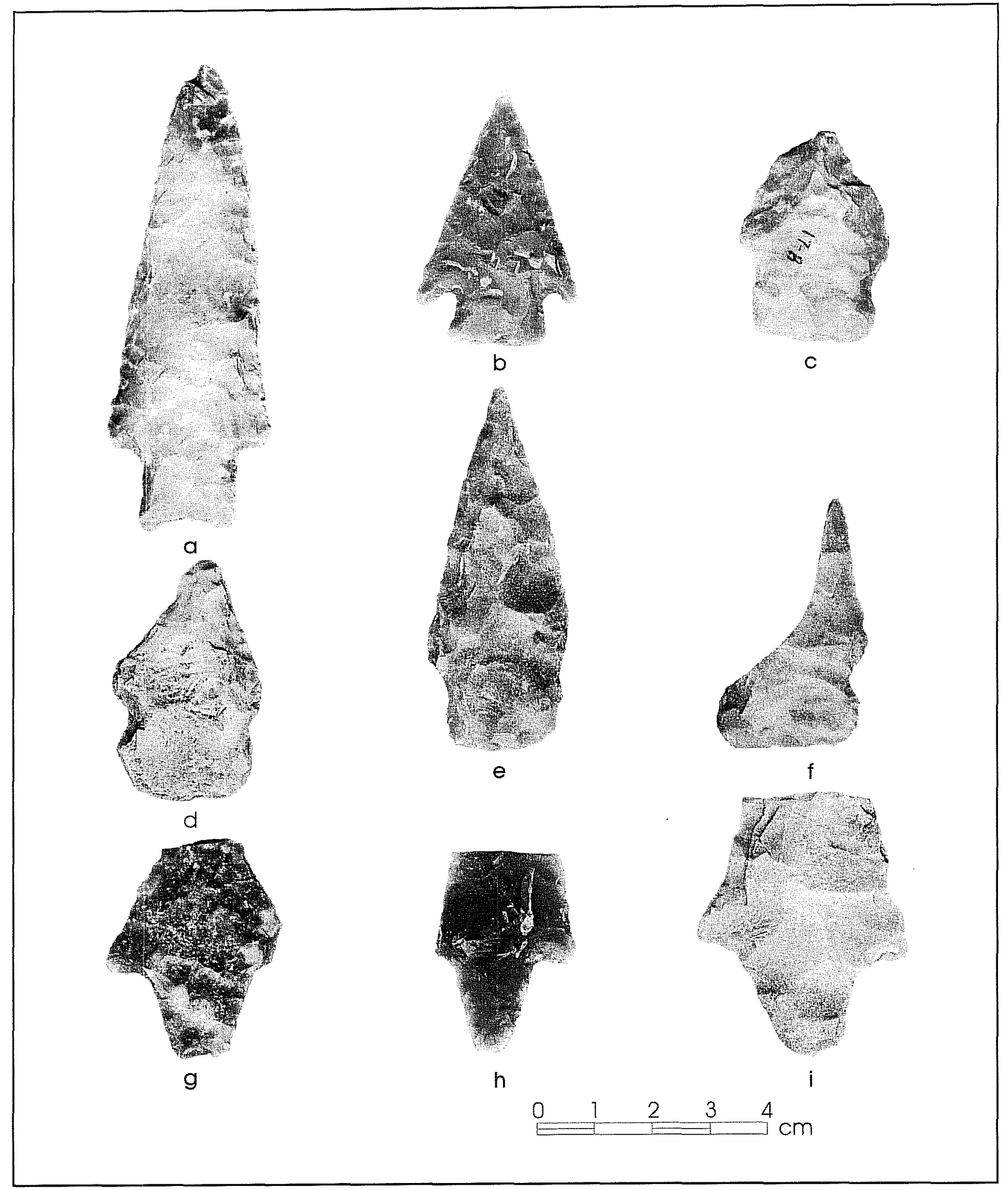

Figure 8-3. Diagnostic artifacts. a: Darl; b: Ellis; c-f: La Jita; g-i: Langtry. 


\section{La Jita}

La Jita was first identified and defined as a provisional type by Hester (1971:74, Figure 11) on the basis of seven points found at the La Jita site in Uvalde County and from sites in Real and Bandera counties. La Jita points have since been reported from a number of sites in the San Antonio-Medina River basin, including 41KE49 (Kelly and Hester 1976); Winans Creek in Bandera County (Carroll 1983); Camp Bullis (41BX36, Gerstle et al. 1978:83, Figure 17), Panther Creek Springs (41BX228, Black and McGraw 1985:117, Figure 21); and Olmos Basin (41BX1, Lukowski 1988:43, Figure 16). Temporally, La Jita points have been found in Early Archaic Clear Fork phase contexts (Hester 1971:118-119; Kelly and Hester 1976; Turner and Hester 1993:140). Black and McGraw (1985:117) suggest La Jita may be roughly contemporaneous with the Nolan type, about 5950-3950 B.P. (Turner and Hester 1993:164). Johnson and Goode (1994) date La Jita to the Nolan-Travis interval at the end of the Middle Archaic, from 4500 B.P. or slightly before to 4300 B.P. Collins (1995:Table 2), however, dates this period to about $4500-4000$ B.P.

The most distinctive attribute of the La Jita type is the rounded stem (Black and McGraw 1985:117) produced by shallow side notches, slightly expanding stems and rounded corners. Straight to convex bases may be slightly indented, possibly as a result of basal thinning, and some stems may be slightly beveled on one or both edges. Potter and Black (1995:47, Figure 27a) suggest that there is an "overlap" among the La Jita, Nolan, and Pandale types in south-central Texas, principally regarding the use of beveling. Turner and Hester (1993:140) have suggested that La Jita may be unfinished Nolan points. Goode (Johnson and Goode 1994:27) notes that La Jita points share manufacturing features with both Nolan and Travis, which he takes as an indication of their contemporaneity.

Four La Jita projectile points were recovered from 41BX126, all with wedge-shaped stems. The first, shown at Figure 8-3c, is made of tan chert, and is $37 \mathrm{~mm}$ long and $26 \mathrm{~mm}$ wide at the shoulders and has an extensively reworked blade exhibiting distal impact damage. It is fairly thick at $10 \mathrm{~mm}$. Although this dart point was initially identified as a possible reworked Castroville (Wood 1994:21), the slightly concave base, rounded corners and convex stem edges produce the typically rounded appearance of a $\mathrm{La}$ Jita stem, which in this case is $13 \mathrm{~mm}$ long with a neck width of $20.5 \mathrm{~mm}$ and a base $19.5 \mathrm{~mm}$ wide. This point was recovered from the midden periphery, Area B, TU 17, Level 2.

The La Jita point in Figure 8-3d is of tan chert with a pinkish cast, suggesting exposure to heat. The very tip appears to be missing, as is one basal corner. All remaining edges exhibit varying degrees of damage (step fractures, crushing), which is probably use wear. The blade is $26 \mathrm{~mm}$ wide at the shoulders and $8 \mathrm{~mm}$ thick. One lateral edge is straight, the other concave, possibly as a result of extensive use as a hafted cutting implement. This circumstance argues against the suggestion by Hester (Turner and Hester 1993:140) that La Jita points may simply be a stage in the Nolan reduction process. The stem is $17 \mathrm{~mm}$ long with a neck width of $21 \mathrm{~mm}$ contracting to a base width of $17 \mathrm{~mm}$. This point was recovered from the midden framework, Area B, TU D, Level 2.

The La Jita in Figure 8-3e is an almost complete point missing only a small piece of the tip. It is made of tan chert with a lighter inclusion which seems to have interfered somewhat with the otherwise excellent workmanship. The point is $63 \mathrm{~mm}$ long and $25 \mathrm{~mm}$ wide at the shoulders, although one shoulder is very weakly developed. The stem is $12 \mathrm{~mm}$ long with convex edges and is $20 \mathrm{~mm}$ wide at the neck, contracting to a very convex base $18.5 \mathrm{~mm}$ wide. This point was recovered from the midden periphery in backdirt near the west end of Trench O, Area B.

The La Jita in Figure 8-3f, is made of tan chert, and sustained a curved diagonal fracture of indeterminate cause that begins at the stem neck and terminates at the opposite edge $27 \mathrm{~mm}$ from the remaining shoulder. The stem is $12 \mathrm{~mm}$ long with a $22 \mathrm{~mm}$ neck and 20 $\mathrm{mm}$ base. Very convex stem edges produce the characteristic rounded look despite a very straight base. This artifact was recovered from the midden framework, Area B, TU 7, Level 5.

\section{Langtry}

Langtry points are a Lower Pecos type, called "Langtry Stemmed" by Kelley (1947b:104) and renamed by Suhm et al. (1954:438) on the basis of points collected 
from the Fate Bell Shelter, Val Verde County, in the Lower Pecos. They noted that more than one point type might be represented in their description, but that distinguishing types or varieties was difficult because features intergraded. Schuetz (1956:141) subsequently separated out the Val Verde type, which does not occur in central Texas (Turner and Hester 1993:192). Bement (1991) confirmed the Val Verde type and has proposed a third type, Arenosa, on the basis of statistical analysis. Langtry points are diagnostic of the Middle Archaic San Felipe period (4100-3200 B.P.) in the Lower Pecos (Shafer and Bryant 1977:Figure 10; Turpin 1991:29--31, 1995:547-548).

Any current definition of the thin, well-made Langtry type still must allow for considerable variability. Langtry points have triangular blades with straight to concave or recurved edges that tend to flare outward to form a short barb. Stems are long and contracting, and may be alternately beveled. Bases may be concave (and sometimes beveled), straight or, rarely, convex (Bement 1991:61; Suhm et al. 1954:438; Turner and Hester 1993:143). For Bement (1991:62), Arenosa points are slightly narrower and thicker than Langtry, and usually do not exhibit stem or base beveling. Langtry points are most common in the Lower Pecos and Coahuila, Mexico, but also occur along the lower Rio Grande, in McMullen County (Suhm et al. 1954) and occasionally in central Texas (Turner and Hester 1993).

Three Langtry points have been recovered from the Culebra Creek site, one of which (Figure 8-3g) was collected from the surface of the midden periphery in Area $\mathrm{B}$, in the $\mathrm{T} 1$ flood terrace between trenches $\mathrm{H}$ and $J$. This point is made of light brown chert with $\tan$ inclusions, and is lightly patinated. One barb is broken and the distal tip is missing, possibly due to an impact fracture. Remaining lateral edges are straight and the barb is square. The blade is $5.5 \mathrm{~mm}$ thick. The stem is $14.5 \mathrm{~mm}$ long and $17 \mathrm{~mm}$ wide at the neck, with straight edges contracting to a $9.5 \mathrm{~mm}$ slightly concave base.

The Langtry in Figure 8-3h is also a proximal fragment, made of light brown semi-translucent chert and terminating in a transverse hinge fracture. Lateral edges are straight and the blade measures $25 \mathrm{~mm}$ at the shoulders and is $5.5 \mathrm{~mm}$ thick. One edge appears to be finely reworked, in that its square shoulder is much shorter than the one opposite, which is very lightly barbed. This gives the appearance that the stem is slightly off center on the body. The sharply contracting stem is $16.5 \mathrm{~mm}$ long with a $15 \mathrm{~mm}$ neck and acutely rounded base from which a small chip is missing. This point was recovered from the block excavation, Area B, TU 19, Level 3.

The Langtry in Figure 8-3i is a large proximal fragment of grayish-tan chert terminating in a transverse fracture of indeterminate nature. Remaining lateral edges are slightly concave and the shoulders flare outward to a width of $37.5 \mathrm{~mm}$. The blade is $7.5 \mathrm{~mm}$ in maximum thickness. The stem is $17 \mathrm{~mm}$ long and is skewed at a $9-10^{\circ}$ angle from the long axis of the body. The neck is $20.5 \mathrm{~mm}$ wide and contracts sharply to a $6 \mathrm{~mm}$ rounded base. This fragment was recovered from the block excavation, Area B, TU 17, Level 4.

\section{Marcos}

This type was defined by Suhm et al. (1954:442, 524, Plate 100) for a very wide area of central Texas and the lower Pecos River valley, on the basis of points recovered from Fate Bell Shelter in Val Verde County, the Morhiss site in Victoria County, and from the Marshall Ford (Lake Travis) and Lake Buchanan basins. Marcos points have broad triangular blades with straight to convex edges. Pronounced barbs, sometimes even with the base, and sharply expanding stems result from deep corner notching. Marcos points resemble Ensor-which usually have a wider neck and shallower notches-and especially Castroville, with which it frequently occurs. Marcos differs from Castroville in having a narrower neck and more sharply expanding stem, nor is it basally notched or endowed with massive squared barbs. Johnson and Goode (1994:37) observe that Marcos points resemble dart points of similar age from the Southern Plains. They date the Marcos interval at about 2250 B.P., the beginning of Johnson's Late Archaic II.

Turner and Hester (1993:147) date Marcos points to the Late to Transitional Archaic from 2550-1750 B.P. Collins (1995:Table 2) dates the Marcos-Montell-Castroville interval of the Late Archaic later, from about 2000 в.P. to perhaps 1600 B.P. In south Texas, Hester (1995:441) places Marcos toward the end of the Late Archaic, which he dates from 2350 B.P. to 1250 or 1350 B.P. 
One projectile point at $41 \mathrm{BX} 126$ was identified as Marcos. This point (Figure 8-4a) is made of a light grayish-tan chert and is missing part of one barb and the corner of the base on the same side. On the same side, lateral edge damage is present from the tip along about 40 percent of the edge. Use wear (step fractures) is evident on the undamaged edge. This point is $58 \mathrm{~mm}$ long and $33 \mathrm{~mm}$ wide at the barbs. The stem is $14 \mathrm{~mm}$ long and $19.5 \mathrm{~mm}$ wide at the neck. This specimen was recovered from the midden periphery in Area $B$ in backdirt from Trench $P$ near the intersection with Trench N.

\section{Marshall}

Marshall points were initially defined by Suhm et al. $(1954: 444,524)$ as a common central Texas type of the Edwards Plateau Aspect dating from 5000 or 6000 B.P. to as late as 1000 B.P. based on the analysis of points from the Marshall Ford and Buchanan reservoir basins, and the Morhiss site. They commented that Kelley (1947b:124, Plate 14, b, i) probably included some Marshall points in his "Smithwick Small Stem" and "Bluffton Barbed." Suhm (1959) conceded that the Marshall style is "somewhat marginal" as defined in 1954.

Johnson (1995:202-206) demonstrated the close relation among the Marshall, Pedernales, and Montell point types and postulates a Bulverde-Pedernales-MarshallMontell/Castroville cultural continuum in the first part of the Late Archaic, with the Marshall interval dating to about 2300 B.P. (Johnson and Goode 1994:29, Figure 2). Collins (1995:Table 2) places this type in the Lange, Marshall, Williams interval of the Late Archaic around 2000 B.P., while Turner and Hester (1993:150) put it in the Middle Archaic about 3000 B.P. or earlier.

Blades vary from triangular with straight sides to oval with markedly convex edges. Shoulders are always barbed and the barbs are often on line with the base. Notches are usually basal and vary from narrow to broad, and stems vary from square to slightly expanding, often short compared to the length of the blade. Bases are concave or straight to slightly convex, although Turner and Hester (1993:149) exclude convex bases from the type definition. Twenty-six Marshall points recovered at the John Ischy site in Williamson County, Texas (Sorrow 1969:167, Figures 13, 14) all had straight to concave bases.
Both Marshall points recovered from 41BX126 have slightly concave bases. One of them (Figure 8-4b) is a massive proximal fragment (the blade is $9.5 \mathrm{~mm}$ thick and $52 \mathrm{~mm}$ wide) with an irregular transverse fracture of indeterminate cause. The convex edges have different degrees of curvature and the basal notches are of unequal depth, producing an unbalanced appearance. The stem is $12.5 \mathrm{~mm}$ long and expands slightly from a $19 \mathrm{~mm}$ neck to a $20 \mathrm{~mm}$ base, from which short thinning flakes have been removed. The point is made of grayish-brown chert and both faces are irregularly patinated. This point was recovered from Area A, Feature 2 in Trench S.

The second Marshall point (Figure 8-4c) is made of a grayish-tan chert with light tan inclusions and some pinkish areas, indicating exposure to heat. It is a large proximal fragment with a transverse hinge fracture. One blade edge is straight, the other is recurved to produce a slightly off-balance appearance enhanced by the different depths of the basal notches. The blade is $44 \mathrm{~mm}$ wide across the barbs and $7.5 \mathrm{~mm}$ thick where it joins the stem. The stem is $11 \mathrm{~mm}$ long and has straight edges expanding from a $17.5 \mathrm{~mm}$ neck to a base $20 \mathrm{~mm}$ wide with short thinning flake scars. FS159 was recovered from the midden central core, Area B, TU 9, Level 2.

\section{Martindale}

"Martindale Fishtail" was named by Kelley, but was first described in print by Miller and Jelks (1952:176). The definition was further refined by Suhm et al. (1954:446), who dropped the "fishtail" and estimated that the type belongs in the Middle to Late Archaic. It was almost three decades, however, before Martindale received clear temporal definition by Prewitt (1981a) as an Early Archaic type that followed various forms of "Early Corner Notched" and "Early Barbed" points in the cultural sequence.

Prewitt (1981a:78) puts Martindale points in his Jarrell phase (6000-5000 B.P.) of the Early Archaic along with Bell, Andice and Uvalde points. Johnson (Johnson and Goode 1994:24) and Collins (1995:Table 2) postulate a Martindale-Uvalde interval at the end of the Early Archaic (7000-6000 B.P.). For South Texas, Hester (1995:436-437) speaks of a Martindale-Uvalde-BakerBandy continuum in the Early Corner-Notched horizon of the Early Archaic, about 8000-5500 B.P. 


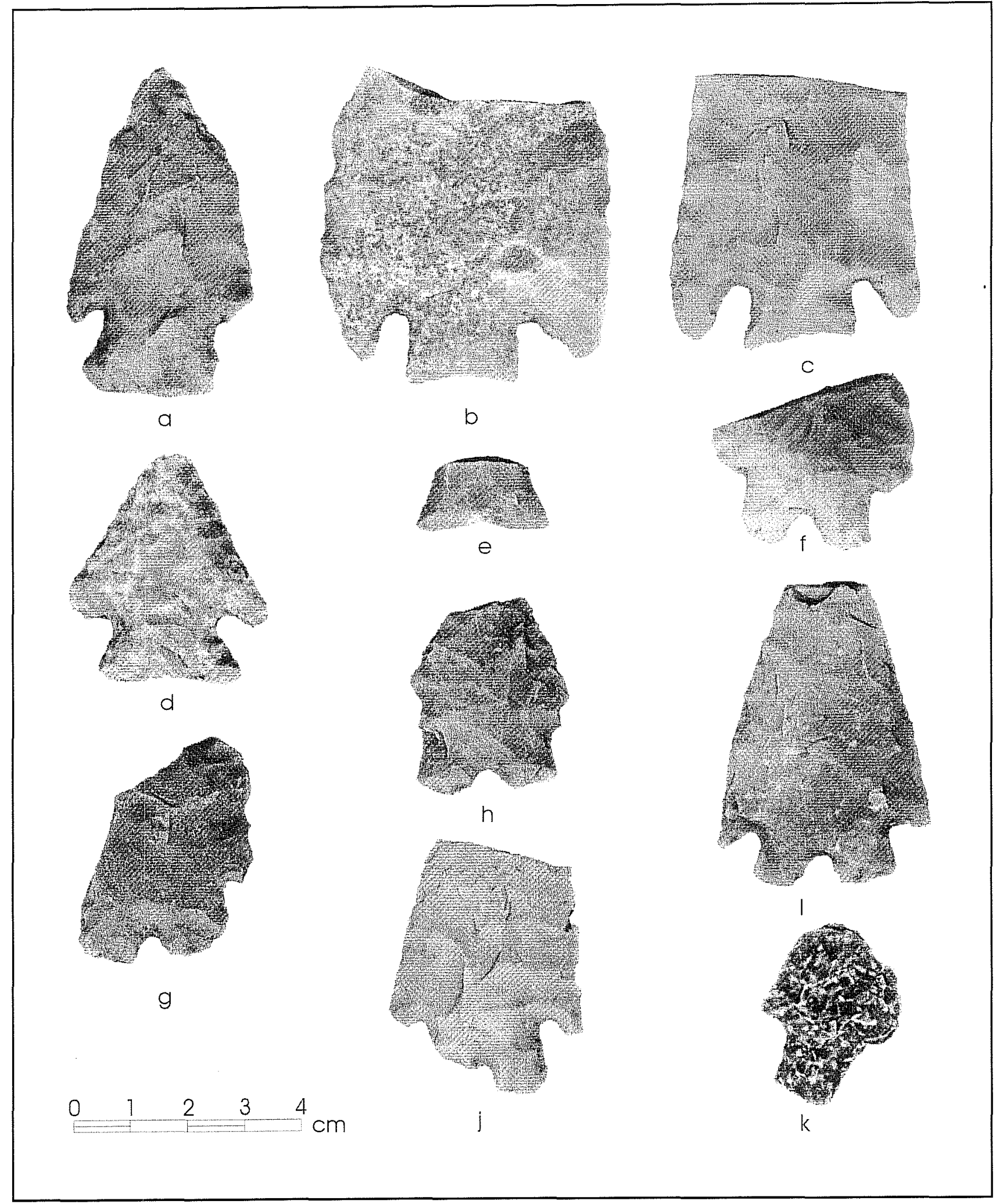

Figure 8-4. Diagnostic artifacts. a: Marcos; b, c: Marshall; d, e: Martindale; f-k: Montell. 
Martindale points are identifiable primarily by their distinctive expanding stems with a "fishtail" base formed by two convex edges meeting to form a depression at the center of the base. Martindale blades are triangular with straight to convex lateral edges and prominent shoulders, commonly well barbed. (Suhm et al. 1954).

Two Martindale points have been recovered from $41 \mathrm{BX} 126$. One (Figure 8-4d) is a nearly complete point with a small impact fracture and damage to one barb. It is made of mottled pinkish-gray chert that may have been exposed to heat. The blade is triangular and alternately beveled on the right edges. It is $36 \mathrm{~mm}$ wide and $6.5 \mathrm{~mm}$ thick. Strong barbs and an expanding stem were formed by corner notching. The stem is $18 \mathrm{~mm}$ wide at the neck and $11 \mathrm{~mm}$ long. One corner of the base is damaged, obscuring the distinctive double convex shape of the base. Wood (1994:20) labeled this specimen an "Early Corner Notched" or "Early Barbed" point. This artifact was recovered from Area C, Shovel Test 16.

The second specimen (Figure 8-4e) is a Martindale stem fragment with a transverse fracture at or about the neck. The stem flares gracefully to $23.5 \mathrm{~mm}$ at the base and the double-convex fish-tail shape is evident. The fragment is made of a pinkish chert with a tan inclusion. Although it may have been heated, the surface of the fragment does not have the lustrous appearance frequently associated with heat treatment. This point was recovered from the midden central core, Area B, TU 9, Level 6.

\section{Montell}

Kelley (1947a:124-127, 525, Plate 14) considered "Montell Split Stem" a diagnostic projectile point of his Uvalde Focus in central and southwest Texas with an age of 800-600 B.P., an estimate not accepted by Suhm et al. (1954:452), who renamed the point Montell and assigned it a temporal range of about 5000 1000 в.P. Prewitt (1981a:81) revived the Uvalde phase name and dated it to $2250-1750$ B.P., with Montell, Marcos, and Castroville as representative projectile points. Turner and Hester (1993:157) put Montell in the Late to Transitional Archaic, 2950-1750 B.P. Johnson, as noted above, sees the Montell type as part of a Bulverde-Pedernales-Montell cultural continuum in the first part of the Late Archaic (Johnson 1995:206;
Johnson and Goode 1994:29, Figure 2), with the Castroville-Montell interval dating about 2950-2500 в.P. However, Collins (1995: Table 2) dates the brief Marcos-Montell-Castroville interval of the Late Archaic from about 2300 B.P. to perhaps 1600 B.P. In south Texas, Hester (1995:441-442), places Montell with Marcos in the Late Archaic about 2350-1350 B.P.

The bifurcated stem, well-developed and frequently barbed shoulders, fine workmanship, and very thin appearance of the broad blades make Montell a distinctive, easily recognized point (Black and McGraw 1985:109). The exceptionally thin Montell blades (thinner than the blades on Pedernales points) are produced by well-executed billet flaking, leaving typically wide flaking scars on blade surfaces (Johnson 1995:196, 207). Stems are usually expanding, although an exceptionally wide corner notch may produce parallel edges. On the basis of points from Fate Bell Shelter, from Kinney County, and from the Marshall Ford and Buchanan reservoir basins, Suhm et al. (1954) note that most Montell bases appear to have been strongly convex before being given a deep V- or Ushaped center notch.

Seven Montell points and fragments have been recovered from the Culebra Creek site. The one shown in Figure 8-4f is a proximal fragment made of light brown semi-translucent chert grading to gray subcortical material. The blade, which terminates in a transverse hinge fracture, is $35.5 \mathrm{~mm}$ wide at a point just above the shoulders. Both barbs are broken. The stem is $11 \mathrm{~mm}$ long and $22 \mathrm{~mm}$ wide at the neck, expanding very slightly to a $22.5 \mathrm{~mm}$ base, which appears to be damaged at the corners. The fragment is $5.5 \mathrm{~mm}$ thick at the neck. This point was recovered from the midden periphery in Area $\mathrm{B}$, in backdirt from Trench $\mathrm{P}$ near its intersection with Trench $\mathrm{N}$.

The Montell in Figure 8-4g is a heavily damaged proximal fragment made of tan chert. Only the basal edges are intact, making identification possible, although one corner is missing. The fragment is $5 \mathrm{~mm}$ thick at the neck. FS9 was recovered from Area A, TU 1, Level 2.

Shown in Figure 8-4h is a proximal fragment made of pinkish-tan chert, indicating possible heating, and is missing the distal tip, both barbs, and one corner of the 
base. The expanding stem is $10 \mathrm{~mm}$ long with a neck $22.5 \mathrm{~mm}$ wide. The fragment is $6.5 \mathrm{~mm}$ thick at the shoulders. This Montell was recovered from the midden periphery in Area B, TU 4, Level 3.

The Montell in Figure 8-4i is made of gray and brown chert and is missing the distal tip and a small part of one barb. The stem is $9.5 \mathrm{~mm}$ long and $22.5 \mathrm{~mm}$ wide at the neck, expanding to a $25.5 \mathrm{~mm}$ base. The blade is 8.5 $\mathrm{mm}$ thick about $15 \mathrm{~mm}$ from the neck, due chiefly to an unreduced high spot on one face. This specimen was recovered from Area A, TU 1, Level 4, Feature 2.

Figure $8-4 \mathrm{j}$ is picture of a basal fragment made of grayish-tan chert with one heavily damaged edge, broken barbs and a broken basal corner. The expanding stem is $12.5 \mathrm{~mm}$ long and $20 \mathrm{~mm}$ wide at the neck. Maximum thickness is $7 \mathrm{~mm}$ just above the neck. This artifact was recovered from the midden periphery, Area B, TU 11, Level 1.

Figure 8-4k shows a stem fragment made of dark brown chert with light patination on both faces. The remaining side notch and square shoulder suggest that at least one lateral edge was rejuvenated after the barb was broken. This Montell fragment was recovered from the midden periphery, Area B, TU 12, Level 1.

Figure 8-5a shows a Montell stem fragment made of tan chert. It suffered at least two transverse fractures, possibly post-depositional. This piece was recovered from Area A, Shovel Test B, Level 1.

\section{Nolan}

Ray (1938) defined a series of beveled stem projectile points which he labeled "Clear Fork Darts 1 and 2" as traits of a "Clear Fork Culture Complex" in the Abilene area of north-central Texas. Both Ray (1938) and Sayles (1935) considered the complex to be contemporary to or earlier than Folsom. Based on their work and a wider set of data for all of central Texas, Kelley (1947b) sought to more securely define the temporal and cultural context of the redesignated "Clear Fork Focus." In the process, he combined Ray's (1938) two stemmed dart points and renamed the type "Nolan Beveled Stem," which he considered the "principal diagnostic element" of the Archaic stage Clear Fork Focus. Kelley dated the beginning of the
Clear Fork Focus on geological and climatic evidence to either 6000 B.P. or 4000 B.P., with an end possibly as late as 450 B.P. Suhm et al. (1954:458) retained Kelley's age estimates but broadened the definition of the Nolan type to include "notably smaller and less well made" points from the Lower Pecos and central Texas coast ("Aransas Focus").

Nolan points have consistently been associated with Travis dart points ("Strawn Stemmed," Kelley 1947a:Plate 14c) ever since Kelley revised the Round Rock phase, although Suhm et al. (1954:484) pointed out that while Travis closely resembles Nolan, it lacks stem beveling and often intergrades with other types, such as Bulverde and Darl. The mutual resemblance of Travis and Nolan points at the Crumley site in Travis County led Kelly (1961:253, Figure 8) to coin the name "Trolan" for several projectile points he thought exhibited intermediate characteristics. Subsequent investigators have made little use of the hybrid term, and since Kelly himself notes that the "Trolan" points lack stem beveling, it seems reasonable to include these artifacts as a local variant within the Travis type. Following Suhm et al. (1954), who perceived a resemblance between Travis and Angostura and had estimated both Nolan and Travis as old as 6000-1450 B.P., Kelly $(1961: 253,255)$ made the perhaps true but nevertheless unfortunate observation that several heavily patinated Travis points recovered at the Crumley site resembled Angostura points, one of which was said to have been encountered in close association with two of the patinated Travis points. That association of Travis and "Trolan" points with other putative Paleoindian artifacts apparently further reinforced the notion of an extremely early date for Nolan and Travis. According to Johnson (Johnson and Goode 1994:17), the excavators of the Canyon Lake sites labored under the misapprehension that the Travis and Nolan styles had evolved directly from Paleoindian types such as Angostura and thus, along with Bulverde, were of Early Archaic provenience (Johnson et al. 1962:121, Figure 45).

Shafer (1963:80-81) accepted an Early Archaic date for Nolan, Travis, and Bulverde at the Youngsport site, but reported two occupation zones underlying the Nolan-Travis layer that gave additional time depth to the Early Archaic. Those findings were supported by Sorrow et al. (1967:40-41) at Stillhouse Hollow and by 


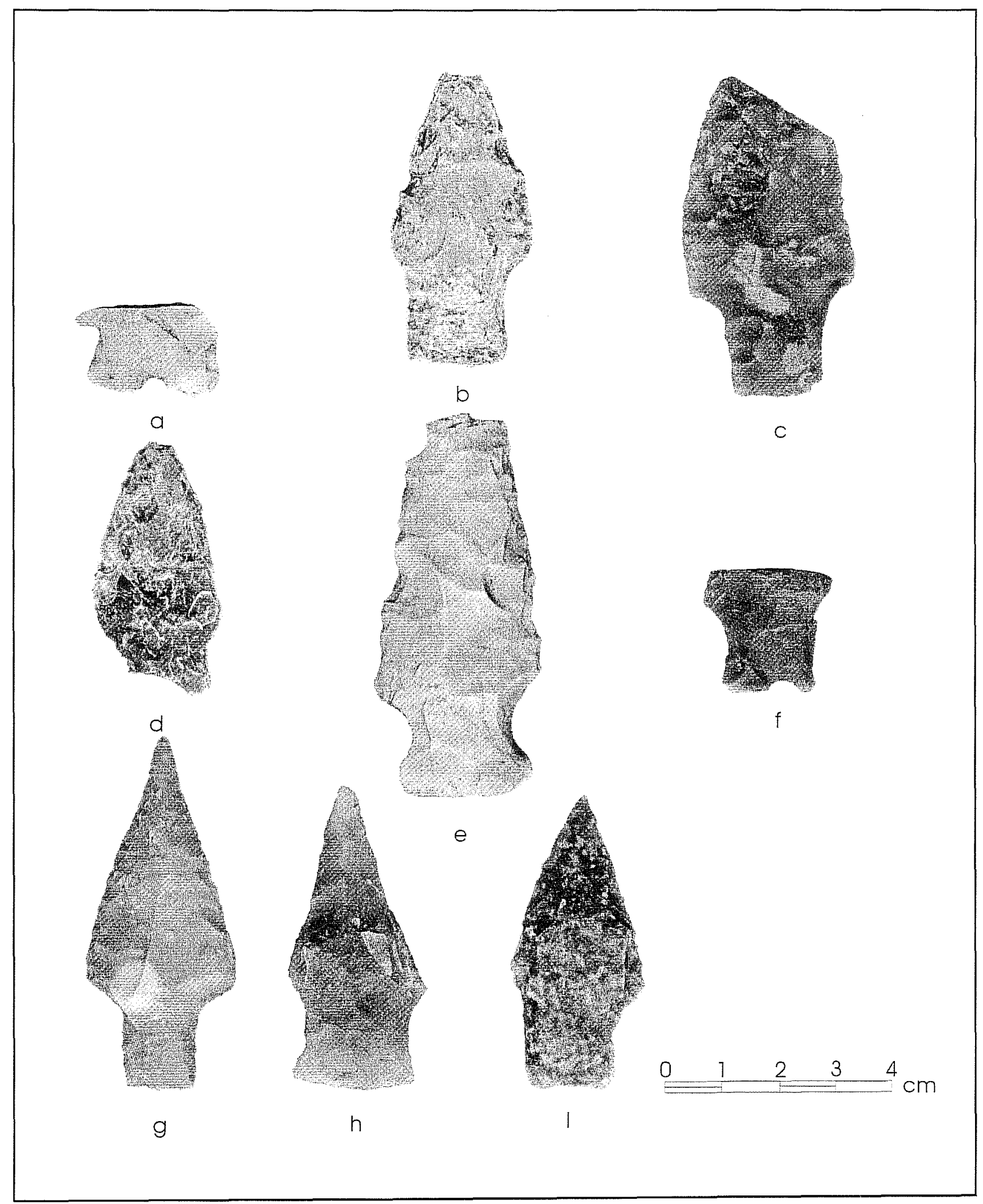

Figure 8-5. Diagnostic artifacts. a: Montell; b, c, f-i: Nolan; d: Nolan-like; e: possible Nolan. 
Sorrow (1969:44) at the John Ischy site, where Early Triangular points (such as Baird and Taylor types) clearly preceded the Nolan-Bulverde period. Similar evidence was obtained from the McCann site (Preston 1969) and La Jita (Hester 1971).

However, Prewitt (1981a:79), in his reordering of the central Texas Archaic, defined Clear Fork, which he estimated to date about $4600-4000$ B.P. on the basis of radiocarbon dating, as the opening phase of the Middle Archaic and he singled out Nolan and Travis as representative projectile points. Prewitt's judgment was accepted by Black and McGraw (1985:117) at the Panther Creek Springs site for their local phase dated at 5000-4000 B.P. Turner and Hester (1993:164) once again broadened the temporal range of Nolan to 6000 4500 B.P. and returned it to the Early Archaic. Nevertheless, Johnson and Goode (1994:24-28), who suggest that the Nolan and Travis types may have been "borrowed" from the Lower Pecos area, consider Nolan to be Middle Archaic, no earlier than 4950 B.P. Collins (1995:384, Table 2) also places the Nolan-Travis interval (4500-4000 B.P.) late in the Middle Archaic.

Seven Nolan points, three of which are complete, and one possible Nolan or Nolan-like point were recovered from the Culebra Creek site. The one shown in Figure $8-5 b$ is made of gray chert with slight patination, and would be complete but for the missing distal tip and one broken corner. The blade has straight edges and strong shoulders and measures $26 \mathrm{~mm}$ across the shoulders and $7 \mathrm{~mm}$ thick at the neck. The stem is $15.5 \mathrm{~mm}$ long and $17 \mathrm{~mm}$ wide at the neck, expanding slightly to a slightly concave base. This point was recovered from the midden framework, Area B, TU D, Level 5.

Figure $8-5 \mathrm{c}$ is a Nolan point made of semi-translucent brown chert with tan inclusions. It is missing a large part of the distal end due to a transverse hinge fracture and is heat damaged on both sides of the blade near the break. The blade is leaf-shaped and has a maximum thickness of $6.5 \mathrm{~mm}$ due to an unreduced inclusion. The body is $30 \mathrm{~mm}$ wide at the shoulders. The stem is alternately beveled on the right and has a straight base. It is $16 \mathrm{~mm}$ long, $16.5 \mathrm{~mm}$ wide at the neck, and $16 \mathrm{~mm}$ wide at the base. This piece was recovered from the midden central core, Area B, TU 9, Level 2.
Shown in Figure $8-5 \mathrm{~d}$ is a Nolan-like point made of dark gray chert. It has a broken stem, which nevertheless can be seen to be alternately beveled on the right. The point is patinated and is badly heat damaged. The leaf-shaped blade is $35 \mathrm{~mm}$ long, $23 \mathrm{~mm}$ wide and $8 \mathrm{~mm}$ thick. The neck of the stem is $15 \mathrm{~mm}$ wide. This artifact was recovered from the block excavation, Area B, TU 12, Level 3.

Figure $8-5 \mathrm{e}$ is a possible Nolan point, assignable to this type on the basis of the strong alternate stem beveling, definite shoulders, and long triangular blade with untypically straight edges. However, the markedly pronounced expanding stem produced by side notching is a distinctly non-Nolan feature. This point is made of grayish-tan chert and exhibits a distal impact fracture. The blade is $30.5 \mathrm{~mm}$ wide at the shoulders and $10 \mathrm{~mm}$ thick. The stem is $12 \mathrm{~mm}$ long, $17.5 \mathrm{~mm}$ wide at the neck and $24.5 \mathrm{~mm}$ wide at the base. It was recovered from the block excavation, Area B, TU 12, Level 3.

The Nolan point in Figure 8-5f is a proximal fragment with one fairly strong shoulder, the other having been removed by a lateral fracture which is intersected by a transverse fracture, producing a pseudo burin. The specimen, $6.5 \mathrm{~mm}$ thick at the break and made of tan chert, also was damaged by a flake removed from the otherwise straight base, giving it a notched appearance. The remaining stem edge is beveled on the right. This point was recovered from the block excavation, Area B, TU 16, Level 3.

Figure 8-5g shows a finely worked complete Nolan point made of gray chert. It is $63.5 \mathrm{~mm}$ long and has slightly recurved lateral edges. The blade is $26.5 \mathrm{~mm}$ across the shoulders and $6.5 \mathrm{~mm}$ thick. The stem is alternately beveled on the right and is $14.5 \mathrm{~mm}$ long and $13 \mathrm{~mm}$ wide at the neck contracting to $12 \mathrm{~mm}$ at the base, which is straight. It was recovered from the block excavation, Area B, TU 23, Level 3.

The Nolan shown in Figure 8-5h is a complete point, made of translucent gray chert, which has been resharpened along one lateral edge from shoulder to tip, producing a slightly concave edge while the opposite edge remains relatively straight. Both lateral edges exhibit moderate step fracturing. The point is $54.5 \mathrm{~mm}$ long, $26 \mathrm{~mm}$ wide at the shoulders and $8.5 \mathrm{~mm}$ thick. 
The stem is $14 \mathrm{~mm}$ long, alternately beveled on the right, expanding from $19.5 \mathrm{~mm}$ at the neck to $22.5 \mathrm{~mm}$ at the convex base. It was recovered from the block excavation, Area B, TU 16, Level 3.

Figure 8-5i shows another complete Nolan point made of dark pink chert lightly patinated on both faces. It is $54 \mathrm{~mm}$ long with straight lateral edges. The blade is $7.5 \mathrm{~mm}$ thick and $24 \mathrm{~mm}$ wide at the shoulders, one of which may be slightly damaged. The stem is lightly beveled alternately on the left. It is $13 \mathrm{~mm}$ long and $16.5 \mathrm{~mm}$ at the neck, contracting slightly to $15 \mathrm{~mm}$ across the base, which is slightly indented. This point was recovered from the block excavation, Area B, TU 17, Level 4.

\section{Pedernales}

Kelley (1947b:99) identified the "Pedernales Indented Base" dart point type and considered it the primary diagnostic element of his Round Rock Focus, first formulated by Sayles (1935) as the Round Rock and Guadalupe phases of the Archaic stage. Based on his study of a number of admittedly mixed sites, Kelley (1947b:100-103) believed his Round Rock and Clear Fork foci were coeval during at least part of their existence and that Pedernales points were contemporary with Nolan points. Suhm et al. (1954:458, 468) did not dispute Kelley's assertion of contemporaneity, although they did observe that both point types occurred throughout the Archaic stage Edwards Plateau Aspect, 5550-1450 B.P. or later. Kelly (1961:251, 253) at the Crumly site was the first to demonstrate convincingly that Pedernales was stratigraphically separated from and considerably later than Nolan and Travis. Black and McGraw (1985:113) originally assigned Pedernales points to Panther Creek Springs local period 7, about 3950-2550 B.P., corresponding to the Clear Fork phase of the Middle Archaic, but Black (Potter and Black 1995:4, 7) prefers now to consider Pedernales diagnostic of the Late Archaic I, 41502750 B.P., roughly in accord with Johnson (Johnson and Goode 1994:29, Figure 2), who dates Late Archaic Period I to 4250-2550 B.P. (calibrated), and Collins (1995:384, Table 2), who postulates a Pedernales-Kinney interval, ca. 3200-2300 в.P., during the first half of the Late Archaic. Although Hester (1995:439; Turner and Hester 1993:171) continues to date the Middle Archaic in south Texas from 4450
2350 в.P. (following Hall et al. 1986), he similarly dates Pedernales about 3950-3150 B.P. Johnson (Johnson and Goode 1994:29-30) sees the Pedernales style as part of a Bulverde-Pedernales-Montell cultural continuum in the first part of the Late Archaic.

Thick, rectangular stems and deeply indented or bifurcated bases with a characteristic flake-scar pattern make up the most identifiable trait of the Pedernales dart point style (Black and McGraw 1985:113; Johnson 1995: 200; Miller and Jelks 1952:175), a fortunate circumstance since Pedernales blades, though nominally triangular, in truth vary quite amazingly in size and shape. One of the most common dart point types in central Texas, where they are frequently associated with burned rock middens (Black and McGraw 1985:113), Pedernales points also are found in south Texas and as a minor type in the Lower Pecos, where there is much less variation in size and stems tend to be slightly contracting and less deeply indented (Suhm et al. 1954:468). Many investigators have attempted to divide the Pedernales type into varieties. Johnson et al. $(1962: 25,27,63,92)$ described at least four varieties and two miscellaneous groupings of Pedernales points at the Canyon Lake sites; Shafer (Sorrow et al. 1967:18-20, 70-73) sorted out as many as eight varieties and several miscellaneous specimens at the Stillhouse Hollow sites; and Sorrow (1969:17-18) found five morphological categories in a large sample of Pedernales points at the John Ischy site in Williamson County.

Johnson et al. (1962) made no temporal claims for their varieties, nor did Shafer (Sorrow et al. 1967). Sorrow (1969) explicitly assigned no chronological significance to his categories. Kelly (1961:251-253) at the Crumly site found no temporal significance in the vertical distribution of 182 Pedernales points with and without barbs. Most subsequent typologists (e.g., Black and McGraw 1985:113) have either rejected attempts to categorize Pedernales variations as having temporal or geographical significance, or have attributed blade shape to variability in resharpening (Turner and Hester 1993:171-173). However, Johnson (1995:190, 198, 201-202, Figures 67, 68), who has quantified Pedernales variability, perceives a differential distribution, with long, narrow, and fairly thick Pedernales points predominating in the eastern half of 
the Edwards Plateau while flat, thin, and wide Pedernales points resembling the Montell and Marshall styles prevail in the southwestern part of the Plateau and on the coastal plain. Moreover, Johnson also argues that most of the originally short and wide Pedernales dart points, given their resemblance to the Montell and Marshall point types with which they intergrade, are later than the longer, slimmer Pedernales specimens. Nevertheless, he concedes that quantitative comparisons of Pedernales points from the Panther Creek Springs and Jonas Terrace sites do not indicate two separate populations, merely extremes of a single shape continuum.

Early on, Suhm et al. (1954:468, Plates 113-115) had already gone to great lengths to document the wide variability in Pedernales blades that they believed arose from the various stages of the manufacture/use/discard trajectory: The largest, they argued, "may never have been trimmed down and finished properly" while "the smallest specimens probably have rechipped blades for the most part" (Suhm et al. 1954:468). Many Pedernales artifacts with large, lanceolate, or oval blades may indeed be preforms rather than finished dart points. Five specimens recovered at the Bull Pen site (41BP280) in Bastrop County, Texas, appear to be unfinished Pedernales points with initial stem preparation well under way before completion of blade thinning and shaping (Ensor and Mueller-Wille 1988:119, Figure $41 \mathrm{a}, \mathrm{b})$. In an appendix to that report, Goode (1988:169-171) describes the results of a replication study of Pedernales points using lithic resources available in the vicinity of the site. During a six-step production model from flake or nodule reduction to use and rejuvenation of the finished point, based on examination of archaeological specimens, Goode began shaping Pedernales stems during the fourth step on the straight basal edges of oval bifaces by removing long thinning flakes, creating the characteristic flutelike scars, and shaping the neck and stem edges, which were virtually finished before final blade thinning was accomplished. Final manufacture, step 5, included final thinning of stem and lanceolate blade. According to this model, in step 6 pressure retouch rejuvenation of Pedernales points over time leads to straight, occasionally beveled, and sometimes concave blade edges. Collins (personal communication 1997), in examining dart points from the Kincaid Rockshelter, has found two populations of Pedernales artifacts based on blade morphology. The first population rapidly becomes narrower with resharpening, to the degree that the shoulders disappear and the points resemble the Kinney type. The second population, the less common of the two, consists of tools that rapidly become shorter, but not at all narrower. Collins argues that the first set of Pedernales were employed as knives and consequently were resharpened along the edges, while the second group were dart points, which required frequent rejuvenation to remove impact fractures.

During three exploratory seasons at the Culebra Creek site, 13 Pedernales dart points and stem fragments as well as two preforms have been collected, making Pedernales the most common projectile point style recovered. None appears to exhibit blade beveling or stem smoothing reported from some other central Texas sites (Johnson 1995:194; Preston 1969:176).

Figure 8-6a shows a deeply indented Pedernales stem fragment made of tan to light gray chert with a remainder of subcortical material on one corner of the base. The base is $23 \mathrm{~mm}$ wide and $6.5 \mathrm{~mm}$ thick near the neck. The base was thinned by one long flake with minor retouch on one side and retouch on the other. This piece was recovered from the midden periphery, Area B, TU 17, Level 3.

The Pedernales in Figure 8-6b appears to have been made on a large flake of light gray chert and still exhibits a slight curvature. It has a relatively small stem and a long, leaf-shaped blade terminating in a transverse fracture that may have originated during manufacture, all of which indicates this may be a preform rather than a finished Pedernales point. The blade is $39 \mathrm{~mm}$ long and has a maximum thickness of $8.5 \mathrm{~mm}$ near the break, where several thinning flakes from one edge hinge out, forming a small, off-center ridge on one face. The stem is $14 \mathrm{~mm}$ long with a parallelsided stem measuring $16 \mathrm{~mm}$ at neck and base. Basal thinning was done with short crescent-shaped flakes on both sides. This point was recovered from the block excavation, Area B, TU C, Level 5.

The Pedernales in Figure 8-6c is a tan chert proximal fragment with a broad blade terminating in a transverse snap. The remaining lateral edges appear to be slightly convex, with a width of $42 \mathrm{~mm}$. The blade has 


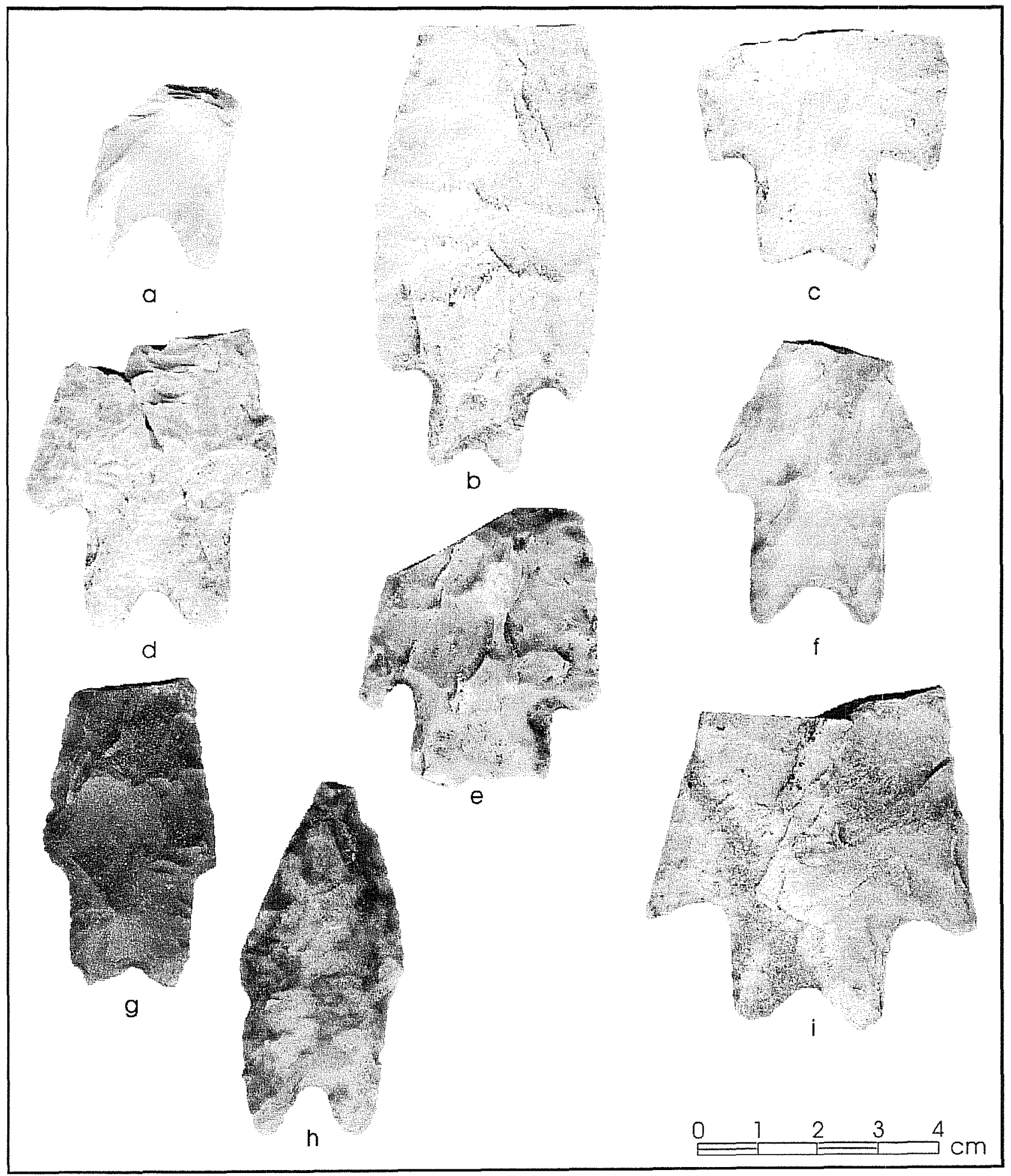

Figure 8-6. Diagnostic artifacts. a-i: Pedernales. 
short barbs, one of which is broken, and appears to have been resharpened more along the broken edge than on the other. Thickness is $9 \mathrm{~mm}$. The stem is 17 $\mathrm{mm}$ long and has parallel edges with neck and base of $20 \mathrm{~mm}$. The base is indented by wide, relatively short thinning flakes. Both the basal indentation and stem edges are trimmed with abrupt thinning flakes, more pronounced on one side than the other. This artifact was recovered from Area C, TU E, Level 4.

The Pedernales in Figure 8-6d is a remarkably thin $(6.5 \mathrm{~mm})$, broad-bladed proximal fragment made of gray chert with a transverse hinge fracture and some additional damage at the point of fracture, possibly sustained during recovery. One barb is missing and the other broken. The stem is $21 \mathrm{~mm}$ long and has parallel sides, with neck and base both measuring 24.5 $\mathrm{mm}$. The base is rounded and has short, crescentshaped basal thinning flake scars. The thinness of both blade and stem make this Pedernales point look almost like a Montell at first glance, until the length of the stem is considered. This point was recovered from Area $\mathrm{C}$ in the backdirt from Trench $\mathrm{C}$. The point illustrated in Figure 8-6e is a reworked basal fragment of light tan chert with pink shadings, indicative of exposure to extreme heat. The blade is broad and terminates in a diagonal hinge fracture; however, it appears that this artifact had been trimmed previously along a transverse distal edge intersected by the more recent diagonal fracture, suggesting the possibility that this point had been reworked into a drill. Both barbs are damaged. This point is thickest $(8 \mathrm{~mm})$ at the neck, which is $23 \mathrm{~mm}$ wide. The stem is slightly expanding to a damaged base. The shallow basal notch was produced by poorly executed basal thinning flakes. This point was recovered from Area B, Trench $G$ in either the framework or periphery of the midden.

Shown in Figure 8-6 $\mathrm{f}$ is a Pedernales made of chert and has a medium blade truncated by a transverse fracture of indeterminate cause that removed the distal tip. One lateral edge is damaged near the tip, and the barb on the lateral edge opposite the damagededge is broken. The blade is $8.5 \mathrm{~mm}$ thick near the neck. The stem is $21 \mathrm{~mm}$ long with a neck width of 22 $\mathrm{mm}$. Stem edges are essentially parallel; however, rounding produced a base only $21 \mathrm{~mm}$ wide. The basal indentation was produced by long crescent flakes on both faces. This point was recovered from Area B, Trench $\mathrm{O}$ in either the framework or periphery of the midden.

Figure 8-6g shows a proximal Pedernales fragment with a narrow blade. It is made of dark brown chert with a lighter, coarse-grained inclusion having poor flaking qualities. This inclusion prevented part of the edge from being thinned or reworked at that point and may have contributed to the transverse fracture that snapped off perhaps a third of the blade. Thickness at the inclusion/break is $6.5 \mathrm{~mm}$, while thickness at the neck is only $6 \mathrm{~mm}$. The blade is $30.5 \mathrm{~mm}$ wide at the shoulders, which lack barbs. The stem is $19 \mathrm{~mm}$ long with parallel edges; both neck and base measure $20 \mathrm{~mm}$ across. The broadly $\mathrm{V}$-shaped basal indentation is formed by several short crescent-shaped thinning flakes. Stem edges are trimmed with abrupt thinning flakes. This point was recovered from the surface in Area C (N1080.566/E 929.027, elevation 108.536 m).

The Pedernales in Figure 8-6h is a very narrow-bladed point made of mottled tan chert, with minimal shoulders, possibly damaged, and a broken distal tip. The stem is $21 \mathrm{~mm}$ long, the neck is $23 \mathrm{~mm}$ across and the base measures $20 \mathrm{~mm}$, with one straight edge and one convex edge. The base is deeply indented but not fluted; only shallow crescent-shaped thinning flake scars remain. Blade and shoulders of this relatively thin $(7 \mathrm{~mm})$ Pedernales point appear to have been extensively resharpened. It was recovered from either the framework or periphery of the midden, Area B, in the Gradall profile north of Trench $\mathrm{O}$.

Shown in Figure 8-6i is a very broad-bladed Pedernales point made of coarse grain gray chert with slightly coarser inclusions. The blade terminates in an irregular transverse fracture of indeterminate origin. The blade is $9.5 \mathrm{~mm}$ thick and $55.5 \mathrm{~mm}$ wide at the barbs, one of which is slightly damaged. The other barb is sharply pointed. The wide, slightly contracting stem measures $26.5 \mathrm{~mm}$ at the neck, $24.5 \mathrm{~mm}$ at the base, and is only $18 \mathrm{~mm}$ long. The base is rounded and moderately indented, with a short thinning flute on one face and at least one broad thinning flake scar on the opposite face. This point was recovered from the midden periphery in Area B in the backdirt at the west end of Trench $\mathrm{O}$. 
The Pedernales piece shown in Figure 8-7a is a proximal fragment made of light brown chert. It is relatively narrow-bladed, with unbarbed shoulders that appear to have been damaged. Maximum thickness $(8 \mathrm{~mm})$ is at the neck. The stem is $13 \mathrm{~mm}$ long with parallel edges and a neck $18 \mathrm{~mm}$ wide. The base has one broken corner and is fluted on one face, with steep, shallow crescent-shaped flake scars on the other. This artifact was recovered from Area A, TU 2, Level 1.

Shown in Figure 8-7b is a probable Pedernales preform made of dark gray chert grading to subcortical material, and has both lateral and transverse fractures of the thick body, which had not been thinned. The base had apparently been completed before one complete corner was broken off, leaving the neck, the deepest part of the basal indentation, and the other half of the base. This artifact was initially identified as a Montell preform; however, when properly oriented it is evident that the stem was originally long and parallel sided, an indication of the Pedernales type, rather than short and expanding, as with Montell. It was recovered from the midden central core, Area B, TU 9, Level 2.

Figure 8-7c shows a complete Pedernales point of pink chert, evidently heat treated, with a strip of subcortical material on one face. The blade has slight impact damage on the tip and possible use wear on one edge near the tip. The narrow blade has been extensively resharpened and has one straight edge and one convex edge. Overall length is $50 \mathrm{~mm}$ and thickness is $9 \mathrm{~mm}$ at the neck. The stem is $17 \mathrm{~mm}$ long and $18.5 \mathrm{~mm}$ wide at the neck, tapering to $16.5 \mathrm{~mm}$ at the base, which is well rounded. The basal indentation is relatively deep, formed by several short thinning flakes on one face and a long thinning flake that terminates with a hinge fracture on the other. This point was recovered from the midden central core, Area B, TU 9, Level 2.

Figure $8-7 \mathrm{~d}$ is a picture of a Pedernales preform of very dark gray to black, coarse-grained chert. Both faces exhibit heat damage and deep pot-lid fracturing, which removed part of the base and one incipient shoulder. Nevertheless, the essentially parallel sides of the stem remain. The basal indentation had been chipped out but apparently not yet thinned on either face. This preform was recovered from the midden periphery, Area B, TU 11, Level 4.
Figure 8-7e shows a thin, broad-bladed proximal fragment with sharp barbs and made of dark brown semitranslucent chert with a light tan inclusion on one face. The blade terminates in a transverse hinge fracture at the estimated midpoint, and one half of the stem is broken. The blade is $6.5 \mathrm{~mm}$ thick and has wide billetflake scars over most of both faces, somewhat in a Montell style. The basal indentation was finished off with a long thinning flake on one face and short crescent-shaped flakes on the other. This Pedernales fragment was recovered from the block excavation, Area B, TU 18, Level 3.

\section{Tortugas}

Type definitions for triangular bifaces in south, central and southwest Texas have led a checkered career since even before the Tortugas type was compiled by Suhm et al. (1954:482) from three triangular points linked by Kelley (1947b:104, Plate 10) to his "Clear Fork Focus." These point types were "Baird Beveled Blade," "Taylor Thinned Base" (both from the Balcones Phase of southwest Texas, [Ray 1938]) and "Tortugas Triangular Blade" from the Gulf Coastal Plain. Suhm et al. (1954) declared that they could not distinguish the three points, and proceeded to lump them into one type they called Tortugas and described as having large, triangular blades with straight to convex, occasionally concave or recurved edges, often alternately beveled to the right, occasionally on both edges of both faces. Bases were said to be straight to concave, often thinned, sometimes with a large thinning flake scar giving the effect of a "flute." Tortugas points were said to be a major point type of the Falcon focus from 5950-950 B.P., and also to be present in the Aransas and Pecos phases and Edwards aspect. However, order was not imposed.

At the Landslide site, Shafer (Sorrow et al. 1967:20, 22) identified two Tortugas points and two groups of stemless triangular points that were thinner and lacked the beveled edges of the Tortugas type description by Suhm et al. (1954:482), and stratigraphically deeper than the one provenienced Tortugas point recovered from the site. Four of the Landslide points also had serrated edges. Sorrow (1969:18-19) suggested those five points were comparable to a group of four bifacially thinned triangular points with broad lateral edge serrations from the John Ischy site, and that both groups 


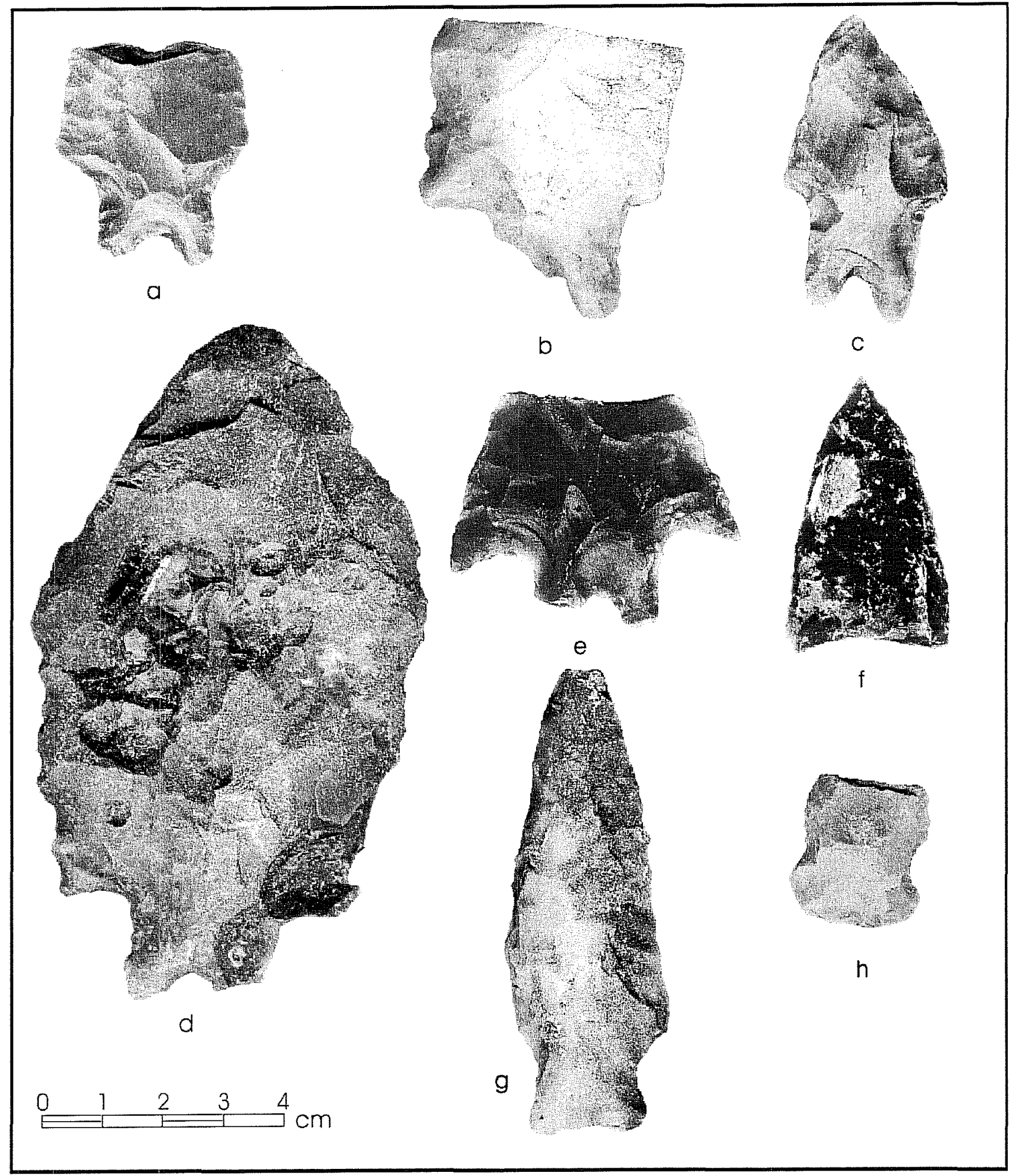

Figure 8-7. Diagnostic artifacts. a, c, e: Pedernales; b, d: Pedernales preform; f: Tortugas; g: Uvalde; h: Williams. 
belonged to Kelley's (1947b) "Taylor Thinned Base" type, which Sorrow provisionally renamed Taylor. Sorrow (1969:19) also renamed a second group of five triangular bifaces at John Ischy, which he compared to Kelley's "Baird Beveled Blade" and called "Baird," and suggested using Tortugas as a type name only for specimens with alternately beveled lateral edges. Turner and Hester (1993:188) have also drawn a distinction, on morphological and stratigraphic grounds, between "Tortugas" points and "Early Triangular" points. They date Tortugas to late in the Middle Archaic (2800-2550 B.P., which would be Late Archaic I for Johnson and Goode [1994] and Collins [1995]) and identify it as a characteristic artifact of south Texas and the lower Rio Grande, occasionally found in central and southwest Texas. Early Triangular, according to Turner and Hester (1993:108-110), is widespread in central, south, and southwest Texas and is stratigraphically earlier than Tortugas. Acknowledging a confusion in typology, they note that such Early Archaic triangular points are what Kelley (1947a) and Sorrow (1969) called "Baird (Beveled Blade)" and "Taylor (Thinned Base)."

One complete Tortugas point (Figure 8-7f) was recovered from 41BX126 during the 1997 investigations. It is made of dark brown semi-translucent chert with coarse inclusions and traces of patination. Both lateral edges are bifacially beveled (supposedly not a characteristic of the type but perhaps a function of resharpening) and converge in a finely pointed tip. The artifact is $46 \mathrm{~mm}$ long, $6.5 \mathrm{~mm}$ thick, and $27 \mathrm{~mm}$ wide at the base, which is concave. The base was thinned on one face by the removal of a long basal thinning flake, the scar of which is covered by a short, wide crescent-shaped flake scar and subsequent pressure flaking. The base is finished on the opposite face with short pressure flakes. The Tortugas point was recovered from the block excavation, Area B, TU 14, Level 4.

\section{Uvalde}

A minor type in central Texas and the Lower Pecos, Uvalde was first described by Suhm et al. (1954:486, 527) on the basis of collections from Fate Bell Shelter in the lower Pecos and the Marshall Ford and Buchanan reservoir basins, and dated to the Archaic somewhere between 5950 B.P. and 950 B.P. They speculated, however, that it might be of more recent origin than other points of the Edwards Plateau Aspect
(Middle to Late Archaic) because of its more restricted geographical range in central Texas, the lower Guadalupe River valley, and the Lower Pecos. Since Uvalde points were never present in great numbers at any site, it was never given much attention. For example, though all five Uvalde points at the Footbridge site (Johnson et al. 1962:75, 118-121, Figure 45), were found in a single mixed level below Nolan, Travis, Bulverde and most of the Pedernales points, which might have suggested an early Archaic date, nothing was made of it and Uvalde was not represented in either the Canyon Lake or the regional chronologies. Weir $(1976: 119,124$, Table I), in his seminal restudy of the Central Texas Archaic, placed Uvalde in his newly defined San Geronimo Phase (8000-4500 B.P.), earlier than Bell or Early Triangular. On the basis of these and other investigations, Uvalde is now accepted as clearly representative of the Early Archaic (Turner and Hester 1993:191). In central Texas, Johnson (Johnson and Goode 1994:24) and Collins (1995:383, Table 2) place Uvalde with Martindale points in the final style interval of the Early Archaic, $6000-7000$ B.P. In south Texas, Hester (1995:436-437) includes the Uvalde type with Martindale, Baker, and Bandy dart point styles in an "Early Corner Notched Horizon" as early as 79505450 B.P.

The Uvalde style is recognized most readily by its split stem and narrow neck, although the type remains very broadly defined with wide variability (Turner and Hester 1993), and grades into Baker, Bandy, and Martindale and may even resemble Gower or small Pedernales points. Suhm (1959:230) acknowledged that the Uvalde type and the morphologically similar but unrelated Frio type are "somewhat marginal forms" as they were defined by Suhm et al. (1954:486), and Sorrow et al. (1967:70) complained that the type needed to be redefined. Nevertheless, based on a review of published illustrations, it can be said that Uvalde has a triangular to leaf-shaped blade having straight to convex lateral edges, rounded or barbed shoulders, and an expanding stem with rounded corners. The neck is usually narrow, from $10-15 \mathrm{~mm}$ wide, and a pronounced basal concavity usually measures $1-4 \mathrm{~mm}$ deep; both traits are identifying characteristics of the type. Sometimes the stem or base is smoothed (Collins et al. 1990:56-57, Figure 19, Table 3; Hester 1971:71, Figure 11, c; Hester et al. 1989:Figure 1d; Johnson et al. 1962:65, Figure 24, d-f; Prewitt 1981b:287, Figure 83, p-r; Sorrow et al. 1967:20, 70, 
Figures 14, 41f, 41g; Suhm and Jelks 1962:Plate 162; Weir 1979:Figure 9).

One probable Uvalde point (Figure 8-7g) was recovered from the site. This is an almost complete artifact with a long, slender blade measuring $26 \mathrm{~mm}$ wide and $61.5 \mathrm{~mm}$ long (overall $87.5 \mathrm{~mm}$ ) even without the distal tip. Lateral edges are straight to slightly convex near the rounded shoulders and the blade is $11 \mathrm{~mm}$ thick. The stem is $11 \mathrm{~mm}$ long and the edges are slightly smoothed on the high points. Neck width is $16.5 \mathrm{~mm}$ and the base is $20 \mathrm{~mm}$ wide with rounded corners. The basal concavity is $1 \mathrm{~mm}$ deep. This specimen was originally listed as a Travis dart point, possibly on the basis of the lanceolate but not distinctive blade, along with a note that the basal concavity was not typical. Although the basal indentation is clearly minimal for a Uvalde and the neck width is somewhat greater than for most points of the type, the stem clearly expands too widely for the Travis style and the point is thus assigned to Uvalde. This point was recovered from the midden central core, Area B, TU 8, Level 5.

\section{Williams}

Williams points have broad triangular blades and rounded convex bases that have a bulbar appearance. This type is similar in many respects to the La Jita, but is larger and has a different geographical and temporal distribution in central Texas during the Middle to Late Archaic. The La Jita is earlier and confined largely to the southeast margins of the Edwards Plateau (Turner and Hester 1993:140, 194-195). Suhm et al. (1954:490), who first described the type, note that Williams - with its broad triangular blade, straight to strongly convex lateral edges and strong, often barbed shoulders - may resemble the Marcos and Castroville types as well as the Palmillas type, which also has a bulb-shaped stem but is smaller than Williams. Bell (1960:96, Plate 48) notes that Williams points occur in eastern Oklahoma in aceramic contexts, especially in the Fourche Maline Valley and elsewhere in the Mississippi Valley.

Although Suhm et al. (1954) assigned Williams a temporal range of 5950-950 B.P., no secure dates seem to be associated with this type. It is considered Middle to Late Archaic on the basis of loose stratigraphic associations with Pedernales, Lange, Marshall, and
Castroville points at several central Texas sites (Kelly 1961:251; Shafer 1963:79-80; Sorrow 1969:Table 1, Table 6), but below Marcos, Montell, and some Marshall points at Youngsport (Shafer 1963:80). Prewitt (1981a:80) lists Williams along with Marshall and Lange points as representative artifacts of the San Marcos phase of the terminal Middle Archaic, 2600-2250 в.P., which would be mid-Late Archaic for Collins (1995:Table 2) and Johnson (Johnson and Goode 1994).

One extensively resharpened Williams point (Figure 8-7h) was recovered from the Culebra Creek site. It is a proximal fragment made of tan chert. The blade terminates in a transverse snap and what appears to be a large distal impact fracture scar sustained prior to the snap. The remainder of the blade is $21 \mathrm{~mm}$ wide at the shoulders and $7 \mathrm{~mm}$ thick at the neck. The stem is $10 \mathrm{~mm}$ long and $17.5 \mathrm{~mm}$ wide at the neck, expanding to $22 \mathrm{~mm}$ at the base, which is very convex and gives the stem the typical bulbar appearance. This base size is at the low end of the range of Williams dimensions reported from other sites and is untypically smaller than many of the La Jita points it closely resembles. This artifact was recovered from the midden periphery, Area B, TU 11, Level 2.

\section{Untyped Dart Points and Untypable Fragments}

Untyped points include those complete enough to determine whether they meet the definition of any accepted projectile point type, but which do not. Untypable points are fragments that can be categorized as dart points but which are missing distinctive parts, such as base, blade or barbs, that might otherwise exhibit identifying traits that would permit type assignment.

Shown in Figure 8-8a is an untyped stemmed biface made of tan chert. The blade terminates in a diagonal hinge fracture and was further fragmented after deposition. The base is indented. This artifact was initially identified as an incomplete Pedernales point (Wood 1994:20-21), then as a possible La Jita, probably on the basis of the convex stem edges and rounded corners. However, although some La Jita bases are slightly concave, the concavity of this base is too great, and is more suggestive of a very weak Pedernales or Montell bifurcation. Nevertheless, since Pedernales stems are usually shaped and all but completed before reduction 
of the blade is initiated, this is unlikely to be a Pedernales preform. This artifact was recovered from Area B, Shovel Test 22, Level 2.

The first untypable piece is a stem fragment of brown chert grading to subcortical material exhibiting an irregular break at the neck. The stem is $8 \mathrm{~mm}$ long and expands with straight edges to a base $26 \mathrm{~mm}$ wide with acute corners. It is wedge shaped in cross-section, tapering evenly from the neck to a thin, sharp basal edge, and thus may have been part of a Castroville dart point. This fragment was found in the midden framework, Area B, TU 18, Level 1.

The second untypable point is made of gray, chalky chert and has been damaged by burning so that not enough of the base is present to permit secure classification, although the long, narrow, straight-edged blade and what is left of one side notch hint that this may have been a Uvalde point. The distal tip and one shoulder also are missing. Maximum thickness of this point is $8 \mathrm{~mm}$ at the neck. This point was recovered from the midden framework, Area B, TU D, Level 7.

The third untypable point is a barb fragment $17.5 \mathrm{~mm}$ long and ending in a point, similar to the long, pronounced barbs often observed on Marshall, Montell, Marcos or Castroville points. It is made of light brown chert. This fragment was recovered from Area C, TU F, Level 6.

The fourth untypable point is a broad, thin, well-made Late Archaic dart point blade made of dark brown, semi-translucent chert. The stem is snapped off at the neck, making further classification impossible and leaving a blade $60 \mathrm{~mm}$ long and $37 \mathrm{~mm}$ wide at the shoulders. Both shoulders are damaged; however, it is evident that blade and barbs were of a style characteristic of Castroville, Montell, Marshall or Marcos points. This artifact was recovered from the midden periphery, Area B, Trench $G$, less than a meter north of TU A.

The fifth untypable point is a proximal fragment of mottled pinkish-gray chert ending in a transverse hinge fracture. The stem is short $(9 \mathrm{~mm})$, wide and expanding from 20 $\mathrm{mm}$ at the neck to $21 \mathrm{~mm}$. The base is convex with an "ear" on one corner. Maximum thickness is $8 \mathrm{~mm}$ at the shoulders, where it does not appear the thinning process was completed. It is tempting to call this a preform. There is nothing symmetrical about this artifact in any way; the only clear trait is that it is a stemmed biface. This fragment was recovered from the midden central core, Area B, TU 8, Level 3.

The sixth untypable point is an extensively resharpened point made of mottled gray chert, with a thick, stubby blade. The distal tip exhibits a massive impact fracture apparently subsequent to the most recent rejuvenation episode. Although a distal tip remains, it may be entirely fortuitous. This point is $41 \mathrm{~mm}$ long and 21 $\mathrm{mm}$ wide at the shoulders. The stem is $17.5 \mathrm{~mm}$ long and $15 \mathrm{~mm}$ at the neck, contracting to $11 \mathrm{~mm}$ at the base. Sides and base are straight. The stem appears to twist and is beveled on the left on one face, possibly both. This point has some resemblance to the Darl type, but the stem seems uncommonly long. This point was recovered from the midden periphery, Area B, TU 10, Level 3.

\section{Bifaces}

Chipped stone artifacts that had been flaked on both sides of the same lateral edge are classified as bifaces. A total of 199 bifaces (excluding projectile points) was collected during the 1993, 1995, and 1997 excavations. For each specimen, the following attributes were recorded: raw material type, raw material grain, burning, presence or absence of cortex, tool completeness, length, width, stage of reduction, and evidence for tool recycling. All bifaces were measured to the nearest millimeter. The details of the attributes are discussed below.

Raw material grain was simply noted as fine or coarse. Burning was either coded as being present or absent and was determined by the presence of crazing, heat fractures, or pot lids. Tool completeness was coded as either complete, incomplete, or indeterminate.

The stage of reduction of a biface was a subjective category coded as either early, middle, late, or indeterminate. To insure consistency, all bifaces were coded by the same laboratory analyst. Early stage bifaces $(n=41)$ usually retain a small to large amount of cortex and have relatively few flake removals, all of which 


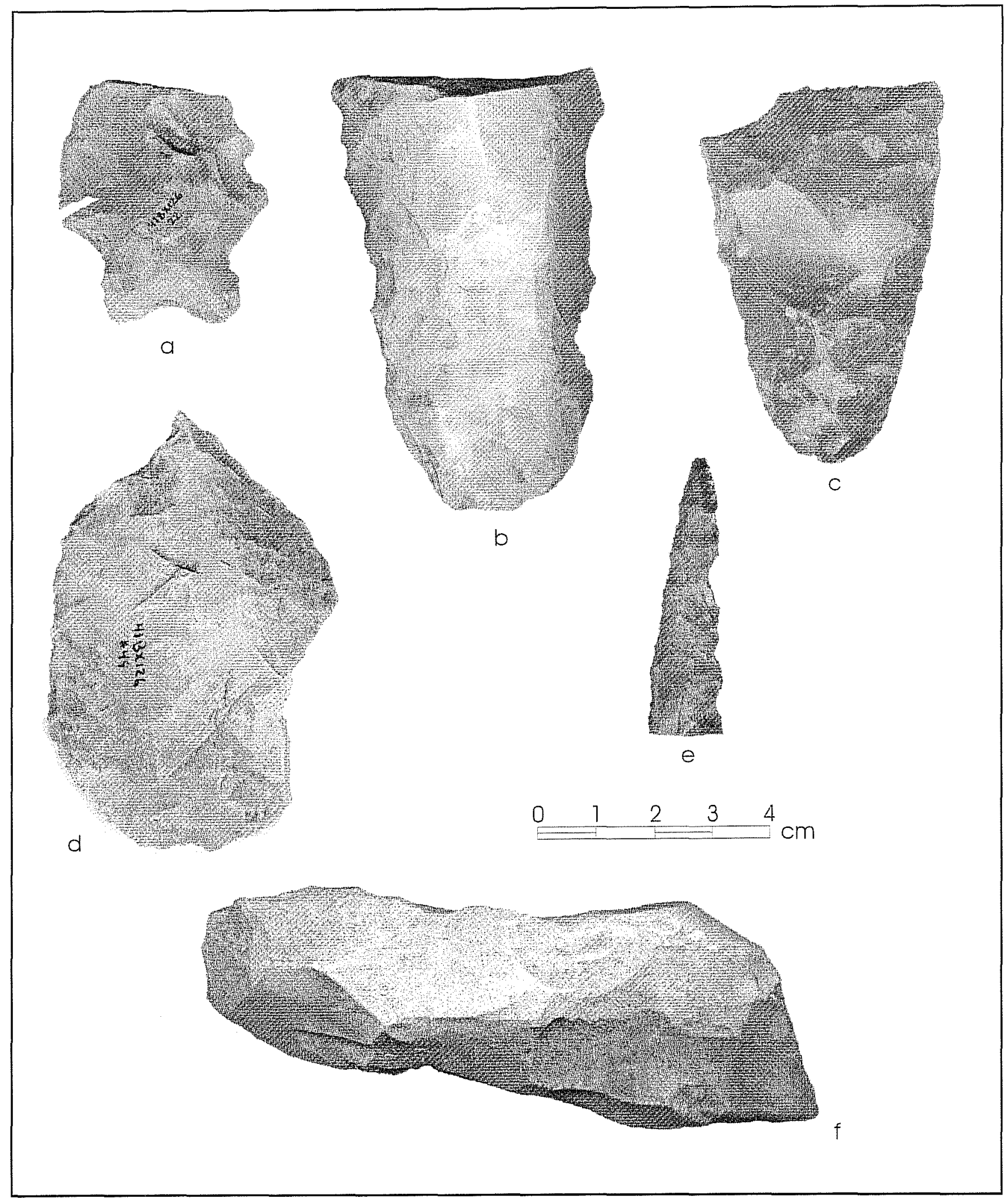

Figure 8-8. Untyped dart points and bifaces. a: untyped dart point; b, c: gouges; d: graver; e: drill; f: Guadalupe tool, right side view with bit to left. 
were removed by hard hammer percussion. The edges of these bifaces are generally very sinuous when viewed in profile. Middle stage reduction bifaces $(n=39)$ are typically thinner than early stage bifaces, have little or no cortex remaining, and have numerous flake scars, many of which may travel beyond the midline of the biface. The edges are less sinuous than those of early stage specimens. Late stage reduction bifaces $(n=111)$ are thin, have no cortex, and have numerous flake scars. Most of the flakes from late stage reduction are removed by billet or soft hammer percussion. Flake scars are, therefore, relatively longer and more shallow than in early stage reduction. The edges of late stage bifaces are usually straight when viewed in profile. If a specimen was too fragmentary to determine its position in this reduction model, it was classified as indeterminate $(n=1)$.

An important consideration related to stage of reduction is that functionally a biface could be used at any step in the process. For example, artifacts typically classified as "choppers" are early stage bifaces with a cortex covered proximal end and a crudely flaked distal end. Their distal ends commonly show use-wear associated with one or more activity, including butchering, woodworking, and hacking (Turner and Hester 1993).

Six formal bifacial tools and one graver manufactured on a late-stage biface were recovered from 41BX126. All but one (San Gabriel biface) are made of finegrained chert, and one gouge appears to be thermally altered. Each tool is described in detail below.

\section{Gouges}

Gouges are subtriangular in form with distal bits. Lateral sides of the gouges are beveled and may be concave or convex. Most often, the narrow proximal ends were hafted. Gouges may be bifacially or unifacially worked. Generally, the distribution of gouges is very broad across Texas. Gouges are found in many archaeological sites that range from the Late Paleoindian to the Late Prehistoric in age.

The Culebra Creek site yielded three nondiagnostic gouges from the 1995 excavation. Two of the gouges are bifacial and one is unifacial (see Unifacial tools below). The first specimen (Figure 8-8b) was recovered from TU D, Level 10 . This subtriangular gouge exhibits a rounded proximal end and slightly concave lateral edges. The distal end is missing. In plan view, the right lateral edge is sinuous and beveled. The specimen measures: maximum length $=77 \mathrm{~mm}$, maximum width $=49 \mathrm{~mm}$, maximum thickness $=28 \mathrm{~mm}$, and width at proximal end $=27 \mathrm{~mm}$.

The second specimen (Figure 8-8c) was found in an undesignated trench backdirt pile. The gouge is subtriangular in form and mostly complete. In plan view, the top left bit edge is broken off. The bit edge is slightly concave while the lateral edges are beveled and slightly convex. The proximal end is rounded and dulled. Measurements are as follows: bit angle $=51^{\circ}$, maximum length $=65 \mathrm{~mm}$, maximum width $=44 \mathrm{~mm}$, maximum thickness $=11 \mathrm{~mm}$.

\section{Gravers}

Gravers are small- to medium-size tools exhibiting carefully chipped, sharp, needlelike protrusions. They are generally made on flakes and can be combined with other tools such as scrapers (Turner and Hester 1993). Gravers were used for a variety of tasks including, but not limited to, engraving, cutting and punching. The distribution of gravers is wide across Texas. They have been found in many archaeological sites ranging from Paleoindian to Late Prehistoric in age. The Culebra Creek site yielded a bifacial graver in the 1995 and a unifacial graver during the 1997 excavation (see Unifacial tools). The bifacial graver (Figure 8-8d) was excavated from TU D, Level 4 . The graver was made on the end of a late stage biface. The edges were carefully trimmed forming a sharp symmetrical protrusion. Step fractures are prevalent near the graver end of the tool. Measurements for the graver are: maximum length $=76 \mathrm{~mm}$, maximum width $=48 \mathrm{~mm}$, and maximum thickness $=14 \mathrm{~mm}$.

\section{Drills/Perforators}

Drills and perforators have bifacially worked bits and proximal ends. The drill has a long, narrow bit or shaft that is often diamond shaped in cross-section (Turner 
and Hester 1993), but can also be of a lenticular shape (Kelly 1961:255,256, Figure 9). The distal tip of a drill/ perforator commonly exhibits a blunted or dulled appearance resulting from use wear. Many Archaic drills have bases similar to those of projectile points indicating a change in the former function of this tool. In contrast, Late Prehistoric drills/perforators are smaller and are usually manufactured from a flake. Drills have a wide distribution in Texas and have been recovered from Archaic and Late Prehistoric sites (Turner and Hester 1993).

One drill (Figure 8-8e) was recovered from TU 22, Level 2 during the CAR investigation. The base of the drill is broken and therefore it is impossible to determine whether the drill is a reworked dart point or if it was made on a flake. The distal tip appears to be thermally altered, exhibiting a reddish color which is not observed on the remaining bit or shaft. Based on observed color differentiation between lateral edge and adjacent area, and the central body, the shaft also appears to have been recently reworked. Projectile points recovered from levels 1-3 (or comparable levels) in adjacent TUs (TU 16, 17, 20) include a Bulverde, Castroville and three Pedernales dart points. Given the presence of Late Archaic dart points and the complete absence of Late Prehistoric artifacts at 41BX126, it is reasonable to assume that the drill is of Archaic origin. Maximum dimensions are: $47 \mathrm{~mm}$ in length, 12.5 $\mathrm{mm}$ in width, and $5 \mathrm{~mm}$ thick.

\section{Guadalupe Tools}

The Guadalupe tool is characterized by thick percussion flaking, a very abruptly beveled distal end and a subtriangular cross section. The reduction sequence that produces this singular morphology is aptly detailed in Brown (1985:80-81) and Turner and Hester (1993:256-260). Working edge angles at the intersection of the bit face and dorsal surface are normally acute, ranging between 55 and 85 (Black and McGraw 1985:151). First designated as a core scraper (Sayles 1935) and later termed an adze or gouge, the term Guadalupe tool was adopted by Hester and Kohnitz (1975) recognizing that the true function of the tool was not understood. Subsequent investigators have suggested the tool may have functioned as a woodworking implement or, alternatively, as part of a hide-defleshing kit (Black and McGraw 1985:149; Goode 1989:135; Sollberger and Carroll 1985).

Guadalupe tools have been reported from across a wide swath of the south Texas Coastal Plain from the lower Guadalupe River west to the Rio Grande, encompassing the Nueces River drainage, and northward onto the southern and eastern margins of the Edwards Plateau (Highley 1984). The distribution pattern is apparently related to the river drainage system flowing off the plateau toward the Gulf Coast, although upland occurrences also are reported. This tool form is most frequently found along the lower and middle Guadalupe River and in the upper reaches of the MedinaSan Antonio River basin in sites such as Panther Springs Creek (41BX228, Black and McGraw 1985:142, 146, Table 14, Figure 29), Granberg II (Brown 1985:95-102; Hester 1980:147-149), and at Camp Bullis (41BX376, 412BX409, Gerstle et al. 1978:102, Table 8).

The Culebra Creek site is located in the Medina River Basin and is within 25 kilometers of the Panther Springs Creek site. Excavations at the Panther Springs Creek site yielded 19 Guadalupe tools while the Culebra Creek site yielded one Guadalupe tool. Chronologically, the Guadalupe tool was only produced for a brief portion of the Early Archaic ca. 6650-5250 в.P. Hester (1995) associates Guadalupe tools with an "Early Corner-Notched Horizon" which ranges from ca. $7950-5450$ B.P.

The Guadalupe tool from the Culebra Creek site (Figure 8-8f) was found during the 1995 excavation in TU D, Level 9 . The tool was bidirectionally flaked on three sides with flake removal running perpendicular to the axis of the artifact. The tool was worked on the distal end of the dorsal side where some of the original shaping remains. The distal end has alternate, bidirectionally obtuse flaking that resembles backing (as with micro lithic tools). The dorsal side bears blade-like flake scars parallel with the long axis. These flake scars are resharpening flakes that originated from the bit. On the midsection of the dorsal face there are a number of long blade-like flake scars linked to the initial preparation of the bit. A series of flake scars terminates in hinge and step fractures at the distal end of the tool, leading up to a narrow, intensively resharpened bit. 
The bit is long, narrow, and triangular. The bit was laterally sharpened on the sides of the bit spine. Although, the bit facet was reduced by width, the bit spine remains close to the original dimension. In comparison, the narrow bit is more extreme than specimen $\mathrm{D}$ from the Lindner Cache (Brown 1985:91, Figure 6).

When plotted on a scattergram showing the relationship between weight and amount of bit arch, the Culebra Creek Guadalupe tool is closest to the Lindner Cache from the Medina River Basin (Brown 1985:120). The measurement for the ratio of bit thickness to width is 0.5 . The tool weighs 157.3 grams. Other measurements for the Guadalupe tool are as follows:

$$
\begin{aligned}
& \text { Dorsal length }=114 \mathrm{~mm} \\
& \text { Ventral length }=96 \mathrm{~mm} \\
& \text { Maximum bit width }=22 \mathrm{~mm} \\
& \text { Maximum tool width }=32 \mathrm{~mm} \\
& \text { Maximum tool thickness }=39 \mathrm{~mm} \\
& \text { Bit thickness }=44 \mathrm{~mm} \\
& \text { Max. depth of bit facet concavity }=0-.5 \mathrm{~mm} \\
& \text { Bit facet or ventral end angle }=122^{\circ} \\
& \text { Bit spine-plane angle }=61^{\circ}
\end{aligned}
$$

\section{Butted Knife}

Butted knives, often known as "hand axes" or "carcass cleavers," are identified by their oblong, pearshaped, or subtriangular outline with a narrow, bifacially thinned distal end. In common with some "choppers," this tool retains nodular cortex on the proximal end, which presumably served as a hand grip. The tool tapers toward the distal end, which may be broadly rounded and is frequently quite delicate and thin, so much so that it is likely that it was used as a cutting implement rather than functioning as an axe. The presence of heavy polish on the distal end of many of these tools also suggests a cutting rather than chopping function (Hester 1971:86; Sollberger 1968; Turner and Hester 1993:243). Microscopic and lipid analysis of residues on the edges of five butted knives from Kendall County (41KE92) indicated that two were used to process floral materials such as sotol, one was used on both animal and floral materials, and a fourth was used on fish parent materials (Chandler and
Marchbanks 1996). One study (Priour 1987:14) indicates that butted knives may be distinguishable from choppers, axes, and other bifacial artifacts with cortex at one end by the acuteness of the edge angle, which is generally 25 or less for butted knives.

The butted knife has a limited distribution, primarily on the southern Edwards Plateau and adjacent areas of the Coastal Plain, and in the Lower Pecos. It is found most commonly on and in the upper levels of burned rock middens, indicating that it was used in the Late Archaic ca. 2600-2250 B.P. (Turner and Hester 1993:243)

One butted knife (Figure 8-9a) was found during the 1997 excavation in TU 6, Level 3. The knife is subtriangular in outline with cortex on the proximal end. Polish is not evident on the distal tip. Measurements for the specimen are: maximum length $=89 \mathrm{~mm}$, maximum width $=76 \mathrm{~mm}$, and maximum thickness (at proximal end) $=24 \mathrm{~mm}$. The edge angle is $26.5^{\circ}$

\section{San Gabriel Biface}

San Gabriel bifaces are broad and triangular in form. The biface generally has gently convex lateral edges with sharply defined basal corners. The base is broad and concave. The San Gabriel biface type is notably thin and well made (Turner and Hester 1993).

The San Gabriel biface was originally described by Prewitt (1981a:105, Figures 37 and 38) from examples at the Loeve-Fox, Loeve, and Tombstone Bluff sites along the San Gabriel River. Although the San Gabriel biface is distributed across much of Central Texas, morphologically similar bifaces have been found in East Texas early Caddoan sites. They are called Gahagan or Copena bifaces. Chronologically, San Gabriel bifaces are associated with the Twin Sisters Phase at the Loeve-Fox site (Prewitt 1981b). This phase ranges from ca. $1750-1450$ B.P. and postdates the similar Gahagan bifaces in age.

One San Gabriel biface (Figure 8-9b) was located during the 1995 excavation in BHT G near the midden area back dirt. The distal end of the biface is missing and a hinge fracture remains. The biface was triangular with 
finely worked and gently convex lateral edges. The proximal end has sharply defined basal corners and a mildly concave base. The broken biface was thinly made. General measurements of the biface are as follows: maximum length (to hinge fracture) $=62 \mathrm{~mm}$, maximum width $=39 \mathrm{~mm}$, and maximum thickness $=8 \mathrm{~mm}$.

\section{Nondiagnostic Biface Forms}

Analysis of bifaces at 41BX126, excluding projectile points and formal tools, indicates a marked preference for fine-grained chert at all stages of the reduction process although, paradoxically, the proportion of bifaces made of coarse-grained materials increased later in the reduction sequence while the proportion of bifaces made of fine-grained material, though still overwhelming, decreased from the early stage to the late stage (Table 8-1).

The second comparison in Table 8-1 shows that the number of bifaces with cortex remaining decreases from the early reduction stage through the late stage, while the number without cortex increases, although the presence or absence of cortex is not an absolute indicator, since two early stage bifaces possessed no cortex and five late stage bifaces still exhibited traces of cortex.

Comparing bifaces made of coarse material with those made of fine-grained chert showed that early and late stage bifaces on average tended to be larger when made of coarse-grained material than when made of a finer fabric (Table 8-1). An exceptionally short average length for middle stage bifaces on coarse material appears to be anomalous, but might be explained by the smaller sample size since the average length for middle-stage bifaces on fine-grained chert appears consistent with the apparent reduction in average length from early to late. It would appear here either that coarse-grained materials are selected for the larger tools or that fine-grained materials are more easily reduced and thus selected for implements that must be smaller.

The proportion of burned specimens in the sample increases from the early reduction stage to the late stage, although the degree of increase is not great (Table 81). This may in some cases indicate thermal treatment incident to the manufacture of projectile points, although the possibility of discard or accidental loss in a hearth or cooking element should not be discounted, especially for tools used as knives during the food preparation process.

A far higher proportion of the bifaces in this sample made of fine-grained chert have cortex than do those made of coarse-grained material (Table 8-2). Bifaces with cortex tend to be longer than those without, although bifaces made of fine-grained chert tend to be shorter, whether with or without cortex, than specimens made of coarser-grained material. As noted above, the length disparity may be related to ease of reduction but since the fine-grained bifaces also tend to exhibit more cortex, it may be that the sizes and locations of source materials and ease of transport influence the sizes of tools being produced and used.

\section{Unifaces}

Artifacts that had been flaked on one surface are classified as unifaces. A total of 427 unifaces (including formal tools) was collected during the 1993, 1995, and 1997 excavations at the Culebra Creek site. For each specimen, the following attributes were recorded: raw material type, raw material grain quality, presence or absence of cortex, burning, uniface type, maximum dimension, and flake type. The first four attributes were coded in the same manner as described above for bifaces. The maximum dimension of each uniface was measured to the nearest millimeter.

Uniface type was recorded as one of the following: edge modified flake (EMF), scraper, burin, graver, denticulate, notched flake, or gouge. Unifaces that were classified as EMF $(n=329)$ displayed modification through use or by intentional flaking. If the uniface was flaked, the edges were not altered drastically to change the general morphology of the original flake. In contrast, scrapers were classified on the basis of drastic intentional flaking on one or more edges of the uniface. Unifaces coded as scraper $(n=39)$ had intensively worked edges that involved a significant change in flake morphology. Denticulates $(n=12)$ were identified on the basis of serrated, teeth-like edges of two or more consecutive undulating "teeth." Notched flakes $(n=43)$, although similar to the troughs of the 


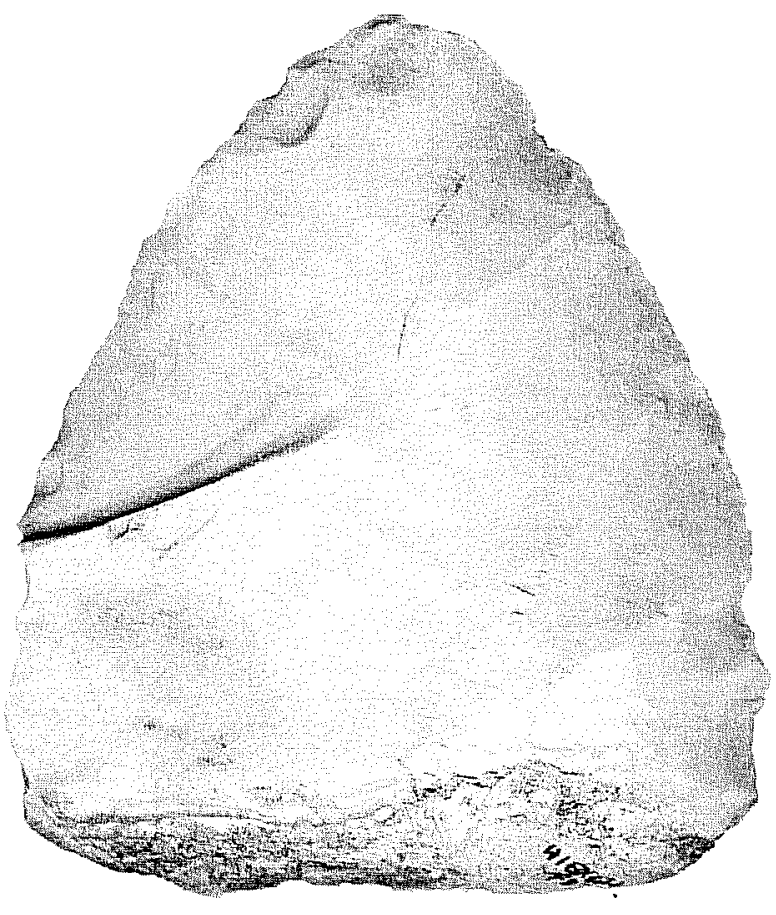

a

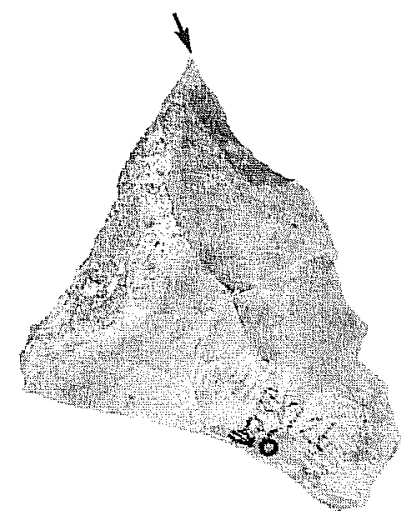

C

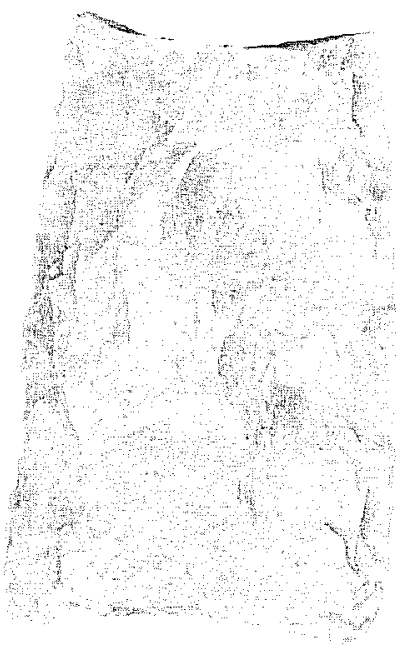

b

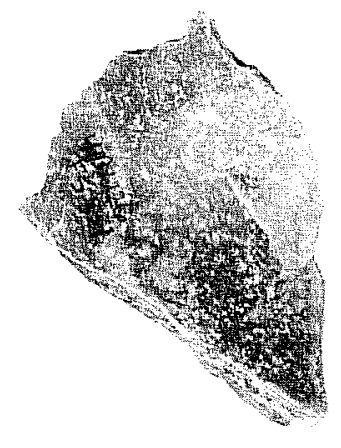

d

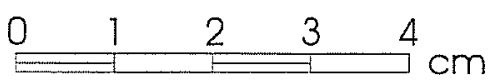

Figure 8-9. Bifaces and unifaces. a: Butted knife; b: San Gabriel biface; c: burin, arrow indicates direction of burin blow; d: graver. 
Table 8-1. Biface Grain Size, Cortex, Burning, and Average Length by Reduction Stage

\begin{tabular}{|c|c|c|c|c|c|c|c|}
\hline & & & \multicolumn{4}{|c|}{ Reduction S tage } & \multirow{2}{*}{ Total } \\
\hline & & & Early & Middle & Late & Indeterminate & \\
\hline \multirow{5}{*}{ 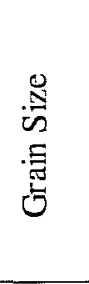 } & \multirow{2}{*}{ Coarse } & $\#$ & 4 & 5 & 17 & 0 & 26 \\
\hline & & $\%$ & 9.8 & 12.8 & 15.2 & & \\
\hline & \multirow{2}{*}{ Fine } & $\#$ & 37 & 34 & 95 & 1 & 167 \\
\hline & & $\%$ & 90.2 & 87.2 & 84.8 & 100 & \\
\hline & \multicolumn{2}{|c|}{ Total } & 41 & 39 & 112 & 1 & 193 \\
\hline \multirow{5}{*}{$\frac{\mathfrak{J}}{\tilde{J}}$} & \multirow{2}{*}{ Absent } & $\#$ & 2 & 22 & 107 & 1 & 132 \\
\hline & & $\%$ & 4.9 & 56.4 & 95.5 & 100.0 & \\
\hline & \multirow{2}{*}{ Present } & $\#$ & 39 & 17 & 5 & 0 & 61 \\
\hline & & $\%$ & 95.1 & 43.6 & 4.5 & & \\
\hline & \multicolumn{2}{|c|}{ Total } & 41 & 39 & 112 & 1 & 193 \\
\hline \multirow{5}{*}{ 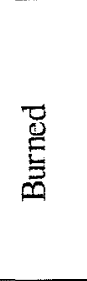 } & \multirow{2}{*}{ No } & $\#$ & 37 & 34 & 94 & 1 & 166 \\
\hline & & $\%$ & 90.2 & 87.2 & 83.9 & 100.0 & \\
\hline & \multirow{2}{*}{ Yes } & $\#$ & 4 & 5 & 18 & 0 & 27 \\
\hline & & $\%$ & 9.8 & 12.8 & 16.1 & & \\
\hline & Total & & 41 & 39 & 112 & 1 & 193 \\
\hline \multirow{3}{*}{ 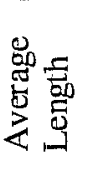 } & \multicolumn{2}{|l|}{ Coarse } & 79.8 & 56.0 & 74.5 & na & 74.8 \\
\hline & \multicolumn{2}{|l|}{ Fine } & 75.7 & 74.5 & 62.9 & 85.0 & 72.4 \\
\hline & \multicolumn{2}{|l|}{ Total } & 76.3 & 73.5 & 65.4 & 85.0 & 72.7 \\
\hline
\end{tabular}

Table 8-2. Frequency and Average Length of Bifaces by Cortex and Grain Size

\begin{tabular}{|c|c|c|c|c|c|c|c|c|}
\hline & \multicolumn{5}{|c|}{ Cortex } & \multicolumn{3}{|c|}{ Average Length } \\
\hline & \multicolumn{2}{|c|}{ Absent } & \multicolumn{2}{|c|}{ Present } & \multirow{2}{*}{ Total } & \multicolumn{2}{|c|}{ Cortex } & \multirow{2}{*}{ Tota } \\
\hline & \# & $\%$ & \# & $\%$ & & Absent & Present & \\
\hline Coarse & 22 & 84.6 & 4 & 15.4 & 26 & 70.8 & 79.8 & 74.8 \\
\hline Fine & 110 & 65.9 & 57 & 34.1 & 167 & 65.5 & 76.4 & 72.4 \\
\hline Total & 132 & & 61 & & 193 & 66.5 & 76.7 & 72.7 \\
\hline
\end{tabular}

denticulate, are not normally consecutive on unifacial flakes. Most flakes are single notched flakes. They are created by the repeated removal of flakes from an uniface edge. Unifaces coded as burin $(n=1)$, graver $(n=1)$, and gouge $(n=2)$ are discussed below in the formal unifacial tools.
Flake type was coded for all of the complete unifacial flakes. These categories are as follows: normal $(\mathrm{n}=133)$, biface thinning $(\mathrm{n}=126)$, uniface $(\mathrm{n}=0)$, notching $(n=0)$, sequent $(n=3)$, and indeterminate flakes $(n=165)$. Definitions of the flake types are further discussed in the debitage analysis section below. 
Four formal unifacial tools were recovered from 41BX126. Of these, only one graver was thermally altered. Each of the unifacial tools is discussed below in detail.

\section{Burins}

Burins are small to large tools made on flakes, blades, bifaces, projectile points, spokeshaves, cores, and scrapers. Burins are made by removing single or multiple parallel-sided flakes (Davis 1991). This flake removal creates a narrow chisel edge with micro-flake scars. Burins may have many functions, as Giddings (1964:211) indicates, "burin implies a group of instruments made by a common technique; it does not imply equivalence of function."

Burins are often called gravers and were used for working wood, bone, leather, stone, and splitting reed for basketry (Epstein 1960:96). Burin distribution is very broad across Texas. They range in age from Paleoindian to Late Prehistoric.

One burin (Figure 8-9c) was found during the 1995 excavations in BHT M back dirt. The burin was made on a unifacially modified flake. Some cortex remains on the dorsal side of the flake. The burin was created from one long narrow burin spall removal and sharpened by retouch. The opposite edge of the burin was intensively modified with many flake removals. Measurements for the burin are as follows: maximum length $=49 \mathrm{~mm}$, maximum width $=34 \mathrm{~mm}$, maximum thickness $=9 \mathrm{~mm}$.

\section{Gravers}

Two gravers - one unifacial and one bifacial-were recovered during the 1995 and 1997 excavations. The unifacial graver (Figure 8-9d) was recovered from TU 15, Level 5. The graver was made on a broken modified flake. Cortex remains on the dorsal side and craze marks indicate thermal alteration of the tool. The protrusion is small, but carefully worked along the edges. Measurements for this specimen are as follows: maximum length $=42 \mathrm{~mm}$, maximum width $=27 \mathrm{~mm}$, and maximum thickness $=20 \mathrm{~mm}$.

\section{Gouges}

Three gouges were recovered from the 1995 excavation. Of these gouges, only one was unifacial (see the Bifacial section for descriptions of the others). Specimen three was recovered from TU C, Level 7 (Figure $8-10 a)$. The gouge is subtriangular in form and unifacially worked. The proximal end has two hinge fractures that may have occurred during use. The lateral edges are slightly convex with several step fractures. The bit is concave with rounded edges. A series of step fractures on the ventral side of the bit indicate heavy use of the gouge. Measurements for the gouge are as follows: bit angle $=38$, maximum length $=69$ $\mathrm{mm}$, maximum width $=41 \mathrm{~mm}$, and maximum thickness $=14 \mathrm{~mm}$.

\section{Clear Fork Tool}

Ray $(1938,1941)$ identified a series of tool forms he called Clear Fork gouges and first described them on the basis of specimens found along the Clear Fork of the Brazos River in the Abilene region of central Texas. He considered the "gouges," along with his "Clear Fork Darts 1 and 2" (Nolan points) as especially diagnostic of his Clear Fork Culture Complex and speculated that they functioned as digging, woodworking, and hideworking implements (Ray 1938). Ray later withdrew his suggestion that they had been used to work hides, but added that they might have functioned as atlat weights (Ray 1959).

The Clear Fork tool in its "classic form" is characterized by a triangular to subtriangular outline, generally with straight to excurvate lateral edges, and a rounded or pointed proximal end. The tools frequently exhibit a dorsal ridge, with maximum thickness generally near the distal end, which is characterized by a sharply beveled bit. The bit may be convex, straight or slightly concave, with a working-edge angle ranging from 60 to 75 in most cases. As with the Guadalupe tool, many Clear Fork tools are almost pyramidal in cross section (Turner and Hester 1993:246-249). Ray (1941) sorted the Abilene area Clear Fork tools into six types, types 1 and 2 being the bifacial and unifacial versions, respectively, of the "classic" triangular form. His classification has been partially validated, in that the 


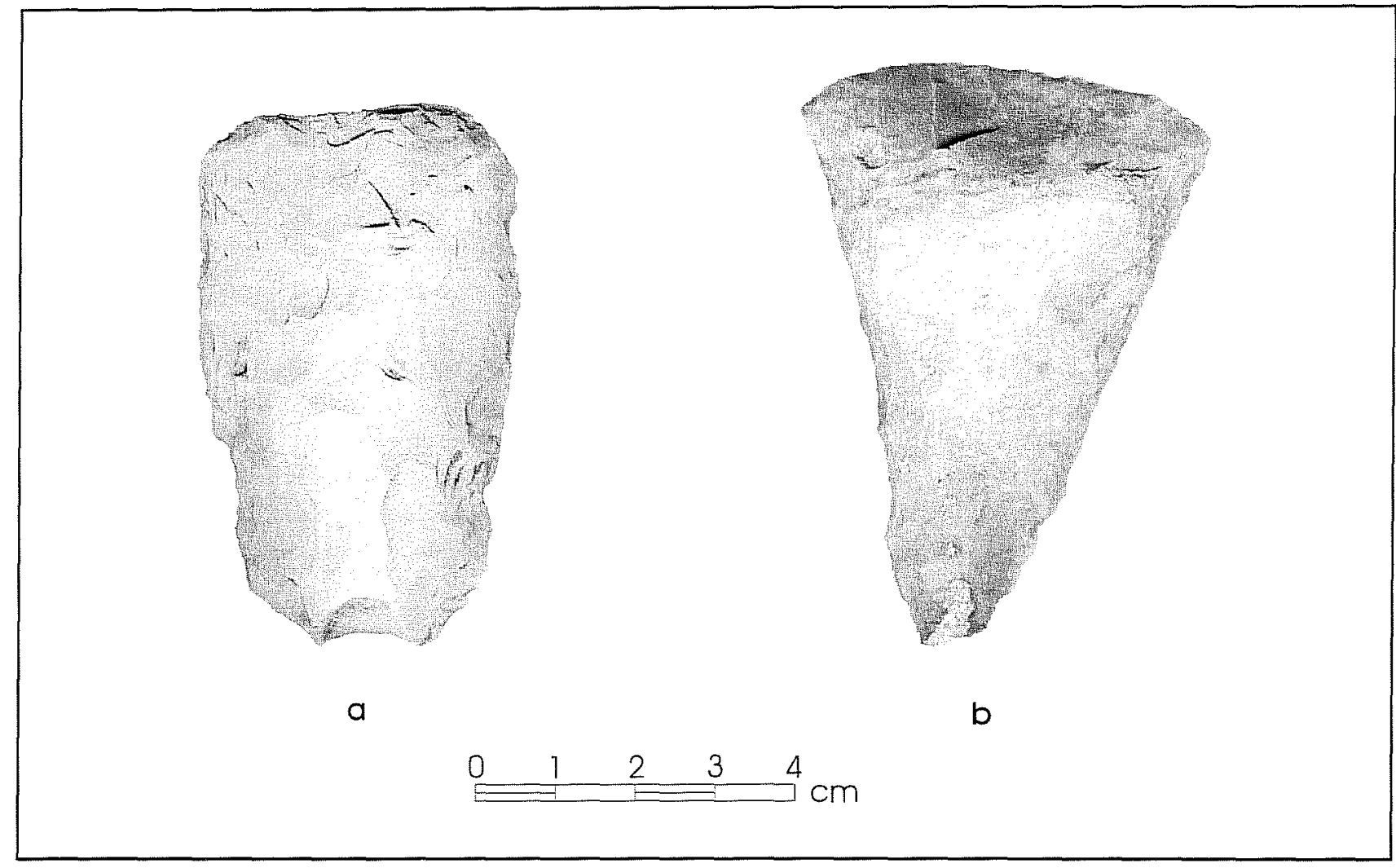

Figure 8-10. Miscellaneous artifacts. a: gouge; b: Clear Fork tool.

triangular bifacial type 1 is generally accepted as one form and types 2 and 3 (a relatively long, narrow unifacial tool) are grouped as second form. Other more variable forms, some with subrectangular outlines, either receive individual treatment or are lumped as "miscellaneous" (Black and McGraw 1985:139, 142; Hall et al. 1982:338).

Functional analyses support the supposition that Clear Fork tools were employed for a variety of tasks, including manufacturing and maintaining wooden implements, hide scraping, and working hard materials such as bone. Among the earliest to bring experimental methods to bear on the question was Howard (1973), who examined use wear patterns on 25 archaeological specimens, then used them in hafted and unhafted modes to scrape, plane, and chop wood. He concluded that the most efficient modes of hafting were the end socket and T-haft, although for some purposes the tools could be used unhafted as well. Howard also concluded that Clear Fork tools were efficient woodworking instruments most probably used to plane or shave wood, although they were probably used for a variety of woodworking tasks. For Howard, they also seemed efficacious in felling trees, although Hudler (Kay et al. 1998) found that the flaking pattern on experimental Clear Fork tool bits compared with archaeological specimens did not suggest uses involving heavy percussion. Hester et al. (1973) also suggested that Clear Fork tools in south Texas were woodworking implements, as did Chandler (1974), who conducted a use-wear analysis and limited experimental study on a series of Clear Fork tools from Falcon Reservoir. He concluded that the tools were used in a pushing fashion on a hard, unyielding surface such as wood, a finding supported by Shiner (1975).

More recent replication studies in conjunction with lowand high-power magnification use-wear analysis of 49 Clear Fork tools recovered from the Wilson-Leonard site and several from other Texas sites suggest that while most Clear Fork tools were used to manufacture and maintain wooden implements, many individual tools in this category were clearly used on other hard 
materials such as bone or antler, as hide defleshers, or perhaps on several different materials at different times. (Hudler, in Kay et al. 1998)

Clear Fork tool forms have an apparently continuous distribution from northeastern Mexico and the south Texas Coastal Plain, through central Texas along the Balcones Escarpment and into south-central Oklahoma (Hester et al. 1973:90; Shiner 1975:186). Forms that are perhaps related have been studied in Missouri and elsewhere in the Southwest and Midwest (Black and McGraw 1985:138). Initially seen as a Paleoindian and Early Archaic phenomenon, Clear Fork tools have been recovered from Archaic and Paleoindian contexts, although not in post-Archaic components. Clear Fork tools have been associated with Late Paleoindian Golondrina points ranging from $9180-9020$ в.P. (Epstein 1969; Hester 1979). Bousman (1997) documents the occurrence of Clear Fork tools in the Wilson component between 10,000 and 9,500 B.P. at the Wilson-Leonard Site. Ray's (1941) initial observations that the larger unifacial Clear Fork tools came from the earlier deposits have largely been supported. In the Choke Canyon Reservoir area, Hall (Hall et al.1982:340,342) found that larger Clear Fork tools predominated in Early Archaic sites. Hester (1995) associates the Clear Fork tool with the "Early Basal-Notched Horizon" ca. 55504950 B.P. The variability in form and inferred function, and the wide temporal and spatial distribution of this interesting implement suggested to Black and McGraw (1985:139) that the Clear Fork tool is not one single type but is rather a general tool form employed for a variety of purposes in many places and times.

One Clear Fork tool (Figure 8-10b) was found at the Culebra Creek site during the 1995 excavations in TU $\mathrm{C}$, Level 8. The tool is triangular with a beveled convex bit and was unifacially flaked. The bit angle measures $61^{\circ}$. A small amount of cortex remains on the dorsal surface of the proximal end. There are ripple scars on the ventral side which suggest that the tool was flaked from the upper right of the bit. This appears on the axis on the right side of the bit.

In plan view, lateral trimming is regular on the right side with step fractures only near the bit. Deep flake scars appear on the left side with final retouching and end in a step or hinge termination. The bit was resharpened and has very few step fractures. A moderately flat flake may have been removed from the ventral side during use. This flake terminated in a hinge fracture. Measurements for the tool are as follows: maximum length $=73 \mathrm{~mm}$, maximum width $=53 \mathrm{~mm}$, bit thickness $=17 \mathrm{~mm}$, and width of bit $=53 \mathrm{~mm}$.

\section{Nondiagnostic Uniface Tool Types}

Analysis of unifacial tools by type of flake on which they were made again indicates an overwhelming preference for fine-grained raw material at 41BX126, although this was not necessarily a criterion by which flakes were specifically selected for unifacial tool production, since fine-grained materials were apparently preferred for all tools at the site and such flakes would have been readily available as a by-product of biface and core tool manufacture (Table 8-3).

It is clear also that normal and biface thinning flakes were the preferred blanks on which unifacial tools were made, although two-thirds of the tools made on normal flakes have cortex whereas almost two-thirds of the unifacial tools on biface thinning flakes lack cortex (Table 8-3). The preferences appear to be less marked in the selection of indeterminate and sequent flakes.

Evidence of burning is present on only a small proportion of tools made on biface thinning flakes, while 20 30 percent of the unifaces made from other types of flakes have been burned (Table 8-3). Whether some of these flakes were subjected to thermal alteration at some point in the lithic reduction sequence that produced them does not seem to be a factor here, especially considering the lack of burning exhibited by the tools on biface thinning flakes. A differential in function and locus of employment may be at work, although why tools on indeterminate, normal, and sequent flakes, especially, should have a higher likelihood of burning is unclear. Possibly those flake types were deemed more suitable for production of expedient tools or were more readily available for use near hearth or rock ovens.

One answer may lie in the dimensions of tools produced on the various types of flakes. Unifacial tools made on normal and indeterminate flakes tend on average to be larger in their maximum dimension, especially those 
that exhibit cortex (Table 8-3). As we have seen above, the preponderance of tools made on these flakes have cortex, indicating a selection for larger size with cortex. Sequent flake tools with cortex also tend to be larger than those without, although we have also seen above that most of these tools lack cortex. Perhaps it is the unique contours of the sequent flake and a cortex backing rather than size that are the selection factors here. This combination of features may have had particular utility in plant food preparation around fires. As for tools on biface thinning flakes, those possessing cortex also tend to be longer than those lacking cortex, though they are slightly shorter than those made on normal and indeterminate flakes. As noted above, however, the great majority of tools made on biface thinning flakes lack cortex, indicating that larger size and cortex are not the selection factors for these tools, and they may have quite different functions, as suggested by the differences in burning occurrence.

\section{Cores}

Cores are primary lithic masses that have multiple flake removals from one or more direction. Cores have faceted platforms and bear negative scars from flake removals. Measurement of cores allow for comparisons between core size and size of flakes recovered.

Fifty-two cores were recovered from the excavations at $41 \mathrm{BX} 126$. For each specimen the following attributes were noted: raw material type, raw material grain quality, burning, presence or absence of cortex, length, width, and thickness. As with the bifaces and unifaces, all cores were measured to the nearest millimeter. Core measurements were taken to compare mean size of flakes with the mean length of the cores.

Table 8-3. Frequency of Uniface Tool Blank Types by Grain Size, Cortex, and Burning; Average Length by Cortex and Tool Blank Types

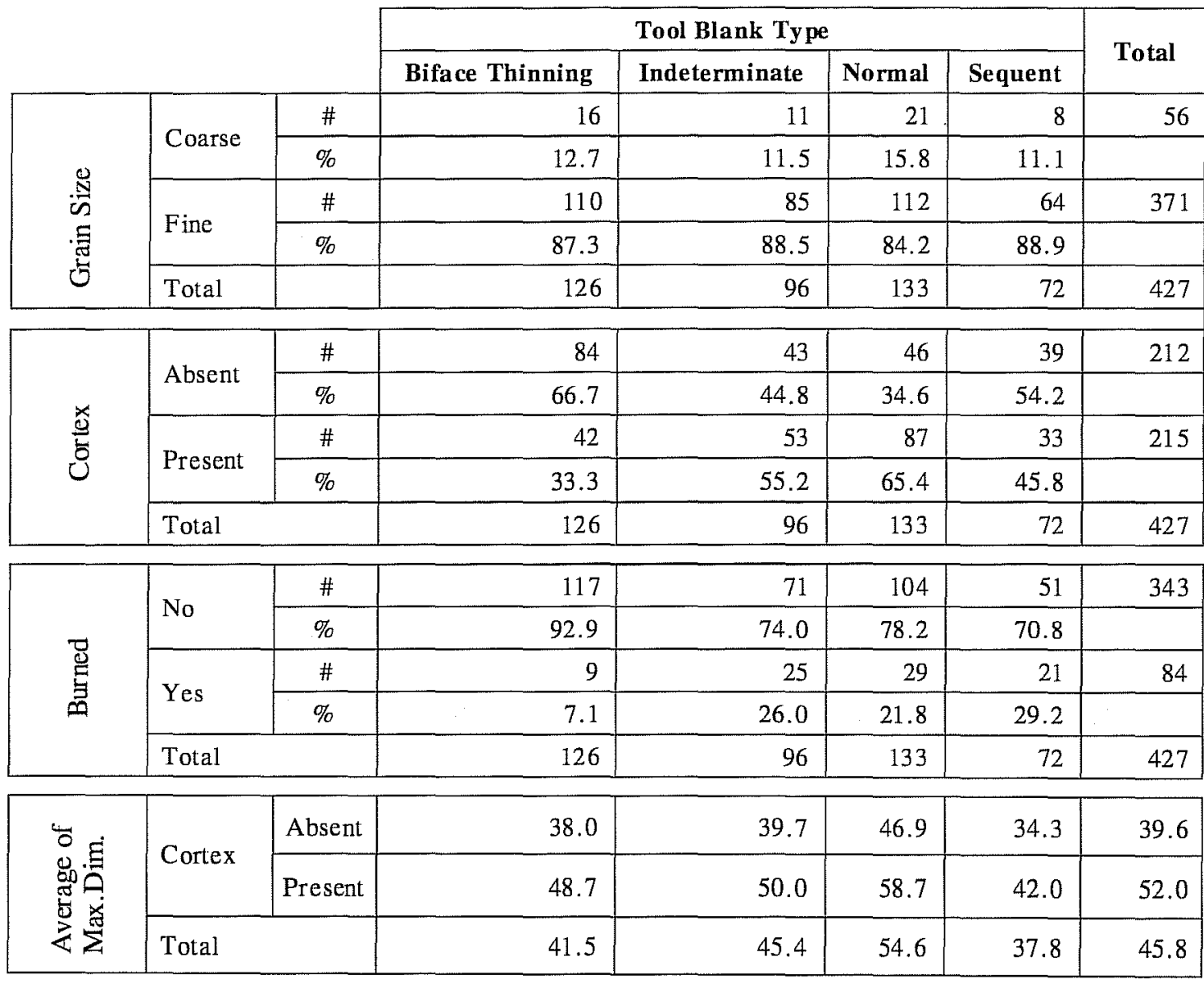


The first comparison in Table 8-4 indicates a selection bias for fine-grained materials, since 61.6 percent of the cores in the sample were made of fine-grained chert. The favored cores are smaller and thus were probably exploited more intensively than the coarsegrained cores, not withstanding that a larger percentage of the coarse-grained specimens (25 percent vs. 9.3 percent) had been reduced to the point that no cortex remained.

However, the second comparison (Table 8-4), which shows that cores of fine-grained chert tend to be smaller than specimens made of coarse-grained chert regardless of the presence or absence of cortex, clearly suggests that cores made of a finer fabric tend to be exploited more intensively and are less likely to be discarded before all cortex is removed.

The third comparison in Table 8-4, between burned and unburned cores, shows little difference on a percentage basis between cores with cortex and cores without. That would indicate that burning, or even thermal treatment, is not a factor in core production/ reduction, and may rather be an accident of post-discard experience.

\section{Choppers}

Choppers are simply cobbles that have multiple flake removals off of one or more end. Cortex often covers the proximal end and was used for gripping the chopper. The distal edge is rough and bifacially worked. Edges of the chopper are sinuous and have several step fractures that derive from impact or crushing. The same attributes noted for cores were used for choppers. The attributes included: raw material type, raw material grain quality, burning, presence or absence of cortex, length, width, and thickness. Again, all measurements were taken to the nearest millimeter.

Two choppers were retrieved from excavations at the Culebra Creek site. Specimen 1 was excavated from TU 3, Level 3. The chopper was bifacially worked on all edges. Some cortex remains on an interior section on one side. The specimen is battered and has step

Table 8-4. Cortex Frequencies by Grain Size and Burning on Cores; Average Length of Cores by Cortex and Grain Size

\begin{tabular}{|c|c|c|c|c|c|}
\hline & & & \multicolumn{2}{|c|}{ Cortex } & \multirow{2}{*}{ Total } \\
\hline & & & Absent & Present & \\
\hline \multirow{5}{*}{ 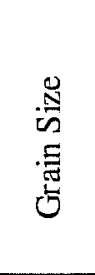 } & \multirow{2}{*}{ Coarse } & $\#$ & 5 & 15 & 20 \\
\hline & & $\%$ & 62.50 & 34.10 & \\
\hline & \multirow{2}{*}{ Fine } & $\#$ & 3 & 29 & 32 \\
\hline & & $\%$ & 37.50 & 65.90 & \\
\hline & \multicolumn{2}{|l|}{ Total } & 8 & 44 & 52 \\
\hline \multirow{5}{*}{$\begin{array}{l}.000 \\
. \\
.5 \\
0\end{array}$} & \multirow{2}{*}{ No } & $\#$ & 7 & 37 & 44 \\
\hline & & $\%$ & $87.50 \%$ & $84.10 \%$ & \\
\hline & \multirow{2}{*}{ Yes } & $\#$ & 1 & 7 & 8 \\
\hline & & $\%$ & $12.50 \%$ & $15.90 \%$ & \\
\hline & \multicolumn{2}{|l|}{ Total } & 8 & 44 & 52 \\
\hline \multirow{3}{*}{ 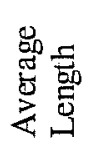 } & \multicolumn{2}{|l|}{ Coarse } & 59.4 & 82.5 & 76.8 \\
\hline & \multicolumn{2}{|l|}{ Fine } & 58.3 & 72.9 & 71.5 \\
\hline & \multicolumn{2}{|l|}{ Total } & 59 & 76.2 & 73.5 \\
\hline
\end{tabular}


fractures on several of the edges. The second specimen was from TU E, Level 1. This specimen was bifacially worked on one edge. A cortex handle remains on the proximal end of the chopper. Several step fractures indicate crushing or impacts on the bifacial edge of the chopper.

\section{Incised Stone}

One incised and abraded stone (Figure 8-11) was found in 1997 at the Culebra Creek site in TU 4, Level 3. The compressed sandstone fragment measures $96 \mathrm{~mm}$ in length, $61 \mathrm{~mm}$ in width, and $22 \mathrm{~mm}$ thick. The stone is incised on a concave plane which is dark red in color. The underside of the stone distinctly turns from dark red to a light brown color.

In plan view, the incisions run perpendicular to an area that is $83 \mathrm{~mm}$ in maximum length. Incision marks are unidirectional and range from $25-40 \mathrm{~mm}$ in length. Abrading marks are random and are shorter than the incision marks. The surface has also been ground smooth.

In contrast, three stones with convex surfaces have been found nearby at the Panther Springs Creek site. Three limestone cobbles with parallel incised lines were described in the site report. Black and McGraw (1985:179) hypothesized that the cobbles were used as "texture anvils" (to texturize leather or bark) or as shaft straighteners. Because the stone from the Culebra Creek site is concave in nature, a different function is suggested for this stone. The incised stone is considered to be an abrading stone which may have been used to shape bone awls (as deduced from the tapering and size of the incisions). Bone awls may have later been ground laterally across the short diameter of the sandstone fragment.

\section{Debitage Analysis}

Two types of analysis were made on unmodified flakes from the Culebra Creek site. Over 59,318 pieces were individually size sorted and counted in a preliminary debitage analysis. This analysis was made on all debitage recovered in 1993, 1995, and 1997. Each piece was size sorted by a concentric circle. Debitage fell into the following size categories: $0.5 \mathrm{~cm}, 1 \mathrm{~cm}, 2 \mathrm{~cm}$, $3 \mathrm{~cm}, 4 \mathrm{~cm}, 5 \mathrm{~cm}, 6 \mathrm{~cm}, 7 \mathrm{~cm}, 8 \mathrm{~cm}, 9 \mathrm{~cm}$, and $10 \mathrm{~cm}$. Debitage in the two smallest size categories (i.e., 0.5 $\mathrm{cm}$ and $1 \mathrm{~cm}$ was analyzed in one-half centimeter increments, while debitage in the remaining size categories (i.e., $2 \mathrm{~cm}$ through $10 \mathrm{~cm}$ ) was analyzed in one centimeter increments. Debitage did not exceed $10 \mathrm{~cm}$ in size.

The second type of analysis was made only on the whole flakes $(n=1,517)$ from the block excavations in Area B, including TU 12 and Price's TU C. For each complete flake, the following attributes were recorded: material type, grain size, burning, size group, dorsal cortex, and flake type. Flakes were assigned to a predefined flake type. These types include: normal, biface thinning, uniface, notching, and sequent flakes. These are defined below.

Normal Flakes: $(\mathrm{n}=707)$

Normal flakes are defined by single-multifaceted platforms. Terminations for this flake type may be feathered, hinge, or overshot.

Bifacial Thinning Flakes: $(n=720)$

These flakes are generally tertiary flakes removed by soft percussion. They are characterized by a multifaceted platform and lipping that occurs on the ventral side of the platform. Biface thinning flakes have a large number of dorsal flake removal scars.

Uniface Flakes: (n=49)

Uniface flakes are usually no bigger than two centimeters. They are characterized by a singlefaceted platform with a double curve profile. Step fracturing may occur on the dorsal surface of the flake.

Notching Flakes: $(\mathrm{n}=31)$

These are flakes that are created during the notching of projectile points or other notched tools. The flakes have distinctive U-shaped platforms and scalloped dorsal surfaces. Like uniface flakes, notching flakes are small. 

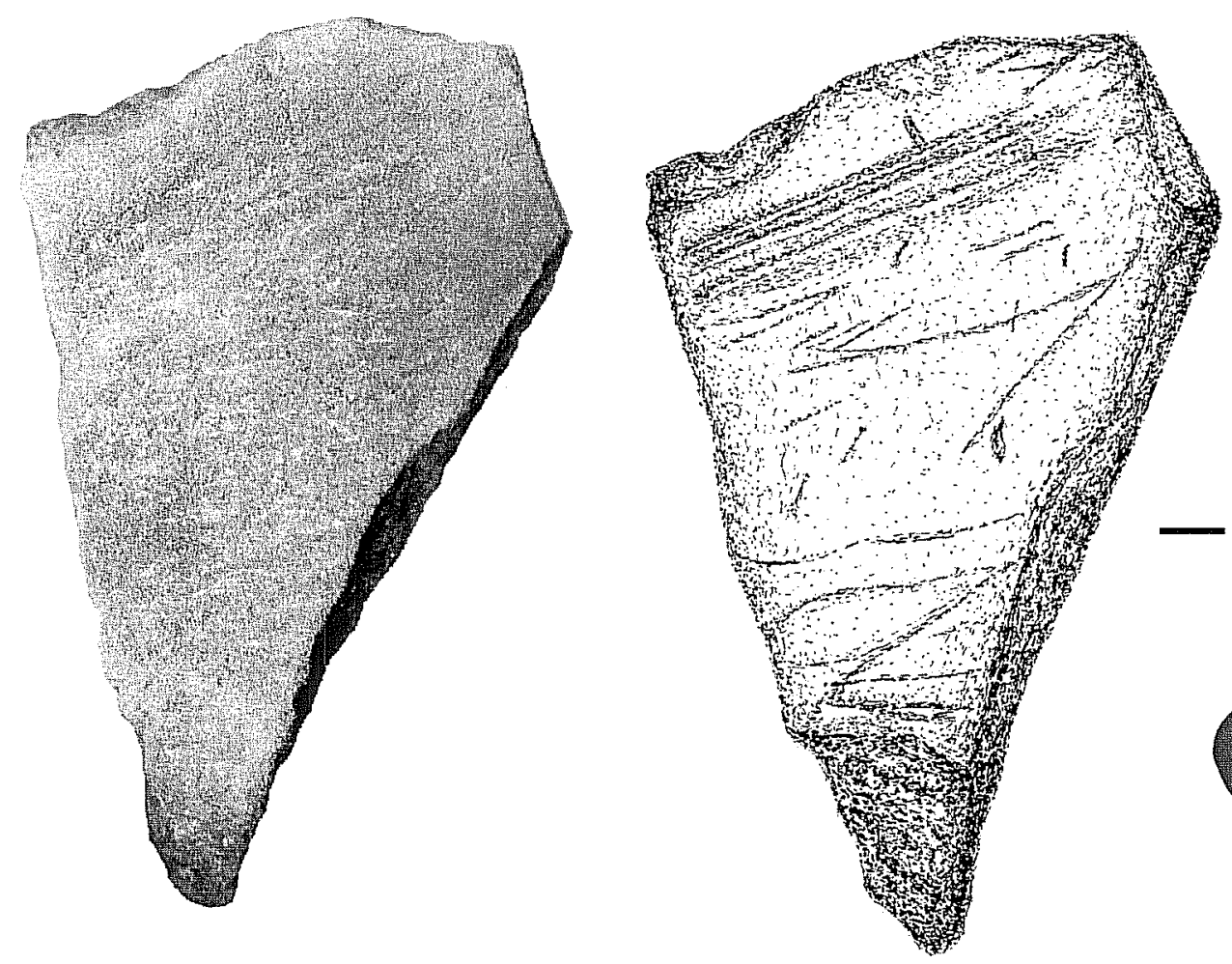

A
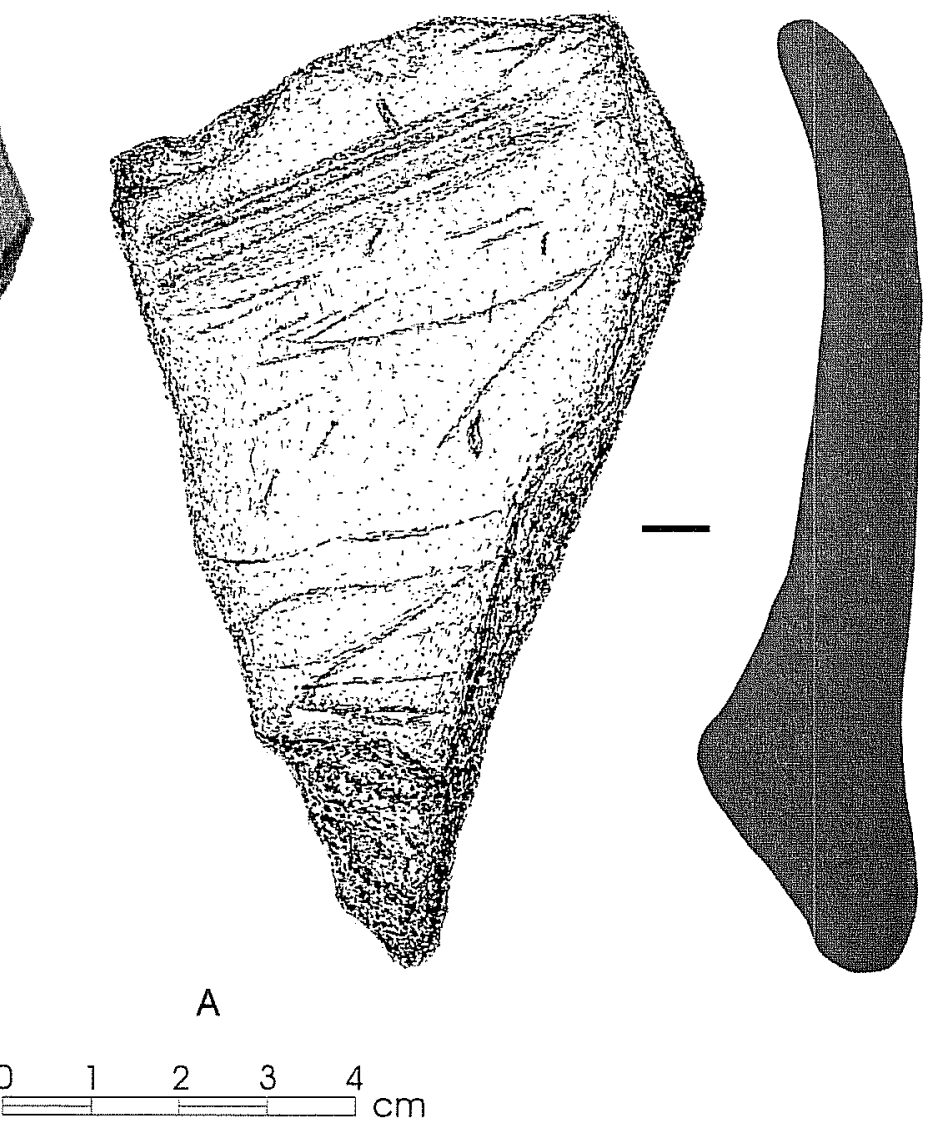

Figure 8-11. Incised stone.

Sequent Flakes: $(n=9)$

These flakes can be recognized by a doublenegative bulb centered above or on the platform with a tabular surface. Sequent flakes are a product of a particular type of core technology, but without a series of them, they are most likely accidental in nature (Jelinek et al. 1971).

\section{Statistical Analysis of Tools and Debitage}

The numerical distribution of major tool and artifact classes by area at 41BX126 is presented in Table 8-5. These numbers represent all recognized and analyzed tools from all three investigation efforts. We assume, unlike the collection of lithic debitage (see Chapter 7) that little or no size selection bias existed in the collection of tools and thus tools from all three investigations were included in this analysis. Some distinct differences are evident.

First, the assemblage with the highest percentages of bifaces, choppers, cores, and projectile points is in Area A. Area $\mathrm{C}$ has the highest percentage of unifaces. These differences may indicate that certain variations in artifact class discard exists among the various areas. If Area $A$ is viewed primarily as a Late Archaic occupation, Area B is seen as a mix of Middle and Late Archaic occupations, and Area $C$ is viewed as resulting from Early to Late Archaic occupations then 
some distinctions may exist in the use of the site through time, unfortunately this pattern cannot be related to any documented shift in subsistence patterns. We should add that it is unlikely that the transportation of sediments and artifacts discussed in Chapter 7 would affect the numerical representation of tools and other artifacts among the three site areas.

\section{Area B}

The distribution of tools and other significant artifact classes in the subareas of Area B are presented in Table 8-6. The observant reader will note that the total for Area B in Table 8-5 does not match the total in Table 8-6. This is because a small number of artifacts were collected, primarily off the surface, in Area B that could not be assigned to one or another subarea. Again, some distinctive patterns are present. For example, biface and projectile point percentages are highest in the core of the midden. However, the small sample size of tools in the core makes these percentages unreliable. Otherwise, the framework has the highest percent of bifaces and the periphery has the highest percent of projectile points. The highest frequency of cores also occurs in the periphery which is also the only area where any ground stone was found. The highest percentage of unifaces comes from the block excavation, but it is unclear, at this point, if the high frequency of unifaces is contemporary with or predates the midden occupations. Considering the arguments presented in Chapter 7 (midden construction and use was accompanied by human transportation of sediments and artifacts, and the redistribution of these sediments and artifacts by erosion occurred after site abandonment), it seems unwarranted to make any behavioral interpretations of these differences.

\section{Block Excavation}

The anthropogenic and geogenic arguments mentioned above and discussed in detail in Chapter 7 would not apply to consideration of the tools from the block excavation. In this excavation a vertical sequence of materials was collected and can be analyzed in behavioral terms. Through time, in general, there is a decline in the frequency of bifaces and cores (Table 8-7). The highest frequency of projectile points occurs in the Nolan component. Also uniface percentages are high in, but especially above the Nolan component. The Nolan component assemblage has one of the lowest percentages of cores on the site (only the core of the midden is lower), and this seems to suggest that knapping activities were focused on the production of bifaces or tool maintenance.

The patterns in chipped stone tool production can be investigated by an analysis of lithic debitage from the block excavation. In Table 8-8 the frequency of flake types among the different analytical units in the block excavation is presented. The Nolan component contains the highest frequency of biface thinning flakes, but the lowest frequency of normal flakes, while the reverse pattern exists in the flakes recovered above the Nolan component.

Table 8-5. Number of Tools and Major Artifact Classes by Area

\begin{tabular}{|l|c|c|c|c|c|c|c|}
\hline \multirow{2}{*}{ Ty pe } & \multicolumn{2}{|c|}{ A } & \multicolumn{2}{c|}{ B } & \multicolumn{2}{c|}{ C } & Total \\
\cline { 2 - 8 } & $\#$ & $\%$ & $\#$ & $\%$ & $\#$ & $\%$ & $\#$ \\
\hline Biface & 15 & 38.5 & 144 & 24.7 & 7 & 10.9 & 166 \\
\hline Chopper & 1 & 2.6 & 0 & & 1 & 1.6 & 2 \\
\hline Core & 4 & 10.3 & 40 & 6.9 & 5 & 7.8 & 49 \\
\hline Ground Stone & 0 & & 1 & 0.2 & 0 & & 1 \\
\hline Projectile Point & 5 & 12.8 & 52 & 8.9 & 5 & 7.8 & 62 \\
\hline Uniface & 14 & 35.9 & 345 & 59.3 & 46 & 71.9 & 405 \\
\hline Total & 39 & & 582 & & 64 & & 685 \\
\hline
\end{tabular}


Table 8-6. Number of Tools and Major Artifact Classes by Subarea in Area B

\begin{tabular}{|c|c|c|c|c|c|c|c|c|c|}
\hline \multirow{2}{*}{ Type } & \multicolumn{2}{|c|}{ Block Excavation } & \multicolumn{2}{|c|}{ Core } & \multicolumn{2}{|c|}{ Framework } & \multicolumn{2}{|c|}{ Periphery } & \multirow{2}{*}{$\frac{\text { Total }}{\#}$} \\
\hline & $\#$ & $\%$ & $\#$ & $\%$ & $\#$ & $\%$ & $\#$ & $\%$ & \\
\hline Biface & 49 & 19.4 & 17 & 47.2 & 34 & 28.8 & 43 & 25.0 & 143 \\
\hline Core & 14 & 5.6 & 1 & 2.8 & 9 & 7.6 & 16 & 9.3 & 40 \\
\hline Ground Stone & 0 & & 0 & & 0 & & 1 & 0.6 & 1 \\
\hline Projectile Point & 14 & 5.6 & 9 & 25.0 & 5 & 4.2 & 22 & 12.8 & 50 \\
\hline Uniface & 175 & 69.4 & 9 & 25.0 & 70 & 59.3 & 90 & 52.3 & 344 \\
\hline Total & 252 & & 36 & & 118 & & 172 & & 578 \\
\hline
\end{tabular}

Assuming that normal flakes were struck from cores, uniface flakes were removed from unifaces, and that biface thinning flakes came off of bifaces or projectile points, the associated ratio between debitage and artifact can be compared. Table 8-9 lists the ratio of normal flakes to cores, uniface flakes to unifaces, and biface thinning flakes to bifaces plus projectile points. In the case of normal flakes/cores and biface thinning flakes/bifaces-projectile points, the Nolan Component has the highest number of flakes per artifact. This suggests that both cores and bifaces and points were discarded at lower rates in the Nolan Component as compared to occupations above and below. However the reverse is true for unifaces. The implication is that bifaces and points as well as cores were discarded elsewhere, either on-site or off-site, by the inhabitants who created the Nolan Component. Unifaces, on the other hand, appear to be discarded more frequently in the area of manufacture or repair in the Nolan Component when compared to the earlier and later occupations.

\section{Historic Artifacts}

Thirty-nine historic artifacts were recovered from the 1993, 1995, and 1993 excavations at the Culebra Creek site. With the exception of an early twentieth-century crock lid, the presence of the Historic artifacts indicate casual littering of the roadside and floodplain areas at the juncture of Loop 1604 and Culebra Creek. The historic artifacts have been divided into broad categories of ceramic $(n=2)$, glass $(n=21)$, metal $(n=9)$, and miscellaneous artifacts $(n=7)$. These artifacts are described individually below.

Table 8-7. Tool Frequencies in Block Excavation

\begin{tabular}{|l|c|c|c|c|c|c|c|}
\hline \multirow{2}{*}{ Type } & \multicolumn{2}{|c|}{ Above Nolan } & \multicolumn{2}{c|}{ Nolan } & \multicolumn{2}{c|}{ Below Nolan } & Total \\
\cline { 2 - 8 } & $\#$ & $\%$ & $\#$ & $\%$ & $\#$ & $\%$ & $\#$ \\
\hline Biface & 23 & 17.0 & 18 & 19.1 & 8 & 34.8 & 49 \\
\hline Core & 8 & 5.9 & 4 & 4.3 & 2 & 8.7 & 14 \\
\hline Projectile Point & 5 & 3.7 & 8 & 8.5 & 1 & 4.3 & 14 \\
\hline Uniface Total & 135 & & 64 & 68.1 & 12 & 52.2 & 175 \\
\hline \multicolumn{2}{r|}{} & 99 & 94 & & 23 & & 252 \\
\hline
\end{tabular}


Table 8-8. Frequency of Flake Types in Block Excavation

\begin{tabular}{|c|c|c|c|c|c|c|c|c|c|c|c|}
\hline \multirow{2}{*}{ Component } & \multicolumn{2}{|c|}{ Biface Thinning } & \multicolumn{2}{|c|}{ Normal } & \multicolumn{2}{|c|}{ Notching } & \multicolumn{2}{|c|}{ Sequent } & \multicolumn{2}{|c|}{ Uniface } & \multirow{2}{*}{$\frac{\text { Total }}{\#}$} \\
\hline & $\#$ & $\%$ & $\#$ & $\%$ & $\#$ & $\%$ & $\#$ & $\%$ & $\#$ & $\%$ & \\
\hline Above Nolan & 265 & 39 & 373 & 54 & 18 & 3 & 4 & 1 & 26 & 4 & 686 \\
\hline Nolan & 288 & 54 & 222 & 41 & 8 & 1 & 4 & 1 & 13 & 2 & 535 \\
\hline Below Nolan & 76 & 47 & 78 & 48 & 2 & 1 & 1 & 1 & 5 & 3 & 162 \\
\hline Total & 629 & 45 & 673 & 49 & 28 & 2 & 9 & 1 & 44 & 3 & 1383 \\
\hline
\end{tabular}

\section{Ceramics}

Two ceramic fragments were excavated from the Culebra Creek site in 1993. The first specimen was recovered from TU 23 (a $50-x-50-\mathrm{cm}$ TU). The specimen is a stoneware crock lid fragment. A band of deep crimson Albany slip encircles the interior indentation of the lid. This crock lid type was probably manufactured by a local German community ca. 1900 (Anne A. Fox, personal communication 1997). The second ceramic fragment was excavated from TU 18, Level 1 . This specimen is a whiteware fragment with a blue glaze on the inside, and a fairly recent date for it is appropriate.

\section{Glass}

Three colors of glass were found at the Culebra Creek site: green $(n=3)$, clear $(n=5)$, and amber $(n=13)$. The proveniences are listed for each item below.
Three green bottle glass fragments were recovered during the 1993 and 1997 excavations. Specimen 1 was excavated in 1993 from TU 11. Specimens 2 and 3 were recovered in 1997 from TU 4, Level 1 and TU 6, Level 1.

Five fragments of clear bottle glass were excavated in 1993. Specimen 1 was from TU 11, Level 1. Specimens 2 and 3 are from TU 24, while specimen 4 came from TU 25. (All TUs were $50 \times 50 \mathrm{~cm}$.)

Thirteen fragments of amber glass bottle glass were recovered during the 1993 excavations. Four specimens were found in TU 24. Two specimens each were found in TU 11, Level 1, TU 18, Level 1, and TU 4, Level 1. One specimen was found in each of the following TUs: TU 2, Level 1, TU 12, Level 1, and TU 6, Level 1.

Table 8-9. Ratio of Normal Flakes to Cores, and Biface Thinning Flakes to Bifaces and Projectile Points

\begin{tabular}{|l|c|c|c|}
\hline \multicolumn{1}{|c|}{ Component } & $\begin{array}{c}\text { Ratio Normal } \\
\text { Flakes/Cores }\end{array}$ & $\begin{array}{c}\text { Ratio Uniface } \\
\text { Flake/Unifaces }\end{array}$ & $\begin{array}{c}\text { Ratio BT Flakes/ } \\
\text { Bifaces \& Points }\end{array}$ \\
\hline Above Nolan & 46.6 & 0.26 & 9.5 \\
\hline Nolan & 55.5 & 0.2 & 11.1 \\
\hline Below Nolan & 39 & 0.42 & 8.4 \\
\hline
\end{tabular}




\section{Metal}

Nine metal objects were recovered from the Culebra Creek site in 1993 and 1995. The items consist of a shell casing, fencing staples, tin can fragments, and bolts. These artifacts are described below.

One .38 caliber (Smith \& Wesson Special) casing was found by Price during his excavation in 1995. The shell casing was found in the backdirt of an indeterminable trench. This caliber is generally associated with law enforcement agencies (Logan 1959:127).

Three fencing staples were located at the Culebra Creek site. One was excavated from TU 1, Level 1 in 1993, and two more fencing staples were recovered in 1995 from TU C, Level 1 and TU D, Level 1.

Three tin can fragments were also found at 41BX126. One tin can fragment was recovered from TU D, Level 1 in 1995. Another two tin can fragments were found in TU 18, Level 1 during the 1995 excavations. The tin fragments were too small for diagnostic purposes.

Two bolts were found during the 1993 and 1997 excavations. The first specimen was found in TU 18, Level 1 (1993). The bolt was broken and had a hexagonal head measuring $20 \mathrm{~mm}$ ( 0.75 inches). The width of the threaded area measured $12 \mathrm{~mm}$ ( 0.5 inches). The second specimen was excavated in 1997 and came from TU 4, Level 2. This specimen also exhibits a hexagonal head which measures $11 \mathrm{~mm}$ ( 0.5 inches). The bolt measures $30 \mathrm{~mm}$ ( 1.2 inches) long.

\section{Miscellaneous Historic Artifacts}

Miscellaneous artifacts found at the Culebra Creek site include plastic fragments, a steak bone, and a celluloid fragment. These are described briefly below.

Five pieces of plastic were recovered from the 1993 and 1997 excavations. The first three specimens are clear and were excavated from TU 25 in 1993. Two other specimens are white plastic fragments from $\mathrm{TU}$ 9, Level 2 and TU 3, Level 3. Both were recovered from the 1997 excavation.
One steak bone fragment with machine saw markings was excavated from TU 12, Level 1 in 1995.

One fragment of celluloid with lettering was located in TU 6, Level 1 during the 1993 excavations. The fragment reads:

$$
\begin{aligned}
& \ldots \text { OMPANY } \\
& \ldots \text { tsburgh PA } 15222 \text { Stoc . . . }
\end{aligned}
$$

This item and the others described above are recent and are probably products of frequent littering events.

\section{Conclusions}

The analysis of artifacts demonstrates that the Middle and Late Archaic hunter-gatherers who occupied the Culebra Creek site, 41BX126, manufactured and maintained a wide variety of chipped stone tools on the site. Raw materials were probably collected from a nearby source or sources, and reduced to cores or bifaces at the site. A limited number of bifaces were further shaped into projectile points, and flakes were manufactured into a number of different types of unifacial tools. The list of tools implies that a wide variety of activities, such as hunting, wood working, hide scraping, and even bone tool production, took place at or near the site. The vertical distribution of historic artifacts indicates that little mixing of materials occurred during the historic period and that the prehistoric assemblages, if mixed (see discussions in Chapter 7), did not suffer greatly from different forms of bioturbation or road construction in the last few hundred years.

The quantitative analysis indicates that significant differences exist among the distribution of major tool classes in the three site areas. Area A has the highest frequency of bifaces, choppers, cores, and projectile points, while Area $\mathrm{C}$ has the highest percentage of unifaces. Area B, the midden, had less extreme frequencies of any tool class. Because of collection bias, lithic debitage could not be compared between the different areas. Nevertheless, this pattern among major tool classes suggests that Area A and Area C may 
have been the locus of more specialized activities (each differing from the other) and that Area $B$ witnessed more intensive activities and a wider range of activities. The quantitative analysis of artifacts in the subareas of Area B does show differences between the areas, but the interpretation of the midden and surrounding subareas as an active anthromantle makes any further interpretation based on artifact distributions unreliable except in the various components identified in the Block Excavation.

Vertical frequency differences in the Block Excavation show that the Nolan Component has the lowest percentage of cores, the highest percentage of projectile points, and moderate percentages of other tool classes. Detailed analysis of lithic debitage indicates that the Nolan Component also has the highest percentage of biface thinning flakes and the lowest percentage of normal flakes. High ratios between normal flakes to cores and biface thinning flakes to bifaces and projectile points indicate that both cores and bifacial tools were probably transported off-site. A low uniface flake to uniface tool ratio indicates that the unifaces were not transported off-site to the same degree. As many of these unifacial tools were edge modified flakes, the ratio pattern and the degree of modification both suggest that these tools were used expediently and discarded at the locus of use. 


\section{Chapter 9: Plant Remains}

\section{J. Philip Dering}

\section{Introduction and Laboratory Methods}

This chapter presents the results of archaeobotanical investigations of samples from 41BX126. The effort to recover plant remains from the Culebra Creek site was divided into two stages. The first stage involved preliminary sorting and scanning of approximately 100 field samples. After this stage was completed, it was determined that the level of recovery was very low. With the exception of a few samples from Level 1 in TU D, no more than a few small fragments of charcoal were observed. Full analysis was restricted to high priority samples located in Features 1.1, 1.2, 1.3, 2, and 4. Nineteen flotation samples (Table 9-1) were analyzed by the Texas A\&M University Archaeobotanical Laboratory. Flotation samples consist of archaeological sediment that has been floated in water to separate lighter charred plant remains from heavier material, and from clays/silts that can be suspended in water and rinsed out of the sample. The sediment samples were floated by CAR personnel, and the light fractions submitted to Texas A\&M University for analysis.

Standard archaeobotanical laboratory procedures were followed during analysis of the flotation samples. Each sample was passed through a series of four nested geological screens with mesh sizes ranging from $4 \mathrm{~mm}$ to $0.450 \mathrm{~mm}$. Each size grade, including the pan, was scanned for plant seeds/fruit under a binocular dissecting microscope at 8 magnifications. Carbonized wood remains from the 1-mm, 2-mm, and 4-mm mesh sieves were separated for examination.

Because the recovery rate was very low, extra effort was expended to locate and quantify the carbonized plant material, even if it was too small or degraded to identify. Charred seeds, fruit, nut fragments, and wood observed in the samples were counted and weighed. Identifications were made using reference collections at Texas A\&M University. All charred material was counted in the flotation sample, and the density was expressed in parts per liter of sediment.

The anatomy of some woods is so similar that it is very difficult to identify to the genus level. In other cases, genera within a plant family are usually distinguishable, but some of the archaeological material is often too fragmented or deteriorated to allow identification to the genus level. For these reasons some taxa were combined into wood types. All identifications in the "type" category represent identifications to the taxon level indicated by the name of the type. The following wood types or categories are used:

Arboreal Legume: Refers to woody members of the bean family (Fabaceae), including mesquite and several species of acacia. Depending on the size and condition of the piece of wood submitted for analysis, it is often difficult to separate the acacias from mesquite.

Live Oak: Refers to diffuse porous wood with very wide rays. The wood of live oak is easily distinguished by other, ring-porous oaks.

Diffuse porous hardwood: Refers to the wood of all seed-bearing, dicotyledonous trees with roughly same-sized pores evenly distributed within an annual growth ring.

Indeterminate Hardwood: Refers to any woody seed-bearing plant, i.e., not a cone-bearing tree such as pine, cypress, or juniper. 
Table 9-1. Flotation Sample Proveniences and Volumes

\begin{tabular}{|c|c|c|c|c|c|c|c|}
\hline \multicolumn{3}{|c|}{ Provenience } & \multicolumn{2}{c|}{ Coordinates } & \multicolumn{2}{c|}{ Elevation } & \multirow{2}{*}{$\begin{array}{c}\text { Volume } \\
\text { (Liters) }\end{array}$} \\
\hline Unit & Level & Feature & East & North & Top & Bottom & Bn \\
\hline 11 & 3 & 1.0 & 987.32 & 1014.25 & 100.10 & 100.00 & 6.60 \\
\hline 11 & 7 & 1.0 & 987.32 & 1014.25 & 99.70 & 99.60 & 8.50 \\
\hline 7 & 3 & 1.1 & 988.04 & 1019.08 & 100.40 & 100.30 & 6.60 \\
\hline 7 & 4 & 1.1 & 988.04 & 1019.08 & 100.30 & 100.20 & 3.80 \\
\hline 7 & 5 & 1.1 & 988.04 & 1019.08 & 100.20 & 100.10 & 8.50 \\
\hline 8 & 5 & 1.2 & 992.33 & 1022.87 & 100.40 & 100.30 & 90.80 \\
\hline 13 & 5 & 1.2 & 991.33 & 1022.87 & 100.40 & 100.30 & 6.60 \\
\hline 8 & 6 & 1.3 & 992.33 & 1022.87 & 100.30 & 100.20 & 46.40 \\
\hline 9 & 6 & 1.3 & 991.32 & 1022.86 & 100.30 & 100.20 & 53.40 \\
\hline 1 & 4 & 2.0 & 1025.69 & 983.68 & 99.30 & 99.20 & 26.50 \\
\hline 1 & 4 & 2.0 & 1025.69 & 983.68 & 99.30 & 99.20 & 14.20 \\
\hline 1 & 5 & 2.0 & 1025.69 & 983.68 & 99.20 & 99.15 & 4.70 \\
\hline 1 & 5 & 2.0 & 1025.69 & 983.68 & 99.15 & 99.10 & 7.60 \\
\hline 1 & 6 & 2.0 & 1025.69 & 983.68 & 99.10 & 99.00 & 9.50 \\
\hline 4 & 4 & 4.0 & 996.48 & 1011.54 & 100.05 & 100.00 & 30.30 \\
\hline 11 & 4 & 0.0 & 987.32 & 1014.25 & 100.00 & 99.90 & 6.60 \\
\hline 11 & 4 & 0.0 & 988.14 & 1014.57 & 99.94 & 99.94 & 46.40 \\
\hline 11 & 5 & 0.0 & 987.32 & 1014.25 & 99.90 & 99.80 & 6.60 \\
\hline 11 & 6 & 0.0 & 987.32 & 1014.25 & 99.80 & 99.70 & 8.50 \\
\hline & & & & & Total \\
\hline
\end{tabular}

\section{Results and Discussion}

Two hundred seventeen wood or woody root fragments and one fruit fragment were noted in the flotation samples. Seed concentration, expressed as the number of seeds, fruit fragments, and edible plant parts per liter of flotation sample, was 0.0026 seeds/liter. Such a return from almost 400 liters of flotation samples can only be described as meager. The taxa, counts and weights identified in the study are listed in Table 9-2.

Five features were represented in the analysis, and the return from each feature was minimal. Features 1.1, 1.2 , and 1.3 are located within the main burned rock midden. Feature 1.1 contained 27 charcoal fragments, including live oak and fragments so small that they were indeterminable. Feature 1.2, located in the midden core, was the most productive, containing arboreal legume (possibly mesquite), hackberry, and live oak. Samples from Feature 1.3 contained agarita, and unidentified diffuse-porous hardwood. A single seed fragment of chittimwood (Bumelia lanuginosa) was recovered from Feature 1.3, TU 9, Level 3, the only seed or fruit fragment noted in the study.

Features 2 and 4 were located away from the midden. Samples from these features contained very few charred plant parts. Three of the five field samples analyzed from Feature 2 did not contain carbonized plant remains. The other two samples contained 10 charcoal fragments, including live oak and tiny, unidentifiable charcoal fragments. Feature 4 yielded only six very small $(<1 \mathrm{~mm})$ fragments of charcoal which did not exhibit identifiable structure.

Problems with identification-most of the samples contained some indeterminable charcoal, or no charcoal whatsoever-are directly related to the size and condition of charred plant remains in the Culebra Creek flotation samples. A particle size analysis of the plant remains is presented in Table 9-3. It illustrates 
Table 9-2. Carbonized Plant Remains

\begin{tabular}{|c|c|c|c|l|l|c|c|}
\hline Feature & Unit & Level & Field Sample & \multicolumn{1}{|c|}{ Common } & Part & Count & Wt (g) \\
\hline 0.0 & 11 & 4 & 212 & Live oak & Wood & 17 & 0.25 \\
\hline 0.0 & 11 & 5 & 231 & No Carbonized Remains & & 0 & 0.00 \\
\hline 0.0 & 11 & 6 & 237 & Hackberry & Wood & 12 & 0.20 \\
\hline 0.0 & 11 & 6 & 237 & Indeterminable & Wood & 7 & 0.02 \\
\hline 0.0 & 11 & 6 & 237 & Live oak & Wood & 4 & 0.05 \\
\hline 1.1 & 7 & 3 & 147 & Indeterminable & Wood & 5 & 0.03 \\
\hline 1.1 & 7 & 4 & 153 & Indeterminable & Wood & 4 & 0.02 \\
\hline 1.1 & 7 & 5 & 163 & Live oak & Wood & 18 & 0.20 \\
\hline 1.2 & 8 & 5 & 178 & Indeterminable & Wood & 24 & 0.10 \\
\hline 1.2 & 8 & 5 & 178 & Arboreal legume & Wood & 6 & 0.30 \\
\hline 1.2 & 8 & 5 & 178 & Live oak & Wood & 24 & 0.30 \\
\hline 1.2 & 13 & 5 & 233 & Hackberry & Wood & 5 & 0.10 \\
\hline 1.3 & 8 & 6 & 229 & Diffuse porous hardwood & Wood & 17 & 0.30 \\
\hline 1.3 & 8 & 6 & 229 & Indeterminable & Wood & 20 & 0.30 \\
\hline 1.3 & 9 & 6 & 207 & Agarita & Wood & 5 & 0.10 \\
\hline 1.3 & 9 & 6 & 207 & Indeterminable & Wood & 29 & 0.20 \\
\hline 1.3 & 9 & 6 & 207 & Coma, chittimwood & Seed & 1 & 0.05 \\
\hline 2.0 & 1 & 4 & 70 & Indeterminable & Wood & 5 & 0.01 \\
\hline 2.0 & 1 & 4 & 70 & No carbonized remains & & 0 & 0.00 \\
\hline 2.0 & 1 & 4 & 25 & Live oak & Wood & 8 & 0.10 \\
\hline 2.0 & 1 & 5 & 92 & Indeterminable & Wood & 2 & 0.01 \\
\hline 2.0 & 1 & 5 & 91 & No carbonized remains & & 0 & 0.00 \\
\hline 2.0 & 1 & 6 & 103 & No carbonized remains & & 0 & 0.00 \\
\hline 4.0 & 4 & 4 & 78 & Indeterminable & Wood & 6 & 0.04 \\
\hline & & & & & Total & $\mathbf{2 1 8}$ & $\mathbf{2 . 6 3}$ \\
\hline & & & & & & \\
\hline
\end{tabular}

that the majority of the charred plant parts, 171 or 78 percent, were smaller than four millimeters, making identification very difficult. Further, problems were exacerbated by the lack of preserved anatomical structure in many of the charcoal pieces.

Plant taxa present in the samples are typical of the south Texas region, both on and just south of the southern Balcones escarpment. Live oak is the most commonly occurring charcoal taxon identified in archaeological sites along the southern escarpment. An excellent fuel wood, it was probably relied upon heavily for firing large earth ovens. In addition, it has readily identifiable anatomical characteristics, even when it has been broken down into very small fragments. Thus, in poor environments of preservation, live oak is most likely identified in archaeological samples more often than other woods that may have been utilized just as often. Hackberry is a good fuel, and occurs commonly on alluvial terraces. Agarita is a very poor fuel wood, and should be considered a chance inclusion, perhaps used as kindling. The presence of a single seed fragment of coma (Bumelia lanuginosa) represents an edible raw fruit (Hedrick 1919:122). Although the seed fragment is not directly related to the utilization of an earth oven or other hearth, it may have been included as part of the fuel load, because chittimwood is a diffuse porous hardwood that is difficult to identify in very small pieces. 
Table 9-3. Size Particle Distribution of Carbonized Wood in the Culebra Midden Samples

\begin{tabular}{|c|c|c|c|c|c|c|c|c|}
\hline Sieve Size (mm) & \multicolumn{2}{|c|}{0.45} & \multicolumn{2}{c|}{1} & \multicolumn{2}{c|}{2} & \multicolumn{2}{c|}{4} \\
\hline & Count & Weight & Count & Weight & Count & Weight & Count & Weight \\
\hline Total & 49 & 0.04 & 49 & 0.21 & 73 & 1.17 & 47 & 0.6 \\
\hline
\end{tabular}

Both prehistoric and historic records indicate that mesquite and oak were widespread in southern Texas and along the Balcones Escarpment prior to the twentieth century. Mesquite wood charcoal is often recovered at archaeological sites in south Texas (Dering 1995, 1997; Holloway 1986), and it was utilized for fuel and food by Archaic populations as early as 8000 B.P. (Dering 1997). Extensive stands of mesquite were limited to erosional breaks, open woodlands along creeks, and rocky uplands, and quite often small groves or mottes of mesquite and solitary trees grew in the uplands (Johnston 1963).

Inglis (1964:19-20) maintains that Terán de los Rios passed through the upper Leon Creek near presentday Helotes in 1691, noting that the low hills supported both mesquite and oak. Other areas on the expedition's path supported large oak trees. Riparian vegetation included cottonwood, oak, mulberry, and a dense growth of vines. The woody plant material identified in the flotation samples do not contradict such a description.

\section{Conclusions}

The 19 floatation samples yielded an assemblage dominated by live oak wood. Recovery of charred plant remains was very poor. Six wood taxa/types and only one charred seed were noted in almost 400 liters of flotation samples. Charred wood fragments totaled 219 , and were small and difficult to identify. The majority of charcoal fragments (171) measured less than four millimeters, and much of the anatomical structure was lost to poor preservation conditions. The best recovery of charred plant remains was noted in Feature 1.2 located in the midden core. The minimal recovery of plant remains suggests that the site has a low potential for yielding more information on the nature and distribution of plant remains in the region.
Further, the distribution of plant remains demonstrates that the most likely area for any data recovery is in centrally located, buried features imbedded in the heart of the midden. It must be realized, however, that microenvironments of adequate preservation may be located in any area of a site. 


\title{
Chapter 10: Vertebrate Faunal Remains and Fish Otoliths
}

\author{
Barbara A. Meissner, Diane A. Cargill, and David L. Nickels
}

\section{Introduction}

Seven hundred and eighty fish otoliths (ear-stones) and 2,374 bones and bone fragments weighing 308.58 $\mathrm{g}$ (see Appendix F) were recovered during the project. This chapter discusses the methodology and results of faunal analysis from 41BX126. Following the first section on general faunal remains is a special section on fish otoliths. In addition to methodology and results, each section contains general research issues surrounding the two subjects.

\section{Faunal Remains}

\section{Methodology}

The vertebrate remains were collected either from excavation, during which $1 / 4$-inch screens were used, or from the processing of flotation soil samples. Bone from Price's 1995 excavations was included in the analysis; however, bone was not recovered during Wood's 1993 investigation. Bones were washed, airdried, and placed in plastic bags labeled with provenience and indicating if the bone was from a flotation sample. Bones were examined under a $4 \mathrm{x}$ magnifying lens, and were identified using the comparative collection at CAR. Several texts on identification of vertebrate remains were also consulted (Gilbert 1990; Hillson 1986; Olsen 1964, 1968; Schmid 1972 ). In addition to count and weight, other data collected from the bone when possible was:

1. Skeletal element.

2. Portion of element.

3. Presence of evidence of juvenile animal.

4. Degree of pitting of bone surface (chemical weathering).

5. Degree of weathering evident on bone.
6. Evidence of alteration by heating.

7. Type of breaks (i.e., do breaks appear to have occurred on fresh or dry bone?)

8. Evidence of gnawing.

9. Tool marks (i.e., evidence of butchering).

10. Notes on approximate size of animal when genus could not be determined.

A complete list of the data collected is included in Appendix F.

The Minimum Number of Individuals (MNI) is a derived statistic which calculates the minimum number of animals needed to account for the identified bone in each species. It is usually used to estimate relative abundance among species. MNI is derived by dividing identified elements for a given species into right and left sides. The count of the side with the most numerous element is the MNI. Evidence of extreme variation in size or juvenile characteristics are also considered. However, as Grayson (1984) notes, the MNI of any species in a collection depends on how the collection is aggregated. For instance, is the bone from a site taken as a whole, or divided by unit, level, area, or some other grouping? The MNI will be different in each case. In this study, MNI was calculated by assuming that bone from non-adjacent units and/ or levels was not from the same individuals. Given the mixed nature of the matrix in the site this assumption may not be valid.

\section{Results}

Only 47 bones and fragments representing 10 genera could be identified in the collection (Table 10-1). The Number of Identified Specimens (NISP) is very low for this collection, only 1.98 percent. This is due to the extremely fragmented nature of almost all the bone. The average weight per bone for the entire collection is only about $0.13 \mathrm{~g}$. 
Table 10-1. Identified Taxa

\begin{tabular}{|l|l|c|c|l|}
\hline \multicolumn{1}{|c|}{ Taxa } & \multicolumn{1}{|c|}{ Common name } & NISP & MNI & \multicolumn{1}{c|}{ Notes } \\
\hline $\begin{array}{l}\text { Aplodinotus } \\
\text { grunniens }\end{array}$ & Freshwater drum & 1 & 1 & $\begin{array}{l}\text { Common in rivers and creeks } \\
\text { throughout South Texas }\end{array}$ \\
\hline Canis sp. & Dog/Wolf/coyote & 1 & 1 & \\
\hline $\begin{array}{l}\text { Lepus } \\
\text { californicus }\end{array}$ & Black-tailed jackrabbit & 3 & 3 & \\
\hline Neotoma sp. & Wood (pack) rats & 1 & 1 & $\begin{array}{l}\text { The ranges of at least 3 closely } \\
\text { related species overlap in the area } \\
\text { today (Davis and Schmidly 1994) }\end{array}$ \\
\hline $\begin{array}{l}\text { Odocoileus } \\
\text { virginianus }\end{array}$ & White-tailed deer & 25 & 9 & \\
\hline Rana sp. & True frogs & 1 & 1 & \\
\hline $\begin{array}{l}\text { Sciurus sp. } \\
\text { Tree squirrels }\end{array}$ & 1 & 1 & $\begin{array}{l}\text { The Eastern Fox Squirrel (S. niger) } \\
\text { is most common in area today. }\end{array}$ \\
\hline $\begin{array}{l}\text { Sigmodon } \\
\text { hispidus }\end{array}$ & Cotton rat & 5 & 4 & $\begin{array}{l}\text { The most common indigenous rat in } \\
\text { South Texas; an almost ubiquitous } \\
\text { find in archaeological sites in the } \\
\text { area. }\end{array}$ \\
\hline Sylvilagus sp. & Cottontail rabbits & 9 & 2 & $\begin{array}{l}\text { Three species overlap in the area } \\
\text { (Davis and Schmidly 1994). }\end{array}$ \\
\hline & \multicolumn{1}{|c|}{ Total Identified } & $\mathbf{4 7}$ & $\mathbf{2 3}$ & \\
\hline Artiodactyl & Even-toed ungulates & 41 & & \\
\hline Rodentia & Rats and mice & 13 & & \\
\hline Mammalia & Mammals & 396 & & \\
\hline Aves & Birds & 55 & & \\
\hline Osteichthyes & Bony fishes & 5 & & \\
\hline Vertebrata & Unidentified bone & 1817 & & \\
\hline Retal Vertebrate & $\mathbf{2 3 7 4}$ & & \\
\hline
\end{tabular}

All of the identified species are native to the region and are commonly found in archaeological sites in South Texas. The most common genera are whitetailed deer (Odocoileus virginianus), jackrabbit (Lepus californicus), cottontail rabbits (Sylvilagus sp.), cotton rats (Sigmodon hispidus), and birds of sparrow size or smaller. Unfortunately, the sample size is too small to allow a great deal of generalization to be made.
Open campsites in South Texas often have few vertebrate faunal remains (Hester 1995:439; for exceptions see Black 1986; Black and McGraw 1985). The few surviving fragments are rarely identifiable. Poor bone preservation is usually considered to be the causative factor. Identification of poorly preserved bone may be impossible, making it "analytically absent" (Lyman and O'Brien 1987). The possibility exists, however, 
that little bone was deposited there in the first place. Ethnographic descriptions of Native American subsistence practices in the sixteenth and seventeenth centuries indicate that at times bones of both land animals and fish were pounded into a fine meal and eaten (Cabeza de Vaca 1966[1542]). Little bone would be expected in a site at which this custom was practiced. If the only animals hunted at the site were very small, such as mice or minnows, one would again not expect a great deal of bone deposition, especially if they were eaten whole (Sobolik 1991:110).

\section{Taphonomy}

Taphonomy is "the study of the transition, in all details, of organics from the biosphere into the lithosphere or geological record"' (Lyman 1994:1). The taphonomy of a faunal collection is the study of factors which cause alteration of the bone after the animal dies. Taphonomic changes include those attributed to human butchering and disposal practices, as well as those natural processes which take place after deposition into the archaeological record. A full discussion of the taphonomic factors which have affected the bone in this collection is beyond the scope of this report. Indeed, 51 percent $(n=1,220)$ of the bone was so fragmented that evidence for various kinds of taphonomic changes was not visible. Evidence of the effects of four major taphonomic factors were evident on the remaining bone: butchering practices, burning, chemical weathering, and atmospheric weathering. It is important to note that these factors cannot always be measured independently. Their combined effect on a given bone specimen is cumulative. For instance, while tool marks and chemical weathering operate independently on the bone, the latter tends to obliterate evidence of the former. Also, clearly, the action of one factor may increase or decrease the action of another.

\section{Butchering Practices}

The degree of chemical weathering on most bone made examination of butchering practices almost impossible. It was possible to estimate whether the bone was fresh or dry when broken on only 6.6 percent $(n=157)$ of the specimens. Of these 118 (75 percent) showed evidence of having been broken while the bone was fresh. However, the sample is very small and nothing can be stated with any confidence about the degree to which this represents the original condition of all bone when it was deposited in the ground. The small size of the bones may be due to poor preservation, but may also, in the case of the long bones of larger animals, be due to the deliberate smashing of the bone to extract marrow and/or prepare for grease extraction by boiling.

Most of the bone was too small and/or too badly affected by other taphonomic changes to show evidence of tool marks. Table 10-2 lists the type of tool marks and count of bones showing these marks. Again, the sample size restricts the potential for inferences.

\section{Heat Alteration}

Heat alteration of the bone could usually be determined even on very small bone. Only smoke-staining might be difficult to accurately identify on very small specimens. Six hundred thirty bones ( 26.5 percent of the total) showed evidence of heat alteration. Table 10-3 lists the number of bones exhibiting different degrees of heat alteration. Of those bones showing heat alteration, 36 percent $(n=228)$ are calcined or partially calcined, indicating exposure to high heat and/or long duration of heating (see Lyman 1994:388-389). This may indicate deliberate disposal of bones in the fires. It has been shown experimentally that natural conditions will regularly carbonize bone but rarely calcine them. The presence of large amounts of calcined bone can be used to infer human-controlled fires (Lyman 1994:389).

Table 10-2. Tool Marks on Bone

\begin{tabular}{|c|c|c|}
\hline Type of Tool Mark & $\#$ & $\%$ \\
\hline Thin cut mark (superficial cut) & 13 & 61.90 \\
\hline Chop mark (deep cut) & 6 & 28.57 \\
\hline Impact scar & 2 & 9.52 \\
\hline Total & 21 & 100.00 \\
\hline
\end{tabular}


Table 10-3. Heat-altered bone

\begin{tabular}{|c|c|c|}
\hline Type of Heat Alteration & $\#$ & $\%$ \\
\hline $\begin{array}{l}\text { None. No evidence of heat } \\
\text { alteration. }\end{array}$ & 1744 & 73.46 \\
\hline $\begin{array}{l}\text { Smoke-stained. Bone appears } \\
\text { discolored by smoke but is not } \\
\text { charred. }\end{array}$ & 218 & 9.18 \\
\hline $\begin{array}{l}\text { Charred. Some or all of the } \\
\text { bone is charred. }\end{array}$ & 184 & 7.75 \\
\hline $\begin{array}{l}\text { Partially Calcined. Bone is } \\
\text { extensively charred with some } \\
\text { portions calcined. }\end{array}$ & 28 & 1.18 \\
\hline $\begin{array}{l}\text { Calcined. Bone is completely } \\
\text { calcined. }\end{array}$ & 200 & 8.43 \\
\hline Total & 2374 & 100.00 \\
\hline
\end{tabular}

\section{Atmospheric Weathering}

Exposure to the atmosphere-where the sun bakes and the bone is repeatedly wet and rapidly dried-causes recognizable changes on bone. A series of weathering stages has been proposed by Behrensmeyer (1978) and extended and revised by Lyman (1994:355). However, the few bones in this collection with evidence of atmospheric weathering were very small, making assignment to one of these weathering stages difficult. Instead, a simplified version of Lyman (1994:355) was used to define three degrees of weathering changes exhibited in this sample. Only 44 bones $(1.85$ percent of the total) showed evidence of atmospheric weathering. The criteria and counts for these bone are listed in Table 10-4.
The bones which exhibit evidence of atmospheric weathering should not be considered a reliable indicator of the percentage of bone which was left exposed on the surface for long periods. Chemical weathering obliterates the early signs of atmospheric weathering. The extremely small size of much of the recovered bone made identification of atmospheric weathering changes impossible in many cases. However, it may well be that a large proportion of the tiny bone fragments recovered exfoliated from larger bones left to weather for many years in the sun. Unfortunately, there is no way to determine this.

\section{Chemical Weathering}

Bone exhibiting the extremely pitted, "chewed" surfaces typical of chemical weathering is common in South Texas (Meissner 1998; Shaffer 1995:306). The reasons for this are not well understood. No detailed examination of the diagenetic processes commonly encountered in archaeological sites in South Texas is currently available, however, Chaplin (1971:16-18) suggests that at least four properties of the depositional matrix affect skeletal tissue preservation: $\mathrm{pH}$, aeration, water regime, and biological (bacterial and fungal) action. In general, acidic soils inhibit bacterial action but will dissolve the mineral component of bone, depending to a large extent on the amount of water percolating through the matrix (Lyman 1994:421). However, in a well-aerated basic matrix the organic component decays more rapidly, exposing the mineral component to leaching. Biological agents, especially bacteria and fungi, will be more

Table 10-4. Evidence of Atmospheric Weathering on Bone

\begin{tabular}{|l|c|c|}
\hline \multicolumn{1}{|c|}{ Degrees of Atmospheric Weathering } & $\#$ & \% \\
\hline $\begin{array}{l}\text { Slightly weathered. Fine longitudinal cracking on long bones, beginning of } \\
\text { mosaic cracking on articular surfaces. }\end{array}$ & 12 & 27.27 \\
\hline $\begin{array}{l}\text { Moderately Weathered. Deeper longitudinal cracking. Some surface } \\
\text { exfoliation. Bone shows some bleaching. }\end{array}$ & 22 & 50.00 \\
\hline $\begin{array}{l}\text { Heavily Weathered. Longitudinal cracks have formed splinters, some of } \\
\text { which have exfoliated. Extensive surficial exfoliation. Bone appears heavily } \\
\text { bleached. }\end{array}$ & 10 & 22.73 \\
\hline Total & $\mathbf{4 4}$ & $\mathbf{1 0 0 . 0 0}$ \\
\hline
\end{tabular}


active in warm, basic, damp (but not waterlogged) soils (Lyman 1994:442). The soil of this site is basic, warm and large amounts of water percolate through it periodically, followed by dry periods, an almost ideal environment for microorganisms.

The degree of chemical weathering could be determined on 691 bones from this collection. While this bone is only about 29 percent of the total bone count, it represents 87 percent $(269.20 \mathrm{~g})$ of the total bone weight. Table 10-5 shows the degree of chemical weathering on the 691 weathered bones. Bone exhibiting moderate to extreme pitting is 67.6 percent of the bone in which degree of chemical weathering could be determined.

There seems to be a relationship between burning and chemical weathering. In general burned bone is either slightly or not burned at all, and the more burned a bone is, the less pitted it is likely to appear (Table 106). Of the 691 for which both heat alteration and chemical weathering data could be taken 83 percent (431/515) of the unburned bone exhibited moderate to extreme pitting, while only 23.3 percent $(7 / 30)$ of the partially calcined and calcined bone showed any evidence of pitting. Heat alteration seems to confer a certain amount of immunity from the chemical weathering taking place at this site. This would most likely be the case if the primary agent of chemical weathering is biogenic, i.e., if the pitting is caused by acids released by microorganisms during the consumption of the organic component of bone (Lyman 1994:391). Burning carbonizes the organic element in bone, making it unavailable to microorganisms (Lyman 1994:391). This suggests that the most likely source of most bone deterioration is chemical weathering through a combination of bacterial action and water leaching. More research on this question is needed, however, because bone preservation in archaeological sites in South Texas is not consistent, suggesting that a complicated, multicausal relationship between cultural practices and environment affects bone preservation.

\section{Discussion and Conclusions}

Faunal data for some of the better-reported sites in the region were reviewed (Table 10-7). The proportion of identifiable specimens ranges between 3 percent and 21 percent with a mean of 8.5 percent, comparable to the 1.98 percent at $41 \mathrm{BX} 126$. The total NISP recovered from these sites ranges between 25 and 1,138 with a mean of 309 , including the extraordinarily high recovery from Panther Springs (41BX228). However, the temporal controls on most collections are poor. Virtually all reported sites in the region with substantial faunal recovery represent assemblages spanning 4,000 to 7,500 years and many include Late Prehistoric components. The best sample is the 200 NISP from the Bammel Site, with a temporal span from terminal Middle Archaic to Late Archaic I;

Table 10-5. Evidence of Chemical Weathering

\begin{tabular}{|l|c|c|}
\hline \multicolumn{1}{|c|}{ Degree of pitting } & $\#$ & \% \\
\hline No pitting. No evidence of chemical weathering. & 119 & 17.22 \\
\hline $\begin{array}{l}\text { Slightly pitted. Pits are individual or over small part of bone. Bone is firm, } \\
\text { and generally smooth. Enamel of teeth appears slightly dull }\end{array}$ & 105 & 15.20 \\
\hline $\begin{array}{l}\text { Moderately pitted. Pitting has affected entire surface, but is not deep. Bone } \\
\text { is still firm, but rough textured. Enamel is dull and is slightly rough. }\end{array}$ & 166 & 24.02 \\
\hline $\begin{array}{l}\text { Heavily pitted. Entire surface has been destroyed. Bone is soft and friable. } \\
\text { Pitting of subsurface bone is extensive. Enamel is soft and somewhat } \\
\text { chalky. }\end{array}$ & 274 & 39.65 \\
\hline $\begin{array}{l}\text { Extremely pitted. Sub-surface layer of bone is heavily pitted. Bone is } \\
\text { crumbling. Enamel is very soft and chalky and may be almost eroded away. }\end{array}$ & 27 & 3.91 \\
\hline \multicolumn{1}{|c|}{ Total } & $\mathbf{6 9 1}$ & $\mathbf{1 0 0 . 0 0}$ \\
\hline
\end{tabular}


Table 10-6. Comparison of Burned and Chemically Weathered Bone

\begin{tabular}{|c|c|c|c|c|c|c|}
\hline & $\begin{array}{l}\stackrel{D}{\varrho} \\
\stackrel{\Xi}{E} \\
\overline{0} \\
Z\end{array}$ & 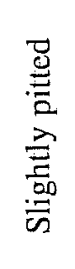 & 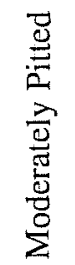 & 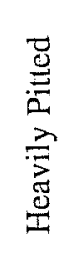 & 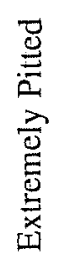 & $\frac{\infty}{\frac{\pi}{0}}$ \\
\hline No heat alteration & 42 & 43 & 144 & 259 & 27 & 515 \\
\hline Smoke-stained & 37 & 54 & 20 & 10 & 0 & 121 \\
\hline Charred & 17 & 4 & 1 & 3 & 0 & 25 \\
\hline Partially calcined & 11 & 2 & 0 & 1 & 0 & 14 \\
\hline Calcined & 12 & 2 & 1 & 1 & 0 & 16 \\
\hline Totals & 119 & 105 & 166 & 274 & 27 & 691 \\
\hline
\end{tabular}

however, both the bone and the site are inadequately reported for most analytical purposes. Black and McGraw (1985) identified components within the Panther Springs site with better chronological control. They have identified small faunal assemblages relating to local subperiods that may represent temporal units as short as 500 to 1,350 years. Unfortunately, as Black and McGraw (1985:273-288) point out, the total NISP represented by these components has limited analytical value.

Faunal data are relevant to questions regarding subsistence, particularly the comparative roles in the subsistence of bison, deer, and small taxa. During the periods represented for example, bison usage has been proposed to be on the increase. Fauna, particularly bison, also has implications for environmental reconstructions. These faunal remains will contribute substantially to building a regional database, with

Table 10-7. Regional faunal recovery.

\begin{tabular}{|c|c|c|c|c|c|c|c|}
\hline \multicolumn{8}{|c|}{ Regional Summary } \\
\hline Site & $\begin{array}{c}\text { Components } \\
\text { (Johnson \& Goode [1994]) }\end{array}$ & $\begin{array}{c}\text { Years } \\
\text { represented }\end{array}$ & Count & NISP & $\begin{array}{c}\% \\
\text { D'd }\end{array}$ & $\begin{array}{c}\text { Report } \\
\text { Reference }\end{array}$ & Principal Taxa \\
\hline $41 \mathrm{~B} \times 228$ & Early Archaic-Late Prehistoric & ca 5000 years & 19795 & 1138 & 5.7 & $\begin{array}{l}\text { Black and McGraw } \\
1985\end{array}$ & $\begin{array}{l}\text { deer, bison, turtle, rabbit, } \\
\text { coyote }\end{array}$ \\
\hline $41 \mathrm{~B} \times 300$ & Middle Archaic-Late Prehistoric & ca 4000 years & 117 & 25 & 21.3 & Katz 1987 & $\begin{array}{l}\text { deer, armadillo, raccoon, } \\
\text { javelina, rabbit }\end{array}$ \\
\hline $41 \mathrm{~B} \times 36$ & Late Paleo-Late Prehistoric & ca 7500 years & 4686 & 256 & 5.4 & Gerstle et al 1978 & deer, bison, rabbit, turtle, rat \\
\hline 41ME29 & Middle Archaic-Late Prehistoric & ca 4000 years & 1334 & 94 & 7 & Johnson 1995 & deer, bison, pronghom \\
\hline 41ME7 & Early Archaic-Late Prehistoric & ca 5500 years & 8718 & 285 & 3.3 & Highley et al. 1978 & $\begin{array}{l}\text { deer, rabbit, rat, bison, fish, } \\
\text { birds, reptiles }\end{array}$ \\
\hline $41 \mathrm{UV} 21$ & Middle Archaic-Late Prehistoric & ca 4000 years & 2078 & 167 & 8 & Hester 1971 & $\begin{array}{l}\text { deer, bison, rabbit, rat, } \\
\text { pronghorn }\end{array}$ \\
\hline $41 \mathrm{KR} 10$ & Middle Archaic-Late Archaic I & ca 2000 years & & 200 & & Beadles 1990 & deer, bison (1/2" screen) \\
\hline \multicolumn{5}{|c|}{ Average $\%$ identified } & 8.5 & & \\
\hline \multicolumn{8}{|c|}{ 41BX228 Detail } \\
\hline Site & Components & $\begin{array}{c}\text { Years } \\
\text { represented } \\
\end{array}$ & & NISP & & $\begin{array}{c}\text { Report } \\
\text { Reference } \\
\end{array}$ & Species \\
\hline $41 \mathrm{~B} \times 228$ & end of Early Archaic-Martindale & ca 1000 years & & 42 & & \multirow{6}{*}{$\begin{array}{c}\text { Black and McGraw } \\
1985\end{array}$} & deer, rabbit \\
\hline $41 \mathrm{~B} \times 228$ & end of Middle Archaic-Nolan & ca 1000 years & & 19 & & & deer, turtle, bison, rabbit \\
\hline $41 \mathrm{BX} 228$ & Late Archaic I - Pedernales & ca 1350 years & & 48 & & & deer, bison, rabbit, turtle \\
\hline $41 \mathrm{BX} 228$ & Late Archaic I - Montell & ca 900 years & & ? & & & deer, bison, rabbit \\
\hline $41 \mathrm{BX} 228$ & Late Archaic II - Ensor & ca 650 years & & 11 & & & $\begin{array}{l}\text { deer, bison, rabbit, } \\
\text { pronghorn }\end{array}$ \\
\hline $41 \mathrm{BX} 228$ & Late Prehistoric-Scallorn, Perdiz & ca 500 years & & 17 & & & deer, bison, turtle, rabbit \\
\hline
\end{tabular}


chronological controls, that will allow examination of diachronic and geographic variation in subsistence.

The small sample size and its poor preservation make it difficult to recover extensive information about animal use at $41 B X 126$. The bone was highly fragmented, and even relatively intact bone was severely impacted by such taphonomic factors as chemical weathering and/or burning. In fact, due to the poor preservation, it is very difficult to determine if the bone recovered from the site is a large or small percentage of the bone originally deposited there by humans. Only 89 (3.74 percent) of the common bones could be identified to the Family taxonomic level, and only 47 (1.98 percent) could be identified to the Genus taxonomic level.

However, 38 of the 47 genus-level specimens are related to wood charcoal radiocarbon dated contexts at the site. Three black-tailed jackrabbits were found: one near the bottom of Feature 1.1, 2 levels below a radiocarbon date of $2980 \pm 50$ B.P.; one near the bottom of Feature 1.3, with an associated radiocarbon date of $4050 \pm 50$ B.P., and; one in Feature 7 with a problematic, modern radiocarbon date. One dog/wolf/coyote phalange was recovered from Unit 11, Level 4 in association with a radiocarbon date of $2170 \pm 50$ B.P.A freshwater drum fish dorsal spine fragment, a true frog radio-ulna, a tree squirrel incisor, two cotton rat fragments, six deer, and all nine cottontail rabbit individual specimens came out of the lower levels of Features 1.2 and 1.3 in the midden's core. Dates obtained from Feature 1.2 are $2950 \pm 70$ B.P., $3040 \pm 70$ B.P. and $4050 \pm 50$ в.P. Three other cotton rat specimens were found: one in Feature 2, Level 4 with an associated radiocarbon date of $2780 \pm 50$ B.P.; one in Feature 1.1 with an associated date of $2980 \pm 50$ B.P., and; one in Unit 11, Level 5 bracketed by dates of $2180 \pm 50$ в.P. and $2750 \pm 50$ в.P. Eleven deer specimens were recovered from Levels 3 through 7 in Unit 11. Radiocarbon dates for Levels 3, 4 and 6 respectively in Unit 11 are $2180 \pm 50$ в.P., $2170 \pm 50$ в.P., and $2750 \pm 50$ в.P.

A wood rat molar was found $20 \mathrm{~cm}$ below the surface in undated context in Unit C, Level 2. A deer specimen was found in Unit 10, Level 2 in an undated (absolute) context. Other undated (absolute) deer came from Unit A, Level 4 (3 each), Unit A, Level 7 (3 each), and Unit B, Level 1 (1 each).
Although the NISP was not as high as at the mean of other sites examined, 41BX126 has, however, provided information which may help in understanding some of the taphonomic processes which affect the preservation of bone in archaeological sites in South Texas. The relatively small amount of chemical weathering on bone which has been altered by heat suggests that microorganisms in the soil are responsible for a large percentage of the chemical weathering. Further research on the subject of diagenetic changes in bone is clearly needed.

\section{Fish Otoliths}

\section{Methodology}

The presence of fish otoliths in the heavy fraction was first observed by CAR staff after the picking of heavy fraction for lithic debitage was well underway. From that point on, several people were employed in the recovery of lithic debitage and fish otoliths, and it is certain that "otolith recognition" varied from person to person. Therefore, the recovery of otoliths from units across the site was conducted in an unsystematic manner with the exception of Unit C. In Unit C, a careful examination of the heavy fraction was made and fish otoliths were systematically recovered. A selected sample of 118 otoliths were examined at Heart of the Hills Research Center in Ingram, Texas by John Prentice, using a $15 \mathrm{X}-90 \mathrm{X}$ transmitted and reflected microscope.

\section{Results}

Given both an unsystematic and systematic manner of recovery, a few statements can be made regarding the presence of fish otoliths at 41BX126. First, they appear to be equally represented across the site (Table 10-8). They are found in both the A and B horizons, or in Nordt's geomorphological identification, stratigraphic units IV and III, respectively (see Chapter 5). In Unit C, the number of fish otoliths decrease in levels 9-13 (Table 10-8), however, this may be due to older soils and preservation issues, rather than a reduced presence represented in stratigraphic unit IV. 
Table 10-8. Fish Otoliths Recovered from 41BX126

\begin{tabular}{|c|c|c|c|c|c|c|c|c|c|c|c|c|c|c|c|c|c|c|c|c|c|c|c|c|}
\hline & \multicolumn{10}{|c|}{ Unit } \\
\hline Lvl. & $\mathbf{1}$ & $\mathbf{2}$ & $\mathbf{3}$ & $\mathbf{4}$ & $\mathbf{5}$ & $\mathbf{6}$ & $\mathbf{7}$ & $\mathbf{8}$ & $\mathbf{9}$ & $\mathbf{1 0}$ & $\mathbf{1 1}$ & $\mathbf{1 2}$ & $\mathbf{1 3}$ & $\mathbf{1 4}$ & $\mathbf{1 6}$ & $\mathbf{1 7}$ & $\mathbf{1 8}$ & $\mathbf{1 9}$ & $\mathbf{2 0}$ & $\mathbf{2 2}$ & $\mathbf{2 3}$ & $\mathbf{C}$ & $\mathbf{D}$ & $\mathbf{E} / \mathbf{F}$ \\
\hline $\mathbf{1}$ & & 2 & & 5 & 5 & & & & & 2 & 1 & 2 & & 1 & 1 & 2 & & & 4 & & & 31 & 18 & \\
\hline $\mathbf{2}$ & 4 & & & 4 & 12 & 2 & & & 4 & & & 15 & & & & & & & & 5 & & 17 & & \\
\hline $\mathbf{3}$ & & 9 & 21 & 3 & & 1 & & & 2 & 1 & & 17 & & & 2 & & & & & 4 & & 15 & & 14 \\
\hline 4 & & 3 & & 14 & & & & 4 & 11 & & 17 & 12 & & & 9 & & 15 & 9 & & & 2 & 61 & & 7 \\
\hline $\mathbf{5}$ & 5 & & & 1 & 1 & & 7 & 16 & 18 & & & 3 & & 13 & & & & & & & 2 & 21 & 12 & 1 \\
\hline $\mathbf{6}$ & & & & & & & 5 & 13 & 39 & & & & 14 & 3 & & & & & & & & 33 & 9 & 1 \\
\hline 7 & & & & & & & 7 & & & & & & & & & & & & & & & 28 & & \\
\hline $\mathbf{8}$ & & & & & & & 9 & & & & & & & & & & & & & & & 69 & & 2 \\
\hline $\mathbf{9}$ & & & & 1 & & & & & & & & & & & & & & & & & & 13 & & 5 \\
\hline 10 & & & & & & & & & & & & & & & & & & & & & & 4 & & \\
\hline 11 & & & & & & & & & & & & & & & & & & & & & & 5 & & \\
\hline $\mathbf{1 2}$ & & & & & & & & & & & & & & & & & & & & & & 8 & & \\
\hline $\mathbf{1 3}$ & & & & & & & & & & & & & & & & & & & & & & 2 & & \\
\hline $\mathbf{1 4}$ & & & & & & & & & & & & & & & & & & & & & & & & \\
\hline $\mathbf{1 5}$ & & & & & & & & & & & & & & & & & & & & & & & & \\
\hline Tot. & $\mathbf{9}$ & $\mathbf{1 4}$ & $\mathbf{2 1}$ & $\mathbf{2 8}$ & $\mathbf{1 8}$ & $\mathbf{3}$ & $\mathbf{2 8}$ & $\mathbf{3 3}$ & $\mathbf{7 4}$ & $\mathbf{3}$ & $\mathbf{1 8}$ & $\mathbf{4 9}$ & $\mathbf{1 4}$ & $\mathbf{1 7}$ & $\mathbf{1 2}$ & $\mathbf{2}$ & $\mathbf{1 5}$ & $\mathbf{9}$ & $\mathbf{4}$ & $\mathbf{9}$ & $\mathbf{4}$ & $\mathbf{3 0 7}$ & $\mathbf{3 9}$ & $\mathbf{3 0}$ \\
\hline
\end{tabular}

As stated previously, John Prentice examined a selected sample of 118 otoliths from 41BX126. Prentice (1997) observed:

"Very little variation in otoliths size and no variation in structure indicates all otoliths came from the same fish size (about 50 to $100 \mathrm{~mm}$ fish total length) and taxonomic group (Family Cyprinidae $=$ minnows). All otoliths have numerous growth rings indicating individuals though small in size had lived for several years and through many seasonal changes, further evidence that these are from the minnow family because they could be adult size and still be only a couple of inches in length. I am surprised that there are not other fish species represented and that these fish are all small individuals."

Selected samples of otoliths recovered from the same levels as ${ }^{14} \mathrm{C}$-dated charcoal from $41 \mathrm{BX} 126$ were submitted to Beta Analytic for radiocarbon dating. This was done in order to see if similar dates could be obtained from both wood charcoal and fish otoliths associated with a similar provenience. The results provided in Table 10-9, demonstrate that the otolith dates are consistently older than the wood charcoal dates; differences range between 1,370 and 3,060 years.

\section{Discussion}

A paucity of freshwater subsistence data exists for the Central Texas region, although Ricklis (1995) has noted a marked increase in fish otoliths occurring in Texas coastal sites around 2300-2000 B.P. Fish otoliths are rarely recovered from archaeological sites due to a combination of their small size and data recovery techniques (i.e., quarter-inch screens). In addition, otoliths are composed of calcium carbonate and are not well preserved except in alkaline or neutral $\mathrm{pH}$ soils (Wheeler and Jones 1989). Nevertheless, the analysis of recovered freshwater fauna (i.e., fish) has not been a focus of subsistence research in central and south Texas. A review of archaeological reports indicate that fish are not generally analyzed beyond the general description of "fish." A more complete analysis of fish remains from archaeological sites could provide data relevant to a changing environment and human adaptation. The analysis of fish otoliths or earstones can lead to the identification of fish species, estimates of fish size, minimum number of individuals, seasonal dating, and the analysis of oxygen isotopes (18/16). By conducting oxygen isotope analysis the temperature of the surrounding water can be calculated, which in turn, aids in the interpretation of the past environment. Fish size may reflect extraction 
Table 10-9. Wood Charcoal and Fish Otolith Dates

\begin{tabular}{|c|c|c|c|c|c|}
\hline Unit & Level & Feature(s) & Wood Charcoal Date & Otolith Date & Difference (years) \\
\hline 8 & 5 & $1.2 / 1.3$ & $4050 \pm 50$ B.P. & $5420 \pm 50$ B.P. & 1370 \\
\hline $8 / 9$ & 6 & 1.3 & $3040 \pm 50$ B.P. & $6100 \pm 60$ B.P. & 3060 \\
\hline 12 & 3 & 7 & $4630 \pm 40$ B.P. & $6360 \pm 60$ B.P. & 1730 \\
\hline C & 8 & 7 & $4940 \pm 50$ B.P. & $6570 \pm 50$ B.P. & 1630 \\
\hline
\end{tabular}

methods (e.g., nets, traps, spears) and seasonal dating is informative in terms of seasonal resource exploitation and seasonal occupation of the site. The data on the use of small freshwater fish by the inhabitants of the Culebra Creek site is a clear example of the importance of flotation sampling and processing of the heavy fraction of site sediments. 


\title{
Chapter 11: Archaeomagnetic and Magnetic Susceptibility Analyses
}

\author{
Wulf A. Gose and David L. Nickels
}

\section{Archaeomagnetic Analyses}

\section{Introduction}

Rock samples from three of the burned features (1.1, 1.2, and 2) uncovered during CAR's 1997 testing at 41BX126 were subjected to archaeomagnetic analyses. Such analyses reveal whether or not a feature has been disturbed since the last heating event and provide an estimate for the temperature to which the rocks were heated. Similar analyses have been applied to several archaeological sites in Texas (e.g., Collins et al. 1990; Gose et al. 1993, 1994a, 1994b) and elsewhere (Collins et al. 1994), but a great deal of additional work is needed to define a secular variation master curve for Texas which would make it possible to use archaeomagnetism for dating burned rock features.

\section{Methods}

CAR collected 120 core samples from fire-cracked limestones in eight features (Table 11-1) by means of a portable rock drill. The cores were oriented according to established paleomagnetic techniques by means of a compass mounted on a goniometer. The elevation of each sample relative to the unit datum was recorded and all samples were identified on a plan-view map.

Twenty-five of the 120 cores were selected for archaeomagnetic analysis based on a review of their context and suitability. These were analyzed in the Paleomagnetic Laboratory, Department of Geological Sciences, The University of Texas at Austin. All samples were subjected to progressive thermal demagnetization in $50^{\circ} \mathrm{C}$ steps from $150^{\circ} \mathrm{C}$ to $500^{\circ} \mathrm{C}$. The characteristic directions of magnetization were obtained after inspection of the data in orthogonal vector projections and principal component analyses (e.g., Butler 1992).
Table 11-1. Archaeomagnetic Samples Collected from 41BX126

Shading Denotes Samples Submitted for Analysis

\begin{tabular}{|c|c|c|c|c|c|}
\hline Sample & $\begin{array}{l}\text { Unit/ } \\
\text { BHT }\end{array}$ & Level & Feature & $\begin{array}{c}\text { Declination } \\
\text { (Degrees) }\end{array}$ & $\begin{array}{r}\text { Inclination } \\
\text { (Degrees) }\end{array}$ \\
\hline 1 & 1 & 4 & 2 & 50 & 40 \\
\hline 2 & 1 & 4 & 2 & 192 & 51 \\
\hline 3 & 1 & 4 & 2 & 296 & 77 \\
\hline 4 & 1 & 4 & 2 & 6 & 74 \\
\hline 5 & 1 & 4 & 2 & 278 & 72 \\
\hline 6 & 1 & 4 & 2 & 118 & 63 \\
\hline 7 & 1 & 4 & 2 & 224 & 51 \\
\hline 8 & 1. & 4 & 2 & 268 & 85 \\
\hline 9 & 1 & 4 & 2 & 48 & 67 \\
\hline 10 & 1 & 4 & 2 & 136 & 80 \\
\hline 11 & 1 & 4 & 2 & 67 & 67 \\
\hline 12 & 1 & 4 & 2 & 154 & 59 \\
\hline 13 & 4 & 4 & 4 & 144 & 62 \\
\hline 14 & 4 & 4 & 4 & 46 & 59 \\
\hline 15 & 4 & 4 & 4 & 52 & 55 \\
\hline 16 & 4 & 4 & 4 & 65 & 42 \\
\hline 17 & 4 & 4 & 4 & 332 & 44 \\
\hline 18 & 4 & 4 & 4 & 321 & 48 \\
\hline 19 & 4 & 4 & 4 & 278 & 51 \\
\hline 20 & 7 & 3 & 1.1 & 216 & 2 \\
\hline 21 & 7 & 3 & 1.1 & 256 & 51 \\
\hline 22 & 7 & 3 & 1.1 & 151 & 51 \\
\hline 23 & 7 & 3 & 1.1 & 190 & 62 \\
\hline 24 & 7 & 3 & 1.1 & 192 & 11 \\
\hline 25 & 7 & 3 & 1.1 & 197 & 11 \\
\hline 26 & 7 & 3 & 1.1 & 241 & 48 \\
\hline 27 & 7 & 3 & 1.1 & 249 & 36 \\
\hline 28 & 7 & 3 & 1.1 & 68 & 65 \\
\hline 29 & 7 & 3 & 1.1 & 109 & 60 \\
\hline 30 & 7 & 3 & 1.1 & 200 & 57 \\
\hline 31 & 7 & 3 & 1.1 & 218 & 56 \\
\hline 32 & 7 & 3 & 1.1 & 351 & 41 \\
\hline 33 & 7 & 4 & 1.1 & 132 & 82 \\
\hline 34 & 7 & 4 & 1.1 & 60 & 70 \\
\hline 35 & 7 & 4 & 1.1 & 322 & 82 \\
\hline
\end{tabular}


Table 11-1. Continued

\begin{tabular}{|c|c|c|c|c|c|}
\hline Sample & $\begin{array}{l}\text { Unit/ } \\
\text { BHT }\end{array}$ & Level & Feature & $\begin{array}{c}\text { Declination } \\
\text { (Degrees) }\end{array}$ & $\begin{array}{c}\text { Inclination } \\
\text { (Degrees) }\end{array}$ \\
\hline 36 & 7 & 3 & 1.1 & 195 & 68 \\
\hline 37 & 7 & 3 & 1.1 & 147 & 37 \\
\hline 38 & 7 & 3 & 1.1 & 350 & 59 \\
\hline 39 & 7 & 3. & 1.1 & 114 & 52 \\
\hline 40 & 7 & 3. & 1.1 & 195 & 67 \\
\hline 41 & 8 & 4 & 1.2 & 352 & 80 \\
\hline 42 & 8 & 4 & 1.2 & 3 & 76 \\
\hline 43 & 8 & 4 & 1.2 & 324 & 70 \\
\hline 44 & 8 & 4 & 1.2 & 4 & 79 \\
\hline 45 & 8 & 4 & 1.2 & 65 & 49 \\
\hline 46 & 8 & 4 & 1.2 & 83 & 69 \\
\hline 47 & 8 & 4 & 1.2 & 106 & 44 \\
\hline 48 & 8 & 4 & 1.2 & 236 & 71 \\
\hline 49 & 8 & 4 & 1.2 & 102 & 36 \\
\hline 50 & 8 & 5 & 1.2 & 97 & 52 \\
\hline 51 & 8 & 5 & 1.2 & 100 & 63 \\
\hline 52 & 8 & 5 & 1.2 & 94 & 66 \\
\hline 53 & 8 & 5 & 1.2 & 7 & 64 \\
\hline 54 & 8 & 5 & 1.2 & 355 & 86 \\
\hline 55 & 8 & 5 & 1.2 & 94 & 61 \\
\hline 56 & 8 & 5 & 1.2 & 234 & 26 \\
\hline 57 & 8 & 5 & 1.2 & 316 & 46 \\
\hline 58 & 8 & 5 & 1.2 & 4 & 70 \\
\hline 59 & 8 & 5 & 1.2 & 6 & 71 \\
\hline 60 & 8 & 5 & 1.2 & 12 & 61 \\
\hline 61 & 8 & 5 & 1.2 & 232 & 37 \\
\hline 62 & 8 & 5 & 1.2 & 118 & 62 \\
\hline 63 & 8 & 5 & 1.2 & 289 & 64 \\
\hline 64 & 8 & 5 & 1.2 & 236 & 68 \\
\hline 65 & 9 & 6 & 1.3 & 10 & 64 \\
\hline 66 & 9 & 6 & 1.3 & 321 & 76 \\
\hline 67 & 9 & 6 & 1.3 & 180 & 54 \\
\hline 68 & 9 & 6 & 1.3 & 179 & 56 \\
\hline 69 & 9 & 6 & 1.3 & 167 & 75 \\
\hline 70 & 9 & 6 & 1.3 & 58 & 55 \\
\hline 71 & 9 & 6 & 1.3 & 359 & 40 \\
\hline 72 & 9 & 6 & 1.3 & 24 & 67 \\
\hline 73 & 9 & 6 & 1.3 & 10 & 70 \\
\hline 74 & 9 & 6 & 1.3 & 250 & 30 \\
\hline 75 & 9 & 6 & 1.3 & 253 & 53 \\
\hline 76 & 12 & 3 & 7 & 113 & 36 \\
\hline 77 & 12 & 3 & 7 & 282 & 52 \\
\hline 78 & 12 & 3 & 7 & 235 & 55 \\
\hline 79 & 12 & 3 & 7 & 297 & 35 \\
\hline 80 & 20 & 2 & 11 & 233 & 57 \\
\hline 81 & 20 & 2 & 11 & 223 & 49 \\
\hline 82 & 20 & 2 & 11 & 145 & 62 \\
\hline 83 & 20 & 2 & 11 & 172 & 49 \\
\hline 84 & 20 & 2 & 11 & 197 & 74 \\
\hline 85 & 20 & 2 & 11 & 126 & 74 \\
\hline 86 & 20 & 2 & 11 & 267 & 65 \\
\hline 87 & 20 & 2 & 11 & 102 & 65 \\
\hline
\end{tabular}

Table 11-1. Continued

\begin{tabular}{|c|c|c|c|c|c|}
\hline Sample & $\begin{array}{l}\text { Unit/ } \\
\text { BHT }\end{array}$ & Level & Feature & $\begin{array}{c}\text { Declination } \\
\text { (Degrees) }\end{array}$ & $\begin{array}{c}\text { Inclination } \\
\text { (Degrees) }\end{array}$ \\
\hline 88 & 19 & 2 & 11 & 232 & 58 \\
\hline 89 & 15 & 2 & 12 & 348 & 40 \\
\hline 90 & 15 & 2 & 12 & 183 & 36 \\
\hline 91 & 20 & 2 & 12 & 38 & 38 \\
\hline 92 & 20 & 2 & 12 & 328 & 40 \\
\hline 93 & 20 & 2 & 12 & 228 & 51 \\
\hline 94 & 14 & 3 & 12 & 292 & 44 \\
\hline 95 & 14 & 3 & 12 & 222 & 22 \\
\hline 96 & 14 & 3 & 12 & 256 & 51 \\
\hline 97 & 14 & 3 & 12 & 241 & 49 \\
\hline 98 & 14 & 3 & 12 & 233 & 39 \\
\hline 99 & 14 & 3 & 12 & 297 & 45 \\
\hline 100 & 14 & 3 & 12 & 160 & 43 \\
\hline 101 & 14 & 3 & 12 & 312 & 47 \\
\hline 102 & 14 & 3 & 12 & 296 & 46 \\
\hline 103 & 14 & 3 & 12 & 79 & 56 \\
\hline 104 & 15 & 3 & 12 & 130 & 72 \\
\hline 105 & 15 & 3 & 12 & 192 & 64 \\
\hline 106 & 15 & 3 & 12 & 146 & 57 \\
\hline 107 & 15 & 3 & 12 & 128 & 70 \\
\hline 108 & 15 & 3 & 12 & 163 & 48 \\
\hline 109 & 15 & 3 & 12 & 314 & 45 \\
\hline 110 & 17 & 3 & 11 & 18 & 48 \\
\hline 111 & 16 & 3 & 11 & 341 & 56 \\
\hline 112 & 16 & 3 & 11 & 28 & 69 \\
\hline 113 & 18 & 3 & 12 & 60 & 48 \\
\hline 114 & 18 & 3 & 12 & 13 & 90 \\
\hline 115 & 18 & 3 & 12 & 219 & 53 \\
\hline 116 & 20 & 3 & 11 & 271 & 56 \\
\hline 117 & 20 & 3 & 11 & 240 & 41 \\
\hline 118 & 20 & 3 & 11 & 307 & 74 \\
\hline 119 & 20 & 3 & 11 & 199 & 52 \\
\hline 120 & 20 & 3 & 11 & 77 & 34 \\
\hline
\end{tabular}

Archaeomagnetic analyses are based on the observation that most rocks contain a small amount of magnetic minerals such as magnetite or hematite. During the process of rock formation, these minerals will align with the ambient magnetic field and impart a remanent magnetization to the rock parallel to the field, usually the geomagnetic field. Under a wide range of conditions, this information is preserved. The directions of magnetization of a random assemblage of rocks will have a random distribution. If the same rocks are heated in a fireplace, they will acquire a new thermoremanent magnetization parallel to the magnetic field present at the time of cooling. By collecting oriented samples from the rocks of a possible fireplace, 
Figure 11-1. Vector component diagrams for samples from Feature 1.1. Open squares are the projection onto the updown-horizontal plane and crosses represent projection onto the N-S-E-W plane Scale is given below the sample number. Samples were thermally demagnetized at $150^{\circ}, 200^{\circ}$, $250^{\circ}, 300^{\circ}, 350^{\circ}, 400^{\circ}, 450^{\circ}$, and $500^{\circ} \mathrm{C}$.

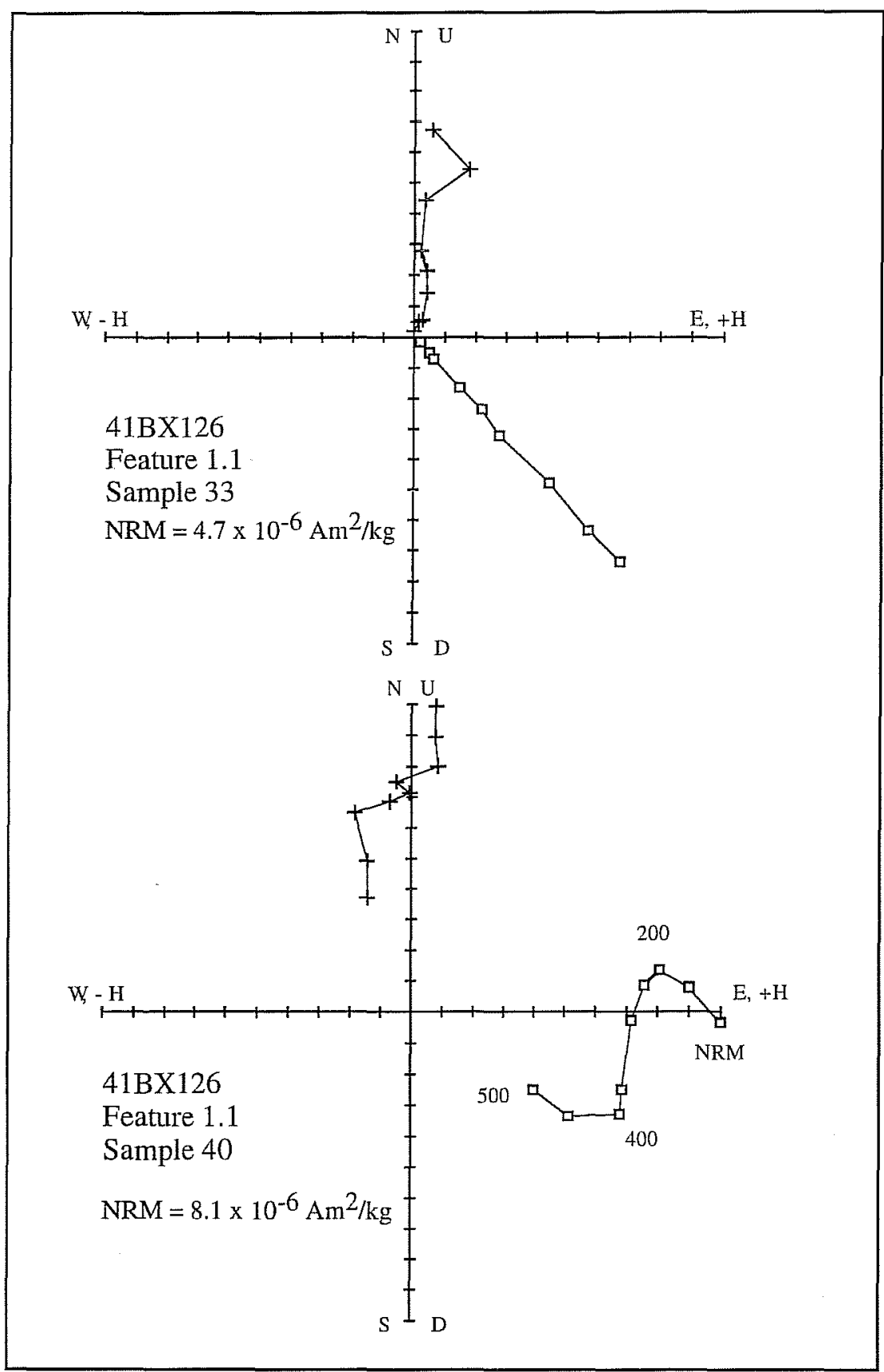

to estimate the maximum temperature the rock sample has experienced.

The results of the magnetic measurements of each sample are inspected in a vector component diagram, an example of which is shown in Figure 11-1. In this diagram, the magnetic vector is projected onto a N-S-E-W plane as well as an UpDown-Horizontal plane. Each point corresponds to the end point of the magnetic vector after a particular demagnetization step. A stable component of magnetization is recognized by three or more colinear points. The advantage of this approach is that multiple components of magnetization can be more readily identified. The components are calculated by the principal component method and then displayed on a stereographic net. In this net, the declination is counted clockwise along the perimeter and the inclination increases from zero at the perimeter to $90^{\circ}$ at the center of the net. Importantly, the stereonet represents both hemispheres. Directions with a positive inclination are shown by solid symbols whereas directions with negative inclinations are depicted by open circles (Figure 11-2).

\section{Burned Rock Features at $41 B X 126$}

\section{Feature 1.1}

Feature 1.1, in the midden framework (Figure 6-22), is interpreted as an intact heating

it can be readily ascertained whether or not these rocks have remained undisturbed since their last heating, i.e., whether or not they do represent a fireplace. Detailed thermal demagnetization makes it sometimes possible element. Figure 11-1 shows the vector component diagrams of two samples from Feature 1.1. Sample 33 exhibits a univectorial decay towards the origin implying that this sample contains only one component 


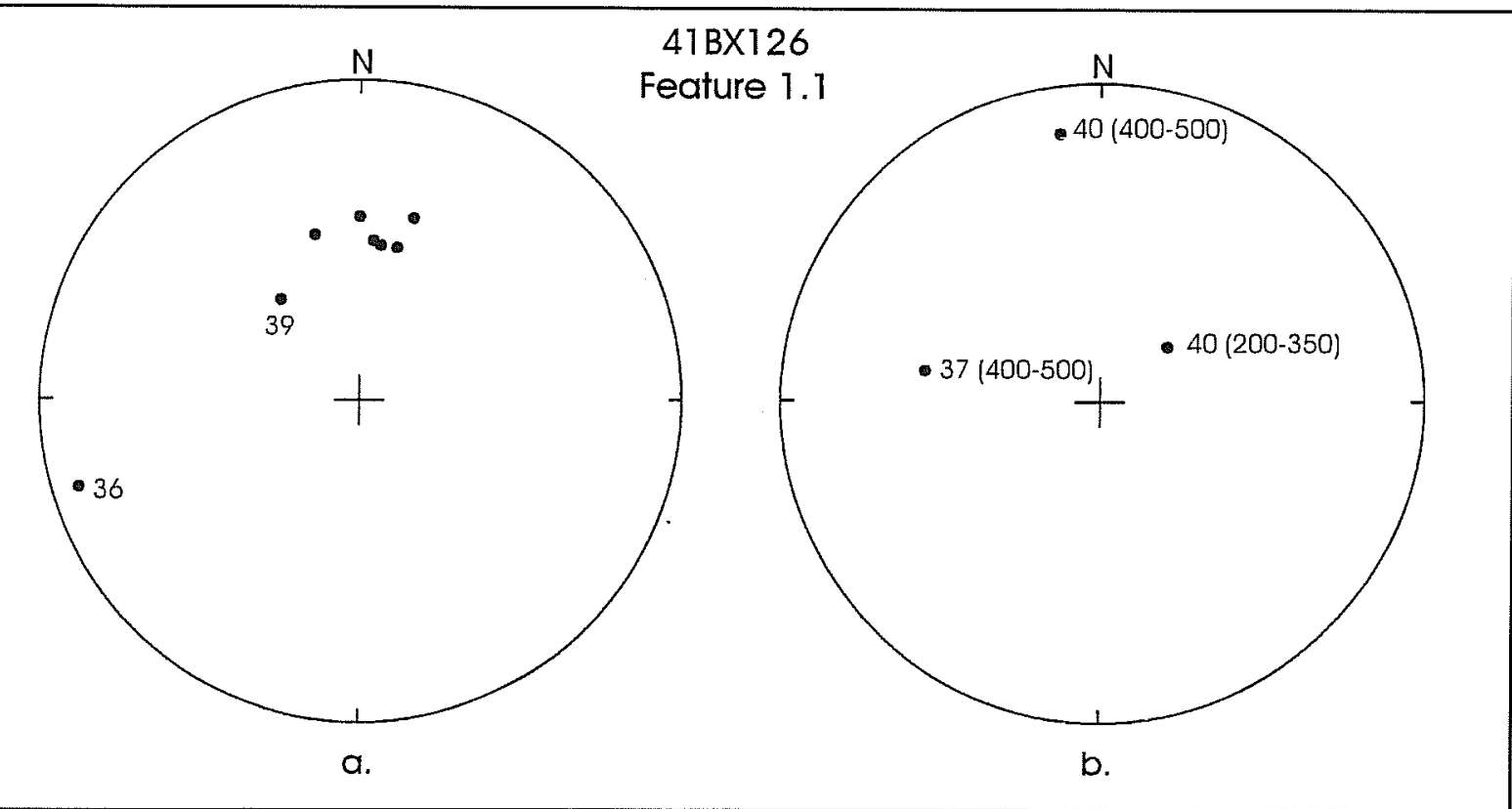

Figure 11-2. Equal-area stereographic projections of the directions of magnetization, calculated by the principal component method, for samples from Feature 1.1. Open symbols are in the northern hemisphere, and solid symbols are in the southern hemisphere. In Figure 11-2b, the numbers in parentheses indicate the temperature range in which the components was identified.

of magnetization. By contrast, Sample 40 indicates three components in the temperature ranges from $\mathrm{NRM}-200^{\circ} \mathrm{C}, 200^{\circ} \mathrm{C}-400^{\circ} \mathrm{C}$, and $400^{\circ} \mathrm{C}-500^{\circ} \mathrm{C}$. The best defined directions of magnetization for the eight rocks from Feature 1.1 are depicted in Figure 11-2a. The directions cluster well except for the direction of Rock 36. Thus all rocks but Rock 36 have remained in situ since their last heating. Figure 11-2b shows the directions of the other magnetic components identified by the principal component analyses (compare with Figure 11-1). These directions are roughly similar to the directions in Figure 11-2a. A possible interpretation is that these two rocks moved after they had reached a temperature in excess of $500^{\circ} \mathrm{C}$ such as may be caused by a collapsing fireplace. Sample 40 moved a second time after cooling to $200^{\circ} \mathrm{C}$. Only its low-temperature component $\left(\mathrm{T}<200^{\circ} \mathrm{C}\right)$ agrees with the other samples and is the direction plotted in Figure 11-2a.

\section{Feature 1.2}

Feature 1.2, in the midden core, is interpreted as a slightly disturbed fireplace (Figure 11-3). The vector component diagrams for samples from Feature 1.2 typically show multiple components of magnetization (Figure 11-4). The corresponding directions are shown in Figure 11-5. The grouping of the best defined directions (Figure 11-5a) implies that the rocks have remained more or less undisturbed. Rock 53 is turned upside down. The directions of the second components is displayed in Figure 11-5b. For all but Rock 64, these directions correspond to the high temperature component. Their scatter appears to be larger than would be expected from a collapsing fireplace. The data suggest that the samples were subjected to multiple heating, i.e., they were recycled.

\section{Feature 2}

Feature 2, in Area A, is interpreted as a disturbed burned rock heating element. Individually, the samples from Feature 2 are magnetically well behaved (Figure 11-6). However, their directions cannot be readily interpreted. Rocks 3, 4, 5, and 6, and possibly Rock 8 have directions which seem to indicate a somewhat disturbed fireplace, but Rocks 1 and 2 have been 


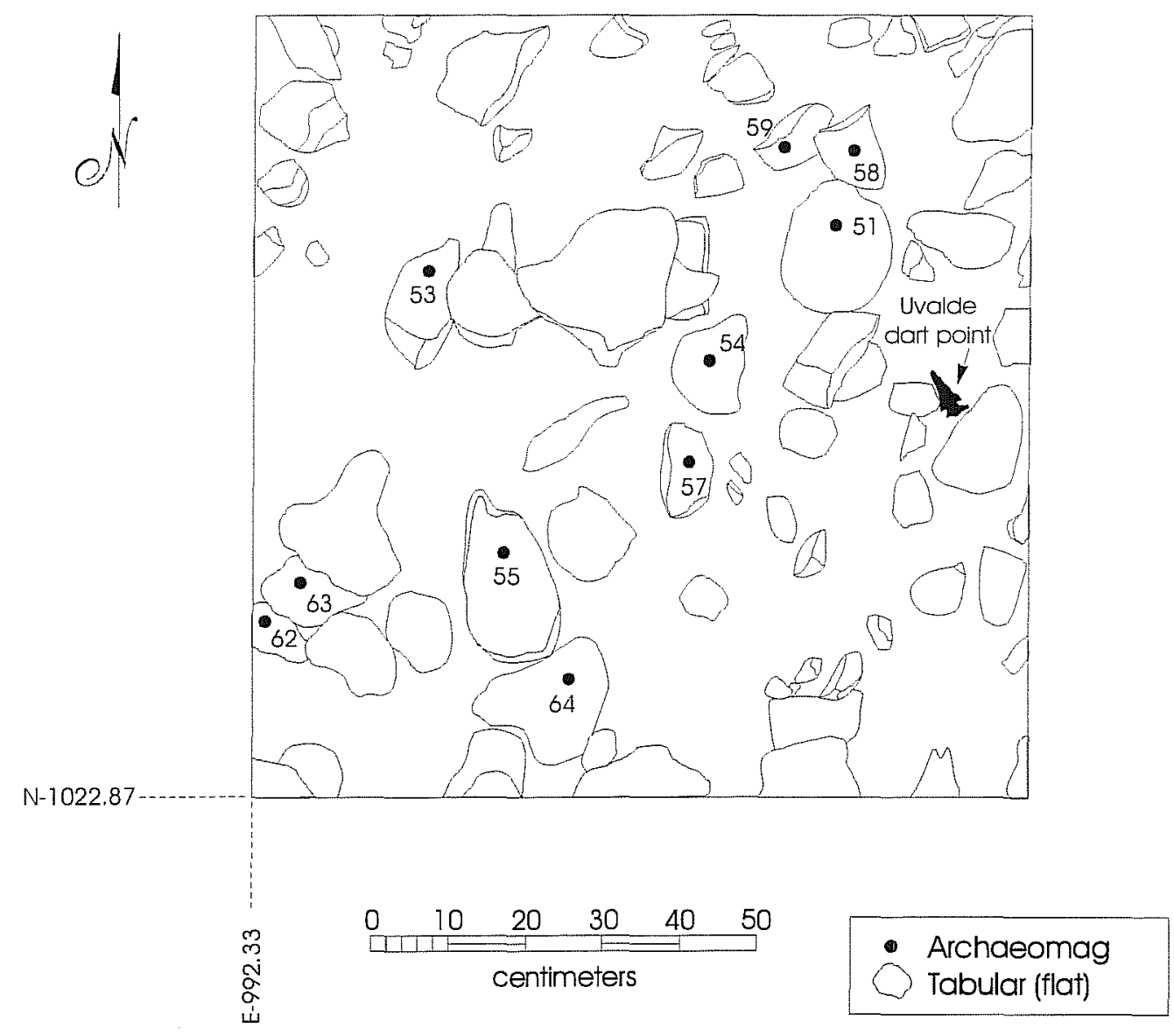

Figure 11-3. Plan view of Feature 1.2 in Level 5 of TU 8 showing locations of archaeomagnetic samples.

flipped (Figure 11-7a). Four rocks have a distinct hightemperature magnetization (Figure 11-7b). Their directions scatter extremely, arguing for a prior heating event.

\section{Magnetic Susceptibility Analyses}

\section{Introduction}

When a piece of material is placed in a magnetic field it will acquire an induced magnetization. For small magnetic fields, of the order of the Earth's magnetic field, this magnetization is linearly proportional to the inducing magnetic field. The constant of proportionality is the magnetic susceptibility (MS). The low-field susceptibility is proportional to the concentration and grain size of the ferro- and ferrimagnetic constituents of the material. The MS of a natural soil sample can be modified by pedogenic as well as cultural processes. Both tend to enhance the MS. In pedogenic studies, a significant increase in MS has been observed in the A horizon of soil profiles, probably due to the creation of maghemite as a result of organic activities (e.g., Singer and Fine 1989). Climatic changes will also effect the MS (e.g., Heller and Evans 1995). The cultural contribution to soil susceptibility derives mainly from the ash of burned wood which can have large MS values, particularly if multiple heating was involved (e.g., McClean and Kean 1993). In carbonaceous soils, such as encountered in Central Texas, the increase in MS due to this cultural input is very significant (Collins et al. 1994). 


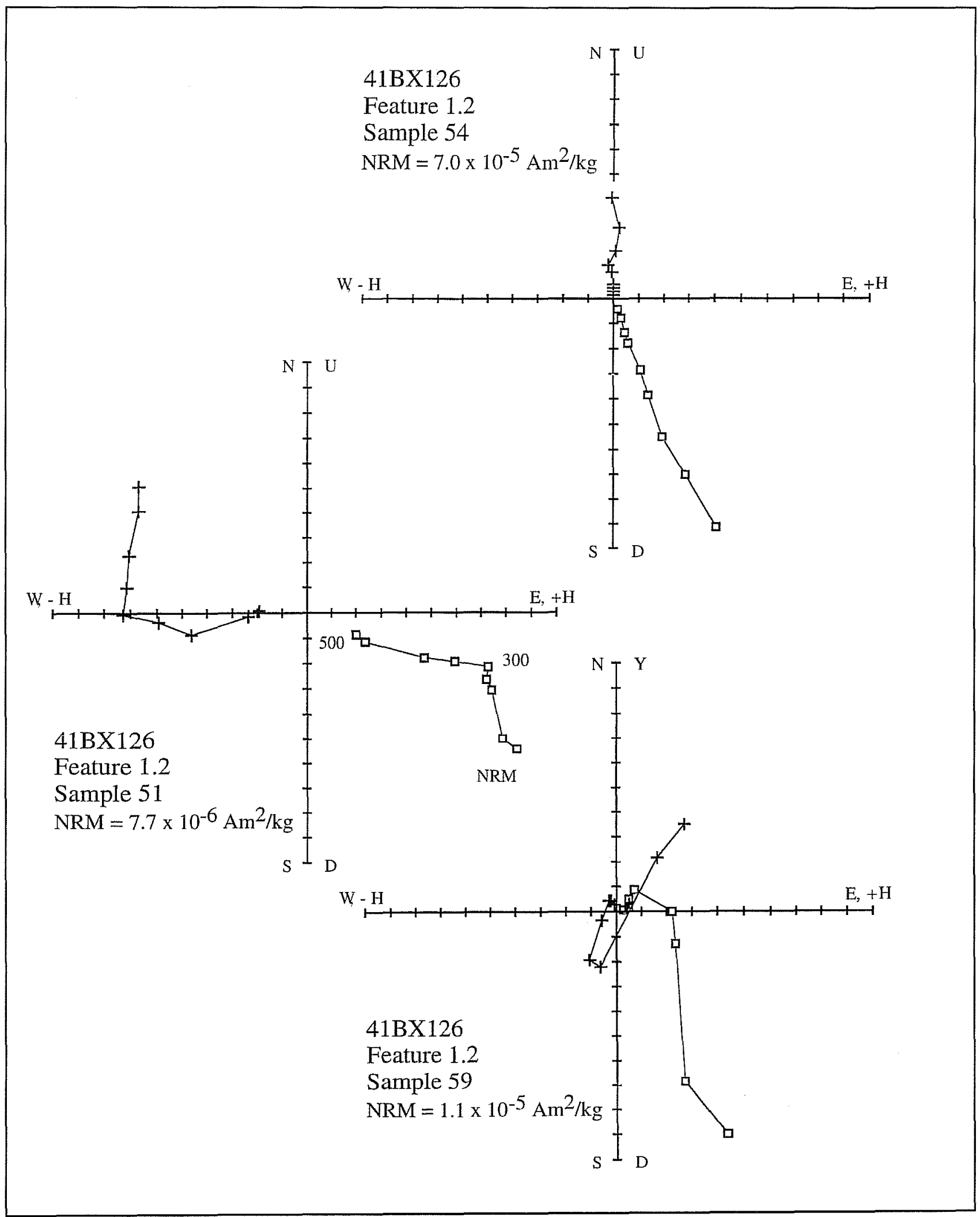

Figure 11-4. Vector component diagrams for samples from Feature 1.2. 


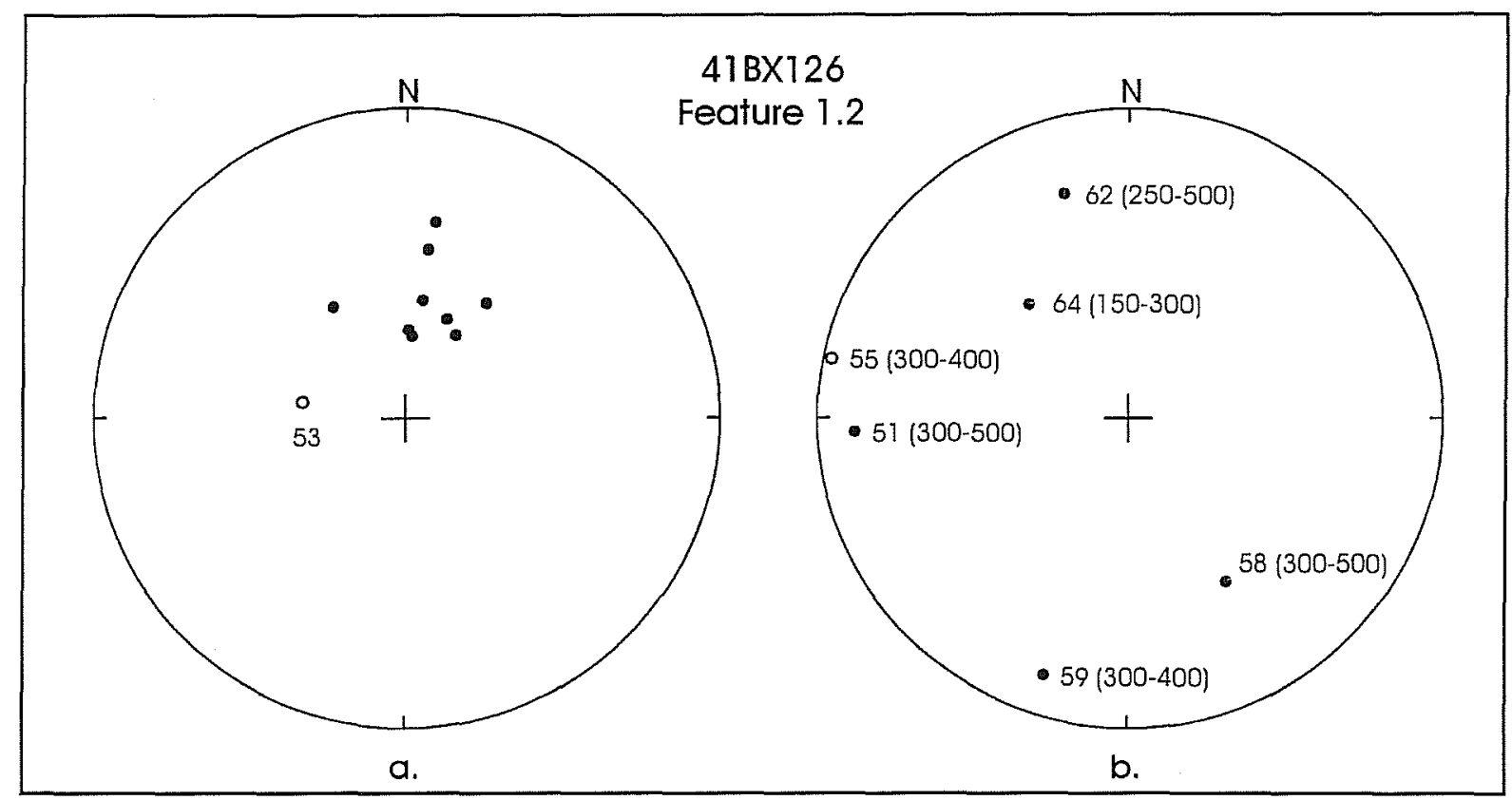

Figure 11-5. Stereographic projections of the characteristic directions of magnetization for samples from Feature 1.2. The net to the right shows the directions of the high temperature components. The scatter suggests recycling.

During CAR's 1997 investigation at 41BX126, samples for magnetic susceptibility studies were collected in four vertical profiles. BHT N was dug in an east-west direction in Area A (Figure 6-14). Susceptibility column 1 was taken from the south wall, one meter west of the junction of BHTs $\mathrm{N}$ and $\mathrm{P}$. The closest feature observed was Feature 7, six meters to the west. BHT S was dug on a north-south plane in Area A (Figure 6-2). Two burned rock features (2 and 3) were exposed in profile. Soil susceptibility column 2 was collected from the west wall, cutting vertically through the north edge of Feature 2. Column 3 was taken from the west wall, $4 \mathrm{~m}$ north of Feature 2, and column 4 from the west wall, $10 \mathrm{~m}$ south of Feature 3.

For each sample column, a 10-cm vertical face of the trench wall was scraped horizontally with a clean trowel to provide a fresh exposure and avoid possible contamination in the open trench. A tape measure was placed vertically on the trench wall and a $>2 \mathrm{~cm}^{3}$ of sediment was taken with a trowel every $3 \mathrm{~cm}$ down the face of the trench. The trowel was wiped clean after each sample was collected, and care was taken to bite into the wall to obtain an uncontaminated sample. Samples were collected in plastic bags which were labeled with provenience information. In the laboratory, the samples were placed in 2- $\mathrm{cm}^{3}$ plastic cubes for measurement in a Bartington susceptibility meter.

\section{Susceptibility Profiles in Area A}

In Area A, three susceptibility profiles were collected, each covering a vertical section of about one meter. Profiles 3 and 4 (Figure 11-8) show very low values of the MS typical for carbonaceous soils, with only minor variations. These profiles do not show any evidence of cultural activity. By contrast, the MS values are greatly enhanced in Profile 2 (Figure 11-8). From 99.53-99.95 $\mathrm{m}$, the MS is about twice that of the values in Profiles 3 and 4. The slight decrease upsection suggests decreasing cultural contribution. Above 99.95 $\mathrm{m}$, the susceptibility steadily increases with large variations among neighboring data points. Because the increase in MS is most certainly due to the contribution from wood ash, the spikes are readily explained by the varying concentrations of ash as was demonstrated for the Dust Cave site in Alabama (Collins et al. 1994). The overall increase in susceptibility above $99.95 \mathrm{~m}$ argues for increased human activity. 


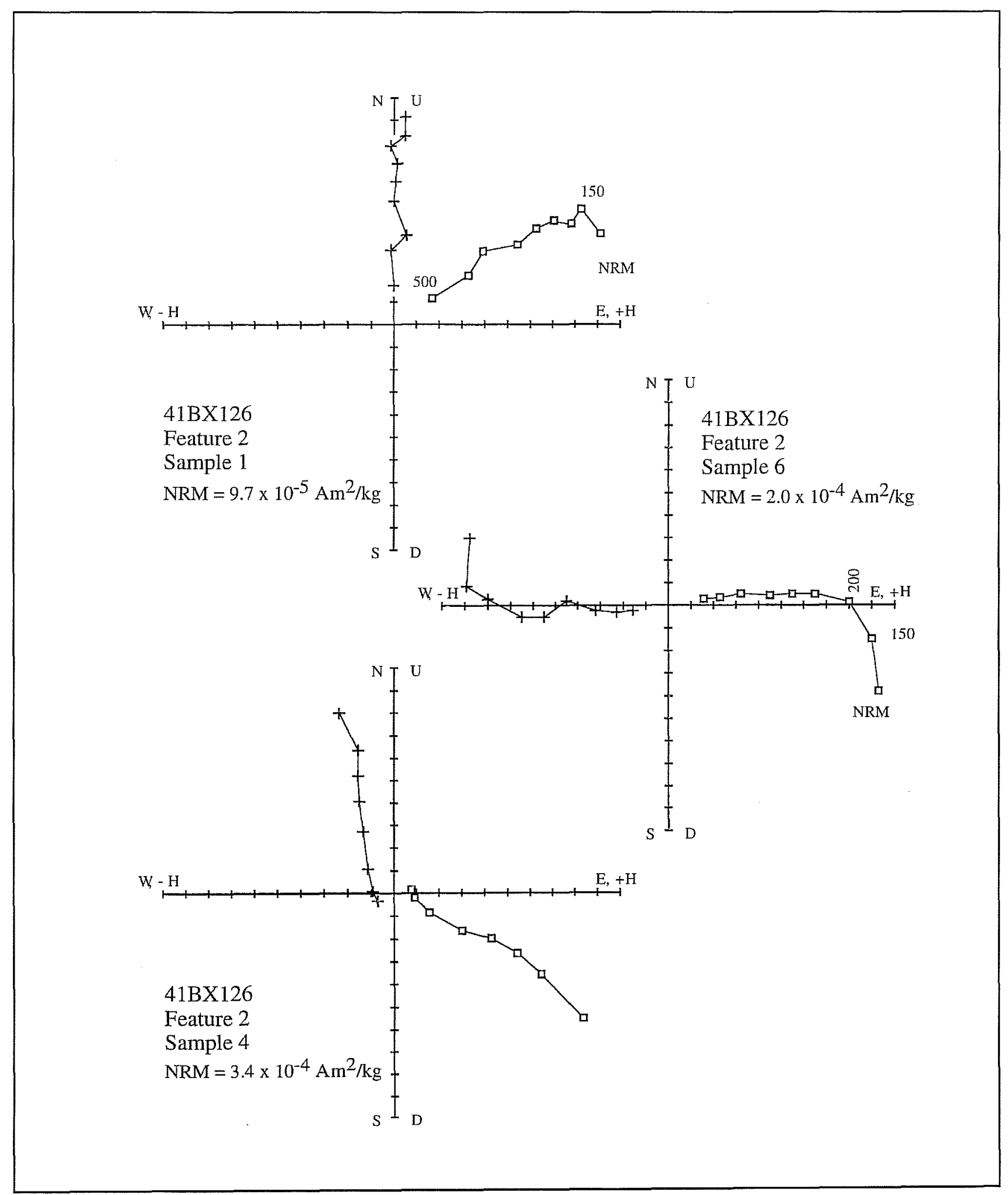

Figure 11-6. Vector component diagrams for samples from Feature 1.2. 


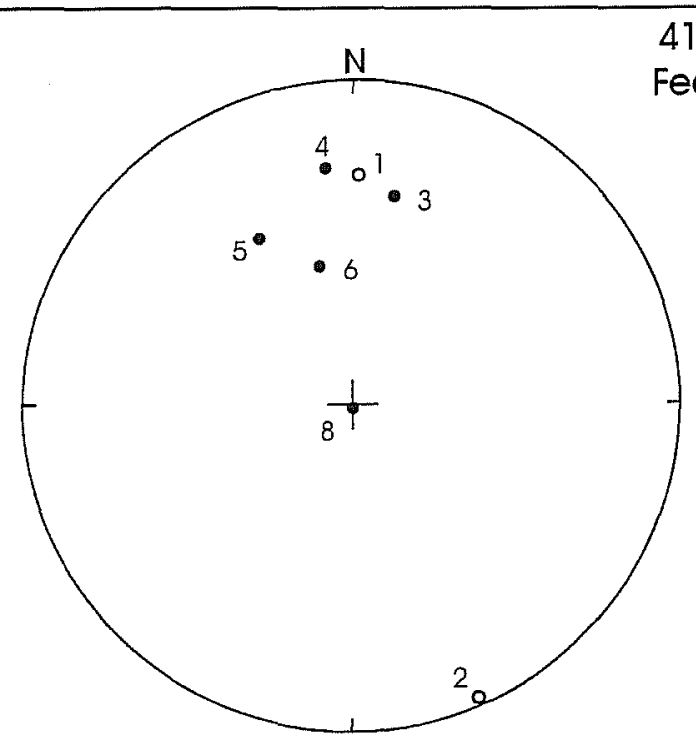

a.

Low Temperature Component
$418 \times 126$

Feature 2

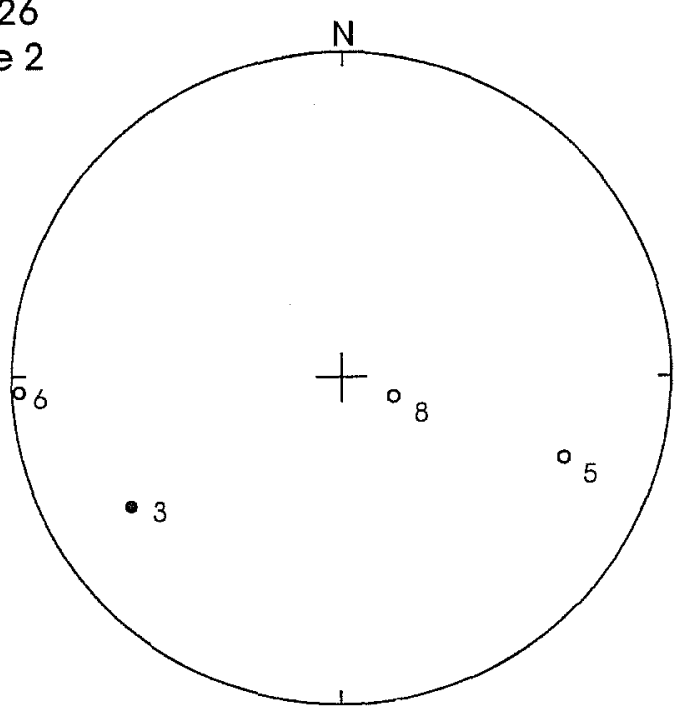

b.

High Temperature Component

Figure 11-7. Directions of the low- and high-temperature components for samples from Feature 2. Samples 1, 6, and 8 have low-temperature components which imply that the rocks have been turned over. The high-temperature components scatter suggesting a prior heating event.

\section{Susceptibility Profile in Area B}

Soil susceptibility column 1 was collected in Area B in the periphery of the main midden (Feature 1). Thus not surprisingly, the susceptibility values are large, greater than the values from Area A (Figure 11-9). The general increase in MS upsection suggests increased human activity up to the $100.29 \mathrm{~m}$ level where the MS starts to decrease. The data could be interpreted to indicate several episodes of occupation.

\section{Discussion}

The MS profiles are readily explained in terms of proximity to burned rock features. In Area A, Profiles 3 and 4 are located away from cooking or heating features and the MS values are typical for carbonaceous soils with no cultural input, whereas Profile 2 cuts vertically through Feature 2. The base of Feature 2 coincides with the marked increase in MS at $100.2 \mathrm{~m}$ elevation. Feature 2 contained wood charcoal dated at $2700 \pm 50$ B.P. and $2780 \pm 50$ B.P. It lies on the surface of a B Horizon, T2 terrace, Depositional Unit IV. The susceptibility values below this horizon are significantly larger than the values in Profiles 3 and 4, suggesting the possibility of buried occupation surfaces to the base of the sampled section.

Profile 1 is located in Area B within the main midden's periphery, and near burned rock Features 7, 11, and 12 of the Nolan component. As expected, the MS readings from the midden and Nolan component area are high when compared to Profiles 3 and 4 in Area A. A general increase in MS between site elevations 100.29 $\mathrm{m}$ and $99.55 \mathrm{~m}$ suggests increased human activity and possibly several episodes of human occupation; coincidentally the peak stem in MS at 100.29 correlates stratigraphically with the base of the midden and Feature 1.3 at site elevation $100.3 \mathrm{~m}$. A noticeable increase in MS occurs between $100.0 \mathrm{~m}$ and $99.8 \mathrm{~m}$, correlating stratigraphically with Feature 7, 11, and 12 in the Nolan component. 

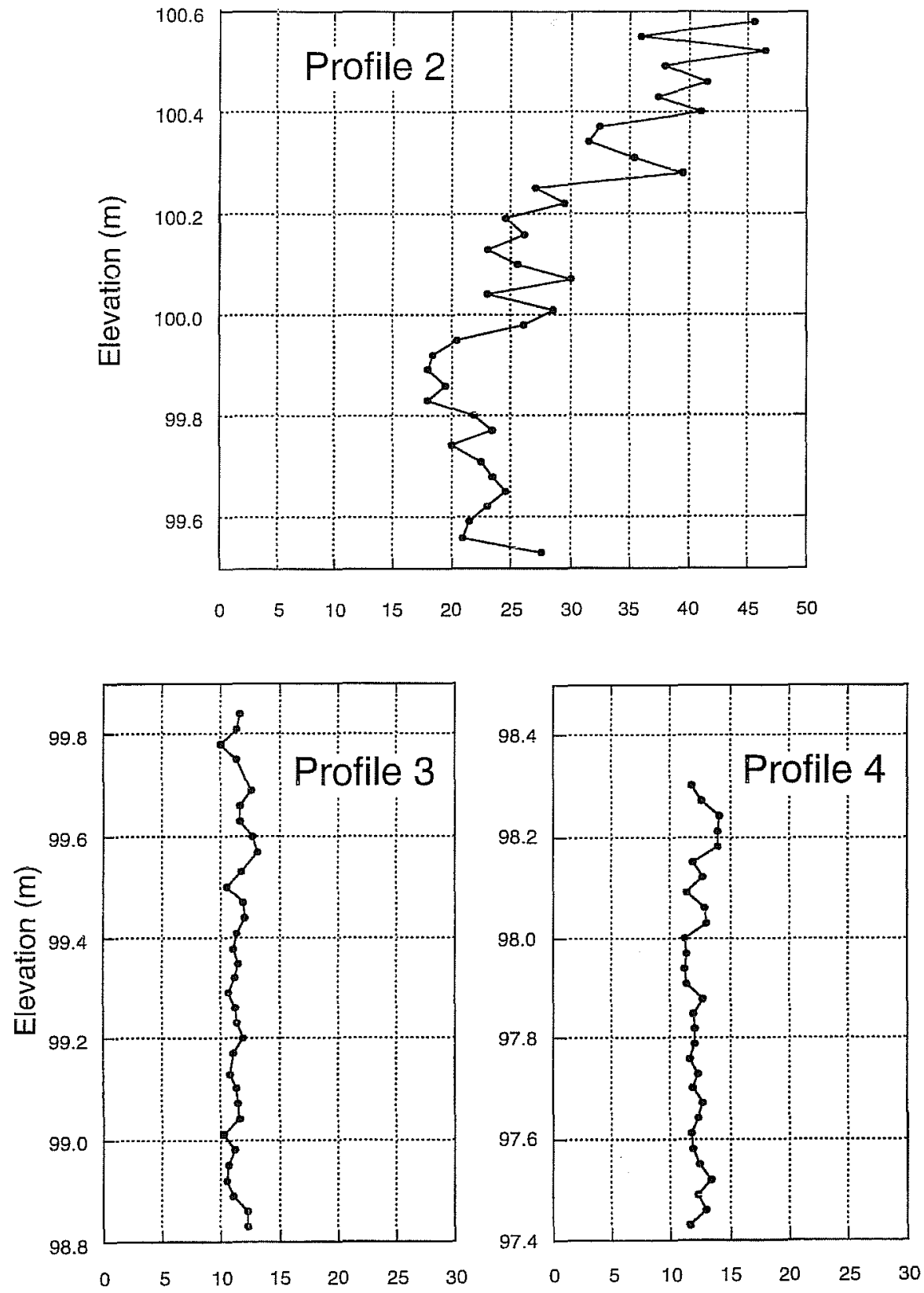

Susceptibility $\left(\times 10^{-6} \mathrm{cgs}\right)$

Figure 11-8. Magnetic susceptibility profiles of soil samples from Area A, BHT S. Only Profile 2 shows evidence of human activity. 


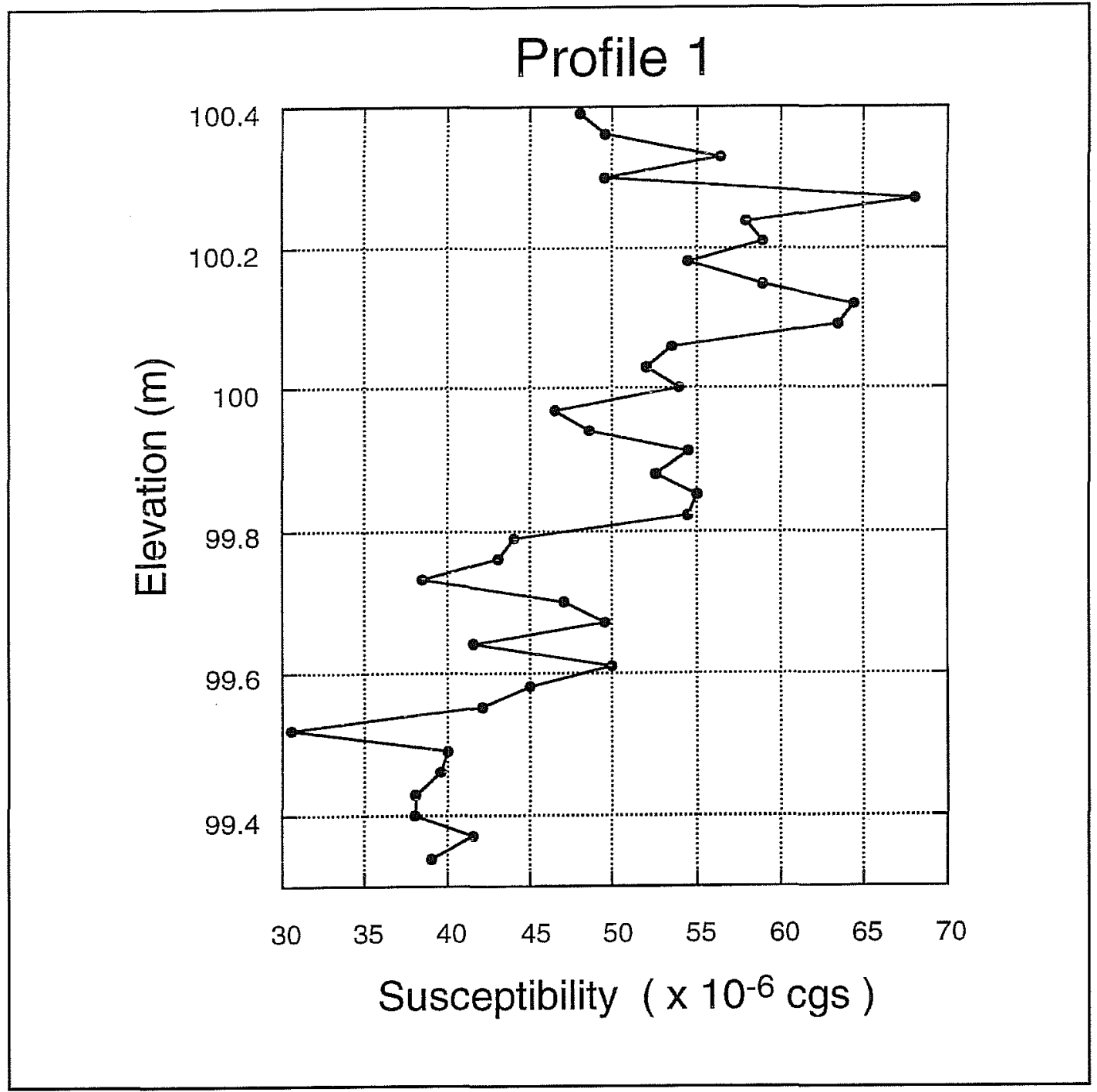

Figure 11-9. Magnetic susceptibility Profile 1 of soil samples from Area $B, B H T N$, located in the periphery of the midden. Note the large values compared to the profiles in Area A. 


\title{
Chapter 12: Summary, Conclusions, and Recommendations
}

\author{
C. Britt Bousman and David L. Nickels
}

\section{Summary of Work}

The purpose of the 1997 testing project by CAR was to synthesize the results of three testing projects at 41BX126; to evaluate the eligibility of 41BX126 for nomination to the National Register of Historic Places, as it was threatened by planned highway construction activities; and to provide the Texas Department of Transportation (TxDOT) with a recommendation concerning further investigations. Two earlier testing projects by TxDOT archaeologists identified cultural resources which required further archaeological investigations (additional testing on a new right-of-way and analysis of all recovered materials) to determine the eligibility of $41 \mathrm{BX} 126$. TxDOT funded the archaeological investigations through state appropriations and acted as the agency for management of archaeological compliance-related activities during the duration of the testing projects. The planned construction project expanding Loop 1604 will include federal funds, making this a federal undertaking.

For management purposes CAR divided the site into three areas: Area A being the new right-of-way east of Loop 1604 investigated only by CAR; Area B being the main midden and its periphery between Area $A$ and Loop 1604 (investigated by all three testing projects); and, Area $\mathrm{C}$ being west of Loop 1604 and investigated primarily by the two TxDOT projects (see Figure 2-1). In all, 37 backhoe trenches were opened and in some cases reopened, $551-\mathrm{x}-1-\mathrm{m}$ and $50-\mathrm{x}-50-\mathrm{cm}$ test units were excavated, 36 shovel tests were dug, and eight Gradall trenches were exposed. The excavations documented 17 burned rock features, six of which were directly associated with the main midden and eleven were interpreted as separate heating or cooking features. A discreet Nolan component was investigated stratigraphically below the base of the midden. Over 59,000 lithic artifacts, 1,655 liters of float samples, 3,337 $\mathrm{kg}$ of burned rock, and nearly $300 \mathrm{~g}$ of faunal material were collected, processed, and analyzed from all three projects by CAR (Chapters 8 and 10; Appendixes E and $F$ ). Nineteen flotation samples were analyzed for macrobotanical remains at Texas A\&M University (Chapter 9). One hundred twenty archaeomagnetic samples were collected from eight features, and 25 of those from three features were processed at the Paleomagnetism Laboratory at The University of Texas at Austin (Chapter 11). Also in Chapter 11 are the analytical results from 136 soil susceptibility samples. In Chapter 5 and Appendix A, geoarchaeological investigations defined the four terraces and four depositional units, thereby contributing to a knowledge of the site's formation processes and Late Quaternary alluvial geology. For chronometric dating, 15 wood-charcoal, six sediment, and four fish-otolith radiocarbon assays were obtained. Sixty-six temporally diagnostic artifacts were recovered.

\section{Archaeological Conclusions}

The available evidence suggests prehistoric inhabitants occupied 41BX126 either continuously or intermittently between approximately 7,000 and 2,000 years ago (Table 6-24). Geological evidence indicates that Culebra Creek left a record of sedimentation that spans some 17,000 years at the site. Portions of four terraces ( $\mathrm{T} 0, \mathrm{~T} 1, \mathrm{~T} 2$, and $\mathrm{T} 3$ ) have escaped erosion by the stream. Within and on these terrace remnants, intact archaeological materials were discovered. The recovery of an Early Archaic Clear Fork gouge, a Guadalupe tool, two Martindale points, and a Uvalde point hint of an earlier human presence, however the present investigations failed to document an intact Early Archaic occupation anywhere at the site.

The three testing projects provided evidence that hunter-gatherers occupied a nearly stable $\mathrm{T} 2$ terrace surface along Culebra Creek and left behind cultural material identified as a discrete Nolan component approximately 4,600 years ago. As the T2 stabilized 
around 4,000 years ago, its surface was occupied by others, primarily Late Archaic hunter-gatherers, who constructed burned rock features, including the main midden. Late Archaic occupations dating to approximately 2700 B.P. occur in slightly later deposits that mantle the eroded surface of the T2 terrace. Diagnostic projectile points include Montell. For some unknown reason, the site or at least this portion of the site was never reoccupied by later groups. These hunter-gatherers utilized a variety of animals including whitetail deer, jackrabbit, cottontail rabbit, squirrel, cotton rat, wood rat, bony fish, and sparrow-sized birds. No plant foods were recovered, although wood charcoal from live oak, hackberry, an arboreal legume, agarita, and chittimwood was recovered.

The midden was a circular subterranean oven that used limestone as a heating element. Indirect evidence suggests that the oven was used many times, although little evidence of the specific food items processed in the oven was recovered. Preliminary results indicate that humans probably transported materials during the construction and use of the burned rock midden, mixing artifacts of different ages in various parts of the midden, and that geological processes redeposited the materials as artifacts were eroded off the framework of the midden down to the midden's periphery. Features identified at the base of the midden may have served as borrow areas for sediment used to construct the oven cap (see Chapter 7). Experimental results also indicate that limestone fractures easily with intensive heating, and thus middens probably built-up rapidly. Gentle flooding episodes and colluvial deposits have and continue to envelope the midden and peripheral burned rock features.

A Nolan component is situated stratigraphically below the midden. The presence of a Nolan component underlying a later Pedernales-Marshall- Montell-Castroville component at a burned rock midden is a pattern repeated at numerous sites (e.g., 41BN63, located northwest of Culebra Creek; 41ME29, Jonas Terrace) including Culebra Creek throughout central and southcentral Texas (Thomas Hester, personal communication 1997). Unfortunately, this situation is often less than ideal, as many of these deposits are often mixed and difficult to separate (e.g., 41BX228, Black and McGraw 1985; 41BX300, Katz 1987; 41BX1,
Lukowski 1988; Wurzbach Parkway; Dan Potter, personal communication 1997). Prewitt (1981a) argues that representative Nolan components existed at the Williams site (Suhm 1959), Crumley site (Kelly 1961), the McCann site (Preston 1969), Greenhaw site (Weir 1979), and Rogers Springs (Prewitt 1974); however, all of these assemblages are mixed components. Later Prewitt (1985) identified several sites with Nolan/ Travis (Clear Fork) components (Table 12-1). However, only one radiocarbon date ( $3750 \pm 90$ B.P.) from the Hawes site (Hays 1982) was assigned by Prewitt to a Nolan component. The single radiocarbon assay ( $4720 \pm 170$ B.P.) from Area I at the Panther Springs site might provide an age estimate for a Nolan component, but this horizon also contains expanding stem projectile point forms that can be considered earlier in time (Black and McGraw 1985). Collins (1995) identified only three moderately well-defined Nolan components at Gibson (Ray 1940), Youngsport (Shafer 1963), and 41GL160 (Kelly 1987); however, all are mixed components and none has associated radiocarbon dates. The two associated radiocarbon dates of $4630 \pm 40$ B.P. and $4940 \pm 50$ B.P. (see Table 6-19) at Culebra Creek provide reliable age estimates for the Nolan component. This determination hints that the assay from Panther Springs may be fairly accurate, although even if it and the assay from Culebra Creek are accurate, a temporal range cannot be estimated.

Area A also appears to have an intact Late Archaic component dominated by Montell projectile points, although a Marshall point and a Pedernales point are also present. Prewitt (1981a) places Montell points along with Marcos and Castroville projectile points in his Uvalde phase, and later argues that this phase spans the interval between 1800 B.P. and 2250 B.P. (Prewitt 1985). However, Collins (1995) suggests that of all the sites that Prewitt uses to construct and date this phase (Table 12-2), only Youngsport and Loeve-Fox sites display even a moderate degree of integrity, and Youngsport lacks radiocarbon assays. Collins (1995) argues that 41TG91 (Creel 1990) does have a Marcos-MontellCastroville component in a geological context with high integrity. At 41TG91, Marcos points are found in a deeply buried context with associated radiocarbon assays. The average of five assays associated with the lower portion of the component is approximately 2620 B.P. The upper portion of this component is 2125 B.P. 
Table 12-1. List of Nolan Components in Texas

Modified from Collins 1995; Prewitt 1981, 1985

Absence of information indicates either poor integrity or no radiocarbon assay.

\begin{tabular}{|c|c|c|}
\hline Site & $\begin{array}{c}{ }^{14} \mathrm{C} \\
\text { Date } \\
\end{array}$ & Reference \\
\hline Dry Comal Creek Survey & & Assad 1978 \\
\hline 41BX1, Olmos Dam & & Assad 1979 \\
\hline Enchanted Rock Survey & & Assad and Potter 1979 \\
\hline Bandera County, no name & & Beasley 1978 \\
\hline Mason Cave & & Benfer and Benfer 1981 \\
\hline $41 \mathrm{~B} \times 228$ & moderate & Black and McGraw 1985 \\
\hline 41B X427, Salado Creek & & Brown et al. 1977 \\
\hline 41WM2, Merrell & & Campbell 1948 \\
\hline 41BX272, Menger & & Chadderdon 1975 \\
\hline 41T V38, Devils Hollow & & Collins 1973 \\
\hline Wilson-Leonard & & Collins et al. 1993; Masson and Collins 1995 \\
\hline Seibel & & Cox 1977 \\
\hline 41LL2, Granite Beach & & Crawford 1965 \\
\hline I-10 Survey & & Crawford 1973 \\
\hline South Concho River survey & & Creel 1978 \\
\hline 41BX126, Culebra Creek & High & Current Project \\
\hline Wurzbach Parkway & & Dan Potter, personal communication \\
\hline 41GL17, No Name Creek & & Denton 1976 \\
\hline Stacy Reservoir survey & & Espey, Huston and Associates 1981 \\
\hline 41GL21, Hop Hill & & Gunn and Mahula 1977 \\
\hline 41WM124, Bryan Fox & & Hays 1982 \\
\hline 41WM267, Cervenka & & Hays 1982 \\
\hline 41W M360 & & Hays 1982 \\
\hline 41W M402 & & Hays 1982 \\
\hline 41W M404 & & Hays 1982 \\
\hline 41WM419 & & Hays 1982 \\
\hline 41WM56, Hawes & & Hays 1982 \\
\hline 41W M57 & & Hays 1982 \\
\hline 41WM61 & & Hays 1982 \\
\hline 41W M65 & & Hays 1982 \\
\hline 41WM71 & & Hays 1982 \\
\hline 41W M73 & & Hays 1982 \\
\hline $41 \mathrm{BN} 63$ & & He ster 1985 \\
\hline 41ME19, La Jita & & He ster and Kelly 1976 \\
\hline 41BC73, Wolf Shelter & & Highley and Lengefeld 1978 \\
\hline 41ME7, Scorpion Cave & & Highley et at. 1977 \\
\hline 41T V627, Booker & & Howard 1983 \\
\hline North Fork testing & & Jackson 1974 \\
\hline $41 \mathrm{HI} 1, \mathrm{Kyle}$ & & Jelks 1962 \\
\hline Proctor Reservoir survey & & Jelks and Tunnell 1960 \\
\hline 41ME29, Jonas Terrace & & Johnson 1995 \\
\hline 41CM2, Footbridge & & Johnson, Suhm, and Tunnell 1962 \\
\hline 41CM3, Wunderlich & & Johnson, Suhm, and Tunnell 1962 \\
\hline $41 \mathrm{~B} \times 300$ & & Katz 1987 \\
\hline
\end{tabular}


Table 12-1. Continued

\begin{tabular}{|c|c|c|}
\hline Site & $\begin{array}{ll}\text { Integrity } & { }^{1 / 4} \mathrm{C} \\
\text { Date }\end{array}$ & Reference \\
\hline 41BX195, Crystal Rivers & & Keller 1976 \\
\hline Lehmann & & Kelley $1947 \mathrm{a}$ \\
\hline 41TV86, Crumley & & Kelly 1961 \\
\hline $41 \mathrm{GL} 160$ & moderate & Kelly 1987 \\
\hline Cibolo Creek survey & & Kelly and Hester 1976 \\
\hline $41 \mathrm{MH} 36$ & & Lintz et al. 1991 \\
\hline $41 \mathrm{KR} 107$, Wounded Eye & & Luke 1980 \\
\hline 41 KR109, Shep & & Luke 1980 \\
\hline Aquilla Lake survey & & Lynott and Peter 1977 \\
\hline Tehuacana Creek survey & & Mallouf and Baskin 1976 \\
\hline Hamilton Creek survey & & McCormick and Filson 1975 \\
\hline Salado Creek survey & & Mc Graw and Valdez 1978 \\
\hline Encino Park survey & & McGraw et al. 1977 \\
\hline Cross Mountain & & McReynolds and Grunewald 1981 \\
\hline Lake Belton & & Miller and Jelks 1952 \\
\hline $41 \mathrm{BN} 8$ & & Patter son 1978 \\
\hline McCann & & Preston 1969 \\
\hline 41TV39, Rogers Springs & & Prewitt 1976 \\
\hline Gibson & moderate & Ray 1940 \\
\hline $\begin{array}{l}\text { 41WM8, Cedar Park } \\
\text { Mound }\end{array}$ & & Schuetz 1957 \\
\hline Cobb's Spring & & Schuetz 1957 \\
\hline Huges & & Schuetz 1957 \\
\hline Lake Locke & & Schuetz 1957 \\
\hline San Gabriel Mound & & Schuetz 1957 \\
\hline Youngsport & moderate & Shafer 1963 \\
\hline $\begin{array}{l}41 \mathrm{CN} 13 \text {, Nor thwest } \\
\text { Laterals }\end{array}$ & & Shafer and Baxter 1976 \\
\hline Granger Lake survey & & Shafer and Corbin 1965 \\
\hline $\begin{array}{l}\text { North \& South non- } \\
\text { Reservoir survey }\end{array}$ & & Shafer and Corbin 1965 \\
\hline $\begin{array}{l}\text { North Fork Reservoir } \\
\text { survey }\end{array}$ & & Shafer and Corbin 1965 \\
\hline $\begin{array}{l}\text { South Fork Reservoir } \\
\text { survey }\end{array}$ & & Shafer and Corbin 1965 \\
\hline Lake Belton testing & & Shafer et al. 1964 \\
\hline 41WM49, John Ischy & & Sorrow 1969 \\
\hline $\begin{array}{l}\text { North Fork Reservoir } \\
\text { testing }\end{array}$ & & Sorrow 1973 \\
\hline 41BL104, Evoe Terrace & & Sorrow et al. 1967 \\
\hline 41BL85, Landslide & & Sorrow et al. 1967 \\
\hline Collins & & Suhm 1955 \\
\hline 41TV42, Smith Shelter & & Suhm 1957 \\
\hline Williams & & Suhm 1959 \\
\hline 41HY29, Greenhaw & & Weir 1979 \\
\hline 41TV151, Jetta Court & & Wesolowsky et al. 1976 \\
\hline 41UV67, Elm Creek & & Young 1979 \\
\hline
\end{tabular}


Table 12-2. List of Montell, Marcos, and Castroville Components in Texas

Modified from Collins 1995; Prewitt 1981, 1985

Absence of information indicates either poor integrity or no radiocarbon assay.

\begin{tabular}{|l|c|c|l|}
\hline \multicolumn{1}{|c|}{ Site } & Integrity & \multicolumn{1}{|c|}{${ }^{14}$ Date } & \multicolumn{1}{|c|}{ Refer ences } \\
\hline 41TG91 & high & yes & Creel 1990 \\
\hline Culebra Creek, 41BX126 & possibly high & yes & Current report \\
\hline La Jita, 41UV21 & & & He ster 1971 \\
\hline Scorpion Cave, 41ME7 & & & Highley et al. 1978 \\
\hline Oblate, 41CM1 & & & Johnson et al. 1962 \\
\hline Wunderlick, 41CM3 & & & Johnson et al. 1962 \\
\hline Crumley, 41TV86 & & & Kelly 1961 \\
\hline Bear Creek Shelter, 41HL17 & & & Lynott 1978 \\
\hline Pohl, 41CM27 & & & Pearson et al. 1965 \\
\hline McCann, 41LM3 & moder ate & yes & Prewitt 1974, 1982 \\
\hline Loeve-Fox, 41W M230 & moderate & & Shafer 1963 \\
\hline Youngsport, 41BL78 & & & Sorrow 1969 \\
\hline John Ischy, 41WM49 & & & Sorrow et al. 1967 \\
\hline Evoe Terrace 41BL104 & & & Story and Shafer 1965 \\
\hline Briton, 41ML37 & & & Valastro et al. 1967 \\
\hline Pecan Springs, 41EL11 & & & Wesolowsky et al. 1976 \\
\hline Jetta Court, 41TV151 & &
\end{tabular}

Creel (1990) notes that Marcos projectile points are found stratified above Montell projectile points in Arenosa Shelter, and implies that these two forms may not occur during the same time spans. The two determinations from intact burned rock features in Area A of the Culebra Creek site ( $2700 \pm 50$ B.P. and $2780 \pm 50$ B.P.) may be an accurate estimation for a Montell component, especially if Montell projectile points were made by a different group of people than those who manufactured Marcos projectile points.

\section{Assessment and Recommendations}

Three aspects at 41BX126 appear to offer the potential for new information. First, the Nolan component was identified and investigated by the block excavation, no unmixed Nolan component is known, and very few, if any, have reliable radiocarbon dates. The block excavation at $41 \mathrm{BX} 126$ did expose an intact, although slightly mixed, Nolan component with burned rock features, and produced reliable and representative radiocarbon assays. The Culebra Creek Nolan component investigation was limited, and although the amount of data recovered appears to constitute a reliable sample for this unique component, additional analysis of cultural material recovered could provide valuable information that would help define the character of an intact Nolan component. Although evidence of Nolan component features were not identified outside the block excavation, without further excavations it cannot be determined exactly how much of the component remains, but a significant intact area probably exists. Should planned construction of the new highway impact the subsurface to the depth of the Nolan component, additional excavations are recommended.

Second, the possible Montell component in Area A has the potential to provide information on this poorly documented interval during the Late Archaic period. The possible Montell component has intact burned rock hearths or cooking features, and a variety of chipped stone tools. The thinness of deposits in this portion of the site and the presence of earlier projectile 
points could be used to argue that the context is poor, but in our opinion this conclusion is unwarranted at this time. Although nearly half of Features 2 and 3 in Area A may have been excavated by CAR, and additional excavations in the Area are limited by privately owned property on the east and a utility trench on the west (Figure 6-2), there is still a substantial portion of the area left intact. Analysis of the cultural material recovered in Area A during the current project indicates this area has the greatest potential to provide high-resolution information regarding residential site spatial organization by these Late Archaic hunter-gatherers. Additional analysis of cultural material recovered during the current project could include chipped stone, but additional samples are required to further evaluate subsistence activities. Within the limited scope of the current project the results are not conclusive, nevertheless the potential for an intact Montell component is intriguing. Only one site, 41TG91, has archaeological occupations from this general period and preliminary results suggest that the occupation in Area A at Culebra Creek and at 41TG91 may represent different intervals that are not contemporaneous.

Third, the basal features of the midden may have served as borrow areas for oven construction. Their confirmation either as borrow pits or natural erosional channels is essential to confirming or denying the argument for sediment borrowing in the earth oven midden formation process (see Chapter 7). Their morphology should provide clues about how they were formed: a single depression will suggest borrowing; while a linear channel suggests natural erosion. Excavation of more than one of these basal features is necessary to confirm their function.

The Nolan and Montell components, and the basal pit features should receive additional archaeological investigation. Either one or all of these aspects can contribute new and significant information to the prehistory of Texas. The archaeological testing investigations at Culebra Creek (41BX126) have demonstrated that the site has the ability to contribute new knowledge concerning the prehistoric inhabitants of the site, the region and the state and thus would qualify under Criterion $\mathrm{D}$ as eligible for listing on the $\mathrm{Na}$ tional Register of Historic Places (see guidelines in 36 CFR 60).

\section{Epilogue}

After submitting the draft report, TxDOT requested that no further work be undertaken at $41 \mathrm{BX} 126$ on Culebra Creek (letter to Dr. James Bruseth from Dr. Nancy Kenmotsu, September 25, 1997). This recommendation was not based on whether the site should be considered eligible for listing on the NRHP; CAR, TXDOT and THC agree that it is eligible. However, CAR recommended further work, but TXDOT and THC did not concur with this recommendation (letter to Dr. Nancy Kenmotsu from Dr. James Bruseth, October 30,1997$)$. To summarize their position, the recommendations for future excavations at a burned rock midden listed in Black et al. 1997 were achieved. These recommendations were to scrape the surface to expose the midden in plan view, bisect the center of the midden with perpendicular trenches, record detailed profiles from the trenches, measure multiple radiocarbon samples from midden features, obtain macrobotanical and other special samples from midden features, conduct a controlled excavation in the central midden feature, the midden framework and the midden periphery. CAR recommended additional excavations that would focus on the basal features, and TxDOT argued that excavation would not provide the type of information necessary to address the function of these features. TxDOT suggested that radiocarbon and macrobotanical analyses would probably produce the only reliable results for the investigation of these features, although CAR suggests above that the configuration of the features would be most informative.

In regard to the Nolan component, TxDOT suggested that too much mixing between occupations had occurred in part because much of the Nolan component was below the younger midden, that the component was much more limited especially to the east than suggested in the draft report, and that a suitable amount had been sampled (letter to Dr. James Bruseth from Dr. Nancy Kenmotsu, September 25, 1997). TxDOT made similar arguments about the Montell component. CAR recommended that a larger sample could provide information regarding the spatial organization of this poorly documented interval. However, TxDOT stated there is no evidence that the features extend to the east beyond BHT S, the utility trench limits the 
westward extension of the component, again the Montell component was mixed, and that a sufficient amount has been excavated. CAR suggests that the mixing with younger components is limited to the highest level and that below this remains an intact Montell component. THC concurred with TxDOT on these matters, and in general stated that the amount of work conducted at $41 \mathrm{BX} 126$ was sufficient to mitigate the impact of road construction. Thus no further archaeological investigations were undertaken. 


\section{References Cited}

Abbott, J. T., and C. D. Frederick

1990 Proton Magnetometer Investigations of Burned Rock Middens in West-Central Texas: Clues to Formation Processes. Journal of Archaeological Science 17:535-545.

Abbott, J. T., and W. N. Trierweiler (editors)

1995 NRHP Significance Testing of 57 Sites on Fort Hood, Texas, Volumes I-II. Archaeological Resource Management Series, Research Report No. 34. United States Army Fort Hood.

Abbott, P. L., and C. M. Woodruff, Jr. (editors)

1986 The Balcones Escarpment. Comet Reproduction Service, Santa Fe Springs, California.

Abbott, J. T., K. Kleinbach, and G. Mehalchick

1996 Features. In Archaeological Testing at Fort Hood: 1994-1995. Volume II, edited by W. N. Trierweiler, pp. 577-617. Archaeological Resource Management Series, Research Report No. 35. United States Army Fort Hood.

Adkins, L., and R. A. Adkins

1982 A Thesaurus of British Archaeology. David and Charles, London.

Alexander, H. L.

1963 The Levi Site: A Paleo-Indian Campsite in Central Texas. American Antiquity 28:510-528.

1983 The Pre-Clovis and Clovis Occupations at the Levi Site. In Peopling of the New World, edited by J. E. Ericson, R. E. Taylor, and R. Berger, pp. 133-145. Ballena, Los Altos, California.

Allison, J. E., G. W. Dittmar, and J. L. Hensell

1975 Soil Survey of Gillespie County, Texas. U.S. Department of Agriculture, Soil Conservation Service. Washington, D.C.

Assad, C.

1978 An Evaluation of Archaeological Sites in the Vicinity of Floodwater Retarding Structure No. 2, Dry Comal Creek, Comal County, Texas. Archaeological Survey Report, No. 50. Center for Archaeological Research, The University of Texas at San Antonio.

1979 Archaeological Testing in the Devine Road Area North of Olmos Dam, San Antonio, Texas. Archaeological Survey Report, No. 53. Center for Archaeological Research, The University of Texas at San Antonio.

Assad, C., and D. R. Potter

1979 An Intensive Archaeological Survey of Enchanted Rock State Natural Area, Llano and Gillespie Counties, Texas. Archaeological Survey Report, No. 84. Center for Archaeological Research, The University of Texas at San Antonio.

Aten, L. E.

1979 Indians of the Upper Texas Coast: Ethnohistoric and Archaeological Frameworks. Unpublished Ph.D. dissertation. The University of Texas at Austin. 
Barnes, V. E.

1983 Geologic Atlas of Texas: San Antonio Sheet. Bureau of Economic Geology. The University of Texas at Austin.

Barret, S. A., and E. W. Gifford

1933 Miwok Material Culture. Bulletin of the Public Museum of the City of Milwaukee 2(4):117-376.

Bass F. A., Jr., and T. R. Hester

1975 An Archaeological Survey of the Upper Cibolo Creek Watershed, Central Texas. Archaeological Survey Report, No. 8. Center for Archaeological Research, The University of Texas at San Antonio.

Beadles, M. L.

1990 Faunal Remains from the Bammel Site, 41KR10, in Kerr County, Texas. La Tierra 17(2):33-36.

Beals, R. L.

1932 The Comparative Ethnology of Northern Mexico Before 1750. Reprinted [1973] by Ibero-Americana 2:93-225. Cooper Square, New York.

Beasley, T. S.

1978 A Site with Edwards Points in Bandera County, Texas. La Tierra 5(4):23-31.

Behrensmeyer, A. K.

1978 Taphonomic and Ecologic Information from Bone Weathering. Paleobiology 4:150-162.

Bell, R. E.

1960 Guide to the Identification of Certain American Indian Projectile Points. Special Bulletin No. 2. Oklahoma Anthropological Society.

Bell, W. H., and E. F. Castetter

1941 Ethnobiological Studies in the American Southwest, VII. The Utilization of Yucca, Sotol and Beargrass by the Aborigines in the American Southwest. Bulletin 372. University of New Mexico, Albuquerque.

Bement, L. C.

1991 The Statistical Analysis of Langtry Variants from Arenosa Shelter, Val Verde County, Texas. In Papers on Lower Pecos Prehistory, edited by S. A. Turpin, pp. 51-64. Studies in Archeology No. 8, Texas Archeological Research Laboratory.

Benfer, R., and A. Benfer

1981 The Mason Ranch Burial Cave, Uvalde County, Texas. La Tierra 8(3):16-26.

Binford, L. R.

1978 Dimensional Analysis of Behavior and Site Structure: Learning from an Eskimo Hunting Stand. American Antiquity 43(3):330-361.

1980 Willow Smoke and Dogs' Tails: Hunter-gatherer Settlement Systems and Archaeological Site Formation. American Antiquity 45:4-20.

1983 In Pursuit of the Past: Decoding the Archaeological Record. Thames and Hudson, New York.

1987 Researching Ambiguity: Frames of Reference and Site Structure. In Method and Theory for Activity Area Research: An Ethnoarchaeological Approach, edited by S. Kent, pp. 449-512. Columbia University Press, New York. 
Black, S. L.

1986 The Clemente and Herminia Hinojosa Site, 41JW8: A Toyah Horizon Campsite in Southern Texas. Special Report No. 18. Center for Archaeological Research, The University of Texas at San Antonio.

1989a Central Texas Plateau Prairie. In From the Gulf Coast to the Rio Grande: Human Adaptation in Central, South and Lower Pecos Texas, by T. R. Hester, S. L. Black, D. G. Steele, B. W. Olive, A. A. Fox, K. J. Reinhard, and L. C. Bement, pp. 17-38. Research Series No. 33. Arkansas Archeological Survey, Fayetteville.

1989b Environmental Setting. In From the Gulf Coast to the Rio Grande: Human Adaptation in the Central, South, and Lower Pecos Texas, by T. R. Hester, S. L. Black, D. G. Steele, B. W. Olive, A. A. Fox, K. J. Reinhard, and L. C. Bement, pp. 5-17. Research Series No. 33. Arkansas Archeological Survey, Fayetteville.

1989c South Texas Plain. In From the Gulf Coast to the Rio Grande: Human Adaptation in the Central, South, and Lower Pecos Texas, by T. R. Hester, S. L. Black, D. G. Steele, B. W. Olive, A. A. Fox, K. J. Reinhard, and L. C. Bement, pp. 39-62. Research Series No. 33. Arkansas Archaeological Survey, Fayetteville.

1995a Archaeological and Historical Background. In Archaeological Investigations at the Loma Sandia Site (41LK28): A Prehistoric Campsite in Live Oak County, Texas. 2 volumes. Studies in Archeology No. 20, pp. 31-45. Texas Archeological Research Laboratory, The University of Texas at Austin.

1995b Letter from Texas Archeological Research Laboratory, The University of Texas at Austin (Steve Black) to Cultural Resources Management, Environmental Affairs Division, Texas Department of Transportation (Ann Irwin), dated March 22, 1995, subject: Geoarcheological Recording and Sampling of the BRM at 41BX126.

1997 Scenarios of Midden Accumulation. In Hot Rock Cooking on the Greater Edwards Plateau: Four Burned Rock Midden Sites in West Central Texas, edited by S. L. Black, L. W. Ellis, D. G. Creel, and G. T. Goode, pp. 140-150. Studies in Archeology 22. Texas Archeological Research Laboratory, The University of Texas at Austin.

Black, S. L., and D. G. Creel

1997 The Central Texas Burned Rock Midden Reconsidered. In Hot Rock Cooking on the greater Edwards Plateau: Four Burned Rock Midden Sites in West Central Texas, edited by S. L. Black, L. W. Ellis, D. G. Creel, and G. T. Goode, pp. 446-515. Studies in Archeology 22. Texas Archeological Research Laboratory, The University of Texas at Austin.

Black, S. L., and A. J. McGraw

1985 The Panther Springs Creek Site: Cultural Change and Continuity in the Upper Salado Creek Drainage, South-Central Texas. Archaeological Survey Report, No. 100. Center for Archaeological Research, The University of Texas at San Antonio.

Black, S. L., L. W. Ellis, D. G. Creel, and G. T. Goode (editors)

1997 Hot Rock Cooking on the Greater Edwards Plateau: Four Burned Rock Midden Sites in West Central Texas. Studies in Archeology 22. Texas Archeological Research Laboratory, The University of Texas at Austin.

Black, S. L., K. Jolly, and D. R. Potter

1993 The Higgins Experiment: Field Report. Wurzbach Project Working Papers. Texas Archeological Research Laboratory, The University of Texas at Austin. 
Black, S. L., and D. R. Potter

1995 Defining Historic Contexts for Prehistoric Sites along the Wurzbach Parkway. In Archaeology Along the Wurzbach Parkway: Module 1. Introduction, Conceptual Framework, and Contexts of Archaeological Investigations in Bexar County, South-Central Texas, edited by D. R. Potter, S. L. Black, and K. Jolly, pp. 45-51. Studies in Archeology 17. Texas Archeological Research Laboratory, The University of Texas at Austin.

Blair, W. F.

1950 The Biotic Provinces of Texas. Texas Journal of Science 2(1):93-117.

Boas, F.

1930 The Salishan Tribes of the Western Plateaus. In The Forty-fifth Annual Report of the Bureau of American Ethnology 1927-1928, edited by J. A. Teit, pp. 23-396. Smithsonian Institution, Washington, D.C.

Bolton, H. E.

1915 Texas in the Middle Eighteenth Century: Studies in Spanish Colonial History and Administration. Volume 3, University of California Publications in History. University of California, Berkeley.

Bousman, C. B.

1992 Preliminary Oxygen-Isotope Evidence for Late Pleistocene-Early Holocene Climatic Change. Current Research in the Pleistocene 11:79-81.

1994 The Central Texas Pollen Record: A Reinterpretation. Current Research in the Pleistocene 11:79-81.

1997 The Late Paleoindian Archeology at the Wilson-Leonard Site. In Archeological Investigations at the Wilson-Leonard Site, edited by M. B. Collins. Texas Archaeological Research Laboratory, The University of Texas at Austin.

1998 Paleoenvironmental Change in Central Texas: The Palynological Evidence. Plains Anthropologist 43(164): 201-219.

Brown, D., P. Lukowski, T. R. Hester, and J. D. Eaton

1977 Archaeological Assessment of Two Sites in the Vicinity of Floodwater Retarding Structure No. 11, Salado Creek Watershed, Bexar County, Texas. Archaeological Survey Report, No. 35. Center for Archaeological Research, The University of Texas at San Antonio.

Brown, K. M.

1985 Three Caches of Guadalupe Tools from South Texas. Bulletin of the Texas Archeological Society 56:75-126.

1987 Early Occupation at Berger Bluff, Goliad County, Texas. Current Research in the Pleistocene 4:3-5.

Brown, R. B., and J. D. Leach

1997 Large-Scale Pit Baking of Succulents in Northern Mexico: Implications for Archaeologists. Paper presented at the 62 annual meeting of the Society for American Archaeology. Nashville.

Brune, G.

1981 Springs of Texas, Volume 1. Branch-Smith, Fort Worth.

Bryant, V. M., Jr., and R. G. Holloway

1985 A Late-Quaternary Paleoenvironmental Record of Texas: An Overview of the Pollen Evidence. In Pollen Records of Late-Quaternary North American Sediments, edited by V. M. Bryant and R. G. Holloway, pp. 39-70. American Association of Stratigraphic Palynologists Foundation, Dallas. 
Bryant, V. M., Jr., and H. J. Shafer

1977 The Late Quaternary Paleoenvironment of Texas: A Model for the Archeologist. Bulletin of the Texas Archeological Society 48:1-25.

Buechner, H. K.

1944 The Range Vegetation of Kerr County, Texas in Relation to Livestock and White-tailed Deer. The American Midland Naturalist 31(3):697-743.

Buckley, V. (compiler)

1990 Burnt Offerings. International Contributions to Burnt Mound Archaeology. Worldwell Ltd. Academic Publications, Dublin.

Butler, R. F.

1992 Paleomagnetism: Magnetic Domains to Geologic Terranes. Blackwell Scientific Publications, Boston.

Butzer, K. W.

1982 Archaeology and Human Ecology: Method and Theory for a Contextual Approach. Cambridge University Press, Cambridge.

Cabeza de Vaca, A. N.

1966[1542] Relation of Alvar Nunez Cabeza de Vaca. Microfilm reprint of 1871 edition, translated by B. Smith, Readex Microprint Corp, New York.

Campbell, T. N.

1948 The Merrell Site: Archeological Remains Associated with Alluvial Terrace Deposits in Central Texas. Bulletin of the Texas Archeological and Paleontological Society 19:7-35.

1975 The Payaya Indians of Southern Texas. Special Publications No. 1. Southern Texas Archaeological Association, San Antonio.

1983 Coahuiltecans and Their Neighbors. In Handbook of North American Indians Volume 10: Southwest, edited by A. Ortiz, pp. 343-358. Smithsonian Institution, Washington, D.C.

1991 Coahuiltecans and Their Neighbors. In Ethnology of the Texas Indians, edited by T. R. Hester. Spanish Borderlands Sourcebooks 7. Garland, New York.

Campbell, T. N., and T. J. Campbell

1981 Historic Indians of the Choke Canyon Reservoir Surrounding Area, Southern Texas. Choke Canyon Series, No. 1. Center for Archaeological Research, The University of Texas at San Antonio.

1985 Indian Groups Associated with Spanish Missions of the San Antonio Missions National Historical Park. Special Report, No. 16. Center for Archaeological Research, The University of Texas at San Antonio.

Carlson G. G., and V. H. Jones

1940 Some Notes on the Use of Plants by the Comanche Indians. In Papers of the Michigan Academy of Science Arts and Letters, Volume 25, edited by E. S. McCartney and W. C. Steele, pp. 517-542.

Carroll, W. B.

1983 The Medina Point: A New Dart Point Type. La Tierra 10(1):29-31. 
Castetter, E. F., and M. E. Opler

1936 The Ethnobiology of the Chiricahua and Mescalero Apache: The Use of Plants for Foods, Beverages and Narcotics. University of New Mexico Bulletin, Biological Series Vol. 4, No. 5. University of New Mexico Press, Albuquerque.

Castetter, E. F., and R. Underhill

1935 The Ethnobiology of the Papago Indians. University of New Mexico Bulletin, Biological Series Vol. 4, No. 3. University of New Mexico Press, Albuquerque.

Castetter, E. F., W. H. Bell, and A. R. Grove

1938 The Early Utilization and the Distribution of Agave in the American Southwest. University of New Mexico Bulletin, Biological Series Vol. 5, No. 4. University of New Mexico Press, Albuquerque.

Chadderdon, M. F.

1975 Notes on the Menger Collection, Site 41BX272, Bexar County, Texas. La Tierra 2(1):15-18.

Chandler, C. K.

1974 Use Wear Analysis of "Clear Fork" Tools from the Falcon Reservoir Area, Southern Texas. La Tierra $1(4): 15-21$.

Chandler, C. K., and K. Hindes

1993 Scottsbluff Points from Atascosa, Frio, and McMullen Counties, South-Central Texas. La Tierra 20(1):31-36.

Chandler, C. K., and M. Marchbanks

1996 Butted Bifaces and Their Use. La Tierra 23(2):3-16.

Chaplin, R. E.

1971 The Study of Animal Bones from Archaeological Sites. Seminar, London.

Chestnut, V. K.

1902 Plants Used by the Indians of Mendocino County, California. Contributions from the U.S. National Herbarium 7(3):294-408.

Chipman, D. E.

1992 Spanish Texas, 1519-1821. University of Texas Press, Austin.

Collins, M. B.

1973 The Devil's Hollow Site, A Stratified Archaic Campsite in Central Texas. Bulletin of the Texas Archeological Society 43:77-100 (1972).

1991 Thoughts on Future Investigation of Burned Rock Middens, In The Burned Rock Middens of Texas: An Archaeological Symposium, edited Thomas R. Hester, pp. 1-24. Studies in Archeology 13. Texas Archeological Research Laboratory, The University of Texas at Austin.

1994 Late Archaic Evidence in the Project Area, In Archaic and Late Prehistoric Human Ecology in the Middle Onion Creek Valley, Hays County, Texas, Volumes I-II, edited by Robert A. Ricklis and Michael B. Collins, pp. 101-189. Studies in Archeology 19. Texas Archeological Research Laboratory, The University of Texas at Austin.

1995 Forty Years of Archaeology in Central Texas. Bulletin of the Texas Archeological Society 66:361-400.

1997 Burned Rocks as Evidence of Prehistoric Hunter-gatherer Adaptations in Texas. Abstracts of the 62nd Annual Meeting of the Society for American Archaeology, Nashville. 
Collins, M. B., B. Ellis, and C. Dodt-Ellis

1990 Excavations at the Camp Pearl Wheat Site (41KR243): An Early Archaic Campsite on Town Creek Kerr County, Texas. Studies in Archeology 6. Texas Archeological Research Laboratory, The University of Texas at Austin.

Collins, M. B., W. A. Gose, and S. Shaw

1994 Preliminary Geomorphological Findings at Dust and Nearby Caves. Journal of Alabama Archaeology $40: 35-56$.

Collins, M. B., C. B. Bousman, P. Goldberg, P. R. Takac, J. C. Guy, J. L. Lanata, T. W. Stafford, and V. T.

Holliday

1993 The Paleoindian Sequence at the Wilson-Leonard Site, Texas. Current Research in the Pleistocene 10:10-12.

Collins, M. B., G. L. Evans, T. N. Campbell, M. C. Winans, and C. E. Mears

1989 Clovis Occupation at Kincaid Rockshelter. Current Research in the Pleistocene 6:3-5.

Cox, D.

1977 A Preliminary Report on "Early Man" Artifacts Found in Northeast Bexar County. La Tierra 4(3):7-9.

Crawford, D. D.

1965 The Granite Beach Site, Llano County, Texas. Bulletin of the Texas Archeological Society 36:71-97.

1973 An Archeological Survey on Interstate Highway 10. Texas Highway Department Publications in Archeology, Report 2.

Creel, D. G.

1978 An Archeological Survey in the South Concho River Area, West Central Texas. Bulletin of the Texas Archeological Society 49:241-307.

1986 A Study of Prehistoric Burned Rock Middens in West Central Texas. Unpublished Ph.D. dissertation, The University of Arizona, Tucson.

1990 Excavations at 41TG91, Tom Green County, Texas, 1978. Publications in Archaeology, Report 38. Texas State Department of Highways and Public Transportation, Austin.

1991 Assessing the Relationship Between Burned Rock Midden Distribution and Archaic Subsistence in West Central Texas, In The Burned Rock Middens of Texas: An Archaeological Symposium, edited by Thomas R. Hester, pp. 33-43. Studies in Archeology 13. Texas Archeological Research Laboratory, The University of Texas at Austin.

1997 Analysis of the Distribution of Burned Rock Midden Sites in the Study Area. In Hot Rock Cooking on the Greater Edwards Plateau: Four Burned Rock Midden Sites in West Central Texas, edited by S. L. Black, L. W. Ellis, D. G. Creel, and G. T. Goode, pp. 151-165. Studies in Archeology 22, Texas Archeological Research Laboratory, The University of Texas at Austin.

Dalbey, T. S.

1993 An Overview Guide to Historic and Prehistoric Cultural Resources Potential on Lackland Air Force Base as Pertains to the National Historic Preservation Act of 1966, as Amended. U.S. Army Corps of Engineers, Fort Worth District, Fort Worth.

Davis, D. R., Jr.

1991 Prehistoric Artifacts of the Texas Indians: An Identification and Reference Guide. Pecos, San Antonio. 
Davis, W. B., and D. J. Schmidly

1994 The Mammals of Texas. Texas Parks and Wildlife Press, Austin.

de la Teja, J. F.

1988 Land and Society in 18th Century San Antonio de Bexar, A Community on New Spain's Northern Frontier. Ph.D. dissertation, The University of Texas at Austin.

Denton, G., and W. Karlen

1973 Holocene Climatic Variations - Their Patterns and Possible Cause. Quaternary Research 3(2):155205.

Denton, J. T.

1976 Archeology on State Highway 16: No-Name Creek Site: A Terrace Site of the Middle and Late Archaic Period in Gillespie County, Texas. Publications in Archeology, Report 7. Texas Department of Highways and Public Transportation.

Dering, J. P.

1995 Modern and Contact-Period Vegetation in the Area of the Jonas Terrace Site of Northern Medina County. In Past Cultures and Climates at Jonas Terrace 41ME29, edited by L. Johnson, pp. 293-300. Report 40. Office of the State Archeologist, Texas Historical Commission, Austin.

1997 Formation Processes and the Plant Economy at Burned Rock Middens: The View from a Rockshelter. Manuscript on file, Center for Environmental Archaeology, Texas A\&M University. College Station.

Diamond, D. D., D. H. Riskind, and S. L. Orzell

1987 A Framework for Plant Community Classification and Conservation in Texas. The Texas Journal of Science 39(3):203-221.

Dibble, D. S., and D. Lorrain

1968 Bonfire Shelter: A Stratified Bison Kill Site, Val Verde County, Texas. Miscellaneous Papers 1. Texas Memorial Museum, Austin.

Dillehay, T.

1974 Late Quaternary Bison Population Changes on the Southern Plains. Plains Anthropologist 19(64):180196.

Dunnell, R. C., and J. K. Stein

1989 Theoretical issues in the Interpretation of Microartifacts. Geoarchaeology 4(1):31-41.

Elias, S. A.

1994 Insect Fossil Evidence of Late Glacial Environments at the Aubrey Clovis Site, Texas [Abstract]. American Quaternary Association, Programs and Abstracts of the 13th Biennial Meeting, pp 77. University of Minnesota, Minneapolis.

Ellis, L. W.

1997 Hot Rock Technology. In Hot Rock Cooking on the greater Edwards Plateau: Four Burned Rock Midden Sites in West Central Texas, edited by S. L. Black, L. W. Ellis, D. G. Creel, and G. T. Goode, pp. 79-139. Studies in Archeology 22, Texas Archeological Research Laboratory, The University of Texas at Austin. 
Ensor, H. B., and C. S. Mueller-Wille

1988 Excavations at the Bull Pen Site 41BP280, Colorado River Drainage, Bastrop County, Texas. Contract Report No. 3. Texas Department of Highways and Public Transportation, Austin.

Epstein, J. F.

1960 Burins from Texas. American Antiquity 26(1):93-97.

1969 The San Isidro Site: An Early Man Campsite in Nuevo Leon, Mexico. Anthropology Series 7. Department of Anthropology, The University of Texas at Austin.

Espey, Huston and Associates

1981 A Cultural Resource Inventory and Assessment of the Proposed Stacy Reservoir, Concho, Coleman, and Runnels Counties, Texas, Vol. 3. Document No. 81052. Espey, Huston and Associates, Austin.

1989 Archaeological Investigations of Kelly Air Force Base, Bexar County, Texas. M. W. Voellinger, principal investigator. Document No. 890604. Espey, Huston and Associates, Austin.

Evans, J. G., and S. Limbrey

1974 The Experimental Earthenwork on Modern Bog, Wareham, Dorset, England: 1963 to 1972. Report on the Experimental Earthenworks Committee of the British Association for the Advancement of Science. Proceedings of the Prehistoric Society, edited by J. Coles, 40:170-192.

Ewers, J. C. (editor)

1969 The Indians of Texas in 1830. Publication series 4745. Smithsonian Institution Press, Washington, D.C.

Fehrenbach, T. R.

1983 Lone Star: A History of Texas and the Texans. American Legacy, New York.

Fisher, J. W. Jr.

1987 Shadows in the Forest: Ethnoarchaeology Among the Efe Pygmies. Unpublished Ph.D. dissertation, University of California, Berkeley.

Fisher, J. W., Jr., and H. C. Strickland

1989 Ethnoarchaeological Among the Efe Pygmies, Zaire: Spatial Organization of Campsites. American Journal of Physical Anthropology 78:473-484.

1991 Dwellings and Fire Places; Keys to Efe Pygmy Campsite Structure. In Ethnoarchaeological Approaches to Mobile Campsites, edited by C. S. Gamble and W. A. Boismer, pp. 215-236.

Fladmark, K. R.

1982 Microdebitage Analysis: Initial Considerations. Journal of Archaeological Science 9:205-220.

Flanagan, S.

1974 Trailing the Longhorns: A Century Later. Madrona, Austin.

Folk, R. L.

1980 Petrology of Sedimentary Rocks. Hemphill, Austin.

Ford, A. L., and O. W. Van Auken

1982 Distribution of Woody Species in the Guadalupe River Flood Plain in the Edwards Plateau of Texas. Southwestern Naturalist 27:383-392. 
Fox, A. A.

1975 An Archaeological Assessment of the Southern Portion of the Olmos Basin, Bexar County, Texas. Archaeological Survey Report No. 9. Center for Archaeological Research, The University of Texas at San Antonio.

Fox, A. A., and D. E. Fox

1967 The Classen Rockshelter, 41BX23. Manuscript on file. Center for Archaeological Research, The University of Texas at San Antonio.

Fox, A. A., I. W. Cox, L. Highley, and D. Hafernik

1989 Archaeological and Historical Investigations at the Site of the New Bexar County Justice Center in Downtown San Antonio, Texas. Archaeological Survey Report, No. 184. Center for Archaeological Research, The University of Texas at San Antonio.

Fox, J., C. B. Smith, and D. O. Lintz

1992 Herd Bunching at the Waco Mammoth Site: Preliminary Investigations, 1978-1987. In Proboscidean and Paleoindian Interactions, edited by J. W. Fox, C. B. Smith, and K. T. Wilkins, pp 51-73. Baylor University Press, Waco.

Fredlund, G.

1994 The Phytolith Record at the Wilson-Leonard Site. Program and Abstracts, 52nd Plains Conference, 65th Annual Meeting of the Texas Archaeological Society. Lubbock.

Freeman, M. D.

1994 Agriculture in Texas: Ranching and Stock Farming on the Eastern Edwards Plateau, 1845-1941. Komatsu/Rangel, Fort Worth.

Gallagher, J. P.

1977 Contemporary Stone Tools in Ethiopia: Implications for Archaeology. Journal of Field Archaeology 4(4):407-414.

Gamble, C. S., and W. A. Boismer

1991 Ethnoarchaeological Approaches to Mobile Campsites: Hunter-Gatherer and Pastoralists Case Studies. International Monographs in Prehistory, Ethnoarchaeological Series 1. Ann Arbor.

Gerstle, A., T. C. Kelly, and C. Assad

1978 The Fort Sam Houston Project: An Archaeological and Historical Assessment. Archaeological Survey Report, No 40. Center for Archaeological Research, The University of Texas at San Antonio.

Giddings, J. L.

1964 The Archeology of Cape Denbigh. Brown University Press, Providence.

Gilbert, B. M.

1990 Mammalian Osteology. Missouri Archaeological Society, Columbia, Missouri.

Givens, R. D.

1968 A Preliminary Report on Excavations at Hitzfelder Cave. Bulletin of the Texas Archeological Society 38:47-50. 
Goldberg, P.

1995 Micromorphological Sampling at Site 41BX228, Appendix A. In Archaeology Along Wurzbach Parkway. Module 2. Initial Testing and Evaluation of Five Prehistoric Sites in the Upper Salado Watershed, Bexar County, Texas, edited by D. R. Potter and S. L. Black, pp. 71-81. Studies in Archeology 18. Texas Archeological Research Laboratory, The University of Texas at Austin.

Goode, G. T.

1988 41BP280 (Bull Pen Site) Lithic Replication Study. In Excavations at the Bull Pen Site 41BP280, Colorado River Drainage, Bastrop County, Texas, edited by H. B. Ensor and C. S. Mueller-Wille. Contract Report No. 3. Texas Department of Highways and Public Transportation, Austin.

1989 Private Collections from the Kennedy Bluffs Site. In Excavations at 41BP19, the Kennedy Bluffs Site, Bastrop County, Texas, edited by L. C. Bement. Contract Report No. 5. Texas Department of Highways and Public Transportation, Austin.

1991 Late Prehistoric Burned Rock Middens in Central Texas, In The Burned Rock Middens of Texas: An Archaeological Symposium, edited by T. R. Hester, pp. 71-93. Studies in Archeology 13. Texas Archeological Research Laboratory, The University of Texas at Austin.

Gose, W. A.

1994a Archeomagnetism. In Archaic and Late Prehistoric Human Ecology in the Middle Onion Creek Valley, Hays County, Texas, R. A. Ricklis and M. B. Collins, editors, pp 507-538. Studies in Archeology 19:507-537. Texas Archeological Research Laboratory, The University of Texas at Austin.

1994b Archeomagnetic Results from Site 41GM224. In Excavations at Site 41GM224 in the Gibbons Creek Lignite Mine Permit Area, Grimes County, Texas, R. Rogers, editor, pp. A1-A11. Document No. 930476. Espey, Huston \& Associates, Austin.

Gose, W. A., K. S. Collins, and M. B. Collins

1993 Paleomagnetic Studies of Burned Limestone Clasts in Historical Architectural Settings: The MooreHancock Farmstead, Austin, Texas. Journal of Field Archaeology 21:125-129.

Gould, F. W.

1975 Texas Plants-A Checklist and Ecological Summary. Bulletin MP-585:5-14. Texas Agricultural Experimentation Station, College Station.

Gould, R. A.

1980 Living Archaeology. Cambridge University Press, Cambridge.

Grayson, D. K.

1984 Quantitative Zooarchaeology. Academic, New York.

Guderjan, T. H., B. Baker, B. Bousman, C. K. Chandler, A. Fox, and B. Meissner

1992 Prehistoric Settlement in the Medina Valley and the 1991 STAA-ITC Field School. La Tierra 19(2):1428.

Guderjan, T. H., B. Meissner, B. Baker, C. K. Chandler, S. Kennedy, D. McReynolds, H. R. Smith, F. Ward, J. Watts, and J. Zapata

1993 The Medina Valley Project and the 1992 STAA-ITC Field School. La Tierra 20(1):12-26.

Gunn, J., and R. Mahula

1977 Hop Hill: Culture and Climatic Change in Central Texas. Special Report, No. 5. Center for Archaeological Research, The University of Texas at San Antonio. 
Gunn, J., D. O. Brown, A. A. Fox, A. Frkuska, D. Watkins, III

1982 Historic and Cultural Landscape Study for the San Antonio Missions. Environmental and Cultural Services, Inc., San Antonio, Texas.

Habig, M.A.

1968a San Antonio's Mission San José, State and National Historic Site, 1720-1968. Naylor, San Antonio.

1968b The Alamo Chain of Missions, A History of San Antonio's Five Old Missions. Franciscan Herald, Chicago.

Hall, G. D.

1981 Allens Creek: A Study in the Cultural Prehistory of the Brazos River Valley, Texas. Research Report 61. Texas Archeological Survey, The University of Texas at Austin.

1995 Prehistoric Cemeteries on the Texas Central Texas Coastal Plain: Interpretations and Hypotheses. Archeological Investigations at the Loma Sandia Site (41LK28): A Prehistoric Cemetery and Campsite in Live Oak County, Texas, pp. 633-646. Studies in Archeology 20, Texas Archeological Research Laboratory, The University of Texas at Austin.

Hall, G. D., S. L. Black, and C. Graves

1982 Archaeological Investigations at Choke Canyon Reservoir; South Texas. The Phase I Findings. Choke Canyon Series, No. 5. Center for Archaeological Research, The University of Texas at San Antonio.

Hall, G. D., T. R. Hester, and S. L. Black (editors)

1986 The Prehistoric Sites at Choke Canyon Reservoir, Southern Texas: Results of the Phase II Archaeological Investigations. Choke Canyon Series, No. 10. Center for Archaeological Research, The University of Texas at San Antonio.

Hard, R. J, and S. Snyder

1997 Where is the Kitchen: Fire Placement and Ethnoarchaeological Models of Site Structure. Paper presented at the 62nd Annual Meeting of the Society For American Archaeology, Nashville, Tennessee.

Hard, R. J., A. A. Fox, I. W. Cox, K. J. Gross, B. A. Meissner, G. Mendez, C. L. Tennis, and J. Zapata

1995 Excavations at Mission San Jose y Miguel de Aguayo, San Antonio, Texas. Archaeological Survey Report, No. 218. Center for Archaeological Research, The University of Texas at San Antonio.

Hardy, R. W.

1977 Travels in the Interior of Mexico, in 1825, 1826, 1827, and 1828. Reprinted by Rio Grande Press, Glorietta, New Mexico.

Harris, E. S.

1985 An Archaeological Study of the Timmeron Rockshelter (41HY95), Hays County, South Central Texas. Special Publication 4. Southern Texas Archaeological Association, San Antonio.

Hays, T. R. (editor)

1982 Archaeological Investigations at the San Gabriel Reservoir Districts, Central Texas. 4 Vols. Report submitted to the U. S. Army Corps of Engineers, Fort Worth District. Archaeology Program, Institute of Applied Sciences, North Texas State University, Denton.

Hedrick, U. P, (editor)

1919 Sturtevant's Notes on Edible Plants. Report of the New York Agricultural Experiment Station for the Year 1919. J. B. Lyon Albany, New York. 
Heller, F., and M. E. Evans

1995 Loess Magnetization. Reviews of Geophysics 33:211-240.

Henderson, J.

1978 Faunal Analysis of Site 41BX36, with Data Presented for 41BX377 and 41BX428. In The Fort Sam Houston Project: An Archaeological and Historical Assessment, edited by A. Gerstle, T. C. Kelly, and C. Assad, pp. 229-252. Archaeological Survey Report, No. 40. Center for Archaeological Research, The University of Texas at San Antonio.

1980 Update on the Texas Highway Department's Excavations at 41BX52 on Leon Creek. Paper presented at a meeting of the Southern Texas Archaeological Association, San Antonio.

Hester, T. R.

1968a Folsom Points from Southwest Texas. Plains Anthropologist 15(50):237-250.

1968b Paleo-Indian Artifacts Along San Miguel Creek: Frio, Atascosa, and McMullen Counties, Texas. Bulletin of the Texas Archeological Society 39:147-162.

1970 Burned Rock Middens on the Southwestern Edge of the Edwards Plateau, Texas. Plains Anthropologist 15:237-250

1971 Archeological Investigations at the La Jita Site, Uvalde County, Texas. Bulletin of the Texas Archeological Society 42:51-148.

1979 Early Populations in Prehistoric Texas. Archaeology 32(6):26-33.

1980 Digging into South Texas Prehistory: A Guide for Amateur Archaeologists. Corona, San Antonio.

1981 Tradition and Adversity Among the Prehistoric Hunters and Gatherers of Southern Texas. Plains Anthropologist 26(92):119-128.

1983 Late Paleo-Indian Occupations at Baker Cave, Southwestern Texas. Bulletin of the Texas Archeological Society 53:101-119.

1985 UTSA Archaeological Field School Excavations in Bandera and Victoria Counties, Texas. Friends of Archaeology Newsletter 2:11-15. Center for Archaeological Research, The University of Texas at San Antonio.

1989 Historic Native American Populations. In From the Gulf to the Rio Grande: Human Adaptation in Central, South, and Lower Pecos Texas, edited by T. R. Hester, S. L. Black, D. G. Steele, B. W. Olive, A. A. Fox, K. J. Reinhard, and L. C. Bement, pp. 77-84. Research Series No. 33. Arkansas Archaeological Survey, Fayetteville.

1990 Plainview Artifacts at the St. Mary's Hall Site, South Central Texas. Current Research in the Pleistocene 7:14-17.

1995 The Prehistory of South Texas. Bulletin of the Texas Archeological Society 66:427-459.

Hester, T. R. (editor)

1991 The Burned Rock Middens of Texas: An Archeological Symposium. Studies in Archeology 13. Texas Archeological Research Laboratory, The University of Texas at Austin.

Hester, T. R., and T. C. Kelly

1976 Archeological Investigations at Sites Near Natalia, Medina County, Texas. Archaeological Survey Report, No. 20. Center for Archaeological Research, The University of Texas at San Antonio.

Hester, T. R., and H. Kohnitz

1975 Chronological Placement of "Guadalupe" Tools. La Tierra 2(2):22-25.

Hester, T. R., D. Gilbow, and A. D. Albee

1973 A Functional Analysis of Clear Fork Artifacts from the Rio Grande Plain, Texas. American Antiquity 38(1):90-96. 
Hester, T. R., J. Huebner, P. Maslyk, C. Ward, and J. Hageman

1989 Notes on South Texas Archaeology: 1989-3, Excavations at Two Sites in Uvalde County, South Central Texas. La Tierra 16(3):3-7.

Hietala, H. J. (editor)

1984 Intrasite Spatial Analysis in Archaeology. Cambridge University Press, Cambridge.

Highley, L.

1984 Guadalupe Tools from Zavala County. La Tierra 11(1):28-35.

Highley, L., and D. Lengefeld

1978 Preliminary Investigations at the Wolf Site, Blanco County, Texas. La Tierra 4(4):16-19.

Highley, L., C. Graves, and G. Judson

1978 Archeological Investigations at Scorpion Cave (41ME7), Medina County, Texas. Bulletin of the Texas Archeological Society 49:139-194.

Highley, L., C. Graves, C. Land, and G. Judson

1977 Archeological Investigations at Scorpion Cave (41ME7) Medina County, Texas. Bulletin of the Texas Archeological Society 49: 139-194.

Hillson, $\mathrm{S}$.

1986 Teeth. Cambridge University Press, Cambridge.

Hitchcock, R. K.

1982 The Ethnoarchaeology of Sedentism: Mobility Strategies and Site Structure Among Foraging and Food Producing Populations in the Eastern Kalahari Desert, Botswana. Unpublished dissertation, University of New Mexico, Albuquerque.

1987 Sedentism and Site Structure: Organizational Changes in Kalahari Basarwa Residential Locations, In Method and Theory for Activity Area Research: An Ethnoarchaeological Approach, edited by S. Kent, pp. 375-423. Columbia University Press, New York.

Hodder, M. A., and L. H. Barfield (editors)

1991 Burnt Mounds and Hot Stone Technology. Papers from the Second International Burnt Mound Conference, Sandwell, October 12-14, 1990. Published by the Director of Technical and Development Services, Sandwell Metropolitan Council, west Midlands.

Hole, F. D.

1961 A Classification of Pedoturbations and Some Other Processes and Factors of Soil Formation in Relation to Isotropism and Anisotropism. Soil Science 91:375-377.

Holloway, R. G.

1986 Macrobotanical Analysis of Phase II Material from the Choke Canyon Reservoir Area, Texas. In The Prehistoric Sites at Choke Canyon Reservoir, Southern Texas: Results of Phase II Archaeological Investigations, edited by G. D. Hall, T. R. Hester, and S. L. Black, pp. 437-451. Choke Canyon Series, Vol. 10. Center for Archaeological Research, The University of Texas at San Antonio.

Holloway, R. G., and V. M. Bryant, Jr.

1984 Picea Glauca Pollen from Late-Glacial Deposits in Central Texas. In Palynology 8:21-32. 
Holt, C.

1946 Shasta Ethnography. University of California Anthropological Records 3(4):299-350.

Hough, W.

1907 Roots. In Handbook of the Indians of Northern Mexico, edited by F. W. Hodge, pp. 395-396. Bureau of Ethnology 1927-1928. Smithsonian Institution, Washington, D.C.

Houk, B. A., and J. C. Lohse

1993 Archaeological Investigations at the Mingo Site, Bandera County, Texas. Bulletin of the Texas Archeological Society 61:193-247.

House, J. W., and T. R. Hester

1967 New Point Type Description: The Carrizo Point. Texas Archeology 11(3):7-9.

Howard, C. D.

1973 A Study of the Clear Fork Gouge. Bulletin of the Texas Archeological Society 44:51-60.

1974 Paleo-Indian Surface Finds in Bexar County. La Tierra 1(4):14-17.

Howard, M. A.

1983 A Quantitative Study of the Booker Site and Other Burned Rock Midden Sites of the Lake Travis Basin, Central Texas. Unpublished Masters thesis, Department of Anthropology, The University of Texas at Austin.

1991 Burned Rock Midden Excavations, Hearths and Botanical Remains, In The Burned Rock Middens of Texas: An Archeological Symposium, edited by Thomas R. Hester, pp. 45-69. Studies in Archeology 13. Texas Archeological Research Laboratory, The University of Texas at Austin.

Huebner, J. A.

1991 Late Prehistoric Bison Populations in Central and Southern Texas. Plains Anthropologist 36(137):343358.

Hulbert, R. C., Jr.

1985 Vertebrate Faunal Remains. In The Panther Springs Creek Site: Cultural Change and Continuity within the Upper Salado Creek Watershed, South-Central Texas, edited by S. L. Black and A. J. McGraw, pp. 209-215. Archaeological Survey Report, No. 100. Center for Archaeological Research, The University of Texas at San Antonio.

Hull, K. L.

1987 Identification of Cultural Site Formation Processes Through Microdebitage Analysis. American Antiquity 52(4):772-783.

Humphrey, J. D., and C. R. Ferring

1994 Stable Isotopic Evidence for Latest Pleistocene and Holocene Climatic Change in North Central Texas. Quaternary Research 41:200-213.

Huskey, V.

1935 An Archaeological Survey of the Nueces Canyon of Texas. In Bulletin of the Texas Archeological and Paleontological Society 7:104-114.

Inglis, J. M.

1964 A History of Vegetation on the Rio Grande Plain. Bulletin 45. Texas Parks and Wildlife Department, Austin. 
Jackson, $\mathrm{J}$.

1986 Los Mestezos: Spanish Ranching in Texas, 1721-1821. Texas A\&M University Press, College Station.

Jackson, M. F.

1974 Archeological Resources of the North Fork Reservoir Area: Results of Survey and Testing-1970 Survey. Report submitted to the National Park Service by the Texas Archeological Survey, The University of Texas at Austin.

Jelks, E. B.

1962 The Kyle Site: A Stratified Central Texas Aspect Site in Hill County, Texas. Archeology Series 5. Department of Anthropology, The University of Texas at Austin.

1978 Diablo Range. In Chronologies in New World Archeology, edited by R. E. Taylor and C. W. Meighan, pp. 71-111. Academic, New York.

Jelks, E. B., and C. D. Tunnell

1960 Appraisal of the Archeological Resources of Proctor Reservoir; Comanche County, Texas. Report submitted to the National Park Service by the Texas Archeological Salvage Project, The University of Texas at Austin.

Jelinek, A., B. Bradley, and B. Huckell

1971 The Production of Secondary Multiple Flakes. American Antiquity 36(2):198-200.

John, E. A. H.

1975 Storms Brewed in Other Men's Worlds: Confrontations of Indians, Spanish and French in the Southwest, 1540-1795. Texas A\&M University Press, College Station.

Johnson, D. I.

1989 Subsurface Stone Lines, Stone Zones, Artifact-manuport Layers, and Biomantles Produced by Bioturbation via Pocket Gophers (Thomomys bottae). American Antiquity 54:370-389.

1990 Biomantle Evolution and the Redistribution of Earth Materials and Artifacts. Soil Science 149.

Johnson, D. L., and D. Watson-Stegner

1990 The Soil-evolution Model as a Framework for Evaluating Pedoturbation in Archaeological Site Formation. In Archaeological Geology of North America, edited by N. P. Lasca and J. Donahue, pp. 541-560. Special Volume 4. Geological Society of America Centennial, Boulder, Colorado.

Johnson, D. L., D. Watson-Stegner, D. N. Johnson, and R. J. Schaetzl

1987 Proisotropic and Proanisotropic Processes of Pedoturbation. Soil Science 143:278-292.

Johnson, L.

1995 Past Cultures and Climates at Jonas Terrace, 41ME29, Medina County, Texas. Office of the State Archeologist Report 40. Texas Department of Transportation and Texas Historical Commission, Austin.

Johnson, L., Jr.

1967 Toward a Statistical Overview of the Archaic Cultures of Central and Southwestern Texas. Bulletin 12. Texas Memorial Museum, Austin.

1987 A Plague of Phases. Bulletin of the Texas Archeological Society 57:1-26.

1994 The Reconstructed Crow Terminology of the Titkanwatits, or Tonkawas, with Inferred Social Correlates. Plains Anthropologist (39)150:377-413. 
Johnson, L., and T. N. Campbell

1992 Sanan: Traces of a Previously Unknown Aboriginal Language in Colonial Coahuila and Texas. Plains Anthropologist 37(140):185-212.

Johnson, L., and G. T. Goode

1994 A New Try at Dating and Characterizing Holocene Climates, as well as Archaeological Periods, on the Eastern Edwards Plateau. Bulletin of the Texas Archeological Society 65:1-51.

Johnson, L. Jr., D. A. Suhm, and C. D. Tunnell

1962 Salvage Archaeology of Canyon Reservoir: The Wunderlich, Footbridge, and Oblate Sites. Bulletin No. 5. Texas Memorial Museum, The University of Texas at Austin.

Johnston, M. C.

1963 Past and Present Grasslands of Southern Texas and Northeastern Mexico. Ecology 44:456-466.

Jones, W. K.

1969 Notes on the History and Material Culture of the Tonkawa Indians. Smithsonian Contributions to Anthropology 2(5). Smithsonian Institution, Washington, D.C.

Judson, S., and M. E. Kauffman

1990 Physical Geology. Prentice Hall, Englewood Cliffs, New Jersey.

Katz, P. R. (editor)

1987 Archaeological Mitigation at 41BX300, Salado Creek Watershed, South-Central Texas. Archaeological Survey Report, No. 130. Center for Archaeological Research, The University of Texas at San Antonio.

Kay, M., D. B. Hudler, B. N. Driskell, and M. B. Collins

1998 Microwear Analysis of Chipped Stone Artifacts. In Wilson-Leonard: An 11,000-year Archeological Record of Hunter-Gatherers in Central Texas. Volume III: Artifacts and Special Artifact Studies, edited by M. B. Collins, pp. 731-794. Studies in Archeology 31. Texas Archeological Research Laboratory, The University of Texas at Austin. Archeology Studies Program, Report 10. Texas Department of Transportation, Environmental Affairs Division, Austin

Keller, J. E.

1976 The Crystal Rivers Site. Publications in Archeology, Report 6. Texas Department of Public Highways and Transportation, Austin.

Kelley, D.

1971 Indian Tribes of Texas, edited by D. H. Winfrey. Texian, Waco.

Kelley, J. C.

1947a The Lehman Rock Shelter: A Stratified Site of the Toyah, Uvalde, and Round Rock Foci. Bulletin of the Texas Archeological and Paleontological Society 18:115-128.

1947b The Cultural Affiliations and Chronological Position of the Clear Fork Focus. American Antiquity 13(2):97-109.

Kelley, J. C., and T. N. Campbell

1942 What Are the Burnt Rock Mounds of Texas? American Antiquity 7:319-322. 
Kelly, T. C.

1961 The Crumley Site: A Stratified Burnt Rock Midden, Travis County, Texas. Bulletin of the Texas Archeological Society 31:239-272.

1987 Archaeology of the Gamenthaler Valley, Gillespie County, Central Texas: A Preliminary Report. $L a$ Tierra 14(1):5-27.

1993 Preceramic Projectile-Point Typology in Belize. Ancient Mesoamerica 4:205-227.

Kelly, T. C., and T. R. Hester

1976 Archaeological Investigations at Sites in the Upper Cibolo Creek Watershed, Central Texas. Archaeological Survey Report 15. Center for Archaeological Research, The University of Texas at San Antonio.

Kent, S. (editor)

1987 Method and Theory for Activity Area Research: An Ethnoarchaeological Approach. Columbia University Press, New York.

Kent, S., and H. Vierich

1989 The Myth of Ecological Determinism - Anticipated Mobility and Site Spatial Organization. In Farmers as Hunters: The Implications of Sedentism, edited by S. Kent, pp. 96-130. Cambridge University Press, New York.

Kleinbach, K., M. Mehalchick, J. T. Abbott, and J. M. Quigg

1995 Other Analyses. In NRHP Significance Testing of 57 Sites on Fort Hood, Texas, Volumes I-II, edited by J. T. Abbot and W. N. Trierweiler, pp. 765-801. Archeological Resource Management Series, Research Report No. 34. United States Army Fort Hood.

Krieger, A. D.

1964 Early Man in the New World. Prehistoric Man in the New World, edited by J. D. Jennings and E. Norbeck, pp 23-81. University of Chicago Press, Chicago.

Kroeber, A. L.

1932 The Patwin and Their Neighbors. University of California Publications in American Archaeology and Ethnology 29(4):253-423.

Kroll, E. M., and T. D. Price (editors)

1991 The Interpretation of Archaeological Spatial Patterning. Plenum, New York.

Leach, J. D., and R. P. Mauldin

1997 Adaptive Shifts and Material Consequences: Perspectives on Burned Rock use in the Northern Chihuahuan Desert. Abstracts of the 62nd Annual Meeting of the Society for American Archaeology, Nashville.

Lehmann, V. W.

1969 Forgotten Legions. Texas Western, The University of Texas at El Paso.

Logan, H. C.

1959 Cartridges: A Pictorial Digest of Small Arms Ammunition. Bonanza, New York. 
León, A., J. B. Chapa, and F. S. de Zamora

1961 Historia de Luevo Leon, con Noticias sobre Coahuila, Tamaulipas, Texas y Nueva Mexico. Estudio Preliminar y Notas de Israel Cavzos Garza. Centrio de Estudios Humanistico. Universidad de Nuevo Leon, Monterrey.

Lintz, C., W. N. Trierweiler, F. M. Oglesby, P. L. O'Neill, W. Doering, and M. McFaul 1991 A Cultural Resource Survey at Mitchell County Reservoir, Mitchell County, Texas. Technical Report 433. Mariah Associates, Austin.

Luke, C. J.

1980 Continuing Archeology on State Highway 16: The Shep Site (41KR109) and the Wounded Eye Site (41KR107). Publications in Archaeology, Report 16. Texas Department of Highways and Public Transportation, Highways Design Division, Austin.

Lukowski, P. D.

1988 Archaeological Investigations at 41BX1, Bexar County, Texas. Archaeological Survey Report, No. 135. Center for Archaeological Research, The University of Texas at San Antonio.

Lyman, R. L.

1994 Vertebrate Taphonomy. Cambridge University Press, Cambridge.

Lyman, R. L., and M. J. O'Brien

1987 Plow-zone Zooarchaeology: Fragmentation and Identifiability. Journal of Field Archaeology 14:493-498.

Lynott, M. J.

1978 An Archaeological Assessment of the Bear Creek Shelter, Lake Whitney, Texas. Research Report 115. Archaeological Research Program, Southern Methodist University, Dallas.

Lynott, M. J., and D. E. Peter

19771975 Archeological Investigations at Aquilla Lake, Texas. Research Report 100. Archeology Research Program, Southern Methodist University, Dallas.

Mallouf, R. J., and B. J. Baskin

1976 Archeological Surveys in the Tehuacana Creek Watershed, Hill and McLennan Counties, Texas. Survey Report 19. Office of the State Archeologist, Texas Historical Commission, Austin.

McClean, R. G., and W. F. Kean

1993 Contributions of Wood Ash Magnetism to Archaeomagnetic Properties of Fire Pits and Hearths. Earth and Planetary Science Letters 119:387-394.

McCormick, O., and R. Filson

1975 Archeological Survey of Portions of Hamilton Creek Watershed, Burnet County, Texas. Institute for Environmental Studies, North Texas State University, Denton.

McGraw, A. J.

1977 A Preliminary Archaeological Survey Along The Medio Creek Drainage, Southwestern Bexar County, Texas. Regional Studies, No. 3. Center for Archaeological Research, The University of Texas at San Antonio. 
McGraw, A. J., and K. Hindes

1987 Chipped Stone and Adobe: A Cultural Resources Assessment of the Proposed Applewhite Reservoir, Bexar County, Texas. Archeological Survey Report, No. 163. Center for Archeological Research, The University of Texas at San Antonio.

McGraw, A. J., and F. Valdez, Jr.

1978 Investigations of Prehistoric Rockshelter and Terrace Sites Along Portions of the Salado Creek Drainage, Northern Bexar County, Texas. Archaeological Survey Report, No. 55. Center for Archaeological Research, The University of Texas at San Antonio.

McGraw, A. J., F. Valdez, Jr., and I. W. Cox

1977 Archaeological Survey of Areas Proposed for Modification in the Encino Park Development, Northern Bexar County, Texas. Archaeological Survey Report, No. 39. Center for Archaeological Research, The University of Texas at San Antonio.

McGuff, P., and E. McGuff

1971 State of Texas Archaeological Site Data Form. Copy on file. Center for Archaeological Research, The University of Texas at San Antonio.

Machette, M. N.

1985 Calcic Soils of the Southwestern United States. In Soils and Quaternary Geology of the Southwestern United States, edited by D. L. Weide, pp. 1-21. Geological Society of America, Special Papers 203. Boulder, Colorado.

McKinney, W. W.

1981 Early Holocene Adaptations in Central and Southern Texas: The Problem of the Paleo-Indian-Archaic Transition. Bulletin of the Texas Archeological Society 52:91-120.

MacNeish, R. S.

1958 Preliminary Archaeological Investigations in the Sierra de Tamaulipas, Mexico. Transactions of the American Philosophical Society 48(6). American Philosophical Society, Philadelphia.

McReynolds, R., and K. Grunewald

1981 An Archeological Sample from an Undocumented Edwards Site in Northern Bexar County, Southern Texas. La Tierra 8(1):15-22.

Masson, M. A., and M. B. Collins

1995 The Wilson-Leonard Site (41WM235). Cultural Resource Management News and Views 7(1):6-10. Texas Historical Commission, Austin.

Meissner, B. A.

1991 Notes on the Excavation of 41BX952. Manuscript on file. Center for Archaeological Research, The University of Texas at San Antonio.

1993 Where the Buffalo Roam: Archaeological Evidence of Bison Populations in South and Central Texas. Manuscript on file. Center for Archaeological Research, The University of Texas at San Antonio.

1998 Vertebrate Faunal Remains. In 41MV120: A Stratified Late Archaic Site in Maverick County, Texas, by B. J. Vierra, pp. 14-1-14-2. Archaeological Survey Report No. 251. Center for Archaeological Research, The University of Texas at San Antonio. 
Meltzer, D. J., and M. R. Bever

1995 Paleoindians of Texas: An Update on the Texas Clovis Fluted Point Survey. Bulletin of the Texas Archeological Society 66:47-81.

Metcalfe, D., and K. M. Heath

1990 Microrefuse and Site Structure: The Hearths and Floors of the Heartbreak Hotel. American Antiquity 55(4):781-796.

Miller, E. O., and E. B. Jelks

1952 Archeological Excavations at the Belton Reservoir, Coryell County, Texas. Bulletin of the Texas Archeological and Paleontological Society 23:168-217.

Milne, G.

1936 Normal Erosion as a Factor in Soil Profile Development. Nature 138:548-549.

Mueggenborg, H. E.

1994 Excavations at the Blue Hole Site, Uvalde County, Texas, 1990. Bulletin of the Texas Archeological Society 62:1-74.

Murray, P.

1980 Discard Location: The Ethnographic Data. American Antiquity 45(3):480-502.

Newcomb, W. W., Jr.

1961 The Indians of Texas: From Prehistoric to Modern Times. University of Texas Press, Austin.

1993 Historic Indians of Central Texas. Bulletin of the Texas Archeological Society 64:1-63. Austin.

Newell, H. P., and A. D. Krieger

1949 The George C. Davis Site, Cherokee County, Texas. Memoirs of the Society for American Archaeology 5. Society for American Archaeology, Menasha, Wisconsin.

Nickels, D. L.

1998 An Archaeological and Geomorphological Investigation of 103-acre Northrup Park, Boerne, Kendall County, Texas. Archaeological Survey Report, No. 247. Center for Archaeological Research, The University of Texas at San Antonio.

Nickels, D. L., D. W. Pease, and C. B. Bousman

1997a Archaeological Survey of Lackland Air Force Base, Bexar County, Texas. Archaeological Survey Report, No. 248. Center for Archaeological Research, The University of Texas at San Antonio.

Nickels, D. L., J. D. Leach, S. K. Tomka, and B. D. Moses

1997b The Moos Site (41BX1232): A Late Paleoindian Component Site in South Central Texas. Current Research in the Pleistocene 14:68-69.

Nordt, L. C.

1992 Archaeological Geology of the Fort Hood Military Reservation, Fort Hood, Texas. United States Army Fort Hood, Archaeological Resource Management Series, Research Report Number 25. Texas A\&M University, College Station.

1995 Geoarchaeological Investigations of Henson Creek: A Low-order Tributary in Central Texas. Geoarchaeology 10:205-221. 
1997 Geoarchaeology. In Archaeological Investigations Along Owl Creek: Results of the 1992 Summer Archaeological Field School, edited by D. L. Carlson. United States Army Fort Hood, Archaeological Resource Management Series, Research Report Number 25. Texas A\&M University, College Station.

Nordt, L. C., T. W. Boutton, J. S. Jacob, and R. Mandel

1994 Late Quaternary Climates of Central Texas Based on the Stable Isotopic Composition of Organic Carbon. Program and Abstracts, 52nd Plains Conference, 65th Annual Meeting of the Texas Archeological Society, Lubbock.

O'Connell, J. F.

1987 Alyawara Site Structure and Its Archaeological Implications. American Antiquity 51(1):74-108.

Olsen, S. J.

1964 Mammal Remains from Archaeological Sites Part I; Southeastern and Southwestern United States. Peabody Museum, Cambridge.

1968 Fish, Amphibian and Reptile Remains from Archaeological Sites, Part I: Southeastern and Southwestern United States. Peabody Museum, Cambridge.

Olson, G. W.

1981 Soils and the Environment: A Guide to Soil Surveys and their Applications. Chapman and Hall, New York.

Opler, E. M.

1941 An Apache Life-Way: The Economical, Social, and Religious Institutions of the Chiricuahua Indians. The University of Chicago Publications in Anthropology, Ethnological Series. University of Chicago Press, Chicago.

Parker, J., and J. Mitchell

1979 Notes on Some Bell Points from a Site in Crosby County, Texas. La Tierra 6(2):26-27.

Patterson, L. W.

1978 An Archaic Rock Midden Site (41BN11), Bandera County, Texas. La Tierra 4(2):6-16.

1988 Intergroup Conflict in Prehistoric Texas. Houston Archeological Society Journal 90:8-10.

Pearce, J. E.

1919 Indian Mounds and Other Relics of Indian Life in Texas. American Anthropologist 21:223-234.

Pearson, F. Jr., E. Mott Davis, M. A. Tamers, and R. J. Johnstone

1965 University of Texas Radiocarbon Dates III. Radiocarbon 7:296-314.

Pennington, C. W.

1963 The Tarahumar of Mexico: Their Environment and Material Culture. University of Utah Press, Salt Lake City.

Peter, D. E.

1982 Alternative Perspectives on Burned Rock Middens. In Archaeological Investigations at the San Gabriel Reservoir Districts, Central Texas, Vol. 2, compiled and edited by T. R. Hays, pp. 20.1-20.15. Archaeology Program, Institute of Applied Sciences, North Texas State University, Denton. 
Potter, D. R., and S. L. Black

1995 Archeology Along the Wurzbach Parkway. Module 2. Initial Testing and Evaluation of Five Prehistoric Sites in the Upper Salado Watershed, Bexar County, Texas. Studies in Archeology 18. Texas Archeological Research Laboratory, The University of Texas at Austin.

Potter, D. R., S. L. Black, and K. Jolly

1995 Archeology Along the Wurzbach Parkway. Module 1. Introduction, Conceptual Framework, and Contexts of Archeological Investigations in Bexar County, South-Central Texas. Studies in Archeology 17. Texas Archeological Research Laboratory, The University of Texas at Austin.

Potter, D. R., C. K. Chandler, and E. Newcomb

1992 Archaeological Salvage Research at 41BX901, a Prehistoric Quarry in Bexar County, Texas. Archaeological Survey Report, No. 211. Center for Archaeological Research, The University of Texas at San Antonio.

Poyo, G. E., and G. M. Hinojosa (editors)

1991 Tejano Origins in Eighteenth-Century San Antonio. University of Texas Press, Austin.

Preston, N. E.

1969 The McCann Site. Bulletin of the Texas Archeological Society 40:167-192.

Prewitt, E. R.

1974 Archeological Investigations at the Loeve-Fox Site, Williamson County, Texas. Research Report 49. Texas Archeological Survey, The University of Texas at Austin.

1976 The Rogers Spring Site: 1974 Investigations. Research Report 54. Texas Archeological Survey, The University of Texas at Austin.

1981a Culture Chronology in Central Texas. Bulletin of the Texas Archeological Society 52:65-89.

1981b Archeological Investigations at the Loeve-Fox, Loeve and Tombstone Bluff Sites in the Granger Lake District of Central Texas. Archaeological Investigations at the San Gabriel Reservoir Districts 4, Institute of Applied Sciences, North Texas State University, Denton.

1982 Archeological Investigations at the Loeve-Fox, Loeve and Tombstone Bluff Sites in the Granger Lake District of Central Texas. Volume 4 of Archeological Investigations of the San Gabriel Reservoir districts, Central Texas, edited by T. R. Hays. Report submitted to the U.S. Army Corps of Engineers, Fort Worth District, by the Archaeology Program, Institute of Applied Sciences, North Texas State University, Denton.

1983 Andice: An Early Archaic Dart Point Type. La Tierra 10(3):1-6.

1985 From Circleville to Toyah: Comments on Central Texas Chronology. Bulletin of the Texas Archeological Society 54:201-238.

1991 Burned Rock Middens: A Summary of Previous Investigations and Interpretations. In The Burned Rock Middens of Texas: An Archeological Symposium, edited T. R. Hester, pp. 25-32. Studies in Archeology 13. Texas Archeological Research Laboratory, The University of Texas at Austin.

Price, D.

1995 Field Notes. On file, Center for Archaeological Research, The University of Texas at San Antonio.

Priour, D. J.

1987 A Preliminary Report on the "Butted Knife" Biface Survey. La Tierra 14(2):5-18 
Quigg, J. M.

1988 Cultural Resources Reconnaissance in Secondary Impact Areas Along Salado Creek at Brooke Army Medical Center, Fort Sam Houston and Camp Bullis, Bexar County, Texas. Technical Reports No. 5. Prewitt and Associates, Austin.

Quigg, J. M., and G. L. Ellis

1994 Burned Rock Mound Chronometric Investigations, In Archaeological Investigations on 571 Prehistoric Sites at Fort Hood, Bell and Coryell Counties, Texas, edited by W. Nicholas Trierweiler, pp. 203-274. Archeological Resource Management Series, Research Report No. 31. United States Army Fort Hood.

Ray, C. N.

1938 The Clear Fork Culture Complex. Bulletin of the Texas Archeological and Paleontological Society 10:193-207.

1940 The Deeply Buried Gibson Site. Bulletin of the Texas Archeological and Paleontological Society 12:223-237.

1941 Various Types of Clear Fork Gouges. Bulletin of the Texas Archeological and Paleontological Society 13:152-162.

1959 Deductions Concerning the Clear Fork Gouge. Bulletin of the Texas Archeological Society 30:199208.

Ricklis, R. A.

1994 Toyah Components: Evidence for Occupation in the Project Area during the Latter Part of the Late Prehistoric. In Archaic and Late Prehistoric Human Ecology in the Middle Onion Creek Valley, Hays County, Texas. Studies in Archeology 19. Texas Archeological Research Laboratory, The University of Texas at Austin.

1995 Prehistoric Occupation of the Central and Lower Texas Coast: A Regional Overview. Bulletin of the Texas Archeological Society 66:265-300.

Robinson, R. L.

1979 Biosilica and Climatic Change at 41GD21 and 41GD21A. In Archaeological Investigations of Two Prehistoric Sites on the Coleto Creek Drainage, Goliad County, Texas, edited by D. E. Fox, pp. 102113. Archaeological Survey Report, No. 69. Center for Archaeological Research, The University of Texas at San Antonio.

1982 Biosilica Analysis of Three Prehistoric Archaeological Sites in the Choke Canyon Reservoir, Live Oak County, Texas: Preliminary Summary of Climatic Implications. In Archaeological Investigations at Choke Canyon Reservoir, South Texas: The Phase I Findings, edited by G. D. Hall, S. L. Black, and C. Graves, pp. 597-610. Choke Canyon Series, No. 5. Center for Archaeological Research, The University of Texas at San Antonio.

Sapir, E., and L. Spier

1943 Notes on the Culture of the Yana. University of California Anthropological Records 3(3):239-298.

Sayles, E. B.

1935 An Archaeological Survey of Texas. Medallion Papers XVII:1-64. Gila Pueblo, Globe, Arizona.

Schiffer, M. B.

1972 Archaeological Context and Systematic Context. American Antiquity 37:156-165.

1975 Archaeology as Behavior Science. American Anthropologist 77:836-848.

1976 Behavioral Archaeology. Academic, New York.

1983 Toward the Identification of Formation Processes. American Antiquity 48:675-706. 
1987 Formation Processes of the Archaeological Record. University of New Mexico Press, Albuquerque.

Schmid, E.

1972 Atlas of Animal Bones for Prehistorians, Archaeologists and Quaternary Geologists. Elsevier, Amsterdam.

Schuetz, M. K.

1956 An Analysis of Val Verde County Cave Material. Bulletin of the Texas Archeological Society 27:129160.

1957 A Report on Williamson County Mound Material. Bulletin of the Texas Archeological Society 28:135168.

Sellards, E. H.

1940 Pleistocene Artifacts and Associated Fossils from Bee County, Texas. Bulletin of the Geological Society of America 51:1627-1658.

Shafer, H. J.

1963 Test Excavations at the Youngsport Site: A Stratified Terrace Site in Bell County, Texas. Bulletin of the Texas Archeological Society 34:56-81

1977 Art and Territoriality in the Lower Pecos Region. Plains Anthropologist 22:13-22.

Shafer, H. J., and E. P. Baxter

1976 An Archaeological Survey of the Lignite Project, Atascosa and McMullen Counties, Texas. Anthropology Laboratory Report No. 7. Texas A\&M University, College Station.

Shafer, H. J., and V. M. Bryant

1977 Archeological and Botanical Studies at Hinds Cave, Val Verde County, Texas. Anthropology Laboratory Special Series No. 1. Texas A\&M University, College Station.

Shafer, H. J., and J. E. Corbin

1965 An Appraisal of the Archeological Resources of North Fork, South Fork, and Laneport Reservoirs, Williamson County, Texas. Report submitted to the National Park Service by the Texas Archeological Salvage Project, The University of Texas at Austin.

Shafer, H. J., and D. A. Suhm, and J. D. Scurlock

1964 An Investigation and Appraisal of the Archeological Resources of Belton Reservoir, Bell and Coryell Counties, Texas, 1962. Miscellaneous Papers No. 1, Texas Archeological Salvage Project.

Shaffer, B. S.

1995 Analysis of Vertebrate Fauna. In Past Cultures and Climates at Jonas Terrace, 41ME29, Medina County, Texas, by L. Johnson, pp. 306-325. Report No. 40. Office of the State Archeologist, Texas Department of Transportation and Texas Historical Commission, Austin.

Shiner, J. L.

1975 The Clear Fork Gouge Revisited. Bulletin of the Texas Archeological Society 46:179-188.

Silberbauer, G. B.

1981 Hunter \& Habitat in the Central Kalahari Desert. Cambridge University Press, Cambridge. 
Singer, M. J., and P. Fine

1989 Pedogenic Factors Affecting Magnetic Susceptibility of Northern California Soils. Soil Science of America Journal 53:1119-1127.

Sjoberg, A. F.

1953a The Culture of the Tonkawa, A Texas Indian Tribe. Texas Journal of Science 5(3):280-304.

1953b Lipan Apache Culture in Historical Perspective. Southwestern Journal of Anthropology 9(1):76-98.

Skelton, D. W.

1977 Archeological Investigations at the Fayette Power Project, Fayette County, Texas. Research Report 60. Texas Archeological Survey, The University of Texas at Austin.

Skinner, S. A.

1981 Aboriginal Demographic Changes in Central Texas. Plains Anthropologist 26(92):111-118.

Smith, H. H.

1933 Enthobotany of the Forest Potawatomi Indians. Bulletin of the Public Museum of the City of Milwaukee $7(1): 1-230$.

Sobolik, K. D.

1991 Prehistoric Diet and Subsistence in the Lower Pecos As Reflected in Coprolites from Baker Cave, Val Verde County, Texas. Studies in Archeology No. 7. Texas Archeological Research Laboratory, The University of Texas at Austin.

Soil Survey Staff

1993 Soil Survey Manual. U.S. Department of Agriculture Handbook Number 18. U.S. Government Printing Press, Washington, D.C.

Sollberger, J. B.

1968 Test Excavations at the Nopal Terrace Site, Val Verde County, Texas, Spring 1967. Papers No. 15. Texas Archeological Survey, The University of Texas at Austin.

Sollberger, J. B., and W. B. Carroll

1985 Guadalupe Tools: Were They Used for Defleshing Hides? La Tierra 12(1):18-22.

Sollberger, J. B., and T. R. Hester

1972 The Strohacker Site: A Review of Pre-Archaic Manifestations in Texas. Plains Anthropologist 17(58):326-344.

Sorenson, E. R.

1976 The Edge of the Forest: Land, Childhood and Change in a New Guinea Protoagriculture Society. Smithsonian Institution Press, Washington, D.C.

Sorrow, W. M.

1969 Archeological Investigations at the Ischy Site: A Burnt Rock Midden in Williamson County, Texas. Papers No. 18. Texas Archeological Salvage Project, The University of Texas at Austin.

1973 Test Excavations in the North Fork Reservoir Area. Report submitted to the National Park Service by the Texas Archeological Survey, The University of Texas at Austin. 
Sorrow, W. M., H. J. Shafer, and R. E. Ross

1967 Excavations at Stillhouse Hollow Reservoir. Papers No. 11. Texas Archeological Survey, The University of Texas at Austin.

Stahle, D. W., and M. K. Cleaveland

1995 Texas Paleoclimatic Data from Daily to Millennial Time Scales. In The Changing Climate of Texas: Predictability and Implications for the Future, edited by J. Norwine, J. R. Giardino, G. R. North, and J. B. Valdes, pp 49-69. GeoBooks, Texas A\&M University, College Station.

Steele, D. G., and C. Assad Hunter

1986 Analysis of Vertebrate Faunal Remains from 41MC222 and 41MC296, McMullen County, Texas. In The Prehistoric Sites at Choke Canyon Reservoir, Southern Texas: Results of Phase II Archaeological Investigations, edited by G. D. Hall, T. R. Hester, and S. L. Black. Choke Canyon Series, No. 10. Center for Archaeological Research, The University of Texas at San Antonio.

Stein, J. K.

1987 Deposits for Archaeologists. In Advances in Archaeological Method and Theory, Volume 11, edited by M. B. Schiffer, pp.337-395. Academic, New York.

1990 Archaeological Stratigraphy. In Archaeological Geology of North America, edited by N. P. Lasca and J. Donahue, pp. 513-523. Special Volume 4. Geological Society of America Centennial, Boulder, Colorado.

Story, D. A.

1985 Adaptive Strategies of Archaic Cultures of the West Gulf Coastal Plain. In Prehistoric Food Production in North America, edited by R. I. Ford, pp. 19-56. Anthropological Papers No. 75. Museum of Anthropology, University of Michigan, Ann Arbor.

Story, D. A., and H. K. Shafer

19651964 Excavations at Waco Reservoir, McLennan County, Texas. The Baylor and Britton Sites. Papers No. 6. Texas Archeological Salvage Project, The University of Texas at Austin.

Stothert, K.

1989 The Archaeology and Early History of the Head of the San Antonio River. Southern Texas Archaeological Association Special Publication No. 5 and Incarnate Word Archaeology Series No. 3, San Antonio.

Stute, M., P. Schlosser, J. F. Clark, and W. S. Broecker

1992 Paleotemperatures in the Southwestern United States Derived from the Noble Gases in Groundwater. Science 256:1000-1003.

Suhm, D. A.

1955 Excavations at the Collins Site, Travis County, Texas. Bulletin of the Texas Archeological Society 26:7-54.

1957 Excavations at the Smith Rockshelter, Travis County, Texas. The Texas Journal of Science 9(1):2658 .

1959 The Williams Site and Central Texas Archaeology. Texas Journal of Science 11(2):218-250.

1960 A Review of Central Texas Archeology. Bulletin of the Texas Archeological Society 29:63-107.

Suhm, D. A., and E. B. Jelks

1962 Handbook of Texas Archeology: Type Descriptions. Texas Archaeological Society Special Publication I and Texas Memorial Museum Bulletin 4. Austin. 
Suhm, D. A., A. D. Krieger, and E. B. Jelks

1954 An Introductory Handbook of Texas Archeology. Bulletin of the Texas Archeological Society 25.

Swanton, J. R.

1952 The Indian Tribes of North America. Bulletin 145. Bureau of American Ethnology, Washington, D.C.

Tani, $M$.

1995 Beyond the Identification of Formation Processes: Behavioral Inference Based on Traces Left by Cultural Formation Processes. Journal of Archaeological Method and Theory 2(3):231-252.

Taylor, A. J., and C. L. Highly

1995 Archaeological Investigations at the Loma Sandia Site (4ILK28): A Prehistoric Campsite in Live Oak County, Texas. 2 volumes. Studies in Archeology No. 20. Texas Archeological Research Laboratory, The University of Texas at Austin.

Taylor, F. B., R. B. Hailey, and D. L. Richmond

1991 Soil Survey of Bexar County, Texas. Soil Conservation Service, U.S. Department of Agriculture, Washington, D.C.

Taylor, R. J.

1982 Vegetation Resources of the Nueces River Floodplain, Texas. Contract No.2-07-50-V0637, U.S. Bureau of Reclamation, ECS Technology Service.

Tennis, C. L.

1996 Archaic Land Use of Upper Leon Creek Terraces: Archaeological Testing in Northern Bexar County, Texas. Archaeological Survey Report No. 234. Center for Archaeological Research, The University of Texas at San Antonio.

Tennis, C. L., and R. J. Hard

1995 Archaeological Survey of the Upper Leon Creek Terraces, Bexar County, Texas. Archaeological Survey Report, No. 233. Center for Archaeological Research, The University of Texas at San Antonio.

Thoms, A. V.

1992 Late Pleistocene and Early Holocene Regional Land Use Patterns: A Perspective from the Preliminary Results of Archaeological Studies at the Richard Beene Site, 41BX831, Lower Medina River, South Texas. In Late Cenozoic Alluvial Stratigraphy and Prehistory of the Inner Gulf Coast Plain, SouthCentral Texas. Series No. 4. Lubbock Lake Quaternary Research Center, San Antonio.

1996 Texas Cooking with Cabeza de Vaca: Implications for Cook-Stone Technology and Past Land Use. Paper presented at the annual meeting of the Texas Archeological Society, San Antonio.

1989 The Northern Roots of Hunter-gatherer Intensification: Camas and the Pacific Northwest. Unpublished Ph.D. dissertation, Washington State University, Pullman.

Thoms, A. V., D. D. Keuhn, B. W. Olive, J. E. Dockall, P. A. Clabaugh, and R. D. Mandel

1996 Early and Middle Holocene Occupations at the Richard Beene Site: The 1995 Southern Texas Archaeological Association Field School Project. La Tierra (23)4:1-36.

Toomey, R. S., and T. W. Stafford, Jr.

1994 Paleoenvironmental and Radiocarbon Study of the Deposits from Hall's Cave, Kerr County, Texas. Program and Abstracts, 52nd Plains Conference, 65th Annual Meeting of the Texas Archeological Society, Lubbock. 
Toomey, R. S., M. D. Blum, and S. Valastro, Jr.

1993 Late Quaternary Climates and Environments of the Edwards Plateau, Texas. Global and Planetary Change 7:299-320.

Treece, A. C., C. Lintz, W. N. Trierweiler, J. M. Quigg, and K. A Miller

1993a Cultural Resource Investigations in the O. H. Ivie Reservoir, Concho, Coleman, and Runnels Counties, Texas. Volume III: Data Recovery Results from Non-Ceramic Sites. Technical Report No. 346-III. Mariah and Associates, Austin.

Treece, A. C., F. M. Oglesby, K. Kibler, P. L. O’Neill, W. N. Trierweiler, C. Frederick, J. M. Quigg, and A. J. Taylor

1993b Cultural Resource Investigations in the O. H. Ivie Reservoir, Concho, Coleman, and Runnels Counties, Texas. Volume II: Test Excavations at Prehistoric Sites and Assessment of Rock Cairn Features. Technical Report No. 346-II. Mariah and Associates, Austin.

Trierweiler, W. N. (editor)

1994 Archaeological Investigations on 571 Prehistoric Sites at Fort Hood, Bell and Coryell Counties, Texas. Archeological Resource Management Series, Research Report No. 31 . United States Army Fort Hood.

1996 Archaeological Testing at Fort Hood: 1994-1995. Volumes I-II. United States Army Fort Hood, Archaeological Resource Management Series, Research Report No. 35.

Tunnel, C., and E. Madrid

1990 Making and Taking Sotol in Chihuahua and Texas. In Papers from the Third Symposium on Resources in the Chihuahuan Desert region, United States and Mexico, 10-12 November 1988, edited by A. M. Poweel, R. R. Hollander, J. C. Barlow, W. B. McGillivray, and D. J. Schmidly, pp. 145-162. Chihuahuan Desert Research Institute, Alpine, Texas.

Turner, E. S., and T. R. Hester

1993 A Field Guide to Stone Artifacts of Texas Indians. Second Edition. Texas Monthly Field Guide Series. Gulf, Houston.

Turpin, S. A.

1991 Time out of Mind: The Radiocarbon Chronology of the Lower Pecos River Region. In Papers on Lower Pecos Prehistory, edited by S. A. Turpin, pp. 1-50. Studies in Archeology 8. Texas Archeological Research Laboratory, The University of Texas at Austin.

1995 The Lower Pecos River Region of Texas and Northern Mexico. Bulletin of the Texas Archeological Society 66:541-560.

Tyler, R. (editor)

1996 The New Handbook of Texas. Six volumes. The Texas State Historical Association, Austin.

Valastro, S. Jr., F. J. Pearson, Jr., and E. Mott Davis

1967 University of Texas Radiocarbon Dates V. Radiocarbon 9:439-453.

Van Auken, O. W.

1988 Woody Vegetation of the Southern Escarpment and Plateau. In Edwards Plateau Vegetation: Plant Ecological Studies in Central Texas, edited by B. B. Amos and F. R. Geilbach, pp. 43-55. Baylor University Press, Waco.

1993 Size Distribution Patterns and Potential Population Change of Some Dominant Woody Species of the Edwards Plateau Region of Texas. The Texas Journal of Science 45(3):199-210. 
Van Auken, O. W., and J. K. Bush

1988 Dynamics of Establishment, Growth, and Development of Black Willow and Cottonwood in the San Antonio River Forest. The Texas Journal of Science 40 (3):269-277.

Vance, E. D.

1987 Microdebitage and Archaeological Activity Analysis. Archaeology 40(4):58-59.

Vierra, B. J.

1997 41MV120: A Stratified Late Archaic Site in an Alluvial Setting of South Texas. Paper presented in the symposium on Finding and Investigating Gisements in Texas, at the Sixty-Eighth Annual Meeting of the Texas Archaeological Society, Odessa, October 31-November 2, 1997.

Wandsnider, L.

1996 Describing and Comparing Archaeological Spatial Structures. Journal of Archaeological Method and Theory 3(4):319-384.

Weber, C. D.

1986 An Analysis of Andice and Bell Points. La Tierra 13(3):32-38

Weir, F. A.

1976 The Central Texas Archaic. Unpublished Ph.D. dissertation. Anthropology Department, Washington State University, Pullman.

1979 The Greenhaw Site in Central Texas. Bulletin of the Texas Archeological Society 50:5-67.

Wenke, R. J.

1990 Patterns in Prehistory: Humankind's First Three Million Years. 3rd Edition. Oxford University Press, Oxford, England.

Wesolowsky, A. B., T. R. Hester, and D. R. Brown

1976 Archeological Investigations at the Jetta Court Site (41TV151), Travis County, Texas. Bulletin of the Texas Archeological Society 47:25-87.

West, E. H. (translator)

1904 A Brief Compendium of the Events Which Have Occurred in the Province of Texas from its Conquest, or Reduction to the Present Day, Written by Antonio Bonilla in 1772. Quarterly of the Texas State Historical Association VIII(1):1-78.

Wheeler, A., and A. K. G. Jones

1989 Cambridge Manuals in Archaeology: Fishes. Cambridge University Press, Cambridge.

Wilkins, K. T.

1989 Burrowing Vertebrates and Their Role in Archaeological Site Decay. In Interdisciplinary Workshop on the Physical-Chemical-Biological Processes Affecting Archaeological Sites, edited by C. C. Mathewson, pp. 195-217. Contract Report EL-89-1. U.S. Army Corps of Engineers, Waterways Experimental Station, Vicksburg, Mississippi.

Wilson, E. W.

1930 Burned Rock Mounds of South-west Texas. Bulletin of the Texas Archeological and Paleontological Society 2:59-63. 
Woerner, C., and L. Highley

1983 The Bromley F. Cooper Collection of Pre-Archaic and Archaic Dart Points from McMullen County. La Tierra 10(1):3-28.

Wood, C. E., and J. K. Wood

1988 Woody Vegetation of the Frio River Riparian Forest, Texas. The Texas Journal of Science 40(3):310 321.

1989 Riparian Forests of the Leona and Sabinal Rivers. The Texas Journal of Science 41(4):395-411.

Wood, G. P.

1994 Archaeological Testing of 41BX126, Bexar County, Texas. Texas Department of Transportation, Austin.

Wood, W. R., and D. L. Johnson

1978 A Survey of Disturbance Processes in Archaeological Site Formation. In Advances in Archaeological Method and Theory, vol. 1, edited by M. B. Schiffer, pp. 315-381. Academic, New York.

Young, W.

1979 Test Excavations at the Elm Creek Site, Uvalde County, Texas. Publications in Archaeology, Report 14. Texas Department of Highways and Public Transportation. Austin. 
Appendices 


\section{Appendix A: Geoarchaeological Investigations}

\section{Charles D. Frederick}

\section{Site Setting}

The site occupies several different constructional terraces near and between the confluence of Culebra and Helotes creeks, in western San Antonio. At least five prominent terraces (T0 to T4, from lowest to highest, respectively) are present in the portion of the site that lies in the right-of-way of Loop 1604. The lowest of these is the floodplain of Culebra Creek (T0) which lies immediately adjacent to the modern channel. The tread of this surface lies 1-3 $\mathrm{m}$ above the modern creek channel, and its morphology is somewhat irregular due to the effects of flooding. In most places the floodplain is densely wooded. A subtle, low relief scarp separates the floodplain from the first terrace, which lies about 3-6 $\mathrm{m}$ above the channel floor. This surface is discontinuous within $41 \mathrm{BX} 126$, and is not present west of the elevated portion of Loop 1604 . The tread is relatively flat and inclined gently toward the south (channel of Culebra Creek).

The second terrace or $\mathrm{T} 2$, lies adjacent to either $\mathrm{Tl}$ (on the east half of the site), or T0 (on the west side of the site), and rises gradually to about 6-8 $\mathrm{m}$ above the channel of Culebra Creek. On the east side of the site a very subtle scarp separates $\mathrm{T} 2$ from $\mathrm{T} 1$; whereas on the west side, a prominent scarp is present between $\mathrm{T} 0$ and $\mathrm{T} 2$. The tread of this surface possesses a noticeable slope toward the valley axis, in part due to the accumulation of slope deposits (colluvium) where it lies adjacent to the limestone upland that forms the Holocene valley wall.

On the west side of the site is a dissected remnant of an older terrace, T3, which lies about seven meters above the creek channel. The elevation of this surface overlaps with $\mathrm{T} 2$, but it was possible to distinguish this surface on the west side of the site by its morphology and the deposit beneath it, which exhibits a substantial calcic soil. However, in reality T2 and T3 may represent a single surface in some areas.
The last terrace is the local ridge crest, which is mantled by an ancient gravel lag and appears to have been cut by a stream (and therefore represents a strath surface). This terrace, T4, lies more than $17 \mathrm{~m}$ above the channel of Culebra Creek, and is primarily a strath terrace with a thin gravel lag. This terrace was probably formed by one or both of these streams in the middle or late Pleistocene.

\section{Methods}

The stratigraphic framework of the site was investigated through mechanical excavation of 13 trenches (Figure A-1). These exposures were subsequently described (see below), and a preliminary stratigraphic sequence compiled (Figure A-2). The stratigraphic units defined here are bodies of sediment bounded by unconformities. These are consistent with allostratigraphic units recognized by the North American Commission of Stratigraphic Nomenclature (1983). Terrace surfaces and soils may serve as unit boundaries, as well as erosional surfaces at depth. Where erosional unconformities are not observed in the field, as is often the case with basal unconformities, the physical location of such features are estimated on the basis of spatial variations in lithology and soil development.

Estimating the age of allostratigraphic units in the field was accomplished by evaluating the relative stratigraphic position and the degree of soil development for each exposure. The principles of stratigraphic superposition are clearly established in the geologic literature (see North American Commission of Stratigraphic Nomenclature 1983), and as with most Quaternary fluvial systems in Texas, the oldest stratigraphic units are found high on the landscape and often far from the modern channel. Within the Holocene valley fill, different age deposits are typically inset adjacent to one another, and separated by unconformities. The arrangement of different age deposits may 


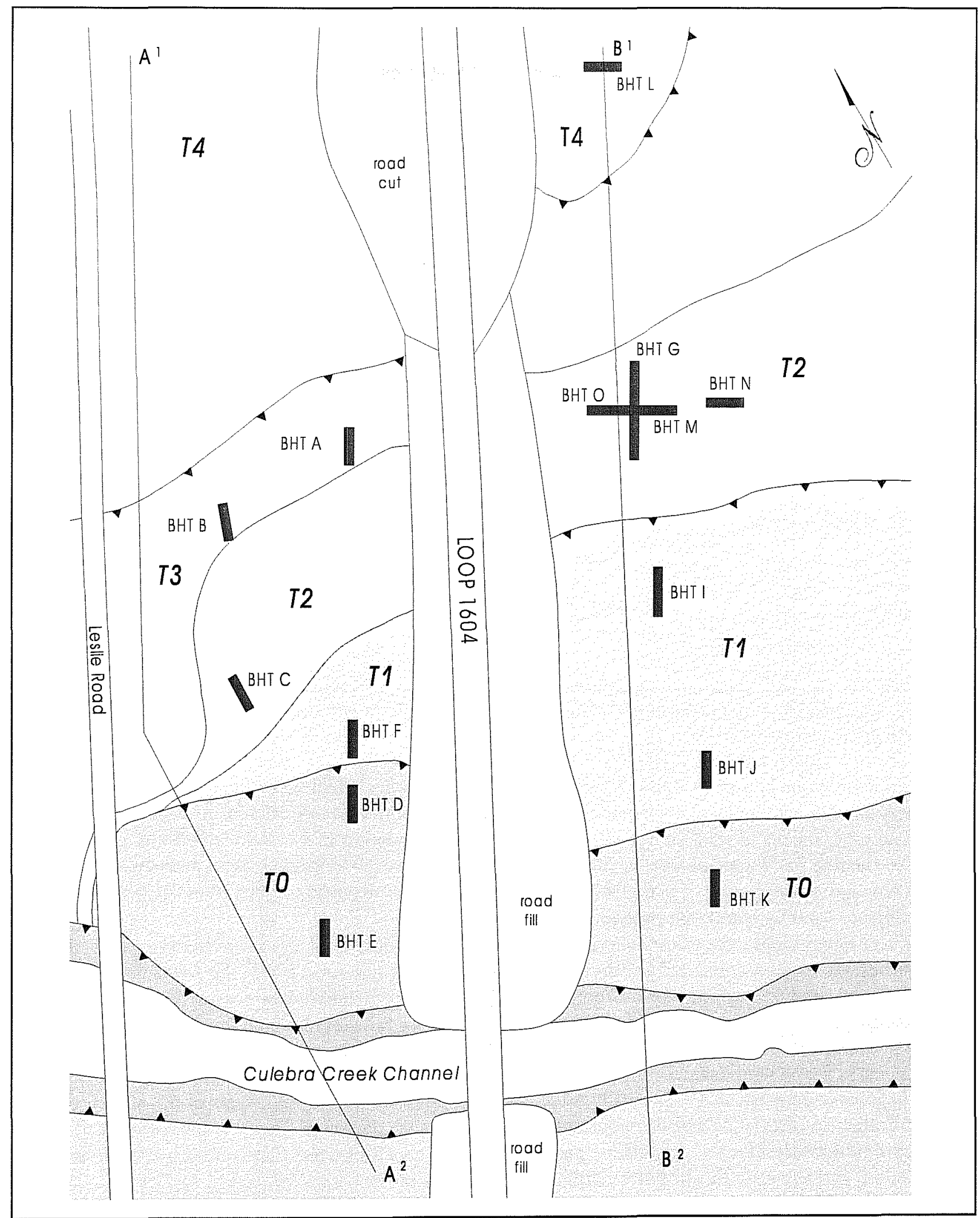

Figure A-1. Location of trenches and stratigraphic units at $41 B X 126$. 


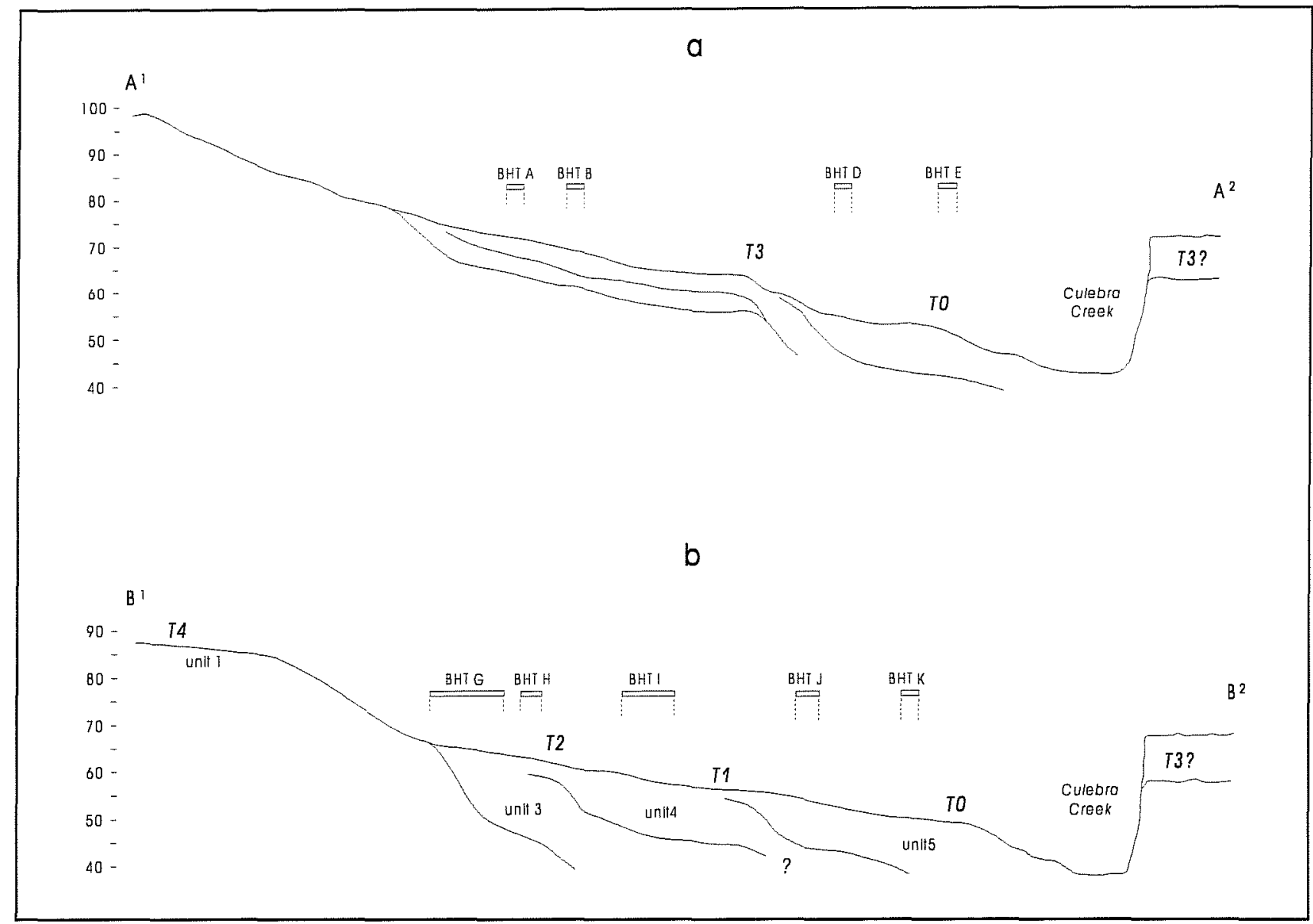

Figure A-2. Stratigraphic cross sections of Culebra Creek at $41 B X 126$ as marked on Figure A-1. a: cross section of $\mathrm{A}^{1}-\mathrm{A}^{2}$; $\mathrm{b}$ : cross section of $\mathrm{B}^{1}-\mathrm{B}^{2}$.

be progressive from one part of the valley to another, or seemingly chaotic, with units of disparate age juxtaposed. The other means of relative age interpretation is by evaluating the degree of weathering of the deposit (a.k.a. soil development or pedogenesis). In the short term $(<10,000$ years), the process of soil formation, a progressive process whereby a geologic deposit is modified in place by soil forming processes, is the most useful weathering index for this purpose. Certain pedogenic attributes such as calcic soil horizons are chronologically sensitive enough to use as relative age indices, although many factors may complicate this process. In particular, it is widely recognized that factors influential in soil development in addition to time include climate, organisms, parent material, relief, and site specific attributes (Holliday 1992:102; Jenny 1941). Other factors involved in generating field estimates of stratigraphic unit age include the preservation of bedding, fossil inclusions, and lithology, which in some cases may vary systematically through time. When much older deposits are considered, other weathering criteria are useful as well, such as the formation of weathering rinds on gravels, the relative strength of gravel clasts, and variations in the lithology of deposits derived from the same source.

For this project, field exposures were cleaned and then described (Table A-1) with the fundamental unit of field observation being the zone, a generic term which allows for full elucidation of geologic and pedogenic variability. Zones were consecutively numbered from the surface downward. For each zone, several specific attributes were recorded, such as the texture of the deposit, the degree of structure, consistency and color at field conditions, reaction to dilute hydrochloric acid, and the morphology, frequency, and size of other attributes like clay films, pedogenic carbonate, mottles, pores, and roots. Where present, the type and extent of bedding or sedimentary structures were noted and described. Each zone was subsequently assigned a soil 
horizon designation (cf. Soil Survey Staff 1990) as well as membership in one of the stratigraphic units, where possible. From the field records, descriptions of each stratigraphic unit were compiled, and additional information such as radiocarbon age was incorporated where available. Specific attributes of the sedimentary record pertinent to the context and distribution of archeological sites were described as well.

\section{Stratigraphy}

Five stratigraphic units were recognized in the field (Tables A-2 and A-3). These are informally identified as Unit 1 to Unit 5, from oldest to youngest, respectively (Figure A-2). These deposits are estimated to range in age from less than 1,000 years (as in the case of Unit 5) to more than 12,000 as in the case of Units 1 and 2 . These age estimates are based upon correlation with similar deposits elsewhere in central Texas, in addition to three humate radiocarbon ages obtained from two of the units.

\section{Unit 1: Ancient Lag Gravel (Middle Pleistocene? = Leona Formation)}

The oldest alluvial deposit recognized in the vicinity of 41BX126 is an ancient lag gravel which drapes the upland surface in the northern half of the site. This surface, where relatively planar in character, is interpreted as a strath terrace of Culebra Creek and/or Helotes Creek and is referred to as T4. It lies more than $17 \mathrm{~m}$ above the channel of Culebra Creek where it is crossed by the Loop 1604 right-of-way. A single trench excavated into this surface exposed a vertisol (a Mollic Torrert) with an Ass-Bw-R soil profile. This soil appears to be formed largely through in situ weathering of limestone bedrock, which in this area is identified as Austin Chalk (Barnes 1983). The Bw horizon contained numerous (few to common) siliceous gravels which are inferred to be associated with the Leona Formation (see Sellards et al. [1932] for a description of the Leona Formation), mapped by Barnes (1983) in the vicinity of this bedrock exposure. This is not considered to be a typical expression of the Leona Formation, but it is a common attribute of other gravel lag deposits in this region, such as the Uvalde Gravels
(Byrd 1971). No buried cultural material was observed in this trench, and the setting and probable origin of the soil preclude finding archaeological materials in good context within this soil. The gravels probably served as a lithic raw material source in this immediate region but the lithology of this deposit was not evaluated in detail.

The Leona Formation was originally defined by Hill and Vaughan (1898) for terrace deposits of Texas streams at elevations between 20 and $120 \mathrm{ft}$ above the local water level or channel. These terraces are considered to be of Pleistocene age, and vertebrate remains of early Pleistocene age have been found in some localities (Sellards et al. 1932:797). The Leona Formation is distinguished from the Uvalde Gravel primarily on the basis of position on the landscape. The Uvalde Gravel occupies a higher topographic position, and according to Sellards et al. (1932:778) occurs only on drainage divides and inter-stream ridges. In general, the Leona Formation has not been widely mapped by the Bureau of Economic Geology, except on the San Antonio Sheet of the Geologic Atlas of Texas. If evenly applied, this map unit would be considerably more extensive than presently mapped.

\section{Unit 2: Late Pleistocene (>12 kya)}

Unit 2 is defined on the basis of a road cut exposed by the narrow blacktop road which parallels Loop 1604 along the west side of the right-of-way. Two trenches (A and B) were placed into a surface of similar elevation and potentially similar deposit, but terminated upon a petrocalcic horizon formed in either gravely alluvium or on top of and within limestone bedrock. The soils exposed in these trenches also exhibited vertic tendencies such as prominent slickensides, and irregular subvertical color variations at depth in the B horizon that are interpreted as old cracks that filled in with darker-colored sediment (A-horizon material) from higher in the profile. The petrocalcic horizon was not fully exposed in either trench, but clearly expressed in the road cut, off site to the west. The soil formed here appears to be a Vertic Calciustoll, and like the soil formed upon and within the Unit 1 gravels, has little potential for in situ archaeological remains. This interpretation may be significantly different if it can 
Table A-1. Field Descriptions of Trench Profiles at 41BX126

\begin{tabular}{|c|c|c|c|c|c|c|c|}
\hline $\begin{array}{l}\text { Trench } \\
\text { No. }\end{array}$ & $\begin{array}{c}\text { Stratigraphic } \\
\text { Unit } \\
\end{array}$ & Depth $(\mathrm{cm})$ & Zone & $\begin{array}{c}\text { Soil } \\
\text { Horizon } \\
\end{array}$ & Munsell Color & Texture & Structure \\
\hline Trench A & Unit 2 or 3 & $\begin{array}{c}0-25 \\
25-60 \\
60-90 \\
90+ \\
\end{array}$ & $\begin{array}{l}1 \\
2 \\
3 \\
4\end{array}$ & $\begin{array}{c}\text { Ass } \\
\text { Bss } \\
\text { Bss } \\
\text { Bkm }\end{array}$ & $\begin{array}{c}\text { 10YR } 3 / 1 \\
\text { 10YR } 3 / 3 \\
10 Y R 3 / 2-3 / 3 \\
-\end{array}$ & $\begin{array}{l}\text { clay } \\
\text { clay } \\
\text { clay sg clay } \\
\text { calcrete }\end{array}$ & $\begin{array}{l}2-3, \mathrm{~m}-\mathrm{c}, \mathrm{abk} \\
2-3, \mathrm{~m}-\mathrm{c}, \mathrm{abk} \\
3, \mathrm{~m}, \mathrm{cpr}\end{array}$ \\
\hline Trench B & Unit 2 or 3 & $\begin{array}{r}0-30 \\
30-80 \\
80-120 \\
120+ \\
\end{array}$ & $\begin{array}{l}1 \\
2 \\
3 \\
4 \\
4\end{array}$ & $\begin{array}{c}\text { A } \\
\text { Bss } \\
\text { Bss } \\
\text { Bkm } \\
\end{array}$ & $\begin{array}{c}10 Y R 3 / 1 \\
10 Y R \quad 4 / 3 \\
10 Y R \quad 4 / 3 \\
- \\
\end{array}$ & $\begin{array}{l}\text { clay } \\
\text { clay } \\
\text { clay } \\
\text { calcrete }\end{array}$ & $\begin{array}{l}2, c, \text { sbk to } 2, f, g r \\
3, m-c, \text { abk } \\
3, \mathrm{~m}, \text { abk } \\
-\end{array}$ \\
\hline Trench C & Unit 3 & $\begin{array}{c}0-35 \\
35-80 \\
80-110 \\
110-180 \\
180-220+\end{array}$ & $\begin{array}{l}1 \\
2 \\
3 \\
4 \\
5\end{array}$ & $\begin{array}{c}\text { Ass } \\
\text { Bk } \\
\text { Bk } \\
\text { Bkss } \\
\text { Bkss }\end{array}$ & $\begin{array}{c}10 \mathrm{YR} 3 / 1 \\
10 \mathrm{YR} 3 / 2-3 / 1 \\
10 Y R 3 / 2 \\
10 \mathrm{YR} 4 / 2 \\
7.5 \mathrm{YR} 5 / 4\end{array}$ & $\begin{array}{l}\text { clay, silty clay loam } \\
\text { clay, silty clay loam } \\
\text { clay } \\
\text { clay } \\
\text { clay }\end{array}$ & $\begin{array}{l}2-3, \mathrm{~m}-\mathrm{c}, \mathrm{gr} \text { to } 2, \mathrm{~m}, \mathrm{sbk} \\
\text { massive to } 2, \mathrm{~m}-\mathrm{c}, \mathrm{gr} \\
2, \mathrm{~m}, \text { sbk to } 1, \mathrm{f}, \mathrm{gr} \\
3, \mathrm{~m}, \mathrm{pr} \\
3, \mathrm{~m}, \mathrm{pr}\end{array}$ \\
\hline Trench $\mathrm{E}$ & Unit 5 & $\begin{array}{l}0-25 \\
25-63 \\
63-73 \\
73-175+\end{array}$ & $\begin{array}{l}1 \\
2 \\
3 \\
4\end{array}$ & $\begin{array}{c}\mathrm{A} \\
\mathrm{AC} \\
2 \mathrm{Ab} \\
2 \mathrm{C}\end{array}$ & $\begin{array}{c}10 \mathrm{YR} 3 / 1 \\
10 \mathrm{YR} 6 / 5-3 / 1 \\
10 \mathrm{YR} 3 / 1 \\
-\end{array}$ & $\begin{array}{l}\text { clay, sg clay } \\
\text { gravel, sandy gravel } \\
\text { muddy gravel, sg silt loam } \\
\text { gravel, muddy gravel }\end{array}$ & $\begin{array}{l}\text { massive to } 1, \mathrm{~m}-\mathrm{f}, \mathrm{gr} \\
\text { structureless } \\
\text { massive } \\
\text { structureless }\end{array}$ \\
\hline Trench $\mathrm{F}$ & $\begin{array}{l}\text { Unit } 5 \\
\text { Unit } 3 \text { or } 4\end{array}$ & $\begin{array}{c}0-30 \\
30-60 \\
60-133 \\
133-160 \\
160-190+ \\
\end{array}$ & $\begin{array}{l}1 \\
2 \\
3 \\
3 \\
4 \\
5\end{array}$ & $\begin{array}{c}\mathrm{A} \\
\mathrm{A} \\
\mathrm{C} \\
\mathrm{C} \\
2 \mathrm{Bk}\end{array}$ & $\begin{array}{c}10 \text { YR } 3 / 1 \\
10 Y R 3 / 1-3 / 2 \\
10 Y R 6 / 5 \\
10 Y R 3 / 1 \\
10 Y R 4 / 3\end{array}$ & $\begin{array}{l}\text { sg clay } \\
\text { sg-g loam } \\
\text { gravel } \\
\text { muddy gravel } \\
\text { loam }\end{array}$ & $\begin{array}{l}\text { massive to } 1, \mathrm{c}, \mathrm{gr} \\
\text { massive to } 1, \mathrm{~m}, \mathrm{sbk} \\
\text { structureless } \\
\text { structureless } \\
\text { massive to } 1, \mathrm{~m}-\mathrm{f}, \mathrm{sbk}\end{array}$ \\
\hline $\begin{array}{l}\text { Trench G } \\
\text { beneath } \\
\text { midden }\end{array}$ & Unit 3 & \begin{tabular}{|c|}
$0-15$ \\
$15-55$ \\
$55-70$ \\
\\
$70-100$ \\
\\
\\
$100-142$ \\
$142-170$
\end{tabular} & $\begin{array}{l}1 \\
2 \\
3\end{array}$ & $\begin{array}{l}\mathrm{Ap} \\
\mathrm{Ap} \\
\mathrm{Ap} \\
\mathrm{Bk}\end{array}$ & $\begin{array}{c}\text { 10YR } 3 / 1-\mathrm{N} 2 / 0 \\
10 Y R 3 / 1-\mathrm{N} 2 / 0 \\
10 Y R 3 / 1 \\
7.5 \text { YR } 4 / 4 \\
\\
7.5 Y R \quad 4 / 2 \\
7.5 \text { YR } 4 / 2\end{array}$ & $\begin{array}{l}\text { silt loam } \\
\text { g silt loam } \\
\text { g silt loam } \\
\text { silt loam } \\
\text { silt loam } \\
\text { sg silty clay loam, clay }\end{array}$ & $\begin{array}{l}\text { massive to } 1, \mathrm{~m}, \mathrm{abk} \\
2, \mathrm{f}, \mathrm{cr} \\
\text { massive } \\
2, \mathrm{~m}-\mathrm{f}, \mathrm{gr} \\
2-3, \mathrm{~m}-\mathrm{f}, \mathrm{gr} \\
2, \mathrm{~m}, \mathrm{cpr} \text { to } 2, \mathrm{f}, \mathrm{abk}\end{array}$ \\
\hline $\begin{array}{l}\text { Trench } G \\
\text { away } \\
\text { from the } \\
\text { midden }\end{array}$ & Unit 3 & \begin{tabular}{|c|}
$0-40$ \\
$40-70$ \\
$70-100$ \\
$100-120+$ \\
\end{tabular} & $\begin{array}{l}2 \\
3 \\
4\end{array}$ & $\begin{array}{l}\mathrm{A} \\
\mathrm{AB} \\
\mathrm{Bk} \\
\mathrm{Bss}\end{array}$ & $\begin{array}{c}10 \text { YR } 3 / 1-\mathrm{N} 2 / 0 \\
10 Y R 3 / 2 \\
10 Y R 3 / 3-4 / 3 \\
10 Y R 4 / 3 \\
\end{array}$ & $\begin{array}{l}\text { silt loam, silty clay loam } \\
\text { silt loam, silty clay loam } \\
\text { silt loam } \\
\text { silt loam, silty clay loam }\end{array}$ & $\begin{array}{l}1, \mathrm{~m}-\mathrm{f}, \mathrm{cr} ; \text { to } 1, \mathrm{~m}-\mathrm{f}, \mathrm{gr} \\
1, \mathrm{f}, \mathrm{sbk} \\
1, \mathrm{f}, \mathrm{cpr} \\
1-2, \mathrm{~m}, \mathrm{sbk}\end{array}$ \\
\hline
\end{tabular}

Key to abbreviations used in Tables A-1 and A-2. Color designations follow Munsell, and represent moist colors unless otherwise noted by a (d) after the color, which indicates dry condition. n. $0 .=$ not observed.

Texture: $\mathrm{S}=$ sand, $\mathrm{LS}=$ loamy sand, $\mathrm{SL}=$ sandy loam, $\mathrm{L}=\mathrm{loam}$, $\mathrm{SiL}=$ silt loam, $\mathrm{SiCL}=$ silty clay loam, $\mathrm{SC}=$ sandy clay, $\mathrm{C}=\mathrm{clay}, \mathrm{CL}=\mathrm{clay}$ loam.

Structure: Grade: 1=weak, 2=moderate, 3=strong; Size: vf=very fine, $\mathrm{f}=$ fine, m=medium, c=coarse, vc=very coarse; $C l a s s: \mathrm{p}=\mathrm{platy}$, $\mathrm{pl=prismatic,} \mathrm{cpr=columnar,}$ abk=angular blocky, sbk=subangular blocky, gr=granular, cr=crumb, $\mathrm{sg}=$ single grain, $m=$ massive

Moist consistency: lo=loose, vfr=very friable, fr=friable, fi=firm, vfi=very fim, efi=extremely firm. 


\begin{tabular}{|c|c|c|c|c|c|}
\hline Consistency & Boundary & $\begin{array}{l}\text { Carbonate } \\
\text { Morphology }\end{array}$ & Pores & Roots & Comments \\
\hline vfr-h & $c, s$ & - & $1-2, \mathrm{vf}, \mathrm{tub}, \mathrm{r}$ & $2, \mathrm{vf}, \mathrm{v}$ & slickensides \\
\hline vfr & c, s & - & $1-2, v_{\text {, tub, } \mathrm{r}}$ & $\begin{array}{l}1, \mathrm{~m}, \mathrm{~h}, 1, \mathrm{vf} \\
\mathrm{v}\end{array}$ & slickensides \\
\hline fi & a, s & - & $1-2$, vf, tub, r & - & slickensides \\
\hline eh & - & - & -- & & - \\
\hline $\mathrm{vfr}$ & $\mathrm{g}, \mathrm{s}$ & - & $2, \mathrm{vf}, \mathrm{tub}, \mathrm{r}$ & $1-2, \mathrm{vf}, \mathrm{v}$ & common worm casts \\
\hline fr & c, s & - & $1-2$, vf, tub, r & $1, \mathrm{vf}, \mathrm{opf}$ & $\begin{array}{l}\text { slickensides; vague, vertically oriented, dark colored areas } \\
\text { that appear to be associated with material filling old } \\
\text { cracks, few, thin clay films on ped faces }\end{array}$ \\
\hline $\mathrm{h}$ & $\mathrm{a}, \mathrm{s}$ & - & $1, \mathrm{vf}, \mathrm{tub}, \mathrm{I}$ & -- & $\begin{array}{l}\text { prominent slickensides; mottling as in zone } 2 \text {; few } \\
\text { manganans on ped faces; few, thin clay films on ped faces }\end{array}$ \\
\hline eh & - & -- & -- & - & appears to be a petrocalcic horizon formed in gravel \\
\hline fr & $c, s$ & - & $1, \mathrm{vf}, \mathrm{tub}, \mathrm{r}$ & $2, v f, v-o p f$ & - \\
\hline $\mathrm{fr}$ & $\mathrm{c}, \mathrm{s}$ & $2-5 \% \mathrm{f}$ & $2, v f, t u b, r$ & $\begin{array}{l}2, \mathrm{~m}, \mathrm{~h}, 1, \mathrm{vf}, \\
\mathrm{r}\end{array}$ & common worm casts \\
\hline $\mathrm{h}$ & c, s & $2-5 \%$ f & $2-3, v f$, tub, $\mathrm{T}$ & $1, \mathrm{~m}, \mathrm{~h}, 1, \mathrm{vf}, \mathrm{r}$ & $\begin{array}{l}\text { some cultural material throughout, but expecially between } \\
52 \text { and } 60 \mathrm{~cm} \text {, and } 80 \mathrm{~cm} \text { depth }\end{array}$ \\
\hline $\mathrm{h}$ & $g, s$ & $5 \% \mathrm{n}$ & $1-2, \mathrm{vf}_{2}$ tub, $\mathrm{r}$ & $1, \mathrm{~m}, \mathrm{opf}$ & $\begin{array}{l}\text { slickensides; carbonate nodules (pedodes) } 1 \mathrm{~cm} \text { in } \\
\text { diameter }\end{array}$ \\
\hline $\mathrm{h}$ & -- & $5-7 \% \quad n$ & $1-2, v F$, tub, $\mathrm{r}$ & $1, \mathrm{~m}$, opf & $\begin{array}{l}\text { carbonate nodules (pedodes) } 1 \mathrm{~cm} \text { in diameter; } \\
\text { slickensides; ped faces slightly darker color than interiors } \\
(7.5 \mathrm{YR} 4 / 2) \text {. }\end{array}$ \\
\hline $\mathrm{vfr}$ & a, w & - & - & $\begin{array}{l}3, \mathrm{vf}, \mathrm{v}, 2, \mathrm{~m}- \\
\mathrm{c}, \mathrm{h}\end{array}$ & mud drape on top of gravel bar \\
\hline lo & $a, s$ & - & - & $2, \mathrm{f}, \mathrm{v}, 1, \mathrm{~m}, \mathrm{v}$ & $\begin{array}{l}\text { partially imbricated gravel with mud coats on top } \\
\text { of clasts }(1, \mathrm{n}, \text { pc cutans); many excrement fabric/worm } \\
\text { or insect casts }\end{array}$ \\
\hline vfr-lo & a, s & - & $1, \mathrm{vf}, \mathrm{tub}, \mathrm{r}$ & $2, \mathrm{~m}, \mathrm{f}, 1, \mathrm{c}, \mathrm{h}$ & $\begin{array}{l}\text { mud drape on top of gravel bar that has infiltrated top of } \\
\text { gravel; numerous excrement fabrics/worm or insect casts }\end{array}$ \\
\hline 10 & - & - & - & - & $\begin{array}{l}\text { gravel is locally imbricated; mud coats on top of gravel } \\
\text { casts ( } 1, \mathrm{n}, \text { pc cutans); multiple bed sets present in gravel } \\
\text { bar }\end{array}$ \\
\hline $\mathrm{fr}$ & $\mathrm{c}, \mathrm{s}$ & - & $1-2, \mathrm{vf}$, tub, $\mathrm{r}$ & $\begin{array}{l}2, \mathrm{vf}, \mathrm{v} ; 1, \mathrm{~m}, \\
\mathrm{~h}\end{array}$ & mud drape on top of gravel bar \\
\hline vfr & $\mathrm{g}, \mathrm{s}$ & $1 \% \mathrm{~F}$ to none & $2, \mathrm{vf}, \mathrm{tub}, \mathrm{r}$ & $\begin{array}{l}1, \mathrm{~m}, \mathrm{~h} ; 1, \mathrm{vf} \\
\mathrm{v}\end{array}$ & $\begin{array}{l}\text { common worm and or other animal excrement casts; few } \\
\text { calcium carbonates at the base of the zone }\end{array}$ \\
\hline 10 & - & - & - & $\mathrm{vf}, \mathrm{v}$ & $\begin{array}{l}\text { common clay coats on top of gravel clasts }(1, n, p e \\
\text { cutans); multiple bed sets }\end{array}$ \\
\hline 10 & $\mathrm{a}, \mathrm{s}$ & - & -- & $1, \mathrm{~m}, \mathrm{~h} ; 1, \mathrm{vf}, \mathrm{v}$ & $\begin{array}{l}\text { base of this fill; rests unconformably upon an older } \\
\text { deposit }\end{array}$ \\
\hline vfr & - & $1-3 \% \mathrm{f}$ & $1-2, \mathrm{vf}$, tub, $\mathrm{I}$ & - & older, more rubified alluvium \\
\hline $\mathrm{vfr}$ & a. $w$ & - & $1, \mathrm{vf}, \mathrm{tub}, \mathrm{r}$ & 2, vf, v & alluvium-colluvium draping midden \\
\hline 10 & c, s & - & 3, vf, irr, r & - & $\begin{array}{l}\text { burned rock midden; fabric of fine grained matrix } \\
\text { dominated by excrement casts }\end{array}$ \\
\hline sh & $c, s$ & $1-3 \% \mathrm{f}$ & 3, vf, tub, r & $1-2, \mathrm{vf}, \mathrm{v}$ & $\begin{array}{l}\text { burned rock midden, this zone appears to be a light gray } \\
\text { color, fabric of fine grained matrix dominated by } \\
\text { excrement casts, including worm and termite }\end{array}$ \\
\hline vfr & c, s & $25-30 \% f$ & $2-3$, vf, tub, $\mathrm{r}$ & - & $\begin{array}{l}\text { abundant excrement fabrics, the many carbonate filaments } \\
\text { impart a higher value to these deposits; the secaondary } \\
\text { carbonate may by vertically translocated ash from the } \\
\text { midden }\end{array}$ \\
\hline vfr & c, s & $5-7 \% \mathrm{f}$ & $2-3$, vf, tub, $\mathrm{r}$ & $1, \mathrm{vf}, \mathrm{v}$ & - \\
\hline h & $c, s$ & $3 \% \mathrm{f}$ & 2, vf, tub, $\mathrm{r}$ & $1, \mathrm{vf}, \mathrm{v}$ & few earthworm casts \\
\hline ff & $\mathrm{g}, \mathrm{s}$ & - & $\begin{array}{l}2, \text { vf, irr, r; } \\
1, \text { vf, tub, r }\end{array}$ & 2, vf, v & common worm casts, few isolated burned rock \\
\hline vfr & $g, s$ & $1-3 \% \mathrm{f}$ & $2, \mathrm{vf}, \mathrm{tub}, \mathrm{r}$ & $1-2, \mathrm{vf}, \mathrm{v}$ & few isolated burned rock \\
\hline$v$ fr & g, s & $10-15 \% \mathrm{f}$ & $1-2, \mathrm{vf}, \mathrm{tub}, \mathrm{r}$ & $1, \mathrm{vf}, \mathrm{v}$ & - \\
\hline vfr & - & $1 \%$ & $1-2, \mathrm{vf}, \mathrm{tub}, \mathrm{r}$ & $1, \mathrm{vf}, \mathrm{v}$ & slickensides \\
\hline
\end{tabular}

Key to abbreviations used in Tables A-1 and A-2 (continued).

Dry consistency: lo=loose, so=sof, sh=slightly hard, h=hard, vh=very hard, eh=extremely hard.

Boundary: Distinctness: a =abrupt, c=clear, g=gradual, $\mathrm{d}=$ =diffuse; Topography: s=smooth, w=wavy, i=irregular, b=broken.

Carbonate morphology/reaction: Abundance: $1=\mathrm{few}, 2=\mathrm{common}, 3=$ many; Morphology: f=filaments, n=nodules or concretions, ss=soft segregations or soft masses; Reaction: nc=noncalcareous, vw=very weakly calcareous, $\mathrm{c}=$ calcareous, $\mathrm{sc}=$ strongly calcareous, vsc=very strongly calcareous.

Gypsum: $1=$ few, $2=$ common, $3=$ many, th=threads. 
Table A-1. continued

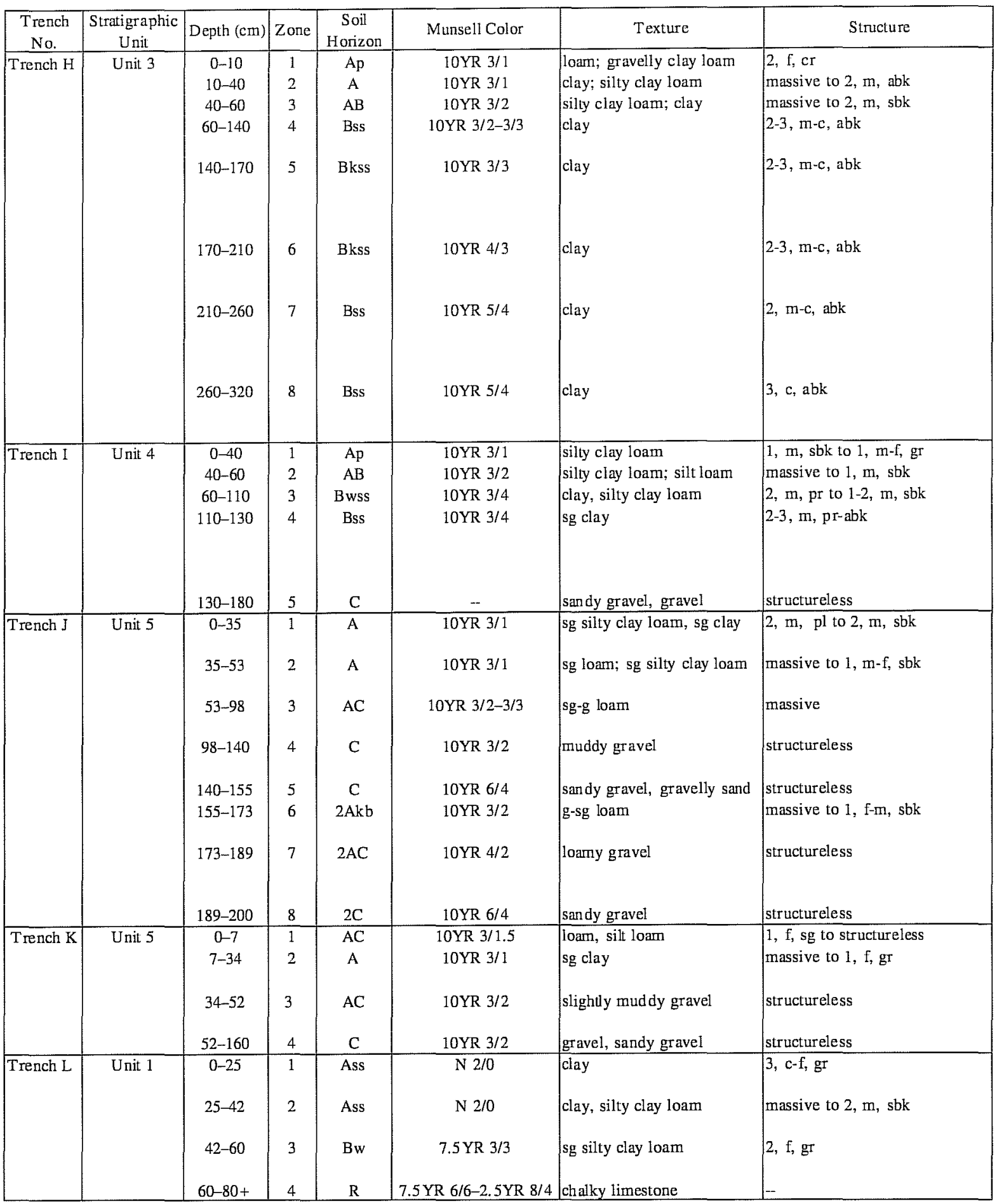




\begin{tabular}{|c|c|c|c|c|c|}
\hline Consistency & Boundary & $\begin{array}{l}\text { Carbonate } \\
\text { Morphology }\end{array}$ & Pores & Roots & Comments \\
\hline vir & $a, s$ & - & -- & -- & rew orked slope deposits; disturbed by vehicular activity \\
\hline fr & c, s & -- & $1-2, \mathrm{vf}, \mathrm{tub}, \mathrm{r}$ & $1-2, v f, v$ & -- \\
\hline fr & $\mathrm{c}, \mathrm{s}$ & -- & 1, vf, tub, r & $1, \mathrm{r}, \mathrm{T}$ & few worm casts \\
\hline fr & g, s & - & 2, vf, tub, $\mathrm{r}$ & $1, \mathrm{vf}$, opf & $\begin{array}{l}\text { large, prominent slickensides, many, vertical, elongate } \\
\text { dark colored (10YR 3/2) crack fils }\end{array}$ \\
\hline fr-fi & $\mathrm{c}, \mathrm{s}$ & -- & $1-3, v f$, tub, $r$ & - & $\begin{array}{l}\text { many, vertical, elongate dark colored (10YR } 3 / 2) \text { crack } \\
\text { fills; a radiocarbon humate sample from this zone (134- } \\
145 \mathrm{~cm} \text { depth) yielded a fractionation uncorrected age of } \\
4,37050 \text { (Beta-81538) }\end{array}$ \\
\hline fi & c, & $1-3 \% \mathrm{n}$ pof & $1-2$, vf, tub, $\mathrm{r}$ & - & $\begin{array}{l}\text { ped faces have few, thin clay films (10YR } 3 / 3) \text {; and few } \\
1 \mathrm{~cm} \text { diameter pedode-like calcium carbonate nodules; } \\
\text { slickensides }\end{array}$ \\
\hline fi & c, s & - & $1-2$, vf, tub, $\mathrm{r}$ & $-\cdots$ & $\begin{array}{l}\text { prominent slickensides, few worm casts; a radiocarbon } \\
\text { humate smaple from this zone (237-253 cm depth) yielded } \\
\text { a fractionation uncorrected age of } 11,54090 \text { (Beta- } \\
81539 \text { ) }\end{array}$ \\
\hline fi & -- & - & $1-2, \mathrm{vf}$, tub, $\mathrm{r}$ & -- & $\begin{array}{l}\text { common manganans on ped faces, which are shiny, } \\
10 Y R 3 / 1 \text { (bluish-black colored); common prominent } \\
\text { slickensides }\end{array}$ \\
\hline vfr & $\mathrm{g}, \mathrm{s}$ & - & $2, \mathrm{vf}, \mathrm{tub}, \mathrm{r}$ & $2, v f, v$ & few flakes and burned rocks in top $20 \mathrm{~cm}$ \\
\hline vfr & c, s & -- & $1-2, v f$, tub, $\mathrm{r}$ & $2, \mathrm{vf}, \mathrm{v}$ & few worm casts \\
\hline fr & c, s & $3 \% \mathrm{f}$ & $1-2$, vf, tub, $\mathrm{r}$ & $1, \mathrm{vf}$, opf & slickensides, few very faint calcium carbonate filaments \\
\hline lo & a, w & - & $1-2$, vf, tub, $\mathrm{r}$ & $1, \mathrm{vf}, \mathrm{r}$ & $\begin{array}{l}\text { few slickensides, worm casts; zone has more clay and } \\
\text { gravel than zone 3; a radiocarbon humate sample from } \\
109-122 \mathrm{~cm} \text { depth yielded a fractionation uncorrected age } \\
\text { of } 3,19060 \text { years B.P. (Beta- } 81540 \text { ). } \\
\text { multiple bed sets, some imbrication present. }\end{array}$ \\
\hline $\mathrm{fr}$ & $g, s$ & - & $1, \mathrm{vf}$, tub, $\mathrm{r}$ & $\begin{array}{l}2, \mathrm{vf}, \mathrm{f} ; \mathrm{l}, \mathrm{m}, \\
\mathrm{h}\end{array}$ & -- \\
\hline fr-vfr & $\mathrm{c}, \mathrm{s}$ & - & $2-3$, vf, irr, $r$ & $\begin{array}{l}1, \mathrm{vf}, \mathrm{r}, 1, \mathrm{~m}, \\
\mathrm{~h}\end{array}$ & many worm casts, more gravel and sand than zone 1. \\
\hline vfr & c, s & $1 \% \mathrm{f}$ & $\begin{array}{l}2, \text { vf, irr, r } \\
1, \text { vf, tub, r }\end{array}$ & $1, \mathrm{~m}, \mathrm{~h}$ & $\begin{array}{l}\text { few calcium carbonate filaments at depth; few, thin caly } \\
\text { films on gravel clasts. }\end{array}$ \\
\hline lo & $a, s$ & - & - & $1, \mathrm{vf}, \mathrm{r}$ & $\begin{array}{l}\text { fabric of the interstitial sediment is largely excrement } \\
\text { casts; few, thin clay films on gravel clasts. }\end{array}$ \\
\hline lo & a, $s$ & - & -- & $1, \mathrm{vf}, \mathrm{r}$ & no significant clay films, more yellow than zone 4 \\
\hline vir & $a, s$ & $10-15 \% \mathrm{f}$ & $2-3$, vf, tub, $\mathrm{r}$ & $1, \mathrm{~m}, \mathrm{~h}$ & $\begin{array}{l}\text { possibly a weak buried A-horizon formed in overbank } \\
\text { mud. }\end{array}$ \\
\hline 10 & a, s & $1 \% \mathrm{f}$ & $\begin{array}{l}1, \text { vf, tub, r } \\
2, \text { vf, irr, r }\end{array}$ & $1, \mathrm{vf}, \mathrm{r}$ & $\begin{array}{l}\text { calcium carbonate filaments encrusting framew ork clasts, } \\
\text { few very incipient carbonate pendents on bottoms of } \\
\text { clasts }\end{array}$ \\
\hline vfr & $a, s$ & - & -- & $2-3, v f, v$ & very recent alluvium \\
\hline fr & $a, s$ & - & 1, vf, tub, $\mathrm{r}$ & $\begin{array}{l}1, \mathrm{~m}, \mathrm{~h} ; 2, \mathrm{vf}- \\
\mathrm{f}, \mathrm{v}\end{array}$ & fine $(2 \mathrm{~mm}$ ) charcoal flecks scattered throughtout \\
\hline 10 & a. s & - & - & $2, \mathrm{f}-\mathrm{vf}, \mathrm{v}$ & $\begin{array}{l}\text { many worm casts in the interstices between framework } \\
\text { clasts }\end{array}$ \\
\hline lo & - & - & - & $1, \mathrm{vf}, \mathrm{v}$ & several bed sets presents; some imbrication present \\
\hline 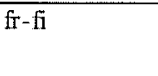 & $\mathrm{c}, \mathrm{s}$ & - & 1, vf, tub, $\mathrm{r}$ & $\begin{array}{l}2, \mathrm{vf}, \mathrm{r} ; 2, \mathrm{~m}, \\
\mathrm{~h}\end{array}$ & slickensides \\
\hline fr-vfr & c, s & - & 2 , vf, tub, $\mathrm{r}$ & $\begin{array}{l}2, v f, v ; 2, m, \\
h\end{array}$ & many worm casts, few slickensides, few siliceous gravels \\
\hline fr & $\mathrm{a}, \mathrm{w}$ & - & $1, \mathrm{vf}$, tub, $\mathrm{r}$ & $\begin{array}{l}1, \mathrm{vf}, \mathrm{r} ; 1, \mathrm{~m}, \\
\mathrm{~h}\end{array}$ & $\begin{array}{l}\text { few to common siliceous gravels (Leona/Uvalde } \\
\text { Formation) }\end{array}$ \\
\hline eh & -- & limestone & -- &.- & no laminar cap, but limestone is locally laminated. \\
\hline
\end{tabular}


Table A-2. Stratigraphic Units at 41BX126 (kya $=1,000$ years ago)

\begin{tabular}{|c|c|c|c|}
\hline $\begin{array}{l}\text { Stratigraphic } \\
\text { Unit }\end{array}$ & $\begin{array}{c}\text { Approximate } \\
\text { Age }\end{array}$ & $\begin{array}{l}\text { Temporal } \\
\text { Estimate } \\
\text { (ky a B.P.) }\end{array}$ & Stratigraphic Description \\
\hline Unit 5 & Latest Holocene & $<1$ & 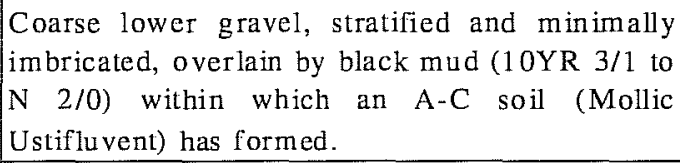 \\
\hline Unit 4 & $\begin{array}{c}\text { Middle to Late } \\
\text { Holocene }\end{array}$ & ca. 3.2 to 1 & $\begin{array}{l}\text { Fine to coarse grained alluvium inferred to be } \\
\text { inset against Unit } 3 \text {. Channel facies consists of } \\
\text { more than a meter of partially imbricated gravel, } \\
\text { and overlain by almost } 2 \mathrm{~m} \text { of clayey alluvium } \\
\text { within which an Ap-AB-Bss soil (a Vertic } \\
\text { Rendoll) has formed. }\end{array}$ \\
\hline Unit 3 & $\begin{array}{l}\text { Terminal } \\
\text { Pleistocene to } \\
\text { Middle } \\
\text { Holocene }\end{array}$ & ca. 11.6 to 4 & $\begin{array}{l}\text { Fine grained alluvium characterized by abundant } \\
\text { shrink-s well clays and a prominent calcic soil. } \\
\text { Soils observed in this unit exhibit Ap-A-AB-Bkss- } \\
\text { Bss to Ass-Bk-Bkss profiles (Vertic Calciustoll). } \\
\text { Calcic horizons formed in the clayey facies of this } \\
\text { fill exhibit small pedode-like glaebules which are } \\
<1 \mathrm{~cm} \text { in diameter or on ped faces. Some } \\
\text { manganans (manganese stains) on ped faces at } \\
\text { depths below } 2.6 \mathrm{~m} \text { depth. }\end{array}$ \\
\hline Unit 2 & Late Pleistocene & $>12$ & $\begin{array}{l}\text { Gravelly terrace fill deposit within which a } \\
\text { petrocalcic soil horizon has formed. A typical } \\
\text { soil profile exhibits an A-Bkm-R profile (Vertic } \\
\text { Calciustoll); not exposed well in any trench, but } \\
\text { apparent on the west side of the site in a road cut. }\end{array}$ \\
\hline Unit 1 & $\begin{array}{c}\text { Middle } \\
\text { Pleistocene? }\end{array}$ & $\begin{array}{c}\text { Leona } \\
\text { Formation (?) }>25\end{array}$ & $\begin{array}{l}\text { Very thin siliceous gravel lag mantling surface } \\
\text { and contained within the B horizon of an Ass-Bw- } \\
\text { R soil profile (Mollic Torrert). }\end{array}$ \\
\hline $\begin{array}{c}\text { Local } \\
\text { Limestone }\end{array}$ & Cretaceous & Austin Chalk > 30 & Chalky, white limestone \\
\hline
\end{tabular}

Table A-3. Location of Trenches at 41BX126 with Respect to the Terraces and the Deposits Beneath Each Surface

\begin{tabular}{|c|c|c|c|}
\hline Surface & $\begin{array}{c}\text { Elevation above } \\
\text { Thalweg }(\mathbf{m})\end{array}$ & $\begin{array}{c}\text { Deposit } \\
\text { Beneath Surface }\end{array}$ & $\begin{array}{c}\text { Trenches Situated on } \\
\text { Each Surface }\end{array}$ \\
\hline T0 & $1.7-2.7$ & Unit 5 & D, E, J, K \\
\hline T1 & $3.6-6.0$ & Units 4 and 5 & I \\
\hline T2 & $6.0-8.0$ & Units 3 and 4 & C, G, H \\
\hline T3 & ca. 7 & Units 2, 3, and 4(?) & A, B \\
\hline T4 & ca. $17+$ & Unit 1 & L \\
\hline
\end{tabular}


be demonstrated that this surface was incrementally flooded during the Holocene and the soil actually cumulic. In this case, there is a potential for in situ buried cultural deposits, but such occupations would be stratigraphically compressed and subject to argilloturbation associated with the vertic properties of the soil. No buried cultural material was observed in these deposits.

\section{Unit 3: Terminal Pleistocene to Middle Holocene (ca. 11.6-4 kya)}

This deposit lies adjacent to the limestone upland and Unit 2 along the northern rim of the Holocene valley of Culebra Creek. The fill appears to be more than three meters thick and composed principally of clayey alluvium deposited in a quiescent overbank setting. The texture of this deposit is relatively coarse immediately adjacent to the valley wall, where gravely colluvium is interbedded with the deposit. At depth this deposit ranges in color from brown (7.5YR 5/4) to yellowish brown (10YR 5/4) to dark grayish brown (10YR 4/2), and generally exhibits well-developed slickensides, some with clay skins on ped faces, manganans (manganese stains) on ped faces at depth, and a calcic soil horizon. The calcic horizon formed in this deposit exhibited nodular morphology between about 100 and $220 \mathrm{~cm}$ in Trench $\mathrm{C}$ and at depths between 170 and $210 \mathrm{~cm}$ in Trench $H$. Coarser textured facies, such as those exposed by Trench $\mathrm{G}$, which has received substantial colluvial contributions, failed to exhibit nodular calcic horizons, and filamentous forms prevailed. With the exception of the colluvial facies, the soil formed in this deposit is vertic in character, and is generally a Vertic Calciustoll.

On the basis of its field appearance and stratigraphic position, this deposit was assumed to be of early to middle Holocene age, and this was confined by two radiocarbon ages on bulk humate samples from Trench $\mathrm{H}$, which yielded ages of $11,540 \pm 50$ B.P. at a depth of $245 \mathrm{~cm}$ (Beta-81539), and $4370 \pm 50$ B.P. at an average depth of $140 \mathrm{~cm}$ (Beta-81538). This suggests that aggradation of the majority of this deposit occurred between ca. 12 and $4 \mathrm{kya}$, and that the tread of this surface may be cumulic during the latter half of the Holocene. This is clearly illustrated by the burial of the burned rock midden exposed in Trench G, where a combination of colluvial and alluvial sediments has buried the feature. If the radiocarbon ages reflect time of sedimentation accurately, these dates suggest that aggradation upon this surface occurred at a more rapid rate in the late Holocene (since ca. $4.4 \mathrm{kya}$ ), than during the early Holocene. Given that a younger deposit is inset into Unit 3, it is probable that the cumulic deposition of the upper part of this deposit occurred concomitant with sedimentation of Unit 4 . On the basis of the radiocarbon age obtained from Trench $\mathrm{H}$, the burned rock midden exposed in Trench $G$ probably dates to the period after 4 kya. The potential for in situ cultural deposits in this setting is relatively good, although the finer textured facies may have experienced some vertical mixing due to the actions of shrink-swell clays. This process, also known as argilloturbation, may have slightly altered the distribution of the materials. A field observation supporting this interpretation is the subvertical orientation of a Pedernales point discovered in the wall of Trench $\mathrm{C}$, which may have been repositioned by the vertic activities of this soil.

\section{Unit 4: Middle to Late Holocene (ca. 3.2-1 kya)}

This deposit was observed in a single trench (Trench I) on the east half of 41BX126. In the field it was difficult to ascertain if this deposit was the same age as Unit 3 given that the overbank facies of each fill is similar (vertic clay) and that no calcic horizon was observed in Trench I. The fact that a gravel was encountered at a depth of $110-180 \mathrm{~cm}$, and that no significant textural variations were observed in Trench $\mathrm{H}$ at a similar depth, suggested that this deposit is a younger alluvial fill inset into Unit 3 . The occurrence of a very subtle scarp between the two trenches also lent support to this hypothesis. A radiocarbon humate sample taken from immediately above the gravel at a depth of about $116 \mathrm{~cm}$ yielded an age of $3190 \pm 60$ в.P. (Beta-81540) and, if correct, supports the hypothesis that the fill exposed by Trench $I$ is indeed a younger deposit inset into Unit 3. The field data suggest that this fill is about two meters thick and inset into and on top of Unit 3. 
The soil formed in this deposit exhibited an A-ABBss-C profile, and lacked a calcic horizon, although a few calcium carbonate filaments are observed in the Bss horizon (the frequency of which were considered to be insufficient to qualify as a calcic horizon). This soil is classified as a Vertic Rendoll. Like the finegrained facies of Unit 3, some argilloturbation may have affected cultural material within this deposit. The only cultural material observed within this unit was located in the top $20 \mathrm{~cm}$ of the profile. It is possible that some of this material came to rest in this area through the pedoturbative actions of dirt bikes, which appear to have favored this locality for some time. No field evidence supporting this interpretation was obtained, and it possible that these cultural materials reflect prehistoric use of this surface.

\section{Unit 5: Latest Holocene (since 1 kya)}

The youngest deposit observed at this site was exposed by five trenches (E, F, D, J, and K) from which it was concluded that this unit occurs beneath $\mathrm{T} 0$, and is also inset into older deposits along the leading edge of the $\mathrm{T} 1$ and $\mathrm{T} 2$ surfaces. This unit has a basal gravel which is in excess of $1.7 \mathrm{~m}$ thick and is overlain by a black mud drape. The gravels within this unit are often imbricated, and multiple bed sets are usually present. Other forms of cross-bedding are uncommon. Thin clay skins on top of gravel clasts are a common attribute of the lower half of the deposit and demonstrate vertical mobility of fine grained sediment through the profile. The mud which rests upon the gravel is minimally modified by pedogenesis, although its organic content may qualify it as an A-horizon. If the mud is considered to be an A-horizon, the soil within this deposit is probably a Mollic Ustifluvent. At the base of the mud, the interstitial material between gravel clasts is dominated by excrement fabrics, which suggests that soil fauna may play an important role in the vertical migration of fines within this unit. No archaeological inclusions were observed within Unit 5. Correlation of this deposit with similar sediments on Salado Creek in north San Antonio suggests deposition during the last millennium and perhaps as recently as the last 500 years.

\section{Stratigraphic Summary}

Five alluvial deposits are recognized in the immediate vicinity of 41BX126. At least two Pleistocene age terrace fill deposits are locally present, and others, not recognized here, undoubtedly occur in the Culebra Creek basin. The Holocene age fills, of which there appear to be at least three, represent fluvial deposition throughout different periods of the Holocene. The oldest Holocene deposit (Unit 3) aggraded during the latest Pleistocene to middle Holocene, and appears to be draped by a veneer of younger sediment that may have accumulated concomitant with Unit 4, and possibly Unit 5. No unconformity was observed separating these deposits, indicating very slow sedimentation. Unit 4, which is inset into Unit 3, appears to have been deposited since slightly before ca. $3.2 \mathrm{kya}$. No age was obtained for this unit, but deposition of this unit is expected to have ceased around 1 kya. The youngest fill, Unit 5, accounts for a significant proportion of the Holocene valley fill deposits and appears to be of recent age. No radiocarbon ages were obtained from this deposit, but it is expected to be less than $1 \mathrm{kya}$, and is considered to be correlative with the youngest alluvial deposit on Salado Creek, which began accumulating between ca. 1 kya and 0.5 kya.

\section{Archaeological Considerations}

Three of the deposits observed within the confines of 41BX126 potentially contain prehistoric cultural remains. The two oldest units (1 and 2) appear to predate human occupation in the New World. Although Units 3, 4, and 5 potentially contain archaeological remains, buried deposits of this type were only observed at the top of Units 3 and 4, and not at all in Unit 5. The cultural material (including the burned rock midden) found near the top of Unit 3 is buried by a veneer of late Holocene sediment which is believed to be contemporaneous with Unit 4, although it is possible that incremental sedimentation occurred throughout the last millennium as well. At a general level, this clearly places occupation of the site in the latter half of the Holocene, and arguably since $4 \mathrm{kya}$. If the context of the cultural material and the humate radiocarbon ages is interpreted strictly, then we may use 
the stratigraphic information to speculate about the major period of prehistoric occupation of this site.

If we assume a linear sedimentation rate and minimal disturbance of the deposits (that is to say that the cultural material was not redeposited by slope processes or recent human disturbance like road construction and motorcycle traffic), then the cultural materials observed only in the top $20 \mathrm{~cm}$ of the profile of Trench I probably represent Transitional Archaic to Late Prehistoric (Late Archaic II to Post-Archaic) occupation of the site. If Unit 4 is assumed to have accumulated between ca. 3.3 and $1 \mathrm{kya}$, then the apparent age of this occupation may be estimated to be around the period between 1400 to 1000 B.P. Alternatively, if the sedimentation rate for Trench I assumes sedimentation throughout the last $3.2 \mathrm{kya}$, then the occupation may be principally Late Prehistoric. If the midden constructed near the top of Unit 3 was of Archaic age, and occupation of the floodplain occurred throughout the period since ca. 3.2 kya, the occurrence of cultural material in Unit 4 is expected to have been greater than observed. Hence, a strict interpretation of this sedimentation and stratigraphic data suggests that the midden may be a transitional Archaic to Late Prehistoric (Late Archaic to Post-Archaic) feature. It is also possible that some of the cultural debris near the base of the midden was deposited before Unit 4 was in place, perhaps between 4 and 3 kya. 


\section{References Cited}

Barnes, V. E.

1983 Geologic Atlas of Texas, San Antonio Sheet. The Bureau of Economic Geology, The University of Texas at Austin.

Byrd, C. L.

1971 Origin and History of the Uvalde Gravel of Central Texas. Baylor Geological Studies Bulletin 20, Waco, Texas.

Hill, R. T., and T. W. Vaughan

1898 Geology of the Edwards Plateau and Rio Grande Plain Adjacent to Austin and San Antonio, Texas, with Reference to the Occurrence of Underground Waters. United States Geological Survey Annual Report 18(2):93-321.

Holliday, V. T.

1992 Soil Formation, Time and Archaeology. In Soils in Archaeology: Landscape Evolution and Human Occupation, edited by V. T. Holliday, pp. 101-118. Smithsonian Institution Press, Washington D. C.

Jenny, $\mathrm{H}$.

1941 Factors of Soil Formation. McGraw-Hill, New York.

North American Commission of Stratigraphic Nomenclature

1983 North American Stratigraphic Code. American Association of Petroleum Geologists Bulletin 67:841875.

Sellards, E. H., W. S. Adkins, and F. B. Plummer

1932 The Geology of Texas, Volume 1, Stratigraphy. Bulletin No. 3232. Bureau of Economic Geology, The University of Texas at Austin.

Soil Survey Staff

1990 Keys to Soil Taxonomy, fourth edition. SMSS Technical Monograph No. 19. Blacksburg, Virginia. 


\title{
Appendix B: Status Report 41BX126 Midden Recording
}

\author{
Charles D. Frederick and Stephen L. Black
}

\section{Introduction}

In late March 1995, several TARL personnel spent time documenting and sampling a burned rock midden that had been trenched and exposed by TxDOT archaeologist Dennis Price at site 41BX126. Prior to the exposure of this feature by trenching, the feature, being in the existing right-of-way of Loop 1604, was suspected to have been disturbed during the previous highway construction. That, however, is not the case.

The midden appears to be of annular morphology, and internal structural elements were observed in several places (Figure B-1), suggesting that from a structural perspective the feature possesses considerable research potential. The most conspicuous "architectural elements" are the semi-lenticular bodies of frameworksupported limestone which compose the outer edges of the feature and are best observed in the N-S trench. These deposits are interpreted as the "ring" or torusshaped portion of an annular burned rock midden. A different, but equally distinctive body of sediment is present between the two ring deposits. This stratum is matrix supported, and consists of large and small rocks suspended in relatively fine-grained matrix. This deposit is interpreted as the central depression of an annular burned rock midden. All but the crest of the midden annulus has been buried by either alluvium or colluvium. On the north side of the feature, nearest the limestone upland slope, the feature is buried by poorly sorted colluvium shed from the slope. On the southern side, the feature has been buried by clayey overbank alluvium deposited by Culebra Creek or a combination of Culebra and Helotes creeks.

Documentation of the feature by TARL personnel consisted of creating a photomosaic of three of the four exposed trench walls, and subsequently drawing overlays of the rocks, features within the midden, and the location of specific samples. Subsequent to mosaic construction, the walls were reanalyzed in the field and potential internal structural elements were identified.

Three of the four exposed walls were photographed in the field to allow construction of a detailed photomosaic, from which the midden's structure and internal 2-D architecture could be easily, and rather faithfully, recorded. Prior to photographing, adhesivebacked markers were affixed to small nails placed into the trench walls at $0.5-\mathrm{m}$ intervals to aid in identifying the location of each photograph. A stadia rod was extended across the ground surface for scale, and a red and white stadia rod positioned vertically was also situated in the field of view for each photograph. A string-line established by Dennis Price was present in the lower portion of most photographs. The walls were photographed at $0.5-\mathrm{m}$ intervals in 35-mm color slides and black-and-white prints, using a macro-lens. The resulting photographs possess some distortion due to inclination of the camera toward the wall and minimal image overlap, but the resulting distortion is still less than would have been incurred by drawing the profile using traditional techniques (drawing on graph paper, measuring distances with tape, and estimating rock shape and size), and does not interfere with the interpretation of the midden structure or stratigraphy. Future efforts of this nature should consider a slightly more formalized approach, such as 1) use of a tripod and a string line to keep the camera a constant distance from the subject wall, 2) use of a level to orient the camera in an upright position in order to avoid distortion, 3) overlap each photograph 50 percent, and 4) superimpose a string grid in order to provide regular control points. Such steps should help minimize the distortion and provide a truer image, but narrow trenches such as those documented here may still present problems. 
A

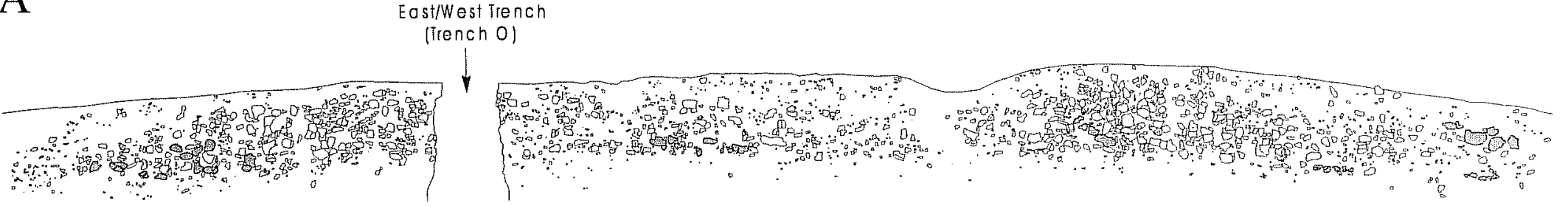

B Eastimest Tiench

(Trench O)

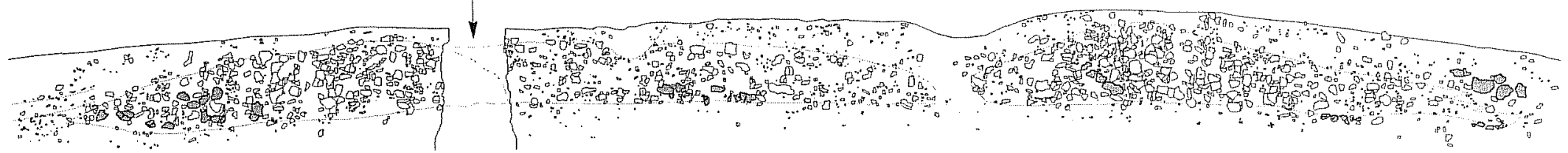

$\mathrm{C}$

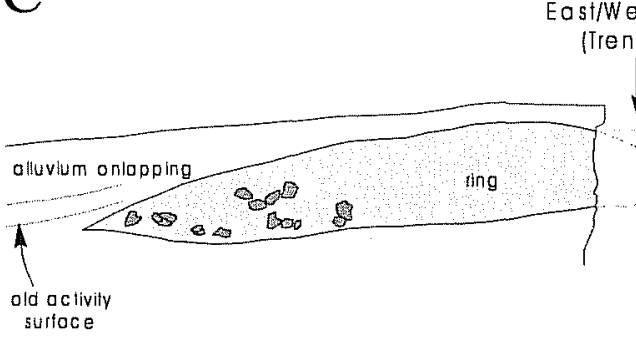

East/West Trench

nch O) colluvium/posi-use fill

$\checkmark$

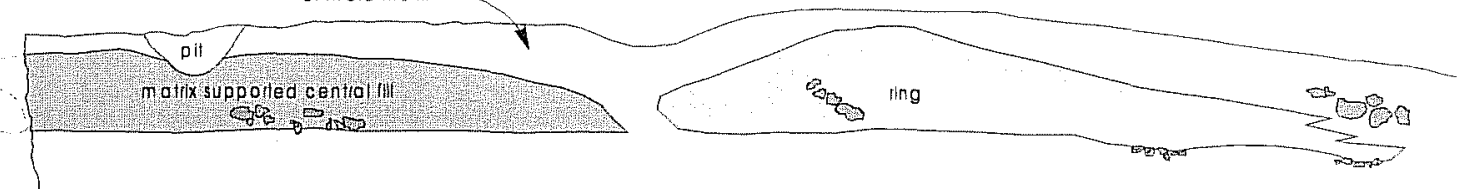

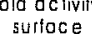

Figure B-1. Profile of BHT G, west wall showing Feature 1. A: distribution of burned rock; note that shaded rocks represent possible intact framework and basal features; B: preliminary interpretation of annular burned rock midden structure; $\mathrm{C}$ : final interpretation of annular burned rock midden structure. 
The mosaics made for this work are more than adequate for their intended purpose. They were made by obtaining color photocopy enlargements of the color slides and then trimming and taping together the photocopies to form a continuous image. Following this procedure, the mosaic images were overlaid with a sheet of clear acetate and the outline of each rock was drawn using permanent color markers. The rendering of the midden produced by this method was then reduced using a photocopier, and used as a base map for interpretation in the field. Two of the enlarged photomosaic profiles were split into four-foot sections, mounted upon plywood boards, and taken to the field to use as an interpretive tool. The relative results of these two approaches were compared in and out of the field for ease of use and utility, and will be discussed at a later date. Photocopy reductions of the resulting acetate tracings of the profiles are attached to this report. The profiles included depict an unannotated rendering of each profile, an annotated rendering, and a graphic interpretation of the middens structural features (Figure B-1).

From the photomosaic, several discrete features (burned-rock-filled pits, possible ash dumps, possible matrix-defined pit features) are recognized within, below, and upon the midden. The macro-structural elements, such as the ring of framework-supported rocks and the matrix-supported central area, are also evident. The success of this work demonstrates the robustness of the technique and clearly supports the application of photomosaic documentation of burned rock middens. 


\title{
Appendix C: Geomorphological Data
}

\author{
Lee C. Nordt
}

\section{BHT C; T1 flood terrace; calcareous throughout.}

\begin{tabular}{|c|c|c|}
\hline$A$ & $0-6 \mathrm{~cm}$ & firm; clear smooth. \\
\hline $\mathrm{Ab}$ & $6-35 \mathrm{~cm}$ & $\begin{array}{l}\text { Unit IVa; black (10YR } 2 / 1) \text { clay loam; moderate medium subangular blocky; firm; } 2 \% \text { pebbles, } \\
\text { matrix-supported subangular, and poorly sorted; gradual smooth. }\end{array}$ \\
\hline Bwlb & $35-52 \mathrm{~cm}$ & $\begin{array}{l}\text { very dark gray (10YR 3/1) clay loam; moderate medium subangular blocky; firm; } 4 \% \text { pebbles, } \\
\text { matrix-supported, subangular, and poorly sorted; clear smooth. }\end{array}$ \\
\hline $\mathrm{Bw} 2 \mathrm{~b}$ & $52-90 \mathrm{~cm}$ & $\begin{array}{l}\text { very dark gray (10YR 3.5/1) clay loam; moderate medium prismatic and angular blocky; very hard; } \\
6 \% \text { pebbles, matrix-supported, subangular to angular, and poorly sorted; gradual smooth. }\end{array}$ \\
\hline $\mathrm{Bw} 3 \mathrm{~b}$ & $90-127 \mathrm{~cm}$ & $\begin{array}{l}\text { dark grayish brown (10YR } 4 / 2) \text { clay loam; moderate medium prismatic and angular blocky; very } \\
\text { hard; } 5 \% \text { brown (10YR } 4 / 3) \text { biocasts; } 5 \% \text { pebbles, matrix-supported, subangular, and poorly sorted; } \\
\text { gradual smooth. }\end{array}$ \\
\hline $\mathrm{Bw} 4 \mathrm{~b}$ & $127-160 \mathrm{~cm}$ & $\begin{array}{l}\text { dark grayish brown (10YR } 4 / 2.5 \text { ) clay loam; moderate medium angular blocky; very hard; } 5 \% \text { very } \\
\text { dark gray (10YR } 3 / 1 \text { ) biocasts; } 2 \% \text { pebbles, matrix-supported, subangular, and poorly sorted. }\end{array}$ \\
\hline
\end{tabular}

\section{BHT G; T2 flood terrace; calcareous throughout.}
A1 0-12 cm Unit IVc; very dark gray (10YR 2.5/1) clay loam; moderate medium subangular blocky; hard; 15\% pebbles, matrix-supported, angular, and poorly sorted; abrupt wavy.
A2 12-27 cm; very dark gray (10YR 3/1) clay loam; moderate fine subangular blocky; hard; $50 \%$ burned limestone,
(midden) matrix-supported; gradual wavy.
Bw $\quad 27-57 \mathrm{~cm} \quad$ very dark grayish brown (10YR 3.5/2) clay loam; moderate fine subangular blocky; (midden) hard; $40 \%$ burned limestone, matrix-supported; abrupt wavy.
Bkb1 57-92 cm Unit IIIc; brown (10YR 4/3) clay loam; moderate medium subangular blocky; hard; 25\% pebbles, matrix-supported, angular, and poorly sorted; $2 \%$ calcium carbonate filaments; abrupt wavy.
$\mathrm{BCbl} 92-116 \mathrm{~cm}$ brown (10YR 4/3.5) clay loam; weak fine subangular blocky; hard; $40 \%$ pebbles and cobbles, mostly matrix-supported, angular, and poorly sorted; abrupt wavy.
Bkmb2 116-153 cm Unit IIc; 50\% pebbles and cobbles, matrix-supported, angular, and poorly sorted; indurated with calcium carbonate, discontinuous laminar cap.

\section{BHT I; T2/T1 flood terrace scarp; calcareous throughout.}

A1 0-17 cm Unit IVa; very dark gray (10YR 3/1) clay loam; moderate coarse angular blocky; very firm; $10 \%$ brown (10YR 4/3) biocasts; gradual wavy.

A2 17-31 cm very dark gray (10YR 3/1) clay loam; moderate medium subangular blocky; very firm; gradual smooth.

Bss $\quad 31-70 \mathrm{~cm} \quad$ dark grayish brown (10YR 4/2) silty clay loam; moderate medium subangular blocky; very firm; $25 \%$ very dark gray (10YR $3 / 1$ ) biocasts; $3 \%$ pebbles, matrix-supported and subrounded to angular, and poorly sorted; common distinct slickensides; clear smooth.

Bssk1 70-105 cm dark grayish brown (10YR 4/2) and brown (10YR 5/3) silty clay; moderate coarse angular blocky; very hard; $20 \%$ very dark gray (10YR 3/1) biocasts; many distinct slickensides; $1 \%$ calcium carbonate nodules, $1 \mathrm{~cm}$ diameter; gradual smooth. 
Bssk2 105-141 cm dark brown $(7.5$ YR 4/3,4/4) silty clay; weak coarse angular blocky; very hard; $25 \%$ very dark gray (10YR 3/1) biocasts; common distinct slickensides; $2 \%$ calcium carbonate nodules, $1 \mathrm{~cm}$ diameter; gradual smooth; ${ }^{14} \mathrm{C}$ age of $3190 \pm 60$ B.P. (Beta-81540) on bulk soil humates from a depth of $116 \mathrm{~cm}$.

Bk1b1 141-166 cm Unit IIa; brown (7.5YR 5/4) clay loam; 2\% dark grayish brown (10YR 4/2) iron depletions; weak medium angular blocky; very hard; $20 \%$ very dark gray (10YR $3 / 1$ ) biocasts; $10 \%$ pebbles, matrixsupported, subrounded, and moderately well sorted; many pebbles encased in calcium carbonate rinds, $1 \mathrm{~mm}$ thick; $5 \%$ calcium carbonate nodules, $1 \mathrm{~cm}$ diameter; $1 \%$ calcium carbonate filaments; clear wavy; a ${ }^{14} \mathrm{C}$ age of 17,670 100 B.P. (Beta-104970) was obtained from bulk sediment humates from a depth of $176-186 \mathrm{~cm}$.

Bk2b1 166-186 cm strong brown (7.5YR 5/6) sandy clay loam; 10\% very dark gray (10YR 3/1) and very dark grayish brown (10YR 4/2) biocasts; massive; very hard; $2 \%$ calcium carbonate filaments; abrupt wavy.

$\mathrm{Cb} 1 \quad 186-346 \mathrm{~cm}$ beds of pebbles and cobbles, grain-supported, subrounded to angular, and poorly sorted; calcium carbonate pendants on gravel bottoms, 1 to $3 \mathrm{~mm}$ diameter; several light brown (7.5YR 6/4) and horizontal sandy beds, 10 to $15 \mathrm{~cm}$ thick.

\section{BHT J; T1 flood terrace; calcareous throughout.}

\begin{tabular}{|c|c|c|}
\hline A & $0-13 \mathrm{~cm}$ & $\begin{array}{l}\text { Unit V; very dark gray (10YR 3/1) silty clay loam; moderate medium subangular blocky; friable; } 3 \% \\
\text { pebbles, matrix-supported, subrounded, and moderately well sorted; clear smooth. }\end{array}$ \\
\hline $\mathrm{Ab}$ & $13-41 \mathrm{~cm}$ & $\begin{array}{l}\text { Unit IVa; black (10YR } 2 / 1 \text { ) silty clay loam; moderate medium subangular blocky; firm; } 8 \% \text { pebbles, } \\
\text { matrix-supported, subrounded to angular, and moderately well sorted; abrupt smooth. }\end{array}$ \\
\hline Bwlb & $41-68 \mathrm{~cm}$ & $\begin{array}{l}\text { very dark grayish brown (10YR 3/2) sandy clay loam; weak coarse angular blocky; very firm; } 15 \% \\
\text { pebbles, matrix-supported, subrounded, and poorly sorted; abrupt wavy. }\end{array}$ \\
\hline $\mathrm{Bw} 2 \mathrm{~b}$ & $68-102 \mathrm{~cm}$ & $\begin{array}{l}\text { very dark gray (10YR 3/1) clay loam; moderate medium angular blocky; very hard; } 15 \% \text { pebbles, } \\
\text { matrix-supported, subrounded, moderately well sorted; } 1 \% \text { carbonate filaments; abrupt wavy. }\end{array}$ \\
\hline $\mathrm{Cb}$ & $102-153 \mathrm{~cm}$ & $\begin{array}{l}\text { very dark gray ( } 10 \text { YR } 3 / 1 \text { ) sandy clay loam; } 70 \% \text { pebbles, mostly grain-supported, subrounded, and } \\
\text { poorly sorted; abrupt wavy. }\end{array}$ \\
\hline Bwb & $153-175 \mathrm{~cm}$ & $\begin{array}{l}\text { very dark grayish brown (10YR } 3 / 2 \text { ) sandy clay loam; } 30 \% \text { brown }(10 \mathrm{YR} 5 / 3 \text { ) sandy pockets; weak } \\
\text { medium angular blocky; hard; } 15 \% \text { pebbles, matrix-supported, subrounded, and poorly sorted; } 1 \% \\
\text { calcium carbonate filaments; a }{ }^{14} \mathrm{C} \text { age of } 2080 \pm 30 \text { B.P. (Beta-104971) was obtained from bulk } \\
\text { sediment humates from a depth of } 154-164 \mathrm{~cm} \text {. }\end{array}$ \\
\hline
\end{tabular}

\section{BHT K; T0 floodplain; calcareous throughout.}

A1 0-16 cm Unit V; very dark gray (10YR 3/1) clay loam; moderate medium subangular blocky; hard; $15 \%$ pebbles, matrix-supported, subangular to angular, and poorly sorted; abrupt wavy.

A2 $\quad 16-31 \mathrm{~cm} \quad$ very dark brown (10YR 3/1) and very dark grayish brown (10YR 3/2) silty clay loam; moderate medium subangular blocky; hard; $10 \%$ pebbles, matrix-supported, subangular to angular, and poorly sorted; abrupt wavy.

$\mathrm{AB} \quad 31-41 \mathrm{~cm} \quad$ very dark gray (10YR 3/1) silty clay loam; weak coarse subangular blocky; hard; $35 \%$ pebbles, mostly grain-supported, subangular, and moderately well sorted; abrupt wavy.

C $\quad 41-120 \mathrm{~cm} \quad 80 \%$ pebbles, grain-supported, subrounded, and moderately well sorted.

\section{BHT M (BSC-7); T2 flood terrace; calcareous throughout.}

Al 0-14 cm Unit IVc; very dark gray (10YR 3/1) clay loam; weak coarse subangular blocky; very firm; $20 \%$ very dark gray (10YR 3/2) biocasts; $8 \%$ pebbles, matrix-supported, angular, and poorly sorted; abrupt wavy.

A2 14-47 cm black (10YR 2/1) clay loam; moderate fine subangular blocky; firm; $10 \%$ brown (10YR (midden) 4/3) biocasts; $60 \%$ burned limestone; gradual wavy.

A3 47-72 cm very dark gray (10YR 3/1) clay loam; weak fine to medium subangular blocky; very firm; $15 \%$ dark (midden) yellowish brown (10YR 4/4) and 5\% black (10YR 2/1) biocasts; $60 \%$ burned limestone, matrixsupported; abrupt wavy. 
Bk1b 72-88 cm Unit IIIc; very dark grayish brown(10YR 3/2) silty clay loam; moderate medium subangular blocky; hard; $30 \%$ very dark grayish brown (10YR $4 / 4$ ) biocasts; $2 \%$ pebbles, matrix-supported, subangular to angular, and poorly sorted; $3 \%$ calcium carbonate filaments; gradual wavy.

Bk2b 88-127 cm dark brown (7.5YR 4/3) silty clay loam; moderate medium prismatic and angular blocky; hard; 8\% very dark gray (10YR 3/1) biocasts; $10 \%$ pebbles, matrix-supported, angular to subrounded, and poorly sorted; $10 \%$ calcium carbonate filaments; gradual smooth.

$\mathrm{Bk3b} \quad 127-155 \mathrm{~cm}$ dark brown (7.5YR 4/3) silty clay loam; moderate coarse prismatic; very hard; $10 \%$ very dark gray (10YR 3/1) biocasts; $5 \%$ pebbles, matrix-supported, angular to subrounded, and poorly sorted; $10 \%$ calcium carbonate filaments; gradual smooth.

\section{BHT S (Feature 2); T2/T1 flood terrace escarpment; calcareous throughout.}

\begin{tabular}{|c|c|c|}
\hline $\mathrm{A} 1$ & $0-9 \mathrm{~cm}$ & $\begin{array}{l}\text { Unit IVa; very dark gray (10YR 2.5/1) clay loam; weak medium angular blocky; very hard; } 5 \% \\
\text { burned limestone; abrupt wavy. }\end{array}$ \\
\hline $\mathrm{A} 2$ & $9-25 \mathrm{~cm}$ & $\begin{array}{l}\text { very dark gray (10YR } 2.5 / 1 \text { ) clay loam; moderate medium subangular blocky; very hard; (hearth) } \\
5 \% \text { brown (10YR } 5 / 3 \text { ) biocasts; } 40 \% \text { burned limestone; abrupt wavy. }\end{array}$ \\
\hline $\mathrm{ABb}$ & $25-34 \mathrm{~cm}$ & $\begin{array}{l}\text { Unit IIIa; brown (10YR } 4 / 3 \text { ) silty clay loam; moderate medium subangular blocky; very hard; } 10 \% \\
\text { very dark gray (10YR } 3 / 1 \text { ) biocasts; } 5 \% \text { pebbles, matrix-supported, angular to subrounded, and } \\
\text { poorly sorted; abrupt wavy. }\end{array}$ \\
\hline Bwb & $34-51 \mathrm{~cm}$ & $\begin{array}{l}\text { dark brown ( } 7.5 \mathrm{YR} 4 / 3) \text { silty clay loam; moderate medium prismatic; hard; } 10 \% \text { very dark gray } \\
\text { (10YR } 3 / 1 \text { ) biocasts; } 5 \% \text { pebbles, matrix-supported, subangular to angular, and poorly sorted; } \\
\text { gradual smooth. }\end{array}$ \\
\hline $\mathrm{Bkb}$ & $51-77 \mathrm{~cm}$ & $\begin{array}{l}\text { dark brown ( } 7.5 \text { YR } 4 / 3 \text { ) silty clay loam; moderate medium prismatic and angular blocky; very hard; } \\
3 \% \text { very dark gray (10YR 3/1) biocasts; } 5 \% \text { pebbles, matrix-supported, subangular to angular, and } \\
\text { poorly sorted; } 3 \% \text { calcium carbonate filaments; gradual smooth. }\end{array}$ \\
\hline Bkssb & $77-113 \mathrm{~cm}$ & $\begin{array}{l}\text { dark brown ( } 7.5 \text { YR } 4 / 3 \text { ) silty clay loam; moderate coarse prismatic; very hard; } 10 \% \text { very dark gray } \\
\text { (10YR } 3 / 1) \text { biocasts; } 5 \% \text { pebbles, matrix-supported, angular to subrounded, and poorly sorted; } 3 \% \\
\text { calcium carbonate filaments; common distinct slickensides; gradual smooth. }\end{array}$ \\
\hline
\end{tabular}

\section{BHT X; T2 flood terrace; calcareous throughout.}

A $\quad 0-23 \mathrm{~cm}$

Bw1 $23-36 \mathrm{~cm}$

Bw2 $36-58 \mathrm{~cm}$

Bwb1 $\quad 58-80 \mathrm{~cm}$

Bss1b1 80-136 cm

Bss2b1 136-190 cm
Unit IVc; black (10YR 2/1) clay loam; $5 \%$ brown (10YR 5/3) biocasts; weak coarse subangular blocky; firm; $8 \%$ pebbles, matrix-supported, angular to subrounded, and poorly sorted; gradual smooth.

very dark gray (10YR 2.5/1) clay loam; $10 \%$ brown (10YR 5/3) biocasts; weak coarse subangular blocky; very firm; $10 \%$ pebbles, matrix-supported, angular to subrounded, and poorly sorted; abrupt wavy.

dark grayish brown (10YR 4/1.5) clay loam; 5\% brown (10YR 5/3) biocasts; moderate (midden) medium subangular blocky; very firm; $15 \%$ burned limestone, matrix-supported; $5 \%$ pebbles, matrix-supported, angular to subrounded, and poorly sorted; clear wavy.

Unit IIIa; grayish brown (10YR 4/2) and 20\% brown (7.5YR 4/4) silty clay loam; $3 \%$ very dark gray (10YR 3/1) biocasts; moderate fine prismatic; very hard; $5 \%$ pebbles, matrix-supported, angular to subrounded, and poorly sorted; gradual wavy.

grayish brown (10YR 4/2) and 30\% dark brown (7.5YR 4/3) silty clay; $10 \%$ very dark gray (10YR $3 / 1$ ) vertical streaks; strong medium angular blocky; very hard; $5 \%$ pebbles, matrix-supported, angular to subrounded, and poorly sorted; few distinct slickensides; gradual wavy.

dark brown (7.5YR 4/3) silty clay; 3\% very dark gray (10YR 3/1) vertical streaks; moderate coarse angular blocky; very hard; $3 \%$ pebbles, matrix-supported, angular to subrounded, and poorly sorted; common distinct slickensides; $1 \%$ calcium carbonate filaments; gradual wavy; a ${ }^{14} \mathrm{C}$ age of $4370 \pm 50$ (Beta- 81538) on bulk soil humates from a depth of $140 \mathrm{~cm}$ as extrapolated from BHT H. 
Bsskb1 190-225 cm dark brown (7.5YR 4/3) silty clay; 3\% very dark gray (10YR 3/1) vertical streaks; moderate medium prismatic and angular blocky; very hard; common distinct slickensides; $1 \%$ carbonate filaments; $1 \%$ calcium carbonate nodules, $1 \mathrm{~cm}$ diameter; gradual wavy; a ${ }^{14} \mathrm{C}$ age of $10,460 \pm 60$ B.P. was obtained from bulk sediment humates from a depth of 210 to $220 \mathrm{~cm}$.

BCb1 225-275 cm dark brown (7.5YR 4/3) and 15\% brown (7.5YR 5/3) clay loam; $2 \%$ very dark gray (10YR 3/1) vertical streaks; weak coarse prismatic; very hard; few faint slickensides; $1 \%$ calcium carbonate filaments; $1 \%$ calcium carbonate nodules; clear wavy; a ${ }^{14} \mathrm{C}$ age of $11,540 \pm 50$ B.P. (Beta 81539) from bulk soil humates from a depth of $245 \mathrm{~cm}$ as extrapolated from BHT H.

Bk1b2 275-299 cm Unit IIa; strong brown (7.5YR 5/6) clay loam; 3\% very dark gray (10YR 3/1) biocasts; few iron manganese stains; weak medium subangular blocky; very hard; $3 \%$ pebbles, matrix-supported, angular to subrounded, and poorly sorted; $50 \%$ calcium carbonate pendants on gravel bottoms, 1 to $4 \mathrm{~mm}$ diameter; $5 \%$ calcium carbonate nodules, $1 \mathrm{~cm}$ diameter; gradual wavy.

Bk2b2 299-333 cm reddish yellow (7.5YR 6/6) clay loam; 3\% very dark gray (10YR 3/1) biocasts; weak coarse subangular blocky; hard; $5 \%$ pebbles, matrix-supported, angular to subrounded, and poorly sorted; $50 \%$ calcium carbonate pendants on gravel bottoms, 1 to $4 \mathrm{~mm}$ diameter; $2 \%$ calcium carbonate filaments; $1 \%$ calcium carbonate nodules, $1 \mathrm{~cm}$ diameter; gradual wavy.

BCkb2 333-387 cm reddish yellow (7.5YR 5/6, 6/6) sandy clay loam; weak coarse subangular blocky; hard; $5 \%$ pebbles, matrix-supported, angular to subrounded, and poorly sorted; $50 \%$ calcium carbonate pendants on gravel bottoms, 1 to $4 \mathrm{~mm}$ diameter; $4 \%$ calcium carbonate filaments; abrupt wavy.

$\mathrm{Cb} 2 \quad 387-400 \mathrm{~cm}$ reddish yellow (7.5YR 5/6, 6/6) sandy clay loam; $70 \%$ pebbles, mostly grain-supported, subrounded, and poorly sorted; few calcium carbonate pendants on gravel bottoms, 1 to $2 \mathrm{~mm}$ diameter; $4 \%$ calcium carbonate filaments.

\section{BHT Y; T2 flood terrace; calcareous throughout.}
Al $\quad 0-32 \mathrm{~cm}$
Unit IIIa; very dark gray (10YR 2.5/1) clay loam; moderate medium subangular blocky; firm; $2 \%$ dark brown (7.5YR 4/3) biocasts; gradual smooth.
Bw1 $\quad 32-52 \mathrm{~cm}$
Bw2 $\quad 52-82 \mathrm{~cm}$
dark brown (7.5YR 4/3) clay loam; moderate medium subangular blocky; firm; 30\% very dark grayish brown (10YR 3/2) and very dark gray (10YR 3/1) biocasts; gradual smooth.
$\begin{array}{ll}\text { Bw2 } & 52-82 \mathrm{~cm} \\ \text { Bkss1 } & 82-122 \mathrm{~cm}\end{array}$ dark brown (7.5YR 4/3) clay loam; weak coarse angular blocky; very hard; $3 \%$ very dark gray (10YR $3 / 1$ ) biocasts; $3 \%$ pebbles, matrix-supported, subrounded, and moderately well sorted; clear wavy. dark brown (7.5YR 4/3) clay loam; moderate medium angular blocky; very hard; $3 \%$ very dark gray (10YR 3/1) biocasts; $1 \%$ pebbles, matrix-supported, subrounded, and moderately well sorted; $2 \%$ calcium carbonate filaments; common distinct slickensides; clear wavy.
Bkss2 122-165 cm dark brown (7.5YR 4/3) clay loam; moderate medium angular blocky; very hard; $1 \%$ very dark gray (10YR 3/1) biocasts; $2 \%$ pebbles, matrix-supported, subrounded, and moderately well sorted; $2 \%$ calcium carbonate filaments; common distinct slickensides; gradual smooth.
BC 165-194 cm dark brown (7.5YR 4/3) clay loam; weak medium coarse angular blocky; very hard; $5 \%$ pebbles, matrix-supported, subrounded, and moderately well sorted; $1 \%$ calcium carbonate filaments; abrupt wavy.
C1 194-220 cm dark brown (7.5YR 4/3) clay loam; 40\% pebbles, matrix-supported, subrounded to angular, and poorly sorted; abrupt wavy.
C2 220-236 cm brown (7.5YR 4/4) clay loam; 60\% matrix and grain-supported pebbles, subrounded to angular, and poor sorted.

\section{Gradall Trench; T2 flood terrace; calcareous throughout.}

A $\quad 0-28 \mathrm{~cm}$

Bw1 28-54 cm
Unit IIIa black (10YR 2/1) clay; moderate medium subangular blocky; very hard; gradual wavy. very dark gray (10YR 3/1) clay; moderate medium prismatic; very hard; $10 \%$ black (10YR $2 / 1)$ and $1 \%$ yellowish brown (10YR 5/4) biocasts; $3 \%$ pebbles, matrix-supported, angular, and poorly sorted; gradual wavy. 
Bw2 $\quad 54-77 \mathrm{~cm} \quad$ dark brown (7.5YR 4/3) clay; moderate medium prismatic and angular blocky; very hard; $10 \%$ very dark gray (10YR 3/1) biocasts; $3 \%$ pebbles, matrix-supported, angular, and poorly sorted; gradual wavy.

Bss $1 \quad 77-100 \mathrm{~cm}$ dark brown (7.5YR 4/2) clay; moderate medium angular blocky; very hard; $10 \%$ black (10YR 2/1) and $10 \%$ brown (7.5YR 5/3) biocasts; $10 \%$ pebbles, matrix-supported, angular, and poorly sorted; few distinct slickensides; gradual wavy.

Bss2 100-125 cm brown (7.5YR 5/4) clay; moderate medium angular blocky; very hard; $10 \%$ very dark gray (10YR 3/1) biocasts; $5 \%$ pebbles, matrix-supported, angular, and poorly sorted; many prominent slickensides. 


\title{
Appendix D: Estimating Rates of Burned Rock Discard: Results from an Experimental Earth Oven
}

\author{
Jeff D. Leach, David L. Nickels, Bruce K. Moses, and Richard Jones
}

\section{Introduction}

In order to estimate the number of cooking events that a given scatter or pile of charred and fragmented rocks represents, it is necessary to have some understanding of the rates and processes of rock discard. Simply, how many times can a given stone be subjected to repeated heating and cooling before it fragments, and thus is discarded. Unfortunately, the answer is complex. Variables such as rock size, lithology, amount and type of fuel wood, length of exposure to heat, type of heat, pit morphology, cooking environment, and so on affect the rates at which rocks are broken and subsequently cycled from their systemic context to an archaeological one. In addition, what constitutes an unusable (e.g., how small is too small) and thus discarded rock is poorly developed in hot-rock cooking. That is, one person's spent rock is another person's reusable one.

Aside from some of the more obvious factors affecting the process of rock discard, the length of time a stone may be curated (Shott 1992) may be linked in no small way to raw material availability. In some environments, where raw materials for cooking stones may be scarce, scavenging and recycling may be the norm. As a result, much of the archaeological burned rock in these settings may be small, having been exhausted through repeated use and curation (Camilli and Ebert 1992). Conversely, in areas where raw materials for cooked stone are abundant, burned rocks may discarded at an accelerated rate. Therefore, raw material source may have an impact on the curation of stones used in hot-rock cooking and thus influence rates of discard.

The current experiment focuses on discard rates for limestone cobbles typically available southeast of the Balcones Escarpment, and how this may be used to model the time frame during which the massive pile of charred and fragmented rocks at the Culebra Creek site accumulated. As a result of our admittedly narrow research focus, other characteristics of thermal alteration, such as color change, fracture type, and so on, were not systematically recorded (Pagoulatos 1992). Nor were multiple experiments conducted that recorded fracture rates on various types of raw materials.

Potential rates for burned rock discard were simulated in an experimental earth oven. Stones used in the experiment consisted of limestone cobbles collected from the stream beds around Culebra and Helotes creeks (adjacent to the Culebra Creek site). The experiment included the cooking of several hundred pounds of food in an earth-oven. During the experiment, temperatures over a 39-hour period were monitored with thermocouples placed at strategic locations in the oven facility. The results of this experiment indicate a shorter effective use life for rocks in earth ovens than is currently being reported for the central Texas area (Black 1997; Black et al. 1997). This is important, as the survival versus failure of limestone rocks used as heat sinks in earth ovens has far reaching implications for burned rock research. Specifically, the rates at which rocks are discarded informs archaeologists about the rate at which the discard pile grew. Simply varying the number of times that a given rock or set or rocks is used may dramatically effect estimates of rock accumulation, from a few seasons, to millennium.

\section{The Experiment}

The experiment was established in an open area behind the lab at CAR. The area was less than ideal, due to the limited space, but did provide a water source in case of emergency. A pit measuring approximately 

$1.30 \mathrm{~m}$ in diameter and $30 \mathrm{~cm}$ in depth was excavated. The overall shape of the pit was round and basinshaped in profile. The substrate was a dry, clayey-loam (B-horizon) with some gravels and larger clasts present.

Approximately $63 \mathrm{kgs}$ (139 lbs) of fuel wood was loaded into the pit. The wood included mostly (ca. 80 percent) mesquite (Prosopis) and some oak (Quercus). Small pieces of unidentified wood species were used for kindling. The fuel wood was then lit with matches; no other artificial flammables were used. The fire was allowed to burn for about 30 minutes before 26 limestone cobbles weighing $91 \mathrm{kgs}$ (ca. $200 \mathrm{lbs}$ ) were added to the pit. The cobbles weighed on average $3.5 \mathrm{kgs}$ ( $7.7 \mathrm{lbs}$ ) and ranged from $16-25 \mathrm{~cm}$ in overall length. The stones used in the experiment were collected from near the Culebra Creek site and are thought to represent the same raw materials sources exploited by the inhabitants of the site.

After about three hours the fire began to die down and a bed of coals had accumulated in the bottom of the pit. During the firing and subsequent heating of the limestone cobbles, every effort was made to keep the rocks in constant contact (on top of) with the burning fuel wood. This was accomplished by constantly moving the stones around with sticks and shovels. In addition, the fuel wood was frequently hit with a stick to accelerate the accumulation of coals. Though not systematically monitored, the temperatures within the hot-rock bed during the initial firing ranged from $650^{\circ}$ $900^{\circ} \mathrm{C}$. During the firing of the oven, no cobbles broke. However, several small fragments (spalls) came flying out of the pit during the initial firing.

Once the fuel wood had been sufficiently reduced to coals ( 3.5 hours), the now-hot rocks were spread in the bottom of the pit. Every effort was made to keep the thick (ca. $10 \mathrm{~cm}$ ) bed of coals under the hot rocks. The rocks and coals were moved about in the pit with long sticks and shovels. Once the hot-rock bed was created, the pit was ready to be loaded with food.

Sotol (Dasylirion wheeleri) bulbs and leaves, and prickly pear (Opuntia phaeacantha) pads were harvested from the surrounding area. A layer of sotol leaves was placed on top of the hot rocks to act as insulation (note that the sotol leaves were not weighed). At this point the oven created a tremendous amount of steam as the moisture in the green leaves vaporized as it came in contact with the hot rocks. Upon this first layer of insulate (packing material), $34 \mathrm{kgs}$ (75 lbs) of prickly pear (Opuntia phaeacantha) pads were laid in the oven. The pads (food) were spread evenly over the bottom of the oven, covering the underlying insulate and hot rocks completely. On top of this, $15 \mathrm{kgs}$ (33 lbs) of deer meat and assorted vegetables wrapped in aluminum foil were placed in the center of the pit. A total of $32 \mathrm{kgs}$ ( $71 \mathrm{lbs}$ ) of sotol hearts was then placed on top of, and around the food in the aluminum foil. The sotol hearts effectively covered the underlying meat and vegetables and most of the prickly pear pads, forming a dome-shaped pile of food. On top of this, another $45 \mathrm{kgs}(100 \mathrm{lbs})$ of prickly pear pads were stacked in the oven, covering all the underlying food and insulate. The whole affair was then covered with another thick insulating layer of sotol leaves. The purpose of the upper layer of insulate was to protect the food from the earthen cap that was then added to seal the oven (see below). Once finished, the entire mass of food rose approximately $75 \mathrm{~cm}$ from the bottom of the pit. The loading of the food and insulate took approximately 10 minutes with four people.

Once the food had been loaded and adequately protected with the upper layer of insulate, $490 \mathrm{kgs}(1,080$ lbs) of earth (clayey-loam) was mounded on top of the oven (Figure D-1). The sediment for the earthen cap was measured and weighed in buckets as it was placed on the oven. The volume of the earthen cap was an estimated $.454 \mathrm{~m}^{3}$ of sediment (454.2 liters). The thickness of the cap varied across the oven, but averaged about $30 \mathrm{~cm}$. It took approximately 20 minutes from the time the coals and hot rocks were spread in the bottom of the oven to completion of the earthen cap.

\section{Placement of the Thermocouples}

Four thermocouples were placed throughout the oven to monitor temperatures (Figure D-1). The first two were placed at the bottom of the oven in the heating element (hot-rock bed). Both thermocouples were placed between the rocks just above the coals, and near the center of the hot-rock bed (under the first layer of insulate). The thermocouples were located 



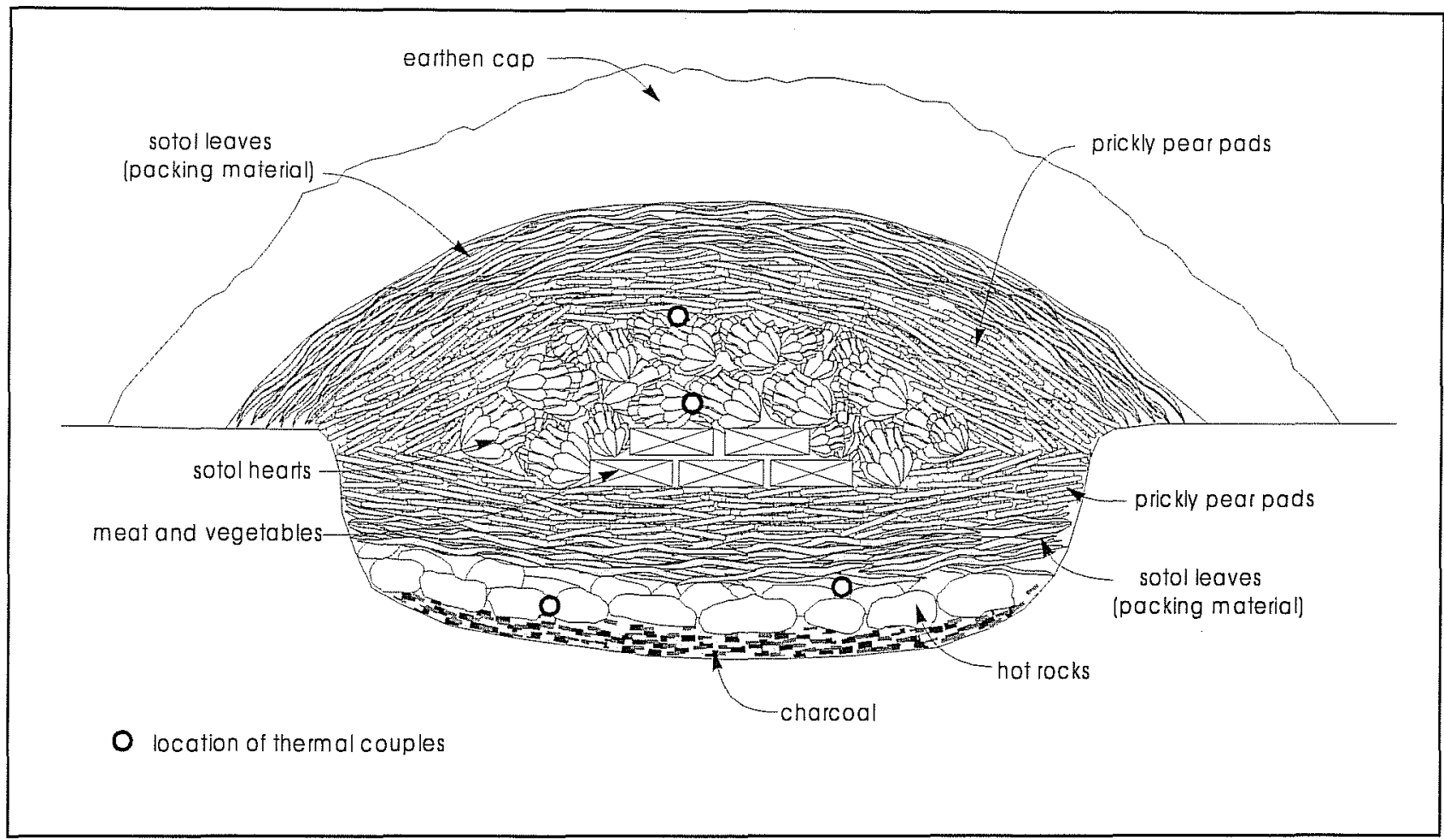

Figure D-1. Schematic of the earth oven showing the various elements and the placement of the thermocouples.

about $20 \mathrm{~cm}$ from each other. The third thermocouple was placed in the largest (ca. $25 \mathrm{~cm}$ diameter) of the sotol hearts in the center of the oven. This was accomplished by drilling a small hole in the sotol heart with a knife. The tip of the thermocouple was located near the center of the heart. The fourth thermocouple was placed between the sotol hearts and the upper layer of prickly pear pads. The thermocouple placement allowed us to monitor the long-term performance of the heating elements, the cooking and temperature of the food, and the overall performance of the oven.

Temperature data was collected via the thermocouples and digitally displayed on a hand-held Omega® Microprocessor Thermometer (Model HH21). The temperature data were monitored at regular intervals (see below) with the processor, and manually recorded in a field $\log$.

\section{Results}

The temperatures recorded (raw data) by the various thermocouples are provided in Table D-1 and graphically displayed in Figure D-2. The first temperature reading (noted as " 0 ") was taken approximately five minutes after the earthen cap was finalized. As shown in Figure D-2, the temperature of the heating element started out just above $550^{\circ} \mathrm{C}$, and quickly began to drop off in the first 5-7 hours. This is caused by the sudden drop in oxygen and dampening of the oven with the earthen cap; effectively smothering the fire. The thermocouple placed on top of the food rises at a much faster rate than the temperature recorded for the food (sotol heart). The more rapid rise in the temperature recorded for the top of the oven is a function of the great amounts of steam as the moisture in the insulate and food is vaporized. The moisture in the 
Table D-1. Cooking Temperatures for the Various Components in the Oven

All time is in hours and temperatures are in centigrade.

\begin{tabular}{|c|c|c|c|c|}
\hline Elapsed Time (hrs.) & Top of Food & $\begin{array}{c}\text { Food } \\
\text { (Sotol heart) }\end{array}$ & $\begin{array}{l}\text { Heating } \\
\text { element }\end{array}$ & $\begin{array}{r}\text { Heating } \\
\text { element }\end{array}$ \\
\hline 0.00 & 39.00 & 34.00 & 554.00 & 583.00 \\
\hline 0.25 & 49.00 & 34.00 & 438.00 & 435.00 \\
\hline 0.50 & 58.00 & 33.00 & 412.00 & 396.00 \\
\hline 0.75 & 65.00 & 35.00 & 390.00 & 371.00 \\
\hline 1.00 & 69.00 & 37.00 & 373.00 & 356.00 \\
\hline 1.25 & 71.00 & 40.00 & 352.00 & 342.00 \\
\hline 1.50 & 72.00 & 43.00 & 334.00 & 330.00 \\
\hline 1.75 & 73.00 & 46.00 & 322.00 & 316.00 \\
\hline 2.25 & 75.00 & 53.00 & 295.00 & 297.00 \\
\hline 2.75 & 76.00 & 58.00 & 277.00 & 282.00 \\
\hline 3.25 & 76.00 & 63.00 & 255.00 & 265.00 \\
\hline 3.75 & 76.00 & 68.00 & 236.00 & 248.00 \\
\hline 4.25 & 76.00 & 70.00 & 224.00 & 237.00 \\
\hline 4.75 & 79.00 & 75.00 & 211.00 & 224.00 \\
\hline 5.25 & 79.00 & 76.00 & 208.00 & 223.00 \\
\hline 5.75 & 77.00 & 79.00 & 204.00 & 211.00 \\
\hline 6.75 & 78.00 & 81.00 & 200.00 & 206.00 \\
\hline 7.75 & 78.00 & 85.00 & 195.00 & 201.00 \\
\hline 8.25 & 79.00 & 88.00 & 192.00 & 194.00 \\
\hline 8.75 & 81.00 & 90.00 & 186.00 & 188.00 \\
\hline 9.25 & 86.00 & 92.00 & 184.00 & 189.00 \\
\hline 9.75 & 89.00 & 92.00 & 181.00 & 179.00 \\
\hline 10.25 & 91.00 & 96.00 & 179.00 & 178.00 \\
\hline 11.25 & 92.00 & 102.00 & 168.00 & 171.00 \\
\hline 12.50 & 93.00 & 109.00 & 168.00 & 170.00 \\
\hline 14.50 & 92.00 & 108.00 & 166.00 & 165.00 \\
\hline 17.50 & 90.00 & 106.00 & 164.00 & 160.00 \\
\hline 21.25 & 87.00 & 106.00 & 158.00 & 154.00 \\
\hline 24.00 & 84.00 & 107.00 & 152.00 & 146.00 \\
\hline 26.00 & 84.00 & 106.00 & 146.00 & 142.00 \\
\hline 28.00 & 80.00 & 105.00 & 138.00 & 141.00 \\
\hline 31.00 & 79.00 & 104.00 & 131.00 & 131.00 \\
\hline 33.00 & 74.00 & 103.00 & 119.00 & 124.00 \\
\hline 34.00 & 75.00 & 100.00 & 101.00 & 115.00 \\
\hline 37.00 & 74.00 & 96.00 & 95.00 & 105.00 \\
\hline 39.00 & 71.00 & 91.00 & 90.00 & 97.00 \\
\hline
\end{tabular}

vegetal material in the oven creates a moist cooking environment. This steam, which rises in the oven, causes the hotter temperatures at the top of the oven. This is similar to the steam that rises from a pot of boiling water when the lid is removed. The food on the other hand, while rising in temperature, increased at a much slower rate in the first five or so hours. If the reader will recall, the thermocouple placed in the sotol heart is monitoring the temperature of the inside of the food and thus took longer for the "core" of the food to heat up. It was not until about 6-7 hours after sealing the oven that food actually reached the temperatures experienced at the top of the oven. As the amount of available moisture in the oven decreased 


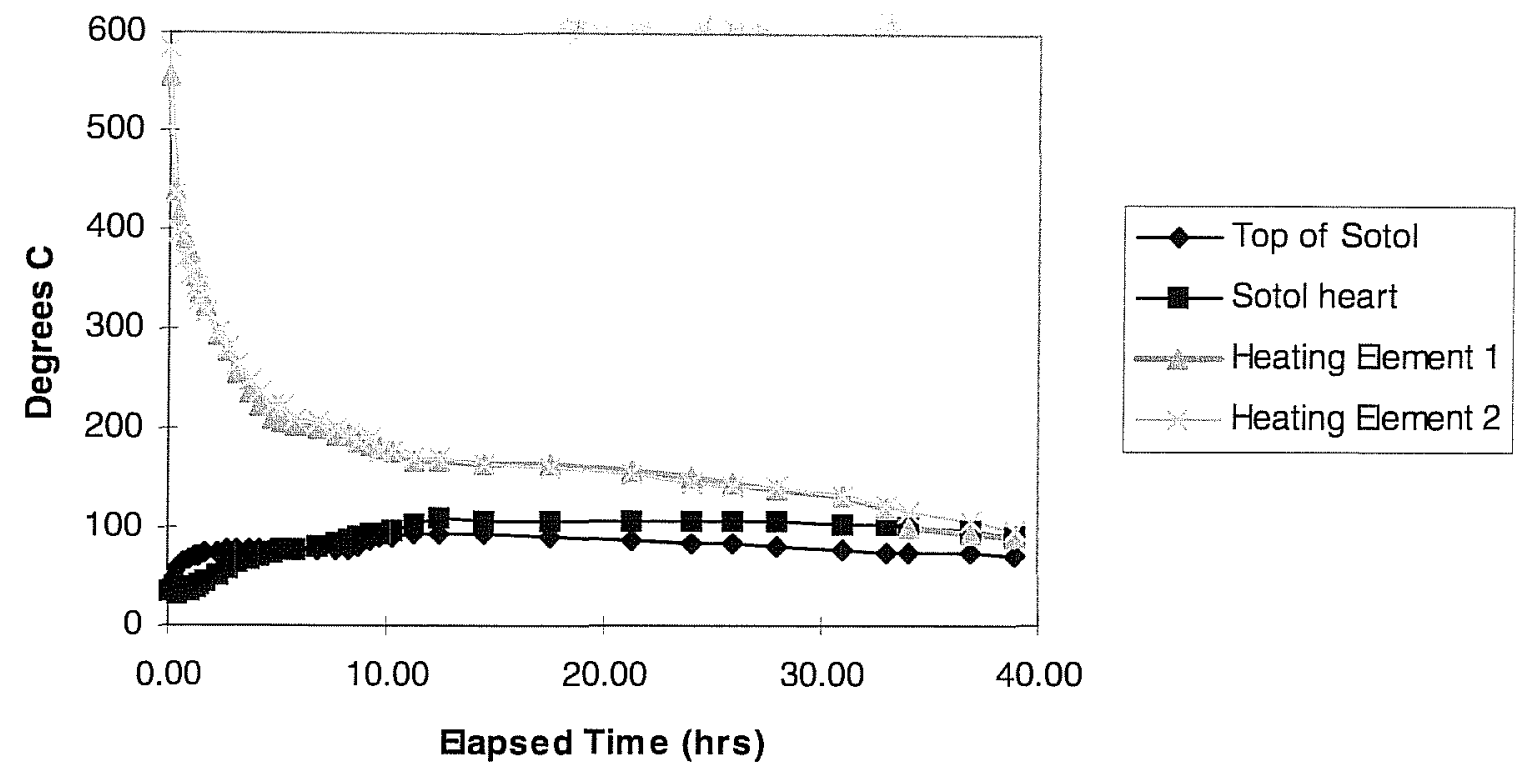

Figure D-2. A line plot of the temperatures recorded within the various components of the oven.

through evaporation, the temperatures at the top of the oven became more reflective of the overall temperatures in the oven and not as much a function of the steam generated early on in the cooking process.

After about $10-15$ hours, the temperature of the heating element started to level off and drop at a much slower rate. During this time period the food and top of the food leveled out around $100^{\circ} \mathrm{C}$. The food temperature stayed at or above $100^{\circ} \mathrm{C}$ until 32 to 35 hours, when the temperature started to drop. After about 33 hours, an abrupt drop in temperature is noted in the heating element. This coincides with the beginning of a light rain. The increasing cool moisture from above contributed to the drop in temperature. After this point, the temperatures throughout the oven began dropping.
We decided to open the oven after 39 hours, before more intensive rains were expected to begin.

The oven was opened by pulling back the earthen cap with shovels. Once the soil was sufficiently cleaned from the cap, the sotol leaf packing overlying the first layer of food (prickly pear) was removed. While the surface earthen cap never felt warm, the upper layer of packing was still warm to the touch. ${ }^{1}$ One layer of food at a time was removed from the oven. The sotol hearts were sweaty, brown (somewhat caramelized) and sweet smelling. The only material charred in the pit was the first layer of sotol leaves placed directly on top of the hot rocks. The hot rocks were still hot to the touch.

${ }^{1}$ It is the authors' opinion that if the surface of the earthen cap ever gets hot, the cap is too thin or is the wrong material (e.g., too coarse/porous). As the object is to cook the food, any heat loss through the cap will only hinder that process. If less than ideal sediments are available, thick earthen caps may mitigate excess loss of heat through the cap. In either case, more is better. 


\section{The Hot Rocks}

The goal of the study was to monitor the fracturing of the rocks as they were heated and subsequently cooled when the oven was sealed. As mentioned above, although several spalls had been noted during the firing of the oven, only a single rock fractured at this time. However, closer examination of the rocks after 39 hours of cooking revealed that 23 of 26 rocks showed evidence of cracking; many had multiple cracks. It was also interesting to note that many of the rocks did not exhibit visible cracks until several hours after they had been removed from the oven.
To assess how the rocks performed during reuse, a second oven was built in the same pit. The procedures for the second oven followed much the same protocol outlined for the first. This included the same amount of wood, same length of heating of the stones, etc. Insulate, prickly pear, and sotol hearts were loaded in the second oven. Sediment for the earthen cap included soil from the first firing and sediment scraped from around the immediate area. The second cap was not weighed or measured but was consistent with the thickness of the first cap. Also note that the temperatures through the cooking process were not systematically monitored.

Table D-2. Analysis of the Burned Rocks after Two Cooking Events

\begin{tabular}{|c|c|c|c|}
\hline Size $^{\mathrm{a}}$ & $\begin{array}{c}\text { Number of } \\
\text { fractures }^{\mathrm{b}}\end{array}$ & Qty. & Comments \\
\hline 1 & 0 & 46 & \\
\hline \multirow[t]{5}{*}{2} & 1 & 6 & \\
\hline & 2 & 26 & \\
\hline & 3 & 15 & \\
\hline & 4 & 3 & \\
\hline & 5 & 1 & \\
\hline \multirow[t]{6}{*}{3} & 1 & 12 & 1 has 2 cracks \\
\hline & 2 & 24 & 1 has crack in middle; 1 has 2 cracks \\
\hline & 3 & 27 & 1 has 2 cracks \\
\hline & 4 & 7 & \\
\hline & 5 & 2 & \\
\hline & 6 & 2 & \\
\hline \multirow[t]{7}{*}{4} & 1 & 11 & \\
\hline & 2 & 12 & \\
\hline & 3 & 5 & 1 has 2 cracks in center \\
\hline & 4 & 7 & 1 has 2 cracks \\
\hline & 5 & 5 & \\
\hline & 6 & 1 & \\
\hline & 7 & 1 & \\
\hline \multirow[t]{3}{*}{5} & 1 & 3 & 1 has 1 crack in center \\
\hline & 2 & 1 & \\
\hline & 4 & 1 & \\
\hline
\end{tabular}

Size categories: $1=2-4 \mathrm{~cm} ; 2=4-8 \mathrm{~cm} ; 3=8-12 \mathrm{~cm} ; 4=12-16 \mathrm{~cm} ; 5=16-20 \mathrm{~cm} ; 6=20-24 \mathrm{~cm} ; 7=>24 \mathrm{~cm}$. Burned rock less than $2 \mathrm{~cm}$ in length was not recorded. informational purposes. 
Following the second firing, all 26 rocks (27 counting the cobble that split during the first firing) fractured into numerous pieces (Table D-2). After only two firings, the original 26 rocks were reduced to 217 pieces (note that this does not include the numerous spalls $[<2 \mathrm{~cm}]$ that littered the bottom of the pit). During the initial firing of the second pit, many of the rocks that showed multiple fractures began breaking as the stones were heated. However, most of the stones were still intact when the oven was loaded with food and sealed for the second time. Thus, it appears that most of the fracturing took place after the oven had been sealed. Many of the stones literally broke in our hands as they were pulled from the bottom of the oven following the second firing. Of the 217 pieces of burned and fractured rocks, many of the now-smaller stones exhibited numerous cracks.

\section{Discussion and Conclusion}

This experimental study considered discard rates for limestone cobbles heated in an earth oven. More specifically, we were interested in the number of uses in an earth oven we could expect from cobbles collected from sources near the Culebra Creek site. In addition, an oven similar in size to the hot-rock beds documented in the central portion of the Culebra Creek midden was constructed. While less than ideal, the experiment did provide insight into discard rates.

Citing the work of Tunnel and Madrid (1990), Black (1997) suggests that limestone rocks used in earth ovens may be reused in as many as four heating episodes. However, the ovens documented by Tunnel and Madrid are very different from those discussed by Black. For example, the ovens documented by Tunnel and Madrid are large, rock-lined earth ovens used to pit bake sotol and agave for making an intoxicating beverage known as sotol in modern and historic viñatas of eastern Chihuahua. These features are about three meters across and as much as $2.5 \mathrm{~m}$ deep (Tunnel and Madrid 1990:153-155). The walls of the pits are nearly vertical and lined with large stones (both limestone and igneous rocks are used). Importantly, the heating of the rocks for the cooking of the sotol and agave is not accomplished by building a fire in the bottom of the pit and throwing rocks on top of the fire. Rather, the bottom half of the pit is a domed-shaped fill of rock with a fire box underneath (Tunnel and Madrid 1990:Figure 7). The rocks are heated from a fire built underneath the bottom layer of rocks. The fire box is accessed from the outside of the pit via a ramp cut down to the bottom of the pit. The arrangement is very similar to an horno for bread making.

Though not explicitly stated by Tunnel and Madrid, this system of heating the rocks differently effects the rocks depending on the distance of the stones from the actual fire. In northern Chihuahua, near the town of Janos, similar pits have been documented (Brown and Leach 1997). Here, the large pits, similar in size to the ones documented by Tunnel and Madrid, are lined with large stones (mostly basalt, but some limestone is used), but the fire box is not a part of the feature. Instead, the bottom of the pit is left unlined with stones. A large fire is built in the bottom of the pit and stones are thrown in. After the fire dies down, the bed of coals and now-hot rock bed is used to cook the sotol and agave. The majority of the stone making up the heating element is discarded following each firing, whereas the stones lining the side of the pits can survive as many 20-30 firings before requiring replacement. The Mescalero Apache are known to discard all the heating element rocks in earth ovens used for pit-baking agave, as the rocks are "no good," having been compromised (as evidenced by cracks) from the first firing (David Carmichael, personal communication 1997).

We suggest that the large, rock-lined pits of Chihuahua used to cooked sotol offer powerful analogs for understanding hot-rock cooking. They do not, however, provide one-to-one correlates for estimating discard rates for limestone rocks in the morphologically smaller features that are documented in the many sites of central-south Texas. The Chihuahuan examples clearly demonstrate that the location of the stone within the pit and how long it was exposed to heat can directly effect the use life of that stone. Simply, rocks in constant contact with heat during the initial and subsequent firings will be subject to greater rates of discard. Whereas stones making up the walls of the pits and those located on the periphery of the "fire," will have longer use lives. 
Why then is the number of times a rock can be reused so important? At a basic level, as pointed out by Black and others (1997), knowing that a pile of rocks (midden) represents hundreds if not thousands of cooking events, can have a sobering effect on the would-be investigator. More importantly, researchers (Black 1997; Black et al. 1997) use these minimum numbers of uses as a proxy for the length of time it must have taken for the midden to form under expected curation rates. More often than not, discard rate estimates often bring the features in line with the date ranges represented by the projectile points recovered from the same feature.

The experimental data presented here suggest that the limestone rocks that made up the midden (discussed as anthromantle in Chapter 7) at Culebra Creek may have been discarded after only a few uses. In fact, many of the burned and fragmented rocks recovered from Culebra Creek excavations broke when removed from excavation levels, suggesting that the stones were originally cracked and possibly discarded early as documented among the Mescalero Apache. This, as pointed out at the beginning of the appendix, may have much to do with a readily available supply of stones in the immediate environ.

The current study was a useful exercise for the Culebra Creek investigators. The digging, collecting, and firing of an earth oven, even a small one, provides some idea of the level of effort needed to make a living from bulk processing (i.e., labor intensive). It is hoped that future investigators follow the lead of Black (1997) and Black and others (1997) and provide some estimates of rock discard, while supporting their inferences about rates of discard and formation of large rock features with systematic (and replicable) actualistic tests. It is only through this process that we will truly understand these impressive masses of burned rock and the role(s) they played on the larger hunter-gatherer landscape. 


\section{References Cited}

Black, S. L.

1997 Scenarios of Midden Accumulation. In Hot Rock Cooking on the Greater Edwards Plateau: Four Burned Rock Midden Sites in West Central Texas, edited by S. L. Black, L. W. Ellis, D. G. Creel, and G. T. Goode, pp. 83-88. Studies in Archeology 22. Texas Archeological Research Laboratory, The University of Texas at Austin.

Black, S. L., L. W. Ellis, D. G. Creel, and G. T. Goode (editors)

1997 Hot Rock Cooking on the Greater Edwards Plateau: Four Burned Rock Midden Sites in West Central Texas. Studies in Archeology 22. 2 Volumes. Texas Archeological Research Laboratory, The University of Texas at Austin.

Brown, R. B., and J. D. Leach

1997 Large-Scale Pit Baking of Succulents in Northern Mexico: Implications for Archaeologists. Paper presented at the 62 annual meeting of the Society for American Archaeology. Nashville.

Camilli, E. L., and J. I. Ebert

1992 Artifact Reuse and Recycling in Continuous Surface Distributions and Implications for Interpreting Land Use Patterns. In Space, Time, and Archaeological Landscapes, edited by J. Rossignol and L. Wandsnider, pp. 113-136. Plenum, New York.

Pagoulatos, P.

1992 The Re-Use of Thermally Altered Stone. North American Archaeologist 13(2):115-129.

Shott, M. J.

1992 Radiocarbon Dating as a Probabilistic Technique: The Childers Site and Late Woodland Occupation in the Ohio Valley. American Antiquity 57(2):202-230.

Tunnel, C., and E. Madrid

1990 Making and Taking Sotol in Chihuahua and Texas. In Papers from the Third Symposium on Resources in the Chihuahuan Desert Region, United States and Mexico, 10-12 November 1988, edited by A. M. Poweel, R. R. Hollander, J. C. Barlow, W. B. McGillivray, and D. J. Schmidly, pp. 145-162. Chihuahuan Desert Research Institute, Alpine, Texas. 


\section{Appendix E: Artifact Data}

Table E-1. Diagnostic Artifacts from 41BX126

\begin{tabular}{|c|c|c|c|c|c|c|}
\hline Area & Type & Interval & Subarea & Provenience & $\begin{array}{c}\text { Level/ } \\
\text { Elev }\end{array}$ & Invest. \\
\hline $\mathrm{A}$ & Butted Knife biface & Late Archaic & & TU 6 & 3 & CAR \\
\hline $\mathrm{A}$ & Marshall & Late Archaic & & BHT S & 2 & CAR \\
\hline $\mathrm{A}$ & Montell & Late Archaic & & TU 1 & 2 & CAR \\
\hline $\mathrm{A}$ & Montell & Late Archaic & & TU 1 & 4 & CAR \\
\hline $\mathrm{A}$ & Montell & Late Archaic & & ST B & 1 & CAR \\
\hline A & Pedernales & Late Archaic & & TU 2 & 1 & CAR \\
\hline $\mathrm{B}$ & Langtry & Middle Archaic & Block Excav. & TU 19 & 3 & CAR \\
\hline $\mathrm{B}$ & Montell & Late Archaic & Block Excav. & TU 12 & 1 & CAR \\
\hline $\mathrm{B}$ & Bulverde & Late Archaic & Block Excav. & TU 16 & 5 & $\mathrm{CAR}$ \\
\hline $\mathrm{B}$ & Castroville & Late Archaic & Block Excav. & TU 16 & 1 & CAR \\
\hline $\mathrm{B}$ & Pedernales & Late Archaic & Block Excav. & TU 18 & 3 & CAR \\
\hline $\mathrm{B}$ & Pedernales & Late Archaic & Block Excav. & Unit C & 5 & Price \\
\hline $\mathrm{B}$ & Uvalde & Early Archaic & Central Core & TU 8 & 5 & CAR \\
\hline $\mathrm{B}$ & Castroville & Late Archaic & Central Core & TU 8 & 3 & CAR \\
\hline $\mathrm{B}$ & Ellis & Late Archaic & Central Core & TU 8 & 2 & CAR \\
\hline $\mathrm{B}$ & Martindale & Early Archaic & Central Core & TU 9 & 6 & CAR \\
\hline $\mathrm{B}$ & Nolan & Middle Archaic & Central Core & TU 9 & 2 & CAR \\
\hline $\mathrm{B}$ & Castroville & Late Archaic & Central Core & TU 9 & 3 & CAR \\
\hline $\mathrm{B}$ & Marshall & Late Archaic & Central Core & TU 9 & 2 & CAR \\
\hline $\mathrm{B}$ & Pedernales & Late Archaic & Central Core & TU 9 & 2 & CAR \\
\hline $\mathrm{B}$ & Pedernales preform & Late Archaic & Central Core & TU 9 & 2 & CAR \\
\hline $\mathrm{B}$ & Clear Fork gouge & Early Archaic & Framework & Unit 18 & 3 & Wood \\
\hline $\mathrm{B}$ & Guadalupe tool & Early Archaic & Framework & Unit D & 9 & Price \\
\hline $\mathrm{B}$ & La Jita & Middle Archaic & Framework & Unit D & 2 & Price \\
\hline $\mathrm{B}$ & Nolan & Middle Archaic & Framework & Unit D & 5 & Price \\
\hline $\mathrm{B}$ & La Jita & Middle Archaic & Framework & TU 7 & 5 & CAR \\
\hline $\mathrm{B}$ & Pedernales & Late Archaic & Framework & GT & 2 & CAR \\
\hline $\mathrm{B}$ & Bulverde & Late Archaic & Framework & Trench G & 9 & Price \\
\hline B & La Jita & Middle Archaic & Periphery & BHT O & Backdirt & CAR \\
\hline $\mathrm{B}$ & Bell & Middle Archaic & Periphery & TU 11 & 7 & CAR \\
\hline $\mathrm{B}$ & Carrizo & Middle Archaic & Periphery & TU 11 & 4 & CAR \\
\hline $\mathrm{B}$ & Carrizo & Middle Archaic & Periphery & TU 11 & 4 & CAR \\
\hline $\mathrm{B}$ & San Gabriel biface & Trans. Archaic & Periphery & Trench $\mathrm{G}$ & Backdirt & Price \\
\hline
\end{tabular}


Table E-1. continued

\begin{tabular}{|c|c|c|c|c|c|c|}
\hline Area & Type & Interval & Subarea & Provenience & $\begin{array}{l}\text { Level/ } \\
\text { Elev }\end{array}$ & Invest. \\
\hline B & Pedernales & Late Archaic & Periphery & BHT O & 100.373 & CAR \\
\hline $\mathrm{B}$ & Pedernales & Late Archaic & Periphery & BHT O & Backdirt & CAR \\
\hline$B$ & Marcos & Late Archaic & Periphery & BHT P & Backdirt & CAR \\
\hline $\mathrm{B}$ & Montell & Late Archaic & Periphery & BHT P & Backdirt & CAR \\
\hline $\mathrm{B}$ & La Jita & Middle Archaic & Periphery & Unit 17 & 2 & Wood \\
\hline B & Castroville & Late Archaic & Periphery & BHT X & 1 & CAR \\
\hline B & Langtry & Late Archaic & Periphery & Surface* & Surface & Price \\
\hline B & Pedernales & Late Archaic & Periphery & Trench G & Backdirt & Price \\
\hline B & Montell & Late Archaic & Periphery & TU 11 & 1 & CAR \\
\hline $\mathrm{B}$ & Pedernales preform & Late Archaic & Periphery & TU 11 & 4 & CAR \\
\hline $\mathrm{B}$ & Williams & Late Archaic & Periphery & TU 11 & 2 & CAR \\
\hline$B$ & Pedernales & Late Archaic & Periphery & Unit 17 & 3 & Wood \\
\hline $\mathrm{B}$ & Bulverde & Late Archaic & Periphery & Unit 20 & 3 & Wood \\
\hline $\mathrm{B}$ & Darl & Late Archaic & Periphery & Unit 20 & 5 & Wood \\
\hline$B$ & Darl & Late Archaic & Periphery & TU 4 & 5 & CAR \\
\hline B & Darl & Late Archaic & Periphery & TU 4 & 6 & CAR \\
\hline $\mathrm{B}$ & Montell & Late Archaic & Periphery & TU 4 & 3 & CAR \\
\hline B & Castroville & Late Archaic & Periphery & Unit A & 1 & Price \\
\hline $\mathrm{B}$ & Nolan & Middle Archaic & Nolan Comp. & TU 12 & $3 \mathrm{U}$ & CAR \\
\hline B & Nolan-like & Middle Archaic & Nolan Comp. & TU 12 & $3 U$ & CAR \\
\hline B & Tortugas & Middle Archaic & Nolan Comp. & TU 14 & $4 U$ & CAR \\
\hline B & Nolan & Middle Archaic & Nolan Comp. & TU 16 & $3 \mathrm{~L}$ & CAR \\
\hline B & Nolan & Middle Archaic & Nolan Comp. & TU 16 & $3 \mathrm{~L}$ & CAR \\
\hline B & Langtry & Middle Archaic & Nolan Comp. & TU 17 & $4 \mathrm{~L}$ & CAR \\
\hline B & Nolan & Middle Archaic & Nolan Comp. & TU 17 & $4 \mathrm{~L}$ & CAR \\
\hline B & Nolan & Middle Archaic & Nolan Comp. & TU 23 & $3 \mathrm{~L}$ & CAR \\
\hline $\mathrm{B}$ & Castroville & Late Archaic & Unknown & BHT ? & Backdirt & Price \\
\hline $\mathrm{B}$ & Castroville & Late Archaic & Unknown & BHT ? & Backdirt & Price \\
\hline $\mathrm{C}$ & Pedernales & Late Archaic & & N1080E929 & Surface & CAR \\
\hline $\mathrm{C}$ & Pedernales & Late Archaic & & Unit $\mathrm{E}$ & 4 & Price \\
\hline $\mathrm{C}$ & Pedernales & Late Archaic & & Trench C & Backdirt & Price \\
\hline $\mathrm{C}$ & Bell & Middle Archaic & & Unit 5 & 3 & Wood \\
\hline $\mathrm{C}$ & Martindale & Late Archaic & & Unit 16 & 3 & Wood \\
\hline
\end{tabular}

* Midway between Trenches $\mathrm{H}$ and $\mathrm{J}$ on the floodplain. 
Table E-2. Cultural Material from Excavation Units

\begin{tabular}{|c|c|c|c|c|c|c|c|c|c|c|}
\hline$\underset{3}{3}$ & $\stackrel{\Xi}{\Xi}$ & $\underbrace{3}_{3}$ & 递 & 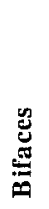 & 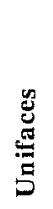 & $\frac{\mathfrak{E}}{\stackrel{5}{E}}$ & 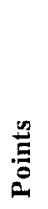 & 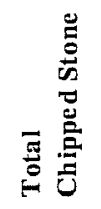 & 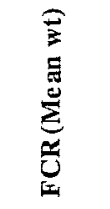 & Remarks \\
\hline \multirow{21}{*}{\multicolumn{2}{|c|}{$\frac{\text { Sub }}{C-3}$}} & 1 & & 1 & 2 & & & 154 & 98.17 & \\
\hline & & 2 & 1 & 2 & 1 & & 1 & 274 & - & \\
\hline & & 3 & & 1 & 3 & & & 420 & 80.42 & \\
\hline & & 4 & & 2 & & & 1 & 550 & 158.75 & \\
\hline & & 5 & & 1 & & & & 342 & 134.88 & \\
\hline & & 6 & & & & & & 40 & 0 & \\
\hline & & 7 & & & & & & 18 & 0 & \\
\hline & & Subtotal & 1 & 7 & 6 & 0 & 2 & 1798 & & \\
\hline & & 1 & & 1 & 1 & & 1 & 257 & & \\
\hline & & 2 & 1 & - & & & & 207 & & \\
\hline & & Subtotal & 1 & 1 & 1 & . & 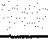 & 464 & & 8 \\
\hline & & 1 & & 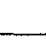 & 1 & & & 129 & & \\
\hline & & 2 & 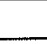 & 1 & 3 & & & 139 & & \\
\hline & & 3 & 1 & 2 & & 1 & & 1405 & & \\
\hline & & 4 & & & & & & 36 & & \\
\hline & & 5 & & & & & & 27 & & \\
\hline & & 6 & & & & & & 18 & & \\
\hline & & 7 & & & & & & 17 & & \\
\hline & & 8 & & & & & & 6 & & \\
\hline & & 9 & & & & & & 0 & & \\
\hline & & 10 & & 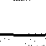 & & & & 0 & & \\
\hline \multicolumn{3}{|c|}{ Subtotal } & 1 & 3 & 4 & 1 & 0 & 1777 & & m \\
\hline \multirow{7}{*}{\multicolumn{2}{|c|}{$C-6$}} & 1 & & & 2 & & & 39 & & \\
\hline & & 2 & & 3 & 2 & & & 191 & & \\
\hline & & 3 & 1 & & $1 *$ & & & 344 & & * Butted knife biface \\
\hline & & 4 & & & & & & 131 & & \\
\hline & & 5 & & & & & & 45 & & \\
\hline & & 6 & & & & & & 22 & & \\
\hline & & 7 & & & & & & 31 & & \\
\hline \multicolumn{3}{|c|}{ Subtotal } & 1 & 3 & 4 & 0 & 0 & 803 & माग & +। \\
\hline \multirow{6}{*}{\multicolumn{2}{|c|}{ C-A }} & 1 & & & & & & 4 & & \\
\hline & & 2 & & & & & & 22 & & \\
\hline & & 3 & & & & & & 45 & & \\
\hline & & 4 & & & & & & 25 & & \\
\hline & & 5 & & & & & & 3 & & \\
\hline & & 6 & & & & & & 2 & & \\
\hline \multicolumn{3}{|c|}{ Subtotal } & 0 & 0 & 0 & 0 & 0 & 101 & 8 & 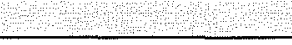 \\
\hline \multirow{5}{*}{\multicolumn{2}{|c|}{ C-B }} & 1 & & & & & 1 & 13 & & \\
\hline & & 2 & & & & & & 8 & & \\
\hline & & 3 & & & & & & 2 & & \\
\hline & & 4 & & & & & & 0 & & \\
\hline & & 5 & & & & & & 1 & & \\
\hline \multicolumn{3}{|c|}{ Subtotal } & 0 & 0 & 0 & 0 & 1 & 24 & & \\
\hline \multirow{5}{*}{\multicolumn{2}{|c|}{$\mathrm{C}-\mathrm{C}$}} & 1 & & & & & & 19 & & \\
\hline & & 2 & & & & & & 8 & & \\
\hline & & 3 & & & & & & 6 & & \\
\hline & & 4 & & & & & & 0 & & \\
\hline & & 5 & & & & & & 2 & & \\
\hline \multicolumn{3}{|c|}{ Subtotal } & 0 & 0 & 0 & 0 & 0 & 35 & & \\
\hline
\end{tabular}


Table E-2. continued

\begin{tabular}{|c|c|c|c|c|c|c|c|c|c|c|}
\hline$\stackrel{5}{己}$ & $\vec{D}$ & 总 & 总 & 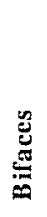 & 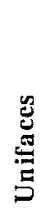 & $\frac{\frac{2}{2}}{\frac{2}{0}}$ & $\vec{E}$ & 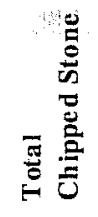 & 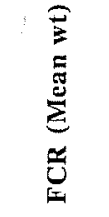 & Remarks \\
\hline \multirow[t]{15}{*}{ A } & \multirow{5}{*}{ C-D } & 1 & & & & & & 37 & & \\
\hline & & 2 & & & & & & 3 & & \\
\hline & & 3 & & & & & & 2 & & \\
\hline & & 4 & & & & & & 21 & & \\
\hline & & 5 & & & & & & 12. & & \\
\hline & \multicolumn{2}{|c|}{ Subtotal } & 0 & 0 & 0 & 0 & 0 & 75 & & \\
\hline & \multirow[t]{6}{*}{$C-E$} & 1 & & & & & & 10 & & \\
\hline & & 2 & & & & & & 10 & & \\
\hline & & 3 & & & & & & 0 & & \\
\hline & & 4 & & & & & & 1 & & \\
\hline & & 5 & & & & & & 2 & & \\
\hline & & 6 & & & & & & 7 & & \\
\hline & \multicolumn{2}{|c|}{ Subtotal } & 0 & 0 & 0 & 0 & 0 & 30 & & \\
\hline & $\mathbf{P}$ & $\mathrm{UNK}$ & 3 & & & & & 3 & & \\
\hline & \multicolumn{2}{|c|}{ Subtotal } & 3 & 0 & 0 & 0 & 0 & 3 & & \\
\hline \multirow[t]{34}{*}{ B } & \multirow[t]{10}{*}{ C-4 } & 1 & & 1 & 1 & & & 233 & & \\
\hline & & 2 & & 1 & & & & 166 & & \\
\hline & & 3 & 2 & & 2 & & 1 & 522 & & \\
\hline & & 4 & & 1 & 2 & & & 1701 & & \\
\hline & & 5 & & & 1 & & 1 & 523 & & \\
\hline & & 6 & & & & & 1 & 260 & & \\
\hline & & 7 & & & & & & 103 & & \\
\hline & & 8 & & & & & & 34 & & \\
\hline & & 9 & & & & & & 111 & & \\
\hline & & 10 & & & & & & 0 & & \\
\hline & \multicolumn{2}{|c|}{ Subtotal } & 2 & 3 & 6 & 0 & 3 & 3653 & & \\
\hline & \multirow[t]{6}{*}{$\mathrm{C}-5$} & 1 & & & & & & 119 & & \\
\hline & & 2 & & 2 & & & & 330 & & \\
\hline & & 3 & & & & & & 30 & & \\
\hline & & 4 & & & & & & 70 & & \\
\hline & & 5 & & & & & & 39 & & \\
\hline & & 6 & & & & & & 34 & & \\
\hline & \multicolumn{2}{|c|}{ Subtotal } & 0 & 2 & 0 & 0 & 0 & 622 & & \\
\hline & \multirow[t]{8}{*}{$C-7$} & 1 & 1 & 3 & & & & 341 & 181.48 & \\
\hline & & 2 & & 2 & & & & 376 & 77.62 & \\
\hline & & 3 & & 1 & & & & 464 & 103.11 & \\
\hline & & 4 & & 1 & & & & 372 & 105.37 & \\
\hline & & 5 & & & & & 1 & 737 & 302.31 & \\
\hline & & 6 & 2 & 2 & 2 & & & 425 & 79.9 & \\
\hline & & 7 & & & 1 & & & 349 & 17.86 & \\
\hline & & 8 & & & & & & 130 & 12.1 & \\
\hline & \multicolumn{2}{|c|}{ Subtotal } & 3 & 9 & 3 & 0 & 1 & 3194 & 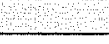 & \\
\hline & \multirow[t]{6}{*}{ C-8 } & 1 & & 3 & & & & 945 & 88.85 & \\
\hline & & 2 & & & & & 1 & 840 & 98.14 & \\
\hline & & 3 & & 4 & & & 1 & 383 & 68.42 & \\
\hline & & 4 & & & 1 & & & 431 & 47.9 & \\
\hline & & 5 & & & & & 1 & 2713 & 90.58 & \\
\hline & & 6 & & & 1 & & & 1403 & 125.43 & \\
\hline & \multicolumn{2}{|c|}{ Subtotal } & 0 & 7 & 2 & 0 & 3 & 6715 & & \\
\hline
\end{tabular}


Table E-2. continued

\begin{tabular}{|c|c|c|c|c|c|c|c|c|c|c|}
\hline$\underset{z}{2}$ & 苛 & 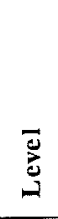 & U⿺尢丶 & $\underset{0}{\stackrel{5}{0}}$ & 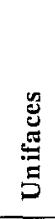 & $\frac{\frac{n}{2}}{\frac{2}{2}}$ & : & 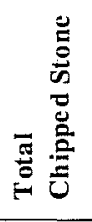 & 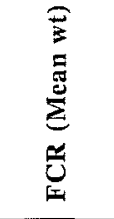 & Remarks \\
\hline \multirow[t]{6}{*}{ B } & \multirow[t]{6}{*}{ C-9 } & 1 & 1 & & 1 & & & 519 & - & \\
\hline & & 2 & & 2 & 1 & & 4 & 686 & 136.95 & \\
\hline & & 3 & & & & & 1 & 425 & 24.08 & \\
\hline & & 4 & & 2 & 1 & & & 361 & 18.76 & \\
\hline & & 5 & & 2 & 2 & & & 1709 & 21.08 & \\
\hline & & 6 & & 2 & 1 & & 1 & 1597 & 17.58 & \\
\hline & \multicolumn{2}{|c|}{ Subtotal } & 1 & 8 & 6 & 0 & 6 & 5297 & & \\
\hline \multirow{4}{*}{\multicolumn{2}{|c|}{ C-10 }} & 1 & & 1 & & & & 146 & & \\
\hline & & 2 & 1 & 1 & & & & 321 & & \\
\hline & & 3 & & & 1 & & 1 & 213 & & \\
\hline & & 4 & & & & & & 80 & & \\
\hline \multicolumn{3}{|c|}{ Subtotal } & 1 & 2 & 1 & 0 & 1 & 760 & & \\
\hline \multirow{7}{*}{\multicolumn{2}{|c|}{ C-11 }} & 1 & & 3 & & & 1 & 728 & & \\
\hline & & 2 & 1 & & 2 & & 1 & 466 & & \\
\hline & & 3 & 1 & 4 & 1 & & & 835 & & \\
\hline & & 4 & 2 & 3 & 2 & & 3 & 1368 & & \\
\hline & & 5 & 1 & 3 & 3 & & & 618 & & \\
\hline & & 6 & 1 & 1 & 2 & & & 262 & & \\
\hline & & 7 & & 1 & & & 1 & 211 & & \\
\hline \multicolumn{3}{|c|}{ Subtotal } & 6 & 15 & 10 & 0 & 6 & 4488 & 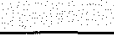 & $\$$ \\
\hline \multirow{5}{*}{\multicolumn{2}{|c|}{ C-12 }} & 1 & & & & & 1 & 250 & & \\
\hline & & 2 & & & & & & 341 & & \\
\hline & & 3 & & 1 & 1 & & 2 & 250 & & \\
\hline & & 4 & & & & & & 251 & & \\
\hline & & 5 & & & & & & 144 & & \\
\hline \multicolumn{3}{|c|}{ Subtotal } & 0 & 1 & 1 & 0 & 3 & 1236 & & \& \\
\hline \multirow{3}{*}{\multicolumn{2}{|c|}{ C-13 }} & $1-4$ & & 3 & & & & 190 & & \\
\hline & & 5 & & 1 & & & & 121 & & \\
\hline & & 6 & & & 1 & & & 24 & & \\
\hline \multicolumn{3}{|c|}{ Subtotal } & 0 & 4 & 1 & 0 & 0 & 335 & 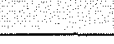 & \\
\hline \multirow{9}{*}{\multicolumn{2}{|c|}{ C-14 }} & 1 & & & 5 & & & 199 & - & \\
\hline & & 2 & 1 & 1 & 5 & & & 323 & - & \\
\hline & & $3 \mathrm{G}$ & & & & & & 0 & 295.77 & \\
\hline & & $3 \mathrm{U}$ & & & 2 & & & 2 & 87.78 & \\
\hline & & $3 \mathrm{~L}$ & & & 10 & & & 10 & - & \\
\hline & & $4 \mathrm{G}$ & & & & & & 0 & 357.66 & \\
\hline & & $4 \mathrm{U}$ & & 2 & 2 & & 1 & 5 & 121.46 & \\
\hline & & $4 \mathrm{~L}$ & & & 2 & & & 2 & 366.95 & \\
\hline & & 5 & & & 1 & & & 173 & 135.85 & \\
\hline \multicolumn{3}{|c|}{ Subtotal } & 1 & 3 & 27 & 0 & 1 & 714 & 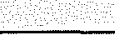 & \\
\hline & C-15 & 1 & & 1 & & & & 174 & - & \\
\hline & & 2 & 1 & 2 & 13 & & & 324 & 200.68 & \\
\hline & & $3 G$ & & & & & & & 240.17 & \\
\hline & & $3 \mathrm{U}$ & 1 & 1 & 4 & & & 6 & 49.5 & \\
\hline & & $3 \mathrm{~L}$ & & & 3 & & & 3 & 95.31 & \\
\hline & & $4 \mathrm{G}$ & & & & & & & 339.46 & \\
\hline & & $4 \mathrm{U}$ & & & 3 & & & 3 & 45.21 & \\
\hline & & $4 \mathrm{~L}$ & & 2 & 2 & & & 4 & 115.57 & \\
\hline & & 5 & & & $1 *$ & & & 274 & 232.08 & $*$ Graver \\
\hline & Subt & tal & 2 & 6 & 25 & 0 & 0 & 788 & 3 & \\
\hline
\end{tabular}


Table E-2. continued

\begin{tabular}{|c|c|c|c|c|c|c|c|c|c|c|}
\hline$\underset{⿱ 乛 龰}{\mathrm{Z}}$ & $\stackrel{\Xi}{\Xi}$ & 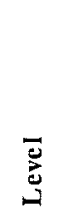 & 莡 & 总 & 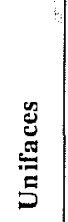 & $\frac{n}{\tilde{D}}$ & 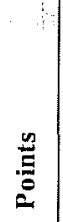 & 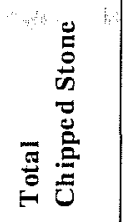 & 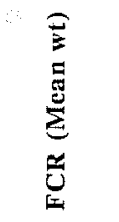 & Remarks \\
\hline \multirow{8}{*}{\multicolumn{2}{|c|}{\begin{tabular}{l|l} 
B & C-16
\end{tabular}}} & 1 & & & 2 & & 1 & 176 & - & \\
\hline & & 2 & 1 & & 13 & & & 322 & - & \\
\hline & & $3 G$ & & & & & & 21 & 230.75 & \\
\hline & & $3 \mathrm{U}$ & 1 & & 4 & & & 261 & 56.22 & \\
\hline & & $3 \mathrm{~L}$ & & & 3 & & 2 & 174 & 89.58 & \\
\hline & & $4 \mathrm{U}$ & & & 3 & & & 118 & 146.15 & \\
\hline & & $4 \mathrm{~L}$ & & & 2 & & & 339 & 156.58 & \\
\hline & & 5 & & & 4 & & 1 & 279 & - & \\
\hline \multicolumn{3}{|c|}{ Subtotal } & 2 & 0 & 31 & 0. & 4 & 1690 & 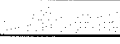 & \\
\hline \multirow{8}{*}{\multicolumn{2}{|c|}{ C-17 }} & 1 & & 1 & 7 & & & 234 & - & \\
\hline & & 2 & & 1 & 2 & & & 302 & 282.11 & \\
\hline & & & & & & & & & 224.33 & \\
\hline & & $3 \mathrm{U}$ & 2 & 1 & 4 & & & 7 & 48.72 & \\
\hline & & $3 \mathrm{~L}$ & & & 2 & & & 2 & 79.56 & \\
\hline & & $4 \mathrm{U}$ & & 1 & 3 & & & 4 & 75.66 & \\
\hline & & $4 \mathrm{~L}$ & & 2 & & & 2 & 4 & 145.25 & \\
\hline & & 5 & & & 1 & & & 156 & 49.9 & \\
\hline \multicolumn{3}{|c|}{ Subtotal } & 2 & 6 & 19 & 0 & 2 & 709 & 2 & 3 \\
\hline \multirow{8}{*}{\multicolumn{2}{|c|}{ C-18 }} & 1 & & & 4 & & & 230 & - & \\
\hline & & 2 & & & 4 & & & 248 & - & \\
\hline & & $3 \mathrm{U}$ & & 1 & 3 & & 1 & 5 & 241.85 & \\
\hline & & $3 \mathrm{~L}$ & & 1 & & & & 1 & & \\
\hline & & $4 \mathrm{U}$ & 1 & & 1 & & & 2 & 96.17 & \\
\hline & & $4 \mathrm{~L}$ & & 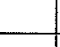 & 1 & & & 1 & 90.42 & \\
\hline & & $4 \mathrm{G}$ & & 1 & & & & 1 & 320.66 & \\
\hline & & 5 & & 1 & 1 & & & 255 & 103.21 & \\
\hline \multicolumn{3}{|c|}{ Subtotal } & 1 & 4 & 14 & 0 & 1 & 743 & 63 & \\
\hline \multirow{8}{*}{\multicolumn{2}{|c|}{ C-19 }} & 1 & & 1 & 2 & & & 236 & - & \\
\hline & & 2 & & 3 & 7 & & & 355 & 60.41 & \\
\hline & & $3 \mathrm{G}$ & & & & & & & 734.42 & \\
\hline & & $3 \mathrm{U}$ & & & & & 1 & 1 & 31.49 & \\
\hline & & $3 \mathrm{~L}$ & & & 1 & & & 1 & 77.74 & \\
\hline & & $4 U$ & & & 1 & & & 1 & 203.96 & \\
\hline & & $4 \mathrm{~L}$ & & & & & & 0 & 169.55 & \\
\hline & & 5 & & 1 & 1 & & & 106 & 100.77 & \\
\hline \multicolumn{3}{|c|}{ Subtotal } & 0 & 5 & 12 & 0 & 1 & 700 & 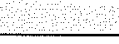 & \\
\hline & \multirow[t]{9}{*}{ C-20 } & 1 & & 2 & 3 & & & 228 & - & \\
\hline & & 2 & & 1 & 2 & & & 261 & 242.14 & \\
\hline & & $3 G$ & & & & & & & 850.91 & \\
\hline & & $3 \mathrm{U}$ & & & 1 & & & 1 & - & \\
\hline & & $3 \mathrm{~L}$ & & & & & & 0 & 48 & \\
\hline & & $4 \mathrm{G}$ & & & 2 & & & 2 & - & \\
\hline & & $4 \mathrm{U}$ & & & 1 & & & 1 & 132.72 & \\
\hline & & $4 \mathrm{~L}$ & & & 2 & & & 2 & 220.5 & \\
\hline & & 5 & & & 1 & & & 121 & 19.2 & \\
\hline & \multicolumn{2}{|c|}{ Subtotal } & 0 & 3 & 12 & 0 & 0 & 616 & & \\
\hline
\end{tabular}


Table E-2. continued

\begin{tabular}{|c|c|c|c|c|c|c|c|c|c|c|}
\hline$\frac{3}{4}$ & $\underset{\Xi}{\ddot{\Xi}}$ & $\stackrel{\vec{J}}{3}$ & 嵌 & 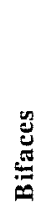 & 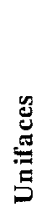 & 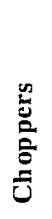 & 莺 & 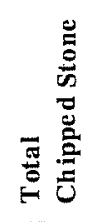 & 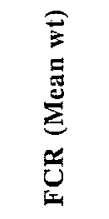 & Remarks \\
\hline \multirow{8}{*}{\multicolumn{2}{|c|}{$C-21$}} & 1 & & 1 & 2 & & & 168 & - & \\
\hline & & 2 & 1 & 2 & 4 & & & 395 & 224.81 & \\
\hline & & $3 \mathrm{U}$ & & 1 & 5 & & & 6 & 70.21 & \\
\hline & & $3 \mathrm{~L}$ & & & 1 & & & 1 & - & \\
\hline & & $4 \mathrm{G}$ & & & & & & & 669.27 & \\
\hline & & $4 \mathrm{U}$ & & & & & & 0 & - & \\
\hline & & $4 \mathrm{~L}$ & 1 & 1 & 3 & & & 5 & 144.79 & \\
\hline & & 5 & & 2 & & & & 95 & 74.25 & \\
\hline \multicolumn{3}{|c|}{ Subtotal } & 2 & 7 & 15 & 0 & 0 & 670 & 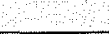 & \\
\hline \multirow{8}{*}{\multicolumn{2}{|c|}{$\mathrm{C}-22$}} & 1 & & & 6 & & & 231 & - & \\
\hline & & 2 & & $1 *$ & 5 & & & 191 & 176.37 & *Drill \\
\hline & & $3 \mathrm{U}$ & & & & & & 0 & - & \\
\hline & & $3 \mathrm{~L}$ & & & 2 & & & 2 & - & \\
\hline & & $3 \mathrm{G}$ & 1 & & & & & 1 & 367.16 & \\
\hline & & $4 \mathrm{U}$ & & & 1 & & & 1 & 80.28 & \\
\hline & & $4 \mathrm{~L}$ & & & 1 & & & 1 & - & \\
\hline & & 5 & 1 & & 1 & & & 60 & 231.92 & \\
\hline \multicolumn{3}{|c|}{ Subtotal } & 2 & 0 & 16 & 0 & 0 & 487 & 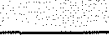 & \\
\hline \multirow{9}{*}{\multicolumn{2}{|c|}{$\mathrm{C}-23$}} & 1 & & 1 & 3 & & & 222 & - & \\
\hline & & 2 & & & 3 & & & 335 & 78.41 & \\
\hline & & $3 \mathrm{G}$ & & & & & & & 127.16 & \\
\hline & & $3 \mathrm{U}$ & & & 1 & & & 1 & 73.38 & \\
\hline & & $3 \mathrm{~L}$ & & & 1 & & & 1 & 111.52 & \\
\hline & & $4 G$ & & & & & & & 357.71 & \\
\hline & & $4 \mathrm{U}$ & 1 & & & & & 1 & 74.93 & \\
\hline & & $4 \mathrm{~L}$ & & & & & & 0 & 74.4 & \\
\hline & & 5 & & & & & & 112 & 114.33 & \\
\hline \multicolumn{3}{|c|}{ Subtotal } & 1 & 1 & 8 & 0 & 0 & 672 & 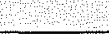 & 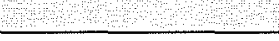 \\
\hline & P-A & 1 & & 1 & 10 & & 1 & 408 & 11.73 & \\
\hline & & 2 & & 1 & 3 & & & 39 & 1.43 & \\
\hline & & 3 & 1 & 1 & 1 & & & 70 & 55.81 & \\
\hline & & 4 & 2 & 7 & 2 & & & 760 & 38.36 & \\
\hline & & 5 & & & 4 & & & 440 & 18.91 & \\
\hline & & 6 & & 1 & 3 & & & 303 & 10.82 & \\
\hline & & 7 & 1 & 4 & 3 & & & 408 & 14.8 & \\
\hline & & 8 & & & & & & 129 & 14.89 & \\
\hline & & 9 & & & 1 & & & 85 & - & \\
\hline & & 10 & & & & & & 21 & - & \\
\hline & & 11 & & & 1 & & & 19 & - & \\
\hline & & 12 & & & & & & 15 & 117.5 & \\
\hline & & 13 & & & & & & 47 & 0.62 & \\
\hline & & 14 & & & 1 & & & 16 & - & \\
\hline & & 15 & & & & & & 15 & - & \\
\hline & \multicolumn{2}{|c|}{ Subtotal } & 4 & 15 & 29 & 0 & 1 & 2775 & 9 & \\
\hline
\end{tabular}


Table E-2. continued

\begin{tabular}{|c|c|c|c|c|c|c|c|c|c|c|}
\hline$\frac{g}{5}$ & $\vec{E}$ & $\begin{array}{l}\overline{0} \\
\text { 리 }\end{array}$ & ن⿺辶ّ & 总 & 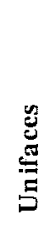 & 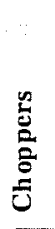 & 总 & 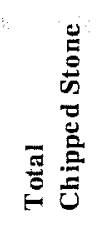 & 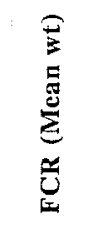 & Remarks \\
\hline \multirow[t]{42}{*}{$\mathrm{B}$} & \multirow[t]{16}{*}{ P-B } & 1 & 2 & & & & & 87 & 5.6 & \\
\hline & & 2 & & & & & & 76 & 13.48 & \\
\hline & & 3 & & & & & & 59 & 23.64 & \\
\hline & & 4 & & & & & & 57 & 89.71 & \\
\hline & & 5 & & & & & & 64 & 15.94 & \\
\hline & & 6 & & & 8 & & & 161 & 0.21 & \\
\hline & & 7 & 1 & & 8 & & & 68 & 4.92 & \\
\hline & & 8 & & 2 & & & & 187 & 3.93 & \\
\hline & & 9 & & 2 & 4 & & & 49 & 3.52 & \\
\hline & & 10 & & 2 & 7 & & & 47 & 4.64 & \\
\hline & & 11 & & & 3 & & & 23 & - & \\
\hline & & 12 & & & & & & 16 & 4.1 & \\
\hline & & 13 & & & & & & 9 & 0.16 & \\
\hline & & 14 & & & & & & 2 & - & \\
\hline & & 15 & & & & & & 2 & 0.25 & \\
\hline & & 16 & & & & & & 5 & 0.33 & \\
\hline & \multirow{13}{*}{ P-C } & Subtotal & 3 & 6 & 30 & 0 & 0 & $\frac{912}{265}$ & 23.79 & \\
\hline & & 2 & & & 1 & & & 106 & 2.42 & \\
\hline & & 3 & & & & & & 10 & 11.74 & \\
\hline & & 4 & & 2 & & & & 138 & 34.41 & \\
\hline & & 5 & & 2 & & & 1 & 427 & 15.94 & \\
\hline & & 6 & & & & & & 149 & 0.21 & \\
\hline & & 7 & & 2 & $1 *$ & & & 96 & 2.75 & $*$ Gouge \\
\hline & & 8 & & 1 & $1^{*}$ & & & 150 & 3.82 & *Clear Fork Tool \\
\hline & & 9 & & & & & & 49 & 3.63 & \\
\hline & & 10 & & & & & & 70 & 17.87 & \\
\hline & & 11 & & & & & & 55 & - & \\
\hline & & 12 & & & & & & 52 & - & \\
\hline & & 13 & & & & & & 27 & 0.66 & \\
\hline & \multicolumn{2}{|c|}{ Subtotal } & 0 & 7 & 1 & 0 & 1 & 1594 & an & \\
\hline & \multirow[t]{11}{*}{ P-D } & 1 & 1 & & 6 & & & 608 & 28.85 & \\
\hline & & $\frac{2}{3}$ & 2 & $\frac{3}{6}$ & $\frac{1}{4}$ & & 1 & $\frac{244}{389}$ & $\frac{38.04}{41.06}$ & \\
\hline & & 4 & 1 & 2 & 4 & & & 689 & 9.68 & \\
\hline & & 5 & & $3 *$ & 1 & & 1 & 444 & 10.12 & * 1 is a graver \\
\hline & & 6 & 1 & & 2 & & & 299 & 14.02 & \\
\hline & & 7 & & 1 & 1 & & & 838 & 271.99 & \\
\hline & & 8 & & 2 & 1 & & & 315 & 2.71 & \\
\hline & & 9 & & $3 *$ & 3 & & & 576 & 22.99 & $* 1$ is a Guadalupe Tool \\
\hline & & 10 & & $1^{*}$ & 4 & & & 692 & 10.7 & *Gouge \\
\hline & & 11 & & & & & & 256 & 40.14 & \\
\hline & & 12 & & & & & & 192 & - & \\
\hline & \multicolumn{2}{|c|}{ Subtotal } & 5 & 14 & 27 & 0 & 2 & 5542 & & \\
\hline
\end{tabular}


Table E-2. continued

\begin{tabular}{|c|c|c|c|c|c|c|c|c|c|c|}
\hline$\underset{⿱ 乛 龰}{Z}$ & $\stackrel{\Xi}{\Xi}$ & $\bar{د}$ & $\stackrel{n}{0}$ & $\underset{0}{0}$ & 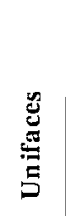 & & $\begin{array}{l}\vec{E} \\
\ddot{0}\end{array}$ & 焉芯 & 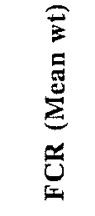 & Remarks \\
\hline \multirow[t]{38}{*}{$\mathrm{B}$} & \multirow[t]{4}{*}{ W-17 } & A & 2 & & 2 & & & 129 & & \\
\hline & & $\mathrm{B}$ & 1 & & & & 1 & 65 & & \\
\hline & & $\mathrm{C}$ & & & 1 & & 1 & 70 & & \\
\hline & & $\mathrm{D}$ & 1 & & & & & 52 & & \\
\hline & \multicolumn{2}{|c|}{ Subtotal } & 4 & 0 & 3 & 0 & 2 & 316 & & \\
\hline & $\mathbf{W}-18$ & A & 1 & & $20^{*}$ & & & 211 & & *Includes 1 Clear Fork gouge \\
\hline & \multicolumn{2}{|c|}{ Subtotal } & 1 & 0 & 20 & 0 & 0 & 211 & & \\
\hline & \multirow[t]{9}{*}{ W-19 } & $\mathrm{A}$ & 2 & & 12 & & & 72 & & \\
\hline & & B & & & & & & 15 & & \\
\hline & & $\mathrm{C}$ & & & & & & 8 & & \\
\hline & & $\mathrm{D}$ & & & 2 & & & 7 & & \\
\hline & & $E / F$ & 1 & & & & & 52 & & \\
\hline & & $\mathrm{G}$ & & & & & & 20 & & \\
\hline & & $\mathrm{H}$ & 1 & & 2 & & & 12 & & \\
\hline & & I & & & & & & 15 & & \\
\hline & & $\mathrm{J}$ & & & 2 & & & 22 & & \\
\hline & \multicolumn{2}{|c|}{ Subtotal } & 4 & 0 & 18 & 0 & 0 & 223 & & \\
\hline & \multirow[t]{7}{*}{$\mathbf{W}-20$} & A & & & 2 & & & 109 & & \\
\hline & & $\mathrm{B}$ & & & 3 & & & 111 & & \\
\hline & & C & & & & & 1 & 103 & & \\
\hline & & $\mathrm{D}$ & & & & & & 94 & & \\
\hline & & $E$ & & & & & 1 & 77 & & \\
\hline & & $\mathrm{F}$ & & & 2 & & & 83 & & \\
\hline & & $\mathrm{G}$ & & & 1 & & & 58 & & \\
\hline & \multicolumn{2}{|c|}{ Subtotal } & 0 & 0 & 8 & 0 & 2 & 635 & 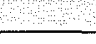 & \\
\hline & \multirow[t]{2}{*}{$W-21$} & A & & & 4 & & & 51 & & \\
\hline & & $?$ & & & & & & 54 & & \\
\hline & \multicolumn{2}{|c|}{ Subtotal } & 0 & 0 & 4 & 0 & 0 & 105 & & \\
\hline & $W-22$ & $\mathrm{~A}$ & & & 2 & & & 236 & & $.5-\mathrm{m}^{2}$ unit \\
\hline & \multicolumn{2}{|c|}{ Subtotal } & & & 2 & 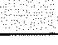 & 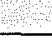 & 236 & 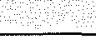 & (4) \\
\hline & $W-23$ & $\mathrm{~A}$ & & & 2 & & & 78 & & $.5-\mathrm{m}^{2}$ unit \\
\hline & \multicolumn{2}{|c|}{ Subtotal } & & & 2 & & & 78 & & \\
\hline & $W-24$ & A & & & & & & 262 & & $.5-\mathrm{m}^{2}$ unit \\
\hline & \multicolumn{2}{|c|}{ Subtotal } & & & 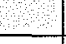 & & 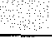 & 262 & & (४४४४ \\
\hline & $W-25$ & A & & & & & & 434 & & $.5-\mathrm{m}^{2}$ unit \\
\hline & \multicolumn{2}{|c|}{ Subtotal } & 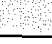 & 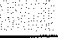 & 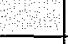 & ?: & 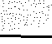 & 434 & 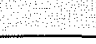 & 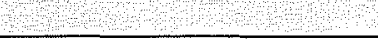 \\
\hline & $w-26$ & $\mathrm{~A}$ & & & & & & 122 & & $.5-\mathrm{m}^{2}$ unit \\
\hline & \multicolumn{2}{|c|}{ Subtotal } & & 8 & 1 & 4 & $\$$ & 122 & 48 & 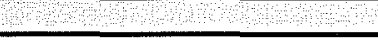 \\
\hline \multirow[t]{11}{*}{ C } & \multirow[t]{10}{*}{ P-E } & 1 & & 1 & 5 & & & 31 & 7.29 & \\
\hline & & 2 & & & & & & 17 & 25.55 & \\
\hline & & 3 & & & & & & 48 & 4.05 & \\
\hline & & 4 & & & & & 1 & 25 & 7.5 & \\
\hline & & 5 & & & & & & 149 & 18.43 & \\
\hline & & 6 & & & 1 & & & 32 & 19.31 & \\
\hline & & 7 & & & & & & 11 & 8.84 & \\
\hline & & 8 & & & & & & 42 & 5.74 & \\
\hline & & 9 & & & & & & 16 & 8.53 & \\
\hline & & 10 & & & & & & 98 & - & \\
\hline & \multicolumn{2}{|c|}{ Subtotal } & 0 & 1 & 6 & 0 & 1 & 469 & & \\
\hline
\end{tabular}


Table E-2. continued

\begin{tabular}{|c|c|c|c|c|c|c|c|c|c|c|}
\hline$\stackrel{g}{\mathscr{E}}$ & 苛 & 总 & 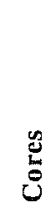 & 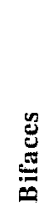 & 窇 & $\frac{\omega}{\grave{D}}$ & 音 & 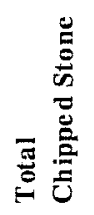 & 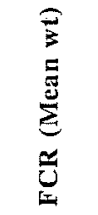 & Remarks \\
\hline \multirow[t]{24}{*}{ C 1} & \multirow[t]{9}{*}{ P-E/F } & 1 & 1 & & 3 & & & 135 & 55.75 & \\
\hline & & 2 & & & 1 & & & 96 & - & \\
\hline & & 3 & & 1 & & & & 41 & 10.8 & \\
\hline & & 4 & & & 1 & & & 20 & 14 & \\
\hline & & 5 & & & & & & 26 & - & \\
\hline & & 6 & & & 1 & & & 53 & 44.88 & \\
\hline & & 7 & & & 2 & & & 45 & 5.73 & \\
\hline & & 8 & & & & & & 150 & - & \\
\hline & & 9 & & 1 & 1 & & & 29 & 42.72 & \\
\hline & \multicolumn{2}{|c|}{ Subtotal } & 1 & 2 & 9 & 0 & 0 & 595 & $\ldots$ & \\
\hline & \multirow[t]{14}{*}{ P-F } & 1 & & & & & & 33 & 1.6 & \\
\hline & & 2 & & & 1 & & & 30 & 2.92 & \\
\hline & & 3 & & 1 & & & & 11 & 5.2 & \\
\hline & & 4 & & & 1 & & & 34 & 0.12 & \\
\hline & & 5 & & & & & & 26 & 20.5 & \\
\hline & & 6 & & & 1 & & & 60 & 24.29 & \\
\hline & & 7 & & & 1 & & & 25 & 49 & \\
\hline & & 8 & & & & & & 23 & 7.63 & \\
\hline & & 9 & & 1 & 1 & & & 33 & 11.63 & \\
\hline & & $\frac{10}{11}$ & & & & & & $\frac{11}{34}$ & $\begin{array}{l}6.1 \\
1.42\end{array}$ & \\
\hline & & 12 & & & & & & 25 & 18.6 & \\
\hline & & 13 & & & & & & 14 & 3.33 & \\
\hline & & 14 & & & & & & 19 & - & \\
\hline & & 15 & & & & & & 20 & 1 & \\
\hline & \multicolumn{2}{|c|}{ Subtotal } & 0 & 2 & 5 & 0 & 0 & 398 & . & 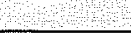 \\
\hline \multirow{4}{*}{\multicolumn{2}{|c|}{ W-1 }} & A & & & & & & 4 & & \\
\hline & & B & & & & & & 18 & & \\
\hline & & C & & & 1 & & & 3 & & \\
\hline & & D & & & & & & 0 & & \\
\hline \multicolumn{3}{|c|}{ Subtotal } & 0 & 0 & 1 & 0 & 0 & 25 & 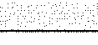 & 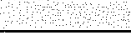 \\
\hline \multirow{4}{*}{\multicolumn{2}{|c|}{ W-2 }} & A & & & 1 & & & 19 & & \\
\hline & & $\mathrm{B}$ & 1 & & & & & 16 & & \\
\hline & & $\mathrm{C}$ & & & & & & 14. & & \\
\hline & & D & & & & & & 14 & & \\
\hline & \multicolumn{2}{|c|}{ Subtotal } & 1 & 0 & 1 & 0 & 0 & 63 & $\square$ & \\
\hline \multirow{3}{*}{\multicolumn{2}{|c|}{ W-3 }} & $\mathrm{A}$ & & & & & & 0 & & \\
\hline & & $\mathrm{B}$ & & 1 & 1 & & & 9 & & \\
\hline & & $\frac{C}{D}$ & & & 1 & & & $\frac{0}{1}$ & & \\
\hline & \multicolumn{2}{|c|}{ Subtotal } & 0 & 1 & 2 & 0 & 0 & 10 & & \\
\hline \multirow{4}{*}{\multicolumn{2}{|c|}{ W-4 }} & A & & & 1 & & & 37 & & \\
\hline & & B & & & & & & 7 & & \\
\hline & & $\mathrm{C}$ & & & 1 & & 1 & 6 & & \\
\hline & & D & & & & & & 0 & & \\
\hline & Subt & tal & 0 & 0 & 2 & 0 & 1 & 50 & & \\
\hline
\end{tabular}


Table E-2. continued

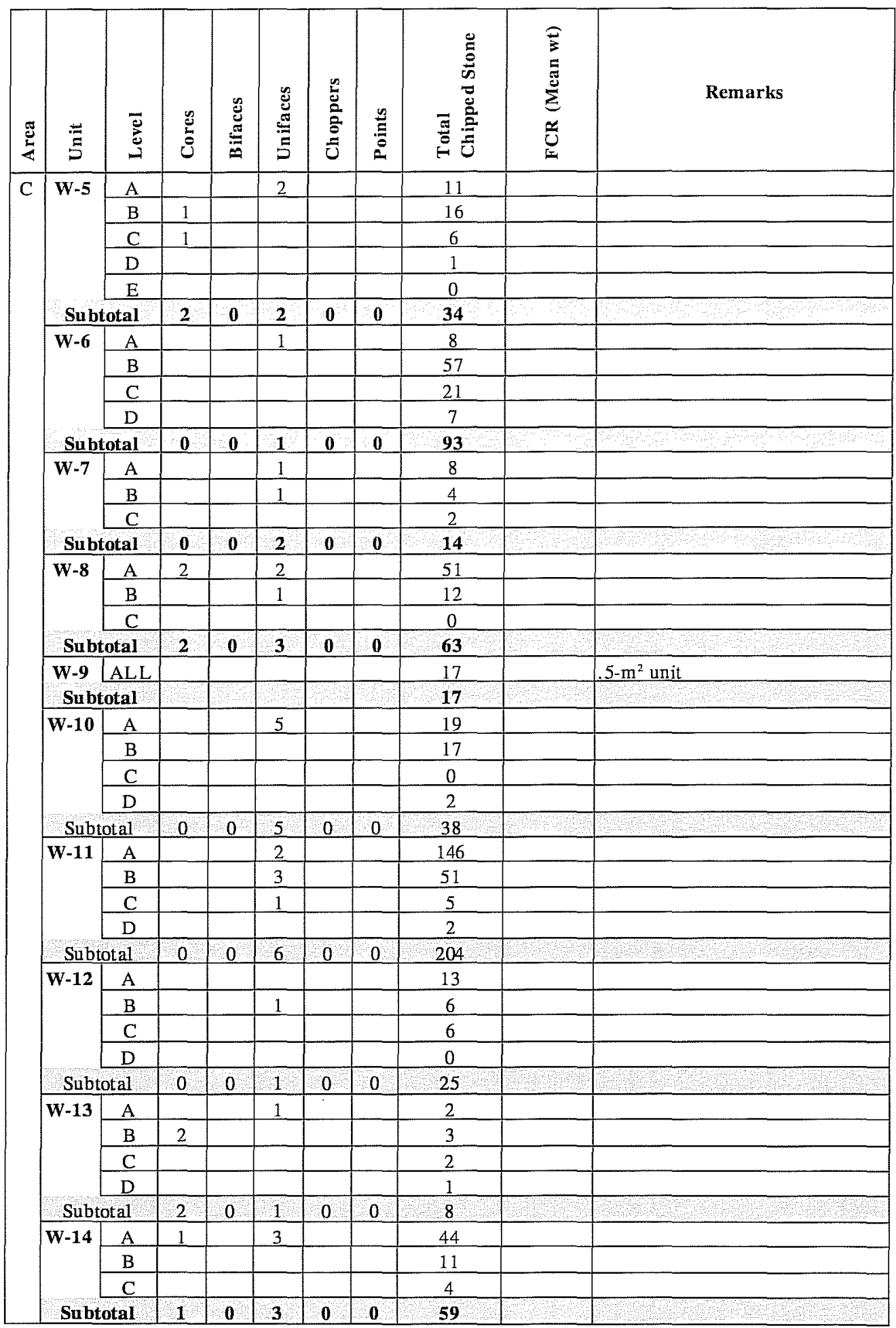


Table E-2. continued

\begin{tabular}{|c|c|c|c|c|c|c|c|c|c|c|}
\hline$\frac{5}{2}$ & $\stackrel{E}{E}$ & ${ }_{J}^{\bar{J}}$ & ن & $\stackrel{\mathscr{E}}{\stackrel{0}{0}}$ & & 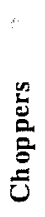 & 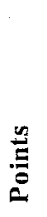 & 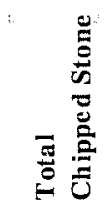 & 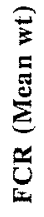 & Remarks \\
\hline & \multirow[t]{5}{*}{ W-15 } & $\mathrm{A}$ & & & & & & 0 & & \\
\hline & & $\mathrm{B}$ & & & & & & 0 & & \\
\hline & & $\mathrm{C}$ & & & & & & 0 & & \\
\hline & & $\mathrm{D}$ & & & & & & 2 & & \\
\hline & & $?$ & & & & & & 2 & & \\
\hline & \multicolumn{2}{|c|}{ Subtotal } & 0 & 0 & 0 & 0 & 0 & 4 & & \\
\hline & W-16 & $A^{*}$ & & & & & 1 & 40 & & $5-m^{2}$ unit \\
\hline & \multicolumn{2}{|c|}{ Subtotal } & & & & & 1 & 40 & & \\
\hline
\end{tabular}

Notes: "C-1" denotes CAR's 1997 Unit 1; "P-A" denotes Price's 1995 Unit A; "W-1" denotes Wood's 1993 Unit 1. "3U"=Level 3, Upper $5 \mathrm{~cm}$; "3L"=Level 3, Lower $5 \mathrm{~cm}$; "3G"=all $10 \mathrm{~cm}$ of Level 3. 
Table E-3. Length (L) of Complete Flakes by Unit and Level

Unit 12

\begin{tabular}{cccccccc}
$\mathrm{L}(\mathrm{cm})$ & 1 & 2 & $3 \mathrm{U}$ & $3 \mathrm{~L}$ & $4 \mathrm{U}$ & $4 \mathrm{~L}$ & 5 \\
\hline 1 & 16 & 13 & 11 & 16 & 5 \\
2 & 13 & 8 & 9 & 14 & 6 \\
3 & 10 & 5 & 9 & & & \\
4 & 1 & & & 7 & 1 \\
5 & 2 & 3 & & 1 & & \\
6 & & & & & & & \\
7 & & & & & & & \\
8 & & & & & & & \\
9 & & & & & & & \\
10 & & & & & & & \\
Total & 42 & 29 & 29 & 0 & 38 & 0 & 12 \\
Mean L & $\mathbf{2 . 0 5}$ & $\mathbf{2 . 0 3}$ & $\mathbf{1 . 9 3}$ & $\mathbf{2 . 0 3}$ & & 1.75
\end{tabular}

\section{Unit 14}

\begin{tabular}{cccccccc}
$\mathrm{L}(\mathrm{cm})$ & 1 & 2 & $3 \mathrm{U}$ & $3 \mathrm{~L}$ & $4 \mathrm{U}$ & $4 \mathrm{~L}$ & 5 \\
\hline 1 & 3 & 5 & 13 & & 7 & 9 & 2 \\
2 & 2 & 15 & 12 & 8 & 8 & 6 & 1 \\
3 & & 15 & 8 & 2 & 2 & 2 & 4 \\
4 & & 4 & 2 & 1 & 2 & 1 & 3 \\
5 & & 2 & 3 & 1 & 2 & & \\
6 & 1 & & & 1 & & & \\
7 & & & & & & & 1 \\
8 & & & & & & 1 & \\
9 & & & & & & & \\
10 & & & & & & &
\end{tabular}

$\begin{array}{llllllll}\text { Total } & 6 & 41 & 38 & 13 & 21 & 19 & 11\end{array}$

$\begin{array}{llllllll}\text { Mean L } & 2.17 & 2.59 & 2.21 & 2.85 & 2.24 & 2.05 & 3.18\end{array}$

Unit 15

\begin{tabular}{cccccccc}
$\mathrm{L}(\mathrm{cm})$ & 1 & 2 & $3 \mathrm{U}$ & $3 \mathrm{~L}$ & $4 \mathrm{U}$ & $4 \mathrm{~L}$ & 5 \\
\hline 1 & 2 & 5 & 4 & 3 & 5 & 1 & 7 \\
2 & 7 & 2 & 12 & 9 & 5 & 8 & \\
3 & 11 & & & 3 & 4 & 1 & \\
4 & 3 & 1 & 1 & 5 & 2 & 2 & 2 \\
5 & 1 & & 1 & 1 & & & 2 \\
6 & & & 1 & & 1 & 1 & \\
7 & & & & & 1 & & \\
8 & & & & & & & \\
9 & & & & & & & \\
10 & & & & & & &
\end{tabular}

$\begin{array}{llllllll}\text { Total } & 24 & 8 & 19 & 21 & 18 & 13 & 11\end{array}$

$\begin{array}{llllllll}\text { Mean L } & 2.75 & 1.63 & 2.26 & 2.62 & 2.67 & 2.62 & 2.27\end{array}$

\section{Unit 16}

\begin{tabular}{cccccccc}
$\mathrm{L}(\mathrm{cm})$ & 1 & 2 & $3 \mathrm{U}$ & $3 \mathrm{~L}$ & $4 \mathrm{U}$ & $4 \mathrm{~L}$ & 5 \\
\hline 1 & & 5 & 9 & 13 & & 5 \\
2 & 5 & 14 & 10 & 8 & 9 & 4 \\
3 & 3 & 7 & 3 & 5 & 6 & 11 \\
4 & 2 & 6 & 3 & 1 & 4 & 1 \\
5 & & 2 & 9 & 3 & & 5 \\
6 & & & & & & 1 & \\
7 & & 1 & & & & & \\
8 & & & & & & & \\
9 & & & & & & & \\
10 & & & & & & & \\
Total & 10 & 35 & 34 & 0 & 30 & 20 & 26 \\
Mean L & $\mathbf{2 . 7}$ & $\mathbf{2 . 7 1}$ & $\mathbf{2 . 7 9}$ & & $\mathbf{2 . 1}$ & $\mathbf{2 . 9}$ & $\mathbf{2 . 8 8}$
\end{tabular}

\section{Unit 17}

\begin{tabular}{cccccccc}
$\mathrm{L}(\mathrm{cm})$ & 1 & 2 & $3 \mathrm{U}$ & $3 \mathrm{~L}$ & $4 \mathrm{U}$ & $4 \mathrm{~L}$ & 5 \\
\hline 1 & 3 & 5 & 11 & & 1 & & 5 \\
2 & 4 & 3 & 19 & 1 & 2 & 6 & 8 \\
3 & 6 & & 6 & 1 & 3 & 2 & 6 \\
4 & 1 & & 5 & 3 & 5 & 4 & 2 \\
5 & & & 4 & 1 & & & \\
6 & 1 & & & 1 & 1 & 1 & \\
7 & & 1 & & & 1 & & 1 \\
8 & & & 1 & & & & \\
9 & & & & & & & \\
10 & & & & & & & \\
Total & 15 & 9 & 46 & 7 & 13 & 13 & 22 \\
Mean L & $\mathbf{2 . 6}$ & $\mathbf{2}$ & $\mathbf{2 . 5}$ & $\mathbf{4}$ & $\mathbf{3 . 6 2}$ & $\mathbf{3 . 0 8}$ & $\mathbf{2 . 4 5}$
\end{tabular}

\section{Unit 18}

\begin{tabular}{cccccccc}
$\mathrm{L}(\mathrm{cm})$ & 1 & 2 & $3 \mathrm{U}$ & $3 \mathrm{~L}$ & $4 \mathrm{U}$ & $4 \mathrm{~L}$ & 5 \\
\hline 1 & 5 & 8 & 9 & & 9 & & 6 \\
2 & 5 & 10 & 2 & 10 & 6 & 3 \\
3 & 1 & 2 & 16 & 5 & 2 & 9 \\
4 & 3 & & 9 & 1 & 2 & 1 \\
5 & 2 & 1 & 1 & & & & 1 \\
6 & 2 & & & & & & \\
7 & & & & & & & \\
8 & & & & 1 & & \\
9 & & & & & 1 & & \\
10 & & & & & & 1 & \\
Total & 18 & 21 & 37 & 0 & 27 & 11 & 20 \\
Mean L & $\mathbf{2 . 8 9}$ & $\mathbf{1 . 8 6}$ & $\mathbf{2 . 7 6}$ & & $\mathbf{2 . 4 1}$ & $\mathbf{3 . 2 7}$ & $\mathbf{2 . 4}$
\end{tabular}


Table E-3. continued

Unit 19

\begin{tabular}{cccccccc}
$\mathrm{L}(\mathrm{cm})$ & 1 & 2 & $3 \mathrm{U}$ & $3 \mathrm{~L}$ & $4 \mathrm{U}$ & $4 \mathrm{~L}$ & 5 \\
\hline 1 & 1 & 3 & 10 & & 3 & & 6 \\
2 & 19 & 11 & 4 & 3 & 3 & 5 & 2 \\
3 & 4 & 7 & 4 & 3 & 2 & 2 & \\
4 & & 2 & 2 & 2 & 2 & 2 & \\
5 & & & & 2 & 1 & & \\
6 & & & & & & & \\
7 & & & & & & & \\
8 & & & & & & & \\
9 & & 1 & & & & & \\
10 & & & & & & & \\
Total & 24 & 24 & 20 & 10 & 11 & 9 & 8 \\
Mean L & $\mathbf{2 . 1 3}$ & $\mathbf{2 . 6 3}$ & $\mathbf{1 . 9}$ & $\mathbf{3 . 3}$ & $\mathbf{2 . 5 5}$ & $\mathbf{2 . 6 7}$ & $\mathbf{1 . 2 5}$
\end{tabular}

\section{Unit 20}

\begin{tabular}{cccccccc}
$\mathrm{L}(\mathrm{cm})$ & 1 & 2 & $3 \mathrm{U}$ & $3 \mathrm{~L}$ & $4 \mathrm{U}$ & $4 \mathrm{~L}$ & 5 \\
\hline 1 & 6 & 5 & 5 & & 6 & & \\
2 & 4 & 18 & 20 & 2 & 2 & 1 & 5 \\
3 & 3 & 4 & 7 & 4 & & 2 & 2 \\
4 & & & 4 & & & & \\
5 & 2 & & 2 & & 1 & & \\
6 & 3 & 1 & & & & & 1 \\
7 & & 1 & & & & & \\
8 & & 1 & & & & & \\
9 & & & & & & & \\
10 & & & & & & & \\
Total & 18 & 30 & 38 & 6 & 9 & 3 & 8
\end{tabular}

$\begin{array}{llllllll}\text { Mean L } & 2.83 & 2.47 & 2.42 & 2.67 & 1.67 & 2.67 & 2.75\end{array}$

\section{Unit 21}

\begin{tabular}{cccccccc}
$\mathrm{L}(\mathrm{cm})$ & 1 & 2 & $3 \mathrm{U}$ & $3 \mathrm{~L}$ & $4 \mathrm{U}$ & $4 \mathrm{~L}$ & 5 \\
\hline 1 & 3 & 4 & 2 & & & 1 & \\
2 & 4 & 24 & 7 & 3 & 1 & 8 & \\
3 & 1 & 7 & 2 & & & 4 & \\
4 & & 1 & & & & 2 & \\
5 & 2 & 1 & 3 & & & & \\
6 & & & 3 & & & & \\
7 & & & 1 & & & & \\
8 & & 1 & & & & & \\
9 & & & & & & & \\
10 & & & & & & & \\
Total & 10 & 38 & 18 & 3 & 1 & 15 & 0 \\
Mean L & $\mathbf{2 . 4}$ & $\mathbf{2 . 3 7}$ & $\mathbf{3 . 4 4}$ & $\mathbf{2}$ & $\mathbf{2}$ & $\mathbf{2 . 4 7}$ &
\end{tabular}

Unit 22

\begin{tabular}{cccccccc}
$\mathrm{L}(\mathrm{cm})$ & 1 & 2 & $3 \mathrm{U}$ & $3 \mathrm{~L}$ & $4 \mathrm{U}$ & $4 \mathrm{~L}$ & 5 \\
\hline 1 & 5 & 4 & 2 & & 7 & & 3 \\
2 & 7 & 4 & 7 & 2 & 6 & 6 & 1 \\
3 & 9 & 2 & 4 & 1 & 1 & 8 & 1 \\
4 & 1 & & & 2 & & 3 & \\
5 & 1 & & 4 & & & 1 & \\
6 & & 1 & 1 & & 1 & & \\
7 & & & & & & & \\
8 & & & & & & & \\
9 & & & & & & & \\
10 & & & & & & & \\
Total & 23 & 11 & 18 & 5 & 15 & 18 & 5 \\
Mean L & $\mathbf{2 . 3 9}$ & $\mathbf{2 . 1 8}$ & $\mathbf{3}$ & $\mathbf{3}$ & $\mathbf{1 . 8 7}$ & $\mathbf{2 . 9 4}$ & $\mathbf{1 . 6}$
\end{tabular}

\section{Unit 23}

\begin{tabular}{cccccccc}
$\mathrm{L}(\mathrm{cm})$ & 1 & 2 & $3 \mathrm{U}$ & $3 \mathrm{~L}$ & $4 \mathrm{U}$ & $4 \mathrm{~L}$ & 5 \\
\hline 1 & 3 & 8 & 7 & & 10 & & 7 \\
2 & 15 & 20 & 7 & 6 & 3 & 3 & 4 \\
3 & 1 & 16 & 3 & 2 & 5 & 5 & 2 \\
4 & 1 & 5 & & 1 & & 2 & \\
5 & 1 & 1 & & & & & \\
6 & 1 & 3 & & & & & \\
7 & & 1 & & & & & \\
8 & 1 & & & & & & \\
9 & & & & & & & \\
10 & & 1 & & & & & \\
Total & 23 & 55 & 17 & 9 & 18 & 10 & 13 \\
Mean L & $\mathbf{2 . 5 7}$ & $\mathbf{2 . 8 4}$ & $\mathbf{1 . 7 6}$ & $\mathbf{2 . 4 4}$ & $\mathbf{1 . 7 2}$ & $\mathbf{2 . 9}$ & $\mathbf{1 . 6 2}$
\end{tabular}

Unit C

\begin{tabular}{cccccccc}
$\mathrm{L}(\mathrm{cm})$ & 1 & 2 & $3 \mathrm{U}$ & $3 \mathrm{~L}$ & $4 \mathrm{U}$ & $4 \mathrm{~L}$ & 5 \\
\hline 1 & 8 & 16 & & & 8 & & 5 \\
2 & 2 & 4 & & & 4 & & 1 \\
3 & & & & & 3 & & 4 \\
4 & & 4 & & & 7 & 3 \\
5 & & & & & & 1 \\
6 & 1 & 1 & & & & 1 \\
7 & 1 & 1 & & & & & \\
8 & & & & & & & \\
9 & & & & & & & \\
10 & & & & & & & \\
Total & 12 & 26 & 0 & 0 & 22 & 0 & 15 \\
Mean L & $\mathbf{2 . 0 8}$ & $\mathbf{2 . 0 4}$ & & & $\mathbf{2 . 4 1}$ & & $\mathbf{2 . 8}$
\end{tabular}




\section{Appendix F: Faunal Data}

\section{Barbara A. Meissner}

Tables F-1 and F-2 contain the list of vertebrate faunal material recovered from 41BX126. No faunal material collected by Wood (1994) was included in this analysis. Table F-1 lists bone from the excavations, Table F-2 lists bone from the flotation samples. Each bone was coded individually. Bone was grouped in Tables F-1 and F2 if it was from the same provenience, if it could be identified only to the class level, and all data in all columns was identical.

The following codes were used in the section labeled "Coded Observations."

Pitted. Pitting of bone surface by chemical weathering.
0 . None
No evidence of chemical weathering.
1. Slight
Pits are individual or over small part of bone. Bone is firm and generally smooth.
2. Moderate Enamel of teeth appears slightly dull.
Pitting has affected entire surface, but is not deep. Bone is still firm, but rough
3. Heavy
4. Extreme textured. Enamel is dull and is slightly rough.
Entire surface has been destroyed. Bone is soft and friable. Pitting of subsurface bone is extensive. Enamel is soft and somewhat chalky.
$\begin{array}{ll}\text { 4. Extreme } & \begin{array}{l}\text { Subsurface layer of bone is heavily pitted. Bone is crum } \\ \text { and chalky and may be almost eroded away. }\end{array} \\ \text { 5. Indeterminate } & \text { Usually due to very small size, or lack of surficial bone. }\end{array}$

Weathered. Evidence of atmospheric weathering.

0 . None

1. Slight

2. Moderate

3. Heavy

4. Indeterminate
No evidence of atmospheric weathering.

Fine longitudinal cracking on long bones, beginning of mosaic cracking on articular surfaces.

Deeper longitudinal cracking. Some surface exfoliation. Bone shows some bleaching.

Longitudinal cracks have formed splinters, some of which have exfoliated. Extensive surficial exfoliation. Bone appears heavily bleached.

Usually due to very small size. 
Burned. Evidence of heat alteration of bone.

0. None No evidence of heat alteration.

1. Smoked Bone appears discolored by smoke but is not charred.

2. Charred Some or all of the bone is charred.

3. Partially calcined Bone is extensively charred with some portions calcined.

4. Calcined Bone is completely calcined.

Broken. Evidence of bone condition when broken.

1. Fresh Appears to have been broken while bone was fresh. Spiral fractures, smooth edges.

2. Dry Appears to have been broken after bone has dried. Angular fractures, rough edges.

3. Both Breaks of both types are present.

4. Indeterminate Usually due to either small size, heavy pitting or weathering, or severe heat alteration.

Gnawing. Evidence of gnawing on bone by animals.

0 None No evidence of gnawing.

1. Rodent Bone appears to have been gnawed by rodents.

2. Carnivore Bone appears to have been gnawed by carnivores.

3. Gnawed Bone appears to have been gnawed, but agent could not be determined, usually due to poor bone condition.

Columns in the "Butcher Marks" section list how many of each type of butcher mark were found on each bone. Butcher mark types are defined as follows:

Thin cut Thin cut mark, superficial.

Chop Deep, heavy cut, or cut through bone.

Peck Impact scar $<1 \mathrm{~cm}$ across.

Impact scar Impact scar showing crushing of surficial bone and/or evidence of interior flaking. 
Table F-1. Faunal Material Recovered During Excavations at 41BX126

\begin{tabular}{|c|c|c|c|c|c|c|c|c|c|c|c|c|c|c|c|c|}
\hline \multirow[b]{2}{*}{$\mathrm{TU}$} & \multirow[b]{2}{*}{ Lvl } & \multirow[b]{2}{*}{ Taxon } & \multirow[b]{2}{*}{$\overrightarrow{\bar{\Xi}}$} & \multirow[b]{2}{*}{$\begin{array}{l}\frac{\vec{E}}{D} \\
\frac{D 0}{3} \\
3\end{array}$} & \multirow[b]{2}{*}{ Element } & \multirow[b]{2}{*}{ Portion } & \multicolumn{5}{|c|}{ Coded Observations } & \multicolumn{4}{|c|}{ Butcher Marks } & \multirow[b]{2}{*}{ Notes } \\
\hline & & & & & & & 芑 & 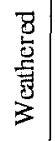 & 鸹 & $\begin{array}{l}\text { : } \\
\text { 产 } \\
\text { 呙 }\end{array}$ & 总 & $\begin{array}{c}\Xi \\
\Xi \\
\Xi \\
\Xi \\
\Xi\end{array}$ & 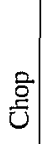 & 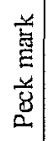 & 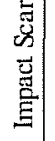 & \\
\hline 1 & 3 & Rodentia & 1 & 0.13 & Tibia & Fragment & 5 & 4 & 4 & 4 & 0 & & & & & \\
\hline \multicolumn{4}{|c|}{ Unit total } & 0.13 & & & & & & & & & & & & \\
\hline 2 & 2 & Vertebrata & 2 & 0.06 & & & 5 & 4 & 4 & 4 & 0 & & & & & \\
\hline \multicolumn{4}{|c|}{ Unit total } & 0.06 & & & & & & & & & & & & \\
\hline 3 & 3 & Osteicthyes & 2 & 0.01 & Otolith & Complete & 5 & 4 & 0 & 4 & 0 & & & & & \\
\hline 3 & 3 & Vertebrata & 2 & 0.01 & & & 5 & 4 & 0 & 4 & 0 & & & & & \\
\hline \multicolumn{4}{|c|}{ Unit total } & 0.02 & & & & & & & & & & & & \\
\hline 4 & 3 & Mammalia & 1 & 0.61 & Long bone & Fragment & 1 & 4 & 1 & 4 & 0 & & & & & \\
\hline 4 & 3 & Mammalia & 1 & 0.35 & Long bone & Fragment & 0 & 4 & 4 & 4 & 0 & & & & & \\
\hline 4 & 3 & Mammalia & 3 & 0.89 & Long bone & Fragment & 3 & 4 & 0 & 4 & 0 & & & & & \\
\hline 4 & 3 & Mammalia & 3 & 0.42 & & & 3 & 4 & 0 & 4 & 0 & & & & & \\
\hline 4 & 3 & Mammalia & 1 & 0.14 & & & 0 & 4 & 1 & 4 & 0 & & & & & \\
\hline 4 & 3 & Mammalia & 1 & 0.50 & & & 0 & 4 & 3 & 4 & 0 & & & & & \\
\hline 4 & 3 & Vertebrata & 2 & 0.09 & & & 5 & 4 & 4 & 4 & 0 & & & & & \\
\hline 4 & 3 & Vertebrata & 3 & 0.06 & & & 0 & 4 & 0 & 4 & 0 & & & & & \\
\hline 4 & 3 & Vertebrata & 3 & 0.02 & & & 5 & 4 & 2 & 4 & 0 & & & & & \\
\hline 4 & 4 & Mammalia & 1 & 0.42 & & & 2 & 4 & 1 & 1 & 0 & & & & & $\begin{array}{l}\text { Smoked on } \\
\text { one end only }\end{array}$ \\
\hline 4 & 4 & Mammalia & 3 & 0.76 & & & 3 & 4 & 0 & 4 & 0 & & & & & \\
\hline 4 & 4 & Mammalia & 9 & 1.51 & & & 2 & 4 & 0 & 4 & 0 & & & & & \\
\hline 4 & 4 & Vertebrata & 1 & 0.10 & & & 1 & 4 & 0 & 4 & 0 & & & & & \\
\hline 4 & 4 & Vertebrata & 1 & 0.07 & & & 1 & 4 & 1 & 4 & 0 & & & & & \\
\hline 4 & 4 & Aves & 1 & 0.01 & Long bone & Fragment & 0 & 4 & 4 & 4 & 0 & & & & & Sparrow-sized \\
\hline 4 & 4 & Mammalia & 4 & 0.75 & & & 3 & 4 & 0 & 4 & 0 & & & & & \\
\hline 4 & 4 & Mammalia & 3 & 0.76 & & & 3 & 4 & 0 & 4 & 0 & & & & & \\
\hline 4 & 4 & Mammalia & 3 & 0.82 & & & 1 & 4 & 1 & 4 & 0 & & & & & \\
\hline 4 & 4 & Mammalia & 1 & 0.41 & & & 3 & 4 & 2 & 4 & 0 & & & & & \\
\hline 4 & 4 & Mammalia & 1 & 0.82 & Long bone & Fragment & 1 & 1 & 1 & 3 & 0 & & & & & \\
\hline 4 & 4 & Mammalia & 3 & 0.40 & & & 2 & 4 & 0 & 4 & 0 & & & & & \\
\hline 4 & 4 & Vertebrata & 2 & 0.03 & & & 5 & 4 & 4 & 4 & 0 & & & & & \\
\hline 4 & 4 & Vertebrata & 1 & 0.04 & & & 5 & 4 & 2 & 4 & 0 & & & & & \\
\hline 4 & 4 & Vertebrata & 84 & 1.16 & & & 5 & 4 & 0 & 4 & 0 & & & & & \\
\hline 4 & 4 & Vertebrata & 3 & 0.29 & & & 5 & 4 & 1 & 4 & 0 & & & & & \\
\hline 4 & 4 & Vertebrata & 7 & 0.18 & & & 5 & 4 & 2 & 4 & 0 & & & & & \\
\hline 4 & 4 & Mammalia & 1 & 0.11 & & & 0 & 4 & 1 & 4 & 0 & & & & & \\
\hline 4 & 5 & Vertebrata & 1 & 0.24 & & & 2 & 4 & 1 & 4 & 0 & & & & & \\
\hline 4 & 5 & Vertebrata & 2 & 0.79 & & & 1 & 4 & 1 & 4 & 0 & & & & & \\
\hline 4 & 5 & Vertebrata & 1 & 0.24 & & & 2 & 4 & 1 & 4 & 0 & & & & & \\
\hline 4 & 5 & Vertebrata & 2 & 0.79 & & & 1 & 4 & 1 & 4 & 0 & & & & & \\
\hline 4 & 5 & Mammalia & 1 & 0.27 & & & 5 & 4 & 4 & 4 & 0 & & & & & \\
\hline 4 & 5 & Mammalia & 2 & 0.31 & & & 1 & 4 & 1 & 4 & 0 & & & & & \\
\hline 4 & 6 & Mammalia & 1 & 0.09 & & & 1 & 4 & 0 & 4 & 0 & & & & & \\
\hline 4 & 6 & Mammalia & 5 & 3.72 & Long bone & Fragment & 2 & 4 & 0 & 1 & 0 & & & & & Deet-sized \\
\hline 4 & 6 & Mammalia & 1 & 0.37 & Long bone & Fragment & 1 & 4 & 0 & 4 & 0 & & & & & \\
\hline 4 & 6 & Mammalia & 1 & 0.40 & Long bone & Fragment & 1 & 4 & 1 & 1 & 0 & & & & & \\
\hline 4 & 6 & Mammalia & 2 & 0.20 & & & 2 & 4 & 0 & 4 & 0 & & & & & \\
\hline 4 & 6 & Mammalia & 2 & 0.15 & & & 0 & 2 & 0 & 4 & 0 & & & & & \\
\hline 4 & 7 & Mammalia & 2 & 0.61 & & & 1 & 4 & 0 & 4 & 0 & & & & & \\
\hline \multicolumn{4}{|c|}{ Unit total } & 19.90 & & & & & & & & & & & & \\
\hline 5 & 5 & Vertebrata & 1 & 0.02 & & & 5 & 4 & 4 & 4 & 0 & & & & & \\
\hline 5 & 6 & Vertebrata & 6 & 0.08 & & & 5 & 4 & 4 & 4 & 0 & & & & & \\
\hline 5 & 6 & Vertebrata & 1 & 0.02 & & & 5 & 4 & 0 & 4 & 0 & & & & & \\
\hline & & Unit total & & 1.20 & & & & & & & & & & & & \\
\hline
\end{tabular}


Table F-1. continued

\begin{tabular}{|c|c|c|c|c|c|c|c|c|c|c|c|c|c|c|c|c|}
\hline \multirow[b]{2}{*}{ TU } & \multirow[b]{2}{*}{ Lvl } & \multirow[b]{2}{*}{ Taxon } & \multirow[b]{2}{*}{$\overrightarrow{\vec{E}}$} & \multirow[b]{2}{*}{$\begin{array}{l}\vec{E} \\
\frac{5}{\vec{D}} \\
3\end{array}$} & \multirow[b]{2}{*}{ Element } & \multirow[b]{2}{*}{ Portion } & \multicolumn{5}{|c|}{ Coded Observations } & \multicolumn{4}{|c|}{ Butcher Marks } & \multirow[b]{2}{*}{ Notes } \\
\hline & & & & & & & 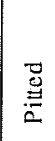 & 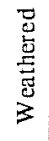 & 总 & 咅 & $\begin{array}{l}\vec{J} \\
\stackrel{\Xi}{0} \\
\tilde{J}\end{array}$ & $\begin{array}{l}\vec{\exists} \\
\text { U. } \\
\text { 들 } \\
\text { E }\end{array}$ & 竞 & 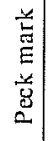 & 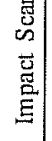 & \\
\hline 6 & 2 & Mammalia & 1 & 0.56 & Long bone & Frag ment & 2 & 4 & 1 & 4 & 0 & & & & & \\
\hline 6 & 3 & Vertebrata & 2 & 0.07 & & & 3 & 4 & 0 & 4 & 0 & & & & & \\
\hline 6 & 3 & Vertebrata & 3 & 0.07 & & & 5 & 4 & 2 & 4 & 0 & & & & & \\
\hline 6 & 3 & Mammalia & 2 & 0.57 & & & 1 & 1 & 1 & 4 & 0 & & & & & \\
\hline \multicolumn{4}{|c|}{ Unit total } & 1.27 & & & & & & & & & & & & \\
\hline 7 & 4 & Mammalia & 1 & 0.33 & & & 1 & 4 & 0 & 1 & 0 & & & & & \\
\hline 7 & 5 & Aves & 1 & 0.01 & & & 1 & 4 & 1 & 4 & 0 & & & & & \\
\hline 7 & 5 & \begin{tabular}{|l|} 
Lepus \\
californicus
\end{tabular} & 1 & 0.02 & Incisor & Complete & 5 & 4 & 4 & 4 & 0 & & & & & \\
\hline 7 & 5 & Mammalia & 5 & 0.24 & & & 5 & 4 & 4 & 4 & 0 & & & & & \\
\hline 7 & 5 & Vertebrata & 1 & 0.01 & & & 5 & 4 & 1 & 4 & 0 & & & & & \\
\hline 7 & 5 & Vertebrata & 2 & 0.04 & & & 5 & 4 & 2 & 4 & 0 & & & & & \\
\hline 7 & 5 & Vertebrata & 12 & 0.13 & & & 5 & 4 & 0 & 4 & 0 & & & & & \\
\hline 7 & 6 & Mammalia & 2 & 0.64 & & & 1 & 4 & 0 & 4 & 0 & & & & & $\begin{array}{l}\text { Has flecks of } \\
\text { charcoal } \\
\text { adhering }\end{array}$ \\
\hline \multicolumn{4}{|c|}{ Unit total } & 1.42 & & & & & & & & & & & & \\
\hline 8 & 1 & Vertebrata & 1 & 0.09 & & & 2 & 4 & 0 & 4 & 0 & & & & & \\
\hline 8 & 1 & Vertebrata & 1 & 0.07 & & & 3 & 4 & 0 & 4 & 0 & & & & & \\
\hline 8 & 1 & Vertebrata & 5 & 0.06 & & & 5 & 4 & 0 & 4 & 0 & & & & & \\
\hline 8 & 3 & $\begin{array}{l}\text { Aplodinotus } \\
\text { grunniens }\end{array}$ & 1 & 0.25 & Dorsal spine & \begin{tabular}{|l|} 
Proximal \\
$1 / 2$ \\
\end{tabular} & 2 & 4 & 0 & 4 & 0 & & & & & \\
\hline 8 & 3 & Artiodactyl & 1 & 2.59 & $\begin{array}{l}\text { Lumbar } \\
\text { vertebra } \\
\end{array}$ & $\begin{array}{l}\text { Transverse } \\
\text { process }\end{array}$ & 2 & 4 & 0 & 3 & 0 & & & & & \\
\hline 8 & 3 & Artiodacty! & 12 & 15.65 & Long bone & & 3 & 0 & 0 & 1 & 0 & & & & & Deer-sized \\
\hline 8 & 3 & Artiodactyl & 5 & 1.35 & Tooth & Fragment & 3 & 0 & 0 & 2 & 0 & & & & & \\
\hline 8 & 3 & Artiodactyl & 10 & 5.79 & Long bone & Fragment & 3 & 0 & 0 & 3 & 0 & & & & & Deer-sized \\
\hline 8 & 3 & Artiodactyl & 6 & 4.09 & Long bone & Fragment & 3 & 0 & 1 & 1 & 0 & & & & & \\
\hline 8 & 3 & Mammalia & 1 & 0.32 & & & 2 & 2 & 0 & 2 & 0 & & & & & \\
\hline 8 & 3 & Mammalia & 1 & 0.18 & & & 1 & 2 & 0 & 4 & 0 & & & & & \\
\hline 8 & 3 & Mammalia & 20 & 3.73 & & & 3 & 4 & 0 & 4 & 0 & & & & & \\
\hline 8 & 3 & Mammalia & 9 & 1.44 & & & 2 & 4 & 0 & 4 & 0 & & & & & \\
\hline 8 & 3 & $\begin{array}{l}\text { Odocoileus } \\
\text { virginianus }\end{array}$ & 1 & 10.55 & Tibia & Diaphysis & 3 & 0 & 0 & 1 & 0 & & & 1 & & \\
\hline 8 & 3 & \begin{tabular}{|l|l}
$\begin{array}{l}\text { Odocoileus } \\
\text { virginianus }\end{array}$ \\
\end{tabular} & 1 & 1.17 & Tibia & $\begin{array}{l}\text { Proximal } \\
\text { fragment }\end{array}$ & 3 & 0 & 0 & 3 & 0 & & & & & \\
\hline 8 & 3 & $\begin{array}{l}\text { Odocoileus } \\
\text { virginianus }\end{array}$ & 1 & 1.95 & Tibia & \begin{tabular}{|l|} 
Proximal \\
fragment
\end{tabular} & 3 & 0 & 0 & 3 & 0 & & & & & \\
\hline 8 & 3 & \begin{tabular}{|l|} 
Odocoileus \\
virginianus
\end{tabular} & 1 & 3.35 & Tibia & $\begin{array}{l}\text { Proximal } \\
\text { fragment }\end{array}$ & 3 & 0 & 0 & 1 & 0 & & & & & \\
\hline 8 & 3 & Vertebrata & 6 & 0.16 & & & 5 & 4 & 0 & 4 & 0 & & & & & \\
\hline 8 & 6 & Aves & 3 & 0.04 & & & 5 & 4 & 2 & 4 & 0 & & & & & \\
\hline 8 & 6 & Aves & 1 & 0.02 & Long bone & & 5 & 4 & 2 & 4 & 0 & & & & & Sparrow-sized \\
\hline 8 & 6 & Mammalia & 1 & 0.01 & Tooth & Fragment & 0 & 0 & 1 & 4 & 0 & & & & & \\
\hline 8 & 6 & Mammalia & 1 & 0.28 & & & 0 & 0 & 1 & 4 & 1 & & & & & \\
\hline 8 & 6 & Mammalia & 1 & 0.04 & & & 5 & 4 & 1 & 4 & 0 & & & & & \\
\hline 8 & 6 & Mammalia & 1 & 0.01 & 1 st phalange & Distal $1 / 2$ & 5 & 4 & 0 & 4 & 0 & & & & & Rat-sized \\
\hline 8 & 6 & Osteicthys & 1 & 0.03 & & & 5 & 4 & 1 & 4 & 0 & & & & & \\
\hline 8 & 6 & Rodentia & 1 & 0.01 & 2nd phalange & \begin{tabular}{|l|} 
Complete \\
\end{tabular} & 0 & 0 & 2 & 0 & 0 & & & & & \\
\hline 8 & 6 & Svlvilagus sp. & 1 & 0.01 & Incisor & Fragment & 5 & 4 & 0 & 4 & 0 & & & & & \\
\hline 8 & 6 & Vertebrata & 33 & 0.58 & & & 5 & 4 & 0 & 4 & 0 & & & & & \\
\hline 8 & 6 & Vertebrata & 11 & 0.25 & & & 5 & 4 & 1 & 4 & 0 & & & & & \\
\hline 8 & 6 & Vertebrata & 4 & 0.11 & & & 5 & 4 & 4 & 4 & 0 & & & & & \\
\hline 8 & 6 & Vertebrata & 7 & 0.13 & & & 5 & 4 & 1 & 4 & 0 & & & & & \\
\hline
\end{tabular}


Table F-1. continued

\begin{tabular}{|c|c|c|c|c|c|c|c|c|c|c|c|c|c|c|c|c|}
\hline \multirow[b]{2}{*}{$\mathrm{TU}$} & \multirow[b]{2}{*}{ Lvl } & \multirow[b]{2}{*}{ Taxon } & \multirow[b]{2}{*}{$\vec{\Xi}$} & \multirow[b]{2}{*}{$\begin{array}{l}\overrightarrow{5} \\
\frac{\vec{b}}{5} \\
3\end{array}$} & \multirow[b]{2}{*}{ Element } & \multirow[b]{2}{*}{ Portion } & \multicolumn{5}{|c|}{ Coded Observations } & \multicolumn{4}{|c|}{ Butcher Marks } & \multirow[b]{2}{*}{ Notes } \\
\hline & & & & & & & $\stackrel{\text { 总 }}{\text { 足 }}$ & $\begin{array}{l}\overline{8} \\
\frac{5}{4} \\
\bar{E} \\
3\end{array}$ & 总 & $\begin{array}{l}\text { Ẽ } \\
\text { 总 } \\
\text { 通 }\end{array}$ & 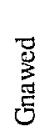 & $\begin{array}{c}\vec{\Xi} \\
. \\
. \vec{E} \\
\vec{E}\end{array}$ & $\frac{}{\circ}$ & 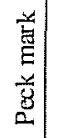 & 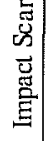 & \\
\hline 8 & 6 & Vertebrata & 14 & 0.13 & & & 5 & 4 & 0 & 4 & 0 & & & & & \\
\hline 8 & 6 & Vertebrata & 3 & 0.07 & & & 5 & 4 & 2 & 4 & 0 & & & & & \\
\hline 8 & 6 & Vertebrata & 12 & 0.31 & & & 5 & 4 & 0 & 4 & 0 & & & & & \\
\hline \multicolumn{4}{|c|}{ Unit total } & 54.82 & & & & & & & & & & & & \\
\hline 9 & 2 & Artiodactyl & 1 & 0.26 & Tooth & Fragment & 3 & 4 & 0 & 4 & 0 & & & & & \\
\hline 9 & 3 & Vertebrata & 2 & 0.03 & & & 5 & 4 & 0 & 4 & 0 & & & & & \\
\hline 9 & 4 & Mammalia & 5 & 2.30 & & & 4 & 4 & 0 & 4 & 0 & & & & & \\
\hline 9 & 4 & Vertebrata & 2 & 1.50 & & & 3 & 2 & 0 & 4 & 0 & & & & & $\begin{array}{l}\text { Evidence of } \\
\text { weathering } \\
\text { largely } \\
\text { destroyed by } \\
\text { pitting }\end{array}$ \\
\hline 9 & 4 & Mammalia & 2 & 0.81 & & & 3 & 4 & 0 & 4 & 0 & & & & & \\
\hline 9 & 4 & Mammalia & 1 & 0.13 & & & 0 & 2 & 0 & 4 & 0 & & & & & \\
\hline 9 & 4 & $\begin{array}{l}\text { Odocoileus } \\
\text { virginianus }\end{array}$ & 1 & 3.60 & Humetus & Fragment & 3 & 4 & 0 & 1 & 0 & & & & & \\
\hline 9 & 5 & Mammalia & 2 & & Long bone & Fragment & 3 & 2 & 0 & 4 & 0 & & & & & $\begin{array}{l}\text { Evidence of } \\
\text { weathering } \\
\text { largely } \\
\text { destroyed by } \\
\text { pitting }\end{array}$ \\
\hline \multicolumn{4}{|c|}{ Unit total } & 8.63 & & & & & & & & & & & & \\
\hline 10 & 2 & Mammalia & 1 & 0.25 & & & 5 & 4 & 2 & 1 & 0 & & & & & \\
\hline 10 & 2 & $\begin{array}{l}\text { Odocoileus } \\
\text { virginianus }\end{array}$ & 1 & 0.69 & $\begin{array}{l}\text { Lower left } \\
\text { deciduous 1st } \\
\text { molar }\end{array}$ & Fragment & 3 & 4 & 0 & 2 & 0 & & & & & Immature \\
\hline 10 & 3 & Mammalia & 1 & 0.38 & & & 3 & 4 & 2 & 4 & 0 & & & & & \\
\hline 10 & 3 & Vertebrata & 1 & 0.01 & & & 5 & 4 & 0 & 4 & 0 & & & & & Rat-sized \\
\hline \multicolumn{4}{|c|}{ Unit total } & 1.33 & & & & & & & & & & & & \\
\hline 11 & 1 & Mammalia & 1 & 0.29 & & & 5 & 4 & 4 & 4 & 0 & & & & & \\
\hline 11 & 1 & Mammalia & 2 & 0.70 & & & 2 & 4 & 0 & 4 & 0 & & & & & \\
\hline 11 & 1 & Mammalia & 1 & 0.45 & & & 2 & 4 & 0 & 4 & 0 & & & & & \\
\hline 11 & 1 & Vertebrata & 1 & 0.60 & & & 3 & 4 & 0 & 4 & 0 & & & & & \\
\hline 11 & 2 & Mammalia & 2 & 0.57 & & & 2 & 4 & 0 & 4 & 0 & 3 & & & & \\
\hline 11 & 2 & Mammalia & 4 & 2.91 & & & 4 & 4 & 0 & 4 & 0 & & & & & \\
\hline 11 & 3 & Mammalia & 5 & 2.41 & & & 1 & 4 & 1 & 1 & 0 & & & & & \\
\hline 11 & 3 & Mammalia & 2 & 0.95 & & & 2 & 4 & 0 & 4 & 0 & & & & & \\
\hline 11 & 3 & Mammalia & 3 & 1.18 & & & 2 & 2 & 0 & 4 & 0 & & & & & \\
\hline 11 & 3 & $\begin{array}{l}\text { Odo coileus } \\
\text { virginianus }\end{array}$ & 1 & 1.76 & 3rd phalange & Complete & 2 & 0 & 0 & 4 & 0 & & & & & \\
\hline 11 & 3 & Vertebrata & 1 & & & & 5 & 4 & 0 & 4 & 0 & & & & & \\
\hline 11 & 4 & Aves & 1 & 0.03 & & & 0 & 4 & 1 & 4 & 0 & & & & & \\
\hline 11 & 4 & Canis sp. & 1 & 0.27 & 1st phalange & Complete & 1 & 0 & 0 & 4 & 0 & & & & & \\
\hline 11 & 4 & Mammalia & 6 & 1.83 & & & 1 & 4 & 1 & 4 & 0 & & & & & \\
\hline 11 & 4 & Mammalia & 7 & 9.75 & Long bone & & 3 & 4 & 0 & 1 & 0 & & & & & Deer-sized \\
\hline 11 & 4 & Mammalia & 1 & 0.10 & Incisor & Fragment & 0 & 4 & 0 & 4 & 0 & & & & & $\begin{array}{l}\text { Large, flat: } \\
\text { possibly } \\
\text { javalina }\end{array}$ \\
\hline 11 & 4 & Mammalia & 30 & 7.89 & & & 3 & 4 & 0 & 4 & 0 & & & & & \\
\hline 11 & 4 & Mammatia & 12 & 5.63 & Long bone & & 2 & 4 & 0 & 4 & 0 & & & & & \\
\hline 11 & 4 & $\begin{array}{l}\text { Odocoileus } \\
\text { virginianus }\end{array}$ & 2 & 0.57 & Molar & Fragment & 1 & 4 & 0 & 4 & 0 & & & & & \\
\hline 11 & 4 & Vertebrata & 6 & 1.42 & & & 2 & 4 & 1 & 4 & 0 & & & & & \\
\hline 11 & 4 & Vertebrata & 5 & 0.10 & & & 5 & 4 & 2 & 4 & 0 & & & & & \\
\hline 11 & 4 & Vertebrata & 147 & 3.81 & & & 5 & 4 & 0 & 4 & 0 & & & & & \\
\hline
\end{tabular}


Table F-1. continued

\begin{tabular}{|c|c|c|c|c|c|c|c|c|c|c|c|c|c|c|c|c|}
\hline \multirow[b]{2}{*}{$\mathrm{TU}$} & \multirow[b]{2}{*}{ Lvl } & \multirow[b]{2}{*}{ Taxon } & \multirow[b]{2}{*}{$\begin{array}{l}\vec{E} \\
\overrightarrow{0}\end{array}$} & \multirow[b]{2}{*}{$\begin{array}{l}\overrightarrow{\vec{a}} \\
\overrightarrow{a b} \\
\vec{b}\end{array}$} & \multirow[b]{2}{*}{ Element } & \multirow[b]{2}{*}{ Portion } & \multicolumn{5}{|c|}{ Coded Observations } & \multicolumn{4}{|c|}{ Bulcher Marks } & \multirow[b]{2}{*}{ Notes } \\
\hline & & & & & & & $\stackrel{\vec{\Xi}}{\stackrel{\Xi}{\Xi}}$ & 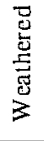 & $\begin{array}{l}\text { 范 } \\
\text { 畐 }\end{array}$ & 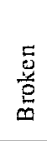 & 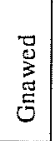 & 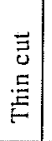 & 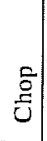 & $\begin{array}{l}\text { 弟 } \\
\text { E } \\
\text { 晜 } \\
0\end{array}$ & 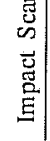 & \\
\hline 11 & 5 & Mammalia & 2 & 3.13 & Long bone & & 2 & 4 & 0 & 4 & 0 & & & & & \\
\hline 11 & 5 & Mammalia & 7 & 3.94 & Long bone & & 3 & 4 & 0 & 4 & 0 & & & & & \\
\hline 11 & 5 & $\begin{array}{l}\text { Odocoileus } \\
\text { virginianus }\end{array}$ & 1 & 10.26 & Astragalus & Complete & 2 & 1 & 0 & 0 & 0 & 1 & & & 1 & \\
\hline 11 & 5 & Vertebrata & 2 & 0.67 & Long bone & & 0 & 4 & 3 & 4 & 0 & & & & & \\
\hline 11 & 5 & Vertebrata & 2 & 0.93 & Long bone & & 0 & 4 & 2 & 4 & 0 & & & & & \\
\hline 11 & 6 & Mammalia & 8 & 2.37 & Long bone & Fragment & 3 & 4 & 0 & 4 & 0 & & & & & \\
\hline 11 & 6 & Mammalia & 2 & 1.37 & Long bone & Fragment & 1 & 4 & 3 & 4 & 0 & & & & & \\
\hline 11 & 7 & Mammalia & 2 & 0.43 & Long bone & Fragment & 2 & 4 & 0 & 1 & 0 & & & & & \\
\hline 11 & 7 & Vertebrata & 3 & 0.06 & & & 5 & 4 & 2 & 4 & 0 & & & & & \\
\hline 11 & 7 & Vertebrata & 9 & 0.24 & & & 5 & 4 & 0 & 4 & 0 & & & & & \\
\hline 11 & 7 & $\begin{array}{l}\text { Odocoileus } \\
\text { virginianus }\end{array}$ & 7 & 27.87 & Scapula & \begin{tabular}{|l} 
Proximal \\
$1 / 3$
\end{tabular} & 3 & 4 & 0 & 2 & 0 & 1 & & & & \\
\hline \multicolumn{4}{|c|}{ Unit total } & 94.49 & & & & & & & & & & & & \\
\hline 14 & 4 & Mammalia & 1 & 3.02 & Long bone & Fragment & 3 & 4 & 0 & 4 & 0 & & & & & Deer-sized \\
\hline \multicolumn{4}{|c|}{ Unit total } & 3.02 & & & & & & & & & & & & \\
\hline 15 & 4 & Vertebrata & 1 & 0.04 & & & 5 & 4 & 4 & 4 & 0 & & & & & \\
\hline 15 & 5 & Mammalia & 2 & 5.73 & Long bone & Fragment & 2 & 4 & 0 & 1 & 0 & & & & & \\
\hline 15 & 5 & Mammalia & 4 & 1.34 & Long bone & Fragment & 2 & 4 & 0 & 4 & 0 & & & & & \\
\hline \multicolumn{4}{|c|}{ Unit total } & 7.11 & & & & & & & & & & & & \\
\hline 17 & 5 & Mammalia & 1 & 0.52 & & & 2 & 4 & 0 & 4 & 0 & & & & & \\
\hline \multicolumn{4}{|c|}{ Unit total } & 0.52 & & & & & & & & & & & & \\
\hline 18 & 5 & \begin{tabular}{|l|}
$\begin{array}{l}\text { Lepus } \\
\text { californicus }\end{array}$ \\
\end{tabular} & 1 & 0.28 & Radius & Fragment & 0 & 0 & 3 & 1 & 0 & 1 & & & & \\
\hline \multicolumn{4}{|c|}{ Unit total } & 0.28 & & & & & & & & & & & & \\
\hline 19 & 2 & Mammalia & 2 & 0.91 & & & 3 & 4 & 0 & 1 & 0 & & & & & Deer-sized \\
\hline 19 & 2 & Vertebrata & 8 & 0.50 & & & 3 & 4 & 0 & 4 & 0 & & & & & \\
\hline 19 & 4 & Mammalia & 2 & 0.33 & & & 3 & 4 & 0 & 4 & 0 & & & & & \\
\hline & & Unit total & & 1.74 & & & & & & & & & & & & \\
\hline 22 & 1 & Vertebrata & 1 & 0.04 & & & 5 & 4 & 4 & 4 & 0 & & & & & \\
\hline 22 & 4 & Mammalia & 3 & 1.57 & & & 3 & 0 & 1 & 2 & 0 & & & & & \\
\hline & & Unit total & & 1.61 & & & & & & & & & & & & \\
\hline 23 & 4 & Mammalia & 1 & 0.14 & & & 3 & 0 & 0 & 4 & 0 & & & & & \\
\hline & & Unit total & & 0.14 & & & & & & & & & & & & \\
\hline $\mathrm{A}$ & 1 & Aves & 1 & 0.19 & & & 1 & 0 & 1 & 3 & 2 & & & & & Sparrow-sized \\
\hline $\mathrm{A}$ & 1 & Aves & 1 & 0.75 & & & 1 & 0 & 1 & 3 & 3 & & & & & Duck-sized \\
\hline $\mathrm{A}$ & 1 & Mammalia & 1 & 0.16 & & & 2 & 0 & 0 & 3 & 0 & & & & & \\
\hline $\mathrm{A}$ & 4 & Artiodactyl & 1 & 0.40 & Tooth & Fragment & 3 & 0 & 4 & 4 & 0 & & & & & \\
\hline $\mathrm{A}$ & 4 & Artiodactyl & 1 & 0.20 & Tooth & Fragment & 2 & 0 & 4 & 4 & 0 & & & & & \\
\hline $\mathrm{A}$ & 4 & Artiodactyl & 1 & 0.39 & Molar & Fragment & 3 & 4 & 0 & 2 & 0 & & & & & \\
\hline $\mathrm{A}$ & 4 & Mammalia & 1 & 0.28 & & & 2 & 4 & 0 & 4 & 3 & & & & & \\
\hline $\mathrm{A}$ & 4 & Mammalia & 1 & 0.07 & & & 2 & 0 & 0 & 3 & 0 & & & & & \\
\hline $\mathrm{A}$ & 4 & Mammalia & 1 & 0.39 & Long bone & & 2 & 0 & 2 & 3 & 0 & & I & & & \\
\hline $\mathrm{A}$ & 4 & Mammalia & 1 & 1.12 & Long bone & Fragment & 3 & 4 & 1 & 3 & 0 & & 1 & & & \\
\hline $\mathrm{A}$ & 4 & Mammalia & 1 & 0.70 & Long bone & Fragment & 0 & 0 & 1 & 3 & 0 & & & & & \\
\hline $\mathrm{A}$ & 4 & $\begin{array}{l}\text { Odocoileus } \\
\text { virginianus }\end{array}$ & 3 & 1.14 & $\begin{array}{l}\text { Upper right } \\
\text { 2nd molar }\end{array}$ & $\begin{array}{l}\text { Mesial 1/2 } \\
\text { of crown }\end{array}$ & 3 & 4 & 0 & 2 & 0 & & & & & \\
\hline $\mathrm{A}$ & 4 & Vertebrata & 2 & 0.36 & & & 1 & 4 & 1 & 4 & 0 & & & & & \\
\hline $\mathrm{A}$ & 4 & Vertebrata & 5 & 0.25 & & & 2 & 4 & 0 & 4 & 0 & & & & & \\
\hline $\mathrm{A}$ & 5 & Mammalia & 1 & 0.54 & Long bone & Fragment & 0 & 0 & 4 & 4 & 0 & & & & & \\
\hline $\mathrm{A}$ & 5 & Mammalia & 1 & 1.01 & Long bone & Fragment & 0 & 0 & 1 & 1 & 0 & 1 & & & & Deer-sized \\
\hline $\mathrm{A}$ & 5 & Mammalia & 1 & 0.98 & Long bone & Fragment & 3 & 4 & 0 & 4 & 0 & & & & & Deer-sized \\
\hline $\mathrm{A}$ & 5 & Mammalia & 1 & 0.85 & Long bone & Fragment & 3 & 4 & 0 & 4 & 0 & & & & & \\
\hline $\mathrm{A}$ & 5 & Vertebrata & 8 & 0.88 & & & 3 & 4 & 0 & 4 & 0 & & & & & \\
\hline
\end{tabular}


Table F-1. continued

\begin{tabular}{|c|c|c|c|c|c|c|c|c|c|c|c|c|c|c|c|c|}
\hline \multirow[b]{2}{*}{ TU } & \multirow[b]{2}{*}{ Lvl } & \multirow[b]{2}{*}{ Taxon } & \multirow[b]{2}{*}{$\vec{\Xi}$} & \multirow[b]{2}{*}{$\begin{array}{l}\overrightarrow{2} \\
\frac{.00}{0} \\
3\end{array}$} & \multirow[b]{2}{*}{ Element } & \multirow[b]{2}{*}{ Portion } & \multicolumn{5}{|c|}{ Coded Observations } & \multicolumn{4}{|c|}{ Butcher Marks } & \multirow[b]{2}{*}{ Notes } \\
\hline & & & & & & & 晜 & 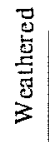 & 总 & $\begin{array}{c}5 \\
0 \\
\text { 总 } \\
0\end{array}$ & $\begin{array}{l}\vec{E} \\
\stackrel{\vec{E}}{E} \\
\text { E. }\end{array}$ & $\begin{array}{c}\vec{\Xi} \\
\vec{U} \\
. \underline{\Xi} \\
\vec{E}\end{array}$ & $\frac{E}{E}$ & 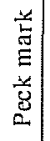 & 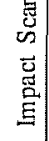 & \\
\hline $\mathrm{A}$ & 7 & Mammalia & 2 & 1.78 & Long bone & Fragment & 3 & 4 & 0 & 4 & 0 & & & & & Deer-sized \\
\hline A & 7 & $\begin{array}{l}\text { Odo coileus } \\
\text { virginianus }\end{array}$ & 1 & 1.75 & $\begin{array}{l}\text { Upper left 2nd } \\
\text { premolar }\end{array}$ & $\begin{array}{l}\text { All but } \\
\text { buccal roots }\end{array}$ & 3 & 4 & 0 & 2 & 0 & & & & & \\
\hline $\mathrm{A}$ & 7 & $\begin{array}{l}\text { Odocoileus } \\
\text { virginianus }\end{array}$ & 1 & 1.76 & $\begin{array}{l}\text { Upper left } \\
\text { deciduous } 3 \text { rd } \\
\text { molar }\end{array}$ & Crown & 3 & 4 & 0 & 2 & 0 & & & & & Immature \\
\hline A & 7 & $\begin{array}{l}\text { Odocoileus } \\
\text { virginianus }\end{array}$ & 1 & 1.88 & $\begin{array}{l}\text { Upper right } \\
1 \text { st molar } \\
\end{array}$ & $\begin{array}{l}\text { All but } \\
\text { buccal roots }\end{array}$ & 3 & 4 & 0 & 2 & 0 & & & & & \\
\hline \multicolumn{4}{|c|}{ Unit total } & 17.83 & & & & & & & & & & & & \\
\hline $\mathrm{B}$ & 6 & Mammalia & 1 & 0.41 & & & 5 & 4 & 4 & 4 & 0 & & & & & \\
\hline $\mathrm{B}$ & 7 & $\begin{array}{l}\text { Odocoileus } \\
\text { virginianus }\end{array}$ & 1 & 2.98 & $\begin{array}{l}\text { Upper left 2nd } \\
\text { molar }\end{array}$ & Crown & 3 & 4 & 0 & 2 & 0 & & & & & \\
\hline $\mathrm{B}$ & 7 & Vertebrata & 1 & 0.23 & & & 3 & 4 & 0 & 4 & 0 & & & & & \\
\hline $\mathrm{B}$ & 7 & Vertebrata & 7 & 1.62 & & & 2 & 4 & 1 & 4 & 0 & & & & & \\
\hline $\mathrm{B}$ & 8 & Mammalia & 1 & 0.42 & Long bone & Fragment & 3 & 4 & 0 & 4 & 0 & & & & & \\
\hline $\mathrm{B}$ & 10 & Vertebrata & 2 & 0.63 & & & 1 & 4 & 2 & 4 & 0 & & & & & \\
\hline $\mathrm{B}$ & 10 & Vertebrata & 1 & 0.22 & & & 2 & 4 & 0 & 4 & 0 & & & & & \\
\hline $\mathrm{B}$ & 11 & Aves & 1 & 0.35 & Long bone & Fragment & 1 & 0 & 0 & 2 & 0 & & & & & Duck-sized \\
\hline B & 11 & Vertebrata & 1 & 0.05 & & & 5 & 4 & 2 & 4 & 0 & & & & & \\
\hline \multicolumn{4}{|c|}{ Unit total } & 6.91 & & & & & & & & & & & & \\
\hline $\mathrm{C}$ & 4 & Artiodactyl & 1 & 0.30 & Tooth & Fragment & 3 & 0 & 0 & 0 & 0 & & & & & Immature \\
\hline $\mathrm{C}$ & 5 & Mammalia & 1 & 0.29 & & & 2 & 0 & 0 & 4 & 0 & & & & & \\
\hline $\mathrm{C}$ & 5 & Vertebrata & 3 & 0.06 & & & 5 & 4 & 0 & 4 & 0 & & & & & \\
\hline $\mathrm{C}$ & 8 & Vertebrata & 1 & 0.42 & & & 3 & 4 & 2 & 4 & 0 & & & & & \\
\hline \multicolumn{4}{|c|}{ Unit total } & 1.07 & & & & & & & & & & & & \\
\hline $\mathrm{D}$ & 3 & Mammalia & 1 & 0.38 & & & 4 & 4 & 0 & 1 & 0 & & & & & \\
\hline $\mathrm{D}$ & 3 & Mammalia & 1 & 0.41 & Tooth & Fragment & 3 & 4 & 0 & 4 & 0 & & & & & \\
\hline D & 5 & Mammalia & 1 & 0.70 & Long bone & Fragment & 1 & 0 & 2 & 1 & 0 & & & & & \\
\hline $\mathrm{D}$ & 6 & Mammalia & 1 & 1.61 & Long bone & Fragment & 1 & 0 & 1 & 3 & 0 & & & & & Deer-sized \\
\hline $\mathrm{D}$ & 7 & Mammalia & 1 & 0.37 & & & 1 & 1 & 4 & 4 & 0 & 1 & & & & \\
\hline $\mathrm{D}$ & 7 & Mammalia & 1 & 0.10 & Long bone & Frag ment & 0 & 2 & 0 & 3 & 0 & & & & & \\
\hline $\mathrm{D}$ & 9 & Vertebrata & 2 & 0.94 & & & 5 & 4 & 4 & 4 & 0 & & & & & \\
\hline \multicolumn{4}{|c|}{ Unit total } & 4.51 & & & & & & & & & & & & \\
\hline $\mathrm{M}$ & $\mathrm{BHT}$ & Mammalia & 1 & 11.60 & Long bone & Fragment & 2 & 2 & 0 & 1 & 0 & & & & & \\
\hline $\mathrm{M}$ & $\mathrm{BHT}$ & Mammalia & 16 & 7.76 & Long bone & Fragment & 2 & 4 & 0 & 1 & 0 & & & & & \\
\hline \multicolumn{4}{|c|}{ Unit total } & 19.36 & & & & & & & & & & & & \\
\hline
\end{tabular}


Table F-2. Faunal Material Recovered From Flotation

\begin{tabular}{|c|c|c|c|c|c|c|c|c|c|c|c|c|c|c|c|c|}
\hline \multirow[b]{2}{*}{ TU } & \multirow[b]{2}{*}{ Lv1 } & \multirow[b]{2}{*}{ Taxon } & \multirow[b]{2}{*}{ 志 } & \multirow[b]{2}{*}{ 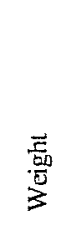 } & \multirow[b]{2}{*}{ Element } & \multirow[b]{2}{*}{ Portion } & \multicolumn{5}{|c|}{ Coded Observations } & \multicolumn{4}{|c|}{ Butcher Marks } & \multirow[b]{2}{*}{ Notes } \\
\hline & & & & & & & 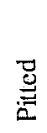 & 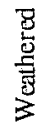 & ${ }_{0}^{\mathbb{E}}$ & $\begin{array}{l}\bar{y} \\
\text { 产 } \\
\text { ตै }\end{array}$ & 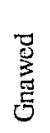 & $\begin{array}{l}\vec{\exists} \\
. \\
. E \\
E \\
E\end{array}$ & 过 & 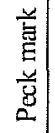 & 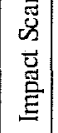 & \\
\hline 9 & 6 & $\begin{array}{l}\text { Lepus } \\
\text { californicus }\end{array}$ & 1 & 0.15 & Femur & Head & 0 & 0 & 1 & 4 & 0 & & & & & \\
\hline 9 & 6 & Mammalia & 1 & 0.35 & & & 3 & 2 & 0 & 4 & 0 & & & & & \\
\hline 9 & 6 & Mammalia & 4 & 0.50 & & & 3 & 4 & 0 & 4 & 0 & & & & & \\
\hline 9 & 6 & Mammalia & 7 & 1.73 & & & 4 & 4 & 0 & 4 & 0 & & & & & \\
\hline 9 & 6 & $\begin{array}{l}\text { Odo coileus } \\
\text { virginianus }\end{array}$ & 1 & 0.63 & Metapodial & $\begin{array}{l}\text { Fragment of } \\
\text { distal end }\end{array}$ & 3 & 0 & 0 & 4 & 0 & & & & & \\
\hline 9 & 6 & Rana sp. & 1 & 0.03 & Radio-ulna & Diaphysis & 5 & 4 & 4 & 4 & 0 & & & & & \\
\hline 9 & 6 & Rodentia & 1 & 0.06 & Cranium & Fragment & 0 & 0 & 1 & 4 & 0 & & & & & \\
\hline 9 & 6 & Rodentia & 1 & 0.01 & Tooth & Fragment & 5 & 4 & 0 & 4 & 0 & & & & & \\
\hline 9 & 6 & Rodentia & 3 & 0.03 & Tooth & Fragment & 5 & 4 & 2 & 4 & 0 & & & & & \\
\hline 9 & 6 & Sciurus sp. & 1 & 0.01 & Incisor & Fragment & 0 & 0 & 0 & 4 & 0 & & & & & \\
\hline 9 & 6 & Verlebrata & 1 & 0.01 & & & 5 & 4 & 1 & 4 & 0 & & & & & \\
\hline 9 & 6 & Vertebrata & 1 & 0.01 & & & 5 & 4 & 1 & 4 & 0 & & & & & \\
\hline 9 & 6 & Vertebrata & 1 & 0.01 & & & 5 & 4 & 2 & 4 & 0 & & & & & \\
\hline 9 & 6 & Vertebrata & 8 & 0.11 & & & 5 & 4 & 0 & 4 & 0 & & & & & \\
\hline 9 & 6 & Vertebrata & 10 & 0.24 & & & 5 & 4 & 4 & 4 & 0 & & & & & \\
\hline 9 & 6 & Vertebrata & 15 & 0.77 & & & 5 & 4 & 2 & 4 & 0 & & & & & \\
\hline 9 & 6 & Vertebrata & 177 & 2.29 & & & 5 & 4 & 0 & 4 & 0 & & & & & \\
\hline 9 & 5 & Aves & 3 & 0.05 & Long bone & Fragment & 0 & 4 & 1 & 4 & 0 & & & & & \\
\hline 9 & 5 & Aves & 4 & 0.16 & Long bone & Fragment & 0 & 4 & 3 & 4 & 0 & & & & & \\
\hline 9 & 5 & Mammalia & 1 & 0.02 & & & 0 & 4 & 0 & 4 & 0 & & & & & Dove-sized \\
\hline 9 & 5 & Mammalia & 1 & 0.07 & Tooth & Fragment & 5 & 4 & 0 & 4 & 0 & & & & & \\
\hline 9 & 5 & Mammalia & 1 & 0.27 & & & 1 & 2 & 0 & 4 & 0 & & & & & Rat-sized \\
\hline 9 & 5 & Mammalia & 1 & 0.23 & & & 1 & 0 & 0 & 4 & 0 & & & & & Deer-sized \\
\hline 9 & 5 & Mammalia & 4 & 1.98 & & & 4 & 0 & 0 & 4 & 0 & & & & & \\
\hline 9 & 5 & Mammalia & 6 & 2.03 & & & 3 & 4 & 0 & 4 & 0 & & & & & \\
\hline 9 & 5 & Mammalia & 10 & 0.96 & & & 5 & 4 & 4 & 4 & 0 & & & & & Rabbit-sized \\
\hline 9 & 5 & Sylvilagus sp. & 1 & 0.06 & Molar & Complete & 5 & 4 & 2 & 4 & 0 & & & & & \\
\hline 9 & 5 & Vertebrata & 1 & 0.02 & & & 2 & 4 & 0 & 4 & 0 & & & & & \\
\hline 9 & 5 & Vertebrata & 1 & 0.01 & & & 5 & 4 & 4 & 4 & 0 & & & & & \\
\hline 9 & 5 & Vertebrata & 1 & & & & 5 & 4 & 2 & 4 & 0 & & & & & \\
\hline 9 & 5 & Vertebrata & 1 & 0.01 & & & 5 & 4 & 4 & 4 & 0 & & & & & \\
\hline 9 & 5 & Vertebrata & 1 & 0.02 & & & 5 & 4 & 4 & 4 & 0 & & & & & \\
\hline 9 & 5 & Vertebrata & 1 & 0.01 & & & 5 & 4 & 2 & 4 & 0 & & & & & Sparrow-sized \\
\hline 9 & 5 & Vertebrata & 1 & 0.65 & & & 1 & 4 & 0 & 4 & 0 & & & & & \\
\hline 9 & 5 & Vertebrata & 1 & 0.30 & & & 3 & 4 & 0 & 4 & 0 & & & & & \\
\hline 9 & 5 & Vertebrata & 2 & 0.03 & & & 5 & 4 & 0 & 4 & 0 & & & & & \\
\hline 9 & 5 & Vertebrata & 2 & 0.04 & & & 5 & 4 & 0 & 4 & 0 & & & & & \\
\hline 9 & 5 & Vertebrata & 2 & 0.05 & & & 5 & 4 & 0 & 4 & 0 & & & & & \\
\hline 9 & 5 & Vertebrata & 3 & 0.03 & & & 5 & 4 & 0 & 4 & 0 & & & & & \\
\hline 9 & 5 & Vertebrata & 4 & 0.07 & & & 5 & 4 & 0 & 4 & 0 & & & & & \\
\hline 9 & 5 & Vertebrata & 4 & 0.08 & & & 5 & 4 & 0 & 4 & 0 & & & & & \\
\hline 9 & 5 & Vertebrata & 4 & & & & 5 & 4 & 4 & 4 & 0 & & & & & \\
\hline 9 & 5 & Vertebrata & 4 & 0.21 & & & 5 & 4 & 4 & 4 & 0 & & & & & \\
\hline 9 & 5 & Vertebrata & 4 & 0.07 & & & 5 & 4 & 0 & 4 & 0 & & & & & \\
\hline 9 & 5 & Vertebrata & 7 & 0.25 & & & 5 & 4 & 1 & 4 & 0 & & & & & \\
\hline 9 & 5 & Vertebrata & 9 & 0.07 & & & 5 & 4 & 0 & 4 & 0 & & & & & \\
\hline 9 & 5 & Vertebrata & 81 & 1.19 & & & 5 & 4 & 0 & 4 & 0 & & & & & \\
\hline 9 & 4 & Mammalia & 1 & 0.07 & & & 5 & 4 & 4 & 4 & 0 & & & & & \\
\hline 9 & 4 & $\begin{array}{l}\begin{array}{l}\text { Sigmodon } \\
\text { hispidus }\end{array} \\
\end{array}$ & 1 & 0.01 & 2nd phalange & Complete & 1 & 0 & 0 & 4 & 0 & & & & & \\
\hline 9 & 4 & Vertebrata & 1 & 0.05 & & & 2 & 2 & 0 & 4 & 0 & & & & & \\
\hline 9 & 4 & Vertebrata & 1 & 0.14 & & & 5 & 4 & 2 & 4 & 0 & & & & & \\
\hline
\end{tabular}


Table F-2. continued

\begin{tabular}{|c|c|c|c|c|c|c|c|c|c|c|c|c|c|c|c|c|}
\hline \multirow[b]{2}{*}{ TU } & \multirow[b]{2}{*}{$\mathrm{Lvl}$} & \multirow[b]{2}{*}{ Taxon } & \multirow[b]{2}{*}{$\overrightarrow{\mathrm{E}}$} & \multirow[b]{2}{*}{$\begin{array}{l}\vec{E} \\
\frac{\vec{D}}{\vec{D}} \\
\overrightarrow{3}\end{array}$} & \multirow[b]{2}{*}{ Element } & \multirow[b]{2}{*}{ Portion } & \multicolumn{5}{|c|}{ Coded Observations } & \multicolumn{4}{|c|}{ Butcher Marks } & \multirow[b]{2}{*}{ Notes } \\
\hline & & & & & & & 异 & 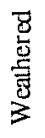 & 鄫 & $\begin{array}{l}\text { 馬 } \\
\text { 产 } \\
\text { 占 }\end{array}$ & 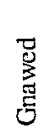 & $\begin{array}{c}\Xi \\
\Xi \\
. E \\
E\end{array}$ & 임 & 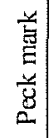 & 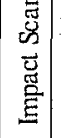 & \\
\hline 9 & 4 & Vertebrata & 5 & 0.10 & & & 5 & 4 & 0 & 4 & 0 & & & & & \\
\hline 9 & 3 & Mammalia & 1 & 0.25 & Tooth & Fragment & 3 & 4 & 0 & 4 & 0 & & & & & \\
\hline 9 & 3 & Mammalia & 1 & 0.18 & & & 5 & 4 & 0 & 4 & 0 & & & & & \\
\hline 9 & 3 & Vertebrata & 1 & 0.01 & & & 1 & 2 & 0 & 1 & 0 & & & & & \\
\hline 9 & 3 & Vertebrata & 2 & 0.01 & & & 5 & 4 & 0 & 4 & 0 & & & & & \\
\hline 9 & 3 & Vertebrata & 2 & 0.44 & & & 4 & 4 & 0 & 4 & 0 & & & & & \\
\hline 9 & 3 & Vertebrata & 2 & 0.05 & & & 5 & 4 & 4 & 4 & 0 & & & & & \\
\hline 9 & 3 & Vertebrata & 3 & 0.04 & & & 1 & 4 & 1 & 4 & 0 & & & & & \\
\hline 9 & 3 & Vertebrata & 3 & 0.07 & & & 5 & 4 & 1 & 4 & 0 & & & & & \\
\hline 9 & 3 & Vertebrata & 4 & 1.55 & & & 4 & 4 & 0 & 4 & 0 & & & & & \\
\hline 9 & 3 & Vertebrata & 4 & 0.06 & & & 5 & 4 & 0 & 4 & 0 & & & & & \\
\hline 9 & 3 & Vertebrata & 4 & 0.14 & & & 2 & 4 & 0 & 4 & 0 & & & & & \\
\hline 9 & 2 & Mammalia & 1 & 0.13 & & & 0 & 4 & 3 & 4 & 0 & & & & & \\
\hline 9 & 2 & Vertebrata & 1 & 0.05 & & & 5 & 4 & 4 & 4 & 0 & & & & & \\
\hline 9 & 2 & Vertebrata & 1 & 0.04 & & & 2 & 1 & 0 & 4 & 0 & & & & & \\
\hline 9 & 2 & Vertebrata & 1 & 0.03 & & & 0 & 4 & 2 & 4 & 0 & & & & & \\
\hline 9 & 2 & Vertebrata & 2 & 0.03 & & & 5 & 4 & 0 & 4 & 0 & & & & & \\
\hline \multicolumn{4}{|c|}{ Unit Total } & 19.47 & & & & & & & & & & & & \\
\hline 8 & 6 & Aves & 1 & 0.01 & Long bone & Fragment & 5 & 4 & 0 & 4 & 0 & & & & & \\
\hline 8 & 6 & Aves & 3 & 0.03 & & & 5 & 4 & 2 & 4 & 0 & & & & & \\
\hline 8 & 6 & Mammalia & 1 & 0.06 & Tooth & Fragment & 5 & 4 & 0 & 4 & 0 & & & & & \\
\hline 8 & 6 & Mammalia & 1 & 0.08 & & & 5 & 4 & 3 & 4 & 0 & & & & & \\
\hline 8 & 6 & Mammalia & 1 & 0.07 & & & 1 & 1 & 0 & 4 & 0 & & & & & \\
\hline 8 & 6 & Mammalia & 2 & 0.17 & & & 2 & 4 & 0 & 4 & 0 & & & & & \\
\hline 8 & 6 & \begin{tabular}{|l|}
$\begin{array}{l}\text { Sigmodon } \\
\text { hispidus }\end{array}$ \\
\end{tabular} & 1 & 0.02 & Molar & Crown & 5 & 4 & 0 & 4 & 0 & & & & & \\
\hline 8 & 6 & Sylvilagus sp. & 1 & 0.02 & Incisor & Fragment & 5 & 4 & 0 & 4 & 0 & & & & & \\
\hline 8 & 6 & Vertebrata & 1 & 0.01 & & & 5 & 4 & 0 & 4 & 0 & & & & & \\
\hline 8 & 6 & Vertebrata & 1 & 0.07 & & & 1 & 0 & 2 & 4 & 0 & & & & & \\
\hline 8 & 6 & Vertebrata & 1 & 0.04 & & & 5 & 4 & 4 & 4 & 0 & & & & & \\
\hline 8 & 6 & Vertebrata & 1 & & & & 5 & 4 & 0 & 4 & 0 & & & & & \\
\hline 8 & 6 & Vertebrata & 1 & 0.01 & & & 5 & 4 & 2 & 4 & 0 & & & & & \\
\hline 8 & 6 & Vertebrata & 2 & 0.05 & & & 5 & 4 & 4 & 4 & 0 & & & & & \\
\hline 8 & 6 & Vertebrata & 2 & 0.04 & & & 5 & 4 & 0 & 4 & 0 & & & & & \\
\hline 8 & 6 & Vertebrata & 4 & 0.17 & & & 5 & 4 & 4 & 4 & 0 & & & & & \\
\hline 8 & 6 & Vertebrata & 4 & 0.06 & & & 5 & 4 & 4 & 4 & 0 & & & & & \\
\hline 8 & 6 & Vertebrata & 5 & 0.04 & & & 5 & 4 & 2 & 4 & 0 & & & & & \\
\hline 8 & 6 & Vertebrata & 7 & 0.08 & & & 5 & 4 & 0 & 4 & 0 & & & & & \\
\hline 8 & 6 & Vertebrata & 8 & 0.55 & & & 5 & 4 & 1 & 4 & 0 & & & & & \\
\hline 8 & 6 & Vertebrata & 9 & 0.24 & & & 5 & 4 & 2 & 4 & 0 & & & & & \\
\hline 8 & 6 & Vertebrata & 13 & 0.16 & & & 5 & 4 & 2 & 4 & 0 & & & & & \\
\hline 8 & 6 & Vertebrata & 14 & 0.25 & & & 5 & 4 & 0 & 4 & 0 & & & & & \\
\hline 8 & 6 & Vertebrata & 17 & 0.27 & & & 5 & 4 & 4 & 4 & 0 & & & & & \\
\hline 8 & 6 & Vertebrata & 25 & 0.25 & & & 5 & 4 & 0 & 4 & 0 & & & & & \\
\hline 8 & 5 & Aves & 1 & 0.03 & & & 0 & 4 & 1 & 4 & 0 & & & & & \\
\hline 8 & 5 & Aves & 1 & 0.01 & & & 0 & 4 & 1 & 4 & 0 & & & & & \\
\hline 8 & 5 & Aves & 1 & 0.03 & Humerus & Distal $1 / 2$ & 5 & 4 & 4 & 4 & 0 & & & & & \\
\hline 8 & 5 & Aves & 1 & 0.03 & & & 5 & 4 & 2 & 4 & 0 & & & & & \\
\hline 8 & 5 & Aves & 3 & 0.04 & & & 5 & 4 & 1 & 4 & 0 & & & & & \\
\hline 8 & 5 & Mammalia & 1 & 0.01 & Tooth & Fragment & 5 & 4 & 2 & 4 & 0 & & & & & \\
\hline 8 & 5 & Mammalia & 1 & 0.05 & & & 5 & 4 & 3 & 4 & 0 & & & & & \\
\hline 8 & 5 & Mammalia & 1 & 0.01 & \begin{tabular}{|l|} 
Tooth \\
\end{tabular} & Fragment & 5 & 4 & 1 & 4 & 0 & & & & & \\
\hline 8 & 5 & Mammalia & 1 & 0.01 & \begin{tabular}{|l|} 
Tooth \\
\end{tabular} & Fragment & 5 & 4 & 2 & 4 & 0 & & & & & \\
\hline 8 & 5 & Mammalia & 2 & 0.30 & & & 5 & 4 & 4 & 4 & 0 & & & & & \\
\hline
\end{tabular}


Table F-2. continued

\begin{tabular}{|c|c|c|c|c|c|c|c|c|c|c|c|c|c|c|c|c|}
\hline \multirow[b]{2}{*}{$\mathrm{TU}$} & \multirow[b]{2}{*}{ Lvl } & \multirow[b]{2}{*}{ Taxon } & \multirow[b]{2}{*}{$\overrightarrow{\bar{\Xi}}$} & \multirow[b]{2}{*}{$\begin{array}{l}\overrightarrow{\vec{D}} \\
\frac{\vec{D}}{\vec{E}} \\
3\end{array}$} & \multirow[b]{2}{*}{ Element } & \multirow[b]{2}{*}{ Portion } & \multicolumn{5}{|c|}{ Coded Observations } & \multicolumn{4}{|c|}{ Butcher Marks } & \multirow[b]{2}{*}{ Notes } \\
\hline & & & & & & & $\stackrel{\vec{e}}{\stackrel{D}{E}}$ & 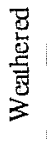 & 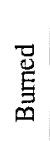 & $\begin{array}{l}\text { E } \\
\text { 总 } \\
\text { p. }\end{array}$ & 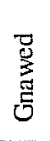 & $\begin{array}{c}\bar{\Xi} \\
\stackrel{\Xi}{\Xi} \\
\stackrel{\Xi}{F}\end{array}$ & 올 & 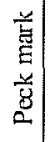 & 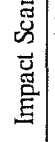 & \\
\hline 8 & 5 & Mammalia & 2 & 0.26 & & & 5 & 4 & 4 & 4 & 0 & & & & & \\
\hline 8 & 5 & Mammalia & 3 & 0.20 & & & 2 & 4 & 0 & 4 & 0 & & & & & \\
\hline 8 & 5 & Mammalia & 3 & 0.50 & & & 3 & 4 & 0 & 4 & 0 & & & & & \\
\hline 8 & 5 & Mammalia & 4 & 0.31 & & & 5 & 4 & 4 & 4 & 0 & & & & & \\
\hline 8 & 5 & Rodentia & 1 & 0.01 & Incisor & Fragment & 5 & 4 & 1 & 4 & 0 & & & & & \\
\hline 8 & 5 & Rodentia & 1 & 0.01 & 2nd phalange & Complete & 5 & 4 & 0 & 4 & 0 & & & & & \\
\hline 8 & 5 & Sylvilagus sp. & 1 & 0.02 & Molar & Complete & 5 & 4 & 1 & 4 & 0 & & & & & \\
\hline 8 & 5 & Sylvilagus sp. & 1 & 0.04 & Incisor & Complete & 0 & 4 & 1 & 4 & 0 & & & & & \\
\hline 8 & 5 & Sylvilagus sp. & 1 & 0.02 & Incisor & Fragment & 5 & 4 & 2 & 4 & 0 & & & & & \\
\hline 8 & 5 & Sylvilagus sp. & 1 & 0.01 & Molar & Fragment & 0 & 0 & 1 & 4 & 0 & & & & & $>$ Sparrow-sized \\
\hline 8 & 5 & Sylvilagus sp. & 1 & 0.01 & 2nd phalange & Fragment & 2 & 4 & 0 & 4 & 0 & & & & & Sparrow-sized \\
\hline 8 & 5 & Vertebrata & 1 & 0.01 & & & 5 & 4 & 0 & 4 & 0 & & & & & \\
\hline 8 & 5 & Vertebrata & 1 & 0.02 & & & 5 & 4 & 2 & 4 & 0 & & & & & \\
\hline 8 & 5 & Vertebrata & 1 & 0.01 & & & 5 & 4 & 0 & 4 & 0 & & & & & \\
\hline 8 & 5 & Vertebrata & 1 & 0.01 & & & 5 & 4 & 0 & 4 & 0 & & & & & \\
\hline 8 & 5 & Vertebrata & 1 & 0.13 & & & 5 & 4 & 4 & 4 & 0 & & & & & \\
\hline 8 & 5 & Vertebrata & 1 & 0.01 & & & 5 & 4 & 2 & 4 & 0 & & & & & \\
\hline 8 & 5 & Vertebrata & 1 & 0.01 & & & 5 & 4 & 0 & 4 & 0 & & & & & \\
\hline 8 & 5 & Vertebrata & 1 & 0.01 & & & 5 & 4 & 4 & 4 & 0 & & & & & \\
\hline 8 & 5 & Vertebrata & 1 & 0.01 & & & 5 & 4 & 0 & 4 & 0 & & & & & \\
\hline 8 & 5 & Vertebrata & 1 & 0.01 & & & 5 & 4 & 2 & 4 & 0 & & & & & \\
\hline 8 & 5 & Vertebrata & 1 & 0.01 & & & 5 & 4 & 0 & 4 & 0 & & & & & Small camivore \\
\hline 8 & 5 & Vertebrata & 1 & 0.04 & & & 3 & 4 & 0 & 4 & 0 & & & & & \\
\hline 8 & 5 & Vertebrata & 1 & 0.01 & & & 5 & 4 & 1 & 4 & 0 & & & & & Mouse-sized \\
\hline 8 & 5 & Vertebrata & 1 & 0.06 & & & 2 & 4 & 0 & 4 & 0 & & & & & \\
\hline 8 & 5 & Vertebrata & 1 & 0.06 & & & 5 & 4 & 4 & 4 & 0 & & & & & \\
\hline 8 & 5 & Vertebrata & 1 & 0.04 & & & 5 & 4 & 0 & 4 & 0 & & & & & \\
\hline 8 & 5 & Vertebrata & 1 & 0.02 & & & 5 & 4 & 0 & 4 & 0 & & & & & \\
\hline 8 & 5 & Vertebrata & 1 & 0.04 & & & 5 & 4 & 4 & 4 & 0 & & & & & \\
\hline 8 & 5 & Vertebrata & 1 & 0.01 & & & 5 & 4 & 3 & 4 & 0 & & & & & \\
\hline 8 & 5 & Vertebrata & 1 & 0.01 & & & 5 & 4 & 2 & 4 & 0 & & & & & \\
\hline 8 & 5 & Vertebrata & 1 & 0.02 & & & 5 & 4 & 2 & 4 & 0 & & & & & \\
\hline 8 & 5 & Vertebrata & 1 & 0.03 & & & 5 & 4 & 0 & 4 & 0 & & & & & \\
\hline 8 & 5 & Vertebrata & 2 & 0.00 & & & 5 & 4 & 0 & 4 & 0 & & & & & \\
\hline 8 & 5 & Vertebrata & 2 & 0.02 & & & 0 & 4 & 0 & 4 & 0 & & & & & \\
\hline 8 & 5 & Vertebrata & 2 & 0.02 & & & 5 & 4 & 4 & 4 & 0 & & & & & \\
\hline 8 & 5 & Vertebrata & 2 & 0.07 & & & 5 & 4 & 0 & 4 & 0 & & & & & \\
\hline 8 & 5 & Vertebrata & 2 & 0.18 & & & 3 & 4 & 0 & 4 & 0 & & & & & \\
\hline 8 & 5 & Vertebrata & 2 & 0.09 & & & 5 & 4 & 0 & 4 & 0 & & & & & \\
\hline 8 & 5 & Vertebrata & 2 & 0.05 & & & 5 & 4 & 2 & 4 & 0 & & & & & \\
\hline 8 & 5 & Vertebrata & 2 & 0.03 & & & 5 & 4 & 0 & 4 & 0 & & & & & \\
\hline 8 & 5 & Vertebrata & 2 & 0.04 & & & 5 & 4 & 2 & 4 & 0 & & & & & \\
\hline 8 & 5 & Vertebrata & 2 & 0.28 & & & 3 & 4 & 0 & 4 & 0 & & & & & \\
\hline 8 & 5 & Vertebrata & 2 & 0.08 & & & 5 & 4 & 1 & 4 & 0 & & & & & \\
\hline 8 & 5 & Vertebrata & 2 & 0.05 & & & 5 & 4 & 2 & 4 & 0 & & & & & \\
\hline 8 & 5 & Vertebrata & 2 & 0.02 & & & 5 & 4 & 4 & 4 & 0 & & & & & \\
\hline 8 & 5 & Vertebrata & 2 & 0.04 & & & 5 & 4 & 1 & 4 & 0 & & & & & \\
\hline 8 & 5 & Vertebrata & 3 & 0.02 & & & 5 & 4 & 2 & 4 & 0 & & & & & \\
\hline 8 & 5 & Vertebrata & 3 & 0.03 & & & 5 & 4 & 0 & 4 & 0 & & & & & \\
\hline 8 & 5 & Vertebrata & 3 & 0.08 & & & 5 & 4 & 0 & 4 & 0 & & & & & \\
\hline 8 & 5 & Vertebrata & 3 & 0.04 & & & 0 & 4 & 2 & 4 & 0 & & & & & \\
\hline 8 & 5 & Vertebrata & 3 & 0.14 & & & 5 & 4 & 1 & 4 & 0 & & & & & \\
\hline 8 & 5 & Vertebrata & 3 & 0.06 & & & 5 & 4 & 1 & 4 & 0 & & & & & \\
\hline 8 & 5 & Vertebrata & 3 & 0.05 & & & 5 & 4 & 0 & 4 & 0 & & & & & \\
\hline
\end{tabular}


Table F-2. continued

\begin{tabular}{|c|c|c|c|c|c|c|c|c|c|c|c|c|c|c|c|c|}
\hline \multirow[b]{2}{*}{ TU } & \multirow[b]{2}{*}{ Lv1 } & \multirow[b]{2}{*}{ Taxon } & \multirow[b]{2}{*}{$\vec{\Xi}$} & \multirow[b]{2}{*}{$\begin{array}{l}\vec{z} \\
\frac{\vec{b}}{0} \\
\overrightarrow{0}\end{array}$} & \multirow[b]{2}{*}{ Element } & \multirow[b]{2}{*}{ Portion } & \multicolumn{5}{|c|}{ Coded Observations } & \multicolumn{4}{|c|}{ Butcher Marks } & \multirow[b]{2}{*}{ Notes } \\
\hline & & & & & & & $\stackrel{\mathscr{B}}{\stackrel{B}{D}}$ & 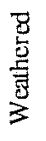 & 总 & $\begin{array}{l}\text { 矛 } \\
\text { 总 } \\
\text { m }\end{array}$ & 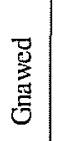 & $\begin{array}{c}\vec{\Xi} \\
. \\
\stackrel{\Xi}{E} \\
ت\end{array}$ & 음 & 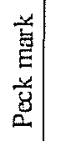 & 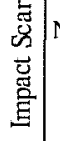 & \\
\hline 8 & 5 & Vertebrata & 3 & 0.15 & & & 5 & 4 & 4 & 4 & 0 & & & & & \\
\hline 8 & 5 & Vertebrata & 3 & 0.03 & & & 5 & 4 & 0 & 4 & 0 & & & & & \\
\hline 8 & 5 & Vertebrata & 3 & 0.10 & & & 5 & 4 & 0 & 4 & 0 & & & & & \\
\hline 8 & 5 & Vertebrata & 4 & 0.09 & & & 5 & 4 & 0 & 4 & 0 & & & & & \\
\hline 8 & 5 & Vertebrata & 4 & 0.02 & & & 5 & 4 & 0 & 4 & 0 & & & & & \\
\hline 8 & 5 & Vertebrata & 4 & 0.07 & & & 5 & 4 & 4 & 4 & 0 & & & & & \\
\hline 8 & 5 & Vertebrata & 4 & 0.06 & & & 5 & 4 & 0 & 4 & 0 & & & & & \\
\hline 8 & 5 & Vertebrata & 4 & 0.12 & & & 5 & 4 & 0 & 4 & 0 & & & & & \\
\hline 8 & 5 & Vertebrala & 4 & 0.04 & & & 5 & 4 & 4 & 4 & 0 & & & & & \\
\hline 8 & 5 & Vertebrata & 5 & 0.13 & & & 5 & 4 & 0 & 4 & 0 & & & & & \\
\hline 8 & 5 & Vertebrata & 5 & 0.08 & & & 5 & 4 & 0 & 4 & 0 & & & & & \\
\hline 8 & 5 & Vertebrata & 7 & 0.09 & & & 5 & 4 & 0 & 4 & 0 & & & & & \\
\hline 8 & 5 & Vertebrata & 7 & 0.63 & & & 5 & 4 & 4 & 4 & 0 & & & & & \\
\hline 8 & 5 & Vertebrata & 8 & 0.08 & & & 5 & 4 & 0 & 4 & 0 & & & & & \\
\hline 8 & 5 & Vertebrata & 10 & 0.16 & & & 5 & 4 & 0 & 4 & 0 & & & & & \\
\hline 8 & 5 & Vertebrata & 11 & 0.30 & & & 5 & 4 & 0 & 4 & 0 & & & & & \\
\hline 8 & 5 & Vertebrata & 26 & 0.24 & & & 5 & 4 & 0 & 4 & 0 & & & & & \\
\hline 8 & 4 & Mammalia & 1 & 0.01 & Tooth & Fragment & 5 & 4 & 0 & 4 & 0 & & & & & \\
\hline 8 & 4 & Vertebrata & 2 & 0.01 & & & 5 & 4 & 4 & 4 & 0 & & & & & \\
\hline 8 & 4 & Vertebrata & 3 & 0.03 & & & 5 & 4 & 1 & 4 & 0 & & & & & \\
\hline 8 & 4 & Vertebrata & 18 & 0.17 & & & 5 & 4 & 0 & 4 & 0 & & & & & \\
\hline 8 & 4 & Vertebrata & 1 & 0.07 & & & 5 & 4 & 4 & 4 & 0 & & & & & \\
\hline 8 & 3 & Mammalia & 1 & 0.20 & & & 5 & 4 & 2 & 4 & 0 & & & & & \\
\hline 8 & 3 & Vertebrata & 1 & 0.09 & & & 5 & 4 & 4 & 4 & 0 & & & & & \\
\hline 8 & 3 & Vertebrata & 1 & 0.02 & & & 5 & 4 & 1 & 4 & 0 & & & & & \\
\hline 8 & 3 & Vertebrata & 2 & 0.06 & & & 5 & 4 & 0 & 4 & 0 & & & & & \\
\hline 8 & 1 & Vertebrata & 1 & 0.01 & & & 5 & 4 & 2 & 4 & 0 & & & & & \\
\hline 8 & 1 & \begin{tabular}{|l} 
Vertebrata \\
\end{tabular} & 1 & 0.01 & & & 5 & 4 & 0 & 4 & 0 & & & & & \\
\hline 8 & 1 & Vertebrata & 1 & 0.01 & & & 5 & 4 & 0 & 4 & 0 & & & & & \\
\hline 8 & 1 & Vertebrata & 1 & 0.01 & & & 5 & 4 & 4 & 4 & 0 & & & & & \\
\hline 8 & 1 & Vertebrata & 2 & 0.14 & & & 3 & 4 & 0 & 4 & 0 & & & & & \\
\hline 8 & 1 & Vertebrata & 2 & 0.01 & & & 5 & 4 & 0 & 4 & 0 & & & & & \\
\hline 8 & 1 & Vertebrata & 3 & 0.07 & & & 5 & 4 & 4 & 4 & 0 & & & & & \\
\hline 8 & 1 & Vertebrata & 3 & 0.08 & & & 5 & 4 & 0 & 4 & 0 & & & & & \\
\hline \multicolumn{4}{|c|}{ Unit Total } & 10.02 & & & & & & & & & & & & \\
\hline 7 & 6 & Aves & 1 & 0.01 & Long bone & Fragment & 5 & 4 & 2 & 4 & 0 & & & & & \\
\hline 7 & 6 & Mammalia & 1 & 0.03 & Rib & Fragment & 0 & 4 & 1 & 4 & 0 & & & & & \\
\hline 7 & 6 & Mammalia & 1 & 0.06 & Tooth & \begin{tabular}{|l|} 
Fragment \\
\end{tabular} & 0 & 4 & 2 & 4 & 0 & & & & & \\
\hline 7 & 6 & Vertebrata & 1 & 0.02 & & & 5 & 4 & 2 & 4 & 0 & & & & & \\
\hline 7 & 6 & Vertebrata & 1 & 0.04 & & & 5 & 4 & 3 & 4 & 0 & & & & & \\
\hline 7 & 6 & Vertebrata & 2 & 0.03 & & & 5 & 4 & 1 & 4 & 0 & & & & & \\
\hline 7 & 6 & Vertebrata & 5 & 0.06 & & & 5 & 4 & 1 & 4 & 0 & & & & & \\
\hline 7 & 5 & Mammalia & 1 & 0.32 & & & 3 & 4 & 0 & 4 & 0 & & & & & \\
\hline 7 & 5 & Mammalia & 6 & 3.69 & Long bone & Fragment & 1 & 4 & 0 & 1 & 0 & & & & & \\
\hline 7 & 5 & Mammalia & 1 & 0.51 & & & 2 & 4 & 1 & 1 & 0 & & & & & \\
\hline 7 & 4 & Mammalia & 1 & 0.01 & Incisor & Fragment & 3 & 4 & 0 & 4 & 0 & & & & & \\
\hline 7 & 4 & Vertebrata & 1 & 1.16 & & & 1 & 4 & 4 & 4 & 0 & & & & & \\
\hline 7 & 4 & Vertebrata & 2 & 0.10 & & & 5 & 4 & 2 & 4 & 0 & & & & & \\
\hline 7 & 4 & Vertebrata & 2 & 0.06 & & & 5 & 4 & 1 & 4 & 0 & & & & & \\
\hline 7 & 4 & Vertebrata & 2 & 0.02 & & & 5 & 4 & 0 & 4 & 0 & & & & & Sparrow-sized \\
\hline 7 & 4 & Vertebrata & 3 & 0.02 & & & 5 & 4 & 2 & 4 & 0 & & & & & Rat-sized \\
\hline 7 & 4 & Vertebrata & 8 & 0.09 & & & 5 & 4 & 0 & 4 & 0 & & & & & Small camivore \\
\hline 7 & 3 & $\begin{array}{l}\text { cf. Sigmodon } \\
\text { hispidus }\end{array}$ & 1 & 0.03 & 1st phalange & Distal 3/4 & 0 & 4 & 1 & 4 & 0 & & & & & \\
\hline
\end{tabular}


Table F-2. continued

\begin{tabular}{|c|c|c|c|c|c|c|c|c|c|c|c|c|c|c|c|c|}
\hline \multirow[b]{2}{*}{ TU } & \multirow[b]{2}{*}{ Lvl } & \multirow[b]{2}{*}{ Taxon } & \multirow[b]{2}{*}{ 豆 } & \multirow[b]{2}{*}{$\begin{array}{l}\vec{E} \\
\vec{D} \\
\vec{B} \\
3\end{array}$} & \multirow[b]{2}{*}{ Element } & \multirow[b]{2}{*}{ Portion } & \multicolumn{5}{|c|}{ Coded Observations } & \multicolumn{4}{|c|}{ Butcher Marks } & \multirow[b]{2}{*}{ Notes } \\
\hline & & & & & & & $\stackrel{\text { 异 }}{:}$ & 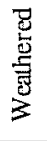 & $\underset{\Xi}{\mathscr{D}}$ & $\begin{array}{l}\bar{E} \\
\text { D } \\
\text { D. }\end{array}$ & 导 & 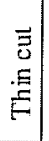 & 总 & 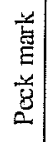 & 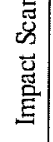 & \\
\hline 7 & 3 & Vertebrata & 1 & 0.06 & & & 0 & 4 & 3 & 4 & 0 & & & & & \\
\hline 7 & 3 & Vertebrata & 1 & 0.02 & & & 5 & 4 & 2 & 4 & 0 & & & & & \\
\hline 7 & 3 & Vertebrata & 1 & 0.03 & & & 0 & 4 & 2 & 4 & 0 & & & & & \\
\hline 7 & 1 & Mammalia & 1 & 0.07 & & & 3 & 4 & 0 & 4 & 0 & & & & & \\
\hline 7 & 1 & Vertebrata & 1 & 0.01 & & & 5 & 4 & 0 & 4 & 0 & & & & & \\
\hline \multicolumn{4}{|c|}{ Unit Total } & 6.45 & & & & & & & & & & & & \\
\hline 6 & 6 & Vertebrata & 1 & 0.01 & & & 2 & 4 & 0 & 4 & 0 & & & & & Mouse-sized \\
\hline \multicolumn{4}{|c|}{ Unit Total } & 0.01 & & & & & & & & & & & & \\
\hline 5 & 4 & Vertebrata & 1 & 0.04 & & & 5 & 4 & 0 & 4 & 0 & & & & & \\
\hline 5 & 2 & Vertebrata & 1 & 0.01 & & & 5 & 4 & 0 & 4 & 0 & & & & & \\
\hline 5 & 2 & Vertebrata & 1 & 0.01 & & & 5 & 4 & 4 & 4 & 0 & & & & & \\
\hline 5 & 2 & Vertebrata & 2 & 0.02 & & & 5 & 4 & 0 & 4 & 0 & & & & & \\
\hline 5 & 1 & Vertebrata & 1 & 0.02 & & & 1 & 4 & 0 & 4 & 0 & & & & & \\
\hline \multicolumn{4}{|c|}{ Unit Total } & 1.00 & & & & & & & & & & & & \\
\hline 4 & 9 & Vertebrata & 1 & 0.04 & & & 5 & 4 & 3 & 4 & 0 & & & & & \\
\hline 4 & 8 & \begin{tabular}{|l|} 
Vertebrata \\
\end{tabular} & 3 & 0.06 & & & 5 & 4 & 0 & 4 & 0 & & & & & \\
\hline 4 & 7 & Vertebrata & 2 & 0.05 & & & 5 & 4 & 0 & 4 & 0 & & & & & \\
\hline 4 & 6 & Vertebrata & 1 & 0.06 & & & 2 & 4 & 0 & 4 & 0 & & & & & \\
\hline 4 & 6 & Vertebrata & 1 & 0.04 & & & 2 & 4 & 0 & 4 & 0 & & & & & \\
\hline 4 & 6 & Vertebrata & 1 & 0.07 & & & 5 & 4 & 2 & 4 & 0 & & & & & \\
\hline 4 & 6 & \begin{tabular}{|l|} 
Vertebrata \\
\end{tabular} & 2 & 0.03 & & & 5 & 4 & 4 & 4 & 0 & & & & & \\
\hline 4 & 6 & Vertebrala & 2 & 0.03 & & & 5 & 4 & 0 & 4 & 0 & & & & & \\
\hline 4 & 5 & Mammalia & 1 & 0.27 & & & 5 & 4 & 4 & 4 & 0 & & & & & \\
\hline 4 & 5 & Mammalia & 2 & 0.31 & & & 1 & 4 & 1 & 4 & 0 & & & & & \\
\hline 4 & 5 & Mammalia & 1 & 0.14 & Tooth & Fragment & 3 & 4 & 0 & 4 & 0 & & & & & \\
\hline 4 & 5 & Mammalia & 1 & 0.53 & & & 3 & 4 & 0 & 4 & 0 & & & & & \\
\hline 4 & 5 & Mammalia & 1 & 0.14 & Tooth & Fragment & 3 & 4 & 0 & 4 & 0 & & & & & \\
\hline 4 & 5 & Mammalia & 1 & 0.53 & & & 3 & 4 & 0 & 4 & 0 & & & & & \\
\hline 4 & 5 & Vertebrata & 1 & 0.05 & & & 0 & 4 & 0 & 4 & 0 & & & & & \\
\hline 4 & 5 & Vertebrata & 1 & 0.09 & & & 5 & 4 & 2 & 4 & 0 & & & & & \\
\hline 4 & 5 & Vertebrata & 1 & 0.04 & & & 2 & 4 & 1 & 4 & 0 & & & & & \\
\hline 4 & 5 & Vertebrata & 1 & 0.05 & & & 5 & 2 & 0 & 4 & 0 & & & & & \\
\hline 4 & 5 & Vertebrata & 1 & 0.03 & & & 5 & 4 & 2 & 4 & 0 & & & & & \\
\hline 4 & 5 & Vertebrata & 1 & 0.05 & & & 0 & 4 & 0 & 4 & 0 & & & & & \\
\hline 4 & 5 & Vertebrata & 1 & 0.09 & & & 5 & 4 & 2 & 4 & 0 & & & & & \\
\hline 4 & 5 & Vertebrata & 1 & 0.04 & & & 2 & 4 & 1 & 4 & 0 & & & & & \\
\hline 4 & 5 & Vertebrata & 1 & & & & 5 & 4 & 0 & 4 & 0 & & & & & \\
\hline 4 & 5 & Vertebrata & 1 & 0.05 & & & 5 & 2 & 0 & 4 & 0 & & & & & \\
\hline 4 & 5 & Vertebrata & 1 & 0.03 & & & 5 & 4 & 2 & 4 & 0 & & & & & \\
\hline 4 & 5 & Vertebrata & 2 & 0.29 & & & 3 & 4 & 0 & 4 & 0 & & & & & \\
\hline 4 & 5 & Vertebrata & 2 & 0.29 & & & 3 & 4 & 0 & 4 & 0 & & & & & \\
\hline 4 & 5 & Vertebrata & 4 & 0.15 & & & 1 & 4 & 1 & 4 & 0 & & & & & \\
\hline 4 & 5 & Vertebrata & 4 & 0.03 & & & 5 & 4 & 0 & 4 & 0 & & & & & \\
\hline 4 & 5 & Vertebrata & 4 & 0.15 & & & 1 & 4 & 1 & 4 & 0 & & & & & \\
\hline 4 & 5 & Vertebrata & 4 & 0.03 & & & 5 & 4 & 0 & 4 & 0 & & & & & \\
\hline 4 & 5 & Vertebrata & 5 & 0.08 & & & 5 & 4 & 0 & 4 & 0 & & & & & \\
\hline 4 & 4 & Aves & 1 & 0.01 & & & 0 & 4 & 1 & 4 & 0 & & & & & Rat-sized \\
\hline 4 & 4 & Aves & 1 & 0.01 & & & 5 & 4 & 1 & 4 & 0 & & & & & \\
\hline 4 & 4 & Aves & 1 & 0.03 & & & 1 & 4 & 1 & 4 & 0 & & & & & \\
\hline 4 & 4 & Aves & 1 & 0.03 & & & 1 & 4 & 1 & 4 & 0 & & & & & \\
\hline 4 & 4 & Aves & 1 & 0.04 & Long bone & Fragment & 0 & 4 & 1 & 4 & 0 & & & & & \\
\hline 4 & 4 & Aves & 1 & 0.02 & & & 0 & 4 & 2 & 4 & 0 & & & & & \\
\hline 4 & 4 & Mammalia & 1 & 0.02 & Tooth & Fragment & 2 & 4 & 0 & 4 & 0 & & & & & \\
\hline 4 & 4 & Mammalia & 1 & 0.16 & & & 3 & 4 & 0 & 4 & 0 & & & & & \\
\hline
\end{tabular}


Table F-2. continued

\begin{tabular}{|c|c|c|c|c|c|c|c|c|c|c|c|c|c|c|c|c|}
\hline \multirow[b]{2}{*}{ TU } & \multirow[b]{2}{*}{ Lvl } & \multirow[b]{2}{*}{ Taxon } & \multirow[b]{2}{*}{ 晜 } & \multirow[b]{2}{*}{ 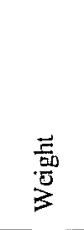 } & \multirow[b]{2}{*}{ Element } & \multirow[b]{2}{*}{ Portion } & \multicolumn{5}{|c|}{ Coded Observations } & \multicolumn{4}{|c|}{ Butcher Marks } & \multirow[b]{2}{*}{ Notes } \\
\hline & & & & & & & $\stackrel{\vec{Z}}{\vec{Z}}$ & $\begin{array}{l}\bar{d} \\
\frac{0}{5} \\
\bar{\Xi} \\
\vec{J} \\
3\end{array}$ & $\begin{array}{l}\text { 邑 } \\
\text { 目 }\end{array}$ & $\begin{array}{c}5 \\
5 \\
\text { 总 } \\
\text { क }\end{array}$ & $\sum_{\substack{0 \\
0}}^{D}$ & $\begin{array}{c}\vec{\Xi} \\
\vec{\Xi} \\
\vec{\Xi} \\
\vec{E}\end{array}$ & 它 & 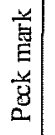 & $\begin{array}{c}\bar{y} \\
\vec{U} \\
\overrightarrow{\mathrm{Z}} \\
\vec{E} \\
\underline{E}\end{array}$ & \\
\hline 4 & 4 & Mammalia & 1 & 0.08 & & & 0 & 1 & 0 & 4 & 0 & & & & & Bison/cow sized \\
\hline 4 & 4 & Mammalia & 3 & 0.21 & Tooth & Fragment & 0 & 3 & 0 & 4 & 0 & & & & & \\
\hline 4 & 4 & Rodentia & 1 & 0.04 & Tibia & $\begin{array}{l}\text { Proximal } \\
1 / 3\end{array}$ & 5 & 4 & 2 & 4 & 0 & & & & & Immature \\
\hline 4 & 4 & Rodentia & 1 & 0.04 & Tibia & \begin{tabular}{|l|} 
Proximal \\
$1 / 3$ \\
\end{tabular} & 0 & 4 & 2 & 4 & 0 & & & & & Immature \\
\hline 4 & 4 & Vertebrata & 1 & 0.02 & & & 5 & 3 & 0 & 4 & 0 & & & & & \\
\hline 4 & 4 & Vertebrata & 1 & 0.03 & & & 1 & 4 & 0 & 4 & 0 & & & & & \\
\hline 4 & 4 & Vertebrata & 1 & 0.01 & & & 5 & 4 & 1 & 4 & 0 & & & & & \\
\hline 4 & 4 & Vertebrata & 1 & 0.01 & & & 5 & 4 & 1 & 4 & 0 & & & & & \\
\hline 4 & 4 & Vertebrata & 1 & 0.02 & & & 5 & 4 & 4 & 4 & 0 & & & & & \\
\hline 4 & 4 & Vertebrata & 1 & 0.05 & & & 5 & 4 & 2 & 4 & 0 & & & & & \\
\hline 4 & 4 & Vertebrata & 1 & 0.02 & & & 5 & 4 & 4 & 4 & 0 & & & & & \\
\hline 4 & 4 & Vertebrata & 2 & 0.11 & & & 5 & 2 & 0 & 4 & 0 & & & & & \\
\hline 4 & 4 & Vertebrata & 2 & 0.02 & & & 5 & 4 & 4 & 4 & 0 & & & & & \\
\hline 4 & 4 & Vertebrata & 2 & 0.02 & & & 5 & 4 & 4 & 4 & 0 & & & & & \\
\hline 4 & 4 & Vertebrata & 2 & 0.19 & & & 3 & 4 & 0 & 4 & 0 & & & & & \\
\hline 4 & 4 & Vertebrata & 3 & 0.06 & & & 5 & 4 & 0 & 4 & 0 & & & & & \\
\hline 4 & 4 & Vertebrata & 3 & 0.11 & & & 0 & 4 & 0 & 4 & 0 & & & & & \\
\hline 4 & 4 & Vertebrata & 3 & 0.23 & & & 0 & 4 & 0 & 4 & 0 & & & & & \\
\hline 4 & 4 & Vertebrata & 3 & 0.37 & & & 2 & 4 & 0 & 4 & 0 & & & & & \\
\hline 4 & 4 & Vertebrata & 3 & 0.14 & & & 2 & 4 & 0 & 4 & 0 & & & & & \\
\hline 4 & 4 & Vertebrata & 3 & 0.14 & & & 2 & 4 & 0 & 4 & 0 & & & & & \\
\hline 4 & 4 & Vertebrata & 3 & 0.08 & & & 5 & 4 & 2 & 4 & 0 & & & & & \\
\hline 4 & 4 & Vertebrata & 4 & 0.13 & & & 5 & 4 & 2 & 4 & 0 & & & & & \\
\hline 4 & 4 & Vertebrata & 5 & 0.44 & & & 3 & 4 & 0 & 4 & 0 & & & & & \\
\hline 4 & 4 & Vertebrata & 5 & 0.23 & & & 5 & 4 & 4 & 4 & 0 & & & & & \\
\hline 4 & 4 & Vertebrata & 6 & 0.28 & & & 0 & 4 & 1 & 4 & 0 & & & & & \\
\hline 4 & 4 & Vertebrata & 6 & 0.51 & & & 2 & 4 & 0 & 4 & 0 & & & & & \\
\hline 4 & 4 & Vertebrata & 6 & 0.41 & & & 1 & 4 & 0 & 4 & 0 & & & & & \\
\hline 4 & 4 & Vertebrata & 6 & 0.36 & & & 3 & 4 & 0 & 4 & 0 & & & & & \\
\hline 4 & 4 & Vertebrata & 6 & 0.36 & & & 5 & 3 & 0 & 4 & 0 & & & & & \\
\hline 4 & 4 & Vertebrata & 7 & 0.35 & & & 5 & 4 & 4 & 4 & 0 & & & & & \\
\hline 4 & 4 & Vertebrata & 8 & 0.10 & & & 5 & 4 & 0 & 4 & 0 & & & & & \\
\hline 4 & 4 & Vertebrata & 9 & 0.21 & & & 0 & 4 & 1 & 4 & 0 & & & & & \\
\hline 4 & 4 & Vertebrata & 10 & 0.39 & & & 5 & 4 & 1 & 4 & 0 & & & & & \\
\hline 4 & 4 & Vertebrata & 13 & 0.16 & & & 5 & 4 & 0 & 4 & 0 & & & & & \\
\hline 4 & 4 & Vertebrata & 16 & 1.64 & & & 3 & 4 & 0 & 4 & 0 & & & & & \\
\hline 4 & 4 & Vertebrala & 19 & 0.43 & & & 5 & 4 & 0 & 4 & 0 & & & & & \\
\hline 4 & 4 & Vertebrata & 48 & 0.92 & & & 5 & 4 & 0 & 4 & 0 & & & & & \\
\hline 4 & 4 & Vertebrata & 56 & 0.93 & & & 5 & 4 & 0 & 4 & 0 & & & & & \\
\hline 4 & 3 & Mammalia & 4 & 0.30 & Tooth & Fragment & 2 & 4 & 0 & 2 & 0 & & & & & \\
\hline 4 & 3 & Vertebrata & 1 & 0.13 & & & 0 & 4 & 2 & 4 & 0 & & & & & \\
\hline 4 & 3 & Vertebrata & 1 & 0.01 & & & 5 & 4 & 4 & 4 & 0 & & & & & \\
\hline 4 & 3 & Mammalia & 1 & 0.06 & Tooth & Fragment & 3 & 4 & 0 & 4 & 0 & & & & & \\
\hline 4 & 3 & Mammalia & 1 & 0.18 & Long bone & Fragment & 1 & 4 & 0 & 1 & 0 & & & & & \\
\hline 4 & 3 & Mammalia & 1 & 0.18 & Long bone & Fragment & 1 & 4 & 0 & 1 & 0 & & & & & \\
\hline 4 & 3 & Vertebrata & 3 & 0.06 & & & 5 & 4 & 0 & 4 & 0 & & & & & \\
\hline 4 & 3 & \begin{tabular}{|l|} 
Vertebrata \\
\end{tabular} & 3 & 0.06 & & & 5 & 4 & 0 & 4 & 1 & & & & & \\
\hline 4 & 3 & \begin{tabular}{|l} 
Vertebrata \\
\end{tabular} & 24 & 0.33 & & & 5 & 4 & 0 & 4 & 0 & & & & & \\
\hline 4 & 1 & Mammalia & 2 & 0.01 & Tooth & Fragment & 5 & 4 & 0 & 4 & 0 & & & & & \\
\hline \multicolumn{4}{|c|}{ Unit Total } & 15.33 & & & & & & & & & & & & \\
\hline 3 & 3 & Vertebrata & 5 & 0.07 & & & 5 & 4 & 0 & 4 & 0 & & & & & \\
\hline \multicolumn{4}{|c|}{ Unit Total } & 0.07 & & & & & & & & & & & & \\
\hline
\end{tabular}


Table F-2. continued

\begin{tabular}{|c|c|c|c|c|c|c|c|c|c|c|c|c|c|c|c|c|}
\hline \multirow[b]{2}{*}{ TU } & \multirow[b]{2}{*}{ Lvil } & \multirow[b]{2}{*}{ Taxon } & \multirow[b]{2}{*}{$\overrightarrow{\mathrm{E}}$} & \multirow[b]{2}{*}{ 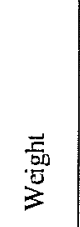 } & \multirow[b]{2}{*}{ Element } & \multirow[b]{2}{*}{ Portion } & \multicolumn{5}{|c|}{ Coded Observations } & \multicolumn{4}{|c|}{ Butcher Marks } & \multirow[b]{2}{*}{ Notes } \\
\hline & & & & & & & 总 & 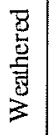 & 总 & $\begin{array}{l}\text { E. } \\
\text { 总 } \\
\text { D. }\end{array}$ & 异 & 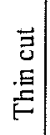 & 물 & 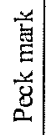 & 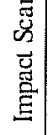 & \\
\hline 2 & 2 & Vertebrata & 4 & 0.05 & & & 5 & 4 & 0 & 4 & 0 & & & & & \\
\hline 2 & 1 & Vertebrata & 3 & 0.05 & & & 1 & 1 & 1 & 1 & 0 & & & & & \\
\hline \multicolumn{4}{|c|}{ Unit Total } & 0.10 & & & & & & & & & & & & \\
\hline 13 & 5 & Mammalia & 1 & 0.27 & Long bone & Fragment & 1 & 0 & 1 & 1 & 0 & & & & & \\
\hline 13 & 5 & Mammalia & 2 & 0.20 & Long bone & Fragment & 5 & 4 & 2 & 4 & 0 & & & & & \\
\hline 13 & 5 & Sylvilagus sp. & 1 & 0.02 & 1st phalange & Distal $1 / 2$ & 0 & 0 & 4 & 1 & 0 & & & & & \\
\hline 13 & 5 & Vertebrata & 1 & 0.01 & & & 5 & 4 & 1 & 4 & 0 & & & & & \\
\hline 13 & 5 & Vertebrata & 9 & 0.10 & & & 5 & 4 & 0 & 4 & 0 & & & & & \\
\hline \multicolumn{4}{|c|}{ Unit Total } & 0.60 & & & & & & & & & & & & \\
\hline 12 & 4 & Vertebrata & 1 & 0.01 & & & 5 & 4 & 4 & 4 & 0 & & & & & \\
\hline 12 & 4 & Vertebrala & 6 & 0.04 & & & 5 & 4 & 0 & 4 & 0 & & & & & \\
\hline 12 & 2 & Vertebrata & 1 & 0.02 & & & 5 & 4 & 2 & 4 & 0 & & & & & \\
\hline 12 & 2 & Vertebrata & 1 & 0.01 & & & 5 & 4 & 0 & 4 & 0 & & & & & \\
\hline 12 & 2 & Vertebrata & 1 & 0.16 & & & 5 & 4 & 3 & 4 & 0 & & & & & \\
\hline 12 & 2 & Vertebrata & 3 & 0.03 & & & 5 & 4 & 0 & 4 & 0 & & & & & \\
\hline 12 & 2 & Vertebrata & 5 & 0.04 & & & 5 & 4 & 4 & 4 & 0 & & & & & \\
\hline \multicolumn{4}{|c|}{ Unit Total } & 0.31 & & & & & & & & & & & & \\
\hline 11 & 7 & Mammalia & 1 & 0.09 & Long bone & Fragment & 5 & 4 & 0 & 4 & 0 & & & & & Sparrow-size \\
\hline 11 & 7 & Vertebrata & 1 & 0.04 & & & 5 & 4 & 2 & 4 & 0 & & & & & Sparrow-sized \\
\hline 11 & 7 & Vertebrata & 1 & 0.02 & & & 5 & 4 & 4 & 4 & 0 & & & & & \\
\hline 11 & 7 & Vertebrata & 2 & 0.04 & & & 5 & 4 & 2 & 4 & 0 & & & & & \\
\hline 11 & 7 & Vertebrata & 3 & 0.03 & & & 5 & 4 & 4 & 4 & 0 & & & & & Rodent-sized \\
\hline 11 & 7 & Vertebrata & 15 & 0.26 & & & 5 & 4 & 0 & 4 & 0 & & & & & \\
\hline 11 & 6 & Aves & 1 & 0.06 & Long bone & Fragment & 0 & 4 & 3 & 1 & 0 & & & & & \\
\hline 11 & 6 & Mammalia & 1 & 0.12 & & & 0 & 0 & 1 & 1 & 0 & & & & & \\
\hline 11 & 6 & Mammalia & 2 & 0.40 & Long bone & Fragment & 2 & 4 & 0 & 4 & 0 & & & & & \\
\hline 11 & 6 & Vertebrata & 1 & 0.12 & & & 5 & 4 & 1 & 4 & 0 & & & & & \\
\hline 11 & 6 & Vertebrata & 1 & 0.01 & & & 5 & 4 & 1 & 4 & 0 & & & & & \\
\hline 11 & 6 & Vertebrata & 1 & 0.11 & & & 3 & 4 & 0 & 4 & 0 & & & & & \\
\hline 11 & 6 & Vertebrata & 2 & 0.05 & & & 5 & 4 & 0 & 4 & 0 & & & & & \\
\hline 11 & 6 & Vertebrata & 6 & 0.10 & & & 5 & 4 & 0 & 4 & 0 & & & & & \\
\hline 11 & 5 & Aves & 1 & 0.07 & \begin{tabular}{|l|} 
Long bone \\
\end{tabular} & & 1 & 0 & 0 & 1 & 0 & & & & & \\
\hline 11 & 5 & Aves & 3 & 0.08 & & & 0 & 0 & 0 & 4 & 0 & & & & & \\
\hline 11 & 5 & Mammalia & 1 & 0.04 & Tooth & Fragment & 5 & 4 & 0 & 4 & 0 & & & & & \\
\hline 11 & 5 & Mammalia & 1 & 0.81 & & & 3 & 4 & 0 & 4 & 0 & & & & & \\
\hline 11 & 5 & Mammalia & 1 & 0.06 & & & 1 & 4 & 1 & 4 & 0 & & & & & \\
\hline 11 & 5 & Mammalia & 1 & 0.33 & Long bone & Fragment & 3 & 4 & 3 & 4 & 0 & & & & & \\
\hline 11 & 5 & Mammalia & 3 & 0.33 & & & 5 & 4 & 2 & 4 & 0 & & & & & \\
\hline 11 & 5 & \begin{tabular}{|l|}
$\begin{array}{l}\text { Sigmodon } \\
\text { hispidus }\end{array}$ \\
\end{tabular} & 1 & 0.03 & Calcaneus & Complete & 0 & 0 & 0 & 0 & 0 & & & & & \\
\hline 11 & 5 & Vertebrata & 1 & 0.01 & & & 5 & 4 & 0 & 4 & 0 & & & & & \\
\hline 11 & 5 & Vertebrata & 2 & 0.07 & & & 5 & 4 & 4 & 4 & 0 & & & & & \\
\hline 11 & 5 & Vertebrata & 3 & 0.16 & & & 2 & 4 & 0 & 4 & 0 & & & & & \\
\hline 11 & 5 & Vertebrata & 5 & 0.11 & & & 1 & 4 & 0 & 4 & 0 & & & & & \\
\hline 11 & 5 & Vertebrata & 18 & 0.94 & & & 5 & 4 & 0 & 4 & 0 & & & & & \\
\hline 11 & 3 & Mammalia & 1 & 0.09 & & & 5 & 4 & 4 & 4 & 0 & & & & & \\
\hline 11 & 3 & Vertebrata & 1 & 0.04 & & & 5 & 4 & 1 & 4 & 0 & & & & & \\
\hline 11 & 3 & Vertebrata & 1 & 0.07 & & & 5 & 4 & 1 & 4 & 0 & & & & & \\
\hline 11 & 3 & Vertebrata & 2 & 0.03 & & & 5 & 4 & 0 & 4 & 0 & & & & & \\
\hline 11 & 3 & Vertebrata & 2 & & & & 5 & 4 & 2 & 4 & 0 & & & & & \\
\hline 11 & 3 & Vertebrata & 3 & & & & 3 & 4 & 0 & 4 & 0 & & & & & \\
\hline 11 & 3 & Vertebrata & 6 & & & & 5 & 4 & 0 & 4 & 0 & & & & & \\
\hline 11 & 2 & Mammalia & 1 & 0.20 & & & 5 & 1 & 0 & 4 & 0 & & & & & \\
\hline 11 & 2 & Vertebrata & 1 & 0.01 & & & 2 & 4 & 0 & 4 & 0 & & & & & \\
\hline
\end{tabular}


Table F-2. continued

\begin{tabular}{|c|c|c|c|c|c|c|c|c|c|c|c|c|c|c|c|c|}
\hline \multirow[b]{2}{*}{$\mathrm{TU}$} & \multirow[b]{2}{*}{ Lvl } & \multirow[b]{2}{*}{ Taxon } & \multirow[b]{2}{*}{$\vec{\Xi}$} & \multirow[b]{2}{*}{$\begin{array}{l}\overrightarrow{\vec{c}} \\
\cdot \vec{b} \\
\vec{b}\end{array}$} & \multirow[b]{2}{*}{ Element } & \multirow[b]{2}{*}{ Portion } & \multicolumn{5}{|c|}{ Coded Observations } & \multicolumn{4}{|c|}{ Butcher Marks } & \multirow[b]{2}{*}{ Notes } \\
\hline & & & & & & & $\stackrel{\vec{g}}{\stackrel{\vec{E}}{E}}$ & 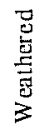 & 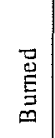 & $\begin{array}{l}\text { 鸹 } \\
\text { : } \\
\text { 总 }\end{array}$ & 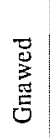 & $\begin{array}{c}\vec{\Xi} \\
\stackrel{\Xi}{\Xi} \\
\stackrel{\Xi}{E}\end{array}$ & 몰 & 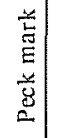 & 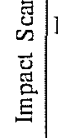 & \\
\hline 11 & 2 & Vertebrata & 2 & 0.02 & & & 5 & 4 & 2 & 4 & 0 & & & & & \\
\hline 11 & 2 & Vertebrata & 2 & 0.16 & & & 5 & 4 & 0 & 4 & 0 & & & & & \\
\hline 11 & 2 & Vertebrata & 2 & 0.03 & & & 5 & 4 & 4 & 4 & 0 & & & & & \\
\hline 11 & 2 & Vertebrata & 4 & 0.13 & & & 5 & 4 & 1 & 4 & 0 & & & & & \\
\hline 11 & 2 & Vertebrata & 11 & 0.15 & & & 5 & 4 & 0 & 4 & 0 & & & & & \\
\hline 11 & 1 & Mammalia & 1 & 0.03 & & & 3 & 4 & 0 & 4 & 0 & & & & & Sparrow-sized \\
\hline 11 & 1 & Vertebrata & 1 & 0.01 & & & 5 & 4 & 0 & 4 & 0 & & & & & Sparrow-sized \\
\hline 11 & 1 & Vertebrata & 1 & 0.03 & & & 5 & 4 & 4 & 4 & 0 & & & & & \\
\hline 11 & 1 & Vertebrata & 3 & 0.26 & & & 2 & 4 & 0 & 4 & 0 & & & & & \\
\hline \multicolumn{4}{|c|}{ Unit Total } & 5.75 & & & & & & & & & & & & \\
\hline 10 & 2 & Mammalia & 1 & 0.02 & Rib & Fragment & 5 & 4 & 0 & 4 & 0 & & & & & \\
\hline 10 & 2 & Mammalia & 2 & 0.19 & & & 1 & 4 & 1 & 1 & 0 & & & & & \\
\hline 10 & 2 & Vertebrata & 1 & 0.01 & & & 5 & 4 & 0 & 4 & 0 & & & & & \\
\hline 10 & 2 & Vertebrata & 1 & 0.01 & & & 5 & 4 & 0 & 4 & 0 & & & & & \\
\hline 10 & 2 & Vertebrata & 1 & & & & 5 & 4 & 0 & 4 & 0 & & & & & \\
\hline 10 & 2 & Vertebrata & 1 & 0.01 & & & 5 & 4 & 0 & 4 & 0 & & & & & \\
\hline 10 & 2 & Vertebrata & 3 & 0.07 & & & 5 & 4 & 2 & 4 & 0 & & & & & \\
\hline 10 & 2 & Vertebrata & 3 & 0.07 & & & 5 & 4 & 2 & 4 & 0 & & & & & \\
\hline 10 & 1 & Vertebrata & 3 & 0.02 & & & 5 & 4 & 0 & 4 & 0 & & & & & \\
\hline 10 & 1 & Vertebrata & 3 & 0.02 & & & 5 & 4 & 0 & 4 & 0 & & & & & \\
\hline \multicolumn{4}{|c|}{ Unit Total } & 0.42 & & & & & & & & & & & & \\
\hline 1 & 5 & Mammalia & 1 & 0.10 & & & 1 & 4 & 0 & 1 & 0 & & & & & \\
\hline 1 & 5 & Mammalia & 1 & 0.10 & & & 1 & 4 & 0 & 4 & 1 & & & & & \\
\hline 1 & 5 & Vertebrata & 1 & 0.06 & & & 5 & 4 & 3 & 4 & 0 & & & & & \\
\hline 1 & 5 & Vertebrata & 1 & 0.01 & & & 5 & 4 & 0 & 4 & 0 & & & & & \\
\hline 1 & 5 & Vertebrata & 1 & 0.06 & & & 5 & 4 & 3 & 4 & 0 & & & & & \\
\hline 1 & 5 & Vertebrata & 1 & 0.01 & & & 5 & 4 & 0 & 4 & 0 & & & & & \\
\hline 1 & 5 & Vertebrata & 2 & 0.10 & & & 5 & 4 & 4 & 4 & 0 & & & & & \\
\hline 1 & 5 & Vertebrata & 7 & 0.06 & & & 5 & 4 & 0 & 4 & 0 & & & & & \\
\hline 1 & 5 & Vertebrata & 7 & 0.06 & & & 5 & 4 & 0 & 4 & 0 & & & & & \\
\hline 1 & 4 & Artiodactyl & 2 & 0.24 & Tooth & Fragment & 3 & 4 & 0 & 4 & 0 & & & & & \\
\hline 1 & 4 & $\begin{array}{l}\text { cf. Sigmodon } \\
\text { hispidus }\end{array}$ & 1 & 0.01 & 3rd phalange & Complete & 5 & 4 & 0 & 4 & 0 & & & & & \\
\hline 1 & 4 & Mammalia & 1 & 0.03 & Tooth & Fragment & 3 & 4 & 0 & 4 & 0 & & & & & \\
\hline 1 & 4 & Vertebrata & 1 & 0.01 & & & 5 & 4 & 4 & 4 & 0 & & & & & \\
\hline 1 & 4 & Vertebrata & 1 & 0.06 & & & 0 & 4 & 0 & 4 & 0 & & & & & \\
\hline 1 & 4 & Vertebrata & 1 & 0.02 & & & 5 & 4 & 0 & 4 & 0 & & & & & \\
\hline 1 & 4 & Vertebrata & 1 & 0.01 & & & 5 & 4 & 0 & 4 & 0 & & & & & \\
\hline 1 & 4 & Vertebrata & 1 & 0.10 & & & 5 & 4 & 2 & 4 & 0 & & & & & \\
\hline 1 & 4 & Vertebrata & 4 & 0.04 & & & 5 & 4 & 0 & 4 & 0 & & & & & $\begin{array}{l}\text { Mouse-sized, no } \\
\text { epiphysis }\end{array}$ \\
\hline 1 & 4 & Vertebrata & 4 & 0.14 & & & 5 & 4 & 2 & 4 & 0 & & & & & \\
\hline 1 & 4 & Vertebrata & 6 & 0.11 & & & 5 & 4 & 0 & 4 & 0 & & & & & \\
\hline 1 & 3 & Mammalia & 3 & 0.08 & Tooth & Fragment & 3 & 4 & 0 & 4 & 0 & & & & & \\
\hline 1 & 3 & Vertebrata & 1 & 0.01 & & & 5 & 4 & 0 & 4 & 0 & & & & & \\
\hline 1 & 3 & Vertebrata & 1 & 0.07 & & & 5 & 4 & 4 & 4 & 0 & & & & & \\
\hline 1 & 3 & Vertebrata & 2 & 0.06 & & & 3 & 4 & 0 & 4 & 0 & & & & & \\
\hline 1 & 2 & Mammalia & 2 & 0.16 & & & 5 & 4 & 0 & 4 & 0 & & & & & \\
\hline 1 & 2 & Rodentia & 1 & 0.01 & \begin{tabular}{|l|}
$\begin{array}{l}\text { Lumbar } \\
\text { vertebra }\end{array}$ \\
\end{tabular} & Centrum & 5 & 4 & 0 & 4 & 0 & & & & & Immature \\
\hline 1 & 2 & Vertebrata & 1 & 0.01 & & & 5 & 4 & 0 & 4 & 0 & & & & & \\
\hline 1 & 2 & Vertebrata & 7 & 0.21 & & & 5 & 4 & 0 & 4 & 0 & & & & & $\begin{array}{l}\text { Very small carnivore } \\
\text { (skunk?) }\end{array}$ \\
\hline 1 & 1 & Vertebrata & 5 & 0.20 & & & 5 & 4 & 2 & 4 & 0 & & & & & Deer-sized \\
\hline \multicolumn{4}{|c|}{ Unit Total } & 2.14 & & & & & & & & & & & & \\
\hline
\end{tabular}


Table F-2. continued

\begin{tabular}{|c|c|c|c|c|c|c|c|c|c|c|c|c|c|c|c|c|}
\hline \multirow[b]{2}{*}{ TU } & \multirow[b]{2}{*}{ Lvl } & \multirow[b]{2}{*}{ Taxon } & \multirow[b]{2}{*}{ 志 } & \multirow[b]{2}{*}{ 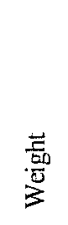 } & \multirow[b]{2}{*}{ Element } & \multirow[b]{2}{*}{ Portion } & \multicolumn{5}{|c|}{ Coded Observalions } & \multicolumn{4}{|c|}{ Butcher Marks } & \multirow[b]{2}{*}{ Notes } \\
\hline & & & & & & & 惢 & 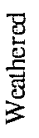 & $\begin{array}{l}\overrightarrow{\mathscr{E}} \\
\text { E् }\end{array}$ & $\begin{array}{l}\text { 可 } \\
\text { 总 } \\
\text { 出 }\end{array}$ & 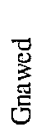 & 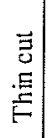 & $\begin{array}{l}0 \\
0 \\
0\end{array}$ & 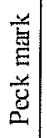 & 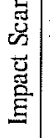 & \\
\hline $\mathrm{D}$ & 9 & Mammalia & 1 & 0.09 & Femur & \begin{tabular}{|l|} 
Proximal \\
$1 / 2$ \\
\end{tabular} & 0 & 0 & 2 & 2 & 0 & & & & & \\
\hline $\mathrm{D}$ & 9 & Mammalia & 1 & 0.01 & Tooth & Root & 0 & 0 & 1 & 0 & 0 & & & & & \\
\hline $\mathrm{D}$ & 7 & Mammalia & 1 & 0.01 & Tooth & Fragment & 0 & 0 & 2 & 2 & 0 & & & & & \\
\hline $\mathrm{D}$ & 7 & Vertebrata & 1 & 0.02 & & & 0 & 0 & 2 & 4 & 0 & & & & & \\
\hline $\mathrm{D}$ & 7 & Vertebrata & 2 & 0.06 & & & 5 & 4 & 4 & 4 & 0 & & & & & \\
\hline $\mathrm{D}$ & 5 & Aves & 1 & 0.01 & Long bone & Fragment & 5 & 4 & 4 & 4 & 0 & & & & & \\
\hline $\mathrm{D}$ & 5 & Vertebrata & 6 & 0.12 & & & 5 & 4 & 0 & 4 & 0 & & 1 & & & Possible chop mark \\
\hline $\mathrm{D}$ & 12 & Aves & 1 & 0.03 & Long bone & Fragment & 5 & 4 & 1 & 4 & 0 & & & & & \\
\hline $\mathrm{D}$ & 12 & Vertebrata & 1 & 0.07 & & & 5 & 4 & 2 & 4 & 0 & & & & & \\
\hline \multicolumn{4}{|c|}{ Unit Total } & 0.42 & & & & & & & & & & & & \\
\hline C & 6 & Vertebrata & 6 & 0.05 & Long bone & Fragment & 0 & 4 & 4 & 4 & 0 & & & & & \\
\hline $\mathrm{C}$ & 4 & Osteicthys & 1 & 0.01 & & & 5 & 4 & 0 & 4 & 0 & & & & & Sparrow-sized \\
\hline $\mathrm{C}$ & 4 & Vertebrata & 4 & 0.06 & & & 2 & 4 & 0 & 3 & 0 & & & & & \\
\hline $\mathrm{C}$ & 3 & Rodentia & 1 & 0.01 & Long bone & Fragment & 0 & 0 & 0 & 0 & 0 & & & & & Rodent-sized \\
\hline $\mathrm{C}$ & 3 & Vertebrata & 5 & 0.11 & & & 5 & 4 & 0 & 4 & 0 & & & & & \\
\hline $\mathrm{C}$ & 2 & Neotoma sp. & 1 & 0.01 & Molar & Fragment & 0 & 0 & 0 & 2 & 0 & & & & & \\
\hline $\mathrm{C}$ & 2 & Vertebrata & 1 & 0.04 & & & 3 & 4 & 0 & 4 & 0 & & & & & Mouse-sized \\
\hline \multicolumn{4}{|c|}{ Unit Total } & 0.29 & & & & & & & & & & & & \\
\hline A & 4 & Mammalia & 1 & 0.70 & Long bone & Fragment & 3 & 4 & 0 & 3 & 0 & & & & & Mouse-sized \\
\hline
\end{tabular}


The following information is provided in accordance with the General Rules of Practice and Procedure, Chapter 41.11 (Investigative Reports), Texas Antiquities Committee:

1. Type of investigation: Testing

2. Project name: Culebra Creek

3. County: Bexar

4. Principal investigators: Robert J. Hard and C. Britt Bousman

5. Name and location of sponsoring agency: Texas Department of Transportation, Austin, Texas 78701

6. Texas Antiquities Permit No.: 1782

7. Published by the Center for Archaeological Research, The University of Texas at San Antonio, 6900 N. Loop 1604 W., San Antonio, Texas 78249-0658, 2001 [1998]

A list of publications offered by the Center for Archaeological Research is available. Call (210) 458-4378; write to the Center for Archaeological Research, The University of Texas at San Antonio, 6900 N. Loop 1604 W., San Antonio, Texas 78249-0658; e-mail to car@Ionestar.utsa.edu; or visit CAR's web site at http://car.utsa.edu. 